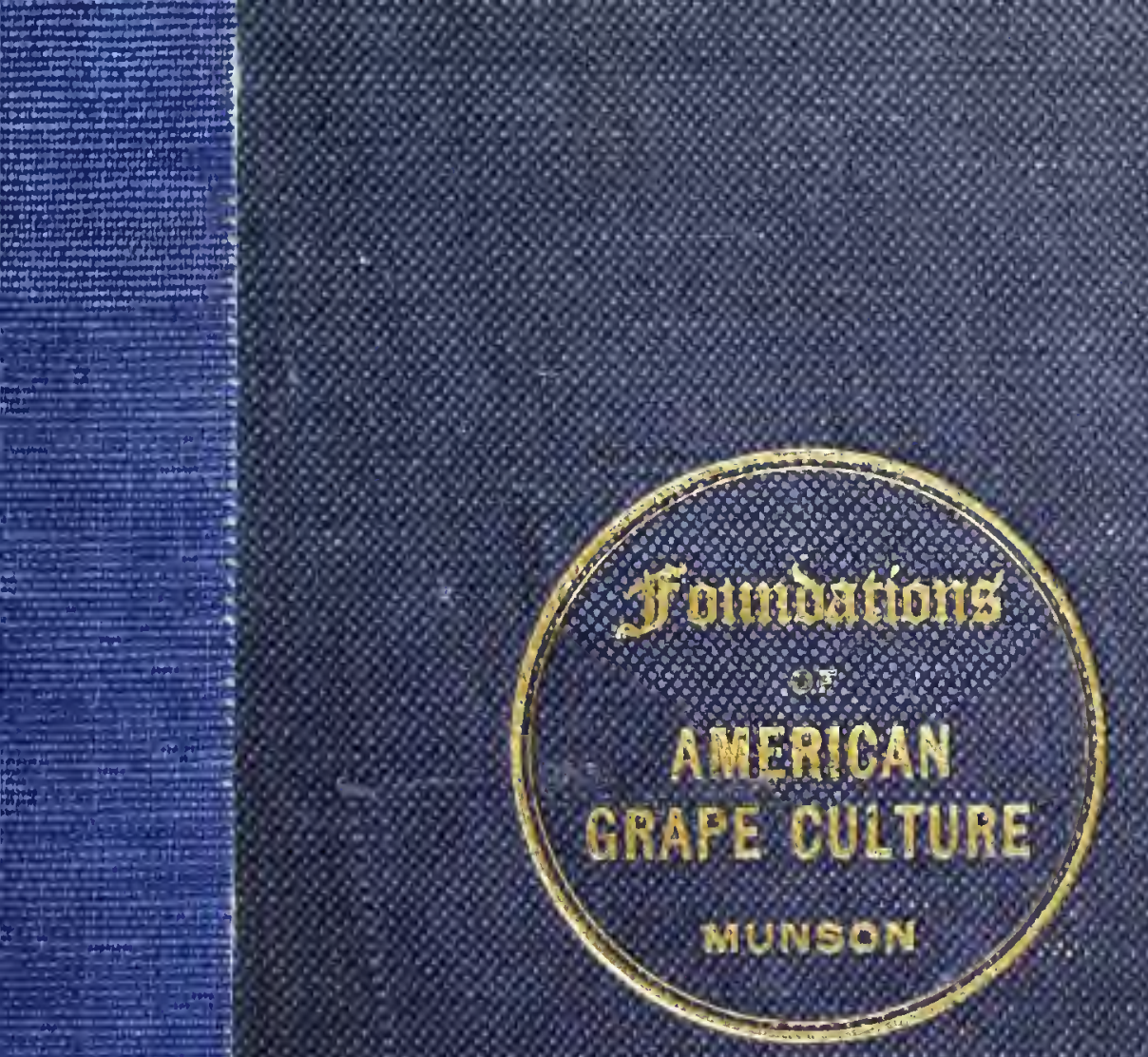


SB389
M975
cop.1

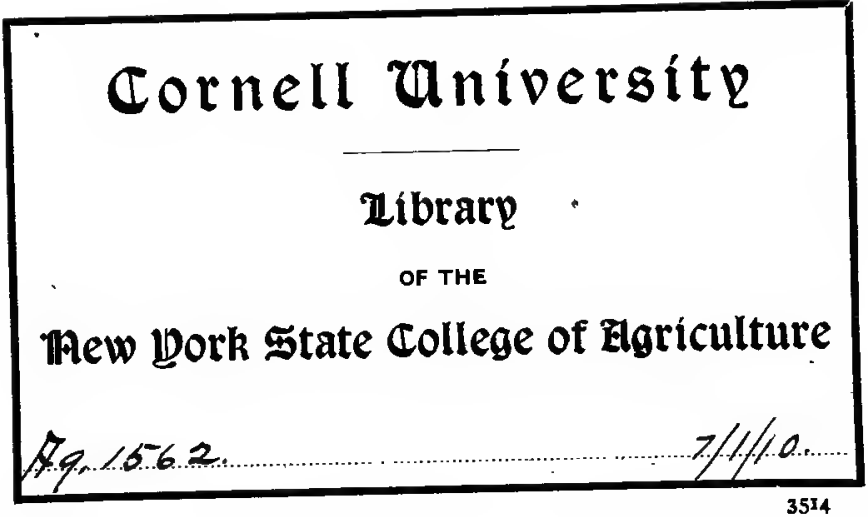




\section{SB 389 Corne!l Univereity Library}

Foundations of American grape culture,

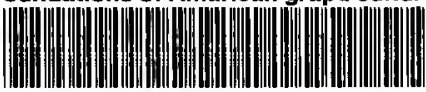

$\begin{array}{llllll}3 & 1924003 & 694 & 084\end{array}$

\section{LIBRARY ANNEX \\ DATE DUE}

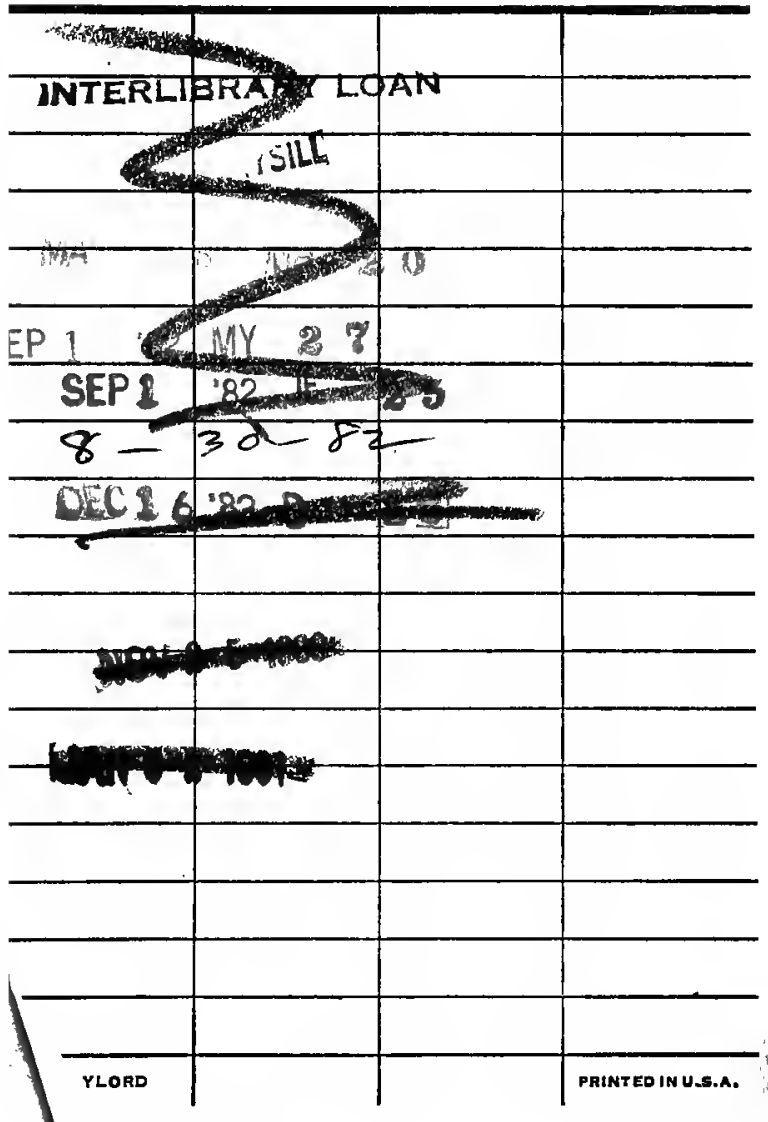




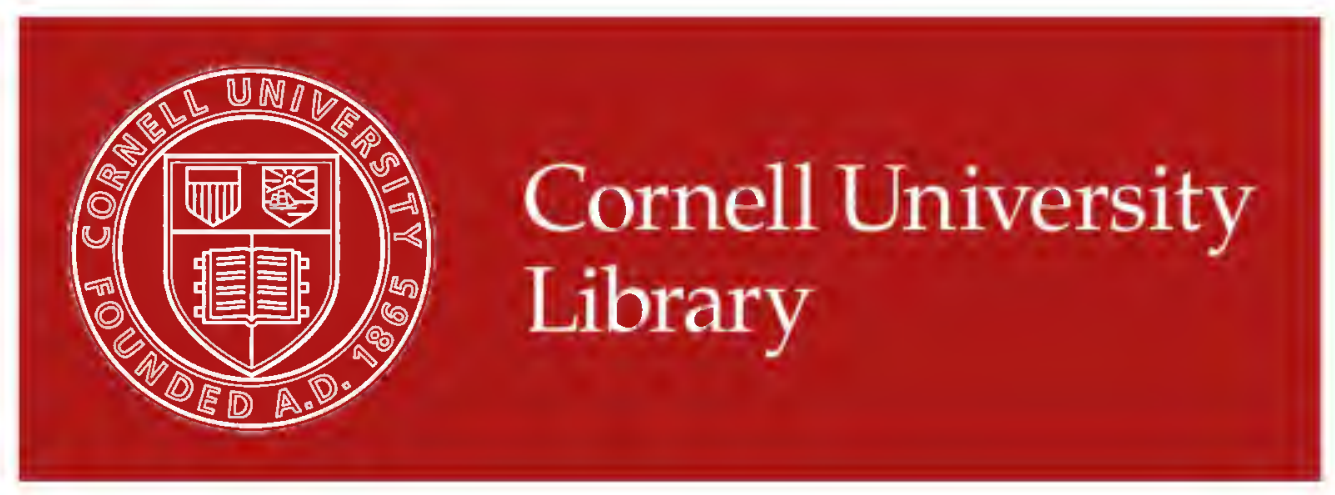

The original of this book is in
the Cornell University Library.

There are no known copyright restrictions in the United States on the use of the text.

http://www.archive.org/details/cu31924003694084 


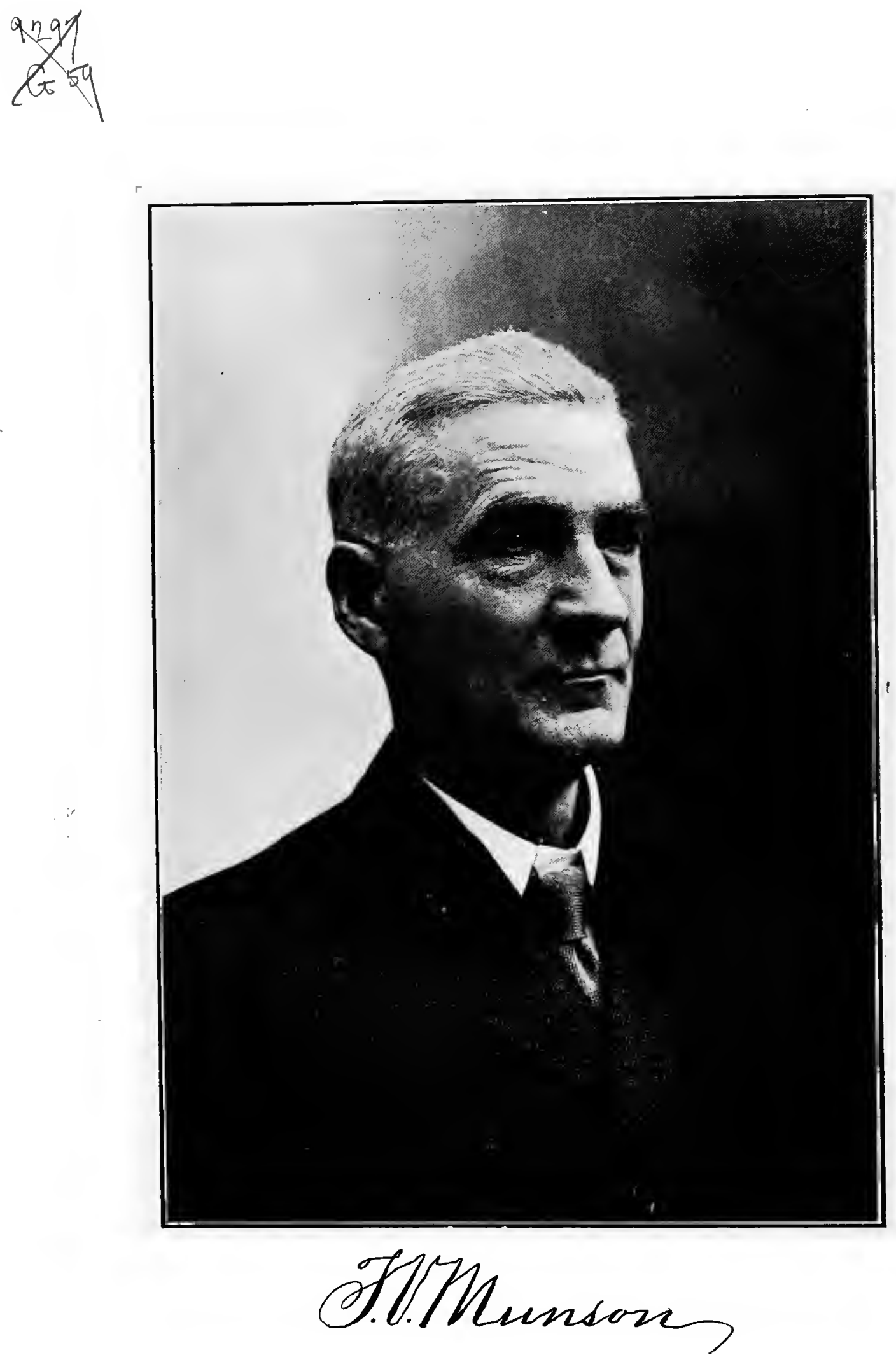


\title{
Foundations of American
}

\section{Grape Culture}

\author{
BY \\ T. V. Munson, D. Sc.
}

Vice-President American Pomological Society.

Honorary Member American Wine Growers' Association.

Honorary Member of the Société des Viticulteurs de France.

Foreign Corresponding Member of the Société Nationale D'Agriculture de France.

Chevalier du Mérite Agricole, in Legion of Honor

Practical Viticulturist and Nurseryman.

Published by

\section{Orange Judd Company, \\ New York}

The rights of reproduction and translation, reserved. 


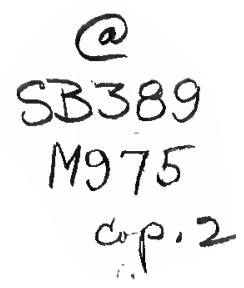

Ag. 1562

Copyright 1909,

By T. V. Munson. 


\section{Dedication}

At beginning of man's civilization, ages old, When the Sumerian, Canaanite savage, dark, Strolled along the banks of Euphrates, And, tired of wandering, settled Nippur town, He longingly remembered the wild sweet grapes That climbed the trees upon the hills he left, And which, all lovely, fringed the Caspian, so grand. He sought a holiday and hied himself away to seek Among the dear. old hills of Ararat, for grapes, Where Noah landed safe, and later got so drunk, poor man! (His better sons, walking backward, to hide his shame, Soft spread in charity over him a lion's skin.) Reaching the loved old haunts, all weary and worn, He ate his fill of many juicy grapes so sweet, As long before, when roving wild in Bactrian. And then on camel's back great loads of grape-filled vines He took to treat his wives and babes in Nippur town. The seeds were scattered round the huts of mud;

Some grew and clambered up the walls, and bloomed all sweet, At length bore fruit, and cooled the huts with shade;

Some few bore better grapes than from the wilds he brought;

Such vines he loved and saved and kindly trained, betimes.

He always gathered from the new and better vines, And planted vacant places with their seeds, select; He gave to kith and kin, who likewise grew and gave. Thus on and on, through old, ten thousand years, Have come adown to all mankind the twining vines Of Ararat, in Muscats, Flame Tokays and Cornichons. The sons of men still hand them on with loving care, Well mingled with those from our free American hills. And now, to all who love the vines and grapes and wines, This book is dedication fruit of one of Noah's sons, Who wishes cause no more to backward spread the lion's skin, But plant and eat and drink, and ne'er get drunk. 
A . " " 


\section{Preface}

For so great a nation as ours, both in expanse of territory and demand for every variety of vineyard product, the foundation of grape culture should be laid most intelligently broad and deep. It is quickly apparent to any practical vineyardist, that the chief material structure of American Viticulture must necessarily be,-

\section{The Native Grapes of America}

Without these we cannot secure adaptability, endurance and resistance to disease. To secure the best results from these, requires that the best wild varieties that have been and may xet be found, should be sought out before they forever perish by browsing cattle and the woodman's ax, brought together and tested for the various uses in which grapes are employed in the home and in commerce; then intermingled with each other and the best adapted varieties of the Old World, as experience may show, to give best results, so as eventually to supply every use and season with this most beautiful, most wholesome and nutritious, most certain and profitable fruit, which will succeed in some one or other of its numerous varieties upon almost every soil and in nearly every climate.

\section{The Passion for Experimentation with Grapes Aroused}

In the fall of 1873 , the writer visited the vineyards of Dr. Robert Peter, residing near Lexington, Kentucky. In these vineyards were all the leading and nearly all the then introduced varieties of American grapes.

The vines were bearing generally, and the fruit on nearly all was ripe or ripening. The Doctor, having been my instructor in Chemistry in Kentucky State Agricultural College, in which I had completed the scientific course in 1870 , discoursed freely upon the character of vine and fruit of the varieties. It seemed to me that there might be numerous combinations, which would naturally occur in such a vineyard, and that one could expect some of the seedlings grown from such crossed seeds to turn out better than any in the vineyard, by combination of excellencies of both parents in the crossed.

This reflection aroused within me a strong desire to test the matter. The Doctor gave me clusters of all wished, some thirty or forty kinds. The seeds of these were carefully saved, separately labeled, and noted as to varieties standing near the vine which bore the seeds. These seeds were planted at my new home in Nebraska, but the season and other conditions being adverse, all were lost, yet the kindled flame of passion for experimentation continued to burn. The timbered belts along the streams of that bleak country were ransacked for the few wild grapes growing there, and the vines bearing the best fruit were marked to be removed to vineyard and later hybridized with larger berried kinds, as the only species there $(V$. vulpina) has small berries, although often quite sweet, and pure-in quality. However, a series of years of adversity,--with drouth, intensely hard winters, and grasshoppers,--coming on, further experimentation there in that line was dropped.

Coming to Denison, Texas, in April, 1876, a rough piece of dark limestone, timbered land on the bluffs of Red River was improved. In the woods surrounding, innumerable wild grapevines grew. On the higher sandy lands, covered with post-oak, black jack, hickory, scarlet oak and other timber, grew many "Post-Oak Grape" vines ( $V$. Lincecumii), generally climbing the postoak trees, hence the name of Post-Oak Grape.

Along the ravines of the uplands, and in the river bottoms, were numerous vines of the "Mustang Grape" (V. candicans), the "Sour Winter Grape" or "Frost Grape" (V. cordifolia), 
and "Sweet Winter Grape" ( $V$. cinerea), the latter penetrating and growing luxuriantly in the lower bottoms, where the others were seldom found. Directly along the high banks of Red River were found vines of the "Sand," or "Bush Grape" (V. Longii), drifted down from the Texas PanHandle regions, where it grows in great profusion. Hybrids of it with the Mustang Grape are often found along Red River. Occasionally are also found vines of the "Riverside Grape" ( $V$. vulpina, or riparia), along Red River banks. There were rarely found on the high bottoms of Red River and larger creeks in this, Grayson County, when the writer came to the State, wild vines of the "Southern Muscadine" ( $V$. rotundifolia), and this appears to be its western limit of distribution along Red River. Here were six or eight good species of wild grapes, several of which had not been seen by me previously. I had found my grape paradise! Surely now, thought $I$, "this is the place for experimentation with grapes!"

It was soon learned from that veteran experimenter with, and writer on, grapes, Mr. Gilbert Onderdonk, and by my own observations, that in all the Southwest, especially in the dry, hot parts of Texas, the northern varieties of Labrusca and its hybrids with Vinifera, were subject to many diseases, short-lived, and their fruit lasted only a short season in July. But here was a profusion of native grapes, perfect'y suited to the soils and climate; little attacked by disease, and "what should hinder the selection, crossing and hybridizing with fine quality grapes?" was the question of my mind.

Thus was rekindled my passion for experimental work with grapes.

Already, pretty familiar with what had been done by others in the improvement of our native grapes, it seemed so inadequate to the needs and capabilities of the country, that I determined to devote a portion of my time and ground to aid the study and development of vine-culture in America.

\section{Special Study of Grape Botany Necessary}

It was at once apparent to me that a thorough botanical investigation of all species of our wild grapes must be made before much valuable work in this field could be done.

The characters and properties of each species must be learned; the climatic and soil conditions under which each thrives best; the climatic and soil conditions in general of the various sections of country, so that varieties best suited to each may be produced, must be sought and thoroughly studied.

Such work requires long continued and extensive investigation. The pioneer originator must travel much in the woods of every section where wild grapes grow, and study the habits; search out and collect together the best varieties from every region and breed up their good properties if he would most certainly produce varieties best adapted to those sections.

At various times during the past thirty years, the writer traveled through forty of the states and territories of the Union, never neglecting any opportunity to hunt and study the wild plants, especially the grapes and other wild fruits. In these journeys not less than fifty thousand miles were traveled by railway, and many hundreds on horseback and on foot, and thousands of vines of nearly every species of American grape were studied growing in their native habitats.

Correspondence was had with botanists, vineyardists and other good observers in nearly every state and territory.

Botanical specimens and vines of all American and most of the Asiatic species were collected. Seeds and plants of the best varieties were obtained of all these species and grown in experimental vineyards.

\section{Critical Study of Grape Botany Taken Up}

The standard botanical classification of American grapes, at the time the study was begun by the writer, was that of Dr. Geo. Engelmann. This, with most of the other works extant upon 
our native grapes, was taken up and carefully studied, and used, in trying to identify the species of the vines found in the woods. Many imperfections and errors were discovered in these works, and it was apparent that they were inadequate, as guides, in identifying all the existing species, and this led the author to undertake the task of completely working over American grape botany into a new, more natural and thorough classification.

Beginning original botanical research among our wild grapes in 1880 , it has been continued up to the present time, rewarding us with the correction of many errors in the old classification and nomenclature, and with the discovery of a number of new species; besides, what was of far more importance to practical vine culture, the finding of much valuable material, such as fine wild varieties with which to start new families of market, table and wine grapes, and most excellent resistant graft stócks, and many cultural principles of great practical value, necessary to apply in order to reach the higher development of vineyard varieties.

The grape herbariums of Harvard in Cambridge; of the Academy of Sciences, Philadelphia; of the Division of Botany and of the National Museum in Washington, D. C.; of Dr. Geo. Engelmann, in the Missouri Botanical Gardens of St. Louis, were studied and noted. All the species and numerous hybrids were studied and noted in germination and development in the seed beds, in the test vineyards and in points for practical vineyard purposes, as well as to learn strict botanical characters, both formal and biological,-life-action and habit. The notes were always made on the spot, in presence of the vines under study.

Several years were spent thus accumulating facts before any attempt was made in constructing a new classification.

At that time the writer was in correspondence with Professors J. E. Planchon, A. Millardet, Pierre Viala, and other leading French ampelographers, who have always held front rank in such subjects. Their works on grape botany were carefully studied.

\section{Resume of the Author's Educational Work on American Grapes and Their Development}

It is presumed that a short mention of the writer's educative work on grapes will not be out of place here.

By invitation of Mr. Parker Earle, President of the American Horticultural Society and Chief of the Horticultural Section of the Cotton Centennial Exposition, at New Or'eans, the writer, in 1885, exhibited, in the Horticultural Hall of the exposition, a complete set of herbarial specimens, classified in glass frames, of all the known species of American grapes and specimen plants of the same growing in pots. This was supplemented by a paper read before the American Horticultural Society, holding its sessions in the exposition building in New Orleans, in February, 1885, and the paper was published in the report of the society for that year. This paper contained my first attempt at a new botanical classification of grape species. The specimens, at the close of the exposition, were presented to the University of Missouri, and were taken in charge by Professor S. M. Tracy, Botanist of the University, and placed in the University herbarium, Columbia, Mo.

This new classification, with some revision, was set forth in a paper by the writer before the American Pomological Society, meeting in Grand Rapids, Michigan, in September, 1885, and was published in the Society's report of that year, and favorably noticed by the horticultural press. The new classification was yet very imperfect.

Following this, during several years, The American Agriculturist, The Rural New-Yorker, The American Gardening, Garden and Forest, Farm and Ranch, The Revue de Viticulture, of France, and other leading horticultural and agricultural journals published illustrated articles upon classification, hybridization and varieties of grapes prepared by the writer at request of . their editors. 
During 1887 to 1892 the author supplied complete sets of botanical specimens of American Grapes, arranged according to his plan of classification, to the herbariums of various educational institutions, one going to the School of Viticulture, Montpellier, France; one each to Harvard University, Cornell University. Columbia University, Philadelphia Academy of Sciences, the National Herbarium in National Museum, and one to the herbarium in the Division of Botany, Department of Agriculture. To Dr. Vasey, Botanist of the Department of Agriculture, eleven sets were supplied. These were placed in as many agricultural colleges. These sets contained young and mature wood, leaves, flowers and fruit of each American species.

Sets of photographs, life size, of wood, leaves, flowers, fruit and seeds of all American species have been supplied to about a dozen colleges and botanists in the United States and Europe.

A large number of complete sets of live plants of all species of American grapes have been supplied to state experiment stations and individuals in the United States and Europe.

To stimulate experimentation, over 1000 packets of hybridized grape seeds of select varieties were distributed, gratis, to some 500 grape-growers, located in all parts of the Union.

In 1889, the Division of Pomology published its Bulletin No. 3, containing an outline skeleton of my classification of grapes, as an announcement of an exhaustive monograph of American grapes, which the Secretary of Agriculture, through the Pomologist, H. E. Van Deman, engaged me to prepare. The manuscript for this monograph, and accurate life-size colored plates of all our native grape species, were prepared and delivered, but from lack of sufficient appropriation by Congress the work remains unpublished.

In 1893, in the Horticultural Building of the Columbian Exposition, Chicago, the writer exhibited all American and most Asiatic species of grapes, represented by growing plants, by roots preserving natural appearance in liquid, by sections of wood from aged and young growth, by pressed leaves, in all stages of development, by flowers, by clusters of ripe fruit in plates, and preserved in liquid in glass jars, by seeds, and by life-size photographs of wood, leaves, flowers, fruit and seeds, all labeled with their common and technical names, and presented in classified arrangement according to the plans shown in Plate I. In addition to this, over 150 old and new varieties, representing all manner of crossed and hybrid combinations, were shown in ripe clusters on plates for three months in succession.

This exhibit was the most complete botanical display of the grape genus ever made. It was presented to the Department of Agriculture, and since the Exposition all its durable parts have been mounted in the Pomological Division, Department of Agriculture, in Washington, D. C.

\section{The Chief Work}

All this botanical and cultural study was only preliminary to the author's chief work with grapes, which has been to collect the best wild and cultivated varieties, to test them side by side, and intermingle them by crossing and hybridizing, to produce new varieties of best possible qualities, in the endeavor to fill out the ideal list of varieties as presented hereafter and to provide the best possible resistant graft stocks upon which to graft Vinifera varieties.

For this undertaking all the details of the science and art of hybridization have been studied, and the different methods put into practice, as amplified to some extent in other parts of this work.

\section{Basis of Improvement of American Grapes}

It was not only necessary to know the general botany of grapes, but as well what was desirable and undesirable in varieties in cultivation, and how much of the season, and market demand they covered, so as to direct effort to the best advantage in creating varieties to fill up the vacancies.

\section{An Ideal List, or Succession of Varieties}

To keep the object of the work clearly in view, an ideal succession of varieties was constructed which might in time be filled with excellent and profitable kinds. 
It was observed that any considerable market demands, all the time, three colors of grapes to satisfy all customers. These are, in the order of preference, or extent of demand: (1) bright. lively red, such as Delaware, Flame Tokay, etc.; (2) black, or dark purple, with clear complexion, such as Black Hamburg, Black Prince, Violet Chasselas, etc.; Concord is too dull, has too much white, flour-like bloom; (3) translucent, yellowish varieties, such as Golden Chasselas, Calabrian, etc. Niagara, when thoroughly ripe in sunny weather does pretty well. Varieties that are green when fully ripe do not sell well.

In the South, some varieties of grapes, such as Champion, begin ripening in June, and by August 1st all the varieties commonly grown in the North are gone in the South, and yet at the time when grapes are most relished, through August, September and October, only Herbemont, LeNoir and the Muscadines, such as Scuppernong and Thomas, could be used to fill up the latter part of the season, yet these pass away in August and early September, still leaving the best half of the season unsupplied, except by importation.

Even the North yet has very few varieties of good quality of commercial value and the South can find" room for many more.

Ripe fruit cannot be profitably retained on the vines in the heat of summer, except in rare cases, longer than about ten days after ripe enough to market. But when the cool nights of September and October come, it can hang twenty to thirty days in good condition. This would give three periods of ten days each for July and August; two periods of fifteen days each for September and one period for October, making nine in all, each requiring three colors, thus giving room for profitable growing no less than twenty-seven varieties, to cover the entire season, in the South, with only one variety of each color at any one time, to say nothing of strictly wine grapes; and to make apparent the needs, the following scheme was devised.

\section{Skeleton for Ideal Succession of Grapes for the South}

27 Varieties.

\begin{tabular}{|c|c|c|c|}
\hline Dates of Ripening. & $\begin{array}{l}\text { Translucent Red. } \\
\text { Should be as good as } \\
\text {. Brighton. }\end{array}$ & $\begin{array}{l}\text { Bright Black. } \\
\text { Never poorer than } \\
\text { Concord. }\end{array}$ & $\begin{array}{l}\text { Translucent Yellow } \\
\text { or White. } \\
\text { Never poorer than } \\
\text { Niagara. }\end{array}$ \\
\hline 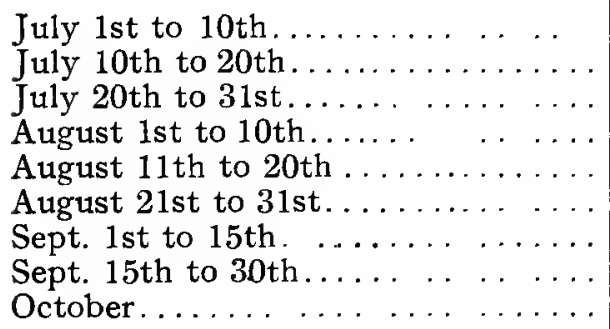 & $\begin{array}{l}1 \\
2 \\
3 \\
4 \\
5 \\
6 \\
7 \\
8 \\
9\end{array}$ & $\begin{array}{l}1 \\
2 \\
3 \\
4 \\
5 \\
6 \\
7 \\
8 \\
9\end{array}$ & $\begin{array}{l}1 \\
2 \\
3 \\
4 \\
5 \\
6 \\
7 \\
8 \\
9\end{array}$ \\
\hline
\end{tabular}

Let any one try to fill this skeleton list with varieties generally cultivated and he will quickly become aware of the inadequacy of existing varieties for the purpose.

We make the attempt in the following, admitting a number of varieties not up to standard of excellence desired, but the best of each season and color available among the commonly grown kinds. In several of the seasons more than one variety of the same color are named, to give greater variety in quality. This shows the $3 \mathrm{rd}$ and 4 th periods well supplied for northern regions which cannot extend beyond the 5 th period, and few of these varieties are satisfactory in the South. 


\section{Most Available List of Common Varieties of Grapes, for North and South}

\begin{tabular}{|c|c|c|}
\hline Red. & Black. & Yellowish Green. \\
\hline $\begin{array}{l}\text { 1. } \\
\text { Moyer. } \\
\text { 2. Norfolk (Progress) } \\
\text { Brighton. } \\
\text { Wyoning. } \\
\text { 3. Delaware. } \\
\text { Lindley. } \\
\text { Salem. Agawam. } \\
\text { Jefferson. } \\
\text { 4. Diana. } \\
\text { 5. Catawba. } \\
\text { Goethe. } \\
\text { 6. Herbemont. } \\
\text { 7. } \\
\text { 8. } \\
\text { 9. }\end{array}$ & $\begin{array}{l}\text { Champion. Early Ohio. } \\
\text { Moore Early. } \\
\text { Nectar. } \\
\text { Campbell Early. } \\
\text { Aminia. } \\
\text { Worden. } \\
\text { Early Victor. } \\
\text { Ives. Herbert. } \\
\text { Concord. } \\
\text { Wilder. Barry. } \\
\text { Highland. } \\
\text { Lenoir. } \\
\text { Thomas. }\end{array}$ & $\begin{array}{l}\text { Martha. } \\
\text { Missouri Riesling. } \\
\text { Pocklington. } \\
\text { Triumph. } \\
\text { Scuppernong. }\end{array}$ \\
\hline
\end{tabular}

This shows the South with little more than half the available time supplied with grapes, and then, when we remember that only some four or five of the varieties named are adapted to the climate, while the others are of ordinary or poor quality, and not a variety in the list without some serious defect, we come to understand the vast work yet to be done by originators of new varieties of grapes.

\section{Vineyards Planted by the Author}

Vineyard No. 1. Two acres, planted in 1878-9, on strong, black limestone soii, containing 25 to 40 per cent carbonate of lime, with eastern exposure at top of Red River bluffs, south side of river, in northern suburbs of Denison, Texas.

Vineyard No. 2. One acre, planted in 1881-2, adjoining vineyard No. 1, lower down the eastern slope.

Vineyard No. 3. One-half acre, adjoining vineyard No. 2, on the south.

Vineyard No. 4. Two acres, planted in 1886-7, on deep light sandy soil on yellow clay subsoil, eastern slope, in southern suburbs of Denison, Texas, two miles southwest of vineyards $1,2,3$.

Vineyard No. 5. Four acres, planted in 1887, southwest of vineyard No. 4, two hundred yards, on a deep reddish sandv soil, on a red clay subsoil 18 to 24 inches below surface, with southern and southwestern exposure.

Vineyard No. 6. Two acres, adjoining vineyard No. 5 on the east, with same character of soil, and southern slope.

Vineyard No. 7. One acre, planted in 1894, adjoining vineyard No. 4 on the south, with same character of soil, with eastern, western and southern slope.

Vineyard No. 8. One-eighth acre, adjoining vineyard No. 6 on the east, with similar soil and exposure.

Vineyard No. 9. Four and one-half acres, eastern exposure, sandy soil, leading old and new kinds, planted in 1904.

Vineyard No. 10. Testing 400 of my latest hybrid-combinations of my older hybrids, one-half acre, planted in 1904 . 
The leading and most of the better American varieties, and a good many Vinifera varieties, and vines of all the native species, were planted in the vineyards. Not all were planted in all the vineyards, but all, or nearly all, were grown in both the limy and sandy soil. The leading varieties were grown in marketable quantities. (See Chapter II. for partial list of species and varieties planted in the vineyards.)

\section{Grape Nurseries, Planted with Cuttings}

Each year since 1880, from one to five acres of land have been devoted to growing plants from cuttings of nearly all introduced varieties that were planted in the vineyards, including, during several years, all the native wild grape species of the United States, excepting $V$. rotundifolia and $V$. Munsoniana, which do not grow from cuttings, but are propagated by layering in vineyard.

\section{Seedling Grape Nurseries}

Since 1881, when the first were planted in Texas, some ten different years, large numbers of select and hybridized grape seeds have been planted, carefully tilled, studied, culled and the young vines transplanted and rigidly tested in test vineyards, as described in Chapter II.

After thus educating myself for the work and making such extensive preparation for the origination of varieties, which were essential to vineyard culture, to enable it to fill its entire sphere, few persons regarded my effort otherwise than that of a "crank," and often have I heard myself mentioned as the "vine crank." This, to me, was good evidence that my object was not comprehended; that the special knowledge necessary to comprehend it, and become interested in it, was lacking generally among grape growers, and even among the majority of writers upon grapes. It was clear to me that, in order to make the work generally beneficial, and regarded with any degree of favor by the public, the people must be educated.

Not until 1885 did the writer attempt a new classification of species, and that has undergone much revision and change in its author's hands.

The exhaustive and complete description and classification of North American Grapes, given in Chapter I., brings this work up to the present date, and I trust this part of the work will be interesting to botanists as well as to viticultural students.

That part of the work upon Breeding Varieties (Chapter II.), I hope will attract the attention of originators and that it may also incite the boys,- and girls, too,-on the farm. and in every home where grapes are grown, to spend some of their recreation time in this fascinating and delightful work.

Part Second is prepared especially to aid those engaged in any way in growing grapes for the family or market. 


\section{Acknowledgments}

To the hundreds of persons, too numerous to mention by name, who so kindly aided me in this work by facts and specimens, I am profoundly grateful.

Mr. G. W. Moore, of Denison, Texas, who made the photographs, from which the half-tones are made, has, by his skill, put into the book its chief attraction.

For the excellent execution of the half-tones, the complete printing and binding of the book, we are indebted to the Greeley Printery of St. Louis, for which they have our deep appreciation.

To my noble son, William Bell Munson, who has so constantly and ably helped me in correspondence and in proofreading this book, I have the most affectionate gratitude.

To my attentive and talented daughter, Viala Laussel, (now Mrs. W. C. Green), for typewriting the manuscript most excellently, tho so difficult, I bear a doting father's deepest affections, and to my five other children and my devoted wife who have so often rendered aid in testing varieties and criticising flavors, I have an equal share of love, of which this book is my memorial.

THE AUTHOR.

\section{Erratum}

On page 252 under "List of Tables" first line "Classification of American Grapes" should read page 24 instead of 124 . 


\section{Chapter I.}

\section{Botany of American Grapes}

\section{Introductory Remarks on Classification}

The importance of such work as this is apparent when we consider that the Vinifera varieties, which all along have supplied the world with wine, with table and raisin grapes, are an easy prey of Phylloxera, Downy Mildew and Black Rot, and that these maladies are yearly spreading, that satisfactory remedies have as yet not been found, save in rot- and phylloxera-resisting American vines, and that we have several species which are eminently resistive, making excellent stocks to graft the Vinifera upon, and also possessed of qualities of fruit, which, by aid of intelligent selection and hybridization, have given direct producers of great value. The importance of not postponing longer such work, is very great, when we consider that no previous special and extended scientific study of the genus, upon growing vines in their native homes and side by side in the vineyard through every stage of growth from the seed to the mature vine, has been made in this country, and that from the character of the vine and the greediness with which the cattle devour all species of it, most of the species of greatest value, in a few years, will become almost extinct in their native habitats by the increasing inroads of land-clearing and stock-browsing, and thus the fine wild varieties, which should be searched out and saved as the basis of future vineyards, will be lost forever and not even their history be known, or in what region those in cultivation had their origin.

It is important in such a treatise, that the classification be based as far as possible upon natural relationships and adaptabilities, that the descriptions be so minute and full that any person with the slightest botanical knowledge can at once identify a species by the descriptions, even if only a part of a plant be had in hand. To construct such descriptions requires great familiarity with and long continued careful observation of many individuals of each species treated. It requires a familiarity with the best authors to avoid confusion in classification and nomenclature. . It requires the study of the species in their native soils and climates, and the extent of their natural distributions. It requires abundant herbarial specimens from many regions for comparison, and also growing vines in vineyard culture, to make such a work comprehensive and enduring. Above all, it requires a keen observer, and unswerving regard for pure facts, correlative comparison and cautious conclusions on every theoretical point.

With these requirements in mind, has the writer pursued this study purely for the love of it, repeatedly reviewing all his former work, revising, correcting and making many new investigations, traveling long journeys, conducting expensive correspondence, sparing no pains or expense to make the work what it should be, regardless of the compensation that might be awarded him in its publication.

\section{Classification}

Various orders of classification might be used according to certain characteristic markings that might be chosen from, roots, wood, leaves, clusters, berries, or seeds, or by combination of two or more such characteristics.

Were it possible to obtain the chronological order of development of the species with their first progenitors as they branched off from the great family of Ampclidece to become true grapes, it would be an easy matter to make the natural and most proper classification, by giving the chronology of procession with the interminglings of the prior species of $A$ mpelidea into hybrids 
which gradually became species, as well as the branches which also became species by natural variation, by being carried to widely differing conditions of soil and climate, and those that may have come by "mutation," or rather by reversion to some former type, according to the Mendellian law.

Wanting the chronology and actual genealogy, we try to infer it as nearly as possible from the similarities in forms of the different parts of individuals of the different species and especially from biological similarities, as in periods of leafing, flowering, ripening, casting of leaves, adaptability to certain climates, altitudes, soils, similarity in flavor, relative ease of growing from cuttings, texture, lines of distribution in nature, fixity and uniformity of type, etc. Though we cannot expect to more than approximate the chronological order of development, yet any approximation in classification is far better upon which to base practical viticulture, than a purely artificial arrangement.

In order to well understand the full scope of the phrase "Improvement of American Grapes," we must have a clear idea of the kinds and character of the wild grapes which are native in the United States, and in what regions, locations and conditions they grow.

Hence, some tangible presentation of the different species is necessary to comprehend their relationships, and why they should be classified one way rather than another, but that would require more space than can be allowed here, so we must make it suffice by presenting some engravings of typical specimens of the species best adapted to be used as first parents in crossing and hybridizing to get varieties profitable in practical vineyard culture; and to show by skeleton or outline classifications how the species have been found by critical study to be related, without attempting to prove such relationships.

At this point, a careful study of all the plates is suggested.

The seeds, Plate I., are shown arranged in groups, designated as Series, according to natural relationships, as nearly as it is possible to do so, after years of critical study of all the species side by side.

The species in each series are much more nearly allied to the other species shown in the same series, than to species in any other series, not only in botanical character, but in habits of growth, flowering, fruiting, and soil and climatic adaptation, hence the recognition of these relationships is of much practical importance in vine culture, especially to the intelligent originator of varieties.

As to the relationships of the series to each other, there is much more division of opinion among botanists, and it is of less practical application.

Plate I. was arranged in 1892 , since when I have found a slight change in relative position of species, which aids systemization, as will be seen by comparing Plate $\mathrm{I}$. with the outline scheme, next to be presented.

With the above considerations in view, a tree-like form of synopsis of classification would best represent the genus; and I suggest the outline grouping of species to be found on page 24 . 


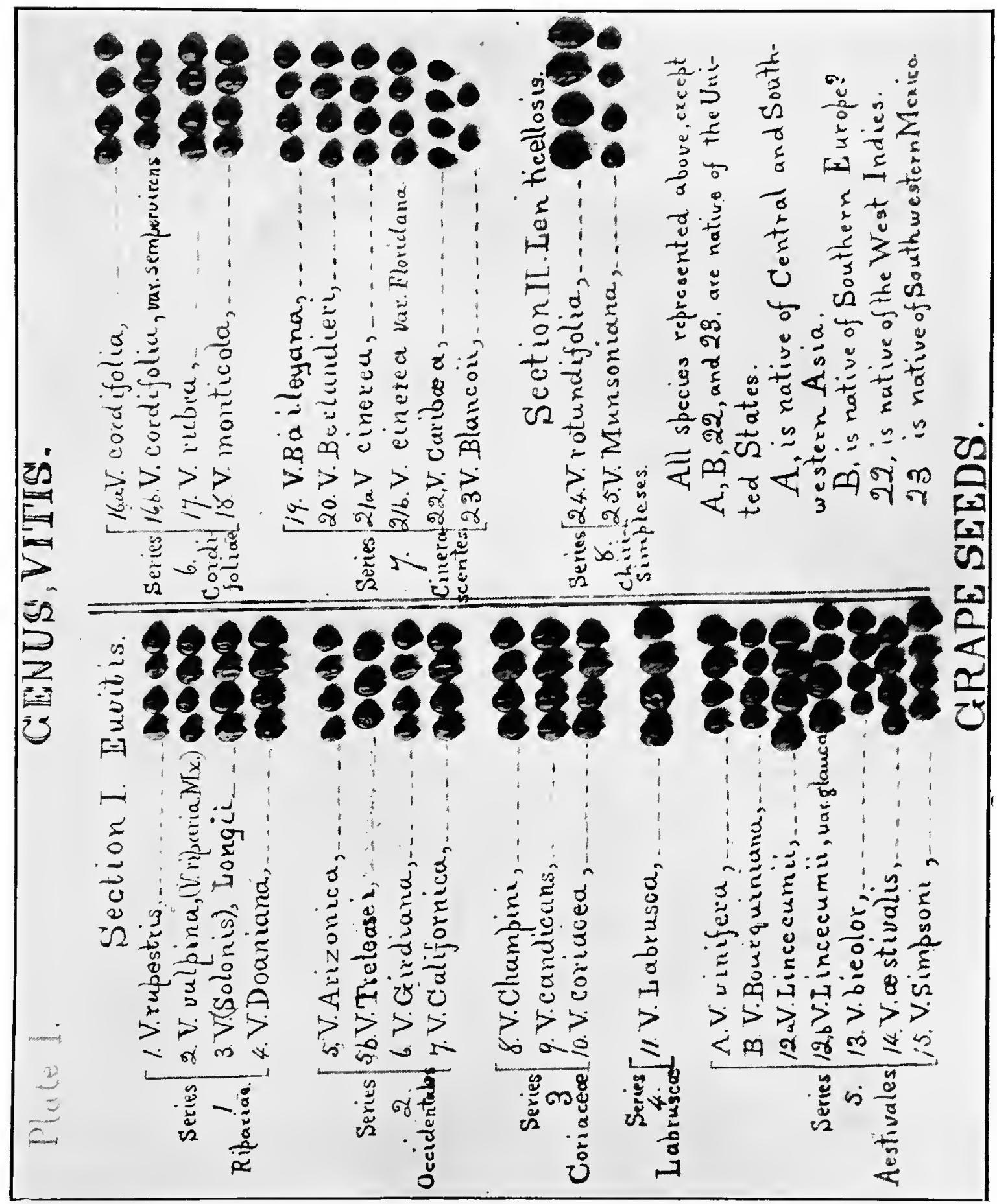

PLATE I.

All plates of grapes, leaves, seeds, wood and flowers in this work are made exactly life-size. 
Explanation of Plate II.

Mature One Year Wood.

2. V. coriacea.

-3. V. candicans.

4. V. Doaniana.

5. V. Champini.

18. V. Californica.

19. V. Girdiana.

20. V. Arizonica.

21. V. Treleasei.

22. V. vulpina. (V.riparia.)

23. V. Longii.

24. V. rupestris. 


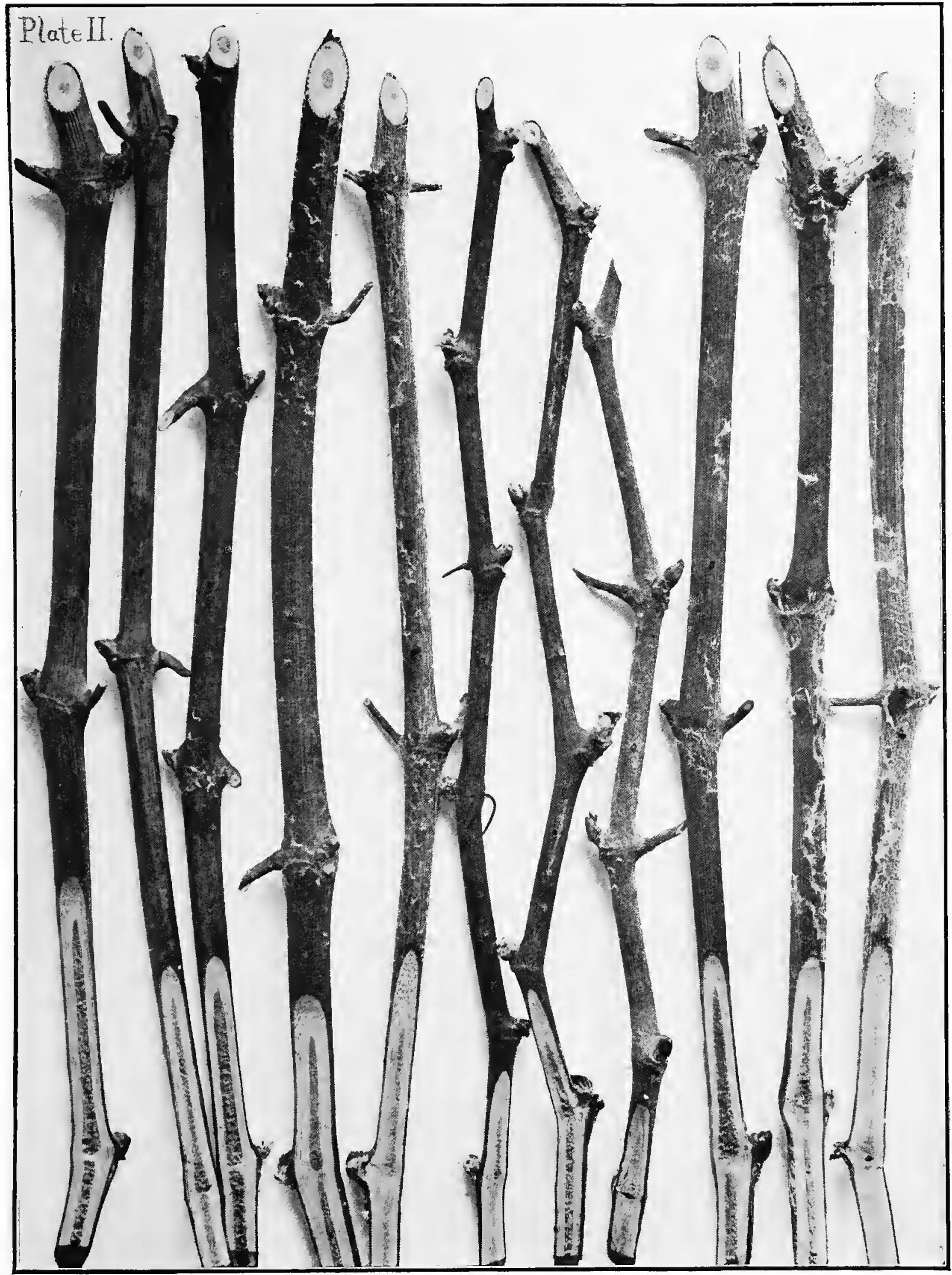

24.

22. 23.

4. 20.

21.

19.

18.

5.

3.

2. 


\section{Explanation of Plate III.}

Mature One Year Wood.

1. V. labrusca.

a. V. vinifera.

b1. V. Bourquiniana. (Herbemont.)

b2. V. Bourquiniana. (Devereux.)

6a. V. Lincecumii. (Typical.)

6b. V. Lincecumii, var. glanca.

7. $V$. bicolor.

8. V. cestivalis.

9. V. Simpsoni. 


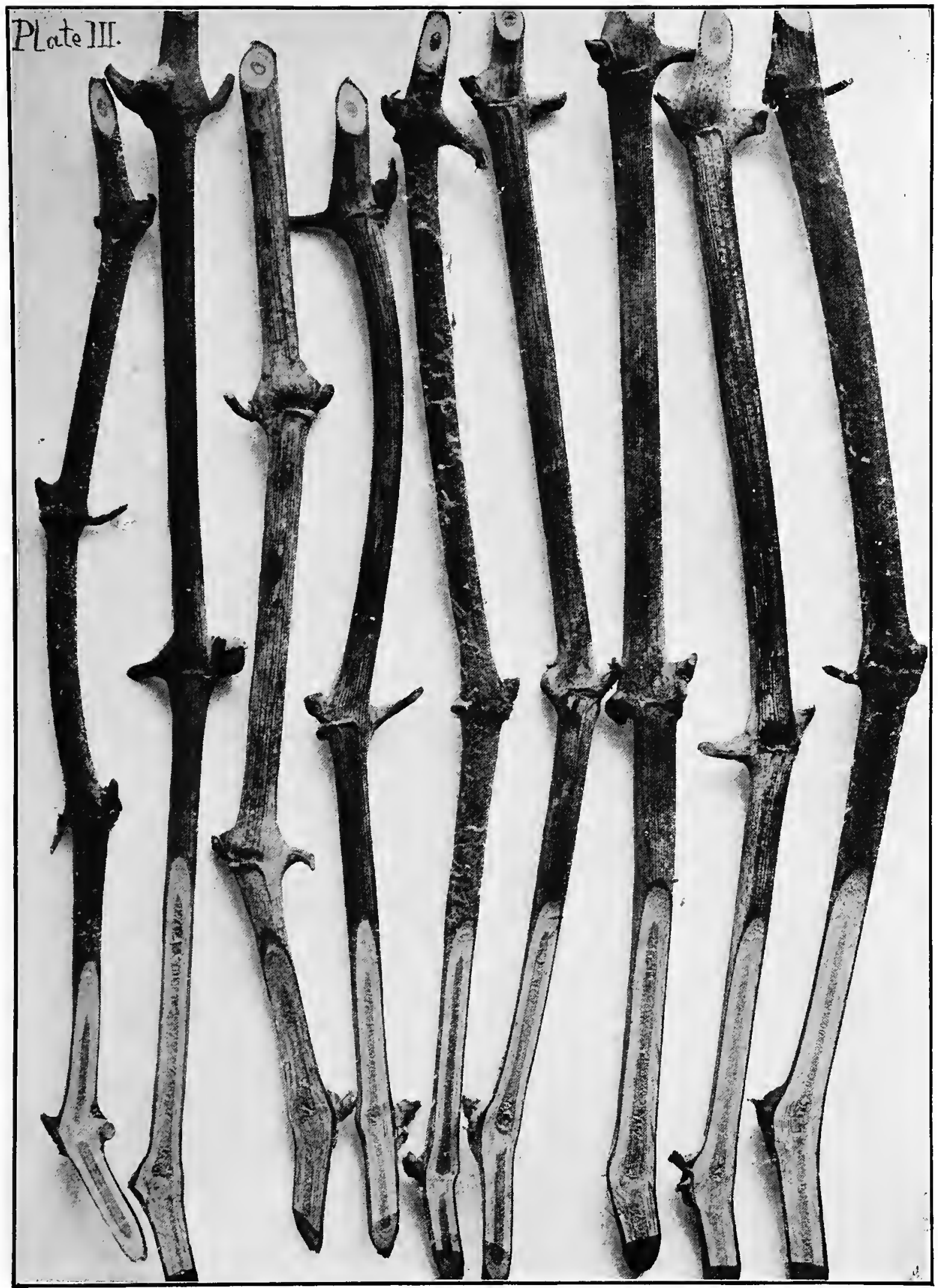

1. a.

b.1. b.2. 6a. $6 \mathrm{~b}$.

7.

8.

9. 


\section{Explanation of Plate IV.}

Mature One Year Wood.

15a. I. cordifolia.

15b. V. cordifolia, var. sempervirens

16. V. rubra.

17. V. Monticola.

10. V. Blancoii.

12a. I cinerea.

12b. V. cincrea, var. Floridana.

13. V. Berlandieri.

14. T. Baileyana. 


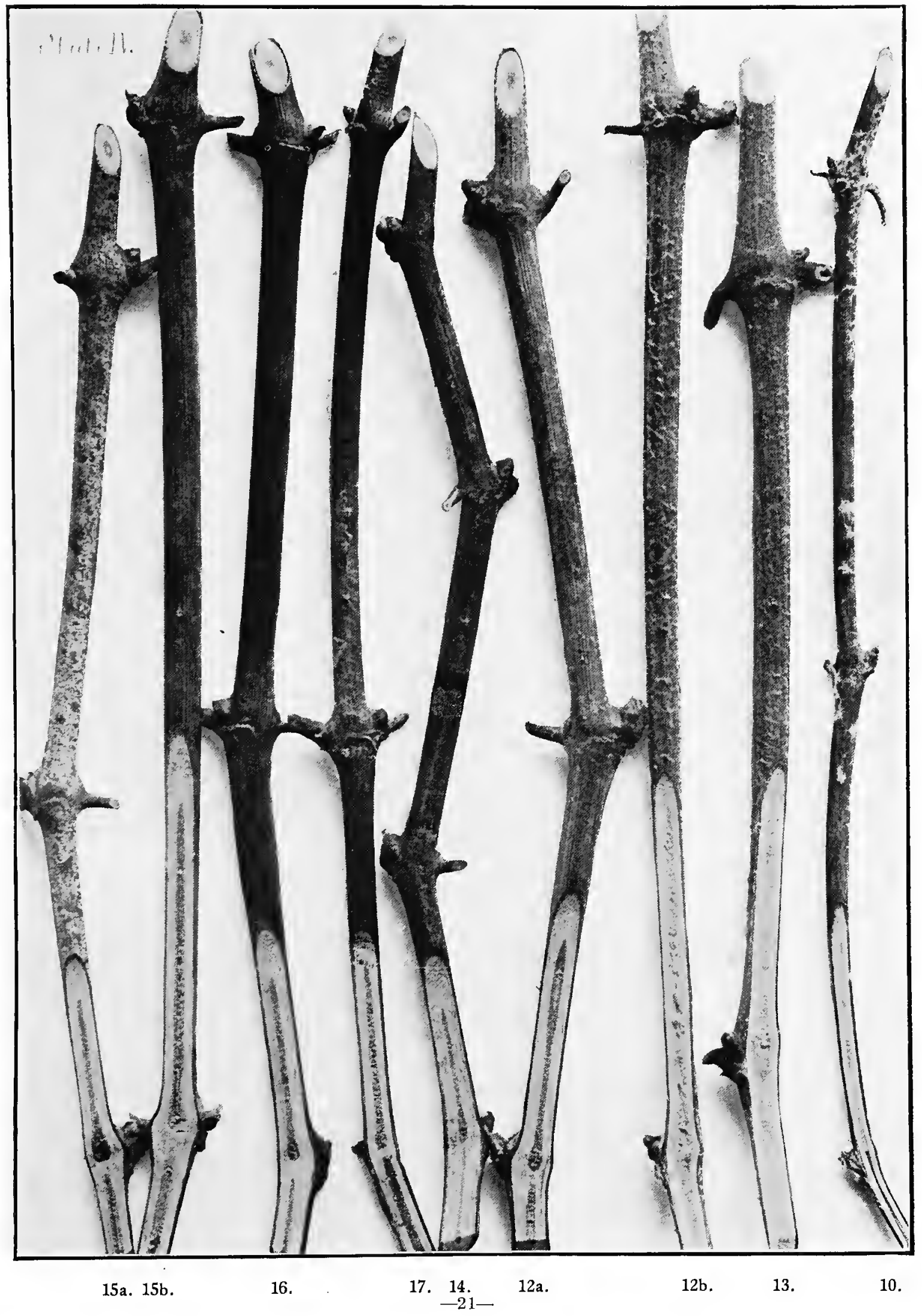


Explanation of Plate V.

Mature One Year Wood.

25. V. rotundifolia.

26. V. Munsoniana. 


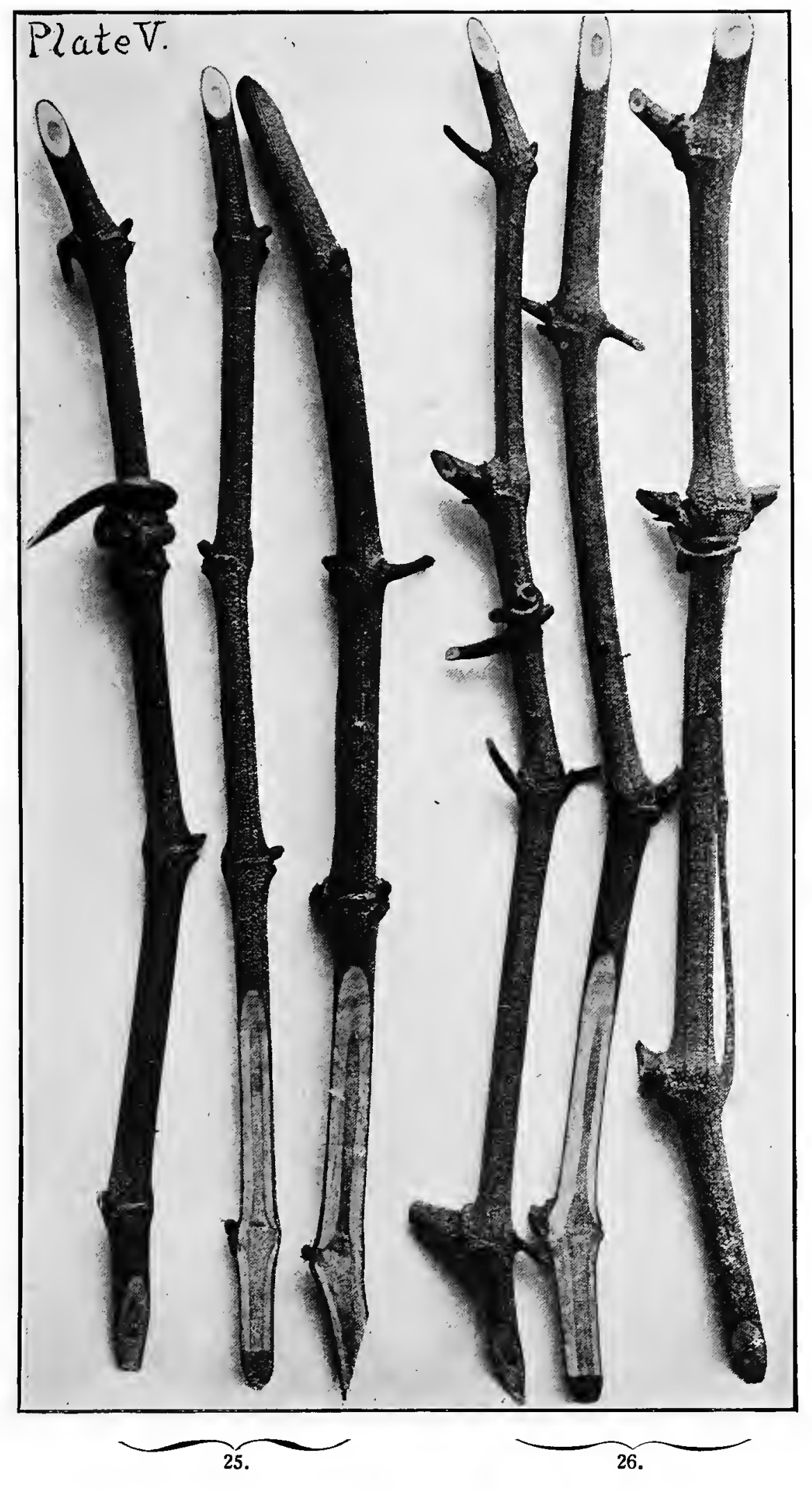




\section{Scheme of Classification of American Grapes}

According to natural relationships as nearly as possible, by T. V. Munson.

Genus.

Sections.

Groups.

Series.

Species.

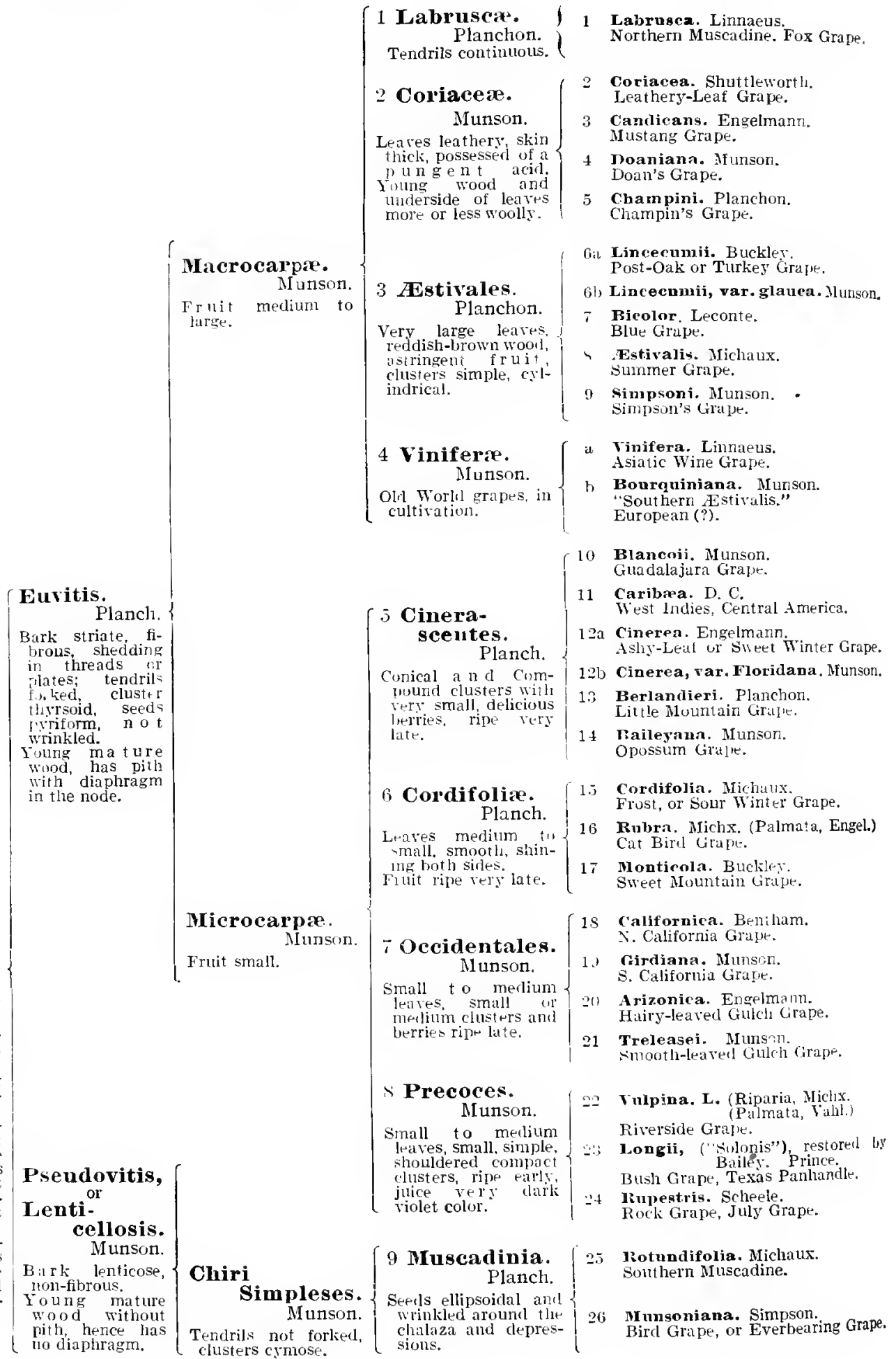

Vitis.

Tonrnefort. (Iil part)

Vintes climbing by ti-luirils opposits ine leaves.

Cololla sheddirg a $s$ a wlicet sliaped cap.

Generally direcious in $\mathrm{w}$ i l ll n a t ure, the female fionirs laving s hor t recurved stamells and not self-fertile.

Many hermaphrodite varietits self-fertile have heen producil under cultisation.
4 Viniferae.
olil Worlil arapes in

\section{Cinera- Planch. \\ Conical a nd Com- small, delicious late.}

\section{Cordifoliae.} Munson.

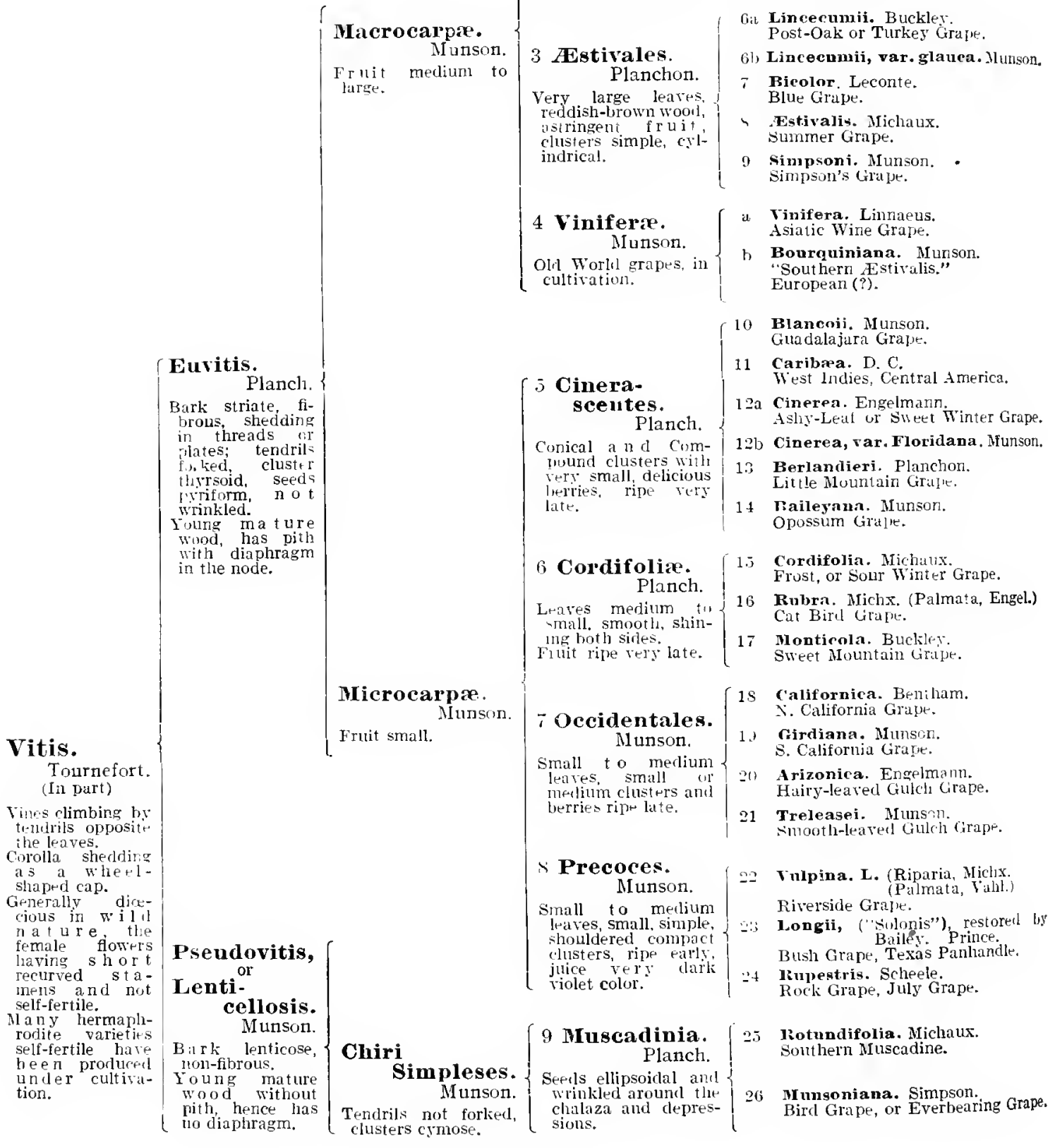




\section{Description of Species}

\section{Series I. Labruscæ}

1. VITIS LABRUSCA, Linnaeus, Spec. 203 in part. (See Plate VI.)

Synonyms: *

V. taurina, Walter, p. 242.

$V$. palmata, pullata and tenuifolia, LeConte, II. cc. 271 and 707 .

$V$ bracteata, LeConte, 11, cc.

"Fox Grape," "Northern Muscadine," "Swamp Grape," in Tennessee.

Plant: Moderately tapering or stocky, climbing 20 to 40 feet or more; leaves expanding slowly, leaving the extending tip of branch somewhat naked in appearance.

Roots: Spreading, rather soft and fleshy, not deeply penetrating.

Wood: When young usually cylindrical or rarely obscurely angled and covered with yellowish or whitish tomentum which becomes flocculent and sheds by end of first season; spinous pubescence, with glandular tips is found on annual wood of many plants; in a few such pubescence is abundant, especially near the nodes, and gives a rasp-like feeling when the hand is rubbed along the shoot. Bark finely and regularly striated, moderately firm when mature, becoming, at maturity, pale or dark brown or chestnut in color; epidermis separating into thin fibrous plates, and shedding the second year; section of annual wood shows rays thin, pores numerous, of medium or small size; nodes bent, moderately enlarged; diaphragm $1 / 12^{\prime}$ to $1 / 8^{\prime} \dagger$ thick; biconcave; buds medium large, conical, acute or less frequently globose-acute, covered with dark brown scales, in expanding, medium to large, rošy, woolly at tip; tendrils, in well grown wood, one on every node, continuous, - a striking characteristic, being the only species possessing generally such tendrils; usually once, but often twice forked, medium to long, cottony when young, smooth and finely striated when mature; color brown, same as wood, persistent; internodes $2^{\prime}$ to $5^{\prime}$ or $6^{\prime}$, sometimes $8^{\prime}$ to $10^{\prime}$ long in very rapid growth, average $3^{\prime}$ to $4^{\prime}$; pith medium, moderately and gradually enlarged at lower end, color light brown.

Leaves: Stipules medium to small, $1 / 8^{\prime}$ to $1 / 6^{\prime}$ long, by $1 / 10^{\prime}$ to $1 / 8^{\prime}$ wide, membranaceous, delicately hairy; petiole large, enlarged for about $1 / 2$ its length next to base, then narrowed for about $1 / 3$ its lenfth, gradually enlarging again to its insertion; obscurely polygonal, without a superior groove, cottony, finely pubescent along line of the obsolete groove. Blade varies from $3^{\prime}$ to $8^{\prime}$ broad by $212^{\prime}$ to $7^{\prime}$ in length, average width about $41 / 2^{\prime}$, commonly twice the length of petiole, average length $4^{\prime}$, nearly plane, sometimes convexing upward, much less than in $V$. candicans in specimens from South Atlantic States, the reverse in more northern specimens; basal sinus rather deep, narrowly or broadly $\Lambda$ shaped, with curved sides, sometimes closed entirely by the lapping limbs, never truncate; generally slightly lobed, often unequally so, as in $V$. cinerea, but less prominent, lobes mostly acute at summit with shallow narrow sinuses; teeth small, usually a very little convexing or with straight margins, mucronate; notches between generally angularly scalloped, obtuse, in some acute, margin eroded as if nibbled by mice; in New York and New England specimens often showing $V$. vulpina characteristics, in sharp teeth and shoulders, and in Virginia, Tennessee and Georgia specimens, small convex teeth, as in $V$. astivalis, or almost entire as in $V$. cinerea. Venation prominent from the 7 to 8 nearly opposite pairs of ribs, partially obscured by the short, dense, whitish or brownish persistent felt on under side between the ribs, the ribs and the petiole being only sparingly cottony; upper surface densely appressed hairy, which is of a buff or pinkish color at first, becoming scattering and floccose and shedding in maturity, leaving a wrinkled, dark dull green surface. Leaves on ground shoots of old wood 3 to 5 lobed; on young seedlings entire.

* No attempt is made to give complete synonymy in this work, but sufficient to clearly indicate the species $t^{\prime}$ A sign for inch. 


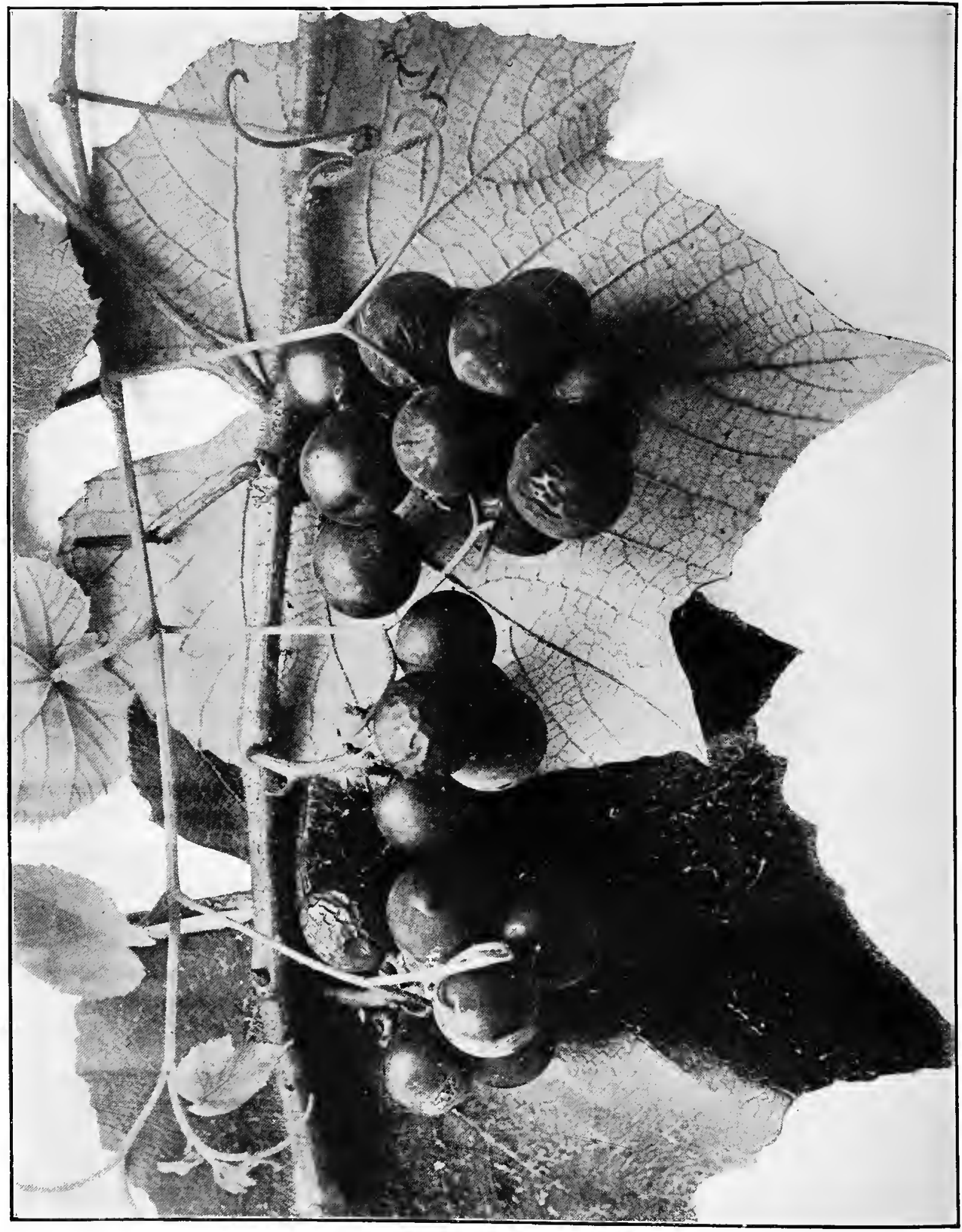

PLATE VI. VITIS LABRUSCA, Linnaeus. (Typical.)

Fox Grape, or Northern Muscadine Grape. From N. Carolina. 
Cluster: Fertile, small to medium, $2^{\prime}$ to $4^{\prime}$ or more long, small shoulder, generally with short peduncle; rachis simple, thinly cottony; pedicels $1 / 8^{\prime}$ to $1 / 4^{\prime}$ long, enlarged at top, more or less warty. Sterile, much larger, compound.

Flowers: Fertile,- - stamens generally short, recurved and bent laterally, but ascending or erect in most cultivated varieties, as in Ives, Perkins, Hartford, Concord, and then readily selffertilizing; ovary small, ovate; style slender, stigma small. Sterile-stamens long, erect, commence blooming a few days earlier than the fertile.

Berries: Medium to very large, $1 / 2^{\prime}$ to $1^{\prime}$ in diameter, spherical, or oblate, color generally dull black, with little or no prunose bloom in purest forms, rarely red or greenish-white in nature, often so produced by cultivation, especially among Concord seedlings, drops readily when ripe, or little persistent; skin generally thick and tough, becoming tender in cultivation, often, in wild varieties, pungent, similar to $V$. candicans, and always possesses a musky odor and flavor, known as "foxy;" pulp tough, slippery, acid.

Seeds : 2 to 4 , medium to large, $1 / 5^{\prime}$ to $1 / 4^{\prime}$ long by $1 / 4^{\prime}$ to $1 / 6^{\prime}$ broad, obcordate, notched at top, color pale purplish or dirty brown at first, darkens with age; beak short, thick, generally well defined; raphe invisible in groove till near its passage over top of seed, then small and slightly elevated to base of beak; chalaza circular, depressed in center, sometimes almost obsolete or merely a crescent-shaped rim on lower edge, seeming like a basin in center of back of seed; groove from beak to chalaza on outer face small, shallow around chalaza, broad and distinct above, running over top of seed, ceasing at commencement of inner ridge; depressions diverging from the beak, broad, distinct, of a lighter yellowish-brown color than body of seed.

Plantlet: Cotyledons (seed-leaves), petiole short, $1 / 16^{\prime}$ to $1 / 12^{\prime}$; blade medium, ovate, acute, dark green; plumule and caulicle light green.

\section{Viticultural Observations and Remarks}

Germination earlier than. in $V$. estivalis, slower than $V$. cordifolia; foliation medium slow; inflorescence early to medium; earliest, such as Ives, soon after $V$. vulpina and continuing much later in such as Martha; at Denison, Texas, blooms generally from the 1st to 12th of May; ripening of fruit very early to medium season.

Growth of plants first year feeble, vigorous when established, in well-drained, alluvial sandy soils; its native vines of New England States endure cold well, but great heat and drouth poorly; little resistant to Phylloxera; Downy Mildew does not affect it much nor does Black Rot often attack its pure native forms, though severe in Concord and its seedlings generally, and very destructive to nearly all hybrids of it with $V$. vinifera. It grows easily from cuttings, though varieties vary much in this respect.

Natural hybrids of it with $V$. vulpina, as in Clinton, Sherman, Taylor, etc., with V. cestivalis in a very slight degree in Norton Virginia and others and with $V$. cordifolia, have been found. Of varieties introduced to cultivation, Isabella and Catawba, and their numerous seedlings, though Eenerally classed as pure $V$. labrusca, undoubtedly possess blood of $V$. vinifera, but we can name Champion, Venango, Ives, Perkins, Dracut Amber, Lutie (an exceedingly foxy, red variety, from Tennessee), and numerous others of the purest type. Some, reported as pure by their originators, give strong evidence of being mixed with $V$. vinifera; such are Iona, Cassady, Niagara, Jefferson, Diana, and a number of others. The Concord, though chiefly of Labrusca blood, clearly shows in itself and many of its seedlings a trace of $V$. vulpina, and it is to that cause, probably, they owe their better quality.

The continuous tendrils, prickles on annual wood, densely rusty felted lower surface of leaves, musky fruit, sunken chalaza and shallow, fibrous roots are characteristics which easily separate it from other species; otherwise, it stands more nearly allied to $V$. Lincecumii, $V$. coriacea and $V$. candicans, than any other species, hence I place it in a separate series in conformity with Planchon. 
The strong, musky odor and flavor is peculiar to this species and found in no other American species save rarely and slightly in $I^{\circ}$. Lincecumii. It is by this odor that skunks, foxes, raccoons and opossums are attracted and select the fruit at night from a vineyard and do not molest other varieties while these remain. There are not a few Americans who from this muskiness prefer this to other species. The peculiar odor and flavor in the "Southern Muscadines"$V$ rotundifolia,- - though very pronounced, is quite different, and greatly refined above the "foxiness" of Labrusca.

I'. labrusca is found naturally in moist, alluvial, sandy soils, from Central New England to South Carolina, Georgia, and Central Tennessee, east of the Alleghanies, and south of the Cumberland ridge. Dr. Engelmann reported that it is not found native within the Mississippi Valley proper. It has been reported to me in Michigan, and in Southwestern Missouri and in Texas, but examination of these claims proved them erroneous. During the summer of 1892 , Professor W. O. Cross, of Louisville, Ky., wrote me that he had for years known of $V$. labrusca being native in some of the southern counties of Indiana and referred me to Prof. A. H. Young, Botanist, of Hanover, Ind., who kindly sent me specimens of $V$. labrusca, taken from a vine found wild in Jefferson Co., Ind, and to Miss Abbie J. Dean, of Marble Hill, Clark Co., Ind., who sent me specimens of two wild vines found in Clark Co., Ind., both of wkich were of the pure I. labrusca, L. These grapes are known in those sections as "Fox Grape," and many vines are reported. Thus it is no longer a doubtful question as to whether $V$. labrusca is native or not west of the Appalachians, but its occurrence so far, as a native, in the Mississippi Valley, as now known, is confined to a limited region in the "Slash" lands of Southern Indiana and again in Maury and adjoining counties in Southern Tennessee, whence Mr. F. M. Ramsey and J. H. H. Boyd sent me specimens of pure wild V. labrusca. Prof. W. O. Cross wrote me in September, 1893, that through reliable sources he had learned that early in the settlement of Kentucky, $Y$ labrusca was a common wild grape in certain tenacious sandy clay lands, "slash land," all through the counties in. Kentucky adjoining the county of Jefferson, in which Louisville is located. Thus it appears that the original native range of this species should have been from and bordering on the Ohio River through Southern Indiana, Kentucky and Tennessee, eastward to the Atlantic, including all the Atlantic states excepting probably Vermont, New Hampshire and Maine.

\section{Series II. Coriaceæ}

\section{VITIS CORIACEA, Shuttleworth. In Herb. Cambridge. (See Plate VII.)}

Synonyms:

V. Coriacea, Chapman, AG.

V. Sinuata, Don Mill. 1. 711.

V. labrusca, var. typica ficifolia. Regel. Comspect. Vitis, 396.

"Florida Grape," "Leather-leaf Grape," "Calloosa Grape."

Plant: Very vigorous, climbing high with age.

Roots: Slender, branching, firm, penetrating.

Wood: When young very woolly, wool becoming floccose and disappearing after first year; shape of section of mature annual wood oval, at first somewhat angled, smooth at maturity; bark: epidermis at end of first year splitting into narrow fibrous plates and shedding second year, true bark finely checked and fibrous with age, persistent, closely resembling $I^{2}$. candicans in this; wood firm but porous, more so than $V$. astivalis; section shows rays distinct, wide apart and pores large; node bulged slightly, somewhat bent; diaphragm very thick, from $1 / 2^{\prime}$ to half way down to next node clearly concave above, buds small, at first conical subtriangular and acute on mature wood, covered with dark brown scales and tipped with red rusty wool, small pinkish in opening, covered with white wool; tendrils generally forked twice, in well developed growth, lengthy, woolly, persistent, medium strength; internodes $2^{\prime}$ to $8^{\prime}$ long, pith enlarged, just above diaphragm and of true pithy character, but below non-fibrous, dense, greenish, drying into discs 


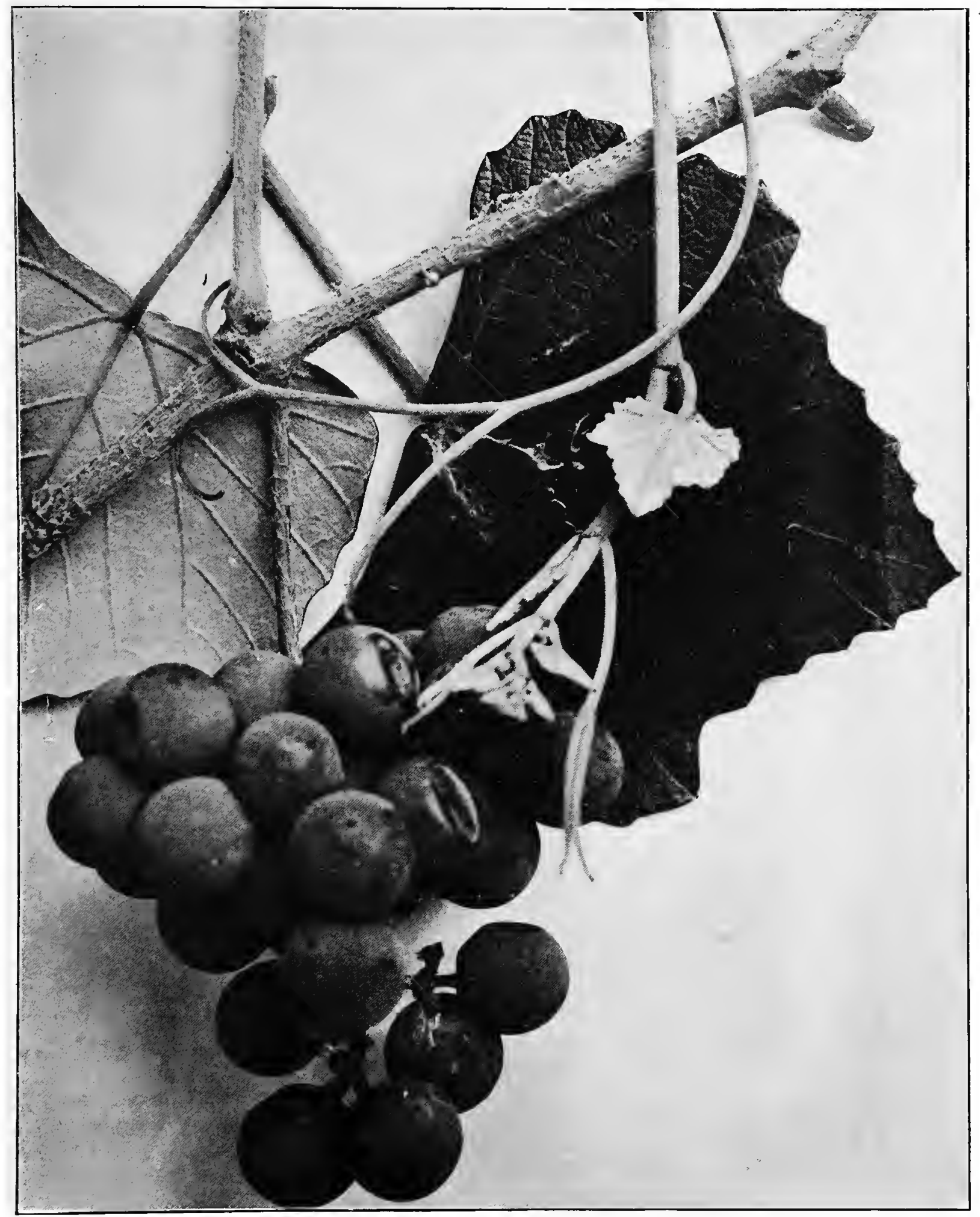

PLATE VII. 2. VITIS CORIACEA, Shuttleworth.

Leatherleaf Grape. Of Florida. 
crosswise, at first white, becoming darker green than the wood, similar to V. Munsoniana, insensibly meeting the diaphragm. All this is very characteristic and clearly distinctive from $V$. candicans, with which some botanists have confused it.

Leaves: Stipules minute, rusty; petiole $1 / 2$ the length of blade, cylindrical, with no visible groove, densely covered with a close felt-like tomentum, whitish when young, brownish with age, similar to underface of blade and young wood though more rusty on petiole, wood and ribs than between the ribs; blade small, width $112^{\prime}$ to $212^{\prime}$, rarely $4^{\prime}$ wide, length $11^{\prime}{ }^{\prime}$ to $2^{\prime}$, rarely $31 / 4^{\prime}$; shape broadly cordate, or nearly reniform, mostly not lobed, generally plane, not convexing upward so much as in $V$. candicans; basal sinus very broad, nearly truncate to broad horse-shoe shaped, acute at insertion of petiole; rarely three lobed with rounded sinuses, summit acute, but not acuminate; margin with shallow, broad scalloped, obtuse, rarely acute teeth; venation, from the generally 6 , sometimes 7 pairs of not prominent, opposite or nearly opposite ribs, which always terminate in a tooth, obscure; upper face at first felt-like, then hairy, floccose and finally smooth, dark shining green, not rugose; under face yellowish-white or rusty or pure white, when very young, felty tomentum, nearly obscuring the ribs and quite so their subdivisions; texture of blade thick, leathery. Leaves of ground shoots from old roots 3 to 5 lobed.

Cluster: Fertile,-small $1 \frac{1}{2} 2^{\prime}$ to $4^{\prime}$, simple or with occasionally one short branch or shoulder; peduncle $11 / 2^{\prime}$ to $21 / 2^{\prime}$ long; rachis thicker than peduncle, both covered with whitish wool; pedicels short, about $1 / 16^{\prime}$ long, enlarging upward, green, warty; receptacle broad, holding well to the red core and white pulp of ripe fruit, as in $V$. candicans, drawing the core out of berry when it is plucked off. This characteristic is peculiar to these two species.

Flowers: Fertile,-bud small green, ovary narrowly ovate, green, lighter toward apex; stigma disc-shaped or hemispherical, lobed, yellow, nearly sessile; sterile,- stamens 5 to 7 , same as in fertile, erect, $1 / 8^{\prime}$ long, smooth, often purple.

Berries few to 16 , medium, $1 / 3^{\prime}$ to $3 / 4^{\prime}$ in diameter, usually dark red or purple, rarely lighter colored, and seldom black; skin thin with red juice around white tough pulp which clings to pedicel; juicy, flavor agreeable, skin not pungent. The fruit clearly reveals its close kinship to $V$. candicans, yet it is a good species, easily distinguished from Candicans.

Seeds: 2 to 5 , small to medium, $1 / 5^{\prime}$ long by $1 / 6^{\prime}$ broad, obcordate, having a notch in top, color of Rio Coffee, when fresh; beak medium size, short, well defined brownish-orange color, paler than body of seed, tip darker, raphe small, becoming obscure in the groove as it passes over top of seed; chalaza distinct in shallow basin, prominent convex narrowly ovate or wedgeshaped, in center of back of seed, gradually passing into raphe; a slight groove extends from basin to beak; ventral depressions curved, distinct, of lighter color than body of seed, short and diverging from beak, color in fresh seeds yellow.

Plantlet: Cotyledons small, ovate, acute, green.

\section{Viticultural Observations and Remarks}

Germination medium to late, little earlier than $V$.candicans, nearly with $V$. Simpsoni, feeble; foliation at Manatee, Florida, about February 20. First species after $V$. Munsoniana there to leaf out, the other species being $V$. Simpsoni, $V$. rotundifolia, $V$. cordifolia; inflorescence at same place, about April 25th to May 1st; fruit ripens there about July 15th. At Denison, Texas, it foliates, flowers and ripens late, about with $V$. Lincecumii or a little earlier than $V$. astivalis. Cuttings grow with the greatest difficulty.

Young plant slender, feeble, but becomes vigorous with age, stronger than $V$. cestivalis, not so strong as $V$. candicans, but of similar habit; endures drouth and heat well but very sensitive to cold, about the same as $V$. vinifera, not enduring the harder winters at Denison, Texas, without protection; resistant to Phylloxera.

It appears to me that this species offers good material upon which to base a valuable strain of table and wine grapes for the Gulf regions where few northern varieties succeed. A variety 
with lobed leaves, found by G. H. Norton near Lake Eustis, bears fruit nearly as large as the Concord, clusters of medium size, quality fair. Birds in Florida are very fond of the fruit of this species, scarcely allowing it to ripen.*

This species, in characteristics, stands between $V$. candicans and $V$. Simpsoni, with smaller, more leathery, more generally not lobed leaves than either, but more nearly allied to $V$. candicans than $V$. Simpsoni.

This species has been found often naturally hybridized with $V$. cordifolia, var. sempervirens, $V$. Simpsoni, and $l^{\circ}$. cinerea, var. Floridana, in Manatee County and other parts of Southern Florida. One of these hybrids with $V$. Simpsoni found by Mr. J. H. Simpson and sent to me is very vigorous, bears well, of a medium sized, good very late fruit, ripe here at Denison, Texas, in September.

Found naturally in rich woods of south half of Florida where nearly all the lands are more or less sandy.

3. VITIS CANDICANS. Engelmann, Grạ̄'s P1. Lindh., 2: 166, 1845. P1. Wright, 1, p. 32, fide Walp.

Ann. Bot. Syst. VII., p. 616. Am. Nat., Aug. 1868.

Synonym:

V. Mustangensis, Buckley, Pat. Off. Rep. 1861, p. 482; Proc. Acad. Sci. Phil. 1861, p. 451.

"Mustang Grape," in Texas.

Plant: Vigorous, rampant, scarcely tapering, climbing the highest trees; making very long annual growth, sometimes 30 or 40 feet.

Roots: Very firm and most deeply penetrating of any species.

Wood: When young more or less angled, densely covered with whitish or yellowish dense to cobwebby wool, becoming floccose late in the season, persistent till second year. Bark on mature annual wood dull grayish-brown, roughish with scattering wart-like blisters, finely striated; on old wood persistent, finely checked, fibrous; wood rather soft under the shears. Sectional view of annual wood cylindrical or oval; rays wide apart, pores between very large and open; nodes moderately enlarged, little bent; diaphragm $1 / 16^{\prime}$ to $1 / 8^{\prime}$ or more thick, nearly plane; bud small, globose or obscurely three-angled, conical, brown when opening, medium pinkish with white woolly covering. Tendrils when well developed nearly always twice forked, very large, strong, clinging well, woolly when young, smooth, pale brown and finely striated when mature; internodes medium to long, $2^{\prime}$ to $6^{\prime}$, sometimes $8^{\prime}$ or $10^{\prime}$; pith medium, dark brown, slightly enlarged at lower end.

Leaves: Stipules of medium length, broad, blunt, crimson or pink, tomentose; petiole $2^{\prime}$ to $3^{\prime}$ long with indistinct groove, densely woolly; blade of medium size, varying in length of midrib from $2 \frac{1}{2}{ }^{\prime}$ to $5^{\prime}$ or more, and in width from $2 \frac{1}{2}{ }^{\prime}$ to $6^{\prime}$ or more, average length $3 \frac{1}{2^{\prime}}$, average width $4^{\prime}$, making a long cordate leaf if it were not so open, or nearly truncate at base, which frequently makes it rounded-deltoid in outline and apparently broad for its length; basal sinus broadly $\Lambda$ shaped or truncate, an acute notch at insertion of petiole, even when the base is truncate; entire or 3 to 5 lobed, border sinuses broad, rounded; summit and lobes right angled or acute; teeth short, usually slightly convex, sometimes scalloped from point, with mucronate point, notches Detween shallow, scalloped. One of the most striking characteristics of this species is the inverted saucer-like shape of blade, being convex toward upper face and attached to petiole at obtuse angle so that the dense foliage of the vine growing over the top of a bush or tree appears somewhat like a canopy shingled with concavo-convex leaves. Venation from the generally 7 opposite or nearly opposite pairs of ribs-each of which terminates a tooth direct, as in $V$. coriacea,-prominent, but obscured by the dense woolly felt on under side, which in young leaves is nearly snow white, becoming dull ashy, never rusty with age, persistent; above, the young leaf is covered

* J. H. Simpson. 


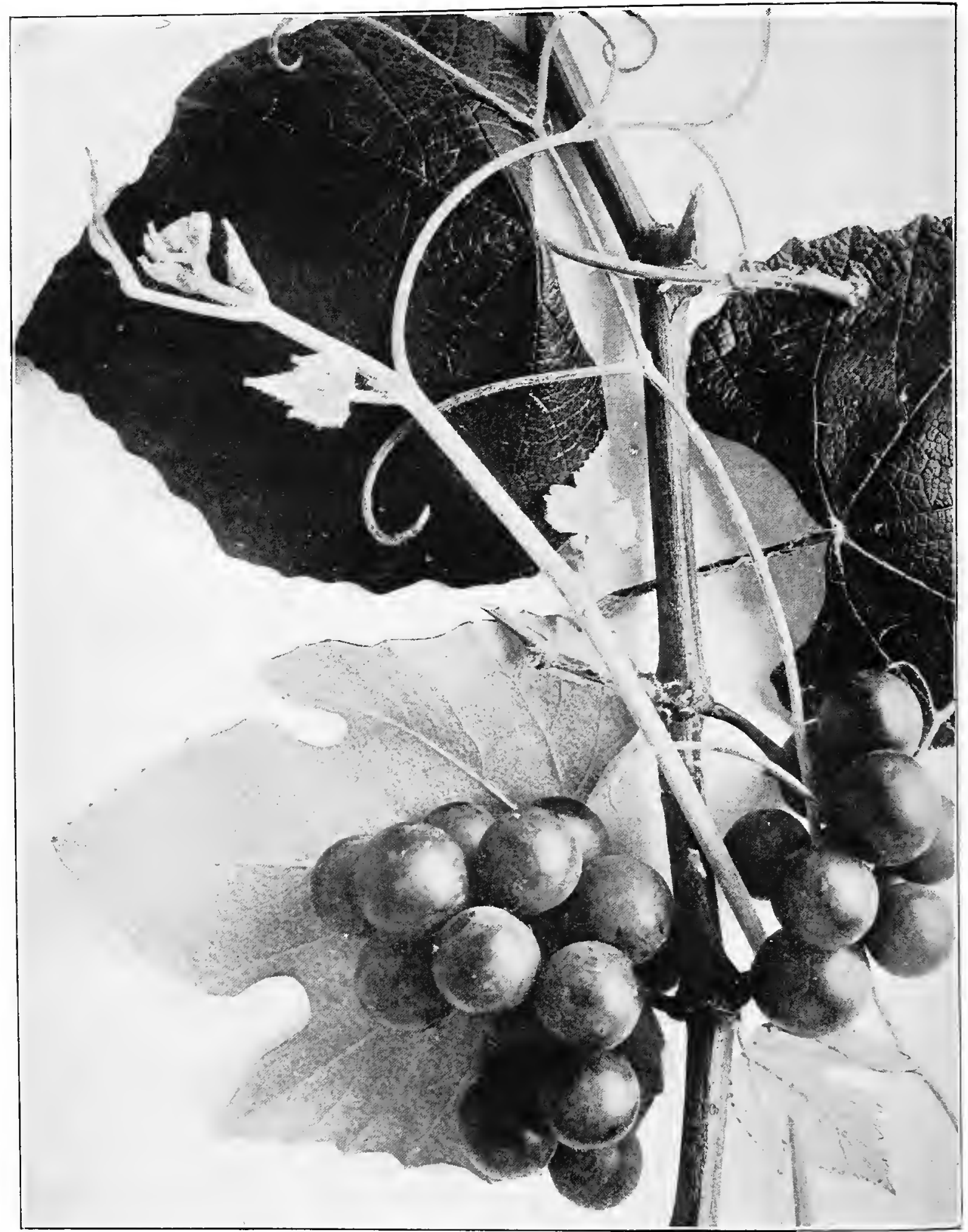

PLATE VIII. VITIS CANDICANS, Engelmann.

Mustang Grape. Northern Texas to Mexico. 
thinly with whitish cobwebby hairs drawn along the surface which become flocculent in maturity and shed late in the season, leaving the upper face dark green, slightly wrinkled, similar to but less than in $V$. labrusca. Leaves on ground shoots of old roots always beautifully palmately 5 to 7 , rarely 9 , lobed; in seedlings 3 to 5 lobed till the third year, which is strikingly different from all other species, in which the leaves are almost entire on young plants.

Cluster: Fertile,-small, $2^{\prime}$ to $3^{\prime}$ long and nearly equally forked; peduncle short and weak; rachis hairy: pedicels long; staminate,-much larger, compound.

Flowers: Fertile,-petals before opening,-the flower-bud-crimson; stamens very short, reflexed and curved laterally; pistil very large; ovary globose; style thick and very short, causing the large white hemispherical stigma to appear nearly sessile; sterile,-flower-bud same as in fertile but smaller, stamens medium strong, with large anther and abundant pollen.

Berries: 5 to 12 in cluster, large to very large, globular, black, very rarely red and still more rarely white; bloom none; skin thick, tough, possessed of a fiery pungency, which renders fruit inedible, unless carefully removed; pulp tough, of a pleasant or rather insipid sweetish taste; betweefl skin and pulp is a jelly-like juice sometimes red, sometimes transparent. Fruit persistent till very late, rarely. if ever, attacked by black rot. Berry separates from the pedicel with difficulty, the pedicel always drawing quite a core, white or crimson, with it from the berry.

Seeds: 2 to 4 of medium size, $1 / 5^{\prime}$ to $1 / t^{\prime}$ long, by $1 / 6^{\prime}$ to $1 / 5^{\prime}$ broad, ovoid when only one in the berry, rounded, not lobed, with a small well defined beak; color of unparched coffee with a brownish tinge; raphe very small, obscure or invisible, nearly imbedded in the ventral ridge; chalaza not very prominent, flat on top, ovate or elliptical, acute at insertion of raphe, center of chalaza rather lower than middle of seed, surrounded by a distinct groove which extends only to top of seed, depressions nearly straight, wide apart, much lighter in color than body of seed.

Plantlet: Caulicle and plumule crimson; seed-leaves small, petiole $1 / 4^{\prime}$; blade generally cupping upward around margin, just the reverse to full grown leaves on old vine; color dark green.

\section{Viticultural Observations and Remarks}

Germination late, about with $V$. astivalis or a little later; foliation early to medium; inflorescence a few days or a week later than $V$. vulpina; fruit ripens early, before $V$. labrusca in most cases but hangs on in good condition till late in autumn.

Plant: Feeble first year from seed, afterward most vigorous, enduring great drouth and heat, but little if any hardier than Herbemont to endure cold; no diseases observed, but it is subject to attacks of the "Leaf-Folder" (Desmia funeralis) which is very fond of it, perhaps owing to the woolly leaves upon which they readily fasten their webs. It is exceedingly difficult to grow from cuttings, lives to great age. The pollen of this species is very effective in fertilizing power upon other species and in impressing characteristics of its own. Even birds will not eat the fruit until dead-ripe, and the only value there may be in it lies in some hybrid forms which will root easily from cuttings and then give a good graft stock, or wine grapes that will succeed well on the "black-waxy" limestone land in which this species is chiefly found.

It has been found naturally hybridized with $V$ : Longii, V. vulpina, V. cinerea, and V. Lincecumii on Red River with Elvira in my vineyard in three instances, one of which is a very handsome red grape of good quality, when no $V$. candicans grew nearer than one-half mile; with $V$. Berlandieri, $V$. monticola, and $V$.rupestris in regions southwest of the Brazos River in many places, northwest from Austin, Texas. In France many artificial hybrids have been produced between this and other species, notably $V$. vinifera, as with Pinot, Aramon, etc., furnishing some excellent wine grapes. Prof E. W. Krause of Waco, Texas, some years ago produced hybrids of it with cultivated varieties.

It ranges from the Arkansas River in Oklahoma southward in Western Arkansas, all Northern Texas as far northward as Clay county, southward through all Texas, east of the 
100th meridian, and in Western Louisiana, and extends across the Rio Grande into Mexico, but so far have been unable to trace it into New Mexico, where it has been reported by some botanists. These were probably the species I have described as $V$. Doaniana. No specimens of it have been received from east of the Mississippi River, except in two instances, from the vicinity of Manatee, Florida, collected by J. H. Simpson. Dr. Enge'mann reported it in Florida, and mentioned nothing of $V$. coriacea there, but after the most diligent search, collection of specimens from many places and growing of seedlings of what was supposed to be it there, only $V$. coriacea, which. might be mistaken for it, save in the instances named above, was found. It would thus appear that Engelmann was correct in reporting it in Florida, though very rare there. It is found of immense size along the overflowed lands of the rivers, along sides and tops of the limy, cretaceous hills of Southwestern Texas, where it luxuriates, and along all the wooded ravines of the black prairies of Texas. It prefers a soil strong in lime, although it thrives in almost any soil. I have seen it with vines 3 to 6 inches in diameter at base extending into tops of cottonwood trees at least 100 feet tall, growing in Red River Bottom in this (Grayson) county.

\section{VITIS DOANIANA, Munson. (See Plate IX.)}

"Doan's Grape."

Plant: Climbing vigorously 15 to 30 feet when among trees, but bushy and ascending when without support, as is often found on the Pease River and Prairie-dog-town-Fork of Red River; when young, covered with white cotton which becomes flocculent on maturity, and upon the dull green leaves gives them a bluish appearance, as also the rapidly expanding young leaves which clothe the growing tips of branches. Seedlings first year rather weak, declining.

Roots: Fibrous, hard, penetrating, tapering from collar in seedlings.

Wood: Mature annual, pale grayish brown; bark finely and regularly striated, old bark finely checked and fibrous, persistent; nodes little bulged; diaphragm medium to thin; buds globose on younger wood, acute on older, large whitish with shade of pink in bursting; tendrils mostly once forked, occasionally twice, medium to strong, woolly or hairy when young; internodes short.

Leaves: Stipules medium $1 / 4^{\prime}$ to $1 / 8^{\prime}$ long by one half as wide, or more, pale pinkish, nearly smooth, or hairy; petiole scarcely more than one-third to one-half width of blade in length, rather thick, distinctly grooved above and striated, cottony in Red River specimens, pubescent in more western from Pease River region; average length of mature blade $4^{\prime}$; average width 4-1/3'; shortest $2^{\prime}$; longest $5^{\prime}$; narrowest $2^{\prime}$; broadest $6^{\prime}$; which represents a regular cordate outline; basal sinus generally $1 / 2^{\prime}$ to $1^{\prime}$ deep, with basal lobes approaching, rarely lapping; blade generally three lobed with narrow, rounded sinuses, closed or open; sometimes shouldered; points of shoulders or lobes acute, as is also summit of central lobe, rarely taper-pointed; teeth medium or shallow, irregular, convex, obtuse or rarely acute; mucronate. Venation from the generally 6 opposite or nearly opposite pairs of ribs, moderately prominent and in upper Red River specimens densely pubescent along ribs and closely felted between with an ashy blue felt, scarcely woolly or cottony, but in Pecos River, Texas, specimens, pubescent along ribs and thickly hairy between; in Red River specimens on upper face wrinkled, cottony and floccose, becoming smooth with age; in western specimens less cottony and less wrinkled; young leaves bearing a dense ashy felt appearing pale bluish in color; color of mature foliage dull dark green; texture thick, dense and leathery. Leaves on ground shoots of old roots 5-, or more, lobed.

Cluster: Small to medium size, peduncle $2^{\prime}$ to $4^{\prime}$ long, compact, shouldered. Staminate much larger than the fertile; rachis and divisions more or less woolly.

Flowers: Fertile,-with short recurved stamens, small anthers, non-virile pollen, pistils short, thick; stile very short, stigma broad; staminate,-stamens ascending, medium in length, anthers large, bearing abundant pollen.

Berries: 1/2' or more in diameter, round, black, with heavy whitish bloom; skin tough, pungent; quality good though a little pulpy; persistent. 


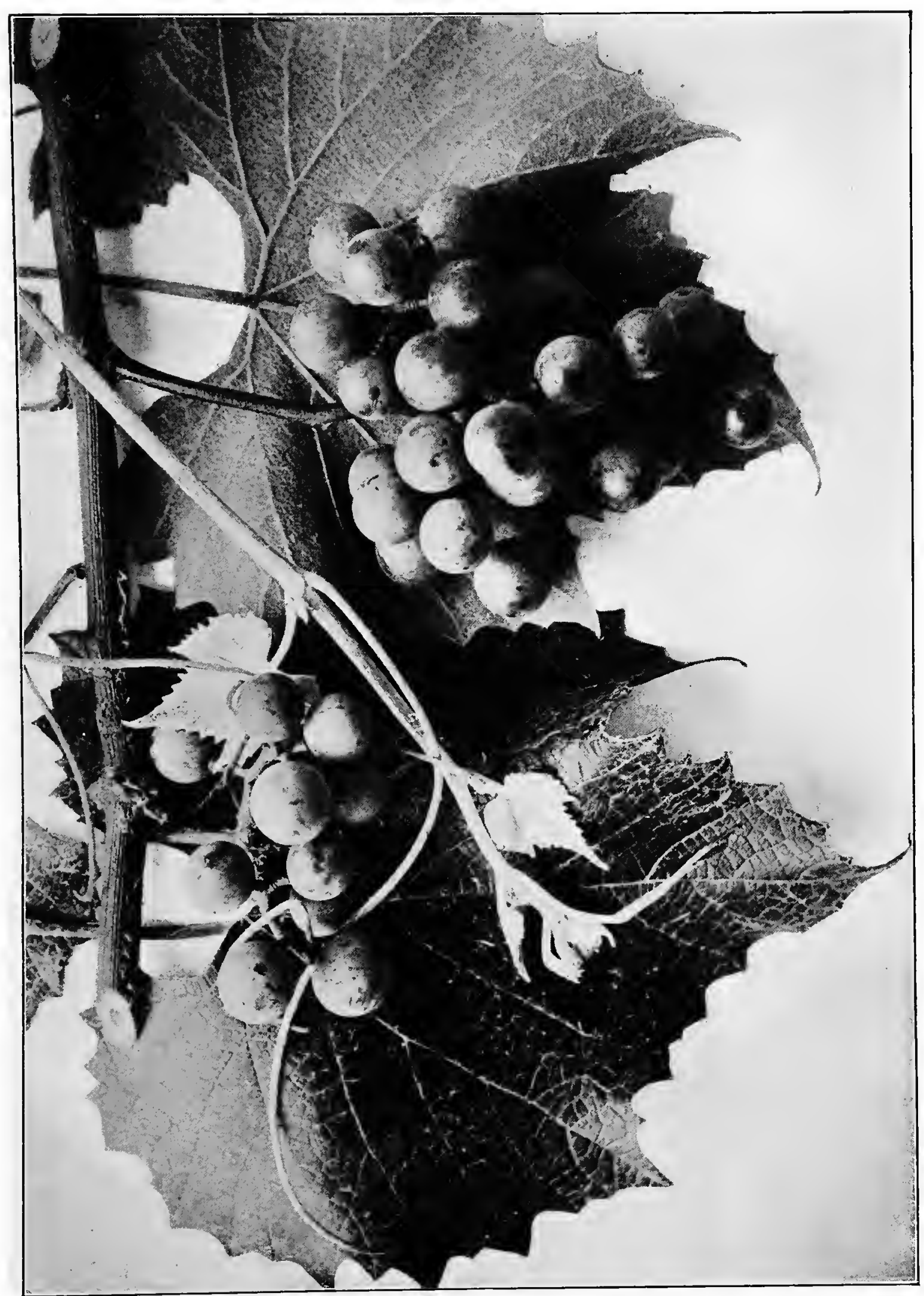

PLATE IX. VITIS DOANIANA, Munson. Doan's Grape. Texas Pan-Handle. 
Seeds: 2 to $4,1 / 4^{\prime}$ or more long, by $1 / 5^{\prime}$ broad, much resembling those of $V$. labrusca in size, shape and color; beak thick, conical, blunt, slightly bilobed at tip, pale yellowish or brownish-white; raphe begins obscurely at beak, becoming distinct $1 / 3$ the way and continuing so to top of seed, which is slightly notched, but raphe is sunken or invisible therein, becoming prominent as it approaches the chalaza; chalaza moderately elevated, narrowly ovate, lying in a shallow basin from the lower end of which a faint groove extends toward the beak; ventral depressions shallow, straight, of same color as beak.

Plantlet: Seed-leaves medium, cordate, pale green.

\section{Viticultural Observations and Remarks}

Germination, foliation, inflorescence and ripening of fruit, early, a little before $V$. labrusca.

This species shows great hardiness in enduring cold, drouth and disease, and promises to be* one of our best species, especially for dry climates. This species seems distantly allied to Ir Arizonica and $V$. candicans though found in regions where neither of these grow. It is nearly related to, and appears to have absorbed some blood of $V$. Longii (as indicated in many specimens seen) in the Red River region, but farther west more of the $V$. Arizonica character. It is clearly separated from $V$. candicans in size of cluster, length of peduncle and quality of fruit and prominently toothed leaves, and from $V$. Arizonica by the much larger leaves, fruit and seeds and greater hardiness.

Its range is through an area of some 300 or 400 miles from Greer County, Oklahoma, along the timber skirts and bushy sand-hills of the streams of the western plains and sand-banks of some streams east of the Pecos River on the Staked Plains in New Mexico and Texas, and probably on the headwaters of the Brazos and Colorado, judging from some reports from those regions. It is possible that this is the form in New Mexico which has been reported as $V$. candicans, have not seen the specimens so reported. I found it abundantly in Donley County, Texas, west of Clarendon. It has been reported to me from Crosby County. Texas, and adjoining counties. All the writer's observations and inquiries failed to secure any evidences of the existence of $I^{r}$. candicans in far Western Texas and New Mexico but find there chiefly the woolly form of $V$ Arizonica and $V$. Doaniana. But investigations in these elevated, rugged and extensive regions have been so limited that one cannot write with a sufficient degree of accuracy of the true character of the native grapes there.

In more recent investigations, since the foregoing was penned, in an extended journey I found no $V$. Doaniana among the mountains west of Pecos River in Texas, in Musa, Limpia, etc., canyons, opening out toward the Pecos River, but plenty of $V$. Arizonica approaching $V$. Longii in some points. It would thus appear that this species ranges from Greer County, Oklahoma, through the Pan-Handle of Texas, and in New Mexico to the Pecos River, but less abundant than $V$. Longii.

$V$. Doaniana fruited in the writer's vineyard in 1890 to 1906 (as did nearly every one of our native species). The fruit in berry and cluster is similar in appearance to the Champion ( $V$. $l a-$ brusca) with longer peduncle, except that it has none of the Labrusca musky or "foxy" odor or flavor, is of pure vinous character, with a slight pungency in skin.

Here then is another wild treasure, from which may spring a grand family of grapes for the arid regions of the West. Judge J. Doan, of Wilbarger County, Texas, for whom the species was named, for years manufactured fine wine from this species, gathered in Greer County, Oklahoma. It is an abundant bearer, and there may be wild varieties found, which will prove profitable for direct production. Judge Doan transplanted a number of the best varieties he found into his grounds years ago.

\section{VITIS CHAMPINI, Planchon. (See Plate X.)}

Plant: Robust, upright, climbing 30 to 40 feet high, with aspect somewhat between $V$. Doaniana and $V$. candicans, with more numerous lateral branches as in $V$. rupestris. 


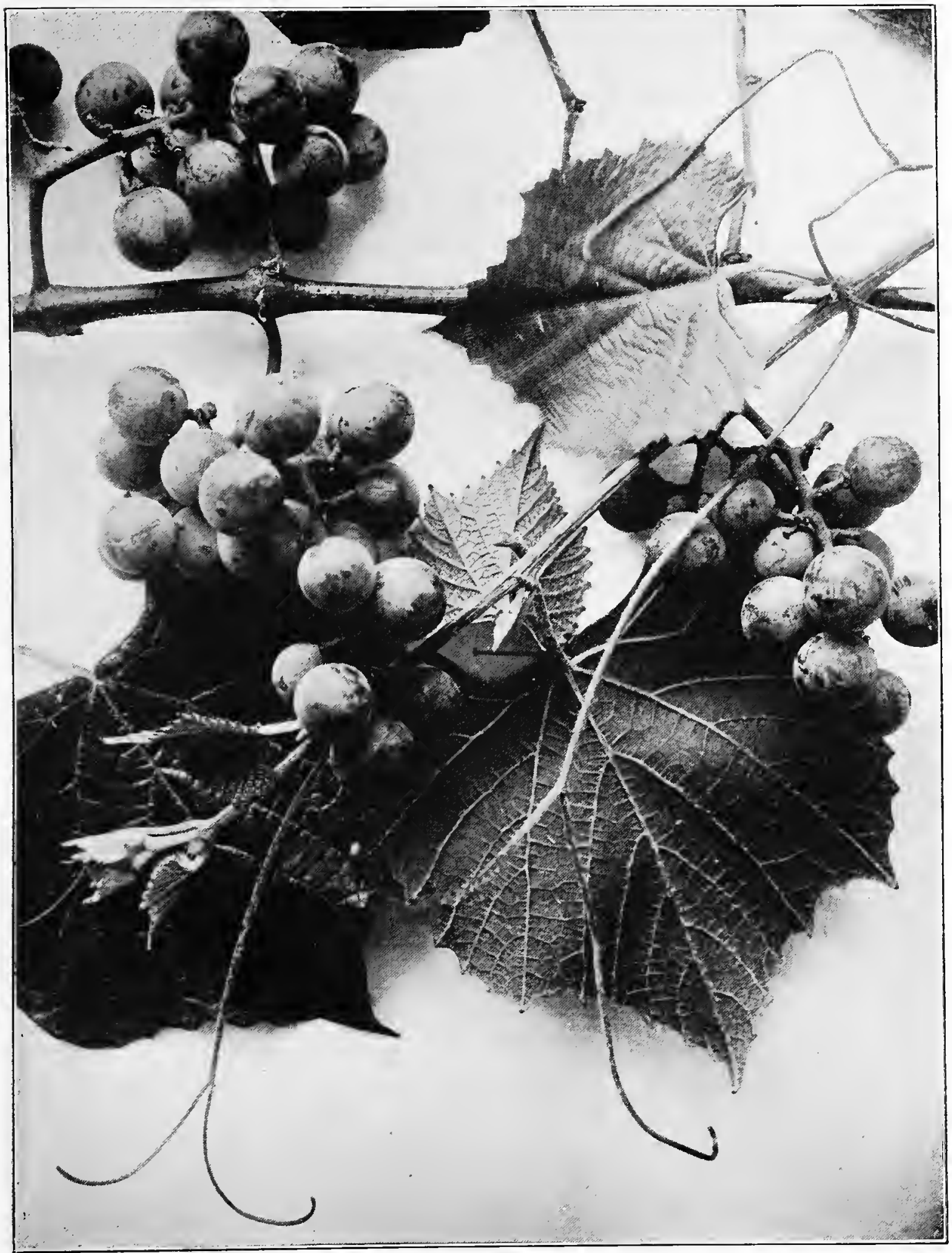

Plate $X$. Vitis ChampinI, Planchon.

Champin's Grape. Llano Co., Texas. 
Roots: In one year seedlings axial, tapering downward; wiry, penetrating very deeply and fully resistant, rooting in the firmest very limy clay soils as well as in sandy land.

Wood: Growing tips less leafy than $V$. Doaniana, more than $V$. candicans, covered with whitish tomentum which mostly disappears with maturity. Wood at first somewhat angled, becoming cylindrical; at first red or green, becoming dark, dull reddish-brown; bark of old wood rather finely checked and persistent; on young wood after first year, flaking off easily, leaving surface beneath of a glossy reddish-brown color; wood firm; nodes swollen, straight; diaphragm $1 / 16^{\prime}$ to $1 / 12^{\prime}$, nearly plane; bud medium, subglobose when dormant, large rusty dark green when expanding; tendrils medium, $3^{\prime}$ to $5^{\prime}$ long, once forked, rarely twice, thinly tomentose; internodes $11 / 2^{\prime}$ to $4^{\prime}$, finely and regularly striated; pith rather thicker in diameter than surrounding annual wood.

Leaves: Stipules $1 / 8^{\prime}$ to $1 / 5^{\prime}$ long by nearly as wide, broad-subovate; thinly tomentose, pale pink at first, browning after two or three days exposure in opening leaves; petiole $1^{\prime}$ to $2^{\prime}$ long, cylindrical, with an obscure groove on upper side, thinly woolly; blade $2 \frac{1}{2}$ ' $^{\prime}$ to $4^{\prime}$ wide, mid-rib $2^{\prime}$ to $3^{\prime}$ long, broad cordate in outline; basal sinus broad, double curved, acute at insertion of petiole; margins rarely lobed, then only with slight shoulders; apex very short, acute; teeth broad, short, irregular, obtuse dentate, with small mucron, usually scalloped between teeth; venation from the generally 6 pairs of ribs; upper surface of blade at first thinly tomentose, becoming dark glossy green at full growth and slightly rugose; lower surface much paler, never glossy, thinly woolly, becoming nearly devoid of tomentum at maturity; foliage has less tomentum and is smaller than V. Doaniana or V. candicans.

Cluster: Fertile, $-112^{\prime}$ to $3^{\prime}$ long, shouldered, shoulder half the length of the main part otherwise simple; peduncle generally as long as cluster; pedicels smooth, $1 / 16^{\prime}$ to $1 / 20^{\prime}$ long staminate, - twice or more as large as the fertile $3^{\prime}$ to $4^{\prime}$ long, shouldered, tomentose, greenish pedicels $1 / 12^{\prime}$ to $1 / 10^{\prime}$ long.

Flowers: Fertile,-large stamens, short recurved, pollen impotent, pistil thick with short thick style and large stigma; staminate,-stamens medium ascending, pollen very abundant.

Berries: Medium, round, black with thin or no prunose bloom when ripe; persistent; skin rather thin, tough, possessed of abundance of coloring matter, little pungency; pulp generally juicy, melting, of rich agreeable flavor, but lacking in sugar.

Seeds: 1 to $3,1 / 6^{\prime}$ to $1 / 4^{\prime}$ long by $1 / 7^{\prime}$ to $1 / 6^{\prime}$ broad, obovoid when but one in a berry; beak short, small or blunt; raphe extends from beak as a very slender imbedded thread or hair in the elevation between two rather deep, nearly parallel ventral depressions which lie close along it, becoming invisible as it passes in the slight groove over the top of the seed and passing gradually into the narrow, elongated, sunken or slightly elevated, chalaza, located in the center of back of seed, or little above, thence a slight groove extends to the beak.

Plantlet: Seed-leaves, petiole $1 / 6^{\prime}$ to $1 / 4^{\prime}$; blade medium, broadly elliptical, acute summit, green, plumule and caulicle crimson; rather vigorous, declining or partly upright first year; leaves always entire on young vines.

\section{Viticultural Observations and Remarks}

Germination later than $V$. Doaniana, about with $V$. vinifera and $V$. cordifolia, foliation with or before $V$. rupestris; inflorescence about with that species; ripening of fruit also nearly as early as $V$. rupestris; exfoliation very late.

Vigorous, stocky habit of growth; grows very readily from cuttings. Takes and carries varieties grafted on it in the best manner, as I have proven in many cases. In quality the fruit. is one of the best of our wild grapes. In view of these qualities it certainly promises to be one of the best graft stocks we have for all soils and especially for regions in France,-as in the Chérente-Inferieur and elsewhere,-where the soils are similar to the dry limy and chalky soils, in which this is so vigorous, in its native habitat, and as a basis to use in hybridizing upon for 
improved varieties. So far as observed, staminate vines of this species are much fewer than are the fertile vines in wild nature.

I now have many excellent varieties of this, found wild, that will do quite well to cultivate for red wine, as it is a very prolific species. I have made hybrids of it with $V$. rupestris, V. monticola, and V. Berlandieri, and with Brilliant and other fine varieties, which are beautiful and vigorous.

For some six years I had been receiving many specimens of this species from Johnson, Llano, Lampasas, Bell, Mills and other counties, regarding it as a hybrid form, and of a similar character to Plachon's V. Champini, which he himself seemed to regard as a young species developed from hybrid strains (p. 237, Ampelidæ, Prod. Vol. 5, 2nd part).

Now having seen many plants of this species growing not very numerously in Bell County and having many from there as well as from the other counties above named, and having hundreds of seedlings growing from these var:ous counties, all with quite uniform and very similar set of characteristics not found among hybrids, I am compelled to regard this as a fairly good and distinct species. It grows readily from cuttings, which is true of no other species found near Belton, Texas, where this is most abundant on the high ridges, all other species there growing from cuttings with the greatest difficulty. I have seen no $V$. rupestris in that vicinity, there being only $V$ monticola, $V$. candicans, and $V$. Berlandieri, besides this, so far as $I$ have traveled or been able to learn from others, and no combination of them could produce this one, having as early foliation, flowering or ripening of fruit. Mr. F. M. Ramsey informed me that he had found this. species quite abundant in some localities in Llano and Gillespie Counties. The vine is readily distinguished by its aspect at a distance.

In Llano, Gillespie, Mason, San Saba, and some adjoining counties where both this and $V$.rupestris are native, they often are hybridized with each other.

The fresh juice of the well ripened fruit, clarified by bringing to boiling point and skimming and hermetically sealed in bottles as "unfermented wine" put up by the writer in past years, was. invariably much preferred by all who tasted, to the juice of thoroughly ripened. Delaware grapes, treated in same way.

It has been tried extensively in parts of California as a graft-stock for Vinifera, and found very satisfactory, especially in limy, adobe, drouthy soils, and it is one of the most resistant. species against the Phylloxera and Anaheim disease. Mr. Wm. Pfeffer, of Cupertino, Cal., has. tried this species extensively and very successfully as a graft-stock and has used it in hybridizing. with good promise.

\section{Series III. Æstivales. Planchon.}

6a. VITIS LINCECUMII, Buckley, Pat. Off. Rep. 1861.*

6b. VITIS LINCECUMII, variety glauca IIunson. Proc. Acad. Phila. 1861, p. 451, and 1870, p. 136. (See Plate XI.)

Synonyms:

V. labrusca, Gray, Proc. Acad. Phila., 1862, p. 162.

V. labrusca, var. astivalis, Regel. Conspect. Vitis, p. 396.

"Post Oak," "Turkey Grape," "Big Summer Grape," "Sand Grape."

There are two forms of this species which I shall designate as $a$ the species, and $b$, a variety of it, var. glauca Munson.

* In July, 1889, while acting as Special Agent of the Department of Agriculture, investigating the native grapes and other wild fruits, for the Division of Pomology, I stopped at the home of Dr. W. B. Morrow, of Navasota, Texas, who was well acquainted with Dr. Gideon Lincecum for whom Dr. Buckley named this species. Dr. Morrow stated that the name was correctly spelled Lincecum, not Linsecom, as some botanists have spelled it. Buckley in the Pat. Off. Rep. 1861, has it Linsecomii, which probably came through the error of the type-setter. 


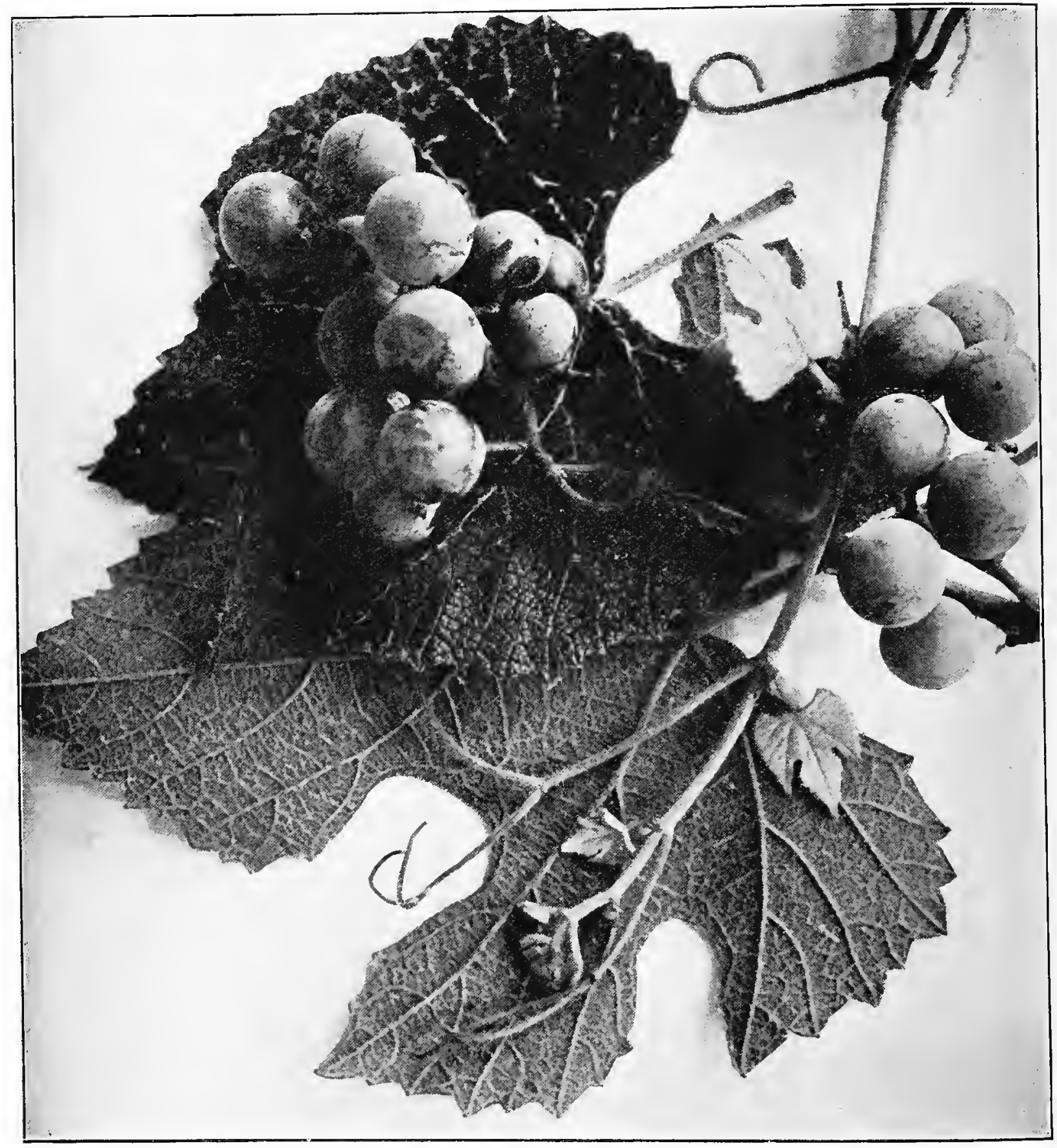

PLATE XI. 6a. VITIS LINCECUMII, Buckley. (Typical.)

Post-Oak Grape. From Caldwell Co., Texas. 
Plant: Very stocky, vigorous, moderately branching, rapidly tapering, climbing moderately, about same as $V$. labrusca, 20 to 40 feet or more in rich sandy soils; expanding tips not leafy; aspect generally open; seldom dense canopy-like, with dark lively green foliage.

Roots: Large, little fibrous, rather fleshy, but very firm, deeply penetrating.

Wood: When young, cylindrical, whitish or brownish tomentose, soon becoming floccose and disappearing in the mature annual wood, which is a dark reddish-brown and often having numerous short, black, glandular prickles, especially near the nodes, as in $V$. labrusca, and a distinct prunose bloom about the nodes and sometimes covering the internodes, which with the prickles remain into winter; wood dense and hard, in sectional view of mature annual wood, showing numerous rays with fine pores between; nodes slightly enlarged, much bent; diaphragm $1 / 16^{\prime}$ to $1 / 10^{\prime}$ thick, biconcave; buds large, globular, conical or obscurely triangular, acute, covered with shining reddish-brown scales, underneath which is an abundance of brownish-red wool, in expanding medium size, open, rosy or crimson; tendrils initermittent, rarely 3 to 5 in succession, ordinarily once forked in var. glauca, twice in the typical forms, long, slightly cottony in glauca, or rarely smooth when young, to densely rusty woolly in the species, at first finely striated, color reddish or green, becoming same color as wood at maturity, strong, persistent; internodes usually short, or of medium length, $2^{\prime}$ to $4^{\prime}$ or more; pith medium, slightly enlarged at lower end near diaphragm, pale brown.

Leaves: Stipules short $1 / 16^{\prime}$ to $1 / 8^{\prime}$ long, broad, pinkish, with thin rusty cotton on outer face; petiole in full grcwn leaf large and strong, average length $5^{\prime}$, cylindrical or slightly flattened, with a very narrow, shallow groove above scarcely noticeable, being hidden by pubescence or tomentum along its margins, striations obscure, with thick, velvety pubescence or tomentum, or both, along the striae, color purplish or pale red; blade large in the species to very large in var. glauca, $4^{\prime}$ to $8^{\prime}$, often more, broad, average width of many leaves $6^{\prime}$; blade always broader than long, generally twice or more the length of petiole; general outline circular; basal sinus generally broadly or narrowly $\wedge$ shaped with double curved sides, sometimes rounded, with limbs approaching or lapping, border sometimes nearly regular, mostly obtusely shouldered or variously 3 to 5 , sometimes 7 lobed; lateral sinuses rounded, occasionally having a large tooth at their base, as in $V$. vinifera, the lobes more or less closing up or lapping across the sinuses, giving a handsome appearance to the leaf; teeth very variable, in $a$ large, irregular, with margins less convex, sometimes scalloped, scarcely mucronate, resembling many $V$. vinifera, while in $b$ smaller, convex, with small, distinct mucron, often approaching $V$. cinerea in this respect; venation from the usually 6 and 7 (in lobed form $a$ ) to 7 and 8 (in shouldered form $b$ ) not quite opposite pairs of very prominent ribs, and covered densely with more or less rusty cotton in the typical form of Southern Texas and Louisiana or whitish tomentum in Northern Texas and Missouri specimens; which becomes floccose with maturity in both. The young opening leaves pinkish or crimson and densely tomentose, the upper surface slightly wrinkled, soon losing its tomentum, becoming smooth, dark lively green; lower surface becoming pale, rusty ash color, abundantly woolly in $a$, and bluish glaucose green, with thin or little wool in $b$.

Cluster: Fertile,--varying from below medium in $a$ to large $3^{\prime}$ to $10^{\prime}$ or more long., in $b$, generally cylindrical with a large shoulder and very compact, generally simple and rather open, in $a$, rarely so in $b$; divisions simple; peduncle medium or short; rachis cottony or nearly smooth, bluish-green when young; pedicels $1 / 6^{\prime}$ to $1 / 4^{\prime}$ long, enlarged at summit, warty; sterile,-much lairger and more compound.

Flowers: Fertile,--tip of buds before opening, crimson, stamens weak, recurved and bending laterally close to base of the large ovary; seldom self-fertile; style short, thick; stigma large to medium, sometimes resembling (in form $a$ ), V. candicans, and (in form $b$ ), $V^{*}$. cinerea. Staminate,bud same as fertile, stamens strong, ascending.

Berries: $1 / 2^{\prime}$ to $1^{\prime}$ in diameter, in $a$ generally much larger than in $b$, often more or less oblate in $a$; spherical in $b$; color black or sometimes dark purple, covered with thin bloom in $a$, more in $b$; in $a$ commonly drops very easily, -as soon as ripe, $-b$ hangs much better and occasionally 
is quite persistent; skin thin and tough in $b$; pulp in $a$ usually tough, dry, rery acid, and astringent; in $b$ more juicy, tender, sometimes quite melting, vinous.

Seeds: 1 to 4 , small in $b$ generally, to very large in $a, 1 / 5^{\prime}$ to $1 / 4^{\prime}$ or more long, by $1 / 6^{\prime}$ to $1 / 5^{\prime}$ broad, obovate pyriform, with sometimes very short or no beak, but generally with a large, orange colored, strong, blunt beak, sometimes in form $b$ small and acute, well defined, resembling $V$. cinerea; color light in $a$ to dark purplish-brown in $b$. Raphe not very prominent, sometimes. depressed; chalaza usually below the middle of seed, slightly expanded, not much elevated, generally ovate, or narrowly elliptical, sometimes circular, convex, surrounded by a distinct. groove which extends to rounded top of seed-rarely over it-and in such cases making the seed appear much as in $V$. labrusca, in which the raphe lies extending down the inner face as a thin thread to beak, as in $V$. vinifera; depressions distinct, slightly curved or straight, nearly parallel, close to the raphe, of characteristic orange color similar to the color of base of beak.

Plantlet: Seed-leaves large, ovate, acute pointed, green, petioles long, $1 / 2^{\prime}$ or more.

\section{Viticultural Observations and Remarks}

Germination slow but strong, later than $V$. cinerea; foliation medium to very late; inflorescence a few days later than $V$. cordifolia, different vines varying much, in form $a$ generally earlier than in form $b$, ripening of fruit from mid-season, or with $V$. labrusca until three or four weeks later.

Vigor and endurance in the changeable western climates remarkable, resisting drouth exceedingly well; Mildew and Rot attack leaves and fruit of some of the vines in regions where these fungi are abundant. Grows from cuttings with the greatest difficulty of any species of this series. Some varieties of $b$ occasionally found making good or better table grapes than many $V$. labrusca varieties in cultivation, examples of which are found in Jaeger's No. 43 and others of his finding; "Early Purple," "Lucky" and some others found by the writer. Jaeger's No. 43 has a large cluster and medium berry, black, good for eating, and makes a fine claret with a little native taste. The clusters of each of these varieties are very compact and ship well. No. 43 fertilizes. itself fairly well some seasons and is very productive. Owing to difficulty of growing this species from cuttings its good varieties have been little disseminated. Some of Jaeger's and my own hybrids of it with improved varieties of other species promise to be very valuable. Jaeger's Nos. 43, 13, Neosho and many Texas varieties found by me, are exceptionally free from attacks. of fungus diseases. The fertile vines of this species are generally incapable of self-fertilization. H. Jaeger stated in a letter to the writer that of about 100 fertile plants tested in his vinevard, only 5 or 6 will fertilize themselves sufficiently to make a crop and the writer's experience corresponds with this. Taking all things into consideration, this species is one of the most remarkable, interesting and promising to viticulturists.

It is frequently found naturally hybridized with $V$ cordifolia, $V$. cinerea, $V$. rupestris, $V$. vulpina and $V$. candicans. The writer has numerous very fine and valuable hybrids of fine grapes upon best varieties of form $b$ which succeed vastly better in the South than the old labrusca varieties and their hybrids from the North. It is generally found on loamy, well drained sandy uplands, where Post Oak (Quercus minor) grows, form $b$ in Southwestern Missouri, Arkansas and Oklahoma, and very abundant in Northern Texas, form $a$ in Eastern Texas, east of the Trinity River and its tributaries, and Eastern Louisiana, and also Central Texas, east of Austin, where the typical form described by Buckley was found. It is not found in Western and Southwestern Texas, west of San Antonio, Austin, and Weatherford, except in isolated places in Gillespie and Blanco counties. It is very abundant and of typical form in parts of Caldwell County, Texas.

Though rather less distinct from $V$. astivalis than $V$. bicolor, it is yet readily separated from the former by having larger berries and seed, larger leaves, and bluish appearance in $b$ to a much larger degree on lower side of leaf, much greater endurance of drouth, and in Missouri and 
Northern Texas, of cold, than $V$. astrvalis. From $V$. bicolor it is at once separated by its much larger berries and usually strongly shouldered clusters, in having cottony-tomentose leaves and young wood, thicker diaphragms, more tapering and stocky vines, much larger seed, leaves much less blue or glaucous beneath, by each occupying a different climate and region from the other, by quicker and more vigorous germination of seed and by very much larger seed-leaves.

7. VITIS BICOLOR, LeConte, Proc. Acad. Phila. 1852, p. 272, 1853.

Synonym: (Regensb. Flora, 36, 708.) (See Plate XIII.)

V. argentifolia, Munson, Proc. S. P. A. S. 1887 , p. 59, No. 15.

"Fall Grape" in Illinois, "Blue Grape" in Ohio, "Winter Grape" in New York and Michigan.

Plant: Climbing moderately, 20 to 40 feet.

Roots: More fibrous and wiry than in other species of the series approaching $V$. vulpina, somewhat in this.

Wood: When young, cylindrical, smooth, crimson or reddish-green; finely striated at maturity and of a clear dark reddish-brown, having a light prunose bloom about the nodes, and occasionally scattering glandular spines, short and black, easily rubbed away; outer bark shedding second year in thin fibrous plates, permanent bark checking coarsely; annual wood dense, sectional view showing rays numerous, with small pores between; nodes slightly bulging and bent; diaphragm $1 / 10^{\prime}$ to $1 / 8^{\prime}$ thick, biconcave; bud broad at base, conical, acute, covered closely with reddish-brown scales beneath which is a layer of pale brown wool protecting the bud, whitish wool at summit, medium, pinkish or rosy in expanding, open tipped; tendrils intermittent, or occasionally several in succession, once or seldom twice forked, long, smooth, red when young, brown when mature, persistent, clinging strongly. Internodes $3^{\prime}$ to $6^{\prime}$ or more long, sometimes $8^{\prime}$ or $9^{\prime}$; pith rather large, somewhat enlarged at lower end, light brown.

Leaves: Stipules minute, membranaceous; petiole, half the width of blade in length, striated, usually smooth, with a very narrow pubescent groove on upper side, color generally red; blade $5^{\prime}$ to $8^{\prime}$, sometimes $10^{\prime}$ or $11^{\prime}$ broad by the same in length, broadly cordate or circular, or beautifully palmately lobed; basal sinus acute, spreading, generally $\Lambda$ `shaped, sometimes $n$ shaped, with double curves, shoulders very prominent; 3 to 5 lobed, sinuses between lobes acute or rounded, lobes approaching; teeth of blade very shallow, convex, with small mucron, depressions between mostly acute, never scalloped; venation moderately prominent from the commonly 7 not quite opposite pairs of ribs, along which latter more or less light pubescence is found, becoming tufts in the forks, sometimes smooth; upper face smooth, of a lively very dark green; lower face smooth, of a characteristic bluish-white appearance, caused by a prunose bloom or glaucous substance. Leaves from ground shoots of old wood usually beautifully 5 to 7 lobed.

Cluster: Fertile, $-23 \mathbf{4}^{\prime}$ to $5 \frac{1}{4^{\prime}}$ or longer, generally slender, cylindrical, compact, with little or no shoulder; peduncle $1 \frac{1}{4}{ }^{\prime}$ to $2{ }^{3}{ }^{\prime}{ }^{\prime}$ in length; rachis smooth, covered thinly with a pale bluishgreen; pedicels 1' ${ }_{4}^{\prime}$ long, enlarging upward, warty or knotty; staminate cluster much larger and diffuse.

Flowers: Very similar to those of $V$. astivalis.

Berries: Generally $1 / 4^{\prime}$ to $1 / 3^{\prime}$ in diameter, spherical, black, with heavy prunose bloom, making the fruit look bluish when ripe; persistent; pulp juicy and vinous sometimes, and a little astringent when fully ripe, even in best varieties, but exceedingly pulpy, dry and astringent in general.

Seeds: Small to medium, $1 / 6^{\prime}$ to $1 / 5^{\prime}$ long, by $1 / 8^{\prime}$ to $1 / 6^{\prime}$ broad, color from light to dark chocolate or slightly-burned coffee; beak short, fairly defined; raphe prominent in the groore, about filling it and continuing well defined nearly to the beak; chalaza rather below the middle of the back, prominent, or often sunken as in $V$. vulpina, nearly circular, surrounded by a distinct groove which extends over the broad top of seed; depressions broad, short, curved, shallow, of a lighter shade than body of seed, often salmon or chocolate color.

Plantlet: Cotyledons small, ovate, with short taper or acute point, green. 


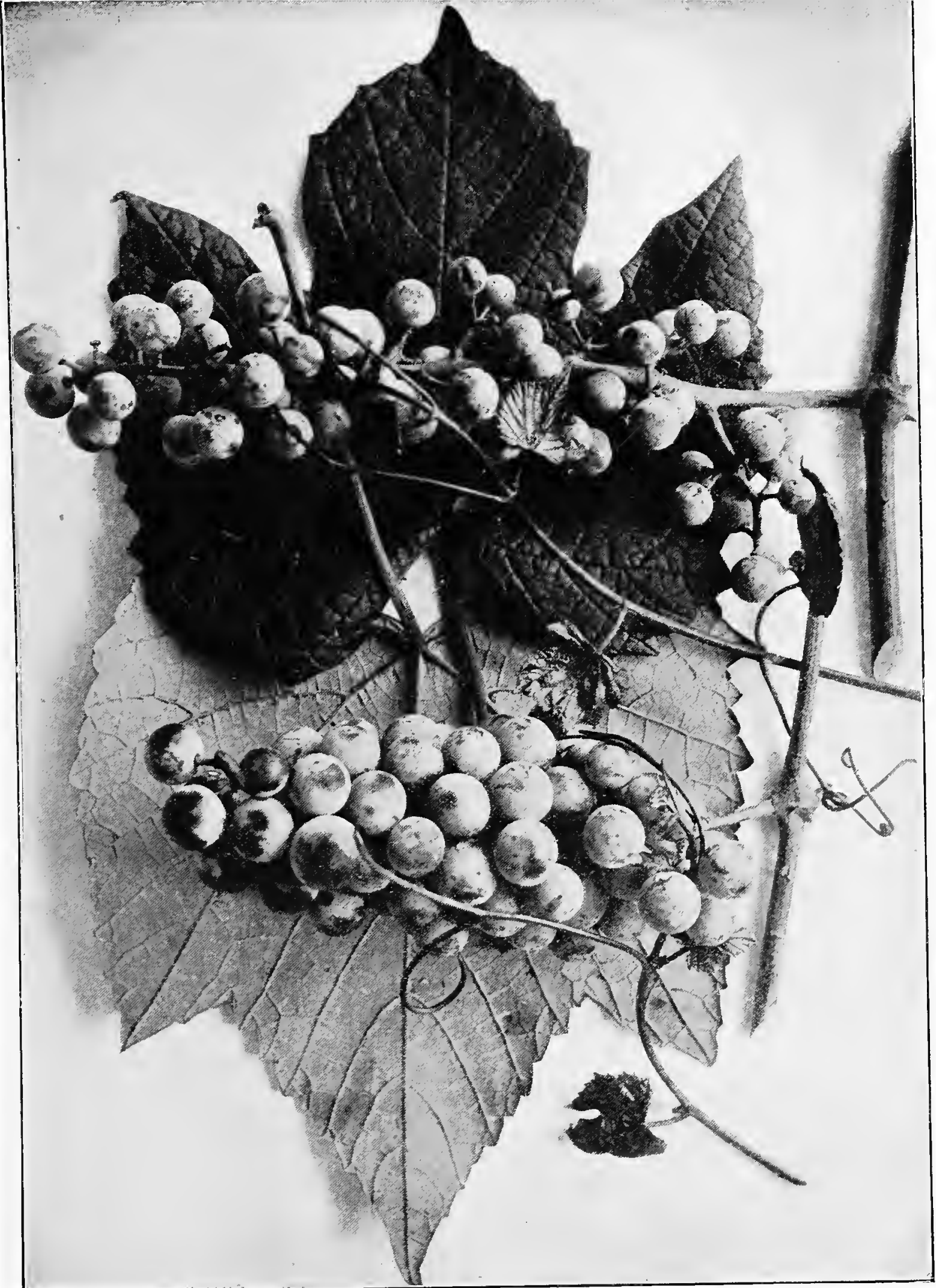

PLATE XIII. 7. VITIS BICOLOR, Leconte.

Blue Grape. From Michigan. 


\section{Viticultural Observations and Remarks}

Germination very slow, later than V. Lincecumii; foliation medium to late; inflorescence, late, about with $V$ astivalis, ripening of fruit after Estivalis.

Strong, robust, hardy to endure cold, enduring - 30 degrees to - 40 degrees in Wisconsin; is subject to attacks of leaf-folder and mildew to some extent. Cuttings root with difficulty. Vines prolific in fruit, a beautiful sight when loaded with the handsome, compact, long, ripe clusters, screened by a dense canopy of leaves. It certainly offers the Northern experimenters material, in combination with $V$ vulpina, $V$. labrusca, $V$. rupestris, $V$. Longii, and the hardier varieties of $V$. Lincecumii, with which valuable strains of wine and table grapes may be produced.

It is found naturally hybridized with $V$. vulpina, the chief species growing in the same region. I have a vine sent me by Mr. David Allerton, of Marlborough, N. Y., said to have been found wild there, that is clearly a hybrid of $V$. bicolor with $V$. labrusca, and another of similar character with very good fruit, found wild in Western N. Y. by Mr. E. S. Bartholomew, Westfield, N. Y. Mr. D. S. Marvin's No. 1, a fine little grape, seems to possess blood of this species to some extent. Dr. Tinker, of New Philadelphia, O., has found a number of good varieties in his region, and is hybridizing them with other species.

It stands related to $V$. cestivalis about as nearly as to $V$. Lincecumii; or comparatively as $V$ Caribcea, and $V$ Berlandieri are to $V$. cinerea, and hence has equal need of being specifically recognized. It appears pretty well separated in the regions west of the Alleghany and Cumberland mountains from $V$. astivalis proper, which lies east and south of those mountains, by its larger leaves, which are smooth bluish-white on under face, its greater hardiness, freedom from rusty wool on all young wood, leaves and tendrils, which is invariably found on the true $V$.estivalis; smaller berries generally, less shouldered clusters, heavy bloom on fruit, and later germination of seed. In vineyard growth it appears even more different from $V$ astivalis than $V$. Lincecumii (a). Its specific name is derived from the peculiar appearance of its foliage owing to the contrast of the heavy bluish-white bloom of the under surface with the dark green of the upper surface of leaves.

It is found in Michigan to 45 degrees north latitude, also in Ontario, Wisconsin, Illinois, Indiana, Ohio, Northern Kentucky, Western New York and Pennsylvania; in New Jersey, Maryland and Northern Virginia, where it has more or less rusty tomentum on young leaves and wood, rarely in New York and New Jersey. The true rusty $V$. astivalis of Michaux takes its place southward, from above named regions, especially in Georgia and Tennessee. The transition to $V$. astivalis is gradual, going south. It is found mostly in rolling, dry sandy, or alluvial clay. soils mixed with sand, and especially loves sunny slopes.

8. VITIS AESTIVALIS, Michaux, Flora bor. Amer. 2, p. 230. (See Plate XIV.) Synonyms:

V. Lacinosa and vinifera, var. Americana, Marsh. Arbust, pp. 165-6.

V. labrusca, Walter, p. 243.

V. vulpina, Poir, Dist. 8, p. 607.

V. vulpina, Jacq. Hort. Schoenb, 4, 13, t. 425 vide Regel.

V. labrusca, Planch. 1. c. 109.

V. Virginiana, Poir. Dist. 8, 608.

$V$. intermedia and labruscoides, Muhl. Cat. 26.

"Summer Grape," in Tennessee, Virginia, Georgia, etc.; "Pigeon Grape" in New Jersey; "Winter Grape" in New York.

Plant: Medium to tall, climbing 30 to 50 feet; branches somewhat tapering; tips quite naked, that is, not enveloped in slowly opening leaves, as in $V$. vulpina.

Roots: Little fibrous, rather hard, penetrating, transversely wrinkled; in one year seedlings enlarging downward from collar. 
Wood: Cylindrical, rusty woolly when young, becoming smooth, bright reddish-brown on maturity, with little prunose bloom near the joints and frequently on vigorous growing shoots thinly beset with spinous pubescence as in $V$. labrusca; finely and evenly striated, hard and dense, less than $V$. Lincecumii; nodes enlarged under the bud, little enlarged on the opposite side; diaphragm $1 / 10^{\prime}$ to $1 / 8^{\prime}$ thick, biconcave; bud globose-conical, obtuse in young shoots, acute in mature, covered with reddish-brown scales with reddish wool at summit in expanding, medium, red rusty, open tip, pinkish; tendrils intermittent, once or sometimes twice forked, long, tomentose when young, soon becoming smooth, finely striated, same color as mature wood, though green or reddish when young, persistent, strong; internodes.medium to long, $2^{\prime}$ to $4^{\prime}$ or even to $6^{\prime}$ or more; pith medium, considerably enlarged at lower end, light brown.

Leaves: Stipules small, $1 / 16^{\prime}$ to $1 / 12^{\prime}$ long, rather narrow, rusty woolly; petiole usually a little less than half as long as width of blade, cylindrical, obscurely striated with narrow shallow groove above, obscured with pubescence or rusty wool, or both; blade $4^{\prime}$ to $7^{\prime}$ in length, similar to $V$. Lincecumii in general outline or more cordate; basal sinus deep acute $\wedge$ shaped to broad $\Lambda$ shaped, approaching, sometimes lapping, generally short, obtuse or acute; of ten 5 rarely 3 lobed, lobes mostly acute, approaching around the rounded, rarely or never toothed lateral sinus; teeth usually small, little elevated, slightly convex, with little or no mucron, notch between, obtuse or scalloped; venation, from the 7 or 8 , generally not quite opposite pairs of ribs, rather prominent; ribs generally both pubescent and rusty woolly with pubescent tufts in forks; blade in unfolding, rusty woolly, upper surface rusty hairy along veins when young, smooth and leathery rugose with maturity, of a dark, moderately lively green color; lower side between ribs thinly or flocculently red rusty woolly. Ground shoots from old plants beautifully 5 to 9 lobed, being palmate, much as in $V$. Lincecumii.

Cluster: From $t^{\prime}$ to 8 ' long, cylindrical, generally simple or with a moderate shoulder and often a false tendril, the peduncle generally long; rachis pale cottony; pedicels thick, $1 / 4^{\prime}$ long, enlarged toward receptacle, with a few small warts.

Flowers: Stamens in fertile flowers reflexed and bent laterally, stamens and pistil more slender than in $V$. Lincecumii, self-sterile.

Berries: $1 / t^{\prime}$ to $1 / 2^{\prime}$ in diameter, small, spherical or oblate, black, with bloom when ripe, persistent; skin thin, tough, with much coloring matter; pulp commonly dry, tough, acid, and astringent, occasionally somewhat tender, juicy and rich in sugar.

Seeds: 2 to $4,1 / 6^{\prime}$ to $1 / 4^{\prime}$ long, by $1 / 8^{\prime}$ to $1 / 6^{\prime}$ broad; ovate, light to dark cinnamon color; beak usually short, blunt, poorly defined, rarely sharp and distinct,--when sharp and defined it generally indicates a mixture with some other species as in Norton Virginia, which has a seed strongly resembling $V$ cinerea. Raphe medium or inconspicuous as it passes top of seed, sometimes disappearing at the top but usually at or a little below the middle or inner face of seed; chalaza generally small, circular or ovate at middle or above back of seed, surrounded by a shallow groove which extends over top of seed, in some cases making it appear slightly lobed, indicating admixture with $V$. labrusca; depressions shallow, irregular in depth, usually wide apart; color little different from body of seed.

Plantlet: Cotyledons small, ovate acute, green.

\section{Viticultural Observations and Remarks}

Germination medium to late; feeble; foliation, inflorescence and ripening late to very late,inflorescence after $V$ cordifolia and usually one to two weeks later than $V$. Lincecumii.

Becomes vigorous after first year from seed; but much less so than $V$. Lincecumii; endures. cold and drouth fairly, and resists mildew and rot well. Cuttings grow with great difficulty. Sometimes found naturally hybridized with $V$. labrusca, $V$. cordifolia, $V$. Baileyana and $V$. cinerea in Virginia and Georgia. 


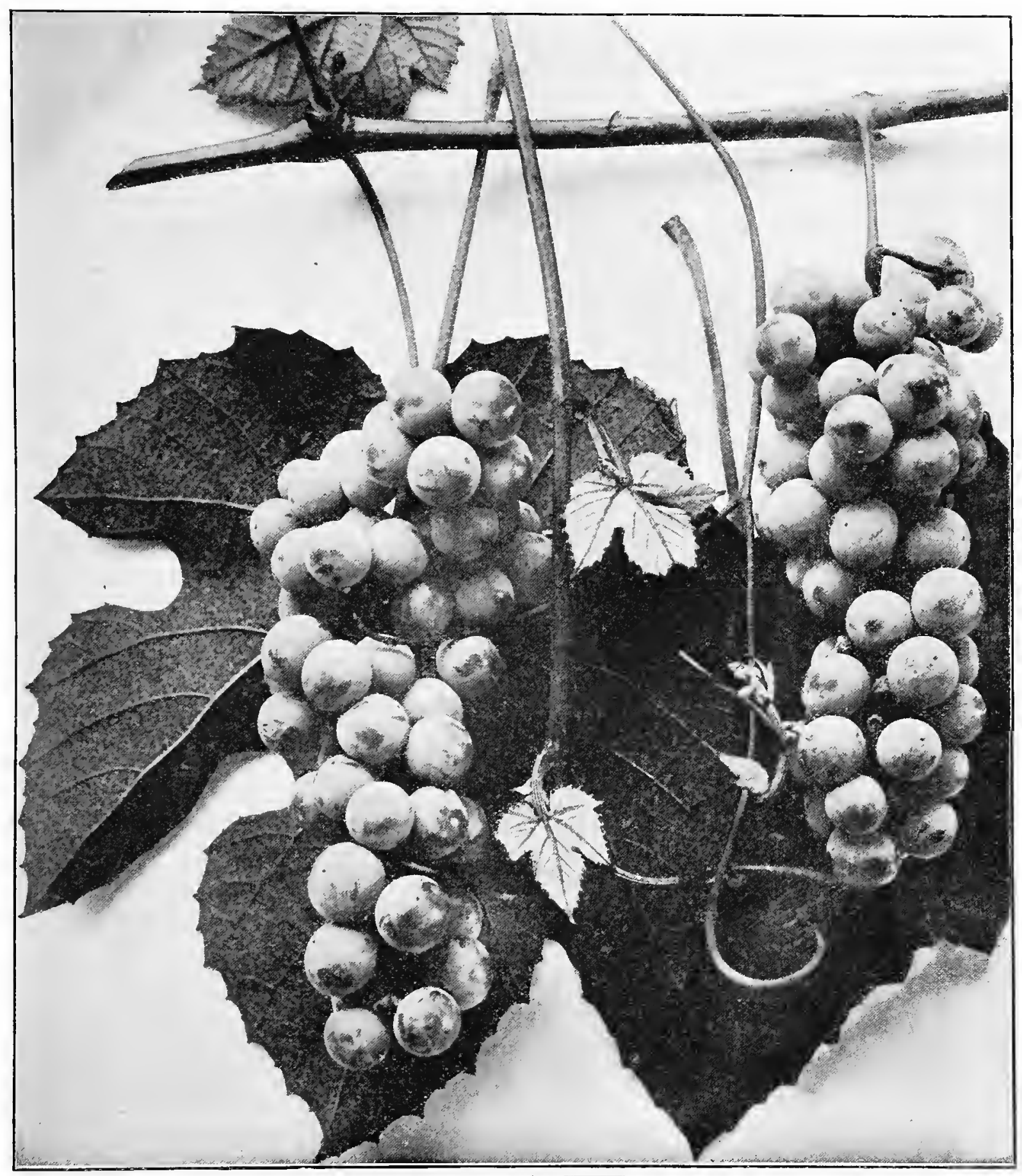

PLATE XV. 8. VITIS eESTIVALIS, Michaux.

Summer Grape. Of Georgia. 
It is found sparingly in New York as "Winter Grape," more plentifully in New Jersey as "Pigeon Grape," in both of which regions it approaches $V$. bicolor closely. It occurs in its purest form chiefly south of the Potomac River and Cumberland Mountains of Tennessee towards the Gulf, east of the Mississippi River. From Maryland to Western New York there is a gradual transition to $V$ bicolor, and a similar transition takes place between Middle Tennessee and Michigan and Wisconsin. It grows naturally on high, sandy loamy, or sandy clay soils.

Though generally supposed to enter into the Eumelan, Delaware and the "Southern AEstivalis," group of varieties ( $V$ Bourquinia, Munson), I am unable to trace it into any of these and find its markings in cultivated species only in Norton Virginia, though in hybrid state in this or its seedlings or hybrids, possessing traces of $V$. labrusca and $V$. cinerea, etc. Cynthiana gives not the slightest evidence, in any botanical point, of being other than a synonym of Norton Virginia. That Cynthiana came from the woods of Arkansas near the Red River, as held by some, is most improbable, in the light of botanical analysis which reveals only $V$. Lincecumii, of the Astivalian series in those regions, never the true $V$. astivalis to which Cynthiana belongs. Eumelan and all its pure seedlings show only $V$ labrusca and $V$. vinifera. Delaware shows $\dot{V}$ labrusca and a form very much like $V$ Bourquiniana, Southern Europe, allied to $V$. cestivalis and $V$. vinifera; its analysis is very puzzling. The large number of synonyms of $V$. cestivalis clearly shows how variable it is as a species. Many minor varieties of it exist, even after separating from it $V$. bicolor (Leconte), and $V$. Simpsoni (Munson), which are, along with $V$. Lincecumii (Buckley), included in it by most writers. This division of the old species appears to me to be fully demanded and justified, in order to be at all consistent, in view of other species admitted by all botanists and more especially so in a viticultural point of view. Thus the aspect of $V$. bicolor could never be mistaken for $V$. Simpsoni. The former can readily endure 30 degrees to 40 degrees below zero, while the latter can hardly endure zero. The former is almost entirely resistant to the Leaf-Folder while the latter is nearly always defoliated late in the summer. There are excellent distinctive botanical characters, which any botanist would observe at once in plants of these different forms when growing side by side.

$V$. astivalis possesses properties that render its better varieties very valuable in the regions where fungus diseases prevail, on account of its great resistance to such diseases, and its high per cent of sugar. Its wild varieties, such as the Norton Virginia, make a fine wine, and furnish excellent material to use in hybridization, to impart health, and fine wine properties, and in combination with large berried kinds to give good commercial kinds, for the moister parts of the South.

\section{VITIS SIMPSONI, Munson. (See Plate XVI.)}

Plant: Slender, rampant grower, climbing very high, much branched, little tapering; tips of growing branche:i rusty tomentose and extended far beyond the fully developed leaves, appearing very naked of leaves, and pendulous.

Roots: Non-fibrous, thickening downward from collar in one year seedlings, for a foot or more, rather fleshy, yet resistant to Phylloxera; deeply penetrating.

Wood: Cylindrical, rusty tomentose in growing tip, becoming paler, ash-colored with age, till the wool becomes flocculent and shedding after first season, leaving the finely, regularly striated mature wood of a very dark dull reddish-brown, without prunose bloom or spinous pubescence in any known example, softer with longer internodes than in other species of this series; nodes little enlarged; diaphragm $3 / 16^{\prime}$ to $1 / 4^{\prime}$ or more thick, biconcave; bud small, sub-conical, acute, covered with reddish-brown scales, and tipped with rusty wool, medium in expanding, densely brown rusty, tip open, crimson; tendrils intermittent, mostly bifid, sometimes trifid, long, slender, red when young, woolly dark brown with age; internodes long, $4^{\prime}$ to $7^{\prime}$ or more in vigorous shoots; pith medium enlarged at lower end, light brown. 


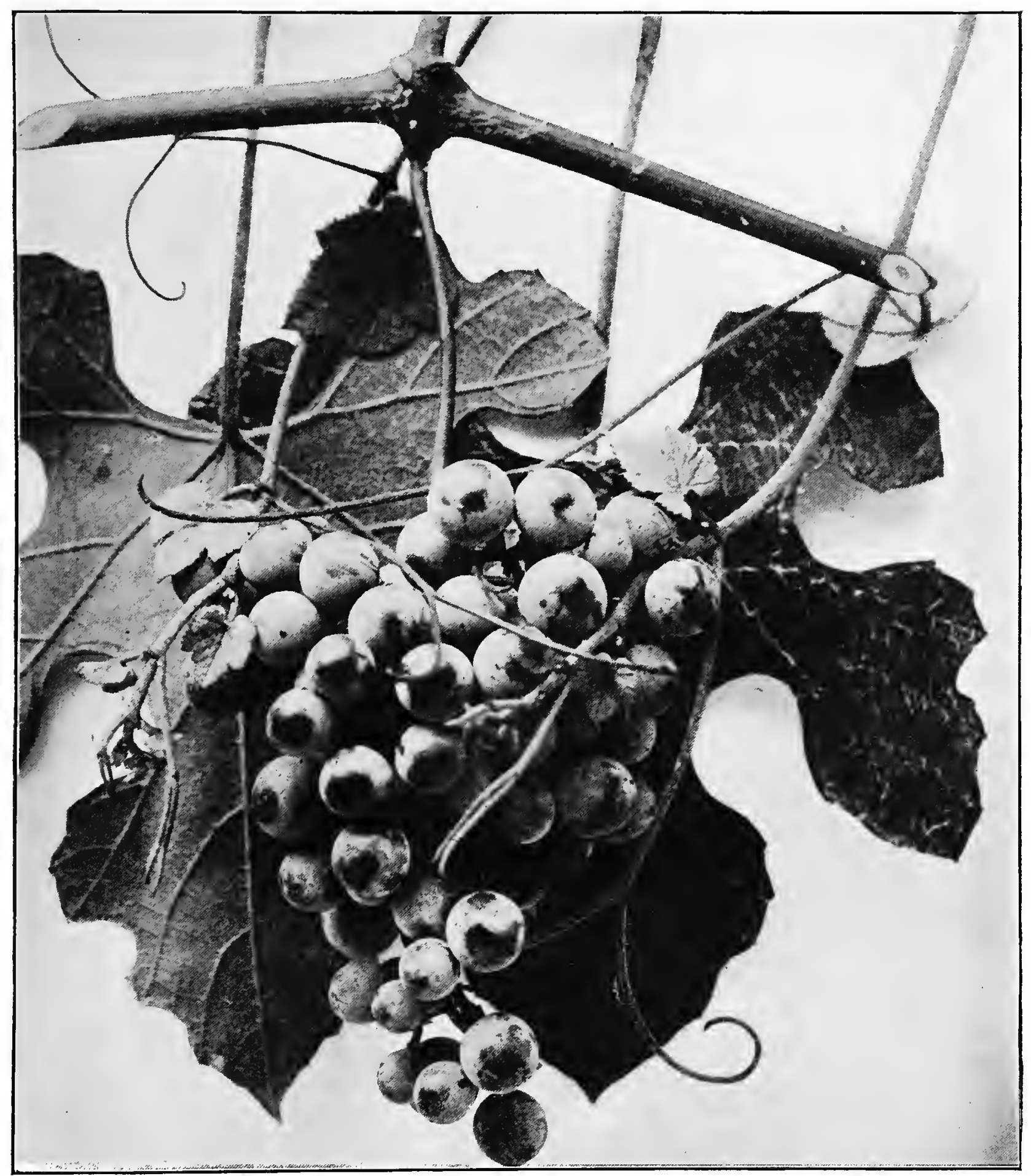

PLATE XVI. 9. VITIS SIMPSONI. Simpson's Grape. Florida. 
Leaves: Stipules minute, long-cordate, brown woolly, young, densely pubescent, pink or crimson, soon curving back from bud; petiole considerably more than half as long as width of blade; cylindrical with obscure groove above dull red, rusty woolly-pubescent all over, same as young wood; blade $21 / 2^{\prime}$ to $6^{\prime}$ wide by $21 / 2^{\prime}$ long, hence circular in general outline; basal sinus acute at insertion of petiole, but quickly expanding to a broad bay, which generally is nearly or quite enclosed by the approach of basal limbs; lobes 5,7 , or 9 , very broad in outer part, then narrowing greatly, leaving large, nearly circular sinuses. The pure species always has leaves thus lobed. Where it comes in contact with other species blooming at or nearly at same period, mixed forms are often found. Palmata, as a descriptive name would apply well to the leaves of the species. The lobes are always short and obtuse, except the mid-lobe is sometimes acute; teeth very short, scalloped or convex with a small mucron; renation, from the 5 to 7 nearly opposite pairs of ribs, obscured by a pale rusty or ash-colored, thin or dense felt all over lower side; ribs thinly woolly, and generally dull red; upper surface at first covered with thin, pale rusty hairs, soon becoming a rather lively light-green, much lighter than $V$. cestivalis, and quite wrinkled, giving a good hold for the Leaf-Folder (Desmia funeralis).

Cluster: $3^{\prime}$ to $5^{\prime}$ long, mostly simple, or moderately compound, open or compact, sometimes with a false tendril; peduncle medium to long, of nearly same diameter throughout, rather larger below tendril; rachis pale cottony or naked; pedicels short $1 / 6^{\prime}$ or $1 / 8^{\prime}$ thick, very warty in clusters of mature fruit.

Flowers: Stamens, pistil and style shorter than in $V$.astivalis; fertile, stamens reflexed and bent laterally; berries $1 / 4^{\prime}$ to $1 / 2^{\prime}$ in diameter, spherical, black with considerable of prunose bloom when ripe, persistent; skin rather thick and tough, with much coloring matter; pulp generally juicy, less tough, acid and astringent than $V$. astivalis, having also less sugar.

Seeds: Commonly 3 about the same average length as in $V$. cestivalis, but averaging broader, and much darker in color,-a dark chocolate; beak short, small, well defined, dark brown; raphe becomes visible at base of beak and is slender and moderately prominent as it passes over top of seed, expanding gradually into the fairly conspicuous chalaza of medium size, lying in a very shallow basin in center of back of seed, with little or no groove toward the beak; ventral depressions very shallow, short, and curving away from raphe, of paler color than body of seed.

Plantlet: Seed-leaves small, broadly ovate, acute apex, green, with medium long petioles.

\section{Viticultural Observations and Remarks}

Germination quicker than $V$. astivalis, feeble to strong; foliation, inflorescence, and ripening of fruit later than in $V$. astivalis. Plant remains very spindling till three years old from seed, then becomes very rampant. Endures drouth and heat very well but very sensitive to cold, about half-hardy at Denison, Texas. Resists mildew and rot very well. Cuttings grow with more difficulty even than those of $V$. astivalis.

It has been found hybridized naturally with $V$. cordifolia, $V$ astivalis, $V$. coriacea, $V$. cinerea, var. Floridana.

It is confined almost entirely in Florida, and with $V$. coriacea and $V$. Munsoniana, is abundant all over the southern half of that State.

One vine growing at Ashtabula, Florida, appears to be a hybrid of this species with $V$. coriacea. It was brought to my attention by G. H. Norton, of Eustis; Florida. Young vines of it with me have borne abundantly a very good grape, little inferior in appearance or quality to Norton Virginia, and might furnish the basis for a noble strain of extreme southern grapes. Another from J. H. Simpson, of Manatee, Fla., found wild by him, appears to be of same hybrid character, with later and larger, good fruit. It is a valuable species for experimentation in the extreme South. 


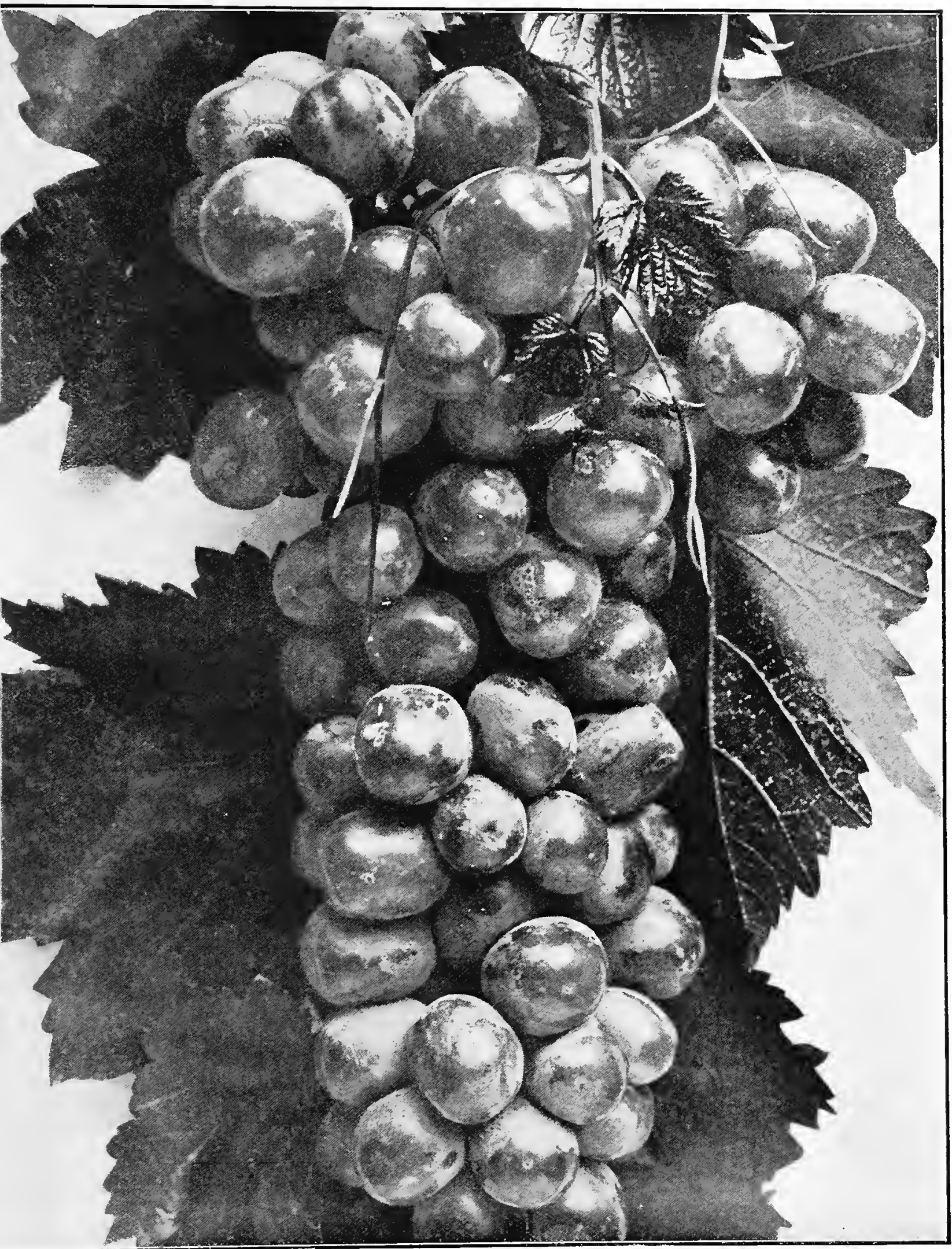

PLATE XVII. VITIS VINIFERA (FLAME TOKAY). 


\section{Series IV. Viniferæ, Munson}

\section{(A) V. VINIFERA, L. (Plate XVII.)}

Although this species is largely cultivated in California, Mexico, and some other parts of America, it is an exotic from Asia, and is so well known and has been so well treated by numerous authors, that $I$ can add nothing of value in treating it as a species. I mention it here merely to indicate where it would find its proper relationship as nearly as possible in our scheme of classification.

(B) VITIS BoURQUINIANA, Munson. (See Plate XVIII.)

Synonym:

Vitis astivalis, Engelmann, Bushberg Cat. 7, p. 16, 1883.

"Southern Estivalis."

Two forms; $a$ such as Herbemont, Lenoir, etc., with distinctly lobed leaves and mostly large compound clusters; and $b$ with leaves only shouldered, each side the mid-lobe or top, and clusters simple such as Devereux, Rulander, etc.

Plant. Climbs vigorously to great height; when young procumbent, slender; foliage lively green until very late.

Roots: Very thick, deeply corrugated bark, moderately firm, penetrating deeply, and quite resistant to Phylloxera.

Wood: When young, green or pale red, smooth or with scattered hairs, cylindrical; bark of a pale cinnamon or reddish-brown color at maturity, obscurely striated, fibrous, true bark finely checked above ground, mature annual wood, with a little prunose bloom about the nodes, and often a fine bristly, or short brown plush-like pubescence, as in Herbemont, is near the nodes; persistent; wood of medium density, more in $a$ than in $b$; sectional view of annual wood oval or circular, rays numerous, pores small, nodes very large, bulged under and opposite the buds, much bent; diaphragm $1 / 16^{\prime}$ (especially in $b$ ) to $1 / 12^{\prime}$ or more thick (in $a$ ), slightly biconcave, less in $b$ than in $a$, buds in $a$ very broad at base, similar to Vinifera, globose, conical, covered with pale brown scales, or in $b$, smaller, more conical and acute, with darker scales, large rusty pink in expanding; tendrils often twice forked in $a$, less so in $b$, long and strong in $a$, less so in $b$; internodes short, $1^{\prime}$ to $3^{\prime}$ or more, long; pith rather small, a little enlarged at lower end, light. brown.

Leaves: Stipules small, short and broad, pale, thinly hairy; petiole half as long as width of blade, or less; generally cylindrical, obscurely striated and grooved, thinly or often densely pubescent in $a$; blade largest in $a, 4^{\prime}$ to $6^{\prime}$ or more wide by $3 \frac{1}{2}{ }^{\prime}$ to $51 / 2^{\prime}$ or more in length; in $b$ $312^{\prime}$ to $4 \frac{1}{2^{\prime}}$ or more wide by $2 \frac{1}{2^{\prime}}$ to $31 / 2^{\prime}$ or more long; outline of blade in the Warren, group $a$, broad cordate. in the Devereux, group $b$, circular; basal sinus deep, acutely $\Lambda$ shaped with curved sides which never or rarely lap; $a$ generally 3 to 5 lobed, acute, with shallow, narrowly rounded sinuses, often having a convex tooth at base of sinuses, apex acute; $b$ broad, obtuse, shouldered, apex broad, short, acute; teeth in both $a$ and $b$ distinctly raised, convex mucronate, with a yellowish-white mucron, notch between teeth acute; venation prominent from the thinly hairy or pubescent, sometimes 6 to generally 7 pairs of nearly opposite ribs, in the forks of which small pubescent tufts are rarely found; young leaves in buds just expanding, pale green or pinkish, later whitish on both sides with silky white wool, never rusty, soon becoming smooth above and a little wrinkled, of a clear, lively dark green color, much paler beneath; texture dense. In $a$ first true leaves small, ovate-acute, green; first year often lobed; in $b$ first true leaves larger. green; on seedlings first year rarely lobed.

Cluster: In a medium to large, simple or compound, usually compact, heavily shouldered. with a false tendril on peduncle,-as in $V$. cestuvalis and $V$ cinerea; rachis smooth; pedicels. very variable, in Herbemont and many of its seedlings, thick, enlarging upward. more slender in Jacquez and Devereux; enlarging towards receptacle, very warty in $a$, less so in $b$. 


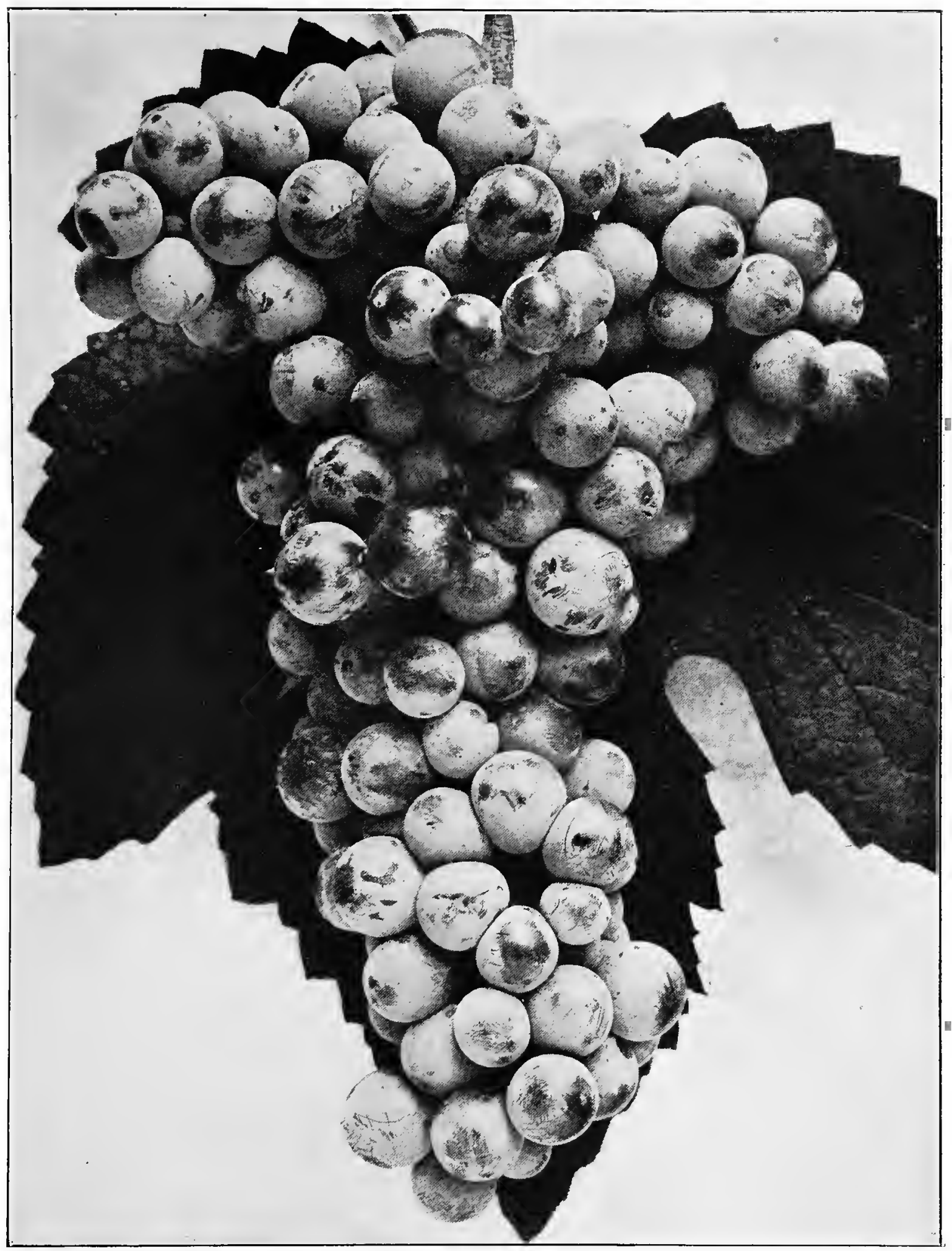

PLATE XVIII. VITIS BOURQUINIANA. (Herbemont.) 
Flowers: Fertile,- - on the majority of seedlings, with long, ascending stamens, rarely recurved, hence are productive without aid of other pollen; ovary small; style rather long and slender; stigma small.

Berries: Small, generally $1 / 3^{\prime}$ to $1 / 2^{\prime}$ in diameter, rarely larger, spherical, color mostly dark purple or pale red, and nearly white, as in Herbemont, Warren, Harwood and many seedlings grown by the writer; very persistent; $a$ Herbemont often produces exquisite translucent, pearly white varieties from seed, rarely black, and almost all without coloring matter; sliin very thin, pliable, tough; pulp very juicy and melting; some Herbemont seedlings are rarely a little meaty, as in Flame Tokay, of true V. vinifera; quality almost invariably fine, sprightly, vinous, and rich in saccharine matter.

Seeds: In $a 1$ to 3 . small, $1 / 6^{\prime}$ to $1 / 5^{\prime}$ long, by $1 / 7^{\prime}$ to $1 / 6^{\prime}$ broad, ovate, dark chocolate color; beak small, well defined, short, rather blunt or quite sharp as in Jacquez; raphe usually prominent continuing distinctly to near the beak; in "Texas," a pure Herbemont seedling, the raphe is invisible from the chalaza till it reaches inner face of seed; chalaza large; circular or oval, convex or flat, rarely wanting, or nearly so, standing above middle of seed, in some pure Herbemont seedlings quite at or near the top (a $V$ vinifera characteristic), surrounded by a distinct groove which passes over top of seed; depressions shallow, nearly straight, close to raphe, of a lighter color than body of seed. In $b$, number of seeds usually 1 to 2 , or 3 , larger than in $a$, of a lighter color, usually same shape but more plump; beak small, well defined; raphe prominent in groove which passes to or orer top of seed and continues distinctly to beak; chalaza large, circular, prominent but flat on top, surrounded by a distinct groove above center of seed, usually less elevated than in $a$.

Plantlet: Generally feeble, seed-leaves, small, green, ovate, acute apex, petiole $1 / \$^{\prime}$ to $1 / t^{\prime}$.

\section{Viticultural Observations and Remarks}

Germination: Medium to late, earlier and stronger in $b$ than in $a$; foliation late, about with $V$ astivalis, inflorescence very late, generally 4 to 6 days later than $V$. astivalis and $T$. Lincecumii; ripens very late, after Norton Virginia and nearly all pure $V$. astivalis, $\mathrm{V}$. Lincecumii and $V$. bicolor. Foliage matures very late, retaining its lively green color and holding on through the long, hot Southern summers; varieties of both groups vigorous after second year from seed and are long-lived in Southern States, enduring drouth remarkably well, but $b$ much more subject to drouth than $a$; much hardier for resisting cold than $V$. vinifera but much less so than either $V$. astivalis or $V$ Lincecumii; little subject to Mildew, Rot, Phylloxera or Leaf-folder, except in the Lenoir (or Jacquez), Mildew, Anthrax and Black Rot are severe. Cuttings root with difficulty in Herbemont and many of its seedlings; easier in Jacquez, and especially fairly well in all of $b$. Jacquez makes a fine, red wine. Many varieties of this species grow too vigorously on strong soils, succeeding best on thin clay or sandy lands, but also do well in limy soils. The French Jacquez is known generally in the South as Lenoir.

A comparison of the preceding careful botanical description with $V$. astivalis, in whose native regions this type appeared first in the United States, according to published reports, will show how distinct it is, and that taken with the following observations and history, make it conclusire that it is not a native but an exotic, and is about mid-way between our $V$. astivalis or some forms of $V$. Lincecumii and $V$ vinifera, with some $V$ cinerea characteristics.

Though this group or species of grapes, from the evidences about to be cited, is certainly not native, yet, owing to its long successful culture in the Southern States, and being considered not only in this country but in Europe as a product of this country (see the Bushberg Catalogue, 1883, p. 16, and "Une Mission Viticole, pp. 119 and 120), and having been long classified as a sub-species, or botanical variety of $V$. estivalis, it is very proper to include it as one of our species viticulturally. That it has specific characteristics, separate from other species, as well as from $V$. vinifera proper, the analysis and description clearly prove. Formerly I had (in an address delivered before the American Horticultural Society in New Orleans) supposed it to be a complex 
hybrid between $V$. estivalis, $V$ cinerea, and $V$ vinifera, inferred upon the general opinion that it was a product of this country purely, and that it was classified as "Southern AEstivalis" (see Engelmann's description, Bush and Son, and Meissner's Catalogue, revised edition, p. 16, and other parts of the same work), and that the analysis of the character of these varieties and many seedlings of them grown by me, would result from a mixture of these three species, and to no others. Such might still be the conclusion if the fact were established that these varieties are natives, from first to last, of the United States. The following facts break down the former theories: On September 16th, 1887, Mr. Gougie Bourquin, of Savannah, Georgia, in reply to inquiries by me, concerning two varieties of grapes, of which Mr. C. L. Hopkins, Assistant Pomologist of the Department of Agriculture,* sent me seeds from grapes he received from G. Bourquin in August, 1887, writes as follows: "I have to-day mailed you leaves of my two varieties of grapes. After 40 years trial have found these two varieties best suited to our climate; have never seen mildew on them, and they are only affected by rot in very wet seasons-from 1st to July 10th. These two varieties were brought from France when Georgia was first settled, and have been in our family ever since. The 'Blue French' I consider the best as to flavor, size of bunch and bearing qualities. They are very long-lived. The vines I now have are grown from a vine now living, 58 years old. This grape commences to color about July 1st, but is not fit to eat until August. Color of juice a light claret, very beautiful. I think a splendid wine could be made from it. The bunches on vines not properly trimmed are mucl smaller but more numerous. One of my friends informed me that on his unpruned vine he had 700 bunches. The description of the 'Brown French' would be similar to the 'Blue;' bunch not quite so large and a little earlier, and a dead sweet. One singularity about the 'Brown' is that some bunches are nearly translucent, while the ones next on same branch may be dark brown. From all information that I have procured, the 'Warren' was found on the banks of a creek in South Carolina and from there carried to Upper Georgia about the beginning of the present century."

Again, on Oct. 14, 1887, Mr. Gougie Bourquin writes: "Monsieur Leopold Charrier, the Belgian Consul, who is a native of France, says that my grapes are very commonly raised in South France and Italy, that he has seen them frequently around Toulon and Marseilles, and that they are generally considered a southern grape. Col. Garrard, who furnished me with cuttings of the Warren from his brother's vines, at Columbus, Georgia, and who has eaten my grapes, says that they are nothing like Warren. One of my neighbors who has a vine of the 'Brown' variety, taken from my old one, had the entire crop this year, light green, none dark. My old vine acted very. similarly to his, a few year's back. I think the "Blue' variety would make an excellent wine."

This peculiarity of varying in color and size in different soils and seasons is a well known characteristic of the Herbemont, and has caused it to be several times renamed, as its synonyms Bottsi, McKee, Dunn, Upson, etc., attest, these having been carefully tested in my grounds and found identical.

*The following is the letter received from Mr. C. L. Hopkins, and which led me into a fuller investigation of the history and origin of Herbemont than I had before made:

Mr. T. V. Munson, Denison, Texas.

Division of Pomology,

WAshingtón, D. C., Aug. 20, 1887.

DEAR SIR:-I enclose to you the seeds of two varieties of Grapes, which came from Savanna, Ga., about two weeks ago. They canie without name, and I took the black one to be Norton's Virginia, and the pale red or amber one to be Herbemont, and wrote Mr. Bourquin to that effect. He replied that they had of ten been taken for those grapes, but as he understood those were American varieties, while both of his grapes were brought from France, and had been in their family for about 150 years, he considered them distinct.

Mr. B. describes them as being strong growers, not attacked by Phylloxera, great bearers and the most highly desirable grapes for his region, within his knowledge; and that he has grown them for the last forty years. I send the seeds to you, thinking you may at least form an opinion as to what the varieties are, and to what species they belong. May it not be that the Herbemont originated from one of these grapes?

Hoping this may be of interest to you, and awaiting the result, I remain, Sir,

Very truly yours,

C. L. HOPKINS,

Division of Pomology, Department of Agriculture. 
From the original Warren vine still growing in 1887 in Warren county, Georgia, from which it takes its name, I grew vines; leaves and growth much like Jacquez, but not identical, certainly not identical with Herbemont; but the seed-leaves, leaves and descriptions of Mr. Bourquin's "Blue French" fit Herbemont exactly and it certainly falls into the group $a$ in my specific description, to which clearly belong the following:

"Blue French," Bourquin's, same as Jacques.

“Brown French," Bourquin's, same as Herbemont.

Cunningham, synonym Long.

Harwood, Southern Texas seedling of Herbemont, with larger berry.

Herbemont, syns. McKee, Bottsi, Dunn, Upson, Brown French.

Jacques, Sys. Lenoir, Black Spanish, Blue French, by some E1 Paso, incorrectly.

Warren, and many seedlings of these, while the following are of group $b, V$. Bourquinia.

Casper, seedling of Louisiana, by Casper Wilde, of New Orleans.

Devereux, Syn. Black July, brought to notice by Devereux, of Spalding Co., Georgia. Louisiana (Rulander), asserted by M. Theard of New Orleans to have been imported from France by his father and planted near Lake Ponchartrain (see Bushberg Cat., p. 118).

This is the most positive historical evidence on record of its origin, and is probably correct. Louisiana (or Rulander) was known in the Madeira Isles as Malmse, though not the true Malmse, before it was known in this country, and was there known to have come at an early period from France, so I was informed by Mr. Casper Wilde of New Orleans, who was well versed in the history of this class of grapes.

Taking all these facts in connection with the botanical characteristics, which show no brown or rusty wool, no astringency, no seeds of same character, a different proportion between width and length of blade of leaves, different green in leaves, different wood entirely, later blooming and ripening, easier growth from cuttings, much greater tenderness to cold, greater climbing capacity of vines, cylindrical, smooth young wood, general absence of red coloring matter in fruit (Lenoir is an exception); many white, and even some meaty-fleshed seedlings; larger, more compound clusters, generally; no return toward pure Astivalis or Cinerea, by atavism in seedlings, as would be the case if they contained hybrid blood of these; their not being found distributed in the native woods, but only here and there old vines in old places gone to ruin or neglect by the death of former owners and their history lost.

But equally by the same botanical analysis their power to resist Phylloxera far better than $V$ vinifera, mildew and mostly the rot; their great vigor and tall-climbing habits; their general much greater resemblance to $V$. estivalis and $V$. Lincecumii, than $V$. vinifera in its pure forms; their much greater difficulty in growing from cuttings than $V$. vinifera; lateness of blooming and ripening; general absencé of meatiness, so characteristic of $V$. vinifera, and many other points, I am well forced to regard them as having a distinct species for their origin, possibly two, closely allied, one for each group, as each group has some specific characteristics not found in the other; and that the original species stands between our native $V$, astivalis and $V$. vinifera with some approaches toward $V$. cinerea, or the group of species to which it belongs. As Mr. Gougie Bourquin has positively shown them to have been imported, and, with his predecessors, demonstrated earlier than others, and certainly, their adaptability to this climate, it is eminently proper that if we do establish a species to contain these, it should be Vitis Bourquiniana, which I propose in his honor.

With such varieties in the yards of gentlemen in one of the entrepots and oldest cities of the South, it is almost impossible but for them to be disseminated through friends, from cuttings and seeds, or by hybridizing seeds, and hence it is quite probable that this is the source of nearly all the representatives of this species in this country. It now seems strange that French vineyardists should import these varieties from the United States as "American Estivalis," but such is the case. 
I have a vine grown from seed obtained from Spain, which has much the aspect and vigor of Herbemont, with same lively green leaves, which are not quite so large, more lobed, and free from fungus diseases. The clusters and berries are similar but not so large, of same juicy, pure, sweet, sprightly character, red and with white juice, with small seeds of same description. These seeds came from the same regions where the fine Valencia raisins are produced-the higher hilly interior regions of Spain. This variety I named Valencia.

I have fruited for many years, both the varieties obtained of Mr. Bourquin, which were taken from old vines on his place, and direct descendants of the vines brought to Savannah, Georgia, by his fore-parents, over 150 years ago; and in every particular I find the "Blue French" identical with Jacquez, and the "Brown French," with Herbemont.

I present here further statements of $\mathrm{Mr}$. Bourquin, which he wrote me in reply to more particular inquiry:

Savannah, March 22nd, 1892.

DEAR SIR:-In regard to your inquiry about the two grapes, would say that Monsieur Francis Chartenet, the French Consul here, has in his yard the "Brown" and "Blue French." I have been in his garden and picked them myself, so that I could be positive that they were the same as mine. His vines were brought direct from France, and are identical with mine. Monsieur L. Charrier, the Belgian Consul, lives with Monsieur Chastenet, and says that these grapes are very common in the Medoc district, that he has often seen and eaten them in various parts of France.

My ancestors were Huguenots, and were living in London at the time of emigrating to Savannah. I find this from records in London, where the three brothers made application for immense land-grants in Georgia and South Carolina.

I do not think there can be any doubt about the French origin of my grapes.

Yours very truly,

T. V. Munson, EsQ.

GOUGIE BOURQUIN.

On receipt of the above, I wrote again for still more definite and ancient history of the grapes if known. In reply I received the following:

Savannah, April 1st, 1892.

DEAR SIR:-I cannot give all the information that you seek, but will furnish all that I can. I do not know that my ancestors kept any record of their grapes. If they did, they were destroyed when our plantation was burned by Sherman's army.

I distinctly recollect a small book, a history of Savannah,- particularly, "The Siege of Savannah," in which the author said: "The two kinds of grapes brought from France by the French Colony, for the purpose of wine-making, did well, but their attempt at making a good wine was a complete failure, as the climate did not suit." This is as near as I can recollect. The work gave the history from the settlement of Georgia up to $1800 \mathrm{~A}$. D. If we had saved this and another, - a directory of Georgia, it would have been of immense value to the present historian. The two kinds of grapes referred to, were certainly the "Blue" and "Brown." These two were in the gardens of nearly all the old French families, and I never saw any other kind of grapes in Savannah, when a boy, excepting the Catawba. I am now 55 years of age, and when a very small boy, I distinctly recollect them,-I saw two immense vines in the yard of my grand-aunt in Savannah, which could not have been at that time less than fifty years old. These varieties live to a great age. In $1873 \mathrm{I}$ got some cuttings from the garden of the late I. V. Connerat, at which time Mr. Connerat told me that the vine was 44 years old. I saw this same vine alive about one year ago, and think it is still alive, and if so, it is 63 years old.

About 15 years ago I wrote an article for the Department of Agriculture at Washington, on the Herbemont, from information furnished me by Mr. Prince, an old citizen of South Carclina, which would give you much information, if you can get hold of it. From it, you will find that writers are entirely wrong in putting Warren and Herbemont as one and the same grape. 
I to-day met on the street, Mr. John D. Charlton, one of our oldest citizens, and upon inquiry, found that he had a very distinct recollection, that when a very small boy, he had eaten "Blue" and "Brown" grapes from our garden, and that they were celebrated for their very fine quality, and for large bunches.

I enclose the Consul's certificates, as you requested.

Yours very truly,

GOUGIE BOURQUIN.

T. V. Muxson, Eso.

\section{Series V. Cinerascentes. Planchon}

\section{VITIS BLANCOII, Munson. (See Plate XIX.)}

Synonyms:

$V$ Caribea, Harvard Herbarium, Dr. E. Palmer, $18 s \&$

Vine: Vigorous, climbing rery high, foliage presenting a pale grayish-green aspect, in dense canopy on small trees.

Roots: Wiry, penetrating very deeply.

Wood: Growing tips extending rapidly beyond the slowly enlarging leaves, densely whitish, or pale rusty woolly, which wool persists during the first year; at first, wood is slightly angled, but becomes smooth cylindrical with maturity, pale dull green at first, very dark, reddish-brown at maturity; outer bark sheds the second year slowly in narrow fibrous plates, leaving the true bark rough pale brown, which with age becomes finely divided lengthwise, as in $V$. cinerea, but of a darker color; wood rather soft, tough and uncommonly flexible; internodes $3^{\prime}$ to $6^{\prime}$ or more long in well grown canes, pith light brown, somewhat greater in diameter than the thickness of mature annual wood from pith outward, expanding and abruptly terminating above, but gradually below the diaphragm, which is about $1 / 16^{\prime}$ thick, cross-section of wood very porous; nodes. little enlarged, or bent, stipular ridge not very prominent, and extending about half way around to base of tendril, then curving downward; tendrils $2^{\prime}$ to $5^{\prime}$ to fork, mostly bifid, whitish tomentose, very strong; buds small, at first subglobose, becoming at full maturity slightly triangular, but remaining blunt at apex, covered with dark brgwn scales, and rusty woolly at summit, in unfolding whitish or pale pink, tip closed.

Leaves: Stipules very small, rusty woolly; petiole $1^{\prime}$ to $2^{\prime}$ long, cylindrical, with distinct narrow groove along upper side, of uniform thickness the entire length, densely whitish woolly; blade long-cordate, entire, when fully grown $3^{\prime}$ to $4^{\prime}$ wide, with mid-rib $4^{\prime}$ to $5^{\prime}$ long; basal sinus $\mathbf{n}$ or in shaped (which is quite different from other species of this series, except sometimes the $n$ shape is found in $V$ Berlandieri; margin rarely slightly lobed or shouldered and finely toothed with sharp, mostly short evect teeth with distinct mucron; apex generally very long taper-pointed; venation from the mostly $S$ pairs of generally alternate ribs. very depressed, and obscured abore by thin cottony wool, and below by dense uihitish, or ash-colored felt; upper face at full maturity. bearing flocculent cotton along the ribs, giving foliage a grayish aspect, elsewhere being a dark dull green with little or no wrinkling.

Cluster: Fertile, of medium size, $3^{\prime}$ to $5^{\prime}$ long; simple, with a shoulder or but littlc compounded; pedicels $2 / 16^{\prime}$ to $3 / 16^{\prime}$ long, slender, scatteringly warty, slightly enlarged at apex; staminate; cluster somewhat larger.

Flowers: Very small and slemler in all its parts.

Berries: Small $1 / 4^{\prime}$ to $1 / 3^{\prime}$ in diameter, spherical, black, with thin bloom whon ripe; skin thin, tough, not pungent, pulp juicy, pure sweet, vinous.

Seeds: 1 to 3 , very small, as broad, or broader than long, $1 / 8^{\prime}$ long, globular when one in a berry, hemispherical when two; pale to dark chocolate colored; beak very short and broad; of darker color than body of seed; raphe very slender and obscure from beak to top of seed, where it becomes distinct in the notch in top, and rapidly expands into the nearly circular prominent 


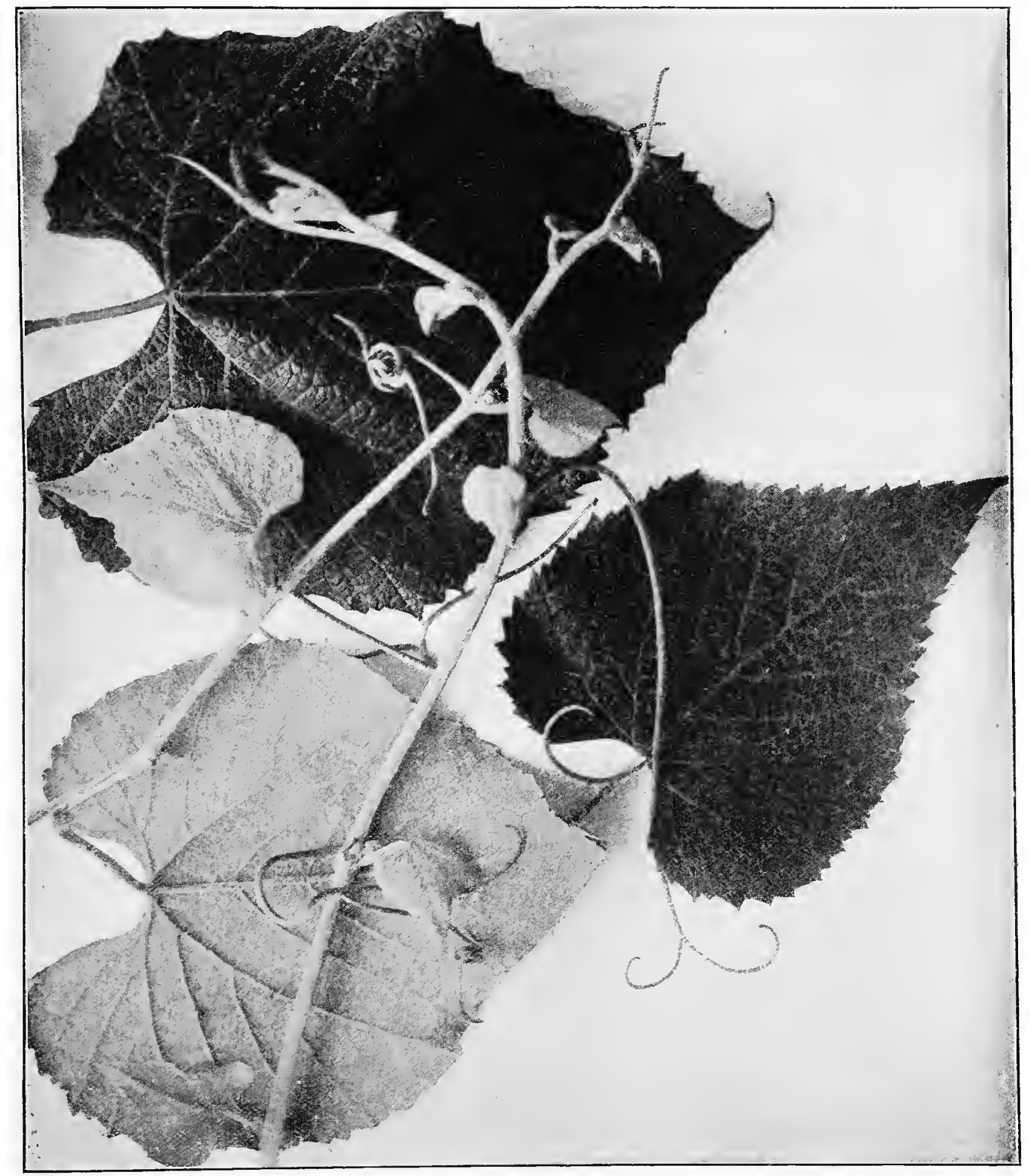

PLATE XIX. 10 VITIS BLANCOII, Munson.

Blanco's Grape. From Guadalajara, Mexico. 
chalaza in a very small shallow basin, a little above the center of the back of seed, from chalaza a shallow groove extends down back of seed to the beak, the ventral depressions diverge widely from raphe, are short and distinct, of a lighter shade of color than body of seed.

Plantlet: Very similar to $V$. cinerea, in having, small pale green cordate seed-leaves, with acute tips, but with shorter petioles.

\section{Viticultural Observations and Remarks}

This species was first brought to my notice in 1887 by Senor Luciana Blanco, of Guadalajara, Mexico, who collected it for me repeatedly along streams in the Sierra Madra Mountains in the State of Jalisco, near the city of Guadalajara. In $1895, \mathrm{Mr}^{\circ}{ }^{\circ} \mathrm{C}$. M. Stuart sent me specimens of it from near Montemorlos, State of Nuevo Leon, Mexico. I have growing a number of plants, which have shown the habit of growth to be similar to, but perhaps stronger than $V$ cinerea.

It germinates and foliates, with or before $V$. cinerea, but the leaf persists much later, or until the vine is killed (at Denison, Texas), it taking only 8 to 10 degrees of frost to destroy the vitality of the vine above ground.

In the Harvard Herbarium, Cambridge, I found the only other specimens in other collections known to me. These were collected by Dr. Edward Palmer in 1886, along the Blanco River, Jalisco, and are included under the name V. Caribca, D. C.

While it is a closely allied species to $V$. Caribaa, it is not identical any more than is $V$. cinerea. The Florida form of $V$. cinerea approaches nearer to $V$. Caribcea than does this. The smaller, sharp-toothed, whitish woolly leaves with $\mathrm{n}$ shaped basal sinus, and long taper point, the much smaller, simple cluster, with short peduncle and berries with prunose bloom and different flavor, the easy growth from cuttings, the much less angled annual wood, and separate distribution in a generally higher altitude, 2000 to 6000 feet across the plateau of Central Mexico, with other differences,. well separate it from DeCandolle's species.

It promises of little interest to viticulture. It is much less subject to mildew than V. Girdiana and $V$. Californica, here at Denison, Texas. It may furnish a basis for hybridization to get varieties for tropical countries.

11. VITIS CARIBEA, DeC. Prodr. 1, p. 634. (See Plate XX.)

Synonyms: Numerous (see Ampelideæ, Planchon, p. 331).

Plant: "Attains large size, climbing high, lives to a great age" (Dr. D. Morris, Director. Botanical Gardens, Kingston, Jamaica).

Roots: Not examined.

Wood: Annual, thick, angled and irregularly striated with a few shallow striæ; growing tips not leafy and densely rusty tomentose: color dark chestnut, set with rusty woolly tomentum, becoming floccose, and with short, stiff pubescence near the nodes; outer bark separating in thin fibrous plates, and shedding second year; true bark in old vine checking fine, slowly shedding by small bits, persistent, much resembling $V$. cinerea, in body of vine, wood dense, tough, fibrous; sectional view, of annual wood, rays numerous, thin, pores large, abundant; nodes but little enlarged, slightly bent; diaphragm very thick, buds globose or sub-conical with rusty wool at the summit; tendrils once or twice forked, long striated, rusty woolly when young, very strong; internodes medium to long, $4^{\prime}$ to $5^{\prime}$ or more; pith nearly twice the thickness of the wood, firm, insensibly passing into the diaphragm.

Leaves: Stipules minute, rusty woolly; petiole about $1 / 2$ the length of midrib, slender, rusty tomentose or pubescent, narrowly grooved above, attached to blade at obtuse angle; blade in length about the same as in width or slightly more, averaging $4^{\prime}$ to $5^{\prime}$; shape orbicular, cordate or truncate at base, plane; basal sinus shallow, broadly $\wedge$ shaped or wanting, shoulders short-acute or wanting; apex, short, slender, acute; margin entire, smooth; teeth mere mucrons, near together, with a slight scallop between; venation from 6 or more, commonly 7 pairs of prominent, little rusty ribs, each of which ends directly in a mucron; nerves between the ribs also prominent; 


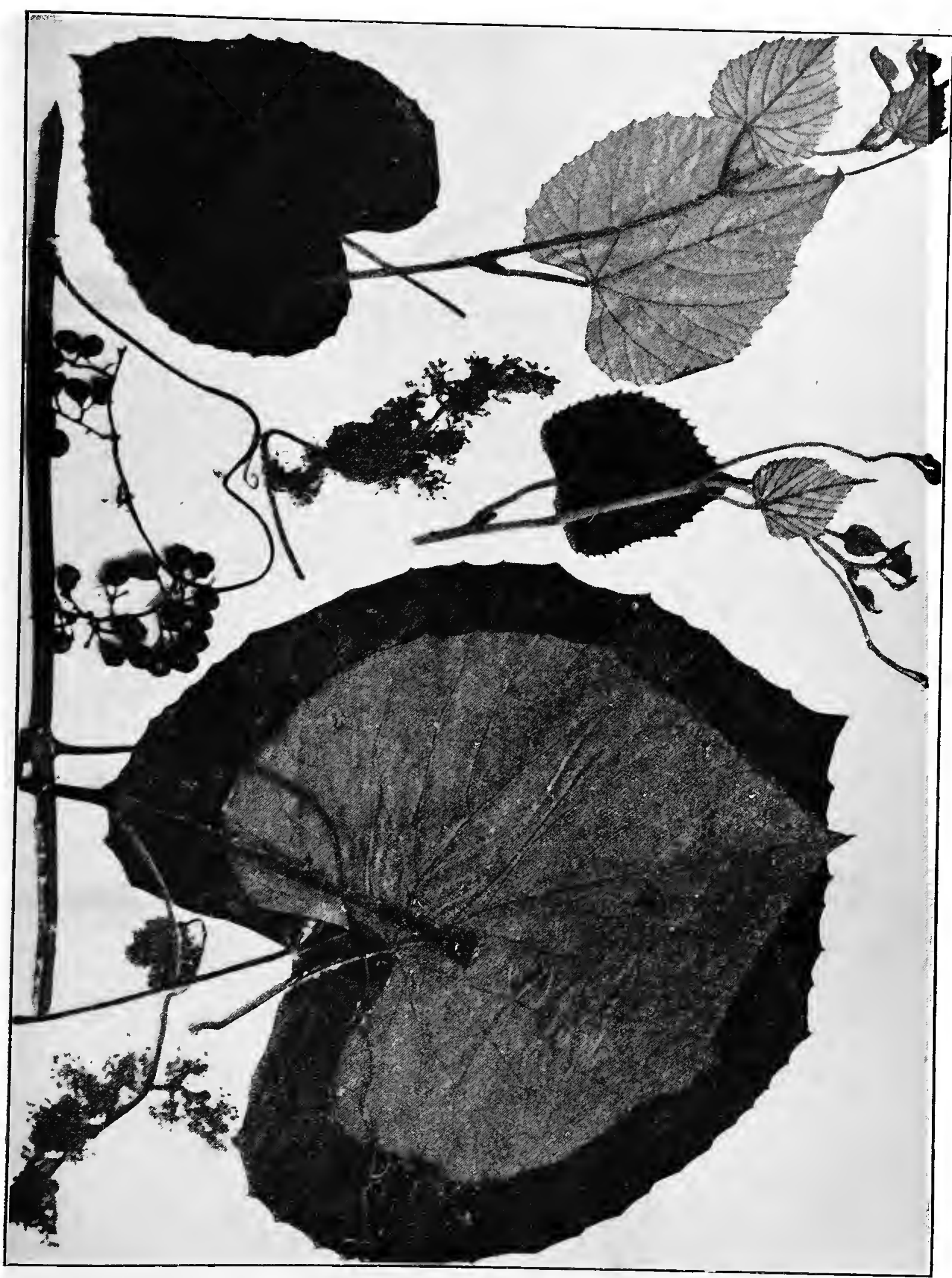

PLATE XX. VITIS CARIBAEA, D.C. From Jamaica. 
upper surface when young covered with cobwebby hairs which become floccose and disappear at. maturity, leaving a dull green finely wrinkled surface in which the ribs are sunken; lower surface covered with thin layer of pale rusty felt-like tomentum, more rusty along the ribs; texture rather leathery.

Cluster: Fertile,-very large compound, generally lax in appearance, similar to $V$. cinerea, of Florida, but with shorter, more slender pedicels; peduncle medium, covered with dull rusty tomentum, rachis thinly rusty woolly, its branches and their short subdivisions densel.y rusty woolly; pedicels many, about $1 / 8^{\prime}$ long, slender, smooth at flowering season; sterile,- not seen by writer, described by DeCandolle as exceeding the leaves in length, which would require a very large cluster.

Flowers: Fertile,-minute, stamens erect or horizontal, nearly as long as the pedicels, disc large; ovary minute, globose-conical; style short.

Berries: Described by D.C. as very small, globular, and glabrous. This description suits. well the berries received from Jamaica and Honduras, Central America.

Seeds: 2 to 3 , very small, ovoid, subcordate, chestnut color, beak short, raphe filiform, chalaza obovate or orbicular, in center of back of seed (D.C.), MacFadeyn F1. Ham., p. 181. Those obtained by me from Jamaica and Honduras agree with this description.

\section{Viticultural Observations and Remarks}

-So far; except where noted otherwise, this description is made from specimens of leaves; branches old and young wood, and fertile flower cluster in bloom, collected for me near Kingston, Jamaica, by Dr. D. Morris, Director of the Botanical Gardens at that time, and others collected in Honduras by Mr. A. Bauer. These specimens bear every evidence of being the typical $V$. Caribca of DeCandolle. After the most diligent inquiry for this form in various parts of Florida and other Southern States and securing specimens of the vine which Prof. A. H. Curtiss has taken to be $V$. Caribcea (sent me by him for examination), I am unable to discover the slightest traces of this species in the United States. Prof. Curtiss' vine seems to be a hybrid between $V$. Simpsoni and $V$. cinerea (?). It is said to produce a medium sized fruit of fine quality, while $V$. Caribca is small and acid. I place this species here as it is so nearly allied to $V$.cinerea and is found welldistributed - according to Planchon-along the coast of Mexico, Central America and among the West Indies, but not in the United States, as classified by Dr. Engelmann, from Prof. Curtiss' Indian River (Fla.) specimens; nor according to Durand's Report of finding it in Arkansas, which Prof. A. Millardet speaks of with doubt in his work upon American vines.

I find in my Arkansas specimens of $V$. cinerea forms approaching $V$. cinerea, var. Floridana, and further eastward the change becomes very marked, and finally the Florida variety prevails, which latter Mr. J. H. Simpson, botanist of Manatee, Florida, took for a time to be V. Caribca; but upon receiving and comparing the true $V$. Caribaa sent me by Dr. Morris from Jamaica and sharing the specimens with Mr. Simpson, he at once agreed with me that what he had found and sent to me as $V$. Caribea was distinct and he is now positive that in many years residence in Florida he has never seen the true $V$. Caribca (as described by MacFadeyn and illustrated by Dr. Morris' specimens) in Florida. States.

Certainly the species offers nothing interesting or valuable to viticulturists in the United

12a. VITIS CINEREA, Engelmann, in Bishberg Cat. 1883, p. 16, No. 8.

12b. VITIS CINEREA, variety, Floridana, Munson. (See Plates XXI and XXII.)

Synonyms: $\quad V$. astivalis, var., Gray, Pl. Lindh., p. 166.

$V$. cestivalis, var. canescens, Engelm. Am. Nat. 2, p. 321.

"Ashy Grape," "Sweet Winter Grape."

Plant: Climbing very high, attaining great size, slender, non-tapering, the slowly expanding leaves on terminals of growing shoots make them appear almost leafless, the latter extending very rapidly and to great length. 


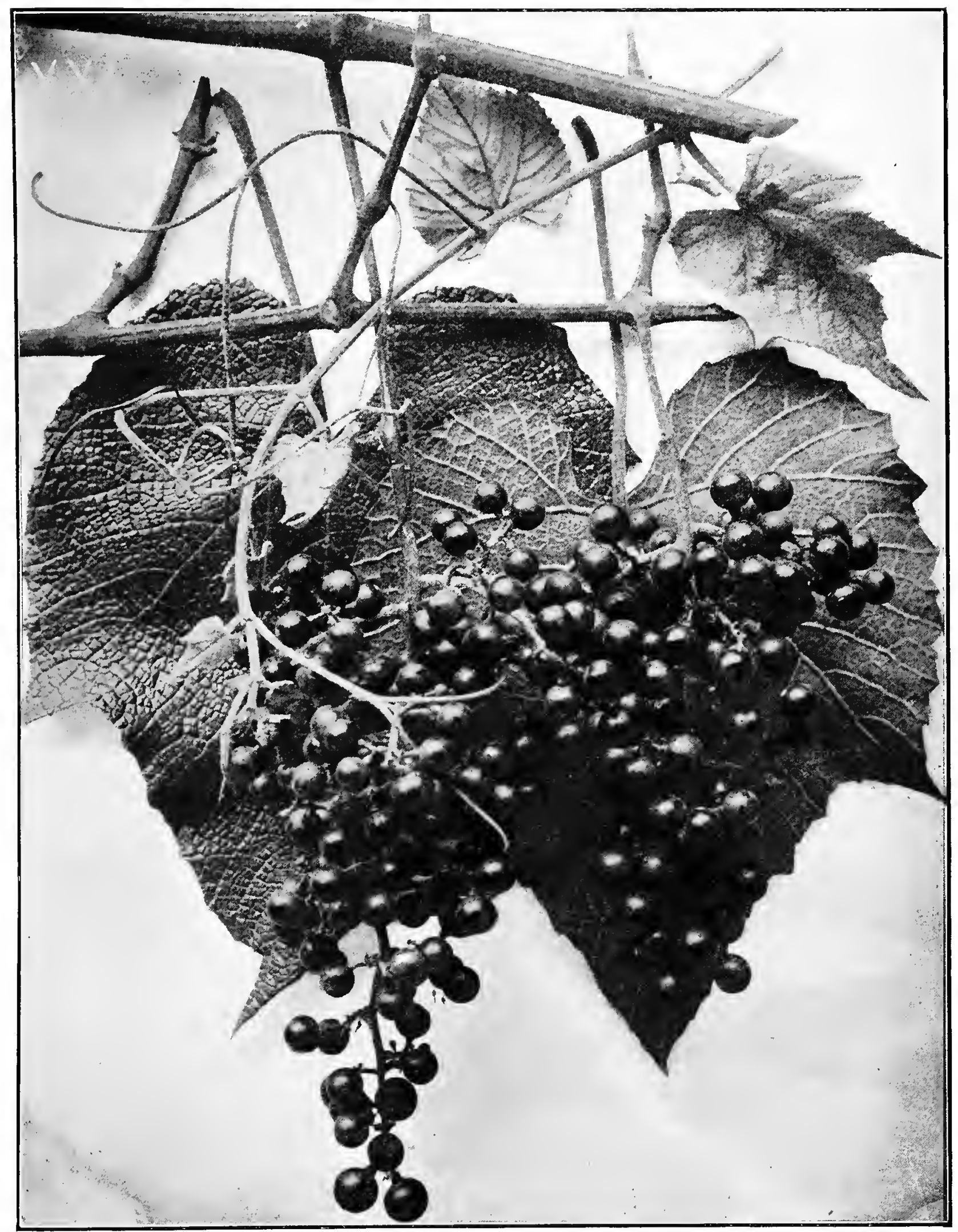

PLATE XXI. 12a. VITIS CINEREA.

Ashy-Leaved Grape, or Sweet Winter Grape. From Arkansas. 
Roots: Little fibrous, rather few divisions, wrinkled transversely, medium hardness, deeply penetrating.

Wood: When young distinctly angled, covered with dense whitish felt, dull green, becoming pale brown or ash colored under the ashy pubescence or floccose cotton or both; outer bark at maturity finely striated, rather persistent, flaking off the second year into fibrous plates; true bark finely dividing into fibrous ridges; wood rather soft to cut; cross section of annual wood shows distinct rays, porous; nodes usually much enlarged; diaphragm commonly $1 / 8^{\prime}$ to $1 / 6^{\prime}$ thick, often much thicker, biconcave; buds small, conical or sub-triangled, acute, grayishbrown, in unfolding, rosy crimson, salmon in var. Floridana, tip closed; tendrils once, or more often twice forked, very long, cottony; smooth with maturity, of same color as mature wood, persistent, strong; internodes long, $2^{\prime}$ to $6^{\prime}$ or more, pith large, enlarged at lower end, brown.

Leaves: Stipules minute, cottony; petiole quite variable, usually less in length than half the width of blade, sometimes more, especially in leaves from ground shoots; petiole terete or prismatic in section, narrowly and deeply grooved, striated, densely velvety or cottony, or both, pubescence obscuring groove, remaining so to maturity, set at obtuse angle with blade; blade sometimes $6^{\prime}$ to $7^{\prime}$, rarely $8^{\prime}$ to $9^{\prime}$ in length, broad, plane or slightly convexing upward, cordate; basal sinus deep, mostly $\wedge$ shaped with double curved sides, narrow or broad, rarely $n$ shaped in specimens from Coahuila, Mexico; basal lobes generally short, obtuse; lateral lobes, or shoulders, approaching the apex, unequal, one commonly more prominent and acute than the other; apex large, long, lanceolate, acute; teeth small, shallow, convex, with small mucron; venation from generally 8 to 9 pairs of mostly opposite, rather prominent ribs; upper surface covered when young with a thick, whitish felt, becoming thinner and drawn out (appressed) along the surface in cobwebby hairs, gradually shedding, becoming floccose and disappearing at maturity of leaf, rugose, dull dark green; all the under face covered closely with a thin, short, hairy or pubescent ash-colored felt, same as on petiole and young wood. Leaves on ground shoots of old roots usually 3 to 5 lobed, with rounded, nearly closed sinuses; entire on seedlings first year.

Cluster: Fertile,-large to medium, generally quite open, peduncle long, striated, more slender from vine to node than next to cluster, usually bearing a simple false tendril, at node, or a small shoulder, or secondary cluster, on long peduncle, when the false tendril is so transformed; rachis usually twice divided,- compound-cottony or pubescent; pedicels numerous, slender, warty.

Flowers: Fertile,-stamens 5 to 6 , generally 5, short, recurved, and bent laterally; ovary and style very small, slender; stigma minute; sterile,-stamens long, slender, ascending.

Berries: $1 / 5^{\prime}$ to $1 / 3^{\prime}$ in diameter, spherical, black or purple, with little or no prunose bloom, not shining unless rubbed, very persistent; skin thin, tough, little coloring matter; pulp tender, melting, juicy, acid till fully ripe, then vinous, sweet, sprightly, pure not pungent.

Seeds: 1 to 3 , generally $3 ; 1 / 6^{\prime}$ to $1 / 5^{\prime}$ long by $5 / 6$ as broad, ovoid when one in a berry, color light purplish-gray; beak small, sharp, well defined; raphe prominent, about filling groove, and extending prominently from the beak to chalaza; chalaza circular or short, ovate, sometimes hastate or truncate at base, as in V. cordifolia, moderately prominent, about even with surface of seed, and lying in the center of back of seed; basin shallow, with border often wrinkled, surrounding chalaza, and extending to or over the rounded top of seed, also a faint groove from chalaza to beak; ventral depressions shallow, near together, of a lighter brownish color than body of seed.

Plantlet: Cotyledons small, medium long, narrowly ovate, taper-pointed, green much the same as in V. Berlandieri.

\section{Viticultural Observations and Remarks}

Germination early to medium; foliation late to very late; inflorescence very late, from the first to the eighth of June at Denison, Texas, some two weeks later than $V$. Lincecumii; ripening of fruit very late,-September, October and November in Northern Texas.

Growth first year from seed or cutting feeble,- - slender and reclining, then becoming very vigorous; enduring cold moderately, - about equally with $V$. astivalis, -and great extremes of drouth and moisture; is remarkably free from disease; very long lived. 


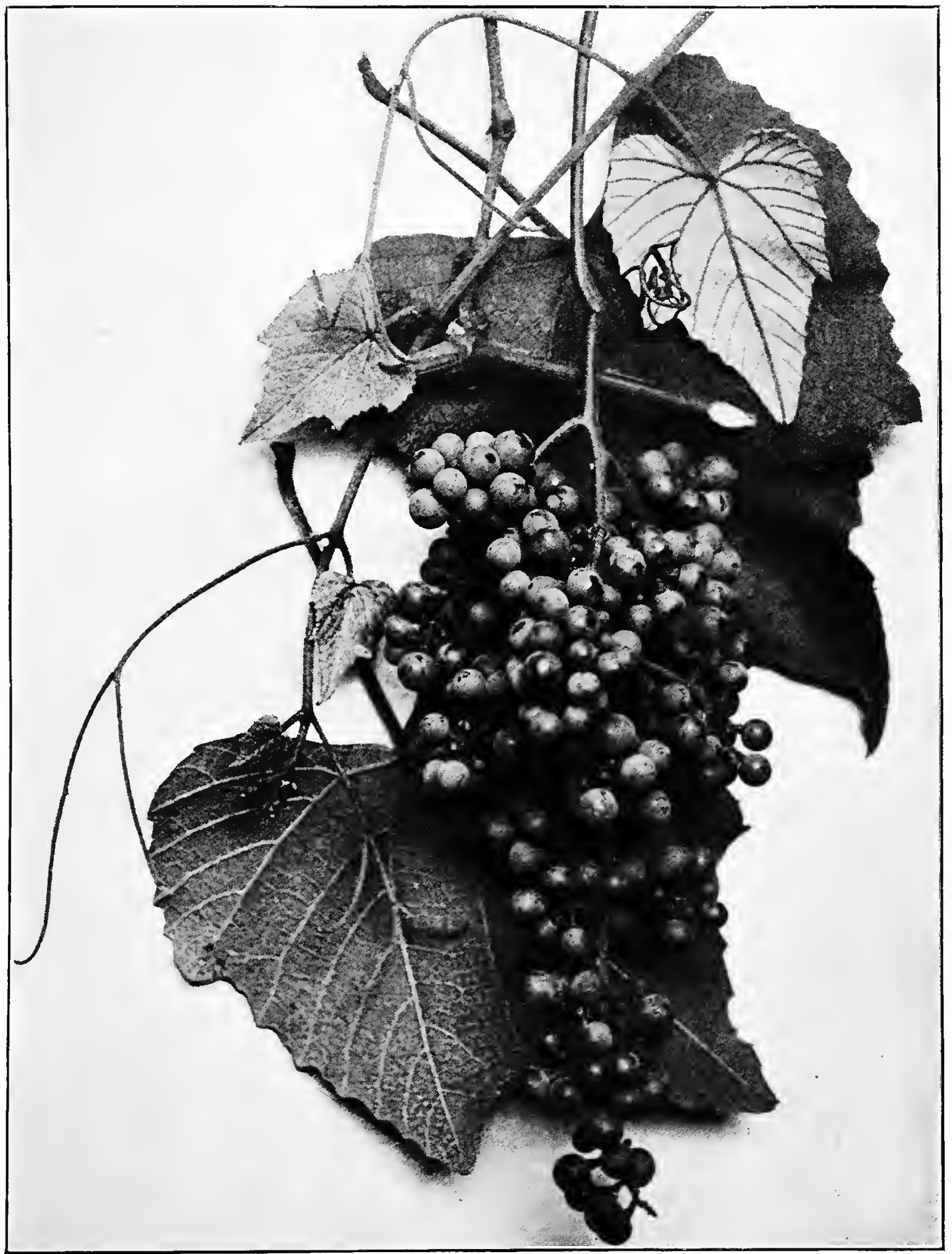

PLATE XXII. Reduced 1/4. VITIS CINEREA, VAR. FLORIDANA,"Munson. Ashy-Leaf Grape, or Sweet Winter Grape, of Florida. 
In its pure form it grows with difficulty from cuttings, with rare exceptions, one of which is found in a fine bearing variety received from Arkansas which propagates fairly well in this way. Mr. H. Jaeger made a most delicious red wine from this species. Its purity of quality, fine properties of vine, large cluster, furnish a good basis for growing a race of grapes suited to low moist lands where mildew and rot destroy most varieties in cultivation, and in the South would give grapes from August to November, where, until recently, we have had only Muscadines in cultivation.

It is often found naturally hybridized with $V$. Lincecumi $i$ and $V$. cordifolia, rarely with $V$. rupestris in Southwestern Missouri, Oklahoma, and Texas; very seldom with $V$.candicans in Texas, abundantly with $V$. cestivalis and $V$. cordifolia, in Alabama, Georgia, Virginia, etc., and. rarely with $V$ labrusca, in the South Altantic States. The writer has two hybrids of it with $V$. Lincecumii, var. glauca, from Southwestern Missouri, which are free from disease, and larger and better than $C y n t h i a n a$, and very prolific, but have reflexed stamens. It has been hybridized with $V$. rupestris, by Prof. A. Millardet, of Bordeaux, France, which combination produces a very excellent stock. The most northern point it is reported is near Canton, Fulton Co., Illinois, and in the southern part of that county the writer has seen it abundantly, with $V$. cordifolia, $V$. bicolor, and $V$. vulpina. It grows abundantly along the Mississippi and Missouri River banks, in Eastern Missouri bottom lands, on all streams from Missouri River to the Gulf, east of the Brazos River and through the Lower Mississippi Valley.

I found a very tomentose form abundant on the Rio Grande near Del Rio, Texas, but nowhere between there and the Brazos. In Southern Georgia and Florida, it runs into a variety with rusty colored young shoots, and having very large, compound clusters of generally smaller, more acid berries than are found farther north, the peduncles are exceedingly long. This variety has been taken for $V$. Caribæa by some botanists. It approaches that species more closely than any other of our species.

I have noted as $V$. cinerea, var. Floridana, Munson, with the following synonyms:

V. Caribca, Engelmann, and Curtiss, Bushberg Cat., p. 15, 1883.

V. Caribcea, Millardet, Especes des Vignes, p. 231.

V. Simpsoni, Munson, Proceedings S. P. A. S., 1887, p. 59.

Having grown numerous fully developed, fruiting vines of this form, it proves to be identical with $V$. cinerea, Engelm., except that the young tips are always red, rusty, tomentose, and the lower surface of leaves rusty cinereous, instead of light cinereous, as in more western and northern forms, and is very much less enduring.in cold than the more northern form.

Leaf-folder defoliates it at Denison, Texas; difficult of propagation from cuttings.

This variety has been found by J. H. Simpson (the discoverer of its distinct character), naturally hybridized with $V$. coriacea, $V$. Simpsoni, and $V$. cordifolia. It is native in Florida and Southern Georgia, proceeding westward along the Gulf Coast and northward, gradually taking the form of $V$. cinerea. It is quite probable that the vine reported from Arkansas and described by Durand as $V$. Caribea, was this form of $V$. cinerea.

The following notes are arranged from Mr. Simpson's pen:

"The fruit.is useless for the table, but would make fair wine. The best grape I have found in this section was one of its hybrids with $V$. coriacea, the vine being the most vigorous one I have seen, the bunches and fruit of good size and flavor, ripening earlier than the species pure, an excellent bearer, and I have no doubt if the vine were properly cultivated it would be far superior to any native grape we have in the State. Another hybrid with $V$. coriacea grows a short distance from it, and might prove valuable in cultivation, though it is later and not so valuable in other respects. This form resembles $V$. cinerea in many points, in others $V$. Caribaa, of the West Indies, while there are often vines that resemble $V$. Simpsoni so much that it takes close observation to tell them apart by the leaves alone. It is very abundant in Southern Florida in the hummock woods and seems to prefer moist land. In some cases the vines grow with crowns but a few inches 
above water, even during the dry season and where the roots must occupy ground perfectly saturated during the rainy season."

13. VITIS BERLANDIERI, Planchon. From specimens collected by Berlandier in Western Texas about 1883. (See Plate XXIII.)

Synonyms:

V. cestivalis monticola, var. Engelm. in Am. Nat., 2, p. 321.

$V$. cestivalis, var. Gray, P1. Wright, 1, p. 32.

V. monticola, Engelm. Bushberg Cat., p. 15, 1883.

V. monticola, Millardet, Especes de Vignes, pp. 199-204, 1885.

"Little Mountain Grape," "Fall Grape," "Winter Grape," "Spanish Grape."

Plant: Rather stocky, with much the same habit as $V$. cinerea though more tapering and branched, climbing somewhat less, yet along streams going to tops of large trees, foliage of a bright, dark lively green color, and shining in light, its chief distinction from $V$. cinerea.

Roots: Little branching, wrinkled transversely, hard, deeply penetrating.

Wood: When young distinctly ang.ed as in $V$. cinerea, covered with dull ashy pubescence and thin cottony hairs, the pubescence remaining through the first year, giving the dull brown, finely striated bark beneath an ashy appearance; wood rather soft; sectional view of annual wood porous, rays distinct, almost identical in structure and hardness with $V$. cinerea; nodes slightly bulged, much bent; diaphragm $1 / 12^{\prime}$ to $1 / 10^{\prime}$ in thickness, nearly plane; buds usually small and conical, sub-triangled, sometimes globose and cottony-like tip, unfolding, pinkish-crimson or salmon, tip closed; tendrils generally once, often twice forked, long, at first cottony and pubescent, then smooth, striated, red or green, persistent; internodes usually short, $2^{\prime}$ to $4^{\prime}$ long, often more, sometimes $6^{\prime}$ or $7^{\prime}$; pith small, enlarged at lower end, light brown or nearly white.

Leaves: Stipules very small; petiole in length about 1/2the width of blade, distinctly striated, groove very narrow and shallow, almost wanting, covered with a thin ashy cotton or closely set with a short velvety pubescence, or both, reddish or green, set at right or obtuse angle with leaf. Blade mostly $2^{\prime}$ to $4^{\prime}$ wide, sometimes $5^{\prime}$ or $6^{\prime}$, the length of the blade from insertion of petiole to summit, less by about $1 / 5$ than its width; circular, slightly cupped toward upper face, with margin bent back a little,-less so than $V$. Arizonica; basal sinus usually $n$ shaped, but also often $\Lambda$ shaped, or acute at insertion of petiole; shoulders usually not very prominent, apex short, acutely tapering; teeth short, small, convex with minute mucron; venation from the usually 6, sometimes 7 pairs of opposite, rather prominent ribs, covered with short, velvety pubescence; leaves when young, pinkish or green, thinly covered with short, delicate hairs, giving an ashy appearance, becoming smooth or slightly rugose, dark glossy green at maturity; the under surface between the ribs, thickly set with short, delicate cottony hairs, when young, smooth and glossy at maturity as if varnished; color dark green; texture dense, leathery; leaves from ground shoots of old wood usually 3 to 5 lobed, with rounded lateral sinuses quite similar in this respect to $\checkmark$ cinerea.

Clusters: Medium to very large, compact, with false tendril which sometimes becomes a secondary cluster, or shoulder; rachis one or twice compounded, pubescent or cottony, pale green; pedicels $1 / 5^{\prime}$ to $1 / 4^{\prime}$ long, slender, enlarged at receptacle, warty.

Flowers: Fertile,_-stamens recurved and bent laterally; ovary sma1l, ovate, style slender; stigma small; staminate,--stamens long, slender, ascending.

Berries: $1 / 5^{\prime}$ to $1 / 3^{\prime}$ in diameter, spherical, black or purple, sometimes red, little to 'much bloom, far more than in $V$. cinerea, a good distinction; skin thin; pulp melting, juicy, vinous, pure and sweet if allowed to hang till frost,--tastes much like fruit of $V$. cinerea.

Seeds: 1 to 3 , usually 1 ; small to medium, $1 / 8^{\prime}$ to $1 / 5^{\prime}$ long by about the same broad; globular or broadly ovoid when only one in a berry; color grayish-coffee to light chocolate brown, wine or pale-purplish; beak very small, short; raphe is generally invisible or a fine thread, quite as prominent in Uvalde County specimens as in V. cinerea; chalaza usually flat or depressed, some- 


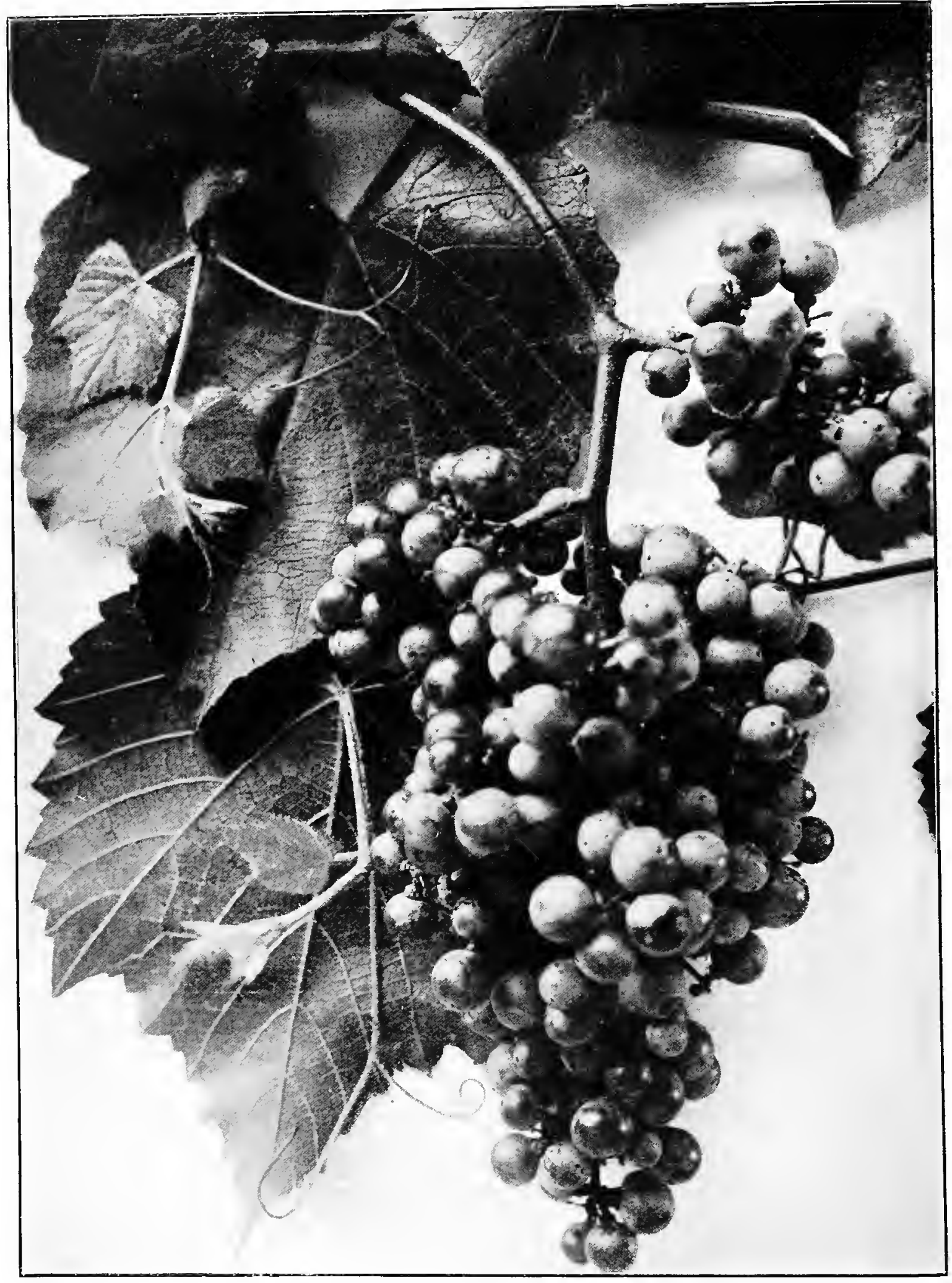

PLATE XXIII. 13. VITIS BERLANCIERI, Planchon.

Little Mountain Grape. Lampasas Co., Texas.

Specimen much above average. 
times convex, ovate or roundish in center of back of seed or above, surrounded by a distinct groove which continues to, or over,top of seed; ventral depressions commonly wide apart at the top, approaching at beak, broad, shallow, color light cinnamon, or nearly same as body of seed.

Plantlet: Cotyledons small, ovate, green, similar to $V$. cinerea; petioles medium long, $1 / 6^{\prime}$ to $1 / 4^{\prime}$.

\section{Viticultural Observations and Remarks}

Germination slow, about with $V$ cinerea, not so late as $V$. Lincecumii, feeble; foliation late to very late, just before or with $V$. cinerea; ripening of fruit very late, September and October at Denison, Texas, somewhat earlier than $V$. cinerea.

First yeary growth feeble, slender and reclining, becoming vigorous after first year but not so rampant as $V$. cinerea; endures cold and drouth; resistant to Black Rot; leaves of most varieties of this species mildew in low lands and wet climates much worse than $V$. cinerea; cuttings grow with difficulty and in only rare exceptions is the contrary true; among many tried I have found but one pure $V$. Berlandieri that was very vigorous and healthy, bearing a good cluster and fair fruit, which grows very readily from cuttings and so far has not been attacked by mildew, offering a fine basis for a group of hybrids to secure a combination of various fine properties for dry, mild climates and for very limy soils. As a stock to succeed in very dry calcareous soils, resist Phylloxera, and live to a great age, we probably have no better species in the United States, but it has one generally serious fault,--the difficulty of propagation from cuttings.

It is often found naturally hybridized with $V$. monticola, $V$. candicans, $V$. rupestris, and toward the Rio Grande with $V$. Arizonica. In some respects it closely approaches $V$. Arizonica, especially so, vines from the Rio Grande region. The best varieties of $V$. Berlandieri may give a basis upon which, by hybridization, a fine strain of grapes may be produced, this species being prolific, of pure quality, and free from rot.

The species is found along the streams among the cretaceous hills of central Southwestern Texas, west of Brazos River to the Rio Grande and into Mexico, and is also abundant on the hillsides and hilltops of the same regions. It grows best in strong limy soils, but will also grow well in moist sandy lands.

Though so nearly allied to $V$. cinerea it is easily distinguished from that species by its lighter green, glossy foliage, with fewer ribs, its usually fewer seeds, its, smaller and more compact clusters with shorter peduncle and generally larger berries with more bloom. The angled, ashy pubescent. annual wood is readily distinguished from $V$. cordifolia, though the foliage might in some cases be mistaken for those of that species. This species is reported as doing best of any tried in the dry chalky soils of the Charente Inferieure, in France. A variety of this species I found abundantly in Southwestern Coahuila, Mexico, is less glossy than the Texas form and roots. much less resistant to Phylloxera.

\section{VITIS BAILEYANA, Munson. (See Plate XXIV.)}

Synonyms:

V. Virginiana, Munson. Bulletin No. 3, Dep. Agr. 1890. Garden and Forest, Oct. 1, 1890, pp. 474-5.

"'Possum Grape."

Plant: Slender, rather feeble, though hardy, climbing moderately, much branched; tips of young growing shoots green, or pale pink, with very little pale, cottony pubescence, considerably extended beyond fully grown leaves; very leafy, owing to the starting of short lateral branches at almost every node, of a lively clear green, of a tint between $V$. cordifolia and $V$. astivalis, the young wood being of the same shade of green as the under side of leaves, which is only a shade paler than the upper surface, and in the growing plant the lower surface shows. about as much as upper surface, owing to the leaves being partly folded together toward 


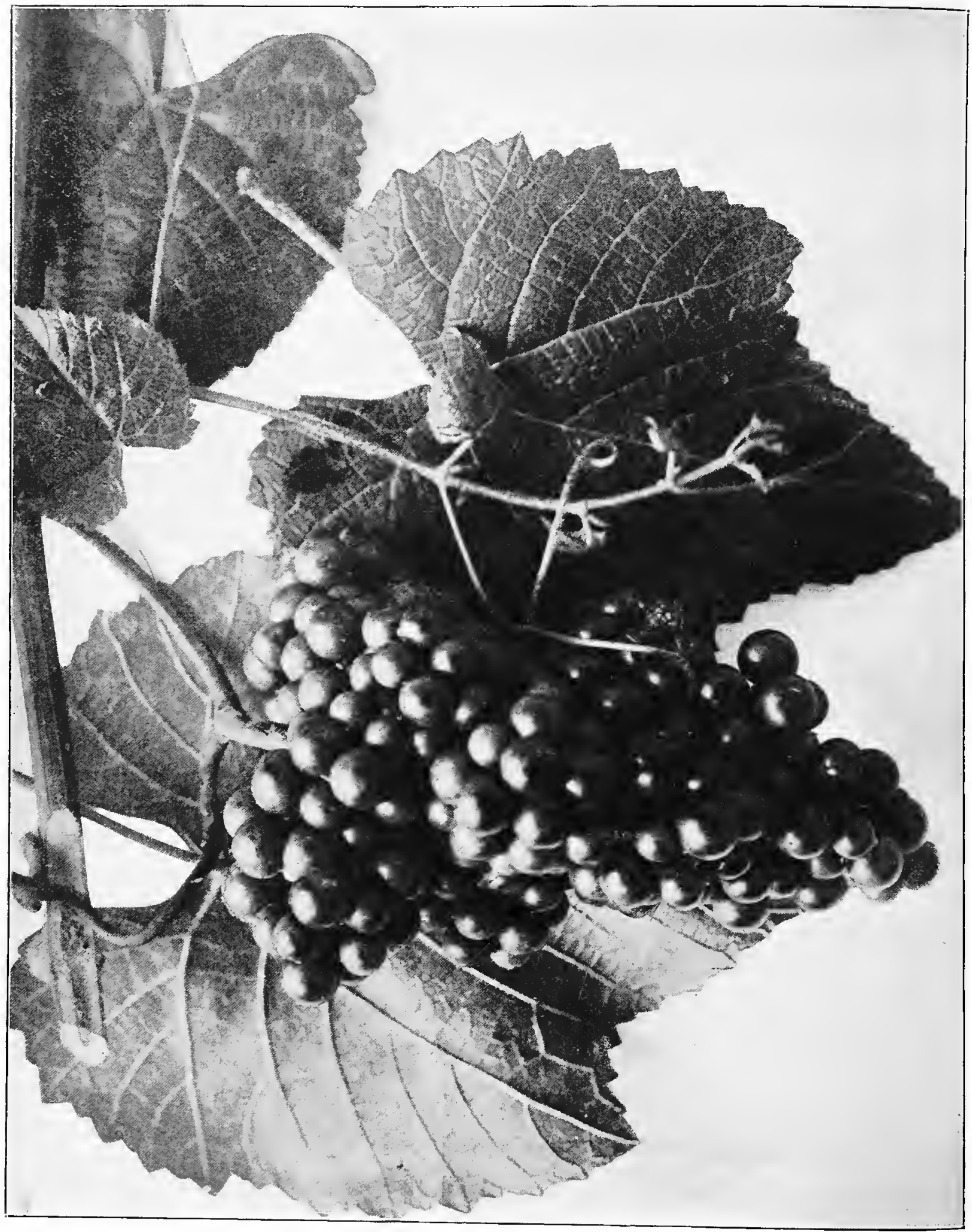

PLATE XXIV. "14. VITIS BAILEYANA, Munson.

"'Possum" Grape. Southern Appalachian Mis. 
upper surface, thus giving the vine quite a distinct aspect from all other species, but more like Berlandieri than any other.

Roots: Thickening downward from collar in one year seedlings and sparingly branched, fleshy, transversely wrinkled, resistant to Phylloxera, moderately penetrating, but not sufficiently to endure the Texas climate well.

Wood: Young angled, becoming nearly cylindrical at maturity, or obscurely angled; finely, but irregularly striated, and smooth, the thin cottony pubescence disappearing before close of first season's growth; color when mature pale hazel or light brown; rather softer than in other species of this series; nodes moderately enlarged; diaphragm $1 / 8^{\prime}$ thick, thicker on side next bud than opposite to it; bud sub-conical, acute, same color as mature annual wood, in unfolding pale brown at first, first appearance of leaves pinkish-green, tip closed; tendrils intermittent, mostly bifid, weak, persistent, green when young, with few cottony hairs; internodes short, 1' to 4', seldom more; pith large, enlarged much at lower end of internode; pale brown.

Leaves: Stipules minute, pale rusty; petiole mostly greater in length than half the width of blade, and $2 / 3$ the length of mid-rib, cylindrical with a distinct narrow groove on upper side; green or pale red, with thin cottony pubescence; of nearly same diameter throughout; blade $2 \frac{1}{2}$ ' to $4^{\prime}$ wide by $2 \frac{1}{2} 2^{\prime}$ to $4^{\prime}$ from insertion of petiole to apex, cordate in general outline, rarely lobed more than to the extent of two unequal shoulders similarly with $V$. cinerea, basal sinus narrowly $\wedge$ shaped, with sides little curved; apex short taper-pointed; teeth irregular, small, short convex, obtuse with distinct mucron; ribs in 7 to 9 nearly opposite pairs, each terminating in the mucron of one of the larger teeth, scarcely at all pubescent, paler green than surface between; both faces generally devoid of pubescent hairs, above moderately wrinkled, not shining and not attacked by the Leaf-folder (Desmia funeralis); persisting to late in the fall.

Cluster: $2 \frac{1}{2} 2^{\prime}$ to $5^{\prime}$ long, very compound and compact, having a false tendril at insertion of peduncle, with rachis; peduncle $1 / 2^{\prime}$ to $1^{\prime}$-very slender-more slender than rachis; rachis thickened, dull green, divisions slender; pedicels $1 / 8^{\prime}$ to $1 / 6^{\prime}$ long, very slender having few small warts, receptacle enlarged when fruit is ripe.

Flowers: Minute, with all parts very delicate, more so than in any other species; stamens and petals mostly 5 , pistil very slender, stigma scarcely visible to naked eye; in fertile flowers stamens reflexed; berries $1 / 6^{\prime}$ to $5 / 16^{\prime}$ in diameter, spherical, shining black with little or no bloom, persistent; skin thin, tough with bright red juice; contents juicy, without pulp, but a greenish matter attached closely to seeds, as in $V$. cordifolia; possessing a similar flavor with $V$. cinerea, pure sprightly, vinous; very acid until fully ripe, then sugary; ripe about with $V$. cordifolia, or earlier.

Seeds: 1 to 3 , mostly $2,1 / 8^{\prime}$ to $1 / 6^{\prime}$ long by $1 / 8^{\prime}$ broad, similar in color to those in $V$ : cinerea, but darker; beak very short, small, distinct, about the same color as body of seed; raphe visible from base of beak as a fine hair to notched top of seed where it disappears in a distinct groove, which enlarges moderately in back of seed, containing only a trace of chalaza, a faint groove extends from basin to beak; ventral depressions broad, distinct, diverging from beak, paler color than body of seed. The seeds from every locality of collection so far have chalaza depressed.

Plantlet: Seed leaves very small, narrowly ovate, acute green. Germination very late, foliation, flowering and ripening about with $V$. cordifolia.

\section{Viticultural Observations and Remarks}

In 1883-4 I received portions of vines with clusters of this peculiar little grape, among specimens of several other species, from Mr. James G. Wertz, of Salem, Roanoke Co., Va. I was unable to classify it satisfactorily with any known species, and planted seeds from which grew a number of vines, some staminate, some pistillate, all of same peculiar character, showing no variation toward any other known species as seedlings of hybrids have invariably done with me. These vines have flowered and fruited many times in my grounds. It appears to be a connecting 
link between $V$. cordifolia and $V$ cinerea, with still other characteristics found in neither of those species, but leaning mostly toward $V$ cinerea. In October, 1889, I found a number of rines of this species along the borders of the Kanawha River in the vicinity of Kanawha Falls, W. Va., and the same year received wood from Mr. J. K. Hoyt, of Duncombe Co., North Carolina, as the "Wild 'Possum Grape," which was grafted and grew, proving to be the same species. In September, 1890, Mr. Hoyt sent me ripe fruit from other vines of the "'Possum Grape" found wild in his vicinity, all being of this species. All plants of the species so far known to me grow along mountain streams at an altitude of 1500 to 3000 feet.

Some of the vines seen at Kanawha Falls, had Phylloxera galls upon their leaves, but the rines were in good health. The formation there is carboniferous limestone, the soil a calcareous clay. The only other species of grapes observed at that point were $V$. cordifolia and $V$. astivalis. From Roanoke Co., Va., I have received in addition to this species, specimens of $V$ astivalis, $V$ labrusca, $V$ cordifolia and $V$ rotundifolia. From Buncombe Co., N. C., I have received besides $V$. Baileyana, $V$ astivalis, $V$. labrusca and $V$. cordifolia, $V$. rotundifolia, reported as not found native there, the altitude, 2000 to $3000 \mathrm{feet}$, being above its range. I have not yet found or obtained any hybrid forms of this species. After having given the species the name of Virginiana, it was noticed that $V$ Virginiana is a synonym for $V$. vulpina and other species, hence I conform to the rule, that a name "once a synonym, always a synonym," and rename my species, dedicating it to my friend Dr. L. H. Bailey.

\section{Series VI. Cordifoliæ, Planchon}

15. (a) VITIS CORDIFOLIA, Lam. 111, 2, p. 134, Michaux, fl. 2, p. 231.

15. (b) VITIS CORDIFOLIA, var. sempervirens, Munson. (See Plate XXV.)

Synonyms:

V. vulpina, in part, Linnaeus.

V. vulpina, Mull. Cat. 26.

V. vulpina, var..cordifolia, Regel. Conspect. Vitis, p. 394. Var. fatida, Engelm. in Am.

Nat. 2, p. 321.

"Winter Grape," "Frost Grape," "Sour Winter Grape," in Texas; "Fox Grape" in Illinois, " 'Possum Grape" in Virginia, North Carolinia and South Carolinia, not distinguishing it from V. Baileyana.

Plant: Vines acquire great size, climbing to the tops of the tallest trees, covering them with an open canopy of dark green glossy leaves, with pendent branches gracefully extending therefrom, from which the naked, rapidly growing tips of the young branches project.

Roots. In one year seedlings, enlarging downward for a foot or more from the collar, forking, non-axial, firm, fully resistant, and penetrates quite successfully very limy as well as sandy soils.

Wood: Young wood cylindrical or oval, angled slightly when quite young, of a pale yellowishgreen, in most of $a$, or bronze-red, always in $b$, and partly so in $a$; the surface about, or on the nodes in immature wood and at the bases of the young branches, covered with short fawn-colored pubescence, especially in the bronzy form; upon mature wood, outer bark but slightly adhering, separating in broad, nearly regular checked plates. which can be easily separated when the wood is but one year old, of a drab or hazel color, with darker and lighter markings, making it in nearly every instance appear mottled, deeply striated; surface smooth, except in some plants a rasp-like feeling when the finger is passed over it; without any or rarely a trace of prunose bloom near the nodes; annual wood rather soft and tough; sectional view open, rays wide apart, pores large; nodes little enlarged, slightly bent, often pubescent; diaphragm thick, $1 / 8^{\prime}$ to $1 / 5^{\prime}$ or more, biconcave; buds medium, sub-conical, sub-acute, terminated with rusty wool, at their opening in the spring of a grayish-purple, or violet, or rusty pink or bronze in the more pubescent form, gradually becoming green with rapid expansion of leaves, tip closed; tendrils usually once forked, rarely twice, intermittent, finely striated, smooth; internodes long to re ${ }^{\prime}:$ long, $3^{\prime}$ to $7^{\prime}$ 
or more; pith large at lower end, rather dark brown, often insensibly meeting the diaphragm above. Extending tip of growing shoot naked,-not enveloped as in $V$. vulpina.

Leaves: Stipules very small to medium, $1 / 10^{\prime}$ to $1 / 5^{\prime}$ long, lance-shaped, fine ciliate edge, soon shedding; petiole long, in length over one-half the width of the blade, striated, with shallow groove above, bordered with stiff pubescence, very abundant on the green form $b$ of a yellowish-green; blade, average length, about $3 \frac{3}{4}$ inches in length by $3 \frac{1}{2}{ }^{\prime}$ in width; long, cordate, plane; basal sinus usually narrowly in $a$, or broadly acute to nearly truncate often in $b$, but sometimes broadly shaped, but in such cases there may be admixture of $V$ vulpina; moderately deep in $a$; basal lobes sometimes closed or overlapping in $a$. Shoulder and summit acute or short taper-pointed, rarely long lance-pointed in the most acute toothed form, nearly as long as in V. rubra; border in the most typical form entire, but shouldered or rarely lobed in the compound, vulpina-like forms, in which the blade is broader than in the simple cordate form; teeth small to large, generally irregular, rarely nearly regular, more or less convex, right-angled or more commonly acute, rarely obtuse, with a distinct, usually long mucron; little or no pubescence along margin; venation from the little elevated; usually 7 pairs of not quite opposite ribs which are pale yellowish-green in $a$ and thinly but stiffly pubescent, the ribs and their larger divisions corresponding in pubescence with petiole; veins when held up to the light, pale yellowish-green in $a$, the ribs and their divisions of the lower face, prominent, densely and stiffly pubescent especially in the bronzy-colored young growth in form $a$, least in the clear green; white pubescent tufts in forks of ribs; surfaces at first slightly hairy, changing from a violet to a clear lively or bronzy green; in mature leaves, upper surface smooth, lively dark shining green when mature; lower surface much paler, of a yellowish or bronzy green when young, old leaves becoming a pale yellow when about to shed if not killed by frost; texture dense, leathery, - much more than in $V$ vulpina. Leaves on ground shoots from old wood generally 3 to 5 lobed with rounded sinuses; on seedlings always entire first and second year. Leaves in $a$ mature and fall earlier than in any other species, while in var. $b$ sempervirens, found chiefly in Florida, and near the Gulf, the leaves hold on very late and growth continues till frozen.

Cluster: Fertile,--medium to large, open, loose, sometimes broadly shouldered, but generally simple; peduncle strong, $1 / 2$ to $2 / 3$ the length of rachis, bracted above middle, smooth or pubescent; rachis little compounded, nearly simple, branches of rachis short, bracted, all smooth, or in bronze form of $a$ pubescent, light yellowish-green or bronzy; pedicels $1 / 6^{\prime}$ to $1 / 4^{\prime}$ long, slender, little enlarged at receptacle, thinly warty; receptacle medium; sterile,-very large, peduncle long, rachis compound, often dividing into several nearly equal short branches, each 3 to 12 flowered, pedicels very slender, $1 / 6^{\prime}$ to $1 / 4^{\prime}$ long, whitish.

Flowers: Fertile,-stamens very short, reflexed, curved latera1ly, having little weak pollen; disc prominently 5 lobed, orange-yellow; ovary small, subconical; style short, slender, pointed; stigma very small; staminate,-stamens usually 5 , often $4,1 / 16^{\prime}$ to $1 / 10^{\prime}$ long, ascending; anthers small, pollen abundant.

Berries: Small, $3 / 16^{\prime}$ to $6 / 16^{\prime}$ in diameter, globular or slightly oblate, sometimes shining, or mostly dull black, rarely has a little bloom, persistent, ripening very late, two months or more later than $V$. vulpina, September in Texas; skin thick or rigid, coloring matter abundant, violet; little pulp, skin possessed of a biting pungency, till well frosted, then becoming vinous and sugary; refreshing but with characteristic flavor, by which alone it can at once be separated from $V$. vulpina, with which it was so long confused, as well as from any other species.

Seeds: $1 / 6^{\prime}$ to $1 / 5^{\prime}$ long, nearly as broad, obovate or sub-globular, of a grizzly dark brown or chocolate color; beak short to medium, sub-bilobed, blunt or acute, of a rusty or reddish-brown color; raphe extends from the extremity of beak prominently over top of seed to chalaza; chalaza circular, or cordate, convex, prominent, lying in the center of back of seed; groove shallow and often continuing faintly to beak; ventral depressions short, shallow, wide apart, curved outward at the top, of same color as beak. Seeds surrounded by dark adhering pigment, when freshly taken from the berry. 
Plantlet: Seed-leaves, large cordate or ovate, acute, green, petioles short; first year, slender, weak, declining, leaves entire.

\section{Viticultùral Observations and Remarks}

Germination early to medium,- - those from Florida (b) quickest; foliation early, medium to late, usually with or a little earlier than $V$. Lincecumii and after $V$. labrusca; inflorescence just after $V$.labrusca, before $V$. Lincecumii; ripening of fruit very late, long after $V$. astivalis, about with $V$. cinerea; foliage and wood mature in $a$ very early, about the first of our native species, leaves turning yellow before frost, falling and exposing the fruit for ripening, while in $b$ the leaves persist very late. Vigor great; plants attain an immense size, one in Ientucky was. measured by the writer, which at six feet from the ground was sixty-six inches in circumference; endures cold about equally with $V$. cinerea; found in same locality, those native in Illinois $a$, being very hardy, while $b$ is quite tender in Northern Texas; resists Phylloxera fully, also mildew and rot." Its hybrids with $V$. rupestris have been found eminently resistant to Phylloxera by Prof. A. Millardet. Some of its wild hybrids with V. labrusca* and V. Lincecumii show much amelioration. Cuttings grow with difficulty. The immense size and age it may attain well suit it for graft-stocks, though the difficulty of rooting the cuttings makes it less desirable than the easier rooting hybrids with $V$. rupestris and $V$. vulpina; mixed with $V$. Longii and $V$. Doaniana. it doubtless would be most excellent, as stocks in dry soils, and with $V$. Champini would be most excellent in very limy soils, though may be no better than pure $V$. Champini.

Numerous natural hybrids of this species with $V . r$ rupestris, $V$. vulpina, V. Lincecumii, and $V$. cinerea were found by $\mathrm{H}$. Jaeger in Southwest Missouri; in Northern Texas by myself with $V$. cinerea and $V$. Lincecumii; by J. H. Simpson in Florida, with V. coriacea, V. Simpsoni, $V$. cestivalis, and rarely even with $V$. Munsoniana, and it has been obtained from Virginia and Georgia hybridized with $V$. cestivalis, $V$. labrusca and $V$. cinerea.

The foregoing analysis is from specimens obtained from Virginia, Kentucky, Ilinois, Missouri, Oklahoma, many parts of Texas, Georgia, and Florida, which show its range. Its northern limit is about 40 degrees, its westward, is through eastern Kansas, central Oklahoma and the Trinity River in Texas. The entire, simple cordate, and shouldered leaf forms, the bronzy pubescent and smooth, clear yellowish-green forms are found intermingled throughout its entire distribution and are poorly defined botanical varieties. Its late foliation, blooming, ripening, thick diaphragm, prominent chalaza and raphe, pungency of fruit, narrowly cordate, thick shiny leaves, fruit without bloom, tall growth, in extensive regions where $V$. vulpina is not found, and many other marks, readily distinguish it from that species, with which it was so long and so much confused by bọtanists. This species prefers argillaceous, alluvial moist bottoms, but in Northern Texas grows with great vigor on strong limy soils, but does not endure drouth there so well as $V$. cinerea or $V$. candicäns.

The variety sempervirens, though so far as seen is always bronze colored in young shoots, and leaves, is chiefly distinguished from the species by the truncate base and deltoid shape of leaves with great persistency of foliage, smaller clusters and later ripening of fruit, and its greater sensitiveness to cold.

* The Ronk's Blue Grape, found many years ago, in the woods in Roanoke County, Va., by a Mr. Ronk, and by him moved into his yard, grew to be a large vine and continued for many years to bear large crops of fruit of quite good quality. The clusters and berries are of medium size, the berry black, ovoid, skin thin, tough, pulp melting, juicy, sprightly without Labrusca flavor but possessing that of $V$.cordifolia to some extent. The writer has bearing vines of it, the characteristics of which are certainly $V$. cordifolia and $V$. labrusca, in wood, leaf and fruit. From seeds of it he has grown a dozen or more plants, most of which are exceedingly like $V$. cordifolia, with the small very late characteristic fruit of that species, while two have large fruit ripening a little after midseason, one large cluster, berry large, ovoid, black, with good melting pulp, much better than its parent. It is without any Labrusca flavor, but has a trace, quite agreeable, of Cordifolia. The other has cluster and berry medium, berry red, quality sweet, fair. The leaves in both show clearly both species, the tendrils on some shoots continuous show $V$. labrusca, certainly. Such result in size and quality from a combination of those two species is ve1y surprising, and shows what grand results lie in store for any persistent, intelligent hybridizer of our native grapes 
16. VITIS RUBRA, Michaux. In Herbario Musaie Parisiensis. (See Plate XXVI.)

Sỵnonym:

V. palmata, Engelm. Bushberg Cat., p. 17, 1883.* ,

"Cat Bird Grape."

Plant: Slender, branching moderately, climbing high; tips of extending branches very naked, not leafy as in $V$. vulpina and $V$. rupestris, similar in habit to $V$. cordifolia, though less rampant, about equal with $V$. monticola, grows in bottom lands; the entire aspect of vine is very graceful and beautiful.

Roots: Rather thick, abundant, finely divided near the surface, but the deeper ones a little wrinkled transversely as in $V$. cordifolia, hard and penetrating.

Wood: First year, always dark crimson red until mature, thinly supplied with whitish cottony hairs and angularly grooved, with a few scattering warts especially near the nodes, otherwise perfectly smooth; when mature of a reddish-brown or chestnut color, finely striated, shining, smooth, or slightly scabrous; bark on old wood separating in wide, thin plates as in $V$. cordifolia; nodes little enlarged, slightly bent; diaphragm quite thick, $1 / 8^{\prime}$ to $1 / 5^{\prime}$ biconcave; buds small, sub-triangular, acute, covered with dark brown scales, in unfolding small, slender, pale crimson, or pinkish-green, closed tip; tendrils intermittent, forked, strong, red when young and having a few cottony hairs, persistent; internodes short, medium, or about the same as $V$. cordifolia; pith small, a little enlarged at lower end.

* Upon the finding of specimens of this species in 1882 near St. Louis, by Mr. H. Eggert, Dr. Engelmann thought he recognized it as Michaux' $V$. rubra, but later (Bushberg Cat. 1883, p. 17) he was of the opinion that it is $V$. palamala (Vahl, Symb. 3, 42), which Watson's Index makes a synonym of $V$. astivalis. Referring to the matter, J. E. Planchon, the most eminent of all ampelographers, in "La. Vigne Americaine," 1884, January number, shows with great care that it is very doubtful whether Vahl's species was this species. Prof. A. Millardet is of the same opinion (Especes de Vignes d'Origine Americaine, p. 224). As both these eminent authors lived in France, where Engelmann claimed Vahl's vine to be growing in the Jardin des Plantes, Paris, "for perhaps one hundred years," they surely ought to know better than Engelmann living in this country. Vahl's specimen was reported from Virginia, where $V$. rubra does not grow, but where palmately-lobed $V$. vulpina is often found, and it is most probable that his specimen belongs to $V$. vulpina, $\mathrm{L}$.

The following was published in the Forest and Garden, N. Y., Dec. 31st, 1890:

"Sir:- I send you the result of some inquiries concerning Vahl's $V$. palmala which seems to settle in this country (it has already been settled in France, where American Grapes are most diligently studied) the dispute as to which name should be used, $V$. rubra, Mx., or $V$. palmata, Vahl, to designate the species of Grape which was rediscovered by H. Eggert on the Mississippi River above St. Louis in 1882, and which Dr. Engelmann, in the Bushberg Catalogue, 1883, claimed to identify as Vahl's $V$. palmata, which he so classified, and which was illustrated for the first time in the July, 1889, Garden and Forest, under Engelmann's name, V. palmala.

In the January number, 1884, of La Vigne Americaine, published in France, J. E. Planchon, referring to Engelmann's use of $V$, palamata, reviewed all the evidence then at command bearing upon the subject (pages 15-20). I make here a few extracts from Planchon's article: 'Sous le nom de Vitis Palmata, le botaniste Danois Vahl, a decrit, en 1794, dans ses Symbolæ Botanicæ (3e partie, p. 42), une vigne qu'il avait recue du Jardin des Plantes de Paris et a laquelle il consacre l'article suivant que je traduis du latin en francais', etc. After Vahl's description as translated by Planchon, the latter remarks: 'Une description aussi incomplete, ne comprenant ni les fleurs, ni le fruit, devait laisser des doutes sur la determination de cette plante. Aussi l'a-t-on rapportee souvent comme synonyme a d'autres especes, par example au Riparia de Michaux, a l'Estivalis du meme auteur, ou meme an Labrusca de Linne.'

From the above it appears that Vahl obtained the plant he described so incompletely, from the Jardin des Plantes in Paris. This plant it appears had several synonyms, such as $V$. Virginiana, $V$. Virginica, and $V$. Vir giniensis (see Planchon's article, pp. 16 and 17). Finally, in summing up the whole matter; Planchon says (p. 20), that the evidence 'me confirme tout a fait dans l'idee que le Vitis rubra, Michaux, est distinct du Palmata, Vahl.'

This decision, from such an eminent ampelographer as J. E. Planchon, should of itself be sufficient; but to make doubly certain, 1 wrote to Professor Pierre Viala, - who was for years associated with Planchon, who, in 1887, visited this country on a special commission from the French government to investigate the native grapes of the United States, who since that time has published the completest works upon our species extant, and who this year spent six months in Paris as a specialist in Viticulture for the French government-to investigate the plant in question, in the Garden of Plants, Paris, and let me know whether it is the true $V$. rubra of Michaux or not; and here is his reply, dated November 11 th, 1890:

'Le $V$. pa!mata de Vahl, du Jardin des Plantes de Paris est un $V$. riparia, et non de vrai $V$. rubra, de Michavx.'

Hence we have in synonymy $V$. rubra, Mx., Syn., $V$. palmala, Engelmann, Bushberg Catlg., 1883, and Garden and Forest, July, 1889 ; $V$. riparia, Mx., Syn. $V$. palmata, Vahl. So $V$. palmata must not be used except as a synonym.

It will be remembered that in an article of mine published in Garden and Forest for October 1st, $V$. palmata was substituted where I had written $V$. rubra.

Denison, Texas, Dec., 1890

T. Y. Munson." 


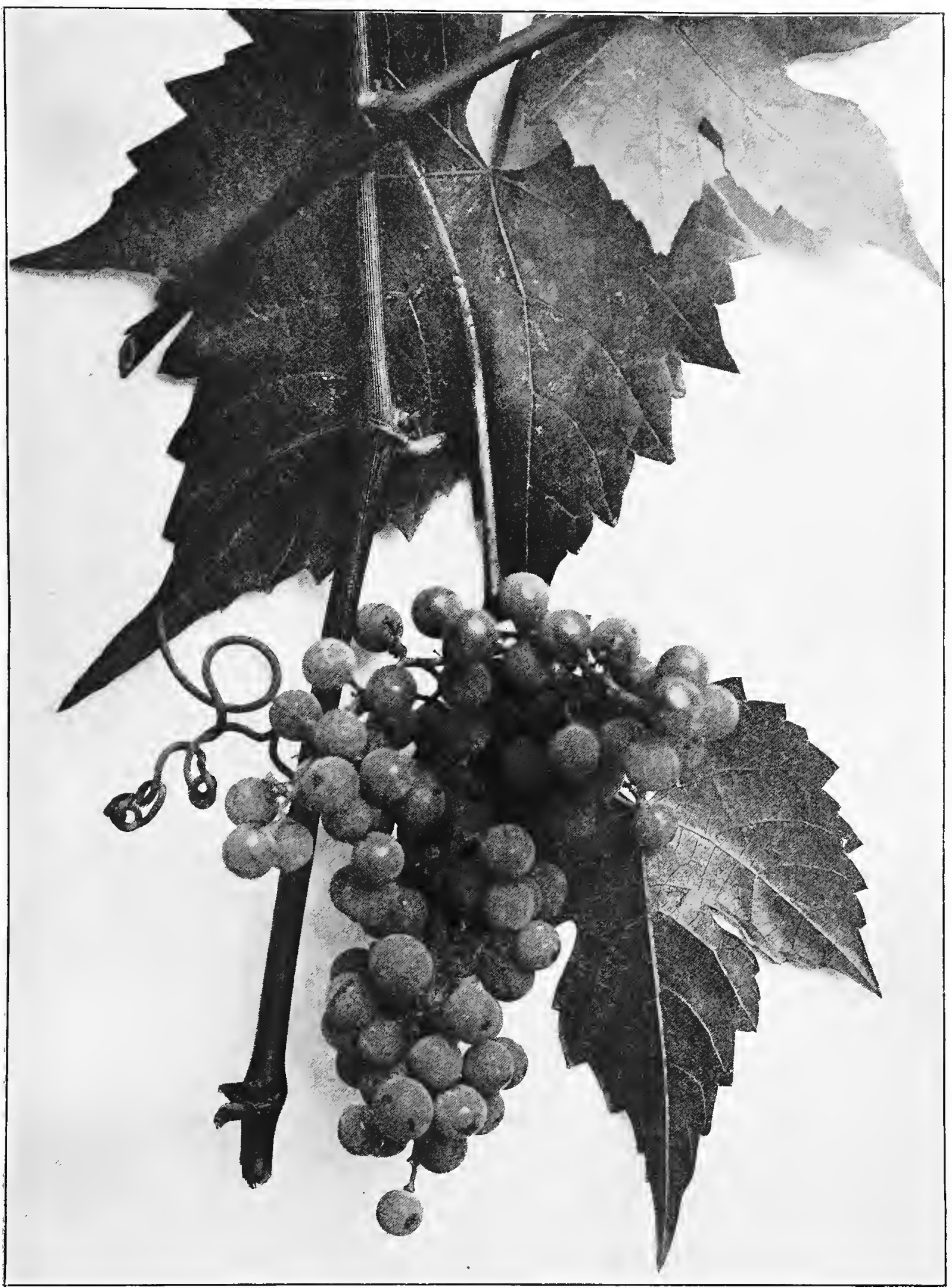

PLATE XXVI. 16. VITIS RUBRA, Michaux.

Cat Bird Grape. From Mississippi River, Ills. 
Leaves: Stipules very small, broad at base, roundish obtuse, membranaceous, ciliate margin, petiole, in length from $1 / 2$ to $2 / 3$ the width of blade, slender, striated with deep narrow groove, pubescent, occasionally has a few cottony hairs; color red, attached to blade at an obtuse angle; blade about $314^{\prime}$ in length by about $234^{\prime}$ in width, very different from $V$ vulpina; in shape long cordate, plane; basal sinus generally $n$ shaped; shoulders, or lobes and summit long, acute, taperpointed; border either sharply shouldered or often three lobed, sometimes five lobed, with narrow, acute or rounded sinuses, frequently all the different forms occurring on the same plant; teeth large, irregular, very acute, margins straight or slightly convex, with long mucron as in $V$. cordifolia, and pubescent; venation, from the usually 6 not quite opposite pairs of prominent ribs and their divisions, on upper surface has short stiff pubescence, on the lower surface few scattering pubescent hairs, with white pubescent tufts in forks; upper surface between veins smooth, lively very dark glossy green; lower surface very smooth, much paler green. Leaves on seedlings not lobed until second year.

Cluster: Fertile,-long, four to six inches in full development, broad, conical, compound; similarly with $V$. cinerea, but more conical; peduncle long, much like $V$. cordifolia, rachis smooth, yellowish-green, or sometimes scatteringly hairy; pedicels about $1 / 5^{\prime}$ long, the same as in $V$. cordifolia, slender, warty near the summit; sterile,-larger than fertile, and more compound, quite similar to $V$. cordifolia in this respect.

Flowers: Fertile,-stamens short, recurved, pistil minute, style slender, stigma small, hemispherical. Staminate,--stamens long, slender, erect, with small anthers, similar to $V$. cordifolia.

Berries: Very small, $1 / 5^{\prime}$ to $1 / 3^{\prime}$, spherical, bluish-black, with little or no bloom, resembling $V$. cordifolia, but of a more intense blue-black; persistent; skin thick, and rigid in breaking same as in $V$. cordifolia and not so delicate and pliable as in $V$. vulpina and $V$. rupestris; possessed of much coloring matter; pulp juicy, with very similar flavor though much less pronounced, than that of $V$. cordifolia, but without its pungency; pure, vinous, sweet, with the viscous character of the juice next skin as in $V$. cordifolia.

Seeds: Usually 1 or 2, large, largest of any species in proportion to size of berry, nearly filling berry, short, thick, $1 / 5^{\prime}$ to $1 / 4^{\prime}$ long by $1 / 6^{\prime}$ to $1 / 5^{\prime}$ broad; when one, globose, when two, hemispherical; color of dark cinnamon bark, or chestnut, beak short, thick, poorly defined, slightly bilobed, color grayish-yellow to dark orange, or chocolate when dead ripe; raphe threadlike from beak to top of seed, there becoming obscure or invisible in a rather deep groove to the chalaza, which is usually depressed or nearly obsolete though sometimes is medium prominent, sub-triangular,-resembling in this some rare forms of $V$. cordifolia found by myself, color same as beak, lying in an elliptical cavity; depressions short, deep, wide apart, separated by a large ridge, color grayish-yellow or pale orange, to chocolate when dead ripe.

Plantlet: Cotyledons medium to large ovate with taper-point, green; petioles $1 / 4$ inch, plumu'e and caulicle light crimson.

\section{Viticultural Observations and Remarks}

Germination very slow, even slower than $V$. Lincecumii and $V$. bicolor; foliation very late; inflorescence latest of any native species, even after $V$. cinerea and $V$. rotundifolia; ripening of fruit very late,- with $V$. cordifol $a$ and $V$. cinerea, but not quite so late as the $V$. cinerea, var. Floridana.

Growth first year, slender, feeble; is hardy to endure cold and drouth when well established; resistant to Phylloxera (Millardet), free from disease. The beauty of the vine should render it a favorite trellis or arbor vine.

No natural hybrids with other species are known to the writer, but he has produced several hybrids of it with Herbemont, etc. 
All specimens of recent finding so far as known to the writer have been obtained through Mr. Henry Eggert, St. Louis, Mo., and Dr. Schreck, of Mt. Carmel, Ill. Prof. L. H. Pammel also secured it for me on the Mississippi above St. Louis. Mr. Eggert finds it along the Mississippi River not far from St. Louis, though he reports that it occurs in Oklahoma, yet so far, all the research of $\mathrm{H}$. Jaeger and the writer failed to find any indications of it there or elsewhere save along the Mississippi and Wabash Rivers. Doubtless, however, it is to be found on most streams of Southern Illinois. It prefers argillaceous, alluvial, moist bottom lands. Dr. J. Reverchon (deceased in 1905), of Dallas, Texas, found it along the Sabine River in East Texas, in 1903, and brought it to me for identification. His specimens were of the pure form and easily identified.

In growth, climbing, extremities of growing branches, thick diaphragm, long slender tendrils, long clusters, with long peduncle, small berries without bloom, size and shape of seed, except chalaza, long cordate leaf outline, except basal sinus, small stipules, late foliation, blooming and ripening, smooth glossy leaves and wood, and flavor of fruit, -in fact the tout ensemble of the plant clearly indicates the closer relationship with $V$. monticola and $V$. cordifolia and not so close with $V$. vulpina, as Professors Planchon and Viala had supposed. (Ampelideæ, Planchon, Une Mission Viticole en Amerique, Viala, p. 88). It is, however, a very distinct and well characterized species, and can with no degree of propriety be included in one species with $V$. vulpina and $V$. cordifolia, as Prof. C. S. Sargent suggested in Garden and Forest, January, 1890, p. 638.

Though the basal sinus of leaves is obtuse as in $V$. vulpina and the chalaza generally depressed, other characteristics, and especially the biological, I have named, must have more weight. The species has been growing and fruiting with me for years near by $V$. vulpina, $V$. monticola, and $V$. cordifolia, and certainly it is far nearer $V$. monticola and $V$. cordifolia than $V$. vulpina and still less akin to $V$. rupestris than $V$. vulpina, hence I group it as shown in my classification. In habit of root-growth it is very much like $V$. cordifolia, and very unlike $V$. vulpina and $V$. rupestris.

17. VITIS MonticolA, Buckley, Pat. Off. Rep. 1861, p. 485. Proc. Acad. Phila. 1861 , p. 450 , and 1870, p. 136. (See Plate XXVII.)

Synonyms:

V. rupestris, Gray, Pat. Off. Rep. 1862, p. 162.

V. vulpina, Gray, P1. Lindh., p. 166.

V. Texana, Munson (S. P. A. S. Rep. N. Y. Aug., 1887, p. 59).

V. Foexeana, Planch. (Amp. Univ., 1887, Vol. V., p. 616).

"Sugar Grape," "Sweet Mountain Grape."

Plant: Vine slender, tapering slowly, climbing 10 to 30 feet in its native regions; exceedingly unique in foliage, with an open, airy aspect.

Roots: Little branched, somewhat thickened and wrinkled, transversely, as in $V$. cord folia and $V$. rubra, with a similar habit of division, also of firmness and penetration;-quite distinct from Precoces in these respects.

Wood: When young distinctly angled, less than in $V$. Berlandieri, at first thinly hairy which becomes floccose, the mature annual wood becoming cylindrical, finely striated, smooth, and of a light reddish-brown color, at first, becoming a dark reddish-brown in winter, the outer bark often splitting and, in fall and following season, separating freely in thin, fibrous strips; wood rather harder than in $V$. vulpina, but very brittle as are other parts of the plant; sectional view of mature annual wood shows very distinct rays and pores between very open; nodes very little enlarged, nearly straight; diaphragm plane, or nearly so, about $1 / 12^{\prime}$ thick, or some thicker than in $V$. Longii. Buds small, sub-globose, in young shoots, becoming conical at maturity; in unfolding small, dull brownish-pink, half open, short, covered with pinkish tomentum. Tendrils intermittent, usually once-forked, sometimes twice, moderately long, a little hairy or cottony like the young wood, becoming smooth later, usually red when young, bright reddish-brown with maturity, 


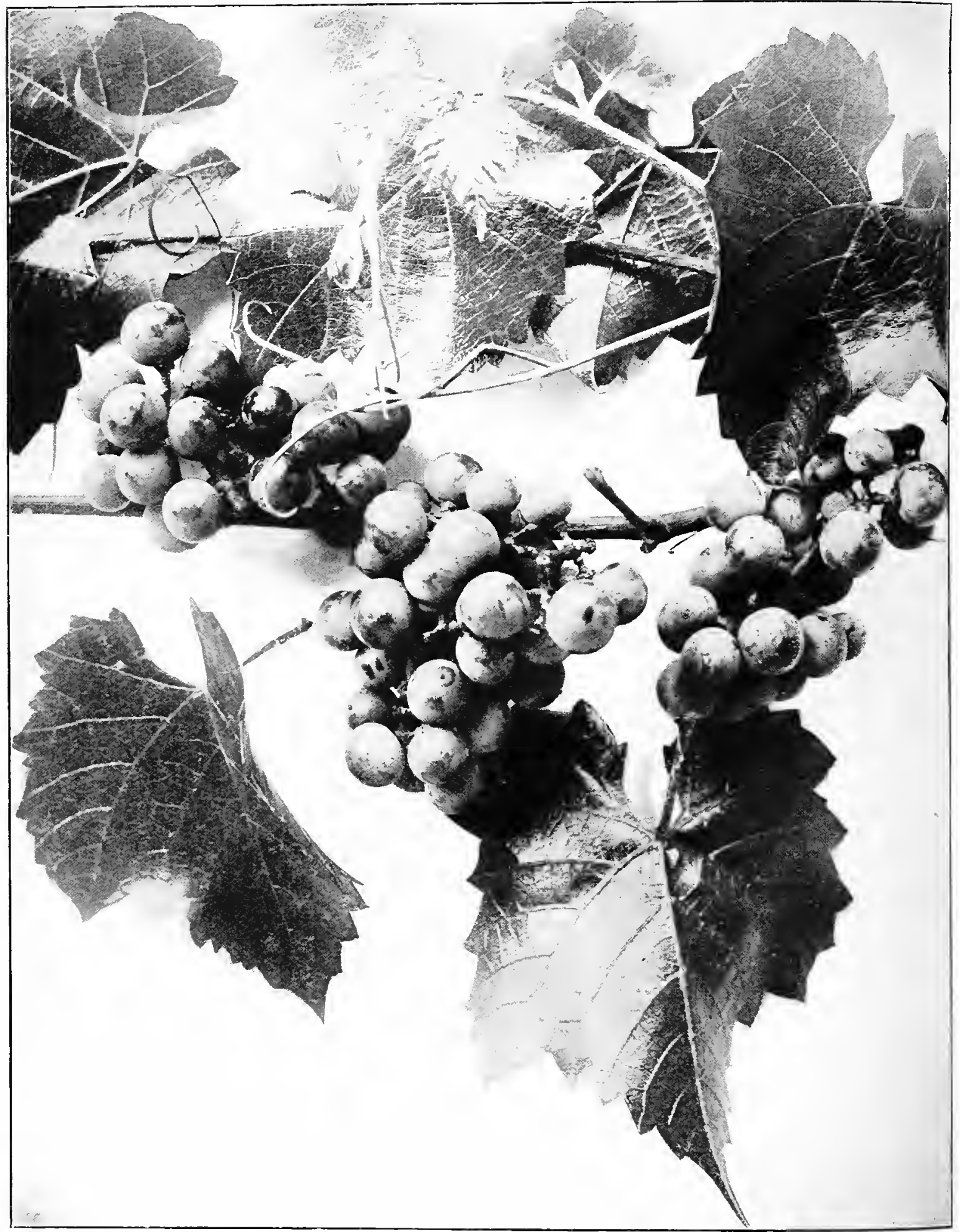

PLATE XXVII. 17. VITIS MONTICOLA, Buckley. Sweet Mountain Grape. Of South Central Texas. 
like the bark, persistent, strong; internodes short to medium in 'ength, $2^{\prime}$ to 5 '; pith 'small, meeting diaphragm abruptly.

Leaves: Stipules small, $1 / 10^{\prime}$ to $1 / 8^{\prime}$ long by $3 / 4$ as wide, slightly hairy outside, usually pink or crimson (or rarely green), soon browning and falling; petiole from $1^{\prime}$ to $2^{\prime}$ long, cylindrical, faintly or not at all grooved, thinly hairy or cottony along obscure striæ when young, becoming smooth or floccose with maturity; color dark red to pale red, or rarely light green, in mature leaf set at right or acute angle with blade; blade,--diameter generally $2^{\prime}$ to $3^{\prime}$ rarely $4^{\prime}$, usually circular in general outline, rarely long cordate or sometimes reniform, sinuately folded about $1 / 4$ toward upper surface; basal sinus usually horse-shoe or $\mathrm{n}$ shaped, sometimes acute, or very obtuse; basal lobes sometimes lapping a little; teeth medium to large, usually a little acute or right angled, with nearly straight margins, rarely convex, mucronulate; ribs from 5 to 6 , rarely 7 pairs, usually alternating on opposite sides of midrib, slightly prominent upon both faces of very young leaves, slightly hairy on lower surface along the ribs; color in very young leaves pale reddish, then becoming bright lively green (several shades lighter than $V$. vulpina or $V$. rupestris)-the lightest green of any species, - soon very smooth and shining as though varnished, especially below; texture dense but brittle. At first sight the leaf greatly reminds one of that of $V$. rotundifolia, in size, shape, toothing, smoothness and color, though being of a lighter green.

Cluster: Fertile,-small, $2^{\prime}$ to $3^{\prime}$ long; peduncle $1^{\prime}$ to $2^{\prime}$, very thick for size of cluster; nearly equally fòrked, branches nearly half as long as cluster; when fruit is ripe of a dull rusty brown, firm, but brittle, pedicels $1 / 8^{\prime}$ to $1 / 6^{\prime}$ long, enlarging rapidly upward, very warty; staminate,similar to fertile but with more numerous flowers.

Flowers: Fertile,--petals and stamens commonly 5, set upon a distinct disc; stamens short recurved; pistil small, short; style, short and very slender, with very small stigma; male; stamens erect, straight, short.

Berries: 12 to $50,1 / 4^{\prime}$ to $1 / 2^{\prime}$ in diameter, spherical or oblate, nearly always black when fully ripe (red or white varieties very rarely found, but long before they are ripe, they assume a rose or pink color, hence are described by some as red grapes), moderate or little bloom; skin thin, bearing brown, rough lenticular dots or lenticels; little pulp, very seedy, not very juicy, astringent, of a sweetish taste, yet with little sugar or acid, with a peculiar, not very pleasant flavor, resembling some apple flavor, often quite similar to $V$. cordifolia.

Seeds: 1 to 4 , large, $1 / 4^{\prime}$ long by $1 / 5^{\prime}$ broad, or less, when one, globular; color cinnamon brown; beak short, thick, blunt; raphe prominent from beak, especially so as it passes the not at all or little grooved top of seed, then expanding rapidly into the generally broad, prominent chalaza, which is on center, or above center of back of seed, with shallow groove about it, with no groove to beak; ventral cavities nearly straight, approaching each other toward the beak, varying little in color from body of seed.

Plantlet: Cotyledons small, cordate or ovate, green.--

\section{Viticultural Observations and Remarks}

Germinates slowly, about with $V$. Berlandieri or a little later, and earlier than $V$. Lincecumii; foliation, flowering, ripening of fruit and foliage, late to very late, about with $V$. cordifolia except that it holds its foliage later. Of fair vigor; growth of seedling vines first year about equal to $V$. cordifolia; not fully erect. Hardy to endure drouth, matures wood early and withstands cold well, having passed through a temperature of 15 degrees (F.) below zero, at Denison, Texas, without the slightest injury, and a much lower degree in Southwestern Missouri. The vine always appears healthy, the foliage resisting mildew well and hanging on late, about the same as $V$. Berlandieri, and the fruit is not affected by Black Rot. Cuttings root with some difficulty, or rather easier than Berlandieri. The fruit is not particularly valuable owing to the smallness of the cluster, and the seedy, dry berry. This vine is valuable stock for grafting in dry climates and very limy soils. Its slenderness in the wild woods was at first thought derogatory, but in cultivation, it becomes quite stocky. 
It is often found hybridized with $V$. candicans, $V$. Berlandieri, V. rupestris. V. Arizonica (in Uvalde County), and with all these except $V$. Arizonica, in Gillespie, Kerr, Llano, Coryell, Lampasas, etc., counties, Texas. Such hybrids in the grounds of the writer grow very vigorously, having large, strong vines, and doubtless would be excellent stocks upon which to graft. Some of them bear a fairly good fruit for wine making.

It grows abundantly on top of the cretaceous limestone hills of Central Southwest Texas, in Coryell, Lampasas, Bell, Llano, Travis, Gillespie, Uvalde, and to greater or less extent in adjoining counties; but so far it has not been found in low situations along streams or in sandy soils, but chiefly on the upper parts of hills from 200 to 500 feet high, which are of a cretaceous strata left in buttes and ridges by the erosion of valleys between. In Uvalde County it takes on a form approaching the form of $V$. Treleasei, yet it is one of the most clearly marked and distinct of species.

Since the discovery of this species and its naming by Buckley, it was collected independently by Mr. Fœx and sent to France and there named V. Fexana, by Prof. J. E. Planchon (Ampelideæ, Plan.). It was a little prior to this supposed by the writer to be new, and was named by him V. Texana, in a paper presented before the Society for the Promotion of Agricultural Science, in New York City, August 18, 1887. This conclusion and the former opinion of A. Millardet that $V$. Berlandieri was Buckley's $V$. Monticola, resulted from the indefiniteness of Buckley's published description of his species. The clearing up of the confusion concerning this and $V$. Berlandieri we owe to Prof. P. Viala, while in this country in 1887 (see Une Mission Viticole, pp. 62-67). In the young seedlings, tips of young shoots, roots, stipules, and seeds, it resembles $V$. Berlandieri, but there the resemblance ceases; in some respects it resembles $V$. rupestris, as in the somewhat erect growth of the young seedlings, the cupping of the leaf toward the upper face, and small compact clusters. Prof. A. Millardet noted this resemblance in a few specimen leaves sent to him. Prof. P. Viala also recognizes its resemblance to V. rupestris, with too much stress, I think (Une Mission Viticole, pp. 67-68). But its slow foliation, blooming, and germination, its small stipules, poor growth of cuttings, its slender climbing habit, naked tips of growing shoots, separate it from all Precoces. It has in vine, young tips, and basal sinus of leaf, a striking likeness to V. rubra. In general aspect in foliage, the small forked cluster and the wartiness on peduncle, rachis and berry, also slight wrinkles about chalaza, it appears to have a slight leaning toward the Muscadine section. It truly is a remarkable and distinct species. It is well worthy of cultivation as an ornamental vine.

\section{Series VII. Occidentales}

18. VITIS CALIFORNICA, Bentham, Bot. Sulp. 10. (See Plate XXVIII.)

Synonym:

Vitis Caribca, Hook and Arn. Bot., Beechey, 327.

"North California Grape."

Plant: Climbing moderately, or vigorously, as seen by the writer in Santa Rosa and Napa Valleys at Chico and at Redding in Sacramento Valley, also at Grant's Pass, Rogue River, Oregon; branches tapering; growing tips little enveloped in expanding leaves; often the vines are seen completely enveloping small trees with a dense canopy of leaves.

Roots: Fibrous, rather soft, transversely wrinkled.

Wood: When young reddish or pale green, angled and somewhat covered with long whitish hairs, becoming floccose and remaining into the winter, or in Eldorado County specimens, covered with short brown pubescence, similar to $V$. cinerea; when mature, brownish or grayish, finely striated, soft, sectional view circular or often oval, rays distinct, pores open; nodes large and a little bent; diaphragm nearly plane, medium thin; bark the second year easily loosening in fibrous plates, on old wood finely striately checked and persistent as in $V$. cinerea; buds small, sub- 


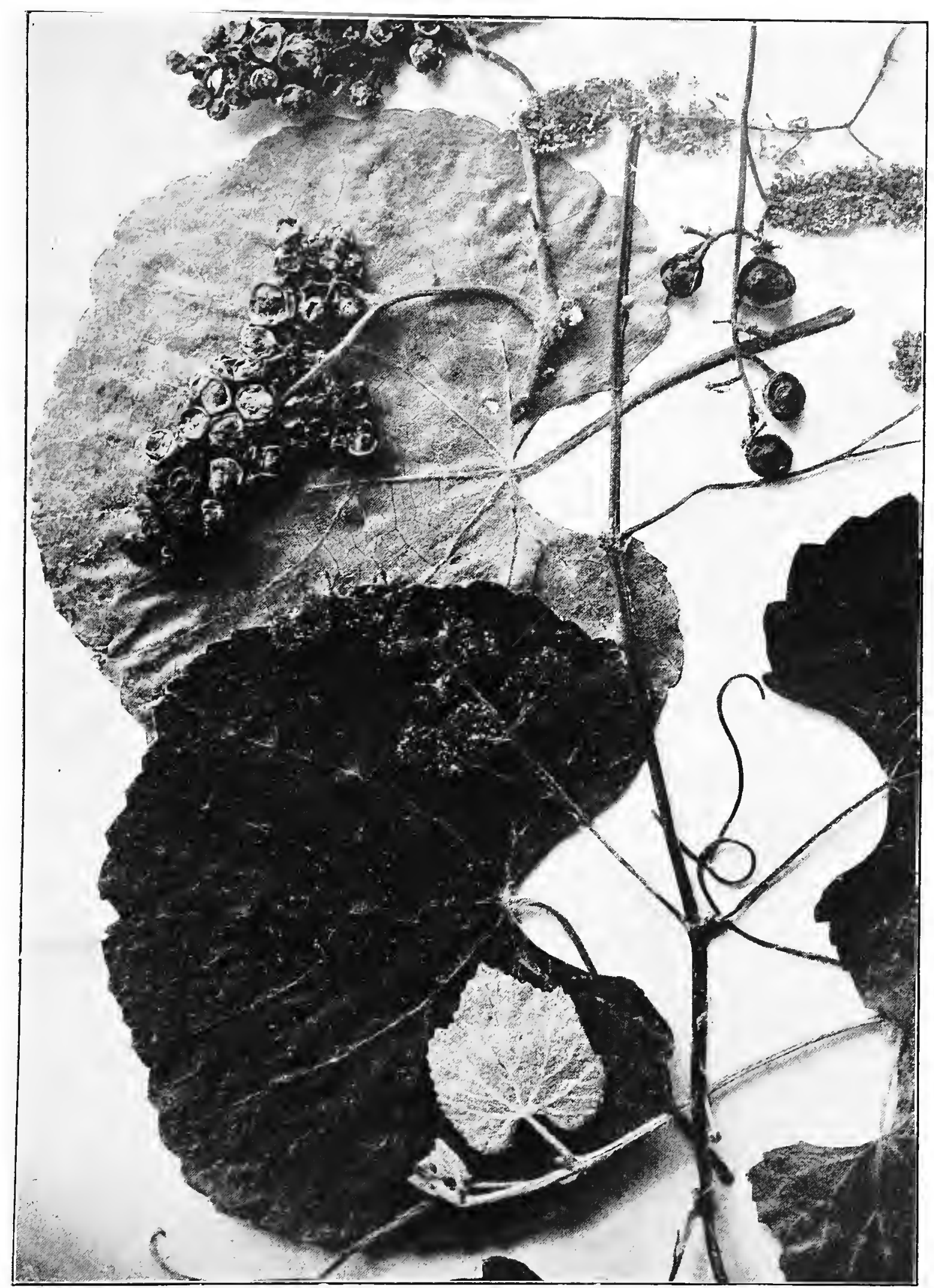

PLATE XXVIII. 18. VITIS CALIFORNICA, Bentham. North California Grape. 
pyramidal, ovoid or acute, covered with whitish or brownish wool at summit, when opening in spring grayish-violet or nearly white, becoming greenish-violet; tendrils mostly once forked, sometimes twice, $3^{\prime}$ to $5^{\prime}$ to fork, intermittent, woolly when young, persistent, internodes medium in length, $3^{\prime}$ to $6^{\prime}$ or more, variable in same branch; pith large, light brown, abruptly and broadly terminating above, narrow and gradually terminating below the diaphragm, especially so in Sierra Nevada Mountain specimens.

Leaves: Stipules small to medium, cordate, membranaceous, hairy; petiole generally about half as long as blade is wide, narrowly grooved on upper side, distinctly striated; thinly covered with white cottony hairs and velvety pubescence, color violet or crimson; blade medium to large; varies in size from $2^{\prime}$ to $4^{\prime}$ in length by $3^{\prime}$ to $5^{\prime}$ or more in width; shape broadly cordate or nearly reniform; basal sinus acute or often obtuse, rounded; basal lobes more or less closed, often lapping; outline usually entire or 3 to rarely 5 shallow, obtuse lobes, with narrow rounded sinuses; summit rounded, or obtuse pointed, teeth medium broad, nearly regular, shallow, convex or with margins nearly straight, obtuse or right angled, not mucronate; venation from generally 6 pairs of not quite opposite, very little elevated, pubescent ribs; pubescent tufts in forks, space between ribs thinly or not at all felted with silky hairs; upper face at first covered with whitish sitky hairs, but soon becoming smooth; at maturity when about to shed, the leaves often change to a bright orange red or scarlet. Leaves on seedlings first year not lobed.

Cluster: Fertile,--small $3^{\prime}$ to $4^{\prime}$ or more long; shouldered heavily, similar to many $V$. vulpina; compact; peduncle very short; rachis usually simple or little compounded, thinly cottony; clear reddish-violet; pedicels $1 / 4^{\prime}$ or less long, rather thick, enlarging rapidly toward the receptacle, warty.

Flowers: As I have never been able to grow the species here to bearing age, owing to sensitiveness to cold and mildew, I have not been able to study the flower sufficiently to give an exact description more than that they are much as in $V$. Arizonica, and in $V$. cinerea, very small and delicate.

Berries: $1 / 3^{\prime}$ to $1 / 2^{\prime}$ in diameter, round or little oblate, black, with heavy prunose bloom; persistent; skin rather thick, pulp seedy with little juice, very sugary and pleasantly flavored.

Seeds: 2 to 4 , mostly 3 , large $1 / 5^{\prime}$ to $1 / 4^{\prime}$ long by $1 / 6^{\prime}$ to $1 / 5^{\prime}$ broad, obovate, of a light brown burnt coffee color, dull, not shining; beak large, short, and blunt; raphe large, prominent, running over the rounded end of the seed and distinct down to base of beak; chalaza long-ovate, prominent, frequently salient above the surface of seed, flat or convex, surrounded by a shallow groove; ventral depressions short, shallow, about parallel with raphe, rather wide apart.

Plantlet: Seed-leaves medium to large, ovate or cordate, pale green with short petioles. Natively it is found along streams, also on hillsides, along dry ravines, etc., in Middle and Northern California, especially in the Sacramento Valley and in the Rogue River Valley in Southwestern Oregon.

My description has been made from specimens of leaves and seeds from Prof. W G. Klee, of Berkeley, California, of leaves, branches, and fruit from Prof. J. P. Munson, Placeryille, California, and many vines in fruit, seen by myself in numerous places in Central and Northern California, and along Rogue River, Southern Oregon. Leaves from Orr Brown, obtained from wild vines in Josephine County, Oregon, and from plants grown by myself at Denison, Texas. Prof. Geo. Husmann sent me specimen leaves and fruit from a vine in Napa Valley, which he thought related to $V$. astivalis and quite different from other wild vines there. This proves to be very much of the character of a hybrid between $V$ Californica and $V$. vinifera.

\section{Viticultural Observations and Remarks}

Germination early, vigorous, about with or little later than $V$. Arizonica; blooms generally with or before $V$. vinifera, ripens rather early to medium. The beautiful crimson tints of the 
leaves of this species at maturity are peculiar, as, so far as known to the writer, a'l our other native species, except $V$ Munsoniana, turn yellow or brown in ripening.

All plants tried at Denison, Texas, prove puny and sensitive to moisture and cold; nonresistant to Phylloxera, according to Prof. A. Millardet, but Prof. Hilgarde regards it as resistant. Certainly it is regarded of little value as a graft stock in France, and now even in California. This species is exceedingly sensitive to. Downy Mildew, more than $V$. Arizonica and many varieties of $V$. vinifera, and it is difficult or impossible to grow plants from seeds in open ground at Denison, Texas, unless preventives of Mildew are used. Grows more or less rapidly from cuttings. The seedy, skinny nature of the fruit will probably prevent any desirable improvements by hybridization. It has been found hybridized with $V$. vinifera of the vineyards of Northern California.

\section{VITIS GIRDIANA, Munson. (See Plate XXIX.)}

\section{"Southern California Grape."}

Plant: Climbing high, robust, in its native regions often forming dense masses, or canopies. on undergrowth and small trees, the foliage presenting a light grayish-green aspect.

Roots: Rather soft, penetrating, not fully resistant to Phylloxera.

Wood: Young, densely whitish woolly, the wool becoming flocculent and shedding at maturity; cylindrical or little angled, finely and regularly striated; bark at maturity cinnamon, or reddishbrown; rays thin, wide apart, pores numerous; rather soft; internodes of medium length, 11/2' to $4^{\prime}$ or $5^{\prime}$, pith small, little enlarged at lower end of internode, nodes enlarged, bent; diaphragm rather thin, $1 / 16^{\prime}$ to $1 / 8^{\prime}$ thick, biconcave, tendrils long and strong, mostly trifid, buds medium to large, subglobose, scales pale brown, both when dormant and expanding, whitish woolly; bark on old : wood finely checking and not shedding readily.

Leaves: Stipules small to medium, rounded, $1 / 8^{\prime}$ long or less, membranaceous, scatteringly hairy, pale; petiole, slender, $1^{\prime}$ to $3^{\prime}$ long, woolly, or pubescent or both, having a distinct narrow groove along upper side; blade generally.long cordate in outline, rarely lobed length of midrib $3^{\prime}$ to 4 ' or more, width of blade $41 / 2{ }^{\prime}$ to 6 ', or more; basal sinus mostly $\Lambda$ shaped, sometimes $n$ shaped, approaching or lapping, margin bearing teeth, generally large convex, often prominent, acute, rarely very short, or obscure, with mucrons; lateral lobes, when present, and apex, prominent, acute; venation from the mostly 7 , sometimes 6 or 8 pairs of small pubescent ribs set alternately, obscure and close together; upper face, when young, densely whitish woolly, the wool becoming thin and flocculent, or shedding at maturity, exposing the pale dull green, slightly wrinkled surface, lower. surface betwëen ribs covered thinly with ash-colored cottony hairs, texture fragile.

Cluster: Fertile,-medium to large, $5^{\prime}$ to $8^{\prime}$ or more long, forked into two nearly equal parts, at. an obtuse or broad angle, each fork generally compoundly divided, peduncle $1^{\prime}$ to $2^{\prime}$ long and. with the pale bluish-green or whitish-green rachis, thinly covered with cottony hairs; pedicel long. $1 / 6^{\prime}$ to $: 1 / 4^{\prime}$, slender, little or not at all warty, pale yellowish-white, enlarging very little upward, cluster difficult to detach from vine. Sterile cluster very large and compound.

Flowers: Staminate, on long slender pedicels, stamens large, erect; fertile,-stamens small, reflexed, short; pistil delicate; slender short style; small stigma.

Berry: Small, $1 / 4^{\prime}$ to $1 / 3^{\prime}$ in diameter, spherical, black with little or no bloom, persistent, skin thin, tough, and pungent to taste, pulp juicy, melting, very acid till very ripe when it is. agreeably sweet, but chemical analysis (Prof E. W. Hilgarde, in report of Experiment Station, Berkeley, California) shows it deficient in sugar, tartaric acid and tannin, as compared with $V$. Californica (Bethem), from the Sacramento Valley.

Seeds: 1 to 3 obovate or broadly obcordate; $1 / 6^{\prime}$ to $1 / 5^{\prime}$ long by $1 / 8^{\prime}$ to $1 / 6^{\prime}$ broad, pale pinkish; beak short, blunt or sometimes small and acute, raphe slender, hair-like from beak to. notch in top of seed, where it becomes obscure; chalaza, in center of back of seed, narrow, depressed, often a mere rim or crescent in a rather deep basin; ventral depressions short, wide apart, shallow. 


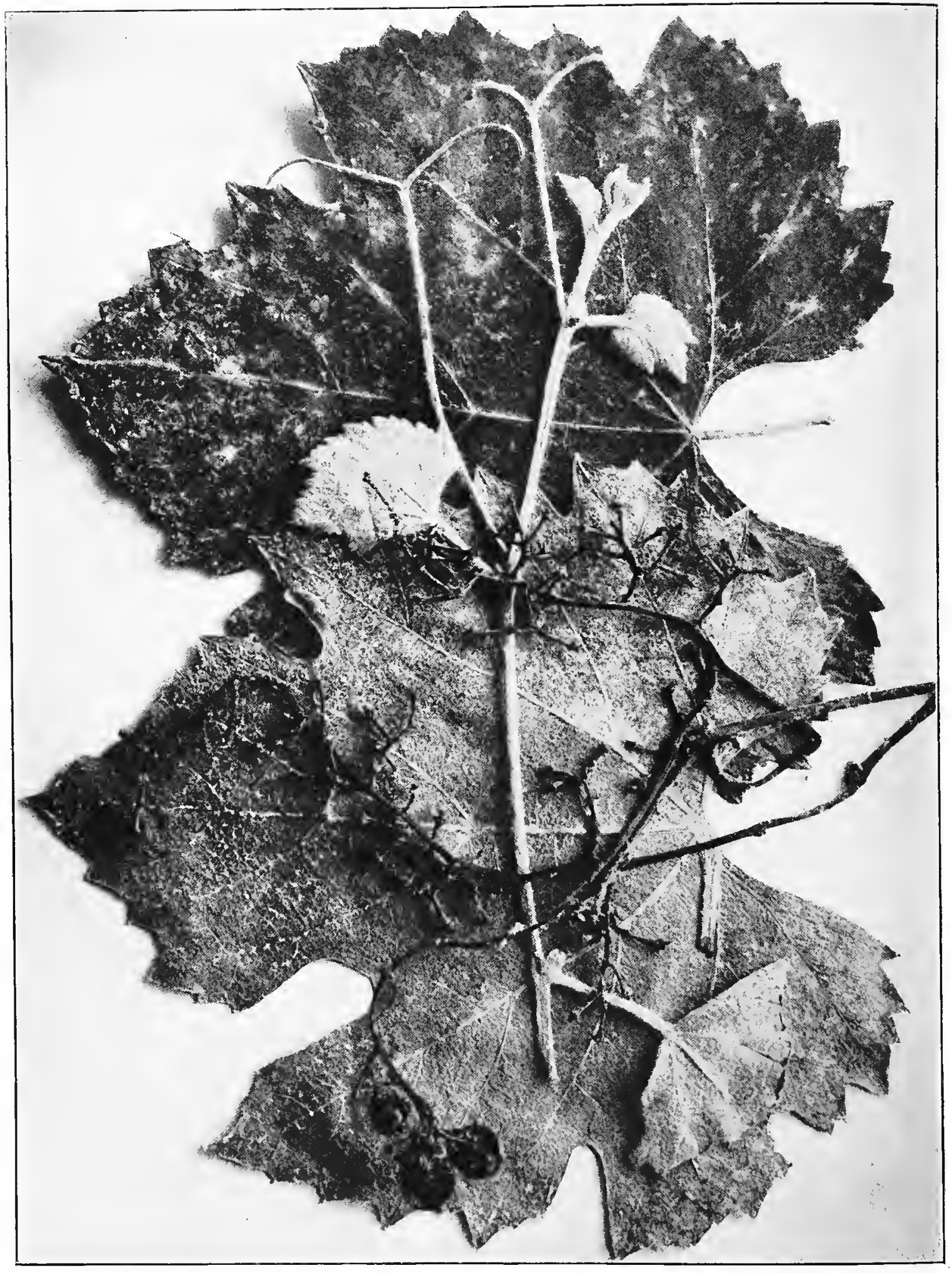

PLATE XXIX. 19. VITIS GIRDIANA, Munson. Gird's Grape or Southern California Grape. 
Plantlet: Seed-leaves medium, broad cordate, with short petiole, pale green; secondary leaves first year, not lobed, plant first year erect or little declining.

\section{Viticultural Observations and Remarks}

The seeds germinate in about the same time with $V$. cordifolia and $V$. Arizonica, the buds push with or later than $V$. vinifera, the flowers open a little earlier than $V$. cordifolia, the fruit ripens about with Norton Virginia or generally with $V$. astivalis; leaves fall late, about with $V$. Arizonica and $V$. Longii, later than $V$. vulpina.

This species is found abundantly in all the valleys of South California, along streams in rich alluvial sandy soils, where the roots can reach permanent moisture.

Until 1889 when I visited California, investigating wild grapes, I had regarded this species as a form of $V$. Arizonica, but after seeing many thousands of the vines, in the vicinity of San Diego, National City at the extreme southern part of the state, along the San Luis Ray, the San Marguerite, the Santa Ana, and the San Gabriel rivers south of the San Bernardino Mountains, and the Ojai Valley, north of Ventura and eastward from Ventura, and finding it the only wild grape of those regions quite uniform in characteristics, and certainly well separated from both $V$. Californica of North California and $V$. Arizonica, I was compelled to give it due recognition, and named it in honor of Mr. H. H. Gird, of Fallbrook, California, who a number of years previously sent me the first specimens of it I had seen.

Unlike $V$. Californica (which is not found near the coast, never, so far as I could find or learn, west of the crest of the Coast Range and rarely in the mountains at all, or the first valleys east of them), it often grows abundantly and luxuriantly within a very few miles of the coast, fully exposed to the sea-breezes, as I found about National City. and Ventura. Here, at Denison, Texas, it is very sensitive to cold, a few degrees below freezing kills it to the ground, and also very subject to mildew and rot, but less so than in V. Californica of North California.

The following comparison will contrast the points of difference between this species and $V$. Californica, with which it has heretofore been included by botanists. The long cordate woolly leaf, blade with average length of mid-rib to width of blade as 5 to $5 \frac{1}{2}$, while $V$. Californica has a nearly smooth round-cordate or reniform blade with average length of midrib to width of blade as 5 to 7 . The large, forked, compound, loose cluster with long slender, wartless, or nearly so, pedicels, with very small berries without bloom, pungent skin and juicy acid pulp, small seed with notched top and sunken chalaza, while $V$. Californica has small to medium compact cluster with short, thick, very warty peduncle, larger berries with abundant bloom, skin not pungent, pulp with little juice, very sweet and differently flavored and seedy, seeds with prominent raphe and chalaza and convex top, clearly separate these forms.

This species is frequently found hybridized with $V$. vinifera, near the old vineyards. One such growing in the grounds of Mr. A. Scott Chapman near San Gabriel was seen by the writer and from it Mr. Chapman sent me clusters of ripe fruit in 1886, that were a foot in length, berries of medium size, and quite a good grape. When I saw the vine it was nearly dead, having been attacked by the Anaheim Grape Disease. Other similar hybrids were seen on Mr. Chapman's place, in 1889.

The old "Mission Grape" of California clearly shows characteristics of V. Girdiana and I am fully of the opinion that it is an accidental hybrid of $V$. Girdiana with $V$. vinifera. Here it is far more subject to mildew, rot and cold than most of the vinifera varieties. Its long stringy compound cluster with delicate yellowish-white rachis, and berries with pungent skin are some of the points indicating V. Girdiana blood.

Little or nothing, probably, of value, can be gained in any way from this species, as it is no hardier or more vigorous in its native regions than $V$. vinifera, and nothing is gained in quality of fruit from it. It was often attacked and destroyed in the forests by the Anaheim disease. 
Synonyms :

V. astivalis, var. Gray, P1 Wright 2, 27.

V. cestivalis, Torrey, Pac. R. Rep. 7, 9.

Plant: In specimens from Western Texas on the Rio Grande and Arizona, weak, much branched, like $V$.rupestris, little climbing, slender, tapering rapidly, angled when young, and cottony, remaining so first season, obscurely striated,-still less than in V. rupestris. Growing tips slightly or not at all enveloped in expanding leaves. The gray cottony hairs upon the leaves give the entire plant a dull ashy appearance.

Roots: Slender, wiry, little transversely wrinkled, in one year seedlings axial, tapering from collar downward.

Wood: Mature bark dark, almost black, cracks after first year and separates into thin, fragile, non-fibrous plates; mature wood very dense and hard; nodes scarcely at all enlarged, mostly straight, diaphragm $1 / 12^{\prime}$, - about the same as in $V$. rupestris, - biconcave; buds small, but large proportionally to branch, globose, whitish, woolly both when dormant and expanding; tendrils mostly once or twice forked, small, about the same length as leaves, cottony, deciduous first year if not clinging to some support, then holds weakly; internodes very short, $3 / 4$ ' to $21 / 2$ ' long.

Leaves: Stipules $1 / 12^{\prime}$ to $1 / 16^{\prime}$ long, thinly cottony. Petiole half as long as the blade is wide, cylindrical, distinctly or faintly grooved on upper side, faintly striate, usually pubescent and cottony; like the tendrils and young wood, dark red when young appearing dull under the cotton, set at acute or right angle with blade; blade $1 \frac{1}{2} 2^{\prime}$ to $4^{\prime}$ wide by same in length; generally beautifully and regularly cordate, sometimes slightly acute lobed; basal sinus usually quite broad, at insertion of petiole, in the more cordate forms, sinus $n$ shaped with limbs partly closing around it; margin curving toward back of leaf, causing upper surface to be somewhat convex; rarely lobed, teeth broad, usually shallow, acute to rarely right angled, mostly convex, sometimes straight on margin, with a very acute or mucronate point; margins of teeth pubescent; venation from the generally 6 , rarely 5 or 7 , pairs of nearly opposite ribs, with little or no prominence; ustually pubescent along the ribs and with pubescent tufts in forks of ribs; surfaces generally covered with gray cottony hairs, giving a dull, ashy appearance; color dark dull green; texture very dense in its native, dry regions; thin and fragile at Denison, Texas. Leaves of seedling first year, entire.

Cluster: Similar to that of $V$. vulpina, but smaller, peduncle and rachis cottony, pedicels $1 / 8^{\prime}$ long, slender.

Flowers: Fertile,-stamens recurved; disc distinct, lobed; ovary globose; style short, thick; stigma broad; staminate,-stamens ascending, slender, pollen grains small.

Berries: Very small, round or ovate, with little bloom; vinous flavor, very sweet, good quality.

Seeds: 1 to 3 , usually $2 ; 1 / 6^{\prime}$ to $1 / 5^{\prime}$ long by $1 / 6^{\prime}$ to $1 / 8^{\prime}$ broad; oval or broadly obcordate, very variable; color pale pinkish-purple; beak very short and blunt or small and acute, well defined; raphe obscure or prominent, becoming a fine distinct thread to the beak; chalaza narrow, in a rather deep basin, its face elevated often, or depressed, so as to appear nearly obsolete, often a mere rim or crescent at base, sometimes invisible, groove extends to or over top of seed; ventral depressions short, rather wide apart, shallow.

Plantlet: Seed-leaves medium to large, ovate, acute, green.

\section{Viticultural Observations and Remarks}

Germination early to medium, foliation and inflorescence medium season, ripening of fruit, medium to late, exfoliation late.

Not vigorous, weak; specimens from Western Arizona weakest; from Jeff Davis County, Texas, at 4000 to 6000 feet altitude, a little stronger with larger fruit; from Uvalde County, Texas. still stronger, some of which approach nearest to $V$. monticola and some to the form of $V$. Ber- 


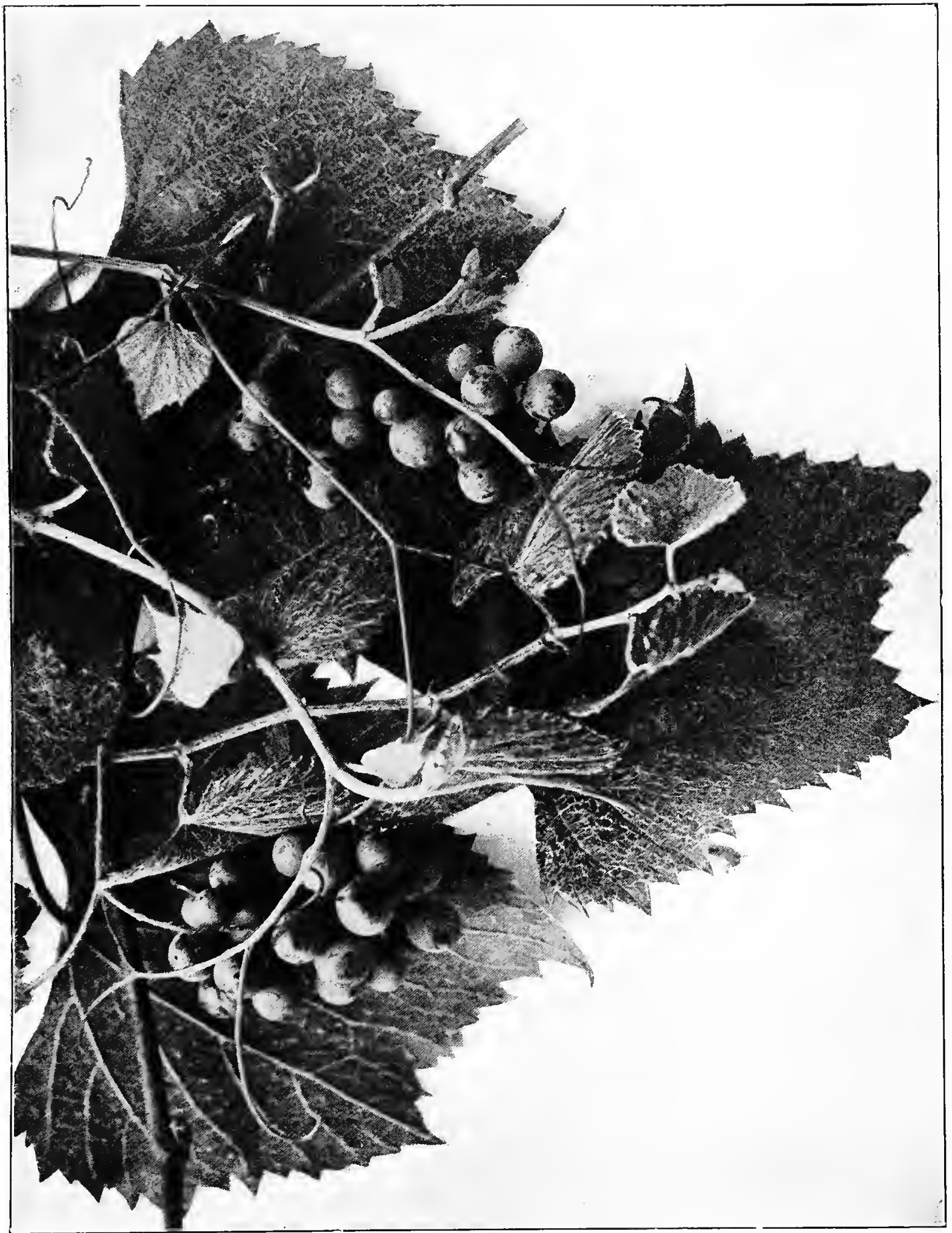

PLATE XXX. 20. VITIS ARIZONICA, Engelmann.

Hairy-Leaved Gulch Grape, Arizona. 
landieri of that region. It was obtained for me at, or rather in the mountains 30 miles north of Phoenix, Arizona, by Dr. Turner; at Chloride, New Mexico, by Mr. Parker, and near Prescott, Arizona, in the Bradshaw Mountains, by Mr. D. Hatz. No wild or artificial hybrids are yet known to the writer, nor does there seem much of value in the species. It endures cold and drouth welI, but excessive moisture injures it, causing mildew and rot. It grows better in sandy than heavy soils. It grows easily from cuttings.

\section{VITIS TRELEASEI, Munson. (See Plate XXXI.)}

Plant: Much branched, shrubby, climbing little, foliage shining, lively green.

Roots: Slender, wiry, little wrinkled transversely; in one year seedlings axial, tapering from collar downward.

Wood: Mature, pale, bark splits after first year and separates into thin somewhat fibrous plates; nodes little or not at all enlarged, straight; diaphragm generally twice as thick as in $V$ vulpina,-about $1 / 16$ of an inch, slightly biconcave; buds small globose, whitish woolly, both wher dormant and in expanding; tendrils small, generally shorter than the leaves and mostly once forked, smooth, or sparingly downy; deciduous first year, unless clasping some object, then holds feebly; internodes short $1^{\prime}$ to $3^{\prime}$. Growing tips naked, as in V.cordifolia.

Leaves: Stipules about $1 / 12^{\prime}$ long, thin membranaceous; petiole generally more than half as long as width of blade, cylindrical grooved on upper side, faintly str ate, smooth or thinly. pubescent, same as tendrils and young wood, bright red when young; blade $3^{\prime}$ to $5^{\prime}$ wide, and mostly wider than long, excluding petiole; basal sinus broad $n$ shaped, and no angle at insertion of petiole, often having shallow acute sinuses either side of central lobe, teeth rather broad, two ranked, very acute pointed, angles between teeth acute or right angled. The leaf generally appears in outline about midway between $V$. vulpina and $V$ cordifolia. Pairs of nearly opposite ribs 5 or 6,both upper and lower surfaces smooth, shining except in the axils of and along the ribs there is short pubescence; wide open or curving backward somewhat around margin as in $V$. Arizonica.

Cluster: Small, $2^{\prime}$ to $3^{\prime}$, peduncle and rachis smooth or having few cottony hairs, slender; peduncles $1 / 5^{\prime}$ to $1 / 4^{\prime}$, little or not at all warty, enlarging moderately at summit.

Flowers: Fertile,- - have stamens recurved, disc distinct, lobed, 'ovary globose, style short, thick, stigma broad; staminate; stamens ascending, slender, pollen grains small.

Berries: $1 / 4^{\prime}$ to $1 / 3^{\prime}$ in diameter, covered with thin bloom, spherical, black, skin thin, juice red, pulp juicy, vinous, pure, sweet, of very agreeable flavor.

Seeds: Mostly 2, varying from 1 to $3,1 / 5^{\prime}$ long by $1 / 6^{\prime}$ broad, obcordate, variable, beak short, blunt, raphe a fine thread prominent over top of seed to chalaza; chalaza prominent, narrow.

Foliation and inflorescence, considerably later than in $V$. vulpina, and earlier somewhat than $V$ Arizonica, ripening of fruit late, exfoliation late. Less vigorous than $V$. vulpina, but endures drouth immensely better.

Observed in Bear Canon near Albuquerque, N. M., McCarty, N. M., Truxton, Flagstaif, and Canon Diablo, Arizona, and have had it collected among Bradshaw Mountains, Arizona, by D. Hatz, and in Goat Creek Canon, Brewster Co., Texas, by E. L. Gage.

Relationship: It appears to stand midway between $V$. vulpina and $V$. Arizonica. In its eastern range, it leans more to $V$. vulpina, and in its western to $V$. Arizonica. Its region covers New Mexico and Arizona, but culminates in the northern parts of this extensive region, while $V$. Arizonica culminates in the southern part. Thus it separates, or connects $V$. vulpina with V. Arizonica.

I first obtained specimens of it in 1887, from the Bradshaw Mountains, Arizona.

The description should be confirmed by comparing a greater number of specimens from numerous localities.

I dedicate the species to my friend Doctor Wm. Trelease.

It has little or no viticultural value. It is very sensitive to downy mildew and black rot. 


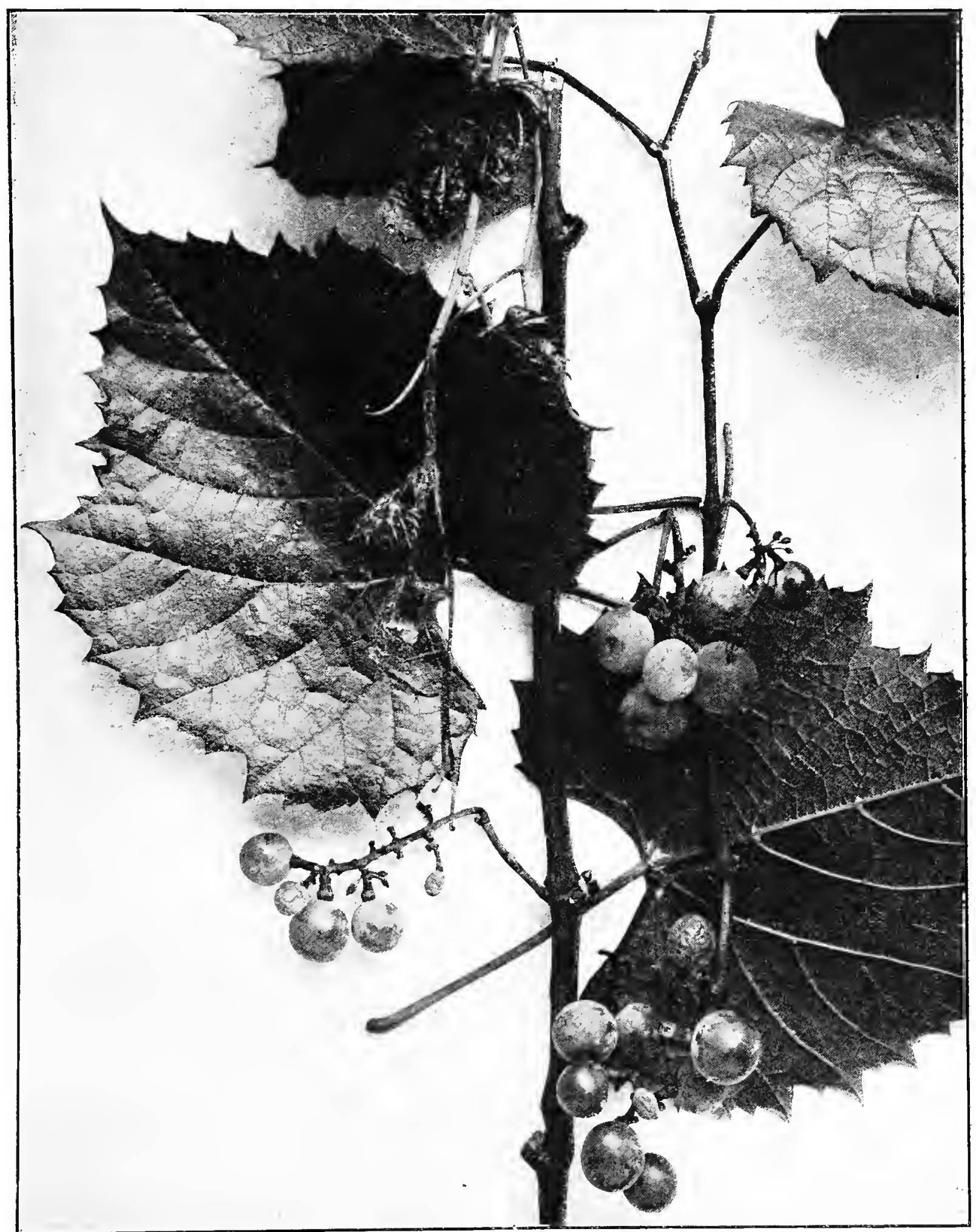

PLATE XXXI. 21. VITIS TRELEASEI, Munson.

Smooth-Leaved Gulch Grape, Arizona. 


\section{Series VIII. Precoces. Munson}

22. VITIS VULPINA, Linnaeus.* Species 203 in part, fide Planchon, L. C. 109. (See Plate XXXII.)

Synonyms:

$V$. riparia, Michaux. F1. 2, p. 231.

$V$. palmata, Vahl. Symb. Bot. III, p. 42, Harvard Herbarium.

$V$. incisa, Jacq. Hort. Schoenb. 4, 14, 7, p. 427.

V. odoratissima, Donn. Cata. Cant., p. 66.

V. cordifo:ia, Darling, F1. Cestr., p. 151.

$V$. cordifolia, var. riparia, Gray, Man., p. 113.

V. vulpina, var. riparia, Regel. Conspect Vitis, p. 395.

"Riverside Grape," "August Grape," in Illinois, "Frost Grape," in Michigan, Wisconsin and Minnesota.

Plant: Little tapering, moderately branching, climbing moderately, 15 to 30 feet or more. The rapidly expanding. leaves, after first opening, make the growing branches appear quite leafy towards the tips in comparison with $V$. cordifolia, yet less so than $V$. Longii and still less. than $V$. rupestris.

Roots: Penetration fair, about with $V$. labrusca, not nearly so good as $V$. cordifolia or $V$. Longii; color whitish; mucilaginous and astringent, not pungent fibrous, slender, hard, little or not at all transversely wrinkled.

Wood: Young terminal wood smooth or pubescent, cylindrical, reddish, becoming clear green, bark of annual wood when mature finely striated, of a dark, in eastern, or light crimson in western specimens, cracking and easily separating into thin, weakly, fibrous plates at close of first year and during the second year. Wood rather soft, probably the softest in the shears of any of our species; section of annual wood shows thin rays with pores quite open between; nodes slightly swollen and little bent, with very thin diaphragm $1 / 20^{\prime}$ to $1 / 30^{\prime}$ thick. Buds" small to medium, globose on young conical or slightly three angled on fully mature annual wood, covered with brown scales except tip, when mature, which is whitish woolly; large globose, rusty green in first opening; tendrils cling well but less strongly by far than $V$. cordifolia; internodes short to medium, $1^{\prime}$ to $4^{\prime}$, cylindrical; pith medium, meeting the diaphragm abruptly, light brown.

Leaves: Stipules large, $3 / 16^{\prime}$ to $5 / 16^{\prime}$ long, $1 / 2$ to $2 / 3$ as wide, membranaceous, becoming light brown and shedding when its leaf is about full size; petiole in length about the width of the blade, cylindrical or slightly elevated on upper side, with a slight groove in elevation, the sides of groove pubescent even in otherwise smooth specimens, in some specimens pubescent all over; color when young usually pale red or green, sometimes dark red, becoming mostly green with age, set at an obtuse or right angle to the blade, which is $3^{\prime}$ to $5^{\prime}$ rarely $6^{\prime}$ to $7^{\prime}$ broad, and about same length from basal sinus to tip, about one-third folded toward upper surface; basal sinus broadly $\mathbf{n}$ shaped, mostly obtuse at insertion of petiole but sometimes acute, as in $V$. cordifolia as is the case with the specimen from Utah; basal lobes rarely if ever lapping; lateral lobes rarely separated by narrow rounded sinuses then giving the leaf a palmate form, as in that classified by Vahl. as V. palmata; outline strongly shouldered with cut-lobes, having taper points, not quite so long or sharp as the terminal point; teeth large, irregular, acute, rarely right angled, with margin mostly straight, scarcely mucronulate but sometimes with margins convex, and then mucronate as in $V$. cordifolia (such forms come from regions where $V$. cordifolia grows

* Columbia Collegge Herrarium, New York, Sept. 29, 1891.

My DeAR Mr. Munson: I am just back from Europe and find your letter of Sept. 4, and the box of grape fruits, for both of which I thank you sincerely. Yes, I looked at the original specimens of Vitis vulpina, Linn., and $I$ think with Planchon that it is $V$, riparia, Michaux. It certainly has nothing to do with $V$. rolundifolia, Michaux.

Yours sincerely,

N. L. BRITTON. 


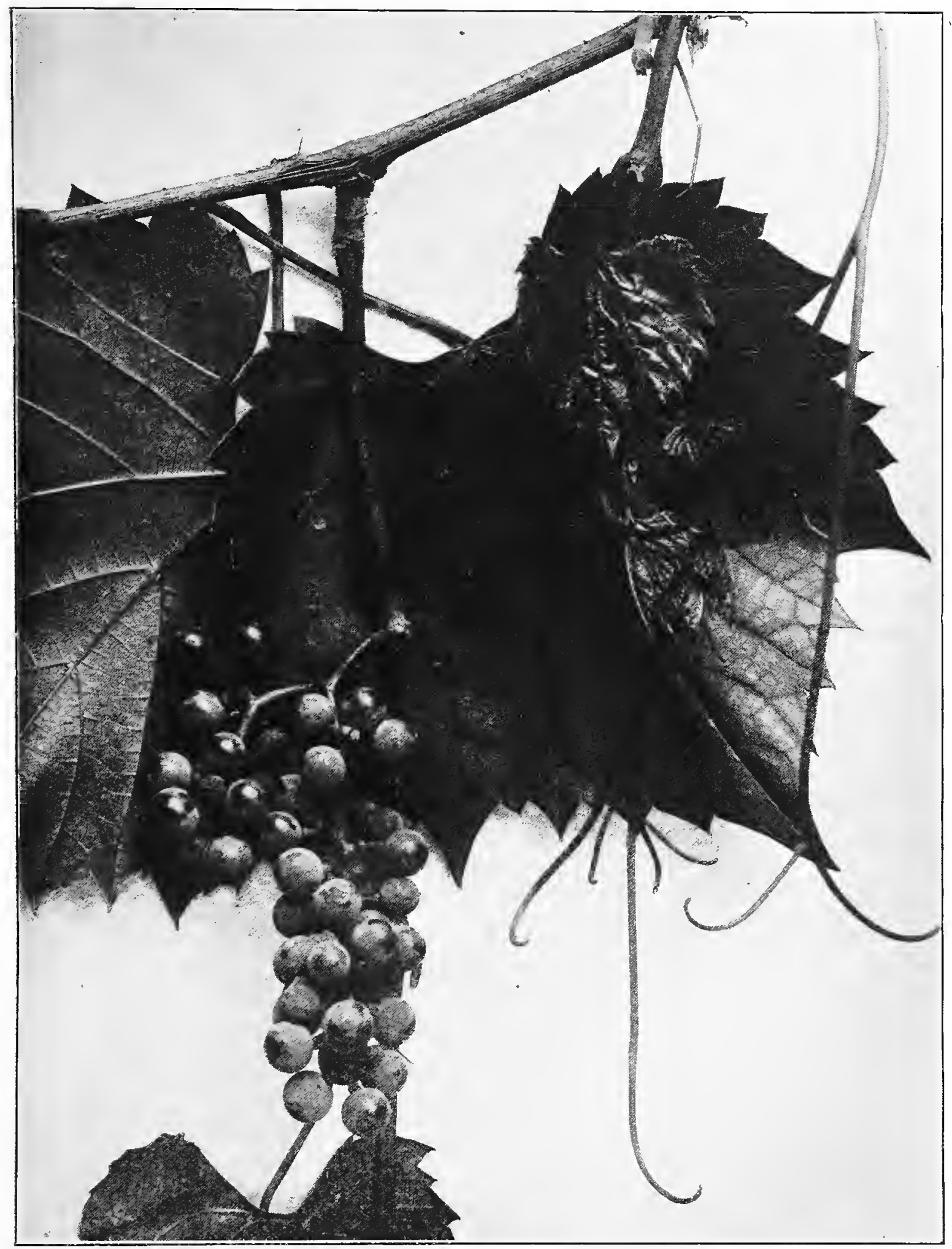

'PLATE XXXII. 22. VITIS VULPINA, Linnaeus. (V. riparia, Mich.) Riverside Grape. From Northern Texas, Red River. 
and may indicate traces of that blood). Venation moderately prominent from the 6, sometimes 7 pairs of not quite opposite ribs; pubescent tufts commonly found in forks of ribs; commonly both surfaces smooth except along the ribs which are pubescent; in the pubescent form the veins on lower surface are also quite pubescent and the tufts in forks of ribs very conspicuous. Color rather dark in eastern, lively green in western forms, texture firm but thin, much firmer and thicker in western than in eastern forms. Leaves from ground shoots generally three lobed; from yearling and seedlings not lobed.

Cluster: Fertile,-small, $3^{\prime}$ to $5^{\prime}$ long, including peduncle which is $1 / 3$ to $1 / 2$ as long as rachis; shoulder $1 / 4$ to $1 / 3$ as large as main cluster; peduncle and rachis pubescent or smooth; pedicels from little divisions of rachis, or direct, $3 / 16^{\prime}$ to $1 / 4^{\prime}$ long, enlarging slightly toward summit; receptacle small or medium, clusters mostly very compact; staminate cluster much larger than fertile.

Flowers:' Very sweetly scented; fertile,-stamens reclining and curving laterally, pollen non-virile when the stamens are reflexed;* staminate,-with long or ascending stamens; pollen very abundant and virile.

Berries: $1 / 4^{\prime}$ to $1 / 3^{\prime}$ rarely $1 / 2^{\prime}$ in diameter, round, black, very rarely white (have one such found wild in Central Minnesota), heavy prunose bloom when ripe; skin thin, pulp juicy, pure and vinous when fully ripe, until then exceedingly acid; fruit persistent.

Seeds: 2 to 4 , very small to medium, $1 / 6^{\prime}$ to $1 / 4^{\prime}$ long, by $1 / 8^{\prime}$ to $3 / 16^{\prime}$ broad, color of old Rio Coffee; beak very short, poorly defined, acute; raphe scarcely visible from chalaza till it reaches the top of seed, thence becoming a well defined thread reaching the beak; chalaza narrowly elliptical, a little elevated, sometimes a mere crescent at lower side, or none in a very shallow narrow basin; more or less distinct groove from chalaza to beak, inner or ventral face with slightly curved, short, nearly parallel slight depressions of lighter color than body of seed.

Plantlet: Cotyledons large, cordate, mostly green or a little reddish.

\section{Viticultural Observations and Remarks}

Germination quick, vigorous; foliation very early, inflorescence very early, with or before $V$. Longii and $V$. rupestris, fruit ripens very early, last of June or first of July, in Northern Texas. with Champion, $V$ rupestris and $V$. Longii, some varieties later by one and two weeks.

In sandy and alluvial soils its vigor is excellent where permanent moisture exists below; in very limy soils and poor clay not good; hardiest of all species to endure cold, as in a large extent of country, covering Wisconsin, Minnesota, Dakota and Manitoba where it is the only native species, it endures from $40^{\circ}$ to $50^{\circ}$ (F.) below zero; but in withstanding severe summer heat and long drouth it fails almost equally with $V$. rupestris, as shown by test in my grounds with vines from many localities in the north. (See Table of Longevity, Chapter II.) Grows quite easily from cuttings. Pollen prepotent upon other species, when blooming together, equally so with $V$. rupestris. The fruit of this species is rich in sugar, tartaric acid and coloring matter, as in other species of this series.

This species is often found hybridized naturally with other species with which it grows in the woods. In Grayson County, Texas, on the bottom lands of Red River, the writer has found it-mixed with $V$. candicans, $V$. cordifolia, and once with $V$. cinerea,-rarely with $V$. Lincecumii. In the Northeastern range, New York, New Jersey, etc., where it comes in contact with $V$ labrusca, it is often intermingled therewith,-as in Clinton, Sherman, Taylor and other wild

* See pp. 82, 83, and 84, Bulletin from the Botanical Department of the State Agriculture College at Ames, Iowa, by Byron D. Halstead, Sc.D., 1885. I have found the same true with all the other species but the fertile flowers having horizontal or ascending stamens, such as Concord, and many $V$. labrusca and $V$. vinifera varieties, in cultivation, furnish pollen capable of fertilizing (but less vigorously than the pollen from purely male plants), the pistils of the same or other fertile vines. In effect, nearly all wild bearing vines are female only and to bear must receive pollen from some vine having erect stamens, either staminate or male vines, or from vines with hermaphrodite flowers. These are important facts either to the practical vineyardist or to the hybridizer. See the Plates XXXVII,
XXXVIII, XXXIX. 
hybrids of fair quality, which have been brougnt into cultivation and have given to us a large number of varieties of improving merit, among which may be named Elvira, Missouri Riesling, Etta, Montefiore, and many others of merit, produced by that veteran, Jacob Rommel, of Missouri, also a number of excellent varieties by D. S. Marvin, of New York, and John Sacksteder, of Indiana, and others. In Michigan and Wisconsin wild hybrids with $V$. bicolor have been found. In Minnesota Louis Suelter found a white variety with which he hybridized Concord, and obtained several varieties, black, of medium size, with very early, pure fruit of fair quality. These hybrid vines have endured unprotected a temperature of $45^{\circ}$ to $50^{\circ}(\mathrm{F}$.) below zero without injury. One of these named Suelter is earlier than Champion and greatly superior, especially for wine-making. Beta and Monitor are also very early and quite good, of the same parentage. They suffer from heat here, in Texas.

Natively, in its pure form, it is found in Nova-Scotia, on St. John's River, New Brunswick, along the St. Lawrence River to 100 miles below Quebec, along the Ottawa River, along the northern side of Lake Superior, thence to the head of Lake Winnipeg, thence 200 miles or more up the Assiniboine River to the Rocky Mountains,* and all southward from that northern limit into Virginia, Tennessee, Arkansas, and west to Denison, on Red River, Texas southeast, Kansas up the Arkansas River, and one locality on Salt Lake, Utah, of doubtful origin. In the cretaceous formations of Southeastern Colorado, Western Oklahoma, Northwestern Texas, and New Mexico, it is replaced by $V$. Longii, a form about midway between it and V. rupestris, rather more like the latter in several respects and with some peculiar characteristics of its own (see $V$. Longii). Prefers moist but well drained, loamy, sandy, high river and lake banks, where it is usually found.

This species offers fine qualities for hybridizing to obtain very early hardy varieties for the extreme north. It, in its largest and best native forms, is especially to be recommended to experimenters, for the purpose of producing (hybridized with such as Ives, Woodruff, Worden, Perkins, Moore Early, Eaton, Moore Diamond, America, Greins Golden, Brilliant, Jaeger No. 100, Etta, etc.) a tribe of "iron-clad" varieties for the extreme northern and northwestern parts of the country, of pure native blood or nearly so, good quality for table or wine, that will endure the climate without protection. There is all the great Northwest region, consisting of Iowa, Wisconsin, Minnesota, Nebraska, Dakota, and parts of Wyoming and Montana, that has a superior climate for extra early grapes, if they can be obtained hardy enough to endure the winters. It is a region free from mildew and rot. There is nothing to prevent it from becoming a great grape country, for the material certainly exists, which can be developed into very excellent varieties. All the streams of that territory have growing along their borders abundance of wild $V$. vulpina, some varieties of which are quite good of themselves; but need enlarging in berry and cluster, an easy accomplishment in the hands of an expert hybridizer. Into this development should be worked the finer varieties of $V$. bicolor in Northern Illinois, Indiana, Ohio, New York, and in Michigan and Wisconsin to the $43 \mathrm{~d}$ parallel.

Owing to the resistance to Phylloxera, ease of growth from cuttings and ease of grafting, $V$. vulpina and $V$.rupestris are now used in Europe far more than any other species upon which to graft their favorite Vinifera varieties, but they are not suited to their very limy soils, such as the cretaceous soils of the Cherente-Inferieure, in which it is found that the V. Berlandieri succeeds best, which see, under "Viticultural Remarks," for that species. 
23. VITIS LONGII. Prince: 184. (See Plate XXXIII.)

Synonyms:

V. Solonis, Hort. Berol. 1868 (Fide Engelmann).*

V. cordifolia Solonis, Laliman;-LaSouys, Millardet.

V. Novo Mexicana, Munson, 1883. Address before Am. Hort. Society.

"Bush Grape," "Sand Grape," "Sugar Grape," "Woolly Riparia."

VITIS LONGII, var. Microsperma (Munson).

Plant: In native situations usually shrubby, stocky, erect, much branched, similar to, but not so profuse of branches, as $V$.rupestris, but more than $V$. vulpina; branches rapidly tapering, angled slightly at first, soon terete; climbing when transplanted into low land and then more vigorous than almost any other species; growing tips quite leafy, like $V$. vulpina, not so much as $V$ rupestris, foliage of a lighter, grayish-green cast, than $V$. vulpina, and easily distinguished at some distance.

Roots: Slender, branching much, very wiry and deeply penetrating; seedlings with tap root, tapering downward, not transversely wrinkled.

Wood: Tips whitish with cottony hairs which become floccose and almost disappear the first year, except about the nodes, where they remain mostly through the winter, young wood soon finely striated, in maturity becoming a light grayish-brown. On old wood the bark is closely persistent for several years, then becoming fibrous, not loose and thready, and sheds thin plates as in $V$. vulpina; sectional view of annual wood much more dense, of a lighter green color, and medullary rays more distinct than in $V$. vulpina; nodes slightly, sometimes much, enlarged, a little bent; diaphragm plane thin, usually about twice as thick as in $V$ vulpina; buds larger and more woolly than in $V$. vulpina; tendrils generally once forked, rarely twice forked, short, slender, and soon falling, unless they take hold early on some support, when they become very much thickened and cling with great strength, at first are cottony, color red; internodes short, $1^{\prime}$ to $3^{\prime}$, pith smaller and lighter colored than in $V$. vulpina, meeting the diaphragm abruptly.

Leaves: Stipules $1 / 5^{\prime}$ to $1 / 4^{\prime}$ or more, long, membranaceous, becoming pale brown and shedding when leaves are about half grown; petiole $1 / 2$ to $3 / 4$ the length of midrib, grooved moderately on upper side, striated, both pubescent and cottony; color pale to dark red, usually set at about right angle with blade; blade $3 \frac{1}{2^{\prime}}$ to $4^{\prime}$, rarely $6^{\prime}$ wide, by $3^{\prime}$ to $5^{\prime}$ long, partially fclded together toward upper surface, similar to, but less than in $V$. rupestris, broadly cordate, nearly round, rarely slightly three lobed or approaching reniform, usually less shouldered than in $V$. vulpina, sometimes not at all; basal sinus generally broadly $\mathrm{n}$ shaped; basal lobes spreading or approaching each other; sometimes lapping; teeth large, usually acute, convex, mucronulate; summit short taper-pointed. Venation of lower surface prominent, mostly 6 sometimes 7 , nearly always opposite pairs of pubescent and slightly cottony ribs; upper surface, when young, appearing white, usually quite hairy, others little hairy, becoming appressed cottony or floccose when grown, and finally smooth and glossy, slightly rugose, dark green; lower surface, aside from ribs and nerves, smooth and much paler green, than upper surface; texture firm, leathery; . leaves on ground shoots of old roots 3 to 5 lobed with lateral sinuses narrow and acute; entire and not lobed on seedlings first year.

Cluster: Fertile, $-2^{\prime}$ to $3^{\prime}$ long, simple, very compact, shouldered, peduncle very short, making clusters appear nearly sessile, without salse tendril rachis forked, the shoulder nearly half as large as main cluster, woolly when young; pedicels short, thick, warty; staminate, medium, simple, little if any larger than the fertile cluster.

Flowers: Very fragrant; buds green; fertile,- - stamens short, weak, reflexed and curved laterally; pollen non-virile; staminate,-stamens long and strong; anthers large; pollen abundant, and very efficient.

* See Solonis, p. 23, Histoire des Principales Varieties et Especes de Vignes d'Origine Americaine. Par A. Millardet, 1885 . 


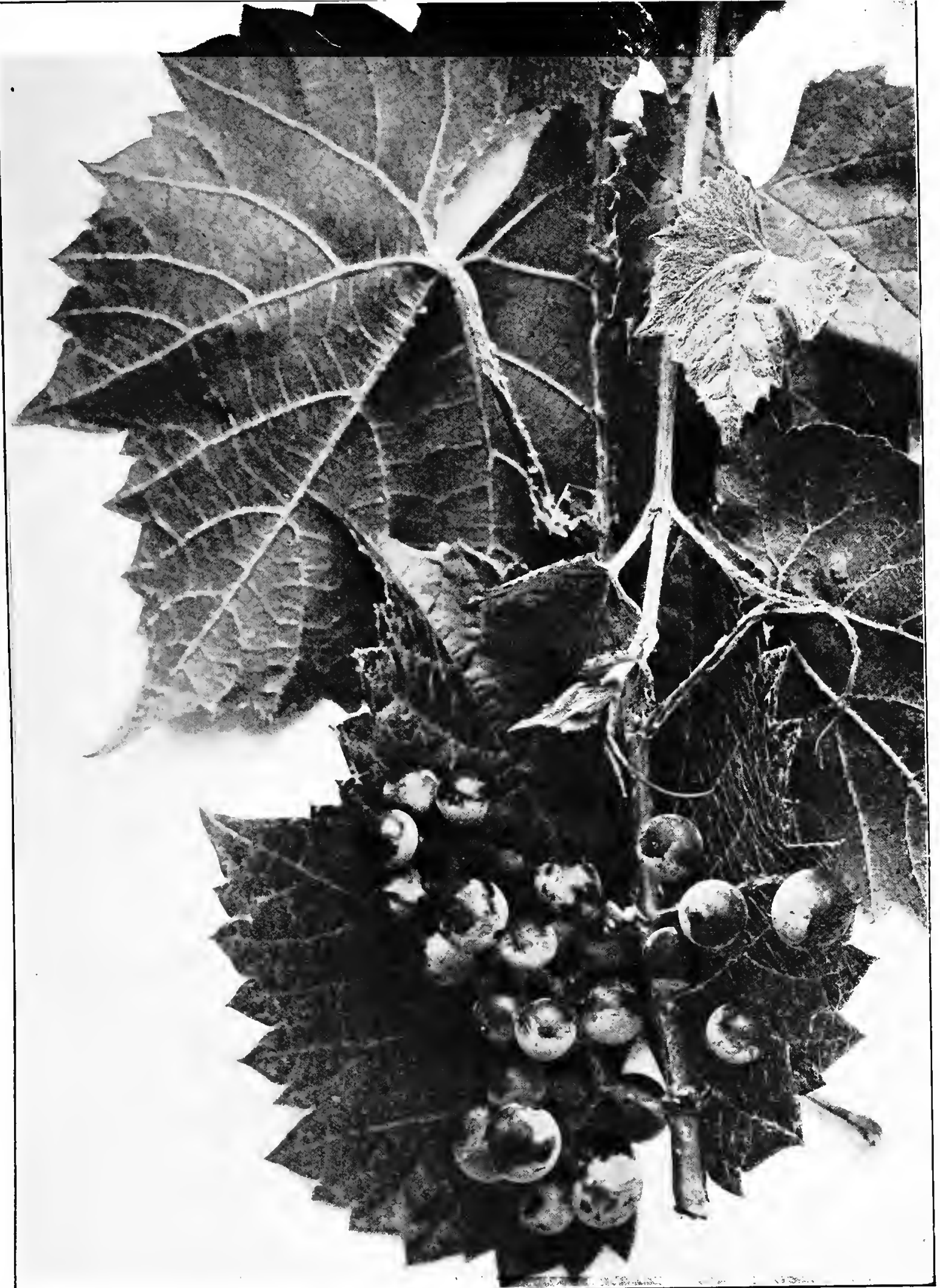

PLATE XXXIII. 23. VITIS LONGII, Prince. (V. Solonis, Hort. Berol.) Bush Grape. Canyon Grape. Northwest Texas. 
Berries: $1 / 3^{\prime}$ to $1 / 2^{\prime}$ in diameter, round or oblate, black with abundant prunose bloom, skin thin, tough, with excessive blood-red coloring matter; somewhat pulpy, very seedy, juicy, taste pure, sprightly, vinous, more acid than in $V$. rupestris, develops much sugar in full maturity; fruit persistent and enduring long after ripe; pigment surrounding seeds, very persistent.

Seeds: Usually 2 to $3,1 / 5^{\prime}$ to $1 / 4^{\prime}$ long by nearly as broad, nearly hemispherical when two, or globose pyriform when one, a little darker reddish-brown than in $V$. vulpina, beak very short, scarcely more than the regular tapering of the seed to an acute point, color scarcely different from body of seed; raphe begins with beak and as a distinct, fine thread, extends in a slight depression to top of seed where it becomes less prominent or nearly obsolete as it passes through the groove extending from top of seed to chalaza, to which it attaches by gradual expansion; chalaza narrowly ovate or elliptical, flat or much depressed to a mere crescent, lying in a distinct basin from which a small groove extends on back of seed to beak; ventral depressions short, wide apart, usually straight, of a paler brown than body of seed, or of a pale olive green color, when quite fresh.

Plantlet: Cotyledons large, ovate, acute-pointed, a little violet at first, but soon green.

$V$. Longii, var. Microsperma, Munson, a distinct form with very small seeds, and vine very rampant, about midway between $V$. Longii and $V$. vulpina, found on bank of Red River, Grayson County, Texas.

\section{Viticultural Observations and Remarks}

Germination, foliation, inflorescence and ripening of fruit among the earliest of our species. Exfoliation later than in V. rupestris or $V$. vulpina.

Though chiefly found in sandy soils it thrives well on limy soils even where very strong, enduring drouth to perfection on such soils but failing in Texas, on upland deep sandy soils in severe drouths. Wood matures well and endures great severity of cold, apparently as hardy in this respect as $V$.rupestris. The variety Microsperma, discovered on the banks of Red River, Grayson County, Texas, by Hermann Jaeger and myself, which has very small seeds, is quite a distinct variety of this species, with wood of a lighter straw color and a vigor of growth most remarkable. Resistant to Phylloxera. In wet seasons mildew and anthracnose attack young leaves of this species from the Texas Panhandle region (but not Microsperma), to some extent, especially in its less woolly forms. Black Rot attacks it very little. Grows readily from cuttings. Pollen of staminate plants very prolific and prepotent in impressing its characteristics in hybridizing with other species, but that of pistillate plants is very feeble, so that alone, bearing vines rarely set fruit unless staminate vines grow near by, when they set full.

Owing to its great vigor, hardiness and ease of growth from cuttings, this species must stand very high as a stock. As a direct producer of wine it is not large enough in cluster but offers great inducements to hybridize upon, as its vinous quality is unsurpassed. Great quantities of this fruit grow wild in the Texas Panhandle and are there gathered largely to make pies and home-made wine.

It has been found naturally hybridized along the Red River in Grayson County and westward up to Pease River, with $V$. candicans, where that species ceases; above this it is occasionally found mixed with $V$. Doaniana, and sometimes in another form which bears some resemblance to $V$. Treleasei. No varieties are yet in cultivation save a few on trial in the writer's vineyard, and some hybrids of it with various of our best cultivated varieties.* Its hybrids with Jaeger's No. 70 (a hybrid of $V$. rupestris with $V$. Lincecumii) are especially promising.

This species is found abundantly along the sand banks thrown up by high water on the Pease River, the main, or "Prairie-dog-town-Fork" and North-Fork of Red River, South Cana-

* A number of these fruited for the first time in 1890 , and some of them are of value for wine, being very prolific, of fair size and very rich in sugar coloring and vinous character. These offer a basis for a very valuable family for the dry Southwest. 
dian, North Canadian, and some branches of the upper Arkansas River, and in cañons and dry sandy ravines opening into the valleys of these streams, in western parts of Oklahoma, all the northwestern part of Texas, eastern part of New Mexico, and southeastern part of Colorado, all on the eastern slope of the Rocky Mountains, and gradually assumes the form of $V$. Arizonica as it passes through the mountains in New Mexico. Through all its range it seems to take the place of $V$.rupestris and $V$. vulpina, as though these two species had been blended, and with also the woolly aspect of $V$. A rizonica, and some taint of $V$. candicans. I do not mean that it is purely and recently a hybrid production, but thus related in its characteristics, for it has a well characterized specific make-up of its own.*

\section{VITIS RUPESTRIS, Schéele, Linn. 21, p. 591. (See Plate XXXIV.)}

Synonyms: Botanical, none.

Synonyms: Common.

"Sand Beach" or "Sugar Grape," "July Grape," "Currant Grape," "Rock Grape."

Plant: Vine tapering rapidly, erect or ascending, much branched, scarcely climbing, rarely more than 4 to 8 feet. Leaves expand very rapidly in unfolding tips, and thus give the summits of branches a very leafy appearance.

Roots: Slender, wiry, penetrating, not transversely wrinkled.

Wood: When young smooth, slightly 5 to 6 angled, red, becoming cylindrical and finely striated when mature, with bark of a dark cinnamon color, grows darker with age, remaining quite persistent, rarely scaling off in plates until third or fourth year and then in broad non-fibrous plates; wood dense, not very hard; sectional view shows rays thin and numerous, with small pores, generally in one row, between; nodes slightly enlarged, nearly straight, diaphragm $1 / 16^{\prime}$ to $1 / 12$ ' thick, nearly plane, buds small, globose or sub-conical, slightly three angled and acute on the most mature annual wood, covered mostly with brown scales in expanding; small, crimson tendrils, smooth; internodes very short $1^{\prime}$ to $3^{\prime}$; pith rather large, enlarging downward in each internode toward diaphragm.

Leaves: Stipules large, lanceolate, membranaceous, crimson; petiole deeply and broadly grooved above throughout its length, distinctly striated, usually smooth, sometimes thinly pubescent along the striæ but always pubescent at the insertion where it forks into ribs, nearly always dark crimson, set at obtuse angle with midrib; blade from insertion of petiole to summit usually about the same length as petiole, and $3 / 5$ to $3 / 4$ the width of leaf,- -very peculiar proportionsusual width $3^{\prime}$ to $4^{\prime}$, often $5^{\prime}$ to $8^{\prime}$, reniform if flattened out, but on the plant, standing on the petiole $1 / 2$ to $3 / 4$ folded together toward the upper surface, thus exposing mostly the lower surface to view and giving pale green aspect to plant when in leaf; the midrib curving downward from the petiole and the blade so full that when pressed out it almost invariably folds upon itself; basal sinus very broad, sometimes truncate, but usually terminating acutely at insertion of petiole; teeth large, shallow convex with short mucronate tips, summit short taper-pointed, margins never pubescent; venation from mostly, 5 , rarely 4 or 6 pairs of generally opposite ribs, with very little prominence; sometimes pubescent tufts in axils of ribs; both surfaces quite smooth; color, above, dark green, below of light yellowish-green; texture dense, somewhat leathery but fragile. Blade on ground shoots of old roots often a little lobed, on one year seedlings rarely if ever lobed.

* A. Millardet in his "Histoire des Principales Varietes et Especes de Vignes d'Origine Americaine," pp. 25 to 29 , regards this a complex hybrid form, but the wide distribution over hundreds of miles of territory in Northwestern Texas, where only this species exists, proves this view erroneous, unless we should say it probably originated in bygone ages as a mixture and now it is sufficiently fixed in type and extended in distribution to rank well, at least among our younger species of Vitis. In a viticultural aspect it is well worthy of specific distinction, and in actual aspect in vineyard among other species it is most readily distinguished. In extended journeys in its native region. the writer has never seen $V$. rupestris or $V$. candicans except the latter along its eastern border of distribution. No other species has been seen by me in that large area where it is so àbundant, save frequently $V$. Doaniana. Both these bear quite uniform specific characteristics throughout that region in millions of separate plants, and to call them all hybrids as friend Viala does in his "Mission Viticole" and "Adaptation" seems to me to be quite a nevr application of the term. 


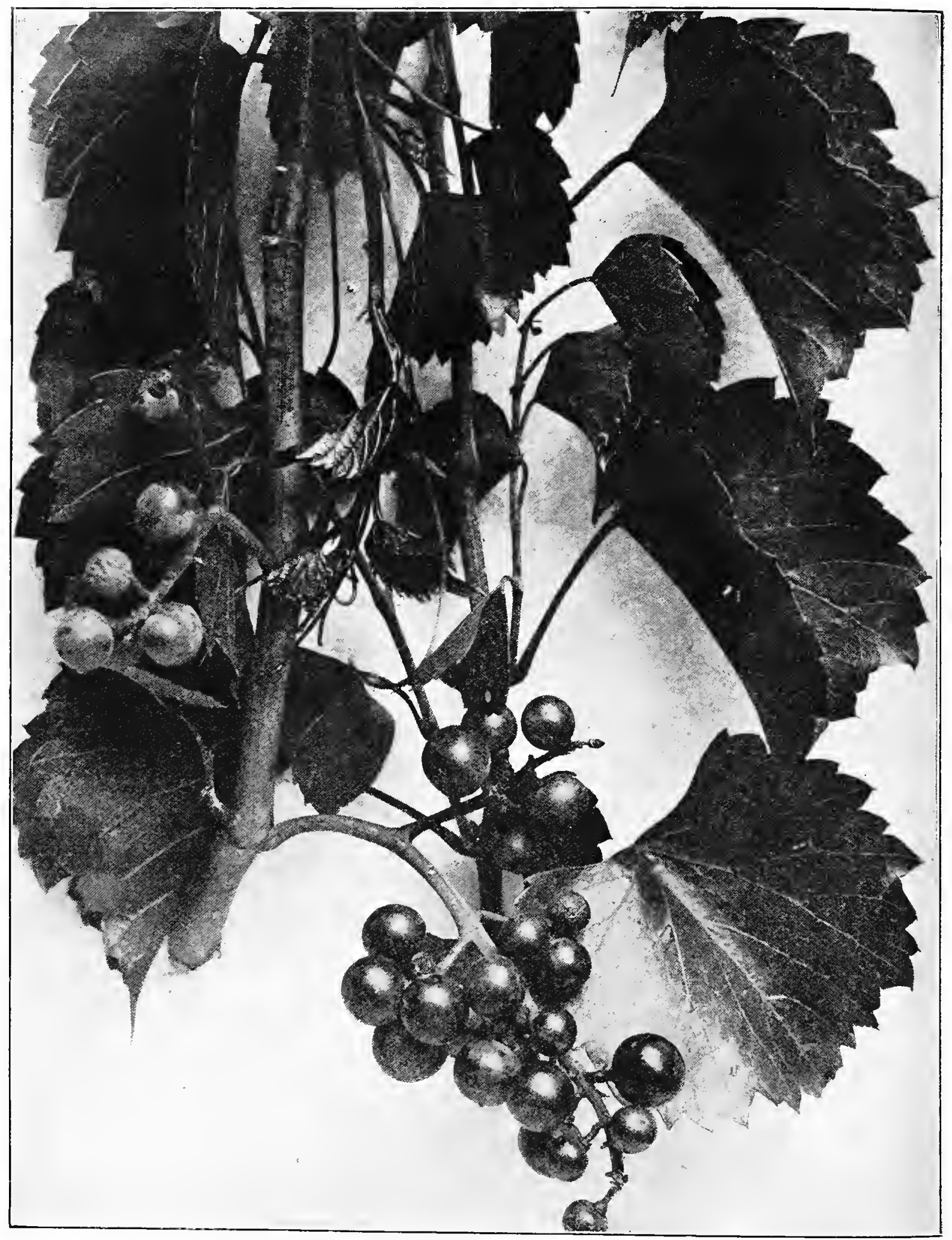

PLATE XXXIV. 24. VITIS RUPESTRIS, Scheele.

Rock Grape. July Grape. 
Cluster: Fertile,-very small, seldom shouldered, peduncle short; rachis smooth, of a pale yellowish-green; pedicels short $1 / 8^{\prime}$, slender, thickened toward receptacle which is medium; staminate cluster much larger with numerous flowers, and generally shouldered.

Flowers: Fertile,--stamens recurved and bent laterally, rarely ascending; pollen of fertile flowers non-virile hence pistillate plants will not often bear alone; ovary globose, style short, slender, stigma medium; staminate,-stamens ascending, anthers large, bearing abundant virile pollen.

Berries: $1 / 4^{\prime}$ to $1 / 2^{\prime}$ in diameter, round or flattened a little from stem to apex and often somewhat doubled, like two berries coalesced; black with little bloom; skin very thin and tender. pulp tender and melting; quality pure; coloring matter excessive, dark crimson or violet, a part of which clings closely to the seed.

Seeds: 3 to 4 , small, $8^{\prime}$ to $3 / 16^{\prime}$ long, by nearly as broad; color light chocolate, beak rather smaller and more defined than in $V$. vulpina, acute, raphe slender, thread-like, extending over the little, or not at all notched top of seed, continuing with little elevation to chalaza which is small, in center of back of seed, appearing as terminus of raphe, slightly enlarged and little elevated, lying in a very shallow, narrowly elliptical basin, ventral depressions short, shallow, of lighter color than body of seed.

Plantlet: Cotyledons small, acute-ovate, cordate and crimson at first.

\section{Viticultural Observations and Remarks}

Germination quick, nearly with $V$. Longii; foliation just after $V$. Longii, fruit ripens early, with or before $V$. Longii and earliest with $V$. vulpina, producing many clusters of very light weight. This species has the faculty of bearing fruit upon young shoots pushed out upon two, three or four year old wood, in case the last year's growth has been destroyed during the winter.

Seedlings little less vigorous than $V$. Longii. Vigor and hardiness in all sandy and alluvial lands very great, where there is permanent moisture a few feet below; endures climatic changes very well when permanent moisture exists within a few feet of the surface, but in sandy soil which dries out in long drouths in great depth $i^{\prime}$, soon perishes. Of one hundred vines well established and very vigorous in such soils in the writer's grounds to the fourth year, passed through a severe drouth and by the sixth year were all dead, evidently from incapacity to resist great drouth, while most other native species under same condition alongside of them are, twenty years later, very vigorous and growing luxuriantly. Foliage well adapted to resist fungus and insect attacks, which it escapes quite well, excepting the speckled form of anthracnose which attacks it very much but with no serious damage. It resists black rot perfectly. Propagates easily from cuttings. Pollen of staminate" plants very prepotent in fertilizing and hybridizing with other species.

This species is found naturally hybridized in Southwestern Missouri with $V$. vulpina, $V$. cordifolia and more rarely with $V$. cinerea and $V$. Lincecumii (H. Jaeger); in Texas with $V$. candicans, V. monticola, V. Berlandieri, and $V$. Arizonica,- the latter toward the Rio Grande. The writer has a number of remarkable hybrids of it with $V$. vulpina, $V$. Longii, $V$. Lincecumii, $V$. labrusca, etc.; Huntington seems to be a hybrid of $V$. rupestris with the Clinton, and has a fruit which makes a good wine and resists black rot, though attacked by anthracriose. One of writer's seedlings of $H$. Jaeger's No. 70 is about the size of Ives Seedling, in berry and cluster, earlier, vigorous, prolific and much superior in quality. It is named America, see its description in Chapter III.

In its pure form, this species is native in sandy gulches, at head of ravines, on high land, on sand hills along streams, in Central Tennessee, Southwestern Missouri, Northern Arkansas, along the Ozark ridges of Oklahoma, then skips quite a wide region in Northwestern Texas (Longii taking its place there). Then occurs abundantly again in Central and Southwestern 
Texas to the Rio Grande, always, so far as known to me, where permanen't moisture is reached in a few feet. The species is reported to me by Dr. N. L. Britton, Botanist, Columbia College, seen by him along streams among the mountains of South Pennsylvania. The species is not reported as a wild vine to any extent north or south from the Ozark hills and mountains, which are but the continuation of the Appalachian uplift by the way of the Cumberland Mountains, westward in Southern Kentucky, Tennessee, Southern Illinois, Southern Missouri, Northwest Arkansas, Oklahoma and Southwest Texas, with Llano County as about the center of the southwestern extremity of the distribution. This is a remarkable range of some 1500 miles in length and probably not over 200 miles in width on an average. Yet the species thrives exceedingly in cultivation far northward and southward from its natural range. Why it has not spread generally over the country as have most other species native of the same latitude, can only be a matter of conjecture. A probable cause, appears to be the browsing of deer and buffalo which formerly ranged over the more level parts of the country and which were very fond of it, and the bushy habit of the species not allowing it to climb trees out of their reach. It is now rapidly disappearing. before the browsing of sheep and cattle, where a few years ago it was plentiful. It succeeds well in very limy as well as sandy soils.

\section{Series IX. Muscadiniá. Planchon}

\section{VITIS ROTUNDIFOLIA, Michx. Flora Amer. 2, 231. (See Plate XXXV.)}

Synonyms :

V. vulpina, Gray Manual, 1868, p. 78, fide Planch. 1. c. 109.

V. vulpina, Young's Flora of Texas, 1873, p. 201.

$V$ vulpina, Chapman, Flora, S. U. S., p. 71.

"Muscadine" or "Southern Fox Grape," "Bullace Grape," "Bull Grape," "Bullet Grape."

Plant: Slender, climbing high.

Roots: Thick, little branched, pale yellowish, wrinkled transversely, penetrating, intensely pungent to taste.

Wood: When young, angled, pale reddish or green, thinly silky, hairy at first, soon smooth, becoming gray and warty along their regular obscure strix; mature outer as well as inner bark very persistent, non-fibrous; wood firm, nodes little bent and not swollen; pith and diaphragm none; buds small, globular or sub-conical, reddish-brown, shining in unfolding, small rusty green, tip closed; tendril simple, $4^{\prime}$ to $6^{\prime}$ long, having node and markings similar to $V$. Munsoniana, red o1 green when young, persistent; internodes $2^{\prime}$ to $4^{\prime}$ or more, circular or nearly so in section first year, becoming oval second year; in place of pith a dense, dark green, cellular, non-fibrous wood.

Leaves: Stipules minute, $1 / 10^{\prime}$, broader than long, truncate margin ciliate; petiole usually longer than half the width of blade, sometimes nearly equal to entire width (very uncommon in V. Munsoniana), narrowly and deeply grooved above, pubescent along obscure striæ, usually dull red, set at acute or right angle to blade, which hangs nearly perpendicularly; average length of blade $21 / 2^{\prime}$, average width $3^{\prime}$, shortest $2^{\prime}$, longest $41 / 4^{\prime}$, narrowest $2^{\prime}$, broadest $5^{\prime}$, general shape broadly cordate; basal sinus generally narrow $\Lambda$ shaped, rarely closed, often broad; blade never lobed, rarely shouldered, summit acute; teeth large,-yet smaller than in $V$. Munsoniana, but not so prominent, generally convex, sometimes mucronate, from 25 to 35 in number; venation from the generally 5 , sometimes 6 , pairs of ribs less prominent than in V. Munsoniana; midrib and ribs thinly and minutely pubescent, with small pubescent tufts in forks; surfaces both smooth and glossy; the upper surface much more wrinkled than in $V$. Munsoniana, and of a darker green; texture more dense and leathery.

Cluster: From node of tendril, smaller than V. Munsoniana, otherwise similar to it, except that the peduncle and pedicels are shorter and thicker, and the latter more warty. 


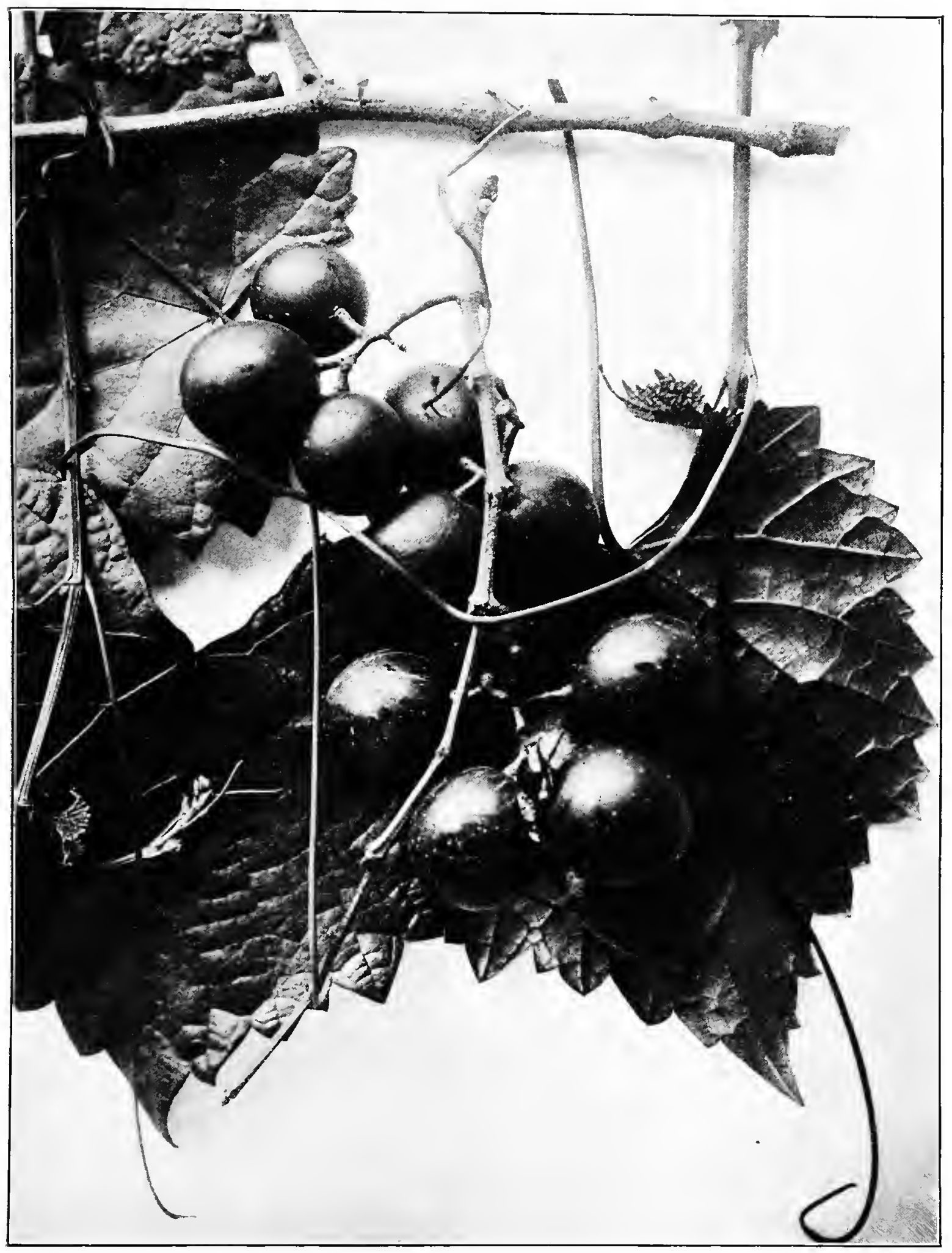

PLATE XXXV. 25. VITIS ROTÚNDIFOLIA, Michx.

Southern Muscadine. From South Carolina. 
Flowers: In fertile cluster 8 to 16 ; stamens and petals generally 5 , sometimes 6 ; stamens in sterile flowers ascending, straight $1 / 5^{\prime}$ to $1 / 4^{\prime}$, in fertile, short recurved and bent laterally upon a visible disc; ovary medium globose, style short conical, stigma small hemispherical.

Berries: 2 to 8 , very large $1 / 2^{\prime}$ to $1^{\prime}$, globular, surface roughish, generally dull black, rarely yellowish bronzy in color as in Scuppernong, and with a very slight prunose bloom and numerous brown dots: drops singly as soon as ripe, juicy, without coloring matter in juice, with pleasant. but peculiar musky flavor and odor; skin thick and tough; pulpy.

Seeds: 2 to 3 , rarely 1 or 4 , very large, $1 / 4^{\prime}$ to $3 / 8^{\prime}$ long, by $1 / 5^{\prime}$ to $1 / 4^{\prime}$ broad, oval-lenticular when 2, ellipsoidal when 1 ; color olive brown when fresh; beak generally no more than the acute termination of the seed, or rarely a very short, rounded point; raphe invisible till the groove ceases, then becomes visible though not much larger than a hair, and passing down the prominent narrow ridge between the ventral depressions; chalaza acute-elliptical, small, in center of back of seed, surrounded by a distinct groove which begins at beak, spreads around chalaza. where its margins are wrinkled, extends to top of seed; depressions long, narrow, deep, straight, except at top where they curve outward from raphe, their outer border being distinctly wrinkled, of lighter brown color than body of seed.

Plantlet: Cotyledons large, ovate, acute, green or pale purple beneath.

\section{Viticultural Observations and Remarks}

Germination later than in V. Munsoniana and more vigorous; foliation and inflorescence very late; ripens after all other species except the Cinerea and Cordifolia series, and V. Munsoniana, in late August and through September in Georgia and Texas.

The vigor, long life and freedom from disease of this species is unsurpassed in Vitis, never attacked by rot or mildew. Cuttings root with the greatest difficulty, but layers of young wood easily if twisted withe-like at one point when covered. This species is said to make fine wine, of which considerable has been manufactured in Southern Georgia, and in the Carolinas.

$V$. rotundifolia has never been found naturally hybridized with any other species than $V$. Munsoniana, so far as is known to the writer, but it has been artificially hybridized with $V$. vinifera by Dr. Peter Wylie (deceased) and with V.rupestris by Prof. Millardet, and this hybrid in the writer's grounds proves sickly, nonproductive and resembles $V$. rupestris more than $V$.rotundifolia. The writer has produced a number of vigorous hybrids of the Scuppernong variety with hybrid varieties of the true bunch-grapes. This fact alone, now well demonstrated, that the most widely separated of our species can be hybridized, is one of vast importance to the careful experimenter, as it enables one to make any combination of the species of this wonderful genus, as fancy or utility may suggest.

$V$. rotandifolia is found throughout the Gulf and the Atlantic States, from the Potomac River to Central Florida, through Georgia, Southern Tennessee, Alabama, Mississippi Arkansas, Louisiana, and Eastern Texas to the lower Trinity, Brazos and Colorado Rivers to Austin, and up Red River to Grayson County, Texas. It usually grows in high bottoms where the land is well drained, and in moist shady situations. Through all the above extended region it is found quite uniform, while in Southern Florida V. Munsoniana is equally uniform, characteristic and very abundant.

The difference of seeds alone of these two forms of Muscadinia is as great, or greater than between any two species in any other series and with the numerous other differences pointed out, certainly entitles the series to two species, as designated. 
26. VITIS MUNSONIANA, Simpson, Am. Pom. Soc. Rep., p. 16, for 1885. (See Plate XXXVI.)

Synonym:

Vitis rotundifolia, var. "Mustang," Chapman, 71.

"Bird Grape," "Everbearing Grape," "Everlasting Grape" in Southeastern Florida, "Mustang Grape."

This description is chiefly copied from letters of Mr. J. H. Simpson to the writer, and is fully confirmed in vineyard at Denison.

Plant: Very slender growth, much more slender than $V$. rotundifolia; often branching, tips extending rapidly. appearing naked, owing to slow expansion of leaves.

Roots: Large, little fibrous, pale yellow, covered with thick, firm warty bark, transversely wrinkled, possessing a fiery pungency, penetrating.

Wood: When young 6 to 7 angled, dark red or crimson, nearly smooth or thinly set with silky hairs, with age becoming covered with numerous minute punctate dots or lenticose cells, like warts set in rows on the fine unequal striæ, becoming more distinct and increasing with age till the vine has a rasp-like feeling as though covered with coarse sand, and acquiring a dark gray color; bark with little checking, no thready fiber, closely persistent; transverse section of tipe wood oval, with age becoming elliptical or even depressed elliptical, dense but less so than $V$. rotundifolia; nodes very little enlarged, and slightly bent; pith and diaphragm none; buds small, globose in young shoots, acute, at maturity, dark reddish-brown in unfolding, very small, slender, rusty green, tip half open; tendrils simple, in rare cases a little forked, one fork being very short, $3^{\prime}$ to $5^{\prime}$ long, with a node $1^{\prime}$ to $2^{\prime}$ from base, from which node in bearing vines the cluster proceeds, the balance of tendril always remaining normal, faintly striated, warty, reddish when young, soon shedding unless clinging to some object, then becoming moderately strong; internodes $1^{\prime}$ to $5^{\prime}$ long; the greenish cellular wood in place of pith medium size, seemingly continuous, but more dense at node than elsewhere, color dark green, very firm but less dense than $I$ rotundifolia, non-fibrous, drying sometimes into discs.

Leaves: Stipules very small, $1 / 12^{\prime}$ long, orbicular, margin ciliate, pale pinkish; petiole usually as long as half the width of blade, sometimes more, more slender than in $V$. rotundifolia and proportionately shorter, deeply and distinctly grooved above, finely pubescent, purplish crimson, attached to blade at right or more acute angle; blade from $1 \frac{1}{2^{\prime}}$ to $2 \frac{1}{2^{\prime}}$ wide, average $134^{\prime}$, by $112^{\prime}$ to $3^{\prime}$ long, average $214^{\prime}$; nearly plane, appearing peltate when at a short distance from the vine, especially when attached to petiole at acute angle; basal sinus narrowly $\Lambda$ shaped, sometimes broad, often closed; generally not lobed, often shouldered, sometimes the shoulders cut with a wide-acute deep notch, partially from the center lobe, making lacinately 3 lobed leaves, apex usually acute pointed, rarely acuminate; teeth broad, 17 to 25 to each leaf, broadly acute to right angled, with margins straight, rarely convex, notches between deeper than in V. rotundifolia; acute or right angled; venation from the generally 4, rarely 3 or 5 pairs of not quite opposite ribs, slightly elevated, more than in $V$. rotundifolia, giving a less rugose appearance to upper surface; small pubescent tufts in forks; young blade folded in bud or growing tip, conduplicate, expanding slowly, delicately hairy, both surfaces smooth at maturity, of a lively green, paler above than in V.rotundifolia; below, a shade paler and more yellowish-green than above, at time of leaf-fall becoming yellow or crimson; texture dense, but less so than in $V$. rotundifolia. Leaves on seedling vines same as in old vine and ground shoots.

Cluster: Forked, cyme-like, from the node of the tendril; divisions obscurely striated, warty, pale rusty brown when mature; pedicels $1 / 4^{\prime}$ to $1 / 3^{\prime}$ long, medium thick, little enlarged upward, warty.

Flowers: 12 to 50 in fertile clusters; stamens and petals usually 5, often 6 and sometimes 7 ; in fertile, stamens about $1 / 12^{\prime}$ long, recurved and bent laterally, little or no perceptible disc; ovary small, broad and short; style very short, about half the thickness of ovary, in length; 


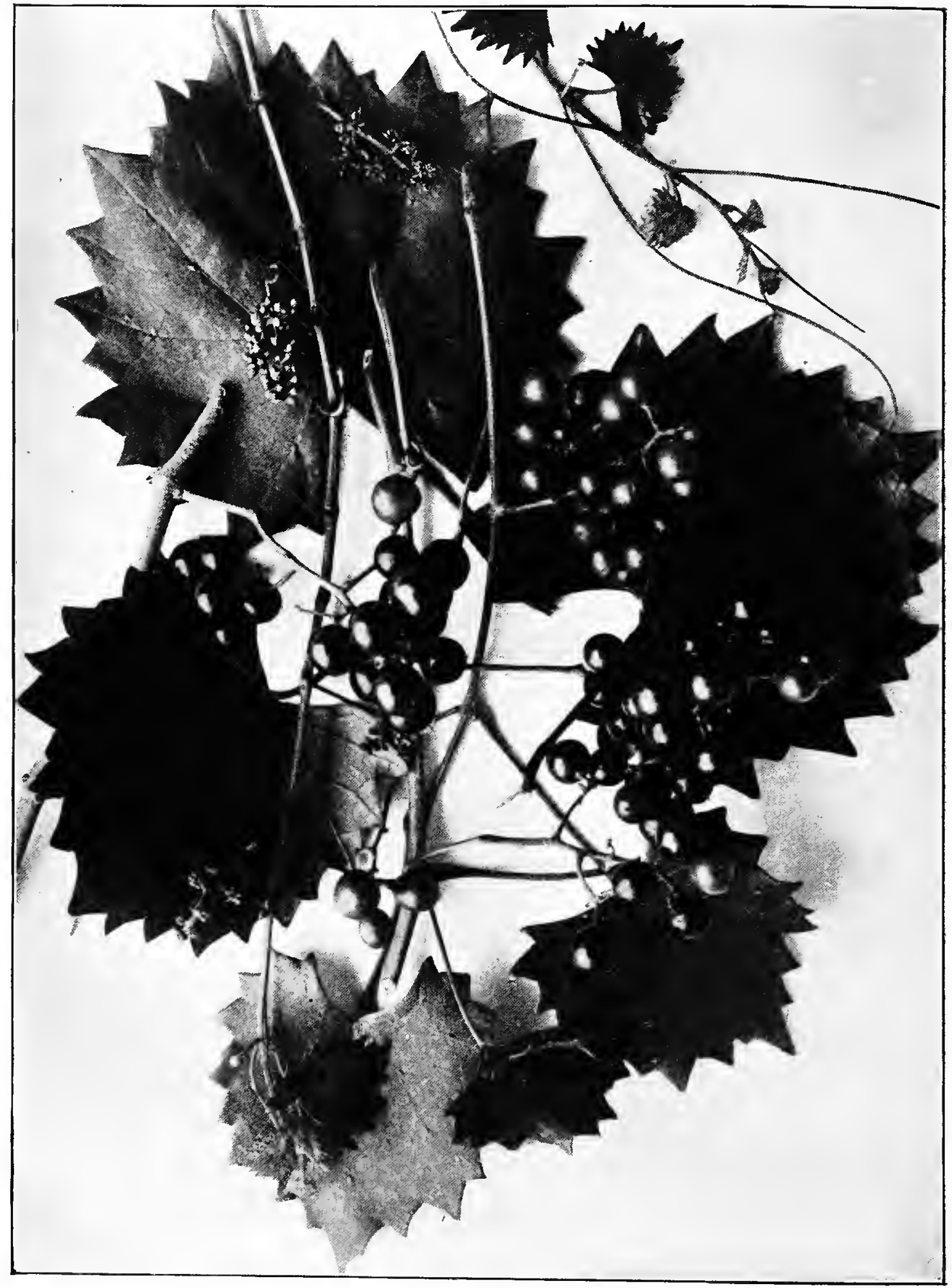

PLATE XXXVI. 26. VITIS MUNSONIANA, Simpson.

Bird Grape, or Everbearing Grape. South Florida. 
stigma very small, semi-globose, nearly sessile; sterile,--stamens long, straight, ascending at an angle of $45^{\circ}$ to $50^{\circ}$ from axis of receptacle extended.

Berries: 12 to 30 , small, $1 / 5^{\prime}$ to $1 / 3^{\prime}$ in diameter, round, shining black, covered with numerous small brown punctate, or lenticose dots, but never having prunose bloom, quite persistent; very little pulp, juicy, with crimson or violet coloring matter next skin, which is thin; vinous, sometimes quite good but generally acid and devoid of the peculiar Muscadine flavor and odor common in $V$. rotundifolia.

Seeds: 3 to 4 in each berry, small, $1 / 6^{\prime}$ to $1 / 5^{\prime}$ long by $1 / 10^{\prime}$ to $1 / 16^{\prime}$ broad, being not more than $1 / 4$ or $1 / 5$ as large in bulk on the average as in $V$. rotundifolia, sides often unequal, surface glossy, dark greenish-brown coffee color, much darker than in $V$. rotundifolia, beak very small, short, acute, or none; raphe plainly or obscurely visible but not prominent within the notch at top of seed till it reaches the inner face, there hair-like; chalaza prominent, acute elliptical, lying within a distinct groove, which starts faintly near the beak, forks aroumd chalaza, passing distinctly to top of seed, where it forms a notch, border finely wrinkled around chalaza; ventral depressions small, rather deep, upper end enlarged, curving a little outward, margins wrinkled, color rusty olive green in new seeds.

Plantlet: Cotyledons small, ovate, acute, nearly sessile, and truncate at base, dark purple beneath.

\section{Viticultural Observations and Remarks}

Germination early to medium; foliation begins about February 5th, continuing to March 15 th, at Manatee, Florida; inflorescence at Manatee continuously from May 15 th to October,J. H. Simpson. At Lake Worth, Fla., commences blooming earlier and continues still later, having flowers, green and ripe fruit on same vine into December,-G. S. Rowley. Hence it is called "Everlasting Grape." This everbearing characteristic does not belong to V. rotundifolia only in a limited degree, and in the same region it begins blooming 6 to 7 weeks later and ceases blooming earlier,-J. H. Simpson. Fruit begins to ripen about August 1st at Manatee; exfoliation very late. In the open ground at Denison, Texas, $V$. Munsoniana holds its leaves much later than $V$. rotundifolia and is the last species among all the rest to have the leaves killed by frost. It there begins blooming and ripening about a week later than $V$. rotundifolia and continues to bloom and make fruit much later, often till stopped by frost.

Vigorous but slender, more upright when young than $V$. rotundifolia, which is less branched and more sprawling in young vines, but becomes much more drooping, or weeping on trellis than $V$. rotundifolia, the lateral branches very slender, almost filiform.

The ever-blooming character of this species, with its smaller seeds, larger clusters, more vinous and acid than $V$. rotundifolia, and its freedom from disease, may render it an excellent material with which to hybridize the finer $V$. vinifera varieties to secure valuable grapes for the extreme south and the tropics. Hybrids of this with $V$. coriacea and probably with other species have been found. It is often intermingled with $V$. rotundifolia in Central Florida where the two coalesce. It has been regarded by Dr. Chapman as being only a variety of $V$ rotundifolia* but a comparison of the characteristics of each, and their distribution as here given from extended observation, demonstrate that these forms differ as widely, if not more, widely, especially in a most vital point,-berry and seeds,-than $V$. rupestris and $V$. vulpina, which are well acknowledged, and than $V$. estivalis and $V$. Lincecumii now separated by Planchon.

* Flora of the Southern States, p. 71.

It first thought this might be Rafinesque's V. Floridana, but after writing Dr. A. Gray and Prof. Thos. Mechan concerning it, their opinion written me in reply was to the effect that Rafinesque's description is so meager and indefinite that it had no certainty of application. Prof. P. Viala (in Une Mission Viticole, p. 166) expresses the opinion that it is Rafinesque's $V$. Floridana, but is in doubt and no means of identifying it as his spect.
Planchon recognizes $V$. Munsoniana and M. Viala also gives $V$. Munsoniana preference, I still hold to it. 
V. Munsoniana is rarely found north of Central Florida, but in all Southern Florida it is by far the most abundant species. It grows equally well in various locations and soils in South Florida from near streams to the poorest pine soils, though found chiefly in rich woods. It is not found native in pine lands until it is cleared and cultivated, when it springs up along fences, etc., where birds drop the seeds, hence called "Bird Grape,"-J. H. Simpson. It has grown and borne well here at Denison, Texas, several years, proving nearly as hardy as $V$. rotundifolia. 


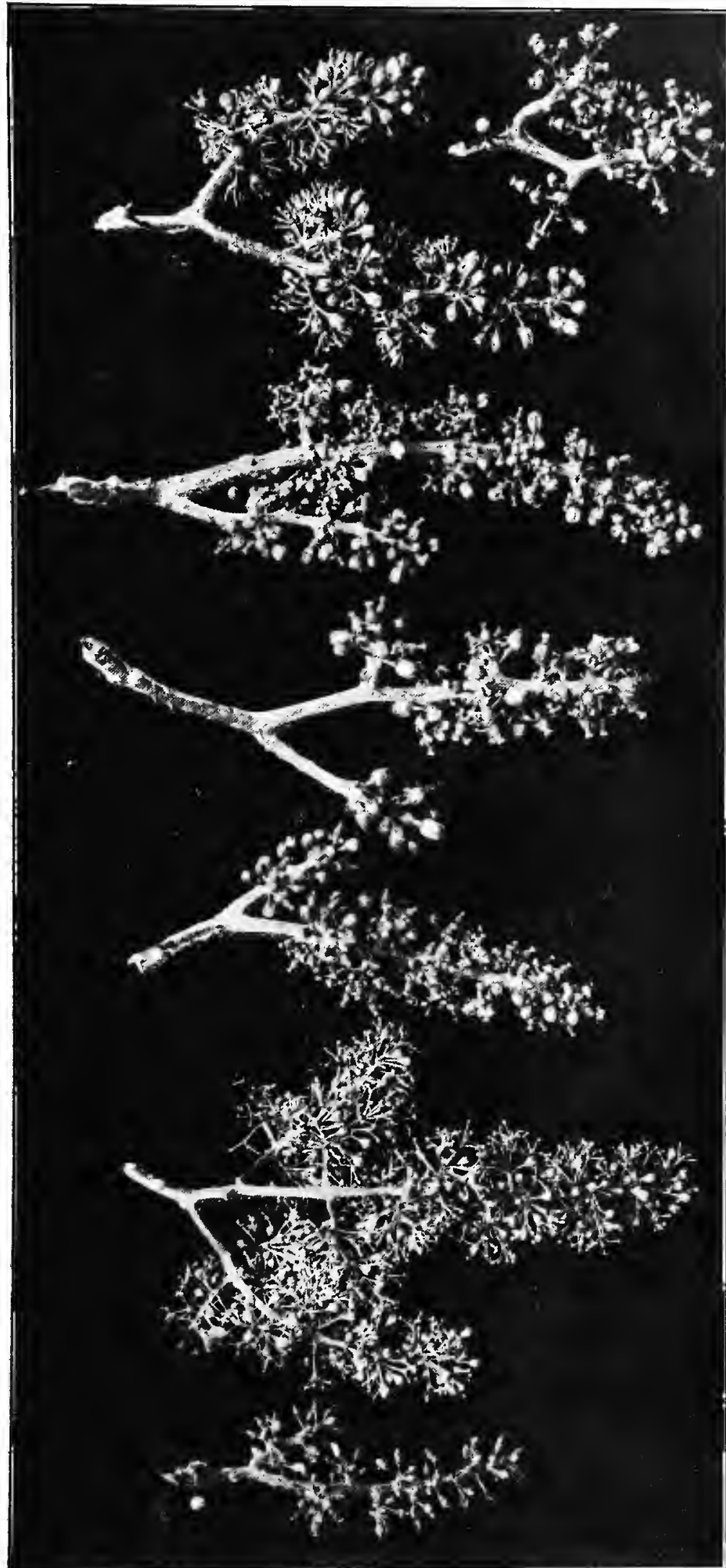

|

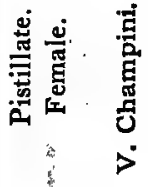

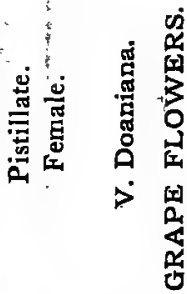

.

| 


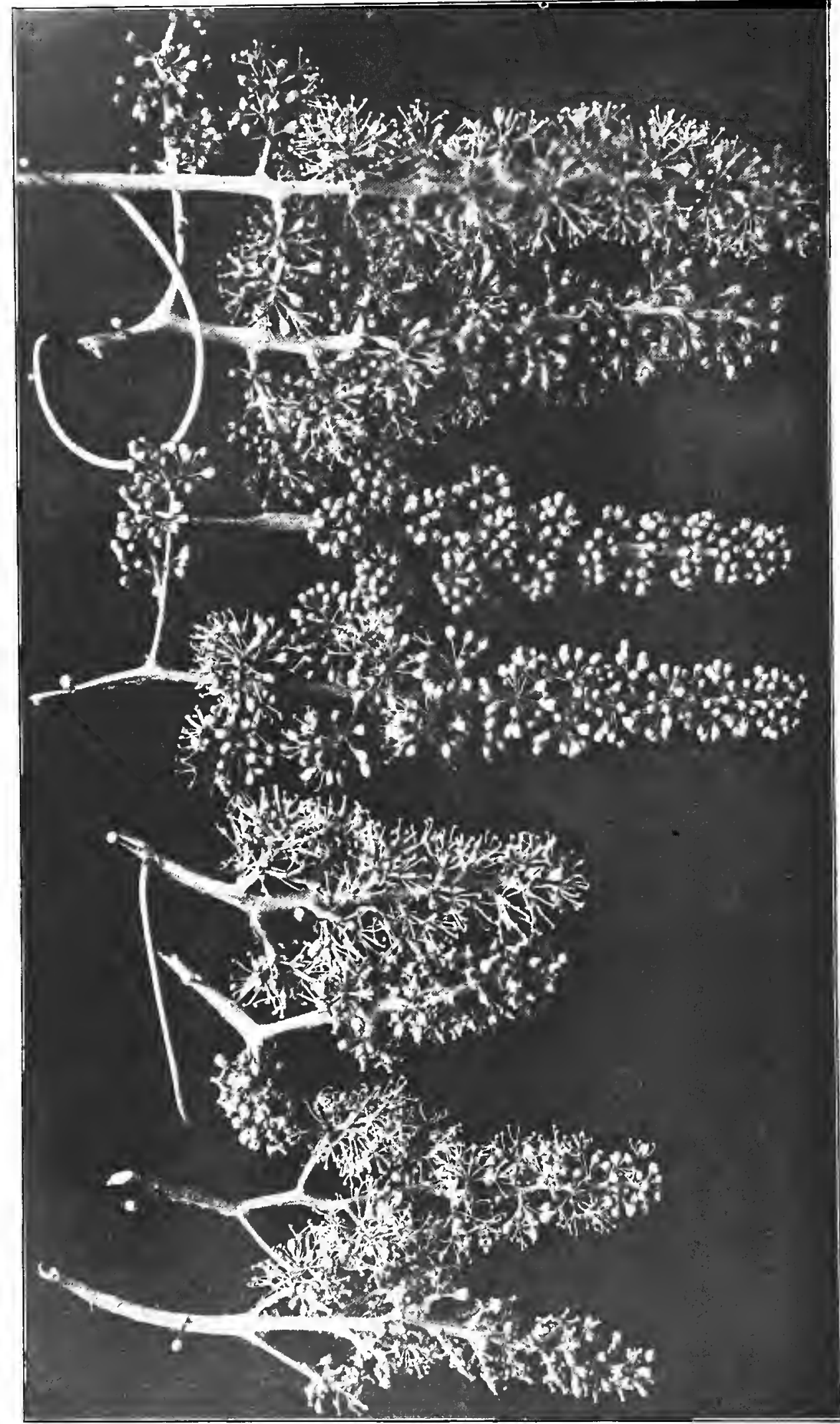

方

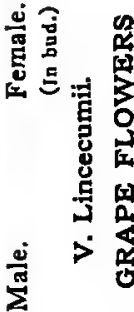

ن

고

동

ฮึ

总

.

宊

吾

淧

:

它蜜 


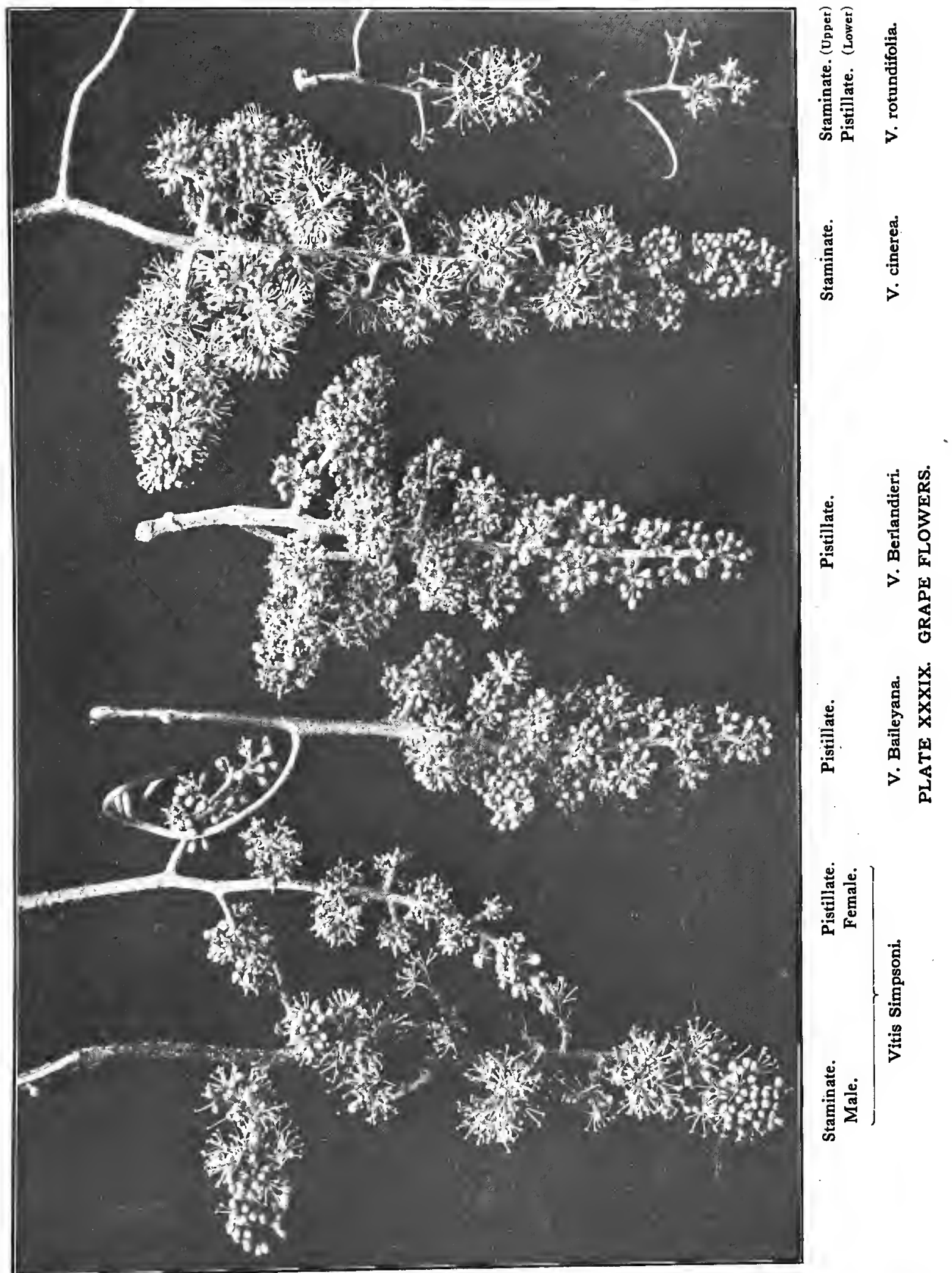




\section{Chapter II}

\section{Breeding of Varieties of Grapes}

The first intelligent step toward starting thorobreds among grapes in the United States was by.Mr. E. S. Rogers, of Massachusetts. But he seemed to look forward to nothing but the immediate hybrids - one generation-produced, yet what a grand start that generation gave us!

Mr. Hermann Jaeger, of Neosho, Mo., went ahead of this, by diligently and intelligently searching extensive ranges of forests where wild grapes grew, collecting the best varieties of several species, and hybridizing them with each other, and with the varieties in cultivation most resistant to grape diseases, which are numerous and destructive in the region where he operated. For more than twenty years did he hunt and hybridize grapes. How few, indeed, were the vines, among all the tens of thousands he examined in the woods, with which he was content to begin with as breeders! The list is soon told. Out of hundreds moved into his grounds and numbered, he used less than half a dozen to breed from!

Of the Post-Oak grape ( $V$. Lincecumii) the Neosho and his No. 43 are the only ones that produced varieties considered good enough to make the foundation of his breed; in combination with a male variety produced from this union was his No. 70, named Munson, and from this has arisen my America family. (See America, Xlnta, Cloeta, etc., Chapter III.) By pollinating his 43 with Herbemont he obtained two very good grapes, which he named Dufour and Longworth. Neosho he never used as a parent, but the writer has, with excellent results. (See Neosho, Muench, Neva, Chapter III.)

This glimpse of my greatly esteemed coworker is given as a small tribute to great merit, and because with him the writer corresponded, visited, exchanged specimens and varieties and discussed every phase of grape development during more than ten years. His sad disappearance was a great loss to the development of American vine culture.

However, the results of his work in either this country or in Europe were not lost. In. France they are reporting fine hybrids on his No. 43 , and best Rupestris for "direct producers" in vineyard culture, and an examination of the Jaeger 43 Family in Chapter III. will show some of its fruits in this country.

So it appears, that to the pioneers in this broader viticultural foundation work, the selection of parents with which to begin the development of new races of vineyard varieties is, in itself, quite a large and expensive task. A careful study of Chapters I. and II. will enable one to better comprehend the full breadth and depth of this foundation.

\section{Thorobred 'Vines}

While there are no truly thorobred varieties of grapes, or other plants, as there are of domestic animals, yet no cause can be shown why good results may not as well be obtained with grapes, so bred, as with cattle or horses. The nearest approach to a thorobred grape that I can cite is the McPike, if its parentage is as reported, a seedling of Worden, which is a seedling of Concord, which is a seedling of a good wild grape of Massachusetts. But such a thorobred is very different in its genealogy from a thorobred animal.

A true thorobred grape would be obtained by intercrossing Concord, Ives, Perkins, Hartford and other distinct, select pure varieties of Labrusca, and then perpetually intercrossing the progeny of each new generation, but avoiding direct "in and in" breeding as of Concord seedlings upon Concord seedlings and these upon their pure progeny perpetually, which would finally run out. 
In the first and better sense we would have a true Labrusca breed, and many other pure Labrusca breeds distinct from this could be established. by starting with another set of wild or distinct varieties. The second would be a pure Concord breed.

But a better breed still, for grapes, it seems, may be made by starting with the best of several species, and then by hybridizing and crossing among these, to reach certain ideals. This very thing in a manner has gradually taken place among several species of Old World grapes, giving the complex Vinifera species in cultivation. This is more a breed of grapes than a species. But it is not strictly thorobred.

\section{Selecting Parent Varieties}

At first thought, it seems a very simple and easy election to make, but when one learns by sad and expensive experience, involving years of nursing and solicitude, that he has been breeding weakness and producing only food which disease will consume, by starting with inherently weak, non-resistant parents, he becomes very cautious in undertaking to originate more varieties. Better to study first the work of others who have made known the errors which lead to failure.

Let a variety be taken for parent, no matter how beautiful and fine in quality of fruit, which is puny, easily hurt by climatic changes and extremes, a prey of insect and fungus diseases, dropping easily from cluster, skin easily cracking, non-productive, etc., and its progeny will bring forth its weaknesses to the third, fourth and even to the tenth generation.

By hybridizing with varieties, very strong in points where the other parents are weak, the maladies can be somewhat counteracted, and much more rapidly reduced than by simply selecting the best, generation after generation, of pure seedlings.

How much more satisfactory, more economical of time, more profitable to originator and planter, would it be to have the parentage on both sides of the very best in constitution and productiveness as well as in quality!

\section{Hunting Good Wild Grapes for Parent Vines}

Bordering Red River, several miles wide, both in Texas and Oklahoma, on the sandy uplands, from Texarkana to above Henrietta, before the lands were so much cleared and browsed by cattle, innumerable Post-Oak grapes grew, when the writer came to Texas thirtyone years ago, and a good many vines yet are to be found, especially on the Oklahoma side. It was my delight for many years to traverse these woods, on horseback, in grape ripening time, where little of the country was fenced, seeking and tasting the fruit of many thousands of vines; hoping, perchance, to find some good enough to move into. my vineyards to use as parents in hybridizing. Hundreds of miles of such travel in this Red River belt only whetted my desire to hunt in others, and I gratified it. I hunted wild grapes about Tyler, Troupe, Jefferson, Palestine, Crockett, and in the counties of Gonzales, Caldwell, McLennan, Bell, Williamson, Burnet, Travis, Blanco, Kerr, Gillespie, Llano, Lampasas, San Saba, Del Rio, Jeff Davis, Donley, Wilbarger, Clay, Montague, Cooke, Denton, Tarrant, Dallas and others, and much in other States. The varieties found in these hunts considered worthy to begin with as parents for table and market grapes did not exceed a score. With these and others found by friends and sent $\mathrm{me}$, in connection with the best introduced varieties, afford a very ample collection from which to choose parents of varieties for any purpose, soil or climate. However, all the good wild grapes have not yet been found, and other experimenters may, as we have, find much recreation, if not money, in hunting for them.

Of the writer's collected varieties, only the cream for special purposes and regions are used, and yet there is room for combinations enough to require the full life of dozens of persons to make, without exhausting the materials. 


\section{Variation and Division}

The tendency in nature of the progeny of any individual to vary and diverge wider and wider from the original parent form with each generation, as influenced by surrounding conditions, is the subtle agency seized by the originator to produce at will whatever product he designs in harmony with the character of the original individual, or individuals, and conditions under which he operates. Even the blind law of "the survival of the fittest," as stated by Herbert Spencer, or of the "unlike," as Professor L. H. Bailey puts it, fills the world with infinite, yet related forms. All forms inherit their chief characteristics from prior forms, and receive modifications from environments that are more or less inherited in the progeny. This is the universal law of inheritance, that the breeder must observe, in order to succeed. The process of individual, varietal, specific and generic variation, is well typified in every tree, by its body, forks, large branches, secondary branches, sprays and buds.

The known grape genus would be represented by a forked tree, having one division much larger than the other. The larger division would represent the true grapes (Euvitis), the smaller the warty-wood section (Lenticellosis). The body below the fork would represent the primordial form,- - once a species itself, but different from any living species, as proven in fossil forms,from which living species have sprung. The larger fork, or division, branched much more numerously than the smaller. Its great branches represent the series Precoces, Occidentales, Coriacece, Labrusca, Estivales, Cordifolice, and Cinerascentes, as shown in the classification of American species in Chapter I., and two or three Asiatic series. The secondary branches represent the species in the series; the sprays represent the sub-species and botanical varieties, and the buds represent the individual vines, which, when we cultivate, we call varieties. They are multiplied not by seeds, but by cuttings, layers, grafts. Seeds produce other distinct individuals, or vineyard varieties.

The smaller division of the tree, representing the warty wood grapes (Lenticellosis), would have only two secondary branches, the whole division, constituting the section Lenticellosis, and also the Series Chiri-Simpleses (simple-tendril species), generally designated by botanists as Muscadinia. In this section, there are but one series and two species known. Botanical varieties are few, although individual vines are very numerous.

The comparatively little variation in this section and its uniform, stubborn resistance to change by hybridizing, indicates that its individuals have been confined to very similar, or almost identical, conditions of climate and soil for a great length of time and have not intermingled to any appreciable degree by natural hybridization with other species, as have the species of true grapes (Euvitis).

\section{Study of Specific and Varietal Characteristics Necessary}

Order of Succession of Periods of Seed Germination of the Different Species of Grapes:

$\begin{array}{rll}\text { 1. V. Longii. } & 15 . & \text { V. rotundifolia. } \\ \text { 2. V. vulpina. } & 16 . & \text { V. labrusca. } \\ \text { 3. V. rupestris. } & 17 . & \text { V. Simpsoni. } \\ \text { 4. V. Treleasei. } & 18 . & \text { V. cinerea. } \\ \text { 5. V. cordifolia var. sempervirens. } & 19 . & \text { V. Berlandieri. } \\ \text { 6. V. Doaniana. } & 20 . & \text { V. coriacea. } \\ \text { 7. V. Champini. } & 21 . & \text { V. monticola. } \\ \text { 8. V. vinifera. } & 22 . & \text { V. Bourquiniana. } \\ 9 . \text { V. cordifolia. N. Texas. } & 23 . & \text { V. candicans. } \\ \text { 10. V. Californica. } & 24 . & \text { V. cestivalis. } \\ \text { 11. V. Blancoii. } & 25 . & \text { V. Lincecumii. } \\ \text { 12. V. Girdiana. } & 26 . & \text { V. bicolor. } \\ \text { 13. V. Arizonica. } & 27 . & \text { V. rubra. } \\ \text { 14. V. Munsoniana. } & & \end{array}$


Order of Succession of Blooming Periods of Different Species of Grapes, with Dates of Blooming at Denison, Texas, Ordinarily

1. V. vulpina

2. V. Longii

3. V. rupestris

4. V. Doaniana

5. V. Champini

6. V. candicans

7. V. labrusca

8. V. Treleasei

9. V. Arizonica

10. V. Girdiana

11. V. Californica

12. V. monticola

13. $V$. cordifolia

14. $V$. vinifera

15. V. astivalis

16. V. Lincecumii

17. V. bicolor

18. V. coriacea

19. V. Bourquiniana

20. V. Simpsoni

21. V. Berlandieri

22. V. Baileyana

23. $V$. cinerea

24. V. Blancoii

25. V. Caribaa

26. V. rotundifolia

27. V. Munsoniana

28. V. rubra
April 15th to 25th.

April 16th to 26th.

April 16th to 26th.

April 17th to 27th.

April 17th to 27th.

April 18th to 28th.

April 25th to May 8th.

April 25th to May 8th.

May 1st to May 10th.

May 1st to May 10th.

May 5th to May 15th.

May 5th to May 15th.

May 10 th to 20th.

May 1 st to 20 th, very variable.

May 12 th to 22 d.

May 14 th to 25 th.

May 16 th to 26 th.

May 16 th to $26 \mathrm{th}$.

May 20th to 30th.

May 25th to June 1st.

May 28th to June 5th.

May 28th to June 5th.

May 30 th to June 8 th.

Not ascertained.

Not ascertained.

June 5 th to June 15 th.

June Ist to June 25th.

June 8 th to June 15 th.

\section{Length of Life of Vines of Various Species and Varieties of Grapes,} Profitableness, and by what Diseases Seriously Affected

In 1886 and 1887 the writer planted about eight acres of grapes on light sandy soil from six inches to three feet deep, resting on red and yellow clay subsoil near Denison, Texas, and this vineyard is still standing, now twenty years old (1906), and part of the vines are yet bearing well and are profitable. Some of the vines perished years ago and others are in a feeble condition, unprofitable, and some dying every year. Careful critical record of all the vines in this vineyard has been kept from the time of the planting, notes on the same always have been taken in the presence of the vines. No Experiment Station record is more carefully kept. From this record mostly the facts in the following pages have been tabulated to guide in propagation and my further experimental work so as to avoid mistakes in the future as far as passible.

The land occupied by the vineyard has had but one application of fertilizer during the nineteen years, which was a heavy coating of cottonseed some twelve years ago, and is now suffering for nourishment (1905).

The conditions and treatment of all the vines in this vineyard, mentioned in the tables, have been identical so far as the uniformity of the soil permitted and it is about as uniform as any equal area of sandy land in Texas.

Besides, I have planted other vineyards on different soils, including black limy soil, that agree in results shown in the tables.

As excess of lime in the soil greatly affects injuriously many varieties, causing the leaves to turn yellow (chlorose) and the vines to dwindle and die within a few years, it is important to -designate those varieties injuriously affected by the excess of lime. 
All species and varieties grow well in sandy soils where carbonate of lime does not exceed twenty-five per cent of the soil. Some varieties cannot well endure more than twenty-five or thirty per cent of carbonate of lime, while others will flourish in fifty and even sixty per cent.

The vines of some species are nearly always found natively in limy soils, and varieties of such species generally succeed well in such soils.

The species found naturally growing in limy soils are the following: Berlandieri, Blancoii, Bourquiniana, Candicans,* Champini,* Cinerea,* Cordifolia,* Coriacea, Doaniana, Monticola,* Rubra, Rupestris,* Vinifera.* All other species named in Table I. are natively found growing in sandy soils. Those just named above followed by a * can flourish in soils having 40 to 60 per cent of carponate of lime. Cultivated varieties of these also succeed well in limy soils if not subject to other maladies.

All very sticky soils, especially the "Black Waxy" are rich in lime. All soils immediately underlaid with limestone and especially with white chalky rock, as found in the black lands of the cretaceous soils of Texas, are strong in lime. In Bell, Lampasas and adjacent counties the lime in places is in such large per cent that very few plants or trees will grow in such places. The Red Cedar trees; Berlandieri, Mustang (Candicans), Champini and Monticola grapes I have found growing in such places without any appearance of chlorosis, while peach trees, Concord and Post-Oak grapevines planted in such soils, quickly yellow and die. Hence, it is necessary, to success in long life in vines, to plant only those adapted to the soils.

I have not conducted any systematic test upon soils having a greater excess of lime than 40 per cent, hence have no tables of experience on such soils to present, but have formed my conclusions on adaptability to such soils by extended observation over the State and from reports of careful experimenters in limy soils in Texas. The Berlandieri, Champini, Doaniana and Rupestris, natives of Texas, with Bourquiniana and Vinifera, foreign, are giving best results in hybridization for very limy soils.

Varieties much subject to rot and mildew should not be planted in regions, such as the forest area of East Texas, unless thoroly treated with spray of sulphate or carbonate of copper solution, but they may do well in Central and Western Texas, if set in proper soil and site, without spraying.

No grape will succeed in boggy or seepy soil, and a high location surrounded by lower grounds is preferable to the reverse location, on account of late frosts and fungus diseases prevailing much more in low than high localities.

A careful study of the following tables will pretty well guide one safely in choosing varieties for profit and long life in various soils and locations.

Those in Table I. followed by the letter 1, are generally found natively growing in limy soils, all others in sandy soils. Those varieties in Table II. followed by the letter 1 , have been found to succeed well in "Black Waxy" soils with clay subsoils; those followed by the letters 11 succeed in "Black Waxy" and "Adobe" soils underlaid with white rock as near as two feet of the surface.

The first table shows clearly the species having long lived vines, healthy vines, and vigorous vines; three prime essentials in the constitution of any valuable variety. Several of them besides Lincecumii are yielding excellent results, but it will require several generations with some to bring out valuable vineyard varieties.

The second table gives the names of each variety, its specific blood, the number of vines of each variety planted in 1886-7, and the number and per cent of vines now alive (1905), degree of profitableness, diseases affecting, and the present condition.

It will be noticed that a number of the varieties contain blood of the native Post-Oak Grape (Vitis Lincecumii) which I consider the most valuable of all American species in many respects for sandy soils, hence I have used it extensively in hybridizing, although I have made hybrid combinations with nearly every species named in the first table in order to discover the best in existence. 


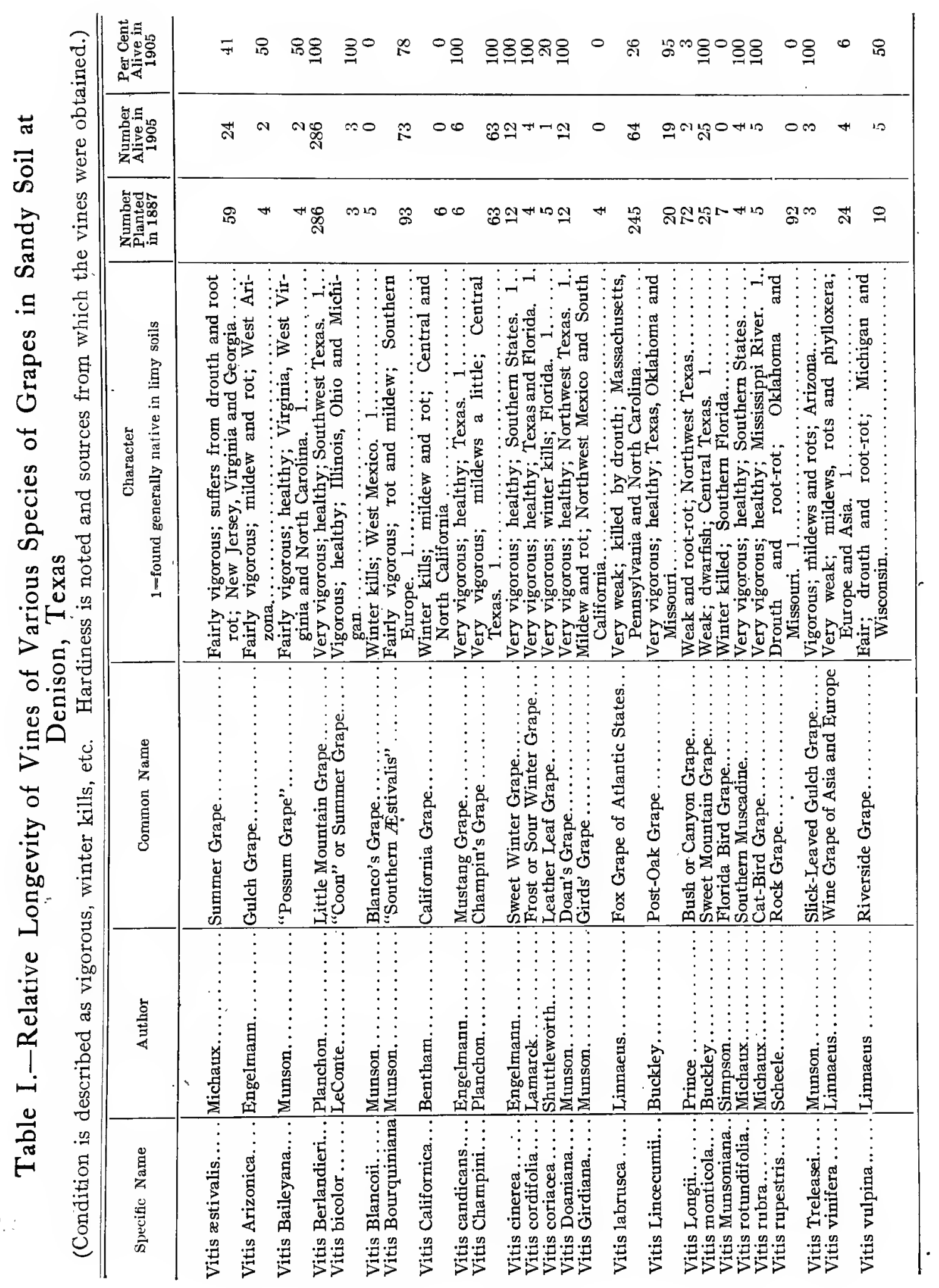




\title{
Table II.-Comparative Longevity and Profitableness of Cultivated Grapes at Denison, Texas
}

(Profitableness, color, use and conditions of vines in 1905 are each indicated by terms following names.)

Names of Varieties and Their Specific Blood.

(For explanation of 1 and 11, see page 118.)

America (black) Lincecumii $\mathbf{x}$ Rupestris. Very profitable; market, wine; no diseases,

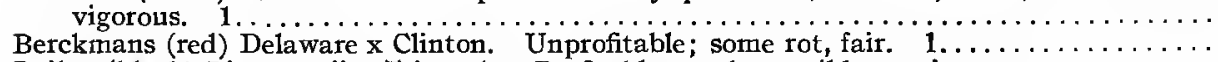

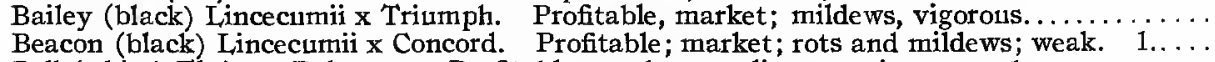
Bell (white) Elvira x Delaware. Profitable; market, no diseases, vigorous. $1 . . . \ldots \ldots \ldots$. Brilliant (red) Lindley x Delaware. Very profitable; market, mildews, feeble. $1 . \ldots \ldots \ldots$

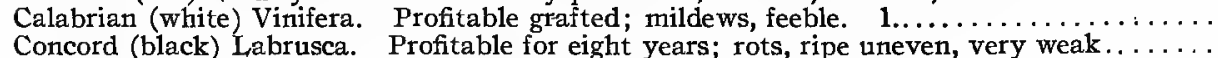

Champion (black) Labrusca. Little profit; weak, very poor quality . . . . . . . . . . . . Cottage (black) Labrusca. Unprofitable, drops, very weak

Delaware (red) Bourquiniana $x$ Labrusca $x$ Vinifera (?). Profitable, mildews, weak. 1....

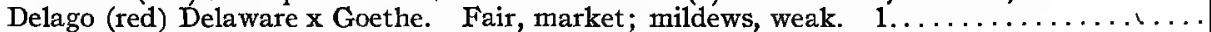
Devereux or Black July (black) Bourquiniana. Unprofitable, root-rot. $1 \ldots \ldots \ldots \ldots \ldots \ldots \ldots$
Diana (red) Labrusca $\mathbf{x}$ Vinifera. Unprofitable; mildews, feeble $\ldots \ldots \ldots \ldots \ldots \ldots \ldots \ldots$

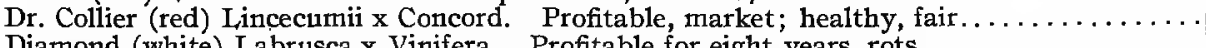
Diamond (white) Labrusca $x$ Vinifera. Profitable for eight years, rots. . . . . . . . . . . .

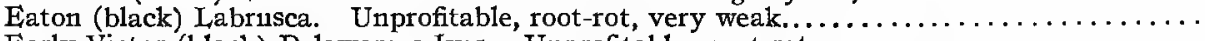
Early Victor (black) Delaware $x$ Ives. Unprofitable; root-rot. . . . . . . . . . . . . . . Elvira (white) Labrusca $x$ Vulpina. Unprofitable; cracks, fair. . . . . . . . . . . . . . Empire State (white) Labrusca $x$ Vinifera. Unprofitable, drops, very weak . . . . . . . . . . Elvicand (red) Elvira x Mustang. For black land; healthy, vigorous. $11 \ldots \ldots \ldots \ldots \ldots \ldots$

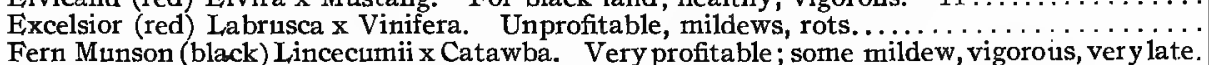
Fern Munson (black) Lincecumii x Catawba. Very profitable; some mildew, vigorous, very late.
Gold Coin (yellow) Norton Virginia x Martha. Very profitable; healthy, weak........... Golden Gem (white) Delaware x Clinton. Unprofitable, rot. $1 \ldots \ldots \ldots \ldots \ldots \ldots \ldots \ldots \ldots \ldots$ Golden Chasselas (yellow) Vinifera. Unprofitable, rot, mildew. Succeeds grafted in South and West Texas. 11

Griesa de.Piemonte (black) Vinifera. Profitable grafted; mildews; weak. $1 \ldots \ldots \ldots \ldots \ldots \ldots$ Herbemont (red-purple) Bourquiniana. Profitable wine; rots; vigorous. $11 \ldots \ldots \ldots \ldots \ldots \ldots$

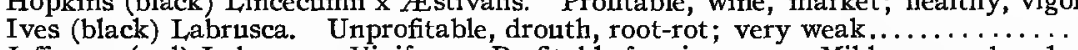
Jefferson (red) Labrusca x Vinifera. Profitable for six years. Mildews, weak. $1 \ldots \ldots \ldots \ldots$ Jaeger No. 43 (black) Lincecumii of S. W. Missouri. Profitable; wine, healthy, very vigorous.

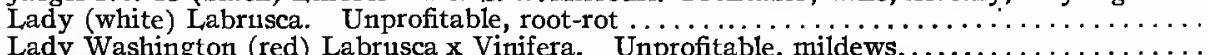

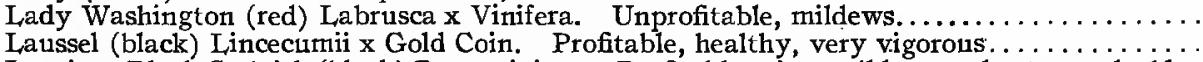
Lenoir or Black Spanish (black) Bourquiniana. Profitable, wine; mildew sand rots, weak. 11 . Lindley (red) Labrusca x Vinifera. Profitable; market, mildews, weak. .

Marguerite(purplish-red)Lincecumiix Bourquiniana. Profitable; wine, market; healthy, vigorous Martha (white) Labrusca, root-rot, unprofitable.

Missouri Riesling (white) Labrusca x Vulpina. Unprofitable; cracks, weak. . . . . . . . . .

Moore Early (black) Labrusca. Unprofitable, shy; root-rot; very weak. . . . . . . . . . . . . . . Montefiore (black) Labrusca x Vulpina. Unprofitable.

Moyer (red) Delaware $x$ Wyoming (?). Unprofitable; drops, rots, weak. $1 \ldots \ldots \ldots \ldots \ldots \ldots$ Muench (black) Lincecumii x Herbemont. Very profitable; some mildew; very vigorous... Muscat (white) Vinifera. Unprofitable; mildews, rots. $11 \ldots \ldots \ldots \ldots \ldots \ldots \ldots \ldots \ldots \ldots$

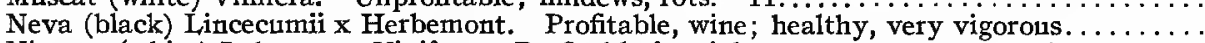
Niagara (white) Labrusca $x$ Vinifera. Profitable for eight years; rots; very weak. . . . . . . .

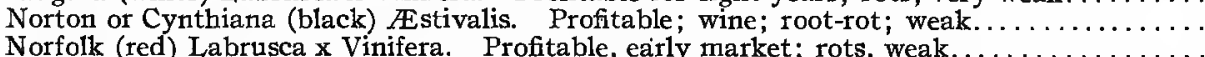

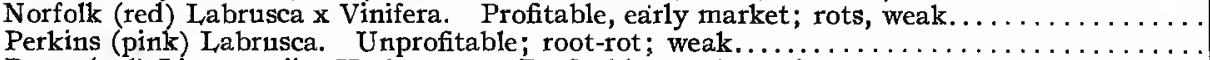

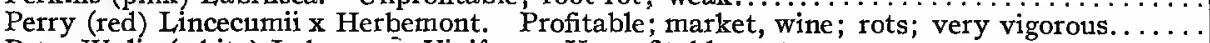

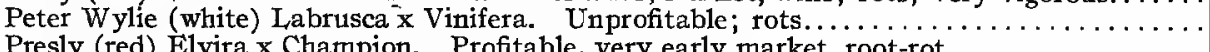
Presly (red) Elvira $x$ Champion. Profitable, very early market, root-rot. $\ldots \ldots \ldots \ldots \ldots \ldots \ldots$

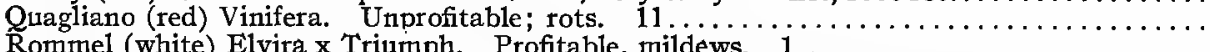

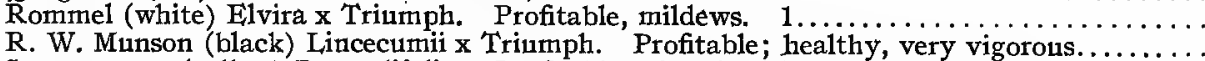

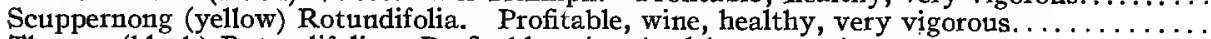
Thomas (black) Rotundifolia, Profitable, wine, healthy, very vigorous $\ldots \ldots \ldots \ldots \ldots \ldots \ldots$ Triumph (white) Concord $x$ Muscat. Profitable, market, cracks, very weak. $i \ldots \ldots \ldots \ldots$ Walter (red) Delaware Seedling. Profitable, market, mildews, weak. $1 \ldots \ldots \ldots \ldots \ldots \ldots$

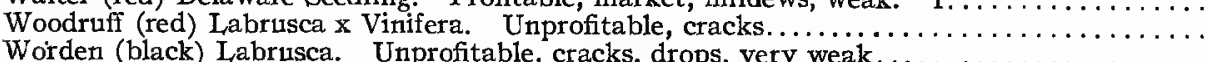

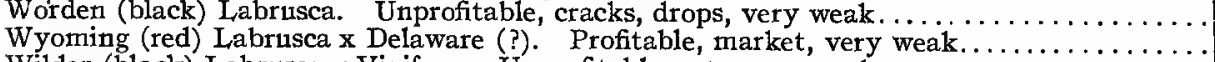
Wilder (black) Labrusca $x$ Vinifera. Unprofitable, rots, very weak $\ldots \ldots \ldots \ldots \ldots \ldots \ldots \ldots \ldots$

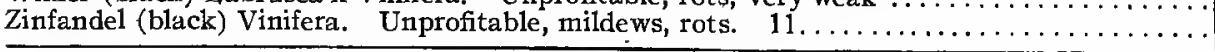

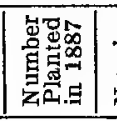
学然总

\author{
47 \\ 20 \\ 20 \\ 33
86 \\ 78 \\ 12 \\ 34 \\ 10 \\ 5
27 \\ 6
}

86
4

145

4

6
22

10

15
33

27

6

3
62
1

40
6

2

10

15
40
18

18

23

10

53

2
13

6
2
1 


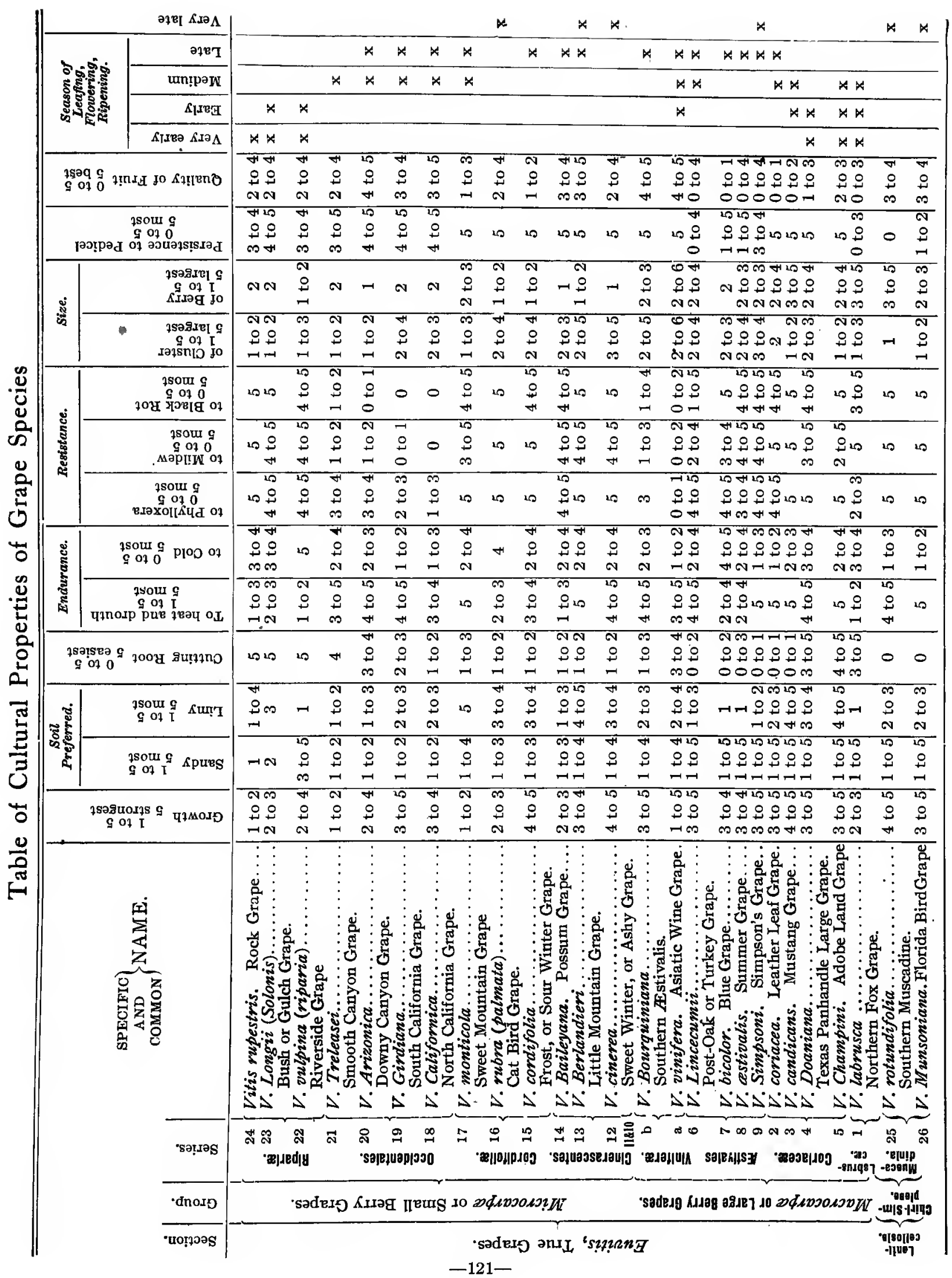




\section{Discussion of the Table}

It will be noticed that species having wide distribution vary greatly among their individual vines from different regions in nearly all their characters, hence vines for experimental purposes taken at random can promise little in development toward improvement of varieties for cultivation. Species native in high, arid regions, as are Vinifera and all the species west of the Rocky Mountains where the air is too dry to permit the growth of mildews and rots, quickly are attacked and greatly weakened or destroyed when transplanted into low, moist climates. Likewise, vines of species growing in regions where Phylloxera does not exist, when transplanted into regions infested by it, soon perish by its attacks, and when the insect is transported into the soil where such vines grow, no matter how well the vines have always grown, will pale and die in three or four years after the insect begins to feed and multiply upon the roots.

The Phylloxera-resistant vines of the world are all native between the Rocky Mountains and the Atlantic Coast in North America, where the Phylloxera is common wherever wild vines grow in all that territory, and by long struggling against the insidious enemy, by "the survival of the fittest" law, now grow luxuriantly, while the louse obtains a precarious living by tugging at the hard wiry roots, which its infinite attacks have developed. Then it is perfectly clear, that to have vines which will resist Phylloxera, mildew and rot, we must select as parents those which are least attacked by these.

\section{Climatic Conditions at the Munson Experiment Grounds}

The section in which the writer lives and has his experiment grounds, latitude $34^{\circ} 30^{\prime}$, is abundantly supplied with Phylloxera in the black limestone soils, mildew, Black-, Brown-, Bird's eye-, Bitter- and other rots, with leaf-folders, and chafers, and no better place could be found in which to test varieties against these maladies. Besides, the climate is an exceedingly variable one, subject to sudden and severe changes, the summer temperature reaching $110^{\circ}$ in the shade rarely, and extreme drouths occur some years, which kill many forest trees in the woods, where a little crowded; sometimes the temperature falls forty, fifty, sixty, and even seventy or more degrees in twenty-four to forty-eight hours, occasionally going as low as 8 to $15^{\circ}$ below zero (F.); where the average annual rainfall is over forty inches, yet some seasons less than 20 , and others near 100 inches. In spite of all these maladies and extremes we have succeeded in finding and producing varieties which resist them all, and annually bear heavy crops of fine fruit.

By critical study of the foregoing table of specific cultural facts, even for one who has not seen the test work, from which it was compiled-a history of which space will not permit herecan quickly select with certainty the species promising best results, either as direct producers, or for graft-stocks for various regions and soils.

\section{Practical Use of the Table}

Selecting thus by the aid of the table, we would get excellent graft-stocks for northern regions of countries like California, France, and other temperate climates where Vinifera grapes " endure, for sandy soils, the following, (1) V. vulpina, (2) V. rupestris, (3) V. Longii, named in order of preference; and for moderately limy soils $V$. rupestris and V. Doaniana. For very limy soil $V$. Champini, where ground does not freeze over 18 inches deep. All of these just named do well in sandy soils in the regions designated.

\section{Comparative Quality of Grapés}

It is not flavor alone that I attempt to treat here but more particularly degree of sugar and tartaric acid. The sugar content of a fruit pretty well determines its food content, and also its agreeableness in eating to many, altho the flavor also has much to do in making or destroying agreeableness. Only taste can determine flavor and tastes differ as to flavor. The lover of the 
Vinifera grapes,- the French for example,--pronounces the flavor of the Concord grape very disagreeable, "foxy" and "buggy," with a very unpleasant earthy acid flavor about the seeds; but an American, especially a New Englander or New Yorker who has been accustomed to eating Concord grapes, regards the foxiness as fine flavor! and the more the better! He breaks the skin and swallows the tough oyster-like acid pulp, seeds and all, whole, and thus avoids the earthy taste about the seeds and lets his stomach wrestle with the oysters and risks appendicitis and declares he is eating the best of all American grapes, when in fact it is about the poorest, as you will learn when noting the table of sweetness and acidity what the very sensitive instruments say, the true test of sweet and acid fruits. The tongue is incapable of determining the exact sugar and acid, but merely determines the combined effect. A grape may be low in sugar, and if also low in acid the taste will say it is sweet, and if high in sugar and yet relatively higher than the other in acid, will pronounce the really sweeter grape more acid. This will clearly appear as the table made from the instrument readings is studied. The varieties tested by me and here tabulated were grown in my vineyards under identically the same conditions as nearly as possible. The season of 1906 was unusually rainy, hence all the readings are 5 to 20 points lower for sugar than in the season of 1907 , which was much warmer and drier, and the acid from 1 to 4 points higher.

A fruit without acid is flat and insipid to the taste, if it has proportionately too much acid, soon "sets the teeth on edge," or is not edible, but with just the right proportion of sweet and acid is very appetizing and agreeable, providing the flavor, also, is agreeable. For making the proper or most satisfactory sprightliness to fruit, or wine, it has been found that the fresh juice as expressed from the pulp, as in making wine, should contain about $80^{\circ}$ of sugar on Oeschle's scale and about 6 per mill acid by Twitchell's Acidometer. Juice containing those quantities, when made into wine, without adding sugar, will develop about 8 per cent of alcohol, and will keep well in bottles in the cellar, and is suitable for light table wine and for medicinal purposes. If the juice does not contain $80^{\circ}$ of sugar, and as much as 6 per mill acid it will not keep, unless fortified with sugar in fermentation, or with brandy. Concord is a grape so low in sugar that its wine will not keep unless strongly fortified.

The varieties tested are given nearly in order of sweetness, the sweetest first, the least sweet last.

The leading old varieties and a good many of my own production are represented, and this is sufficient to indicate the specific bloods that produce varieties high or low in sugar and acid. But some combinations are sweeter than either parent. Limy soils produce sweeter fruit, as a rule, than very sandy soil, and dry seasons than wet ones. 
Sugar and Acid in Grapes, at Denison, Texas, in Sandy Soil, in 1906 (an excessively wet and cool season), and in 1907 (a much drier and warmer season)

Oeschle's Scale was used to Test for Sugar, and Twitchell's Acidometer for Acid. To Get Balling's Scale, Divide Oeschle's Readings by 3.9

\begin{tabular}{|c|c|c|c|c|c|c|c|c|c|c|}
\hline \multirow{3}{*}{$\begin{array}{c}\text { NAME } \\
\text { OF } \\
\text { VARIETY }\end{array}$} & \multirow{3}{*}{ 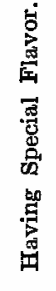 } & \multirow{3}{*}{ 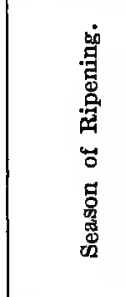 } & \multirow{3}{*}{$\begin{array}{l}\dot{\vec{E}} \\
\text { 由 } \\
\text { 亗 } \\
\dot{0} \\
\dot{0}\end{array}$} & \multirow{3}{*}{ 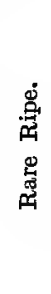 } & \multirow{3}{*}{$\begin{array}{l}\text { 密 } \\
\text { 章 }\end{array}$} & \multirow{3}{*}{$\begin{array}{l}\text { COLOR } \\
\text { OF } \\
\text { JUICE. }\end{array}$} & \multicolumn{4}{|c|}{ Richness of Juice. } \\
\hline & & & & & & & \multicolumn{2}{|c|}{1906.} & \multicolumn{2}{|c|}{1907.} \\
\hline & & & & & & & $\begin{array}{l}\text { 窤 } \\
\overrightarrow{3} \\
\text { m }\end{array}$ & 总 & $\begin{array}{l}\text { 要 } \\
\text { 昜 }\end{array}$ & 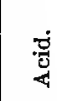 \\
\hline 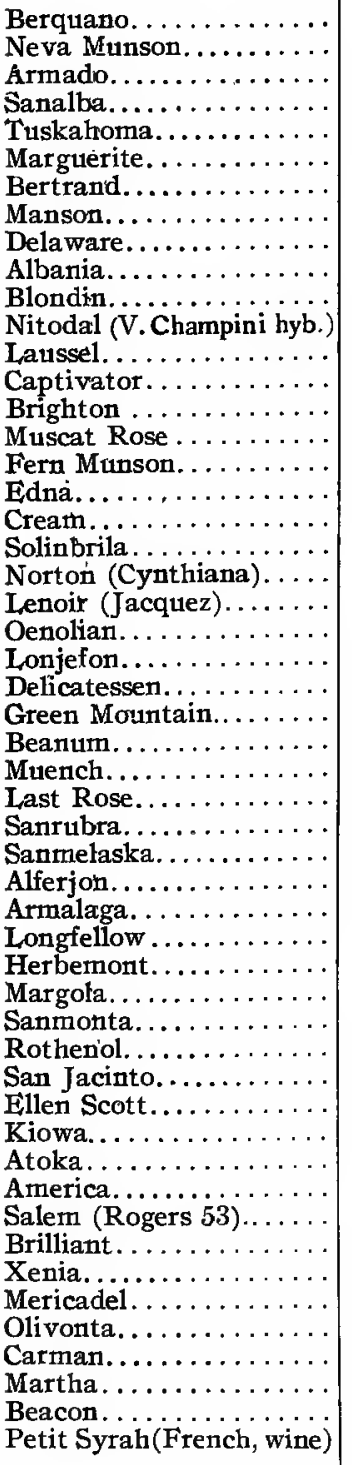 & $\begin{array}{l}\mathbf{x} \\
\mathbf{x} \\
\mathbf{x} \\
\mathbf{x} \\
\mathbf{x} \\
\mathbf{x}\end{array}$ & $\begin{array}{l}\text { v. late } \\
\text { v. late } \\
\text { v. late } \\
\text { v. late } \\
\text { early } \\
\text { v. late } \\
\text { v. late } \\
\text { late } \\
\text { early } \\
\text { v. late } \\
\text { late } \\
\text { early } \\
\text { v. late } \\
\text { early } \\
\text { early } \\
\text { early } \\
\text { v. late } \\
\text { v. late } \\
\text { v. late } \\
\text { late } \\
\text { late } \\
\text { late } \\
\text { v. late } \\
\text { v. late } \\
\text { late } \\
\text { v. early } \\
\text { medium } \\
\text { v. late } \\
\text { latest } \\
\text { v. late } \\
\text { v. late } \\
\text { v. late } \\
\text { v. late } \\
\text { late } \\
\text { v. late } \\
\text { v. late } \\
\text { v. late } \\
\text { v. late } \\
\text { v. late } \\
\text { v. late } \\
\text { late } \\
\text { late } \\
\text { medium } \\
\text { early } \\
\text { early } \\
\text { late } \\
\text { medium } \\
\text { medium } \\
\text { late } \\
\text { early } \\
\text { early } \\
\text { medium }\end{array}$ & $\begin{array}{l}\text { black } \\
\text { dk. purple } \\
\text { black } \\
\text { white } \\
\text { cl. red } \\
\text { red } \\
\text { black } \\
\text { yellow } \\
\text { cl. red } \\
\text { white } \\
\text { white } \\
\text { cl. red } \\
\text { brownish } \\
\text { cl. red } \\
\text { red } \\
\text { violet } \\
\text { dark red } \\
\text { white } \\
\text { white } \\
\text { black } \\
\text { black } \\
\text { black } \\
\text { black } \\
\text { black } \\
\text { black } \\
\text { white } \\
\text { black } \\
\text { dark purple } \\
\text { light rose } \\
\text { red } \\
\text { black } \\
\text { white } \\
\text { white } \\
\text { black } \\
\text { brown } \\
\text { black } \\
\text { black } \\
\text { cl. red } \\
\text { black } \\
\text { cl. violet } \\
\text { black } \\
\text { dark red } \\
\text { black } \\
\text { red } \\
\text { red } \\
\text { white } \\
\text { cl. red } \\
\text { black } \\
\text { black } \\
\text { yellow } \\
\text { black } \\
\text { black } \\
\end{array}$ & $\begin{array}{l}\mathbf{x} \\
\mathbf{x}\end{array}$ & $\begin{array}{l}\mathbf{x} \\
\mathbf{x} \\
\mathbf{x} \\
\mathbf{x} \\
\mathbf{x} \\
\mathbf{x} \\
\mathbf{x} \\
\mathbf{x} \\
\mathbf{x} \\
\mathbf{x} \\
\mathbf{x} \\
\mathbf{x} \\
\mathbf{x} \\
\mathbf{x} \\
\mathbf{x} \\
\mathbf{x} \\
\mathbf{x} \\
\mathbf{x} \\
\mathbf{x} \\
\mathbf{x} \\
\mathbf{x} \\
\mathbf{x} \\
\mathbf{x} \\
\mathbf{x} \\
\mathbf{x} \\
\mathbf{x} \\
\mathbf{x} \\
\mathbf{x} \\
\mathbf{x} \\
\mathbf{x} \\
\mathbf{x} \\
\mathbf{x} \\
\mathbf{x} \\
\mathbf{x} \\
\mathbf{x} \\
\mathbf{x} \\
\mathbf{x} \\
\mathbf{x} \\
\mathbf{x} \\
\mathbf{x} \\
\mathbf{x} \\
\mathbf{x} \\
\mathbf{x} \\
\mathbf{x} \\
\mathbf{x}\end{array}$ & $\begin{array}{l}\text { pl. red } \\
\text { white } \\
\text { 1t. claret } \\
\text { 1t. claret } \\
\text { it. claret } \\
\text { pl. red } \\
\text { brownish } \\
\text { white } \\
\text { wbite } \\
\text { white } \\
\text { white } \\
\text { pink } \\
\text { white } \\
\text { wbite } \\
\text { brownish } \\
\text { white } \\
\text { cl. red } \\
\text { white } \\
\text { wbite } \\
\text { dark claret } \\
\text { claret } \\
\text { claret } \\
\text { claret } \\
\text { white } \\
\text { claret } \\
\text { white } \\
\text { pink } \\
\text { brownish } \\
\text { white } \\
\text { white } \\
\text { carmine } \\
\text { white } \\
\text { white } \\
\text { pl. red } \\
\text { white } \\
\text { red } \\
\text { red } \\
\text { white } \\
\text { white } \\
\text { white } \\
\text { red } \\
\text { cl. red } \\
\text { violet } \\
\text { white } \\
\text { white } \\
\text { white } \\
\text { pink } \\
\text { brownish } \\
\text { brownish } \\
\text { white } \\
\text { claret } \\
\text { claret }\end{array}$ & $\begin{array}{l}93 \\
92 \\
92 \\
\\
87 \\
\\
81 \\
\\
76 \\
\\
76 \\
76 \\
76 \\
75 \\
75 \\
66 \\
74 \\
73 \\
\\
76 \\
73 \\
73 \\
73 \\
72 \\
72 \\
72 \\
71 \\
65\end{array}$ & $\begin{array}{c}8.5 \\
7.5 \\
10.5 \\
6 . \\
6 . \\
10.9 \\
7.2 \\
\\
6.5 \\
10 . \\
8.5 \\
7.5 \\
6.3 \\
8.5 \\
8 \\
9 . \\
10.5 \\
9.5 \\
10.5 \\
8 . \\
8.5 \\
7.5 \\
6.5 \\
10 . \\
6 .\end{array}$ & $\begin{array}{r}102 \\
93 \\
102 \\
92 \\
90 \\
88 \\
88 \\
87 \\
85 \\
84 \\
87 \\
92 \\
86 \\
84 \\
91 \\
90 \\
88 \\
86 \\
84 \\
88 \\
89 \\
85 \\
83 \\
85 \\
83 \\
82 \\
86 \\
70 \\
83 \\
81 \\
82 \\
81 \\
80 \\
79 \\
78 \\
77 \\
75 \\
76 \\
75 \\
73 \\
71 \\
76 \\
71 \\
70 \\
71\end{array}$ & $\begin{array}{c}10 . \\
7 . \\
10.5 \\
7.5 \\
6.5 \\
9 . \\
9 . \\
4 . \\
6 . \\
4.5 \\
6 . \\
9.5 . \\
6.5 \\
5.5 \\
7.2 \\
7 . \\
8 . \\
8.5 \\
9 . \\
8 . \\
9 . \\
7.5 \\
8 . \\
7 . \\
5 . \\
9 . \\
5 . \\
7 . \\
7 . \\
6.2 \\
6 . \\
8 . \\
8 . \\
7 . \\
7 . \\
8.5 \\
7 . \\
5.8 \\
9.5 \\
5.5 \\
10.5 \\
4.5 \\
4.5 \\
5.5 \\
5.5\end{array}$ \\
\hline
\end{tabular}




\begin{tabular}{|c|c|c|c|c|c|c|c|c|c|c|}
\hline \multirow{3}{*}{$\begin{array}{c}\text { NAME } \\
\text { OF } \\
\text { VARIETY }\end{array}$} & \multirow{3}{*}{ 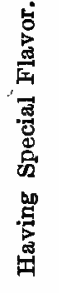 } & \multirow{3}{*}{ 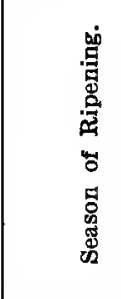 } & \multirow{3}{*}{ 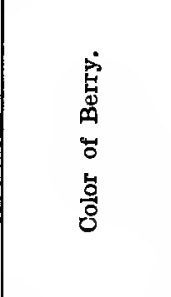 } & \multirow{3}{*}{ 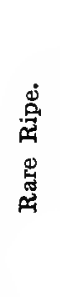 } & \multirow{3}{*}{ 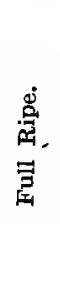 } & \multirow{3}{*}{$\begin{array}{c}\text { COLOR } \\
\text { OF } \\
\text { JUICE. }\end{array}$} & \multicolumn{4}{|c|}{ Richness of Juice. } \\
\hline & & & & & & & \multicolumn{2}{|c|}{1906.} & \multicolumn{2}{|c|}{1907.} \\
\hline & & & & & & & 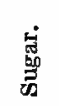 & :ृّ & $\begin{array}{l}\text { 勇 } \\
\text { 岂 }\end{array}$ & :ृृ \\
\hline 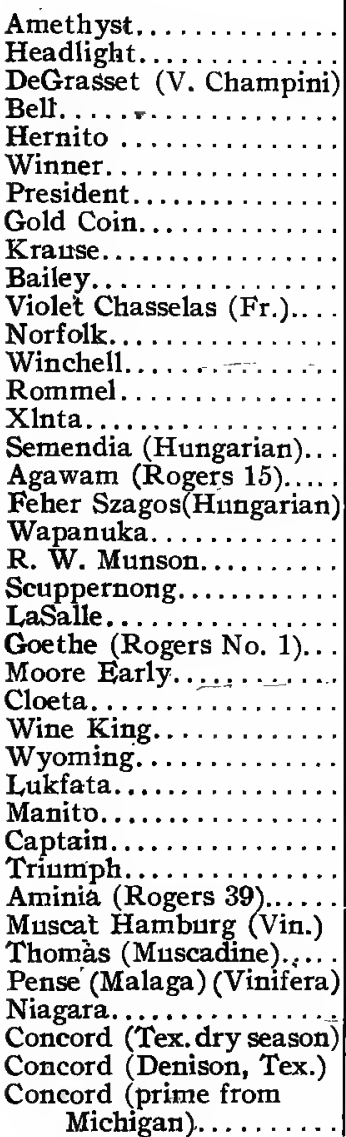 & $\begin{array}{l}\mathbf{x} \\
\mathbf{x} \\
\mathbf{x} \\
\mathbf{x} \\
\mathbf{x} \\
\mathbf{x} \\
\\
\mathbf{x} \\
\mathbf{x} \\
\mathbf{x} \\
\mathbf{x} \\
\mathbf{x} \\
\mathbf{x} \\
\mathbf{x} \\
\mathbf{x} \\
\mathbf{x} \\
\mathbf{x} \\
\mathbf{x} \\
\mathbf{x} \\
\mathbf{x} \\
\mathbf{x} \\
\mathbf{x}\end{array}$ & $\begin{array}{l}\text { early } \\
\text { v. early } \\
\text { early } \\
\text { early } \\
\text { medium } \\
\text { medium } \\
\text { early } \\
\text { late } \\
\text { medium } \\
\text { late } \\
\text { early } \\
\text { early } \\
\text { early } \\
\text { medium } \\
\text { medium } \\
\text { medium } \\
\text { medium } \\
\text { medium } \\
\text { early } \\
\text { early } \\
\text { v. late } \\
\text { v. late } \\
\text { v. late } \\
\text { v. early } \\
\text { medium } \\
\text { late } \\
\text { early } \\
\text { medium } \\
\text { early } \\
\text { early } \\
\text { late } \\
\text { v. early } \\
\text { medium } \\
\text { v. lt. } \\
\text { late } \\
\text { medium } \\
\text { medium } \\
\text { medium } \\
\text { medium }\end{array}$ & $\begin{array}{l}\text { red } \\
\text { red } \\
\text { black } \\
\text { white } \\
\text { black } \\
\text { black } \\
\text { black } \\
\text { yellow } \\
\text { white } \\
\text { black } \\
\text { violet } \\
\text { red } \\
\text { white } \\
\text { white } \\
\text { black } \\
\text { yellow } \\
\text { red } \\
\text { white } \\
\text { white } \\
\text { black } \\
\text { bronzy } \\
\text { black } \\
\text { pink } \\
\text { black } \\
\text { black } \\
\text { black } \\
\text { cl. red } \\
\text { black } \\
\text { black } \\
\text { black } \\
\text { white } \\
\text { dark purple } \\
\text { violet } \\
\text { black } \\
\text { white } \\
\text { white } \\
\text { black } \\
\text { black } \\
\text { black } \\
\end{array}$ & $\begin{array}{l}\mathrm{x} \\
\mathrm{x}\end{array}$ & $\begin{array}{l}\mathbf{x} \\
\mathbf{x} \\
\mathbf{x} \\
\mathbf{x} \\
\mathbf{x} \\
\mathbf{x} \\
\mathbf{x} \\
\mathbf{x} \\
\mathbf{x} \\
\mathbf{x} \\
\mathbf{x} \\
\mathbf{x} \\
\mathbf{x} \\
\mathbf{x} \\
\mathbf{x} \\
\mathbf{x} \\
\mathbf{x} \\
\mathbf{x} \\
\mathbf{x} \\
\mathbf{x} \\
\mathbf{x} \\
\mathbf{x} \\
\mathbf{x} \\
\end{array}$ & $\begin{array}{l}\text { white } \\
\text { white } \\
\text { violet } \\
\text { white } \\
\text { claret } \\
\text { claret } \\
\text { claret } \\
\text { white } \\
\text { white } \\
\text { claret } \\
\text { brownish } \\
\text { pink } \\
\text { white } \\
\text { white } \\
\text { claret } \\
\text { white } \\
\text { brownish } \\
\text { white } \\
\text { white } \\
\text { claret } \\
\text { white } \\
\text { white } \\
\text { white } \\
\text { claret } \\
\text { claret } \\
\text { claret } \\
\text { white } \\
\text { claret } \\
\text { pl. ted } \\
\text { pl. red } \\
\text { white } \\
\text { lt. red } \\
\text { white } \\
\text { pink } \\
\text { white } \\
\text { white } \\
\text { claret } \\
\text { claret } \\
\text { claret } \\
\text { claret }\end{array}$ & $\begin{array}{l}66 \\
65 \\
\\
65 \\
66 \\
62 \\
64 \\
62 \\
61 \\
61 \\
61 \\
60 \\
60 \\
60 \\
59 \\
60 \\
58 \\
58 \\
58 \\
58\end{array}$ & $\begin{array}{l}4.5 \\
4.5 \\
\\
4.3 \\
7.5 \\
8.5 \\
7.5 \\
4.3 \\
8 . \\
7.5 \\
6 . \\
8 . \\
7 . \\
6 . \\
7 . \\
9 . \\
8.5 \\
6.6 \\
4.5 \\
8 .\end{array}$ & $\begin{array}{l}65 \\
65 \\
57 \\
56 \\
65 \\
64 \\
64 \\
62 \\
62 \\
61 \\
60 \\
59 \\
60 \\
63 \\
58 \\
61 \\
61 \\
61 \\
59\end{array}$ & $\begin{array}{l}5 . \\
5.5 \\
6 . \\
6 . \\
7 . \\
6 . \\
5 . \\
6 . \\
6.5 \\
6 . \\
4 . \\
6 . \\
6.5 \\
5 . \\
6 . \\
4 . \\
1 . \\
6 . \\
9 .\end{array}$ \\
\hline
\end{tabular}

For specific blood of varieties, see List of Described Varieties, Chapter III.

\section{Discussion of the Table}

Persons, who have given quality in grapes little study, will find many a surprise in the difference in sweetness among varieties; will be surprised to find some of their favorites well toward the bottom of the list. Those who like the Labrusca "foxy" flavor, will find their favorites near the bottom in Concord, Niagara, Moore Early, Martha, Hernito; those fond of the Post-Oak Grape flavors, will like such as Captain, Cloeta, Xlnta, Winner, Carman, Mericadel, America, Delicatessen, with moderate sugar, spiciness, and rich variety of flavors, and wine-makers seeking table clarets with much bouquet, can make them abundantly from these; those delighted with the rich fruity flavor of the Southern Muscadines, will discover it, exquisitely refined, in Scupper- 
nong, LaSalle, San Jacinto, Sanmelaska, Sanrubra and Sanalba; candy-lovers will be "tickled to death" with Gold Coin, Headlight, Bell, Amethyst, Brilliant, Salem, Alferjon, Green Mountain, Brighton, Nitodal, Delaware, Manson, Tuskahoma, Neva Munson; the devotees of the large, delicate-skinned, fine complexioned, meaty, sprightly, pure sweet and acid, small soft-seeded kinds will rush to Pense (Malaga), Triumph, Semendia, Violet Chasselas, Ellen Scott, Armalaga, Edna; the connoisseurs that know the most perfect combinations of skin, flesh, seeds, sweets, acids and bumble-bee-nectar flavors, will rest on such as Goethe, Wapanuka, Rommel, Xenia, Muscat Rose, Captivator, and those wanting to make the highest grade of delicate wines, in shades of red, amber and white, will be found selecting Muench, Winner, Petit Syrah, Olivonta, Herbemont, Delicatessen, Oenolian, Lenoir, Solinbrila, Cream, Albania, Neva, and Berquano.

Such is my estimation, but others will differ from me.

It is true that the degrees of sweet and acid vary with season, soil, condition and age of vines, and with change of weather; but varieties generally maintain their relative positions throughout the changes, with some unimportant exceptions.

\section{Graft Stocks for Very Hot, Dry Regions,}

in any soil, such as Southwest Texas, and South California:

(1) V. Champini, (2) V. Doaniana, (3) V. Berlandieri, (4) V. candicans, (5) V. monticola.

The last three, being difficult to grow from cuttings, are better utilized in hybrid varieties with the first two and with $V$. rupestris. $V$. monticola, V. Berlandieri, V.candicans, and V.Champini, while doing finely in sandy soil, grow the best of any species in very limy soils, up to $60 \%$ of carbonate of lime.

\section{Selecting to Breed Direct Producers of Fruit for the North}

For market and table, for the North, we would select best varieties of $V$. labrusca, $V$. vulpina, V. Lincecumii, V. bicolor, V. rupestris, V. Doaniana, and use $V$. vinifera, its hardiest, healthiest varieties, in attenuation of $1 / 4$ to $1 / 8$ or less, by using hybrids of hybrids as parents, such as Brighton, Brilliant, Moore Diamond, Jefferson, etc.

\section{Breeding Direct Producers for the South}

Here is almost unlimited range. All the above named for the North, V. labrusca, V. vulpina, and Vinifera, in attenuation not over 1/4, with the addition of V. Champini, V. Bourquiniana, $V$. Berlandieri, $V$. monticola, $V$. rotundifolia, and for Gulf regions and Florida, $V$. Simpsoni and $V$. Munsoniana. In another place it will be shown that all these species have given good evidence of their usefulness alone or in combination. (See Chapter describing varieties.)

\section{Best Species for Wine}

It is found that small-berry species generally possess properties for wine-making far superior to the large-berry species, hence if one seeks to produce varieties for wine-making he should not neglect those with small berries.

The species possessing best wine properties are those in the series Precoces, Viniferce, Estivaies, Cinerascentes and Coriacece, especially the species Rupestris, Bourquiniana, Lincecumii, Berlandier, Champini, Doaniana and Vinifera. 
We thus reach the conclusion as to,-

\section{The Specific Basis of American Viticulture}

Rupestris, Longii. Vulpina, Monticola. Berlandieri Bourquiniana. Vinifera. Lincecumii. Bicolor, Æstivalis Simpsoni. Candicans. Doaniana. Champini, Labrusca, Rotundifolia، Munsoniana, seventeen in all,

These with proper application as to climate and soil can well supply all parts, from Puget's Sound and Dakota to Puerto Rico.

All the other species can be neglected without loss

An abridgment of the above, which would still supply nearly every requirement, and be the best possible list for the number of species included. would be Rupestris. Vulpina. Berlandieri, Bourquiniana, Vinifera, Lincecumii. Simpsoni, Doaniana, Champini, Labrusca, Rotundifolia. But for any limited region a half dozen species will be abundant, and few hybridizers will be found using that many. Most breeders so far have used only two to four.

\section{Partial List of Varieties of Grapes that have been, or are Growing in the Munson Experiment Grounds}

For Study, Testing, Improvement and Market Purposes, not .Including Varieties Originated by the Writer

\section{Explanation}

After each species and variety are placed some characters and figures; for example, $V . r u-$ pestris $\dagger,{ }_{20}{ }^{40}$. This $(\dagger)$ means that the vine or vines have staminate flowers. This $($,$) that$ the vine or vines have flowers with pistils and reflexed stamens and can bear fruit if the flowers are pollenized by vines having erect stamens, but cannot fertilize themselves. In other words. $(\dagger)$ means male vine or vines and (,) means female vine or vines: (") means, hermaphrodite - or perfect flowers with erect stamens. The figures tell the date at which the species or variety blooms at Denison. Texas.* The upper figure is for the month, the lower for the day of month. The above figures mean April 20th to 30th. b. means black, r. red, and w. white: thus. Concord - $\frac{5}{5} \mathrm{~b}$ b. means that Concord has perfect flower, erect stamens, blooms May 5 th to 10 th, at Denison, and is black.

This will be found a very convenient and useful table both for,the experimenter and practical vineyardist, as varieties with reflexed stamens must have vines with erect stamens. flowering at same time near by to bear well.

\section{List}

\section{Species.}

Individual Vines or Varieties.

V. rupestris, $\dagger, \frac{4}{20} \overline{0^{4}}$, about 125 vines, from Texas and Missouri, including Mr. Jaeger's best kinds.

$\boldsymbol{V}$. Longii, $\dagger, \frac{2 \pi}{20} \frac{\mathbf{3}}{\mathbf{3}}$, twenty-five or more vines from various parts of Northwestern Texas. and hybrids for graft-stock.

V. vulpina, $\dagger, \mathbf{I 6}^{\frac{4}{25}}$, over a dozen vines from Minn., Wis., Mịch., N. Y., Mo., Kans., Okla.. (riparia.) and hybrids with Concord and other varieties.

V. Treleasei, $\dagger, 5^{-\frac{5}{15}}$, from Bradshaw Mountains, Ariz.

$V$. Arizonica, $\dagger, \frac{5}{10} \frac{5}{2}$, a score of vines from Western Ariz. and South California

V. Girdiana, $\dagger, 5^{-5}$, a dozen vines from Southern California and Mexico.

$V$. Californica, $\uparrow, 1 \sigma^{5} \frac{5}{2} \delta$, many vines from Napa, Sacramento, and Feather River, Cal., and Rogue River, Oregon. 
V. monticola, $\dagger, \frac{5}{20}$, a score or more of vines, collected from San Saba, Lampasas, Llano, Coryell, Bell, Travis, Burnet, Kerr, Uvalde, and other counties of Texas, and its hybrids with other species.

$V$. rubra (or palmata), $\dagger,{ }_{10}^{6}$, a dozen or more vines from Mississippi River bottom, above St. Louis.

$V$. cordifolia, $\dagger, \frac{5}{5} \frac{5}{15}$, many vines from Fla., Mo., Tex.

V. Baileyana, $\uparrow, \frac{5}{25}$ to $\frac{6}{5}$, some dozen vines from Va., W. Va., N. Car.

$V$. Berlandieri, $\dagger, \frac{5}{25}$ to $\frac{6}{5}, 100$ or more vines from same counties in which $V$. monticola was obtained, also hybrids.

$V$. cinerea, $\dagger, \frac{5}{26}$ to $\frac{6}{10}$, many vines from Fl., Ark., Mo., Texas, and Coahuila, Mex.

V. Bourquiniana, cultivated varieties. Herbemont ' $\frac{15}{18} \frac{5}{5}$, LeNoir ' $\frac{5}{1520}$, Cunningham ' $\frac{5}{16}$, Pauline, Purple Favorite $` \frac{5}{18}$, Deveraux $\frac{5}{16}$, Warren, Louisiana $\frac{5}{18}$, Harwood ' $\frac{5}{18}$, Bertrand ' $\frac{5}{18}$, and many seedlings and hybrids of Herbemont.

$V$. vinifera, $5^{-\frac{5}{15}}$, cultivated varieties, Black Hamburg ', Black Morocco ', Calabrian, * w., Carminet du Medoc 'b., Chavoochee ' w., Crujidero 'w., Faher Szagos ' w., Favorita 'w., Flame Tokay ' r., Golden Champion ' w., Griesa de Piemonte 'b., Malaga 'w., Mission • r., Millennium, 'w., Olivet de Cadinet , b., Quagliano ' r., Rose of Peru 'b., Sauvignon Jaune 'w., Verdelho 'w., Violet Chasselas, and others from different parts of Europe, Persia, and Japan, more than sixty kinds.

$V$. Lincecumii $\dagger, \frac{5}{8 \frac{5}{2}}$, numerous vines from Southwest Missouri, Northeast and South Texas, and some hybrids of it with other species.

$V$. bicolor, $\dagger$, $\frac{5}{155}$, several vines from Wis., Mich., Ills., Ind., Ohio, N. Y., N. J., and hybrid with $V$. vulpina.

$V$. astivalis, $\dagger, \frac{5}{8 \frac{2}{2}}$, from Va., including Norton ' $\frac{5}{7^{5}}$ b., N. Car., S. Car., Ga., Tenn.

$V$. Simpsoni, $\dagger, \frac{5}{20} \overline{3}$, a score or more from different parts of Fla., and hybrids with $V$. coriacea and $V$. cinerea.

V. coriacea, $\dagger, \frac{15}{55}$, six or eight vines from Central and South Florida.

$V$. candicans, $\dagger, \frac{4}{2}$ to $\frac{5}{4}$, many vines from various parts of Texas.

V. Champini, $\frac{4}{2} \frac{4}{5}$ to $\frac{5}{5}$, a dozen or more vines collected from San Saba, Lampasas, Llano, and Bell counties, and hybrids.

l. Doaniana, $\dagger, \frac{4}{2030}$, more than a dozen vines from Greer Co., Okla., and Wilbarger, Donlcy and Motley counties in the Texas Pan-Handle.

V. labrusca, $\dagger, \mathbf{I}^{-5}$, wild varieties from N. Car., Tenn., Md., Pa., Mass., and many cultivated varieties, as follows:

\section{Cultivated Pure Labrusca Varieties.}

Ann Arbor ' ${ }_{5}^{\frac{5}{5}}$, w., Concord ' $\frac{5}{510}$, b., Champion ' $\frac{5}{1 \frac{5}{5}}, \mathrm{~b}$., Columbian ("Columbian Impe-

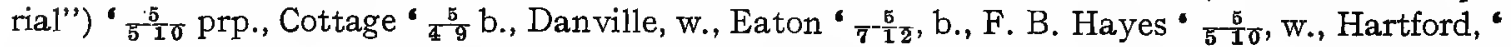
$\frac{5}{1^{5}}$, b., Hicks ' ${ }_{5}^{5} \frac{5}{10}$, b. Ives ' $\frac{5}{15}$, b., Lady $\frac{5}{4}$, w., Lutie ${ }^{6} \frac{5}{5}$, Martha ${ }^{6}{ }_{5}^{\frac{5}{10}}$, w., Mary Ann, b., Moore Early ' $\frac{5}{88}$, b., Perkins ' $\frac{5}{38}$, r., Pocklington ' $\frac{5}{812}$, y., Red Giant, $\frac{5}{49}$, r., Rockwood ' $\frac{5}{510}$, b., Whitehall ' $\frac{5}{5 \frac{5}{10}}$, w., Worden ' $\frac{5}{88}$, b., Zylphan b.

\section{Labrusca $\times$ Vinifera Hybrids.}

Agawam ' $\frac{5}{5}$, r., Barry , $\frac{5}{4}$, b., Black Eagle s $\frac{5}{60}$, Brighton , $\frac{5}{8}$ r., Catawba, ‘ $\frac{5}{8} \frac{5}{3}$, r., Campbell Early ${ }^{6} \frac{5}{4}$, b., Dutches $\frac{5}{5} \frac{5}{10}$, w., Dinkel $\frac{6}{813}$, r., Delawba $\frac{5}{5} \frac{5}{10}$, r., Diamond $\frac{5}{49}$, w., Diana ‘ $\frac{5}{611}$, r., Eumelan, $\frac{5}{10}$, b., Excelsior $\frac{5}{1218}$, r., Empire State ${ }^{-} \frac{5}{610}$, w., Goethe $\frac{5}{612}$, r., Geneva ' $\frac{5}{10 \frac{5}{15}}$, w., Green Mountain ' $\frac{5}{4}$, w., Herbert, $\frac{5}{4}$, b., Irving $\frac{5}{5}$, w., Isabella *

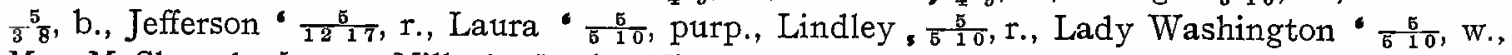
Mrs. McClure ' $\frac{5}{610}$, w., Mills ‘ $\frac{5}{812}$, b., Niagara ‘ $\frac{5}{4}$, w., Naomi ‘ $\frac{5}{712}$, w., Norfolk $\frac{5}{8} \frac{5}{8}$, r., Peter Wylie $\frac{5}{6 \frac{1}{1}}$, w., Prentiss $\frac{5}{4} \frac{5}{9}$, w., Rogers No. 2, $\frac{5}{1015}$, b., Ruckland $\frac{5}{1015}$, r., Salem , 


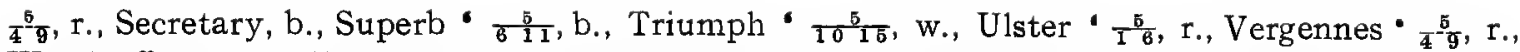
Woodruff $\frac{5}{2}$, r., Wyoming . $\frac{5}{10}$, r., Wilder , $\frac{5}{10}$, b., Waverly, b., and others received from originators for testing.

\section{Labrusca $\times$ Vulpina Hybrids.}

Bacchus ' $\frac{4}{26}$ to $\frac{5}{1}$, b., Bartholomew $\frac{5}{2} \frac{5}{7}$, b., Berckmans $=($ Clinton $\times$ Delaware $) \cdot \frac{5}{4}$, r., Clinton ' ${ }_{24}^{4} \frac{4}{30}$, b., Elvira ' $\frac{5}{8} \frac{5}{8}$, w., Missouri Riesling $\frac{5}{8}$, b., Montefiore $\frac{5}{8}$, b., Nectar $\frac{5}{5}$,

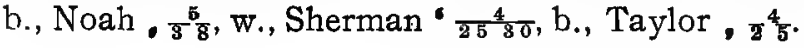

\section{Supposed Labrusca $\times$ Bourquiniana Hybrids.}

Delaware ' $\frac{5}{5 \frac{5}{10}}$, r., Early Victor ' $\frac{5}{27}$, b., Golden Gem ' $\frac{4}{80}$ to $\frac{5}{4}$, w., Jessica ' , w., Poughkeepsie $\frac{5}{813}$, r., Walter $\frac{5}{1015}, \mathrm{r}$.

$V$. rotundifolia $\dagger, \mathbb{S}_{15}^{6}$, a number of wild vines from Arkansas and East Texas, and the following cultivated varieties, - Flowers , $\frac{6}{8}$, b., James, $\frac{\theta}{5 \frac{1}{10}}$, b., Scuppernong , $\frac{6}{8}$, amber, Tenderpulp, $\frac{6}{510}, \mathrm{~b}$. . Thomas $, \frac{6}{515}, \mathrm{~b}$.

$V$. Munsoniana $\dagger, \mathbf{5}^{-\frac{6}{15}}, \mathrm{~b}$., more than a score of vines from different parts of Florida.

From the foregoing list it appears that the most promising elements in American and foreign grapes have been before the writer for study and use in his work of selecting and hybridizing. (See results in Chapter IV.)

\section{The Ideal Variety}

In order to make intelligent selection of vines for parents, it is not only necessary to have abundance of material, that is, varieties of diverse character to suit all purposes, but the originator must have determined the special character of variety desired, to suit a particular soil and climate, and best serve the use for which it is designed, as for market, table or wine.

But included in every variety for special purposes, there are general qualities that every valuable variety must possess, and these general qualities, combined, go to make up the ideal vine.

These general qualities are:-

1. Great vigor, hardiness, long life, in the climate for which it is desired.

2. Greatest possible resistance to Phylloxera, Downy Mildew, Black Rot, and Leaf Folder.

3. Easily grown from cuttings.

4. Perfect flowers, so that the vine will bear well standing alone.

5. Prolific bearing.

6. Large, full, handsome clusters.

7. Berries persistent to the pedicels, with thin, delicate, yet tough, non-cracking skin, without astringency or bitterness; color bright; pulp meaty, yet tender, juicy, readily freeing the seeds, of pure fine quality, rich in sugar and agreeably sprightly with acid, and having a pleasing characteristic flavor; seeds few and small; if for table or market, berry large; of good keeping quality.

Of course, no such perfectly ideal varieties are ever found wild, but the more of these points possessed by the parent the less the time required in breeding to secure valuable varieties.

With the very best that nature ever does, there yet remains a vast amount for the experimenter to accomplish by selection and hybridization.

\section{Personal Qualifications Necessary in the Originator}

This work requires not only theoretical knowledge, but also direct personal knowledge, experience, skill, and much of the inventive faculty, with great patience and perseverance, without the stimulus of money-making in it, for there is little to the originator. There is no law providing protection to the ilventions (varieties) of an originator, as there is to the less meri- 
torious mechanical inventor. The originator must have a great fund of enthusiasm, and an ambition to add something to the general fund of human development for the benefit of the world at large, and, that he may reap some personal compensation, or enjoyment, he must have an intense love of close communion with nature, causing him to admire the infinite correlated life movements; to study the loves and hates prevailing in all organic life and growth, discovering the great fundamental truth in ethics, as well as in the development of organic beings, that love breeds life, hate breeds death. Such a spirit of investigation leads the student of biology, especially when working in this field of most practical application of the principles of biology, to the contemplation of the all-binding energies and impulses belonging to and circulating through, by mutual reciprocation, influencing and controlling all objects, thus creating the best concept of the self-governed Infinite.

\section{Pure Breeding, Crossing and Hybridizing}

If a vine is grown from a Concord seed, produced by receiving Concord pollen, then the vine is termed a pure seedling of Concord. If this should produce likewise pure seedlings of itself, and these still others, and so on under intelligent selection, as of large berries, or cluster, or both combined, presently a fixed type would be secured to the extent, that all the progeny would have large berries and large clusters, and thus far a pure-breed or thorobred, of the "in and in bred" type would be secured. Experience shows that such breeds become feeble in constitution and growth, and cease to be prolific, easily succumbing to attacks of disease. Concord in several of its third and fourth generations of pure-bred varieties, Lady, for example, and all of a lot of pure Moore Early seedlings grown by me, are feeble and poor bearers.

Crossing and hybridizing come to our rescue here, and enable us, by judicious selection of parents, to derive full benefit of selection, and give the added benefit of often increasing vigor and actually creating new flavors, and increasing quality, just as in chemistry the union of two or more different substances gives us practically a new substance, often little resembling either component part.

In practice, crossing and hybridizing are identically the same in manipulation, but in the selection of parents, different; those in a cross being chosen from the same species, as if Concord and Ives should be united, the progeny would be a cross, and of pure Labrusca blood still; but if Concord and Black Hamburg, or Black Prince, as was the case in producing the Black Eagle variety by Mr. S. W. Underhill, the result is a Labrusca $x$ Vinifera hybrid, and the variety shows characters not like either parent, but usually intermediately between the two, so.that a botanist will quickly decide that the vine is not of pure specific blood, but a combination of the two species,. Labrusca and Vinifera.

Thus, selection and cross- and hybrid-pollination are the conjury of the originator in intelligently creating new and valuable varieties.

How is it done?

\section{Simple Selection}

To produce varieties one may know nothing about the flowers, their parts and functions. The best of a lot of seedlings are selected. Seeds of these are planted, and when these bear, seeds of the best again are taken, regardless of whether they are pure or cross pollenized in flowering.

Farmers and gardeners everywhere practice this much in preserving and improving their varieties. How much they are failing to advance as rapidly as they might, did they use judicious hybridization and crossing, they will never realize until they study and practice cross pollenization.

This requires an intimate knowledge of the essential organs of the flowers of the species to be operated upon, the periods of successful conjugation of the pollen grain and ovule, and how to screen away pollen not wanted and apply that selected. 


\section{Structure of Grape Flowers}

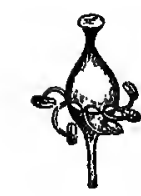

1

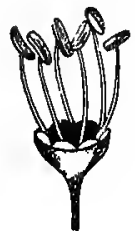

2

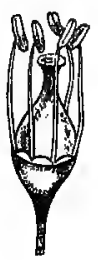

3

\section{Grape Flowers (Enlarged agout 6 Diameters)}

(See Plates XXXVII., XXXVIII. and XXXIX. for flowers natural size.)

There are three kinds of flowers in grapes, as shown in the cut greatly enlarged.

Fig. 1, the practically pistillate flower, with weak, recurved stamens, generally incapable of self-impregnation.

Fig. 2, a staminate, or male, flower, with abundance of virile pollen. Non-bearing.

Fig. 3 represents the perfect, hermaphrodite, self-impregnating flower.

\section{Discussion of Sex and Impregnation in Grapes}

The vines producing male or purely staminate flowers are non-bearing in the very necessity of their character, having no pistil, the part in bearing vines that develops into the grape.

But the pistil in the great majority of cases will not develop into a grape unless one or more of the ovules (female germs) within it have been impregnated by a pollen grain.

\section{Seedless Varieties}

In rare cases such development takes place without the ovules being impregnated, as in Seedless Sultania and Sultanina (Thompson's Seedless), both of the Vinifera species. There is no known way to produce seedless varieties at will. Such are accidental, yet we believe there is a cause for such, whether practically controllable by human agency or not. The cause is undiscovered.

\section{Nature's Method of Impregnation}

Nature's preferred method, and the only one we can practically apply, is to place pollen grains upon the stigma, when in a receptive condition, which is shortly after the flower has opened, and the stigma has thrown out a minute quantity of protoplasm upon its surface, appearing moist. In this liquid the pollen grain germinates within 30 to 60 minutes, when the temperature is $70^{\circ}$ to $90^{\circ}$, and the light, and fair weather present. Naturally, gentle winds and small winged insects, which visit the flowers, carry pollen from flower to flower. The slender, thread-like root of the pollen grain grows down one of the microscopic tubes in the style and pistil until it comes against the ovule cell-wall, which it penetrates and then intermingles its substanceprotoplasm-with the protoplasm of the ovule, by pairing or grouping the chromosomes in new combination. The pistil holding such impregnated ovule or ovules at once begins to enlarge, and in time becomes a mature grape, and the ovules mature seeds within.

As the male flower has no pistil it is clear that its vine cannot bear, unless the vine changes its action from producing purely staminate flowers, to bearing pistillate flowers, which in two or three instances only, in all my observation, have I known to occur.

\section{Male Vines should not be Neglected}

The male vines are certainly of value to the species or they would not have been developed in nature. They come, by the law of division of labor; in reproducing the species, and thus not 
burden a vine with a double function, that of furnishing both male and female elements in reproduction. It seems that the genus Vitis (grapes) has in comparatively recent epochs, geologically speaking, developed separate sexes, for by cultivation and stimulation we cause them to develop true hermaphrodite flowers - both sexes in one flower-as in most vineyard varieties, just as all other genera of the grape family (Vitacex) have; thus easily going back to a less developed or specialized state. By dividing the burden of reproduction between separate individuals greater vigor and longer individual life is maintained among the vines, and the pollen from a male vine is more virile - potent - than that from a hermaphrodite vine, and still more than that from a vine with weak recurved stamens. The flowering of the male vines appears to be as great a strain upon them as the bearing of fruit is upon the vines having recurved stamens-practically pistillate flowers-incapable of impregnating themselves with their own pollen. In fact, in a large number of vines of $V$. rupestris, about equally staminate and pistillate, from seed of the same vine, the male vines, although at first as vigorous, or more vigorous than the bearing vines, soonest began to die by exhaustion, although the pistillate vines bore heavily annually. No other cause of such earlier failure could be discovered. It is to be noted that the clusters of flowers on male or staminate vines are far larger-often two to four times as large as the clusters on bearing vines, showing that nature provides the male element far more abundantly than the female, providing for great losses that must occur by wind, rain and insect consumption.

It is a pretty general rule in nature for the females to outlive the males. This preserves the species better than for the males to outlive the females.

To state the whole matter of pollination or impregnation among grapes, but not to be too rigidly exact, as many other causes come in to have their effects, the following are suggested as

\section{General Laws of Constitutional Development in Grapes with Reference to Parentage, in Pollination}

1. The most vigorous and enduring progeny are produced by vines, as mothers, -other things being the same,- which have recurved stamens and well developed pistils, when pollinated by purely staminate vines, as, for example, when Moyer, Lindley, Brighton, etc., are pollinated by staminate seedlings of say Dracut, Perkins, Presley, etc.

2. Next in vigor are the progeny of mothers having reflexed stamens with large pistils, impregnated by hermaphrodite vines; e. g., Brighton or Lindley by Concord, Ives, Dela ware, etc.

3. The third in vigor and endurance would be the progeny of hermaphrodite vines, such as Concord, Ives, Perkins, Catawba, and the majority of varieties in cultivation (see the Tables of Varieties, pages 124 and 125), impregnated by staminate vines. But in this case the majority of the progeny will be staminate vines.

4. Fourth in vigor would be the progeny of hermaphrodite vines pollinated by other hermaphrodite vines; for example, Concord pollinated by Delaware or Ives, and still weaker if pollinated by itself, or its own progeny, such as Moore Early, Worden, Martha, etc., making "in and in" breeding. The progeny of such impregnations generally have hermaphrodite or selfpollinating flowers, the kind preferred by vineyardists, who do not understand sex among vines, because they bear planted alone in vineyard. Most hybrids of Labrusca with Vinifera have been of this class.

5. More feeble still, when any progeny at all are produced, is that of vines with recurved stamens, impregnated by varieties with recurved stamens, as in case Moyer could be impregnated by Brighton, or Lindley.

6. In case a variety with recurved stamens should impregnate itself,-if possible,Mr. Jaeger thought his No. 43 did that-we would expect the feeblest progeny. Such impregnations, however, are very rare, if at all. Pistillate varieties thus pollinated generally cast the pistils in a few days afterward, but the pistils may first enlarge a little. Professor S. A. Beach has designated such varieties "self-excitant," or "self-irritant.' but sterile. 


\section{Desirability of Hermaphrodite Vines}

As has been stated, the vineyardist not understanding pollination prefers varieties with hermaphrodite flowers, so that they will bear in solid vineyard of one kind. To produce such, and yet maintain as much vigor as possible, the parentage mentioned under Laws 2 and 3 is preferable, if possible to get varieties with erect stamens thereby.

But under method 4 , there is more certainty of getting perfect flower kinds, and if that is used then the parents had better be of distinct species, or, if of same species, then entirely distinct varieties in origin.

With these hints the ingenious originator will find it easy to select parents to good advantage, remembering that vigor, hardiness, healthiness and productiveness are always essentials every variety must possess to retain position with practical vineyardists.

Having now prepared the way we can venture into the details of

\section{Crossing and Hybridizing}

As the operation is the same in each after we have selected our parents, we can include both under one description of method. Crossing is uniting varieties of the same species; hybridizing is uniting varieties of different species.

The common, old method has so often been given, of lifting the flower caps, removing the anthers from the mother flowers, applying the pollen with a moist camel's hair pencil, enclosing the cluster in gauze or tissue paper sack, etc., that more than the mere mention of it would be out of place at this late date.

\section{Speedy Method}

As few hybrids, as well as simple seedlings, prove to be truly valuable, the hybridizer, to make speedy progress, must have some way of more rapidly doing the work than by the common method.

It has been shown that the best mother, other things being the same, is a vine having short, recurved stamens, incapable of self-impregnation, hence, in the operation of pollenizing, the anthers need not be removed, and this permits a very speedy method.

The writer has, by much practice, found the following to be very speedy and certain, when the mother vine has reflexed stamens. (See Variety Tables, giving character of flowers and date of flowering, at end of Chapter III.) Nearly all wild bearing vines have such flowers, and that largely accounts for such endless variation among wild grapes.

The selected mother vine should be in the best condition, and as soon as the flower-clusters appear, the small and illy-shaped ones should be clipped off and the others noticed daily until they begin to flower. Then clip off every flower that has opened.

Enclose each cluster in a tissue paper sack so insects cannot enter. The next day, if warm, still and sunny, visit the vine, and if found blooming within the sacks, collect a few clusters of the variety or varieties to be used as male parents, seeing that many flowers on such clusters are freshly opening. Remove the paper sacks, one at a time, from the clusters of the mother vine, and brush each over gently with one of the pollenizing clusters. This will knock off all the caps, exposing the stigmas and spilling pollen profusely in the air all through and about the cluster and each exposed stigma will be almost certain to receive pollen from the cluster used as pollenizer. Then, if the clusters used for pollenizing are numerous enough, put one in each sack, above and resting on the cluster being impregnated, enclosing both together until the next day, when, with fresh clusters from the same pollenizing vines, the operation is repeated, the old pollen cluster thrown out and a new one put in each day for three to five days in succession. After each operation other flowers on the enclosed clusters will open and the process of pollenization continues after the operator has gone. The sacks are allowed to remain on several days longer, until all flowers 
on the enclosed mother clusters have opened. Then the number of little grapes set on the clusters will show what has been the success. It is almost certain that all seeds borne by the sacked clusters will be crossed or hybridized by the variety used as the pollenizing parent.

By this method probably a hundredfold more hybrid seeds may be produced with the same expense of time and far less tediousness in manipulation than by the old method, with equal or greater certainty of making the greater number of different combinations and more individuals of each combination during the flowering season, than he can by the old method.

If a variety with hermaphrodite flowers, such as Concord, Herbemont, etc., is chosen for mother vine, then there is no surer or better method than that commonly recommended. However, by planting the two vines to be crossed or hybridized side by side in the vineyard row, the writer has been enabled to greatly expedite the work. The selection of parents was made when the vineyards were planted, and the various crosses or hybrids intended arranged by planting the pairs of vines in vineyard, to be operated upon when coming into bearing. In pruning time, an arm of each parent is trained alongside each other on same wire, and at flowering time a shoot of the mother vine has all the open flowers clipped off, and then all caps just about ready to shed, which will lift by inserting the point of a needle at base of petals and lifting gently, are removed, the anthers all hooked off with a minute hook, made by bending the point of a pin back upon itself at an acute angle, the hook being about one-sixteenth of an inch long.

After all flowers that will release their caps are thus treated, a cluster in bloom from the other parent vine is taken, turning it so as to touch the disc of the stigma of the emasculated flower, with the opening face of an anther just discharging pollen, each exposed stigma is thus treated and then the shoot with the clusters of emasculated flowers, along with a shoot having flowers abundantly opening on it, from the other vine, are completely enclosed in gauze, or cheese cloth, to keep off insects and outer pollen in the wind. If many seeds are wanted, all the bearing shoots of the arm of each parent trained together may be treated and protected together. Each day at 9 or $10 \mathrm{~A}$. M. the operation must be repeated so as to have all flowers of the mother vine, enclosed, emasculated before they have pollinated themselves. At the last operation all unopened flowers on the shoots enclosed of the mother vine must be removed, as they would become self-pollinated. Whatever fruit ripens on the enclosed shoots of the mother vine are supposed to be crossed or hybridized.

If the mother vine have reflexed stamens while the other growing by its side has erect stamens, either male purely, or hermaphrodite, all that is necessary is to cover both vines together with a sheet or other sufficiently light cloth, so insects cannot readily enter, during blooming time, and daily shake the pollen-bearing vine, to cause the pollen to be well distributed all inside the covering. All the seeds developing on the vine with reflexed stamens will quite surely be impregnated by pollen from the other vine.

\section{Hybridizing Varieties not Blooming Together}

When the intended parent vines do not bloom at same time, then either the earlier variety must be retarded, by cutting off the primary shoots, and thus forcing the secondary later; or the later must be made to bloom earlier by pruning close in the fall soon after leaf-fall, and the earlier belated as directed above, or by not pruning until buds start in spring, or by both, if natural times of flowering of the two intended parents are wide apart, or else by saving pollen of the earlier to apply to the stigma of the later.

Pollen can be preserved for weeks, and even a year, and still be efficient in impregnating, as proven by the writer, by practicing the following method.

\section{Collecting, Preserving and Using.Pollen}

From the vine chosen to be male parent, which must be either staminate or hermaphrodite, collect the clusters when fullest of opening flowers, which time will generally be from 10 to $11 \mathrm{~A}$. M. 
of a still sunny morning. Carry the clusters at once, without shaking or jarring, to a well lighted, dry, warm room, free from currents of air. Having provided a new, clean tin box, say three inches square by one inch deep, with tightly fitting lid, take up each cluster by the stem and strike it gently several times into the open box. This will cause the pollen to fall out of all open anthers and adhere either to the bottom or sides of the box, the pollen being a little gummy. When all the clusters have been so treated, then with small sharp scissors clip off all the anthers of open flowers, into the box, and set the box, open, on window sill, window closed, so strong diffused light, but not direct sun rays, enters the box. Every twenty or thirty minutes close the lid of box and shake sharply, then open and expose to light again. Repeat the shaking three or four times, when all the pollen will be dislodged from the anthers that will come out; then gently winnow off the shriveled anthers, corollas, and other foreign particles that may have fallen in with them from the clusters. The pollen will appear as a pale yellow flour about the sides, top and bottom of the box. Now let the box stand open in the warm air and diffused light for an hour or two, when it will be dry and in good keeping condition. Close the box and paste over the seam between lid and box a strip of paper to keep out air and minute insects. Wrap and label the box with variety name of grape, and keep in a dry, warm room, never below $60^{\circ}$ nor above $80^{\circ}$ if possible.

When the flowers to be pollenized are opening, properly prepare them, as heretofore directed, and with the tip of a delicate camel's hair (or cat's-tail hair) pencil, moistened in pure water, take up some of the dry pollen from the box and apply to the stigmas, and cover the pollenized clusters in tissue paper sacks.

\section{Labeling and Saving the Seeds}

Every cluster thus pollenized in our work is at once labeled and recorded, and the fruit carefully guarded, by sacking, and gathered as soon as well colored. The seeds are taken from the berries and dried on paper in room, then carefully wrapped, labeled as to parentage, and put away from mice.

\section{Planting the Seeds}

A warm, rich piece of level or nearly level soil, free from weed seeds as possible, protected from sweeping winds, and scratching fowls, is selected and pulverized deeply with spade or plow, made fine and smooth with the rake, in November or December. The seeds are then sown in drills, about three feet apart, and about as thickly along the drills as radish seeds are sown, and one to one and a half inches deep; covered with mellow soil and firmly pressed down, by walking on the row after covering, then smoothing again with rake. Each variety is labeled on a stake driven at its beginning, and a record of the plantation made in the experiment book.

The seeds germinate slowly, and being very hard, nut-like, do better to thus get frozen in the moist soil. The plantlets of the early leafing species will appear in spring about with the young oak leaves, some varieties much sooner than others, the slowest species coming two, three or four weeks later than the first. As will be observed in Table of Cultural Characters, page 121, species which leaf out, or germinate early, will generally also flower and ripen early. There are, however, some exceptions to this rule, the $V$. candicans (Mustang) being one such, which leaves, flowers and ripens early, but the seeds germinate very late.

\section{Tending and Culling the Seedlings}

In spring the seed bed is carefully watched, and no weed seeds allowed to more than show their germs above ground until they are destroyed, and the soil kept well pulverized without disturbing the grape seeds.

As soon as the grape plantlets are well up and have formed their second leaves, they are carefully gone over, and every weakly and deformed plant pulled out. Within a month after first 
culling, and when the hot moist weather of May and June is very favorable to development of mildew, the plants are again critically examined, every feeble and.mildewed plant pulled out. Plants which resist mildew at this stage will rarely, if ever, be injuriously attacked when older.

When the plants are five or six inches high, they are staked, as the gardener stakes peas which climb, and none allowed to sprawl on the ground. By thus carefully cultivating and training the first year, they generally fruit a year sooner than if not staked and well cultivated.

\section{Testing, Noting and Selecting Varieties for Introduction}

By using good fresh land, well prepared, and planting the selected one-year seedlings in November, cut back to three or four buds, four feet apart betwcen plants and rows eight feet apart, and trellising at once, or before growth starts in spring, so as to train onto the trellis the first season after setting, and allowing only a single shoot to grow up, the writer has succeeded in getting about three-fourths of the vines to fruit the second season after transplanting, or third season after sowing the seeds. The remainder fruit the next year. As ordinarily grown, it requires one to two years longer than this. This is a big clear gain to one doing much experimental work, and in the course of fifteen or twenty years of extensive experimentation makes a large saving in time and labor.

While the vines are fruiting the first time, they are very carefully examined and noted in every particular of growth, foliage, season of leafing, flowering, ripening, quality, diseases affecting, leaf-fall; the character of flower, whether staminate, pistillate or hermaphrodite; degree of perfection in setting fruit, persistence to pedicel, etc., are recorded.

After all the vines that can bear (some will be staminate) have fruited, and those decidedly not worthy further trial are grafted to the most promising (it will be found the great majority are not worth trying further), then comes the long, careful test of three to five years, to determine the complete character of the few that turn out worthy of recommendation for general trial over the country. Their record in all points should"be high, approaching the "ideal vine" in character. Several vines of each of those of high merit are planted in various different soils and situations and fruited several years before they are disseminated.

\section{Time Required for the Full Development of a Variety}

On an average, it requires about eight years from germination, under good treatment, for a variety to fully display its true permanent character, hence should not be disseminated until that age, unless its parentage is exceptionally good, and itself every way satisfactory.

Oftener there is improvement rather than deterioration in a young variety, but sometimes a variety changes from good promise to worthlessness.

\section{Percentage of Meritorious Varieties}

Out of over 75,000 grape seedlings, chiefly hybrids, having been subject to culling and selecting by the writer, not over 100 have passed meritoriously through the entire period of testing and been considered worthy of recommendation for general trial by planters.

Hence it may be safely estimated that one really good variety to every 1,000 carefully selected and hybridized grape seeds will be the originator's reward.

However, this is a ratio obtained by starting with much new material-untried combinations of new species in a large degree. By now using only the best of the varieties tested and new ones produced, a much greater percentage of worthy varieties should be obtained.

Some lots of hybrids, especially in my later work, have yielded as high as one or two per cent of good varieties, and as the work progresses farther and farther toward thorobreds, the greater and greater will be the percentage of valuable varieties; providing all the laws of adaptation, congeniality, health, etc., and fine judgment in selecting and making combinations, are employed. 


\section{Breeding for Special Character and Purpose}

While it appears that there is no direct road in breeding up to a special purpose ideal, yet the only way to approach such ideal is to have it clearly in mind and continue from generation to generation to select and pair varieties which embody the greatest number of the elements of the ideal.

All of many seedlings of Triumph (a white variety, a Concord $x$ Muscat hybrid), grown by the writer, were white. Of a large number of pure seedlings of Elvira, a greenish-white variety, the majority were white, some black and some amber or pale red. Elvira crossed by Triumph produced all white varieties, the Rommel being one of the lot. Pure Rommel seedlings were all white. Rommel crossed with Brilliant produced all yellowish-white varieties, of which Wapanuka is one. In this case the white blood is most potent as to color but the vines of this cross resemble Brilliant more than Rommel, yet Rommel was the mother. The Gold Coin, a hybrid of Norton, black, impregnated by Martha, a pure greenish-white seedling of Concord, has produced many pure seedlings for the writer, all yellowish-white. Concord is well known to occasionally produce white varieties among its pure seedlings: Of Norton I have grown many pure seedlings, of which about one-third were yellowish-white, none as good as the parent, and the others all black, a few equal, and the Winona a little superior to the parent. Neither Concord nor Norton has ever produced pure, red seedlings. The tendency to white or albino varieties in them when united, as in the Gold Coin, completely dominates the color in all its pure seedlings, and these seedlings are all much more feeble in growth than the black varieties, resulting from hybridizing Concord and Norton. Many other examples following the same course can be produced, but these are considered sufficient illustration of the general law, that to produce white varieties surely, cross or hybridize white varieties. To avoid or overcome the element of weak growth in white varieties, only the most vigorous of this color should be used for parents.

This consideration of producing white varieties has been specially amplified, because the writer was once told by an eminent hybridizer of grapes that he thought that white grapes could be produced as readily out of black varieties as out of white, and cited Empire State as an example, said to be a hybrid of Hartford and Clinton, two black varieties. But the botanical characters in Empire State do not show the least bit of Clinton, but plainly some light wooded Vinifera, or Labrusca $x$ Vinifera hybrid, proving clearly an error in the supposed parentage.

In my work with red (see Lindley, Delaware and Delago families, in Chapter III.) and black varieties (see America, Concord and other families of blackgrapes, Chapter III.), there is abundant proof that the same law holds good as with white varieties, that " like produces like," the commonly accepted rule as to reproduction in nature, yet in this matter of white and red varieties occasionally coming out of black varieties, as they surely do, from some occult cause not fully understood, we must admit that the law is not absolute, but has occasional exceptions.

It has likewise been found generally true, yet with occasional exceptions, that early ripening parents produce early ripening progeny. Where there is much variation from this rule in pure seedlings of a variety as in Concord, in which the majority are early or medium, as Moore Early, Worden, etc., while rarely like Miner Victoria, some of its seedlings are very late; or as in Jaeger No. 70, and America, a combination of Rupestris, a very early species, and Jaeger No. 43 , a very late variety of Lincecumii, a late species, the progeny ripen all along from early to late. It would seem that such varieties, the progeny of which vary much in season and other characteristics, contain different specific blood in their make-up. The latest introduced variety produced by the writer is the Marguerite, a hybrid of a very late Post-Oak grape with Herbemont, a very late variety; and a much later kind still is the Winterwine, a hybrid of $V$. Simpsoni with Marguerite, both very late, Simpsoni being latest. Little or nothing could be gained by uniting very early with very late kinds.

Generally season of leafing, flowering and ripening belongs to species, as the Table of Cultural Characters in Chapter II., p. 121, shows. 
Like season, size of cluster and berry belongs originally to different species, altho it varies considerably in all the species, and in some, as $V$. Lincecumii, greatly. The rule holds good generally throughout the genus, that where the berry is large, the cluster is small, and where the cluster is large, the berry is small; but several species have both berry and cluster small. This is true of all the earliest ripening species.

It seems a necessary result from this fact that the large-clustered, large-berried varieties are the result of selection and breeding by man. History of grape culture sustains this conclusion. It is in this particular piece of development where the hybridizer of American grapes may accomplish wonders. Contemplate the union of the largest berried Labrusca, Lincecumii, Rotundifolia and Vinifera varieties (see Red Giant, Early Purple and Thomas plates) with the numerously berried clusters of Berlandieri! The largest clustered foreign grapes may be excelled in American species some day.

It is found generally with grapes, as with most other fruits, that "as size goes up, quality comes down." This will probably ever remain so with wine grapes, for it appears that the perfecting of the juices, developing large percentage of sugar and other desirable wine properties, the berries must be small to admit better action of light and air to the smaller packages of juice; in other words, giving greater surface to the same amount of juice to be acted upon. But by developing size and texture of pulp with flavors agreeable to the palate, large grapes may be produced of excellent table quality which would have very ordinary or poor wine properties.

So the originator finds his wits taxed to the utmost in endeavoring to get into one variety a large cluster, with large, handsome berry, of very fine quality. It surely has been done in a number of foreign grapes, such as Muscat, Hamburg, Malaga and others, and why not in the thorobred American grape as well?

In the matter of quality, the common law, that "like produces like" holds more rigidly than in almost any other character, and is brought out by long and careful selection through many generations.

\section{Prepotency of Parents in Controlling Vine and Fruit Characteristics}

Some experienced hybridizers have claimed that it is a general law among grapes and other fruits that the mother transmits more of the vine, or tree characteristics, while the male, or pollen parent, more of the fruit characteristics. After observing and studying my crosses and hybrids with reference to this point, there seems no adequate ground of support to lay it down as a law, farther than that the mother appears to transmit its degree of hardiness in resisting climatic extremes and diseases better than the male parent. Theoretically this would be reasonable, as the ovule, after impregnation, receives all its support and growth from the mother, until it becomes a mature seed; hence the mother vine should always have greatest capability possible to endure hardships and resist disease and yet include excellence in fruit.

The following list of species and varieties which have been used in cross and hybrid combinations is given for what it is worth, which seems little, as the point has not been put to the test of special experimentation.

The species, or variety in each pair, which is italicized, seems to be strongest in impressing its characters upon the progeny in the unions made. Where they unite equally, both are in Roman print. Where the union produces puny, sickly progeny, when both parents are vigorous, they are marked Incongenial. The first named is always the mother.

Scientific demonstration is not claimed in this work. It is only tentative, and it is hoped will call out careful work on this subject from others.

Rupestris $\mathrm{x}$ Vulpina.

Rupestris $\mathrm{x}$ Longii.

Rupestris $\mathrm{x}$ Candicans. Rupestris $\mathrm{x}$ Labrusca.

Rupestris $\mathrm{x}$ Vinifera; Rupestris controls vine, Vinifera the fruit.

Rupestris x Bourquiniana (Herbemont \& Rulander). 
Rupestris $\mathrm{x}$ Lincecumii. Rupestris $\mathrm{x}$ Cinerea; Cinerea controls the vine and fruit.

Rupestris x Berlandieri. Rupestris x Monticola.

Rupestris $\mathrm{x}$ Rotundifolia, Incongenial.

Longii x Lincecumii. Longii x Candicans.

Longii $\mathrm{x}$ Labrusca; Longii controls vine, Labrusca the fruit.

Vulpina $\mathrm{x}$ Longii. Vulpina $\mathrm{x}$ Candicans.

Vulpina $\mathrm{x}$ Labrusca; Vulpina controls the vine, Labrusca the fruit.

Vulpina $x$ Bicolor. Vulpina $x$ Cinerea.

Vulpina $\mathrm{x}$ Vinifera; Vulpina controls the vine, Vinifera the fruit.

Girdiana x Vinifera.

Champini x Labrusca; Champini controls the vine, Labrusca the fruit.

Champini $\mathrm{x}$ (Labrusca $\mathrm{x}$ Vinifera); the hybrid controls fruit.

Candicans $\times$ Rupestris; Candicans controls vine, and fruit.

Labrusca $\times$ Vinifera; Labrusca controls vine, Vinifera the fruit.

Labrusca $\times$ Vulpina. Equalize well in most cases.

Bourquiniana (Herbemont) $\times$ Labrusca (Martha).

Bourquiniana (Herbemont) $x$ Estivalis (Norton).

Bourquiniana (Herbemont) $\mathrm{x}$ Triumph; Herbemont controls vine, Triumph the fruit.

Lincecumii $\mathrm{x}$ Rupestris, Lincecumii $\mathrm{x}$ Labrusca; Lincecumii controls vine, Labrusca the fruit.

Lincecumii x Candicans.

Lincecumii $\times$ Cordifolia.

Lincecumii $\times$ Herbemont; Lincecumii controls vine, Herbemont the fruit.

(Lincecumii $\times$ Herbemont) $x$ Vinifera. In these Vinifera appeared to control vine in botanical markings, but Herbemont and Lincecumii in vigor and fruit. Several such hybrids were quite uniform. Estivalis (Norton) $\mathrm{x}$ Labrusca (Concord), the union quite even.

Cinerea x Cordifolia. Berlandieri x Monticola.

Monticola x Rupestris. Monticola x (Lincecumii x Catawba) Fern.

Berlandieri x Champini. Berlandieri x Fern.

Berlandieri $\mathrm{x}$ Vinifera (Quagliano). Generally equalize well.

Rubra x Herbemont.

Rotundifolia (Scuppernong) x Post-Oak Grape hybrid. Rotundifolia is very persistent in impressing its character upon its hybrid progeny, both in vine and fruit, even to the second generation.

Rotundifolia x Munsoniana.

Generally, the more distinct and uniform a species the more prepotent it is over less distinct and less uniform species. In conformity to this the more complex a hybrid is the less it shows of itself in combination with a pure variety of a pure species. This should be expected as a corollary of Mendel's law of heredity.

Also in conformity to this law, the more complex a hybrid is, the more variable among themselves are its pure seedlings.

We may expect the male parent to more often control in appearance and quality in fruit, and the female in vine; yet, if we designate it a general law, there will be found many exceptions.

\section{Field of Development}

When we view the development, both natural and artificial, arrived at, and then reflect and compare the small cymose cluster and minute, skinny, seedy, pungent fruit of the Virginia Creeper (Ampelopsis quinquefolia) with the larger clustered, but scarcely larger berried, skinny, seedy, pungent, Frost Grape ( $V$. Cordifolia) we can notice a decided advance in quality. When we compare the Frost Grape with the Fox Grape ( $V$. labrusca), the Southern Muscadine ( $V$. rotundi- 
folia), or the Post-Oak Grape ( $V$. Lincecumii), we fall in love with nature for teaching us what wonderful development, the blind, haphazard selection by natural circumstances, aided doubtlessly by birds and other animals eating the best and carrying the seeds into new regions to start new and better families, have produced during several million years, since the true grapes were evolved out of a wild vine, with probably inferior fruit to the Ampelopsis or Sumach. But when we compare the best wild grapes ever found with a Malaga, Cornichon, Muscat, Black Hamburg, and know that the keen yet unsystematic selection of man for only a few thousand years has done this, and when such men as E. S. Rogers have taught us that by hybridization we can, at a single bound, transplant these fine fruits, almost perfect, into our vigorous, healthy natives, we enjoy an encouragement unknown to the ancient, slow-plodaing world. Moreover, our native species excel in many points the Old World grapes. Some have rare delicious flavors unknown in the Vinifera varieties, others great size of cluster, others very large berries, others small and few seeds, nearly all great vigor and resistance to disease, adaptability to a most variable climate, and our experience clearly shows that all the species can be intermingled at will of the intelligent hybridizer. The lists of American varieties given in this book with their parentage are ample proof that the process of selection and hybridization can produce almost any desired character within a comparatively short time.

We are assured by all these facts that the field of development is illimitable and full of grand prospects and encouragement. 


\section{Chapter III}

\section{Select Families and Varieties of Grapes, for Practical Vine-Growers}

It is not the object of this work to give a complete descriptive list and history of all varieties. of grapes originated in America. That would be encyclopedic, and of far less value to the practical vineyardist, and even to the breeder of varieties, than the best tried selections of the different. species and their combinations, and would be valuable chiefly as history. Others have written that. This work is designed for the practical man.

The alphabetical order of species and groups of hybrids is followed.

In this category I have tried to the utmost to give a vivid exhibit of the very best there is in American Grape culture, but make no claim to have mentioned all that is valuable. If $I$ have in any way done injustice to any varieties, it is because a diligent, careful, enthusiastic student, trying to get at the truth for over thirty years, is incapable of correctly compassing the whole matter.

It will be noticed that varieties originated by the writer occupy much of the space. This is accounted for by the fact of the great extent of his work in breeding grapes in diverse directions and specific combinations, never attempted by any other hybridizer, and from the multiplicity of hybrids made, all of which carried through years of testing would run into many thousands, including only the best of some 75,000 hybrid seedlings germinated in the nursery rows, and culled with extreme care. Hundreds of varieties better than Concord have been thrown away. A number of varieties that promised well at first, did not come up to their promise after introducing, were withdrawn and suppressed, and some, that seemed unworthy at first, proved to be valuable.

All the varieties mentioned in this list are not recommended to the planter, but are mentioned to assist in elucidating the composition or character of other varieties. At the end of the chapter will be found a list of varieties recommended to practical planters, for adaptation to the various. sections, soils and climates. It is hoped that the whole chapter will be found worthy of careful study by both vineyardists and breeders of grapes, for it comes as the cream of over thirty years. study and work as a practical vineyardist, breeder of and writer on grapes.

The Concord being considered by the majority of persons, in regions where it is much grown, as the standard market grape, it is used as the minimum standard of comparison for quality, and the Delaware, generally recognized as our highest in quality, is taken as the maximum for comparison. Nothing poorer than Concord should be tolerated where it or better kinds can be grown, and we should ever try to excel even the best we have.

Life-size, half-tone engravings of varieties are distributed thru the list to give a better conception of them, and to illustrate the results of certain combinations.

\section{Explanation}

Immediately following the name of a variety is given its origin, then its parentage, and then its character of flower and average date of flowering at Denison, Texas, if known, and after that the description of vine, cluster, fruit, etc.

If the variety has a perfect flower, it is indicated by a heavy inverted comma, thus ("); if imperfect, by a heavy comma, thus (, ). Immediately following the comma is given the average: date of flowering, thus: $\left(\frac{5}{6}\right)$, the upper figure denoting the month, the lower, the date. Example, 
( $\frac{5}{6}$ ) is read, flower perfect, date of flowering, May sixth. A perfect flowered variety generally bears well, when planted alone, but there are a few varieties with apparently perfect flowers that do not pollinate themselves well. The fact, if known, is mentioned in describing a variety of that character. Varieties having flowers with short, reflexed stamens almost invariably cannot fertilize their own ovules, hence require, to be planted near them, a variety with perfect flowers, blooming at same time. When cool, rainy, or stormy weather prevails during the entire blooming period of a variety, it prevents pollination, and consequently the "setting" of a full crop, and there is no remedy, but it seldom happens. If a variety is about to begin flowering when the rain sets in, it will remain with its flowers closed several days later than if clear weather had continued, waiting for favorable time to open, but if bad weather continues too long, or just as the vine has burst into bloom, a sudden and long-continued storm comes on, failure follows.

When such phrases as "eight to ten feet" occur in the descriptions, it has reference to the distance apart the vines should be planted in the row; "Medium arms," "Short arms," "Long arms," has reference to length the canes should be cut when pruning.--See Chapter on Pruning.

\section{Estivalis Varieties}

The only variety of this species in general cultivation, is the

NORTON (Syn. Cynthiana). ( $\left.\frac{5}{16}\right)$. Found wild on Cedar Island, in James River, near Richmond, Va., in 1835 , by Dr.F.A. Lemosque, and named and introduced by Dr. D. N. Norton, of Richmond.

Vine very vigorous and free from all disease, prolific, leaves large, leathery, with tufts of brown wool on under side, clusters large, compact and somewhat compounded for this species, with long peduncle; berries small, globular, black, persistent, skin thin, tough, never cracks; pulp not very juicy, of pure vinous sprightly flavor, seeds small, juice claret-red, blooms and ripens late, some two weeks after Concord.

\section{Æstivalis-Labrusca Hybrids}

GOLD COIN, T. V. M. 1885 (Norton x Martha) ( $\left(\frac{5}{12}\right)$. Growth medium. Cluster medium or above, ovate shouldered, proper degree of compactness. Always sets a crop of well-filled clusters; peduncle medium to long. Berries large, globular, yellowish when fully ripe, persistent; skin thin, tough, never cracks, and rarely attacked by rot; pulp about same consistency as Concord, very juicy and exceedingly sweet; retains a little of the Martha flavor; liked by most persons. Very handsome in the basket and markets excellently; has always been very profitable. Ripens with Catawba, endures all extremes of climate well. Favorable reports of it from all parts of the South, and as far north as 40 degrees latitude. Eight to ten feet. Medium arms. Requires good soil cultivation and fetilization to maintain its vigor.

KENTUCKY (Norton $x$ Concord), an accidental seedling found by James Childer, of Auburn, $\mathrm{Ky}$, in his garden, in 1887 ( $\frac{5}{12}$ ). Vine vigorous, hardy, healthy, prolific. Growing tips rusty like the Norton, leaves large, leathery, tendrils long, skipping every third node; bunch large, compound, conical, compact; berry medium, round, black; skin thin, tough, pulp tender, juice very red, quality verygood; seeds small; a good market and fine red wine grape; ripens with Norton.

\section{Estivalis-Lincecumii-Rupestris Hybrids}

WINE KING (Winona x America), produced by T. V. M. 1898. ( $\frac{5}{11}$ ). Winona was a pure seedling of Norton, of better quality than parent, produced in 1889, and accidentally destroyed (see America, p. 196, for its parentage).

A vigorous, perfectly healthy vine every way, foliage very dark green, prolific, blooms a little earlier than Norton; flowers perfect; cluster long, cylindrical, rarely shouldered; long peduncle; berries a size larger than in Norton; persistent, round; skin thin, does not crack, pulp tender, juicy; juice violet, sprightly, having a little trace of America flavor, very agreeable, rather small for market, a very fine red wine grape; seeds small; entirely resistant to Phylloxera, mildew and rot. 


\section{Bourquiniana Varieties}

For discussion of the prime origin of this class of grapes see pages 54-60, see Plate XVIII.

HERBEMONT (Syn. Brown French, Nei1). ( $\left.\frac{(5}{20}\right)$. Vine exceedingly vigorous, healthy and long-lived in all the South. The extreme endurance of cold in winter temperature of the dormant wood of this variety is $15^{\circ}$ below zero (F.). The buds are often damaged at zero or a few degrees below. Endures great heat, long and severe drouth equally with the natives of Southwest Texas. The fruit in moist regions is subject to Black Rot. The plate shows a well-grown average size cluster. The vine is prolific; the berries are of a dull brownish-red color; skin thin, tough, never cracks, pulp all juice, of a sprightly very sweet agreeable flavor when fully ripe; seeds small. The berries are too small to compete successfully in market against larger kinds, but the variety makes a fine white or amber wine, with excellent keeping qualities; ripens a week or more after Norton.

LENOIR (Syn. Black Spanish, Blue French, Jacquez). Origin, so far as known, same as Herbemont. ( $\left(\frac{5}{16}\right)$. Vine vigoroủs, but less so than Herbemont; foliage larger and darker green, and very sensitive to Downy Mildew in moist regions, also the fruit to Black Rot, but in Southwest Texas it flourishes in health and bears great crops of very long, rather open clusters of round, small, black berries, with rich sprightly red juice; makes a fine claret; ripens a little before Herbemont.

There are a number of other varieties of this species, such as Baldwin, Bertrand, Cunningham, Devereux, Elsingburgh, Harwood, Lincoln, Louisiana, Pauline, Rulander, mostly very little planted or entirely out of cultivation. All have small berries. The Ohio, or Cigar Box, variety, has been placed in this class by other writers, but it does not belong here (see Vulpina $x$ Vinifera Hybrid).

\section{Bourquiniana-Labrusca-Vinifera Hybrids}

The prime origin of the Bourquiniana species being unknown, this, like the last group, is theoretical in part, based upon botanical analysis, and reversion in seedlings. All, like Delaware, are subject to mildew in foliage, generally resist Black Rot, but subject to Ripe Rot in fruit.

AMETHYST, T. V. M. 1896, parentage Delago x Brilliant. ( ' $\frac{5}{10}$ ). Vine similar in habit to Delaware, more vigorous, leaves larger, with more pubescence on lower side, much heavier cropper than Delaware. Cluster medium; berry large, ovoid, clear red, with delicate bloom; skin thin and tough; pulp tender, quality the best. Uses, market, table, white wine. Medium season, with Concord. Plant 8 feet apart, short arm. Requires spraying. (See Plate $\mathrm{XL}$., page 144.)

AUGUSTINA, T. V. M. 1899, sister of Amethyst. ( $\left(\frac{5}{12}\right)$. Combination of Delaware, Goethe, Brilliant. Cluster large; berry very large, translucent carmine red; very handsome; skin thin and tough; pulp meaty, tender and juicy, quality the best, with very delicious characteristic flavor. Good grower, very prolific, table, market, white wine. Season very late, after Catawba. Plant 8 feet, short arm pruning. Spray.

DELAGO, T. V. M. 1884, Delaware x Goethe. (, $\left.\frac{5}{8}\right)$. Vine same habit as.Delaware, a little more vigorous, with leaves a little larger, and slightly more downy on lower side; clusters small to medium, long peduncle, fairly compact, shouldered; berries large ovoid, bronzy red, skin tough, but not very thick, pulp fairly tender, very sweet, highly flavored, Muscat-like, of best quality; seeds few; rather large, ripe soon after Delaware. Vine requires pollenizing and spraying.

DELAWARE. Originated in garden of Paul H.. Provost, a Swiss vineyardist, of Frenchtown, N. J., where it was found after Provost moved away, about 1850, and was first brought to public notice about 1855 by $A$. Thompson, of Delaware, Ohio, and was generally disseminated some ten years later by G. W. Campbell, of Delaware, Ohio. ( $\left.\frac{5}{5}\right)$. 


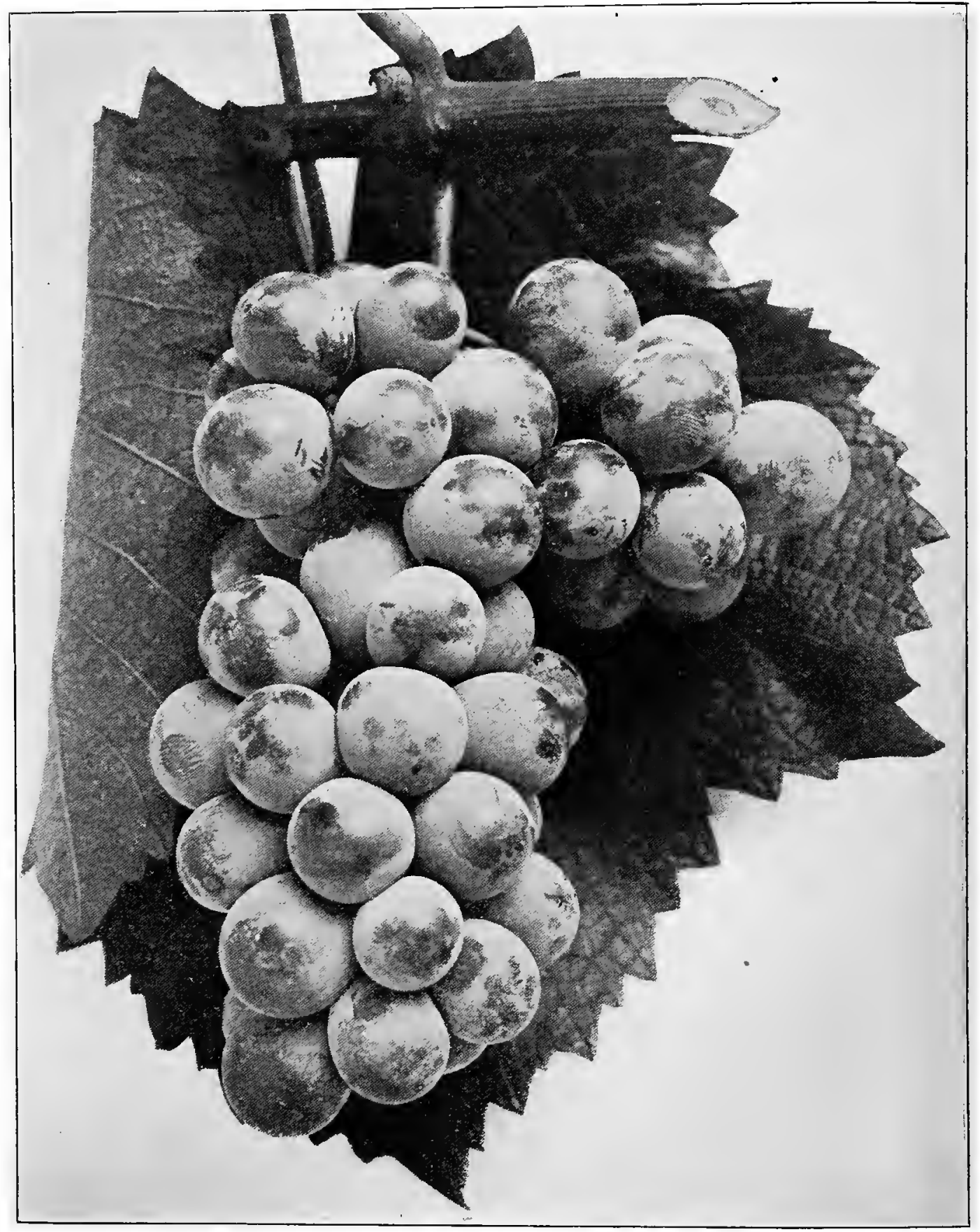

PLATE XL. AMETHYST. (See page 143.) 


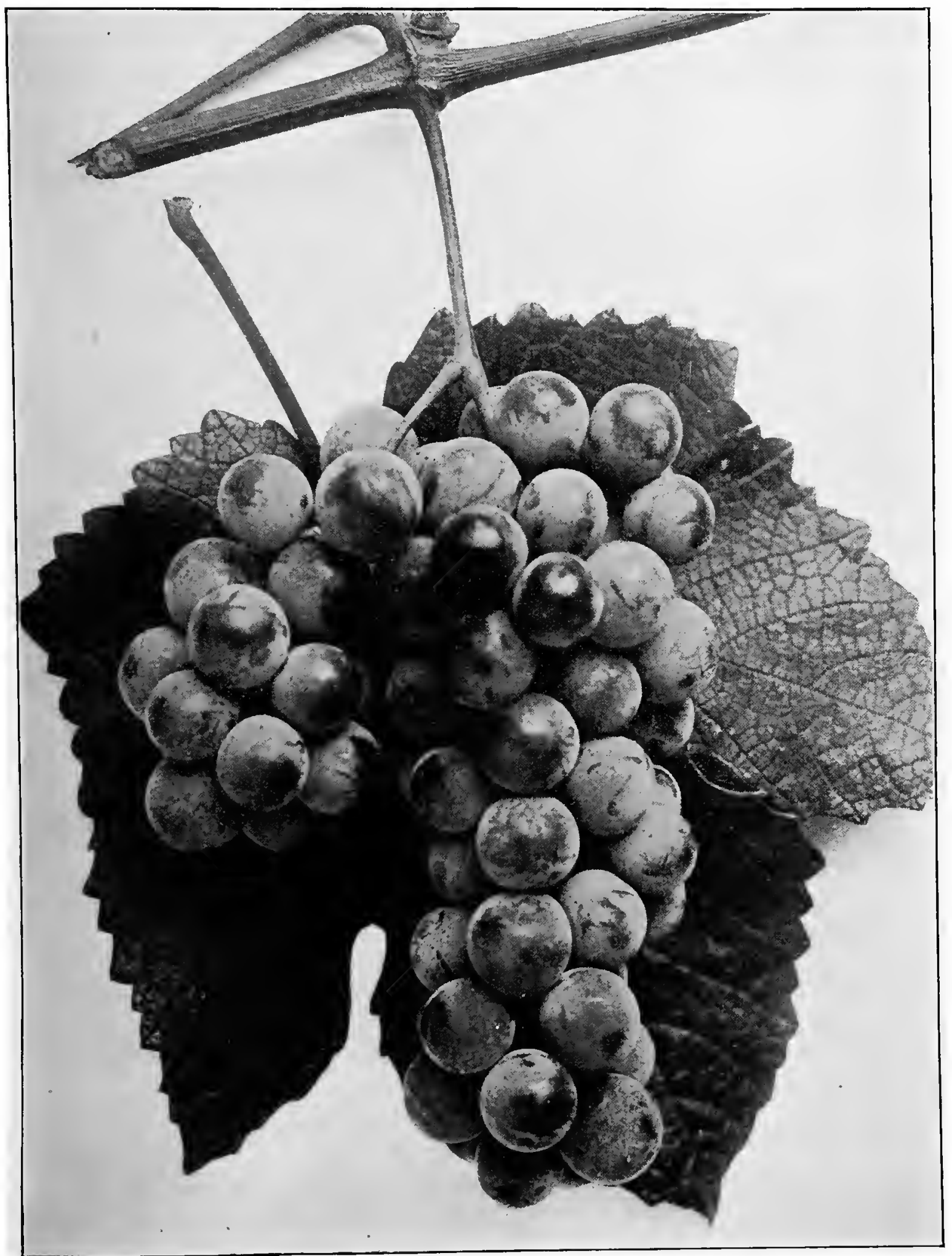

PLATE XLI. DELAWARE. (See page 143.) 


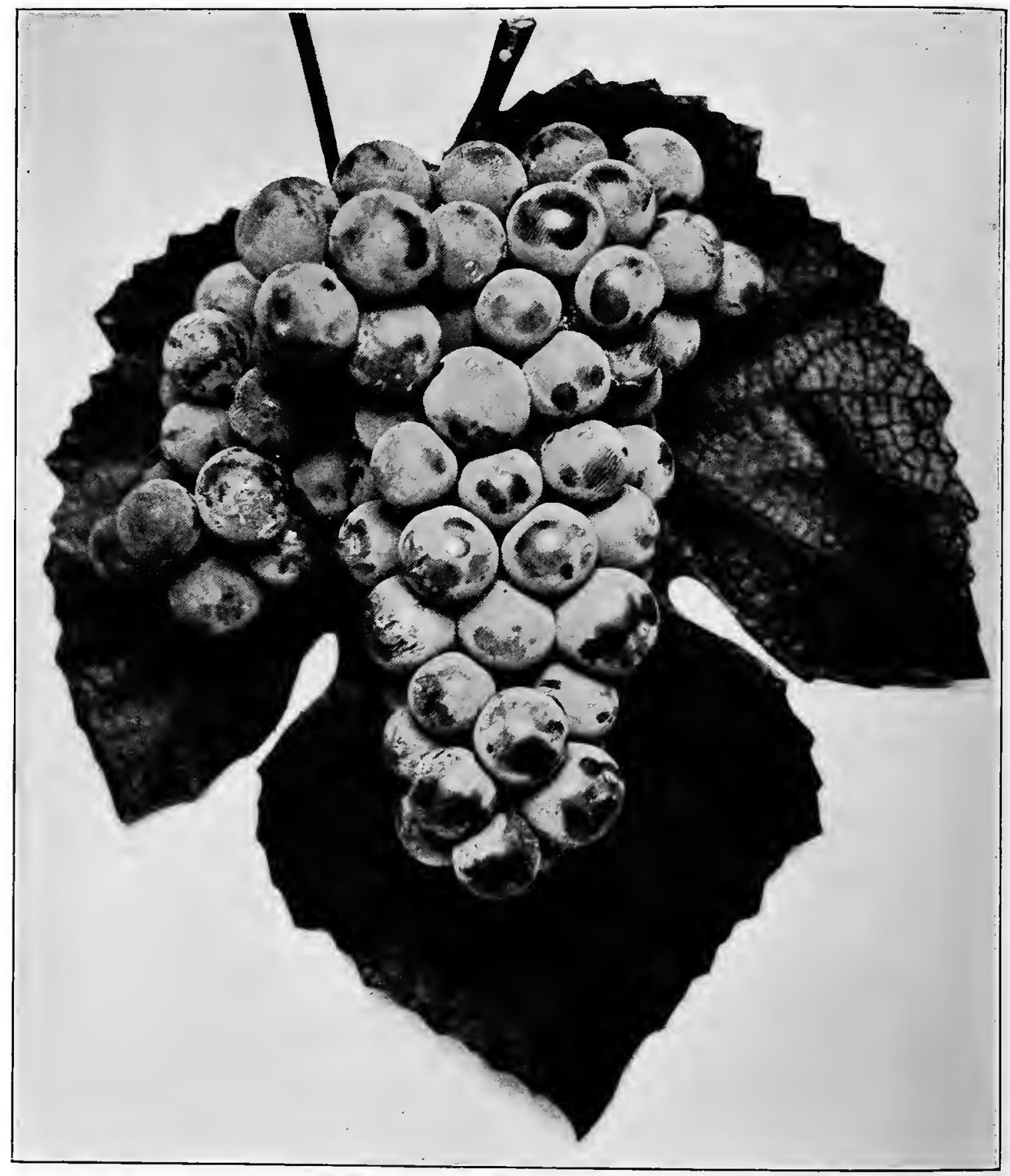

Plate XliI. HeAdLight. (See page 148.) 


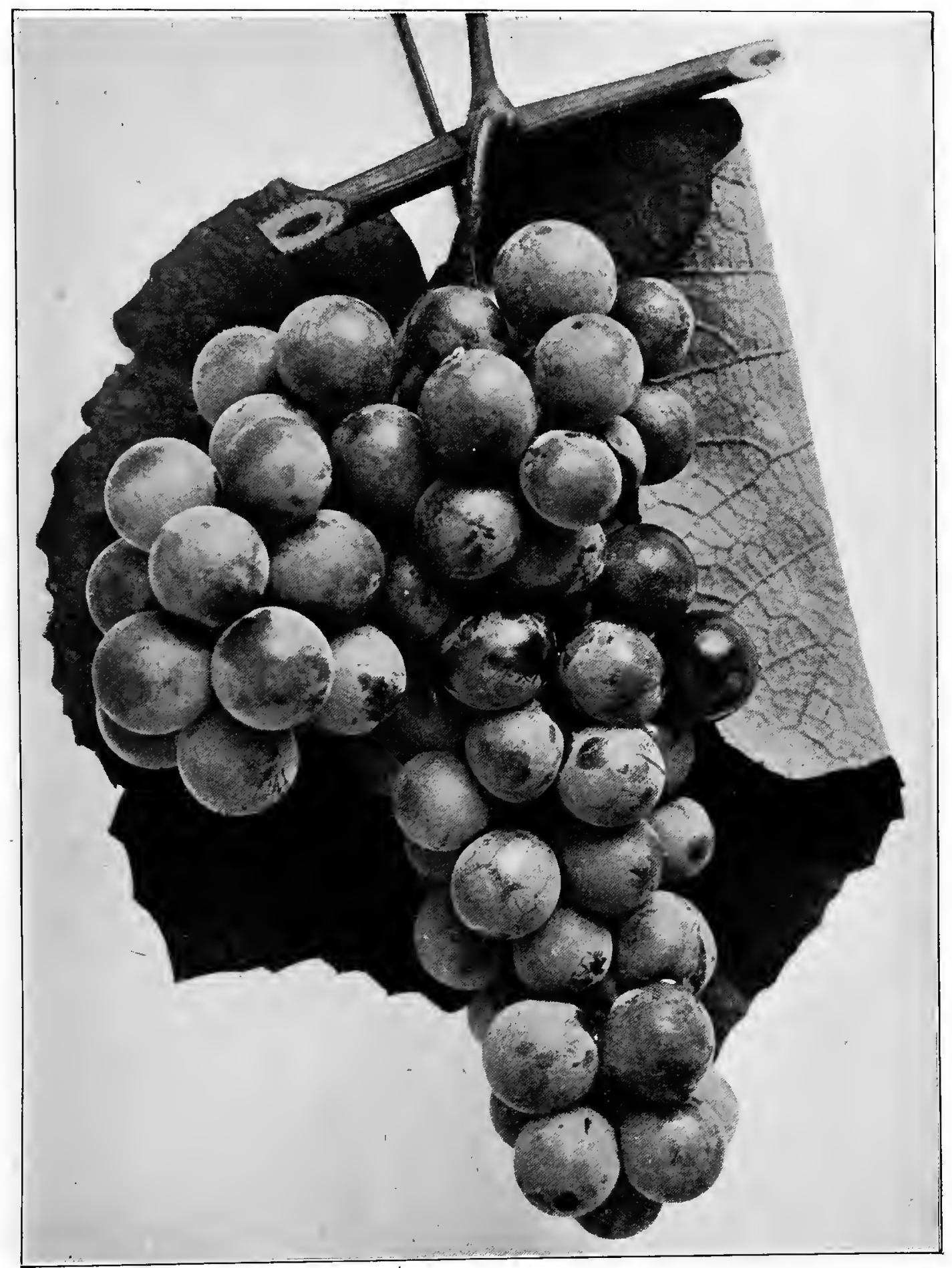

PLATE XLIII. HIDALGO. (See page 148.) 
Many years before the Delaware was first known, both the Eisingburgh and Catawba were known along the Delaware river, and undoubtedly were grown by Provost, as well as a number of varieties he brought from Switzerland. As the Delaware is clearly not pure Vinifera, but in its analysis, shows characteristics of Bourquiniana, Labrusca and Vinifera, we must conclude it was an accidental hybrid with Mr. Provost. But if it is a product of only one natural crossing in garden of Provost, one of the parents must have been a hybrid, and in all probability a red variety. But one variety was then known of such character,-the Catawba-and the Elsingburgh fills the requirements for the other blood-Bourquiniana-it having three-lobed leaves, much like Delaware, with same clear lively green similar to Herbemont, with slender vine and same habit of Delaware, clusters much the shape of Delaware, and berries smaller with white juice, tough dark purple skin, seeds small, a true Bourquiniana-which may have been brought from Europe by Provost, but it is far hardier to resist cold than Herbemont ( $\left.\frac{6}{8}\right)$; ripens early. Here we have at hand, in the same region, at the right time, the right elements to make Delaware, and no other such elements known to exist, hence I take this as the most probable source of origin of the Delaware. There is no need to describe Delaware, as every American knows it. It succeeds better South than North, resisting Black Rot but requires spraying to ward off Downy Mildew. (See Plate XLI., page 145.)

HEADLIGHT, 1896, T. V. M., Moyer x Brilliant. (, $\left.\frac{5}{4}\right)$. Moyer is a Canadian hybrid of Delaware with some early Labrusca kind, probably. (See Brilliant, page 167, for its parentage.)

Vine slender, but more robust than Delaware, and making much longer vines, less attacked by mildew, leaves resembling those of Brilliant, but not so large; clusters small to medium, very compact, shouldered; berries clear red, globular, medium or above in size, very persistent; skin thin, tough; pulp tender, very sweet, almost equal to Delaware in quality; seeds few; ripe the earliest of any American grape,-June 25th to July 1st, at Denison. Texas, making it valuable as an extra early market grape, supplanting such poor things as Champion. (See Plate XLII., page 146.)

HIDALGO, T. V. M. 1889, Delago x Brilliant. ( $\left.\frac{5}{7}\right)$. Cluster large; berry large, ovate, yellowish-white, translucent. skin thin and tough; pulp tender and melting, quality best; uses, table, market, white wine. Early, handsome, delicious. Eight feet, short arm pruning. (See Plate XLIII., page 147.) Often larger than as shown in plate.

KRAUSE, T. V. M. 1893, seedling of a hybrid of Herbemont with Niagara, produced by Prof. E. W. Krause, of Waco, Texas. ( $\left.\frac{5}{12}\right)$. Vine vigorous, slightly attacked by mildew in damp seasons, prolific; cluster large, shouldered; berries large, globular, pearly white, handsome, skin thin, tough, pulp tender, melting, of fine quality, little attacked by rot, a valuable market and table grape, for the South, north to Kansas and Kentucky. (See Plate XLIV., page 150:)

ONDERDONK, T. V. M. 1885, Herbemont x Irving. ( $\frac{5}{15}$ ). Vine vigorous, considerably hardier than Herbemont, little attacked by mildew, and rarely by rot; leaf larger than Herbemont, of a less lively green, with more pubescence on lower side, very prolific of large, compact clusters, berries persistent, globular, pearly white, about same size as Herbemont; skin thin, tough, does not crack, pulp all juice, very sprightly, and equal to Herbemont: ripens a little before Herbemont. Successful wherever Herbemont does well; makes a fine white wine.

TUSKAHOMA, T. V. M. 1896, sister of Amethyst. ( $\left.\frac{5}{6}\right)$. Vine good grower, prolific, mildews about same as Delaware, resembles Amethyst; cluster medium, shouldered, compact, berries globular, above medium, clear bright, translucent red, with delicate bloom, persistent, skin thin, tough, pulp tender, very rich, highest quality. Well adapted to Middle and Western Texas, Oklahoma and Southwest Kansas. (See Plate XLV., page 151.)

WALTER. Produced by A. J. Caywood, of Poughkeepsie, N. Y., by crossing Delaware with Diana, the latter a seedling of Catawba. ( $\left.\frac{5}{10}\right)$. It much resembles Delaware in vine and fruit, 
the cluster is of same shape but more compact, and the berries a little larger and more pulpy, quality otherwise similar. Requires spraying.

XENIA, T. V. M. 1896, Delago x Gov. Ross. ( $\left(\frac{5}{10}\right)$. Gov. Ross is a pure seedling of Triumph, which see page 167. Vine vigorous, prolific; foliage subject to mildew in wet seasons; clusters medium to large, compact, berry very large, white; skin thin and tough; pulp meaty, tender, sprightly, highly flavored, best. Very late, with Fern or just before. Eight feet, short arm.

\section{Champini-Labrusca Hybrids}

The $V$. Champini, a very vigorous, healthy species, native of the very limy hills of South Central Texas, northwest of Austin, has been found not only one of the very best resistant stocks for grafting, but also very responsive and promising as a basis of fine quality and beautiful varieties, adapted to very limy soils and dry; hot climate, with power to endure $15^{\circ}$ to $20^{\circ}$ below zero (F.). See Plate X., page 37. A few selected from many hybrids, produced by the author, are described below.

CHAMPANEL, T. V. M. 1893. ( $\left(\frac{5}{5}\right)$. (V. Champini $x$ Worden). Growth rampant, exceedingly resistant to heat and drouth, growing well in limy, black soils. Clusters large, conical, with long peduncle, rather open. Berries globular, large, black, with white bloom, persistent; skin thin, tough; pulp tender, juicy, very sprightly, acid unless well ripened, then quite agreeable; seeds rather large, easily leaving the pulp. Ripe about with Concord, which it resembles very much in cluster and berry. Does well in any soil, but valuable for black waxy lands of the South, where few other varieties will grow. Ripens evenly and not given to cracking or dropping as is the Concord or Worden in the South. Ten to twelve feet. Long arm pruning.

LUKFATA, T. V. M. 1893. (, $\left.\frac{5}{5}\right)$. (V. Champini $x$ Moore Early.) Growth strong. Endures heat, drouth and cold remarkably well. Succeeds in black, limy soils. Not injured by mildew. Cluster medium, ovate, sometimes shouldered, compact; berries globular, large, persistent; does not crack; pulp about same as Moore Early, more juicy and very sweet and agreeable. Ripens early and evenly. Sells in the market as well or better than Concord and ships far better. Little attacked by rot. A good market and a fair table grape. Flowers have reflexed stamens, hence it must be grown near some variety with erect stamens flowering at same time, such as Ives; then it bears well. Plant 10 to 12 feet apart. Give long pruning. (See Plate XLVI., page 152.)

\section{Champini-Labrusca-Vinifera-Bourquiniana Hybrids}

SALADO, T. V. M. 1893 (Champini, De Grasset $x$ Brilliant). (, $\left.\frac{5}{1}\right)$. Vine vigorous, foliage somewhat subject to mildew, dark green, leathery, less pubescent than Brilliant, and not so large; cluster medium to large, handsome; berry above medium, round, black without bloom, persistent, skin medium thickness, tough, pulp tender, juicy, colors early, but quite acid until very ripe, then rich, sprightly and good. Not disseminated. Used as a mother to breed from. The next two following are best selections from several hundred hybrids.

LADANO, T. V. M. 1902 (Salado $\mathrm{x}$ Headlight). ( $\left.\cdot \frac{5}{4}\right)$. Vine vigorous, healthy, foliage similar to that of Headlight; cluster medium, compact; berry medium or above, dark clear purplish-red, translucent, round, skin thin, tough, pulp tender, melting, rich, pure and sweet, seeds few, ripe early.

LOMANTO, T. V. M. 1902 (Salado x Pense). ( $\left(\frac{4}{20}\right)$. Vine vigorous, prolific, healthy, no rot or mildew; leaf medium, having little pubescence; cluster above medium, conical, properly compact; berry very persistent, medium to large, spherical, black, skin thin, tough; pulp melting, excellent quality; juice claret red; sugar $66^{\circ}$, acid 7 per mill, in very wet season; seeds small, few. Valuable for limy soils and hot climate. 


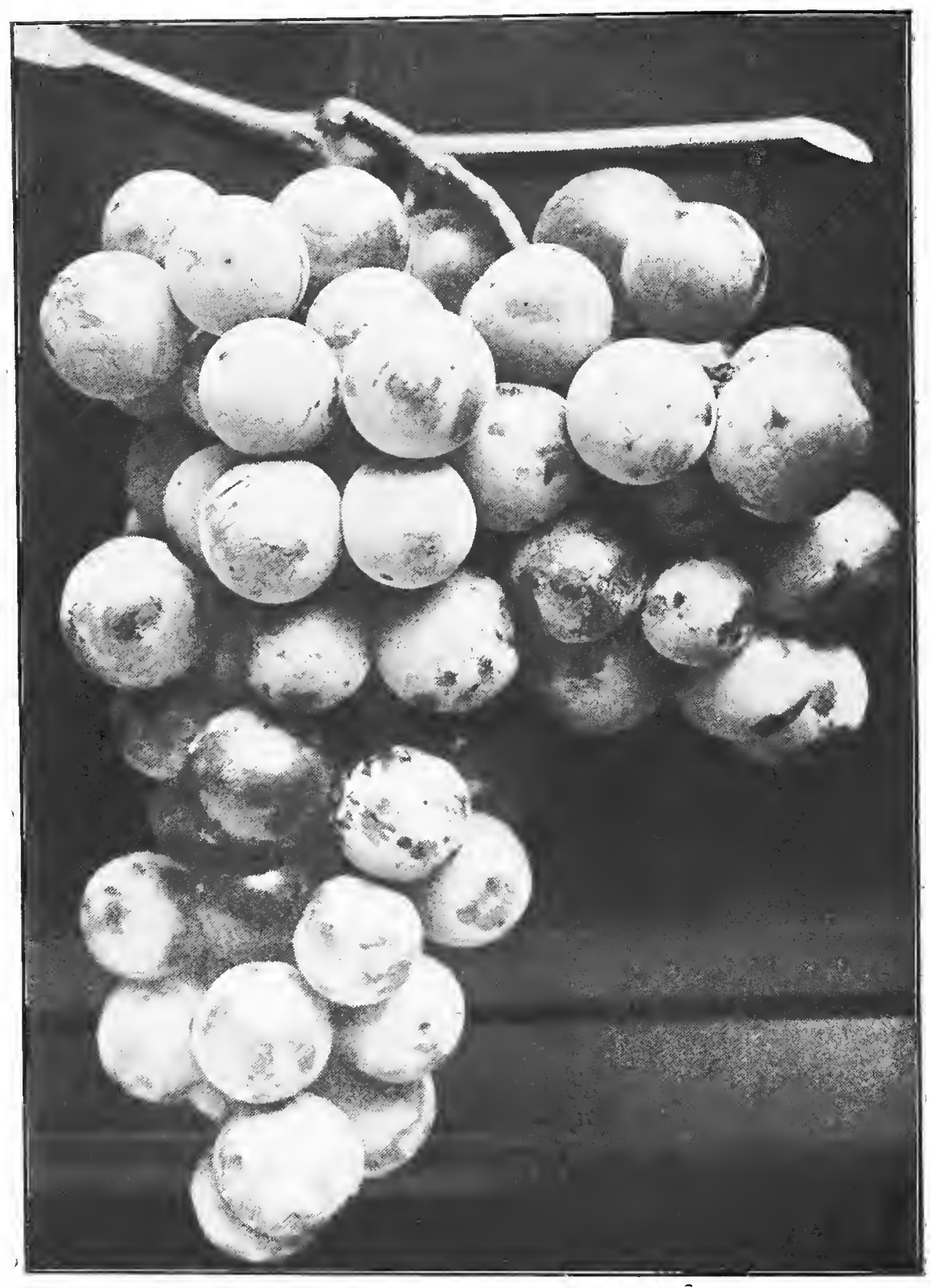

PLATE XLIV. KRAUSE. (See page 148.) 


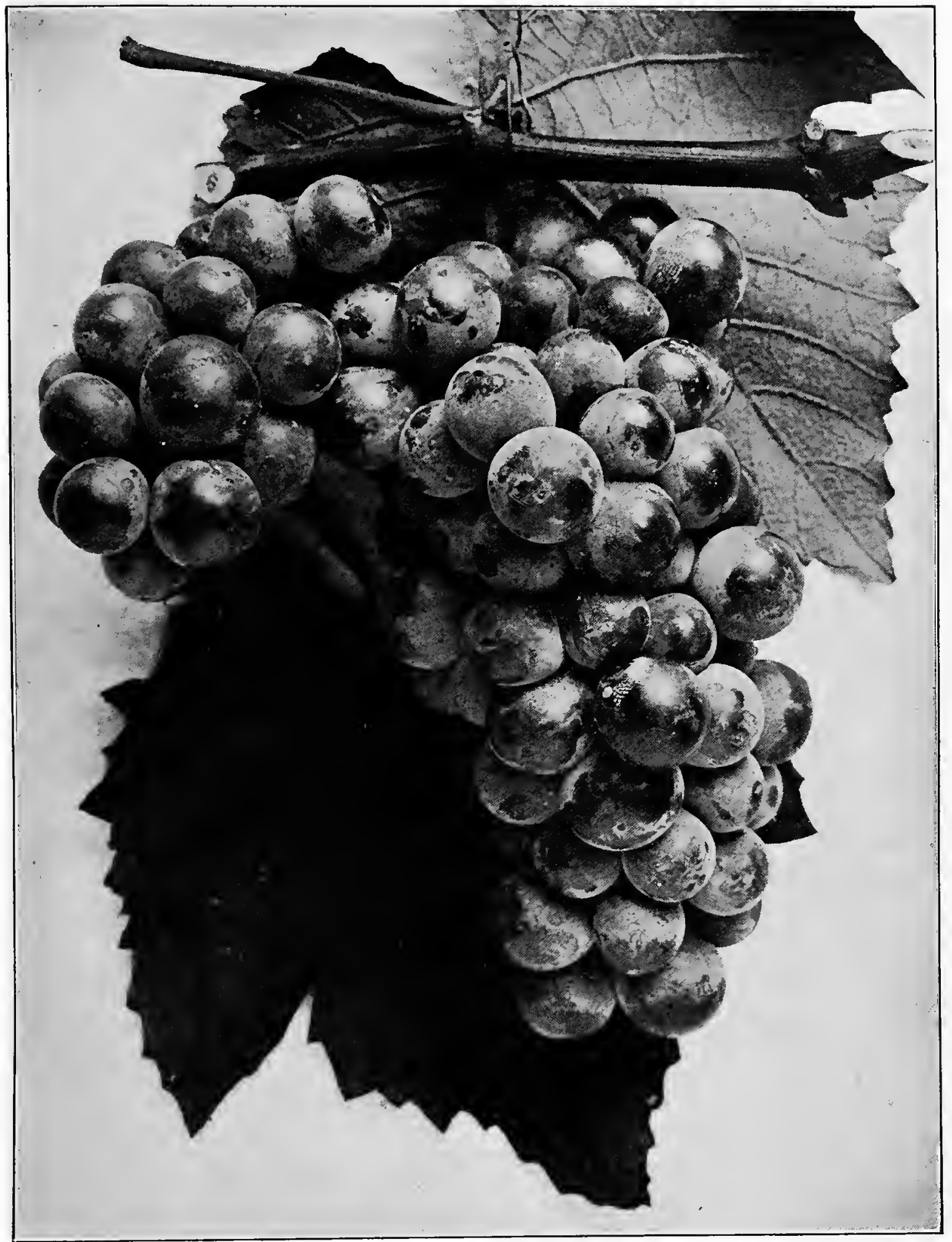

PLATE XLV. TUSKAHOMA. (See page 148.) 


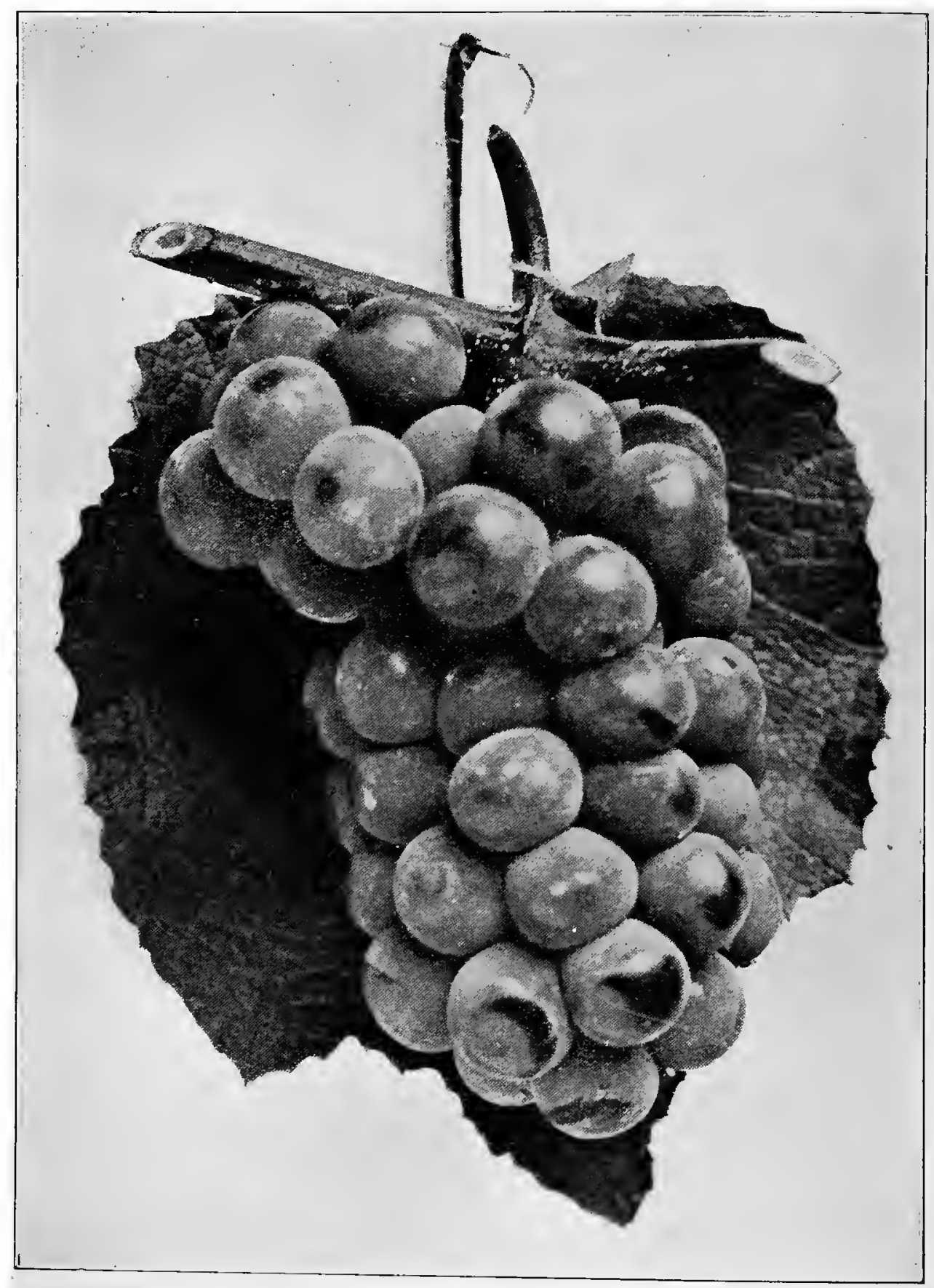

PLATE XLVI. LUKFata. (Sée page 149.) 


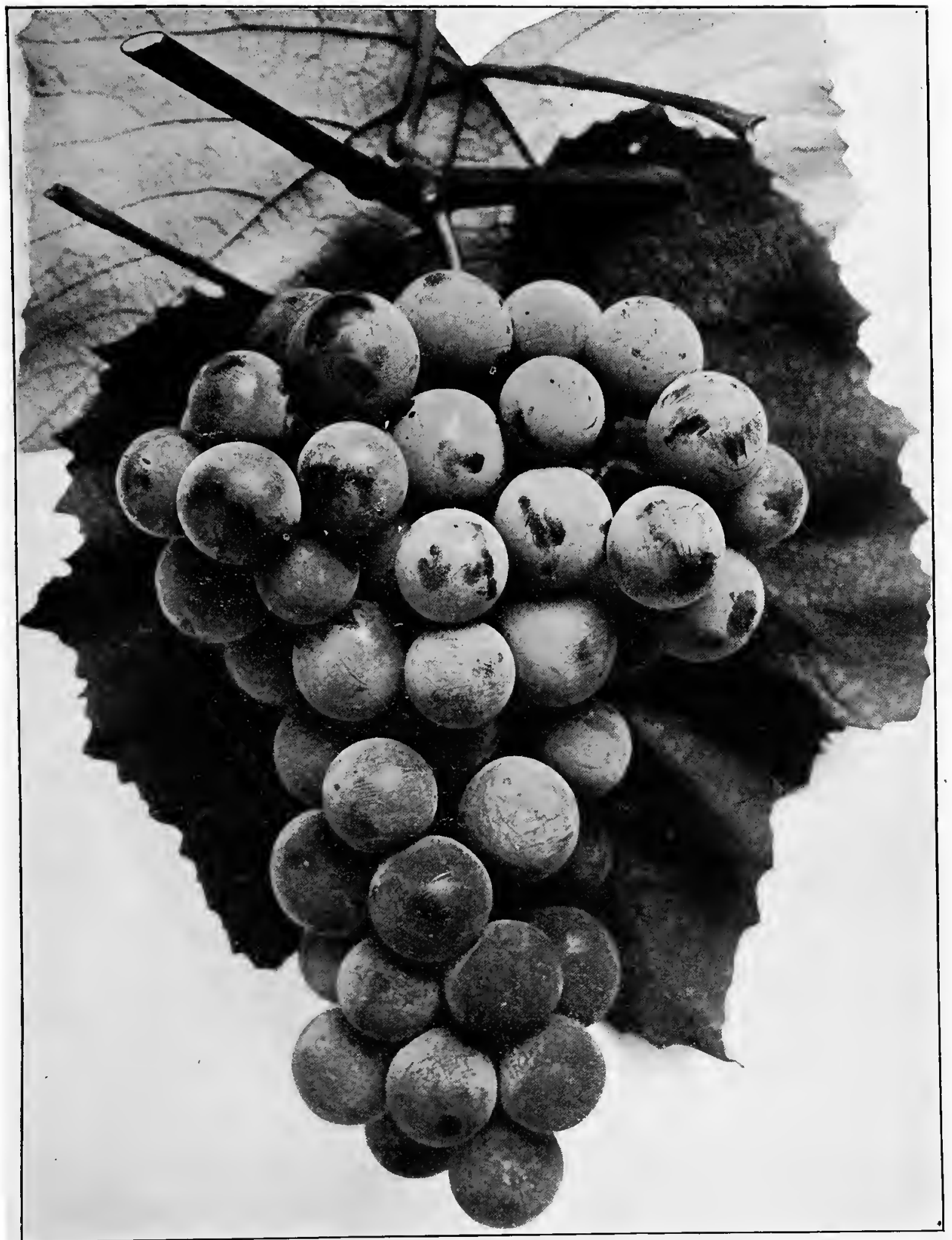

PLATE XLVII. CONCORD. (See page 155.) 
NITODAL, T. V. M. 1902 (Saladox Pense). (“ $\left.\frac{4}{23}\right)$. Vine vigorous, healthy; leaf medium with little pubescence; cluster medium to large, conical, handsome; berry persistent, above medium, spherical, translucent, dark red, skin thin, never cracks; pulp melting, pure, fine; juice pale pink, sugar $67^{\circ}$, acid 6 per mill in very wet season; seeds small, few. Altogether very attractive and valuable, especially in limy soils in hot climate.

SABINAL, T. V. M. 1902 (Salado x Brilliant). ( $\frac{5}{8}$ ). Vine a rampant grower, healthy; leaf large, entire or sublobed, very little downy pubescence on under side and on young wood; cluster medium; berry very large, pale clear red; beautiful, skin thin, not cracking, pulp melting, very juicy, sprightly, sweet and good; ripe late, persistent.

\section{Labrusca Varieties}

\section{(See Plate XLVII., Concord, page 153.)}

The foundation of grape-culture in the North up to the present has rested upon $V$. labrusca chiefly, supplemented with its hybrids with $V$. Vinifera and $V$. vulpina.

I give the descriptions of twenty pure varieties of this species, not because all are valuable, but to exhibit what the great North is trying to build upon, grouped together.

The merits of this species are, that its vines endure great cold, and are little subject to mildew and rot, root easily from cuttings, have large berries, and generally tough skins that do not crack easily, bear four and five clusters continuously without skipping every third joint (node), as do other species.

Its weaknesses are, weak resistance to Phylloxera, having a resisting power of only four to eight points, out of a scale of twenty points, the highest, or complete resisting power, which the Southern'Muscadines possess, and when united in hybrids with Vinifera (which stands at zero in resistance), makes varieties of low resisting power of three to four; small clusters, with little or no peduncle (cluster stem), making the fruit difficult to gather without marring; little power of the berry to cling to cluster, causing some varieties to drop badly; thick astringent skins, tough, slippery pulp; possessed of a very intense foxy aroma and flavor, which to grape connoisseurs, are very disagreeable; very low per cent of sugar; large, very hard seeds; little endurance of severe drouth and heat, rendering them unsuitable for dry, hot countries; dull, unattractive colors.

It would probably be to the advantage of grape development in the North if all its Labrusca varieties, except Colerian, Concord, Dracut Amber, Early Ohio, Ives, Moore Early, Pocklington and Worden were destroyed, and with these begin a more judicious hybridization. Dracut Amber would be probably the best basis for early red varieties, Early Ohio and Moore Early for early black varieties, Colerian for early white varieties; Concord, Ives, and Worden for mid season, making Pocklington for late kinds. But, scanning the many hybrids of these with Vinifera, for hardy, healthy high quality grapes, there is little hope to do better in that direction. The Clinton, Elvira, Taylor, Monitor, combinations of Labrusca with Vulpina, and the Kentucky, a Concord $\mathrm{x}$ Norton Virginia hybrid, point surely a better way. The large berried Post-Oak grapes (V. Lincecumii) of Missouri, hardier than Norton, offer a still better base. Even the best selections of $V$. bicolor of Ohio, Michigan, Illinois and Wisconsin, present a very inviting and promising material to work up northern viticulture, admitting into the combinations some blood of the very hardiest, healthiest, best quality Vinifera, such as Malaga, Calabrian, Muscat Rose, Semendia, Violet Chasselas, Rose of Peru, and Muscat of Alexandria.

CHAMPION, originated with R. J. Donnelly, near Rochester, N. Y. before 1873 . ( $\frac{5}{2}$ ). Vine very healthy, vigorous and prolific, leaves large, leathery, much felted pubescence on lower face, slightly three lobed; clusters medium, compact, shouldered; berries large, globular, black, with heavy white bloom, skin seldom cracks; pulp not very tough; quality very poor, -almost. wanting, would better express it; earliest of this group.

COLERIAN, originated from Concord seed by David Bundy, of Colerian, Ohio; introduced in 1885. ( $\frac{5}{6}$ ). Vine with Concord character, abundant bearer, cluster full medium, shouldered; 
berry greenish-white, with thin white bloom; skin thin, tender; flesh juicy, very sweet for this species; pulp tender with few seeds; ripens a week before Concord, and hangs well to bunch; Concord has produced many other pure white seedlings, but generally they are weak in growth and not prolific, have very thin skins given to cracking. The Colerian is probably the best of the lot.

CONCORD, originated by Ephraim W. Bull, of Concord, Mass., the best of many second generation seedlings, from seeds saved from some wild grapes handed $\mathrm{Mr}$. Bull by some passing 'boys, who had been grape-hunting, in the woods, about the year 1845, near Mr. Bull's home. ( $\left(\frac{5}{8}\right)$. It was first shown to the public in an exhibition of the Massachusetts Horticultural Society, in Boston, 1853 , and attracted much attention, and was soon thereafter introduced to vinegrowers with much favor. Since then it has been more extensively planted than any other variety east of the Rocky Mountains. It is too well known to need description. In Plate XLVII., page 153, is presented a life-size picture of leaves, and a typical, well-grown cluster.

Numerous seedlings and hybrids of it have been produced, no pure-blood seedling of it has ever excelled it as a market variety. Worden is larger in cluster, and a little better in quality, but vine not so vigorous, and more subject to cracking and dropping of berries. Moore Early is much earlier and nearly equal in quality and is the best early black grape of that class. A number of white Concord seedlings are more tender and sweeter than Concord, but much less vigorous and prolific and profitable. Several of its hybrids are fine, attractive grapes, and some of good value, altho its quality is so ordinary and it has several serious defects, yet its production was of vast value in establishing profitable grape-growing thruout the North, and to some extent in the South. It resists mildew well, but its fruit ripens very unevenly in the South, and Black Rot attacks it severely, unless well sprayed. It cracks and drops badly in wet seasons in the South, and its vines are short-lived. Its juice requires to be heavily sweetened to make a wine that will keep any length of time. It makes a very good fresh grape juice and some large factories are engaged in making and selling such product.

COTTAGE is a sister of Concord, grown by Mr. E. W. Bull. ( $\left.\frac{5}{4}\right)$. It is similar in appearance to Concord, but is smaller in cluster, and drops its berries more freely, spoiling it for market. It does not crack and rot so badly; it is less prolific and a little earlier, but not so good in quality. It is now generally discarded.

DRACUT AMBER, originated by J. W. Manning, of Dracut, Mass., nearly half a century ago. Bred from the wild "Fox Grape," of that region. ( ' $\left.\frac{5}{3}\right)$. Bunch medium, cylindrical, compact; berries large, globular, dull red; very thick skin, pulpy and very foxy. Vine vigorous, prolific, healthy, fruit free from rot; very early, berries drop from cluster in basket, valueless in market, but fine for jellies.

EARLY OHIO, originated with R. A. Hunt, Enclid, Ohio, in 1882.' (' $\left.\frac{5}{4}\right)$. It seems to be a seedling of Hartford, probably crossed with Concord, or vice-versa. It is earlier than Hartford, more prolific, clings much better to cluster, of somewhat better quality, but yet is very poor in quality. Valuable only in the North for early market, but greatly needs improving. Vine vigorous and healthy in foliage and fruit. Moore Early is much better in quality.

EATON, seedling of Concord originated by Calvin Eaton, of Concord, Mass. (' $\left.\frac{5}{8}\right)$. Every way much like Concord, except the berries are very much larger, and the vine is a much more uncertain and less prolific bearer. Of little value, unless to breed from for size.

HARTFORD, originated with Mr. Steel, of Hartford, Conn., over fifty years ago. (' $\frac{5}{4}$ ) Vine vigorous, prolific, bunch medium, shouldered, berry medium, globular, black, drops easily when ripe, very early. Now valueless. Very pulpy and foxy.

HAYES, a Concord seedling raised by J. B. Moore, of Concord, Mass. ( ( $\left.\frac{5}{6}\right)$. Every way. much like Martha, except less foxy and of some better quality. Too light a bearer to be profitable. 


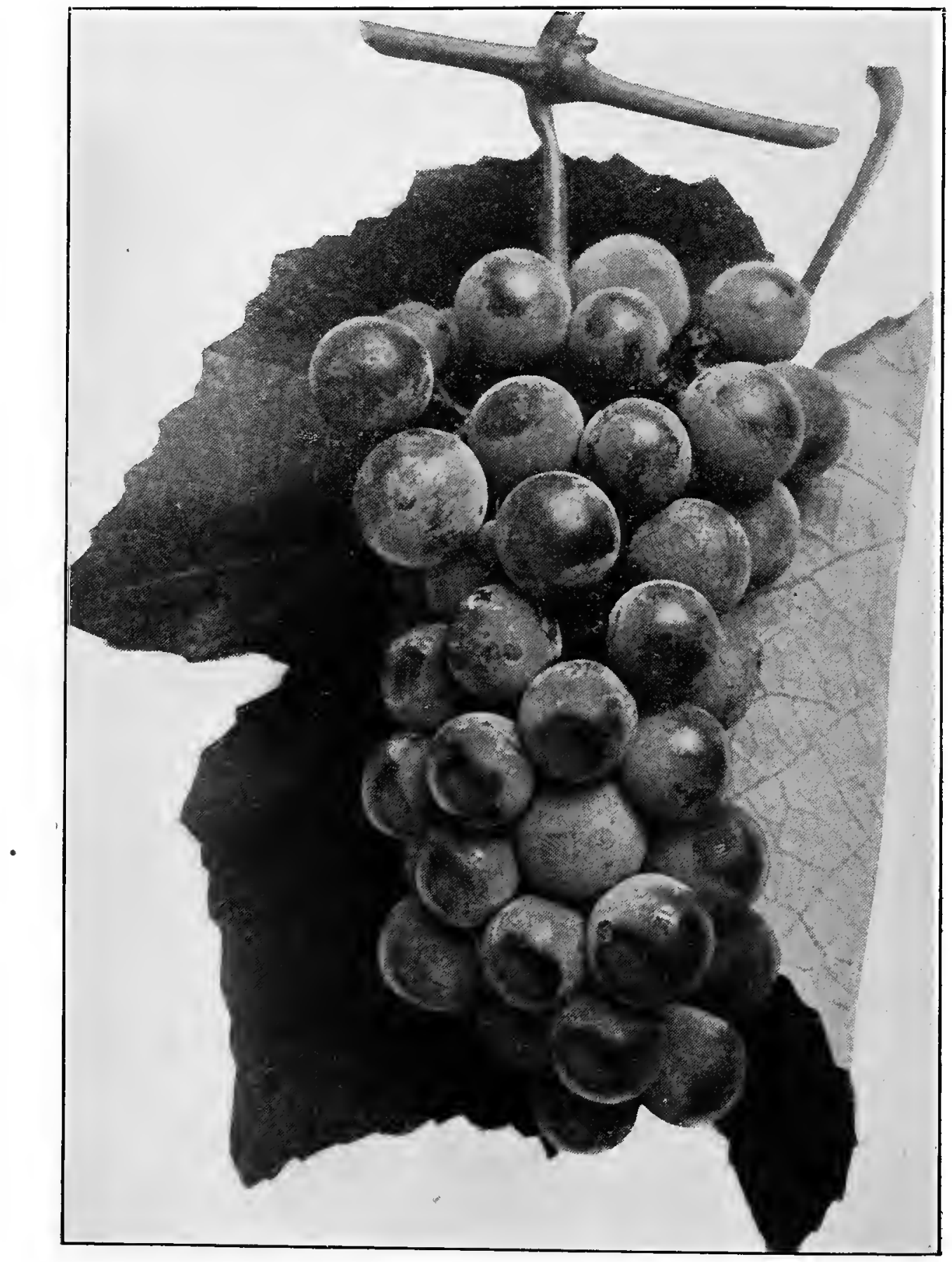

PLATE XLVIII. IVES. (See page 160.) 


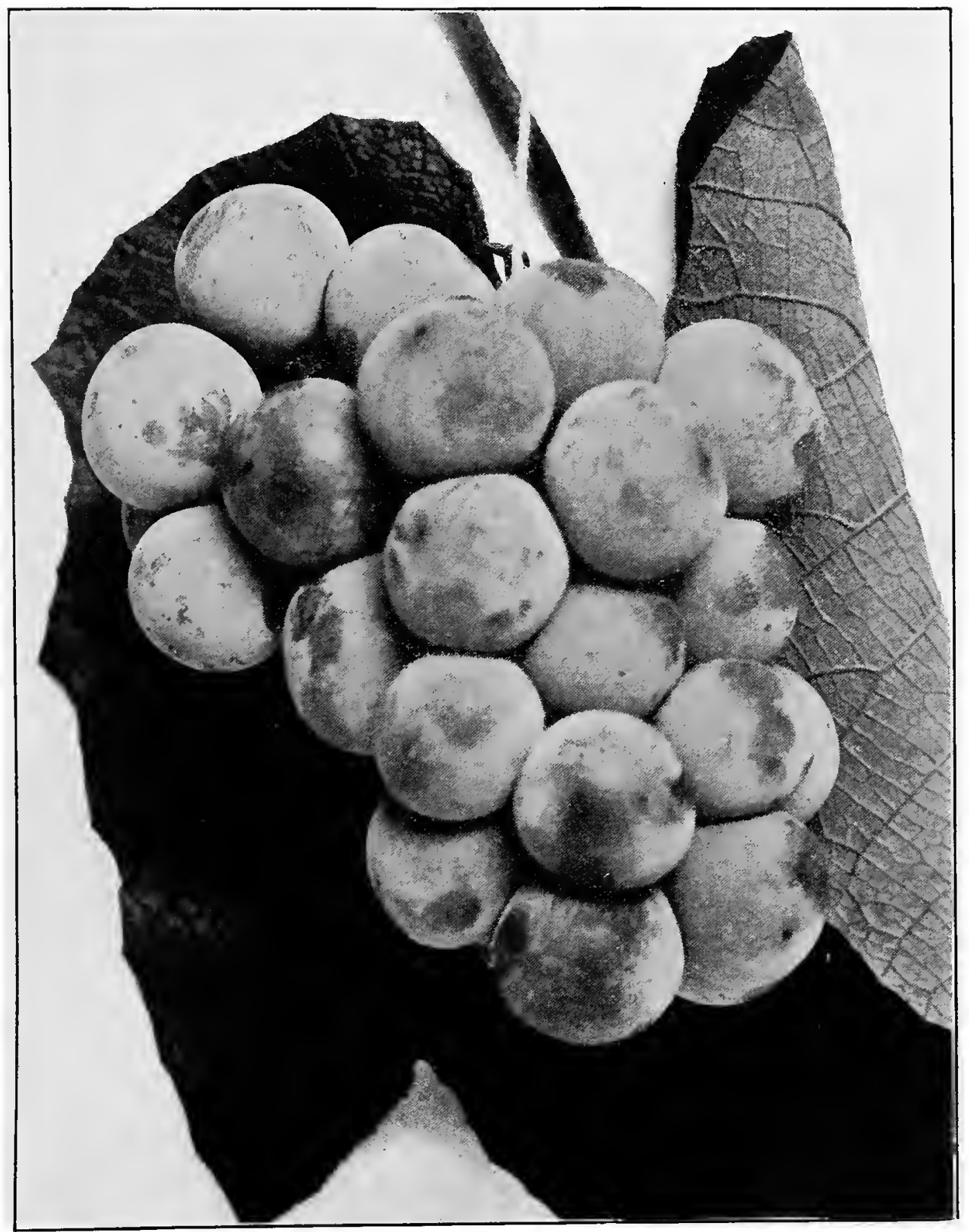

PLATE XLIX. RED GIANT. (See page 161.) 


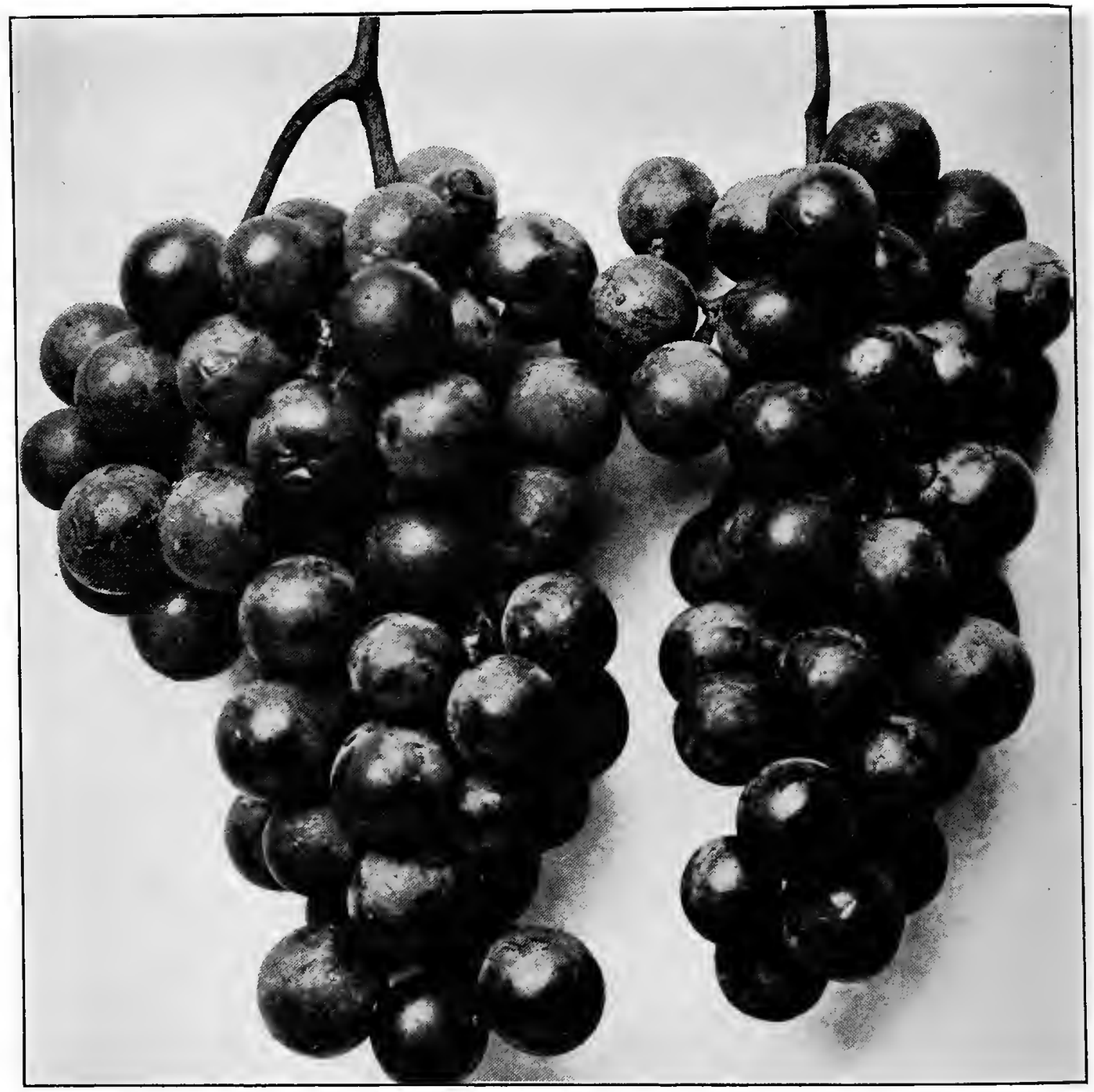

Plate L. CATAWBa. (See page 161.) 


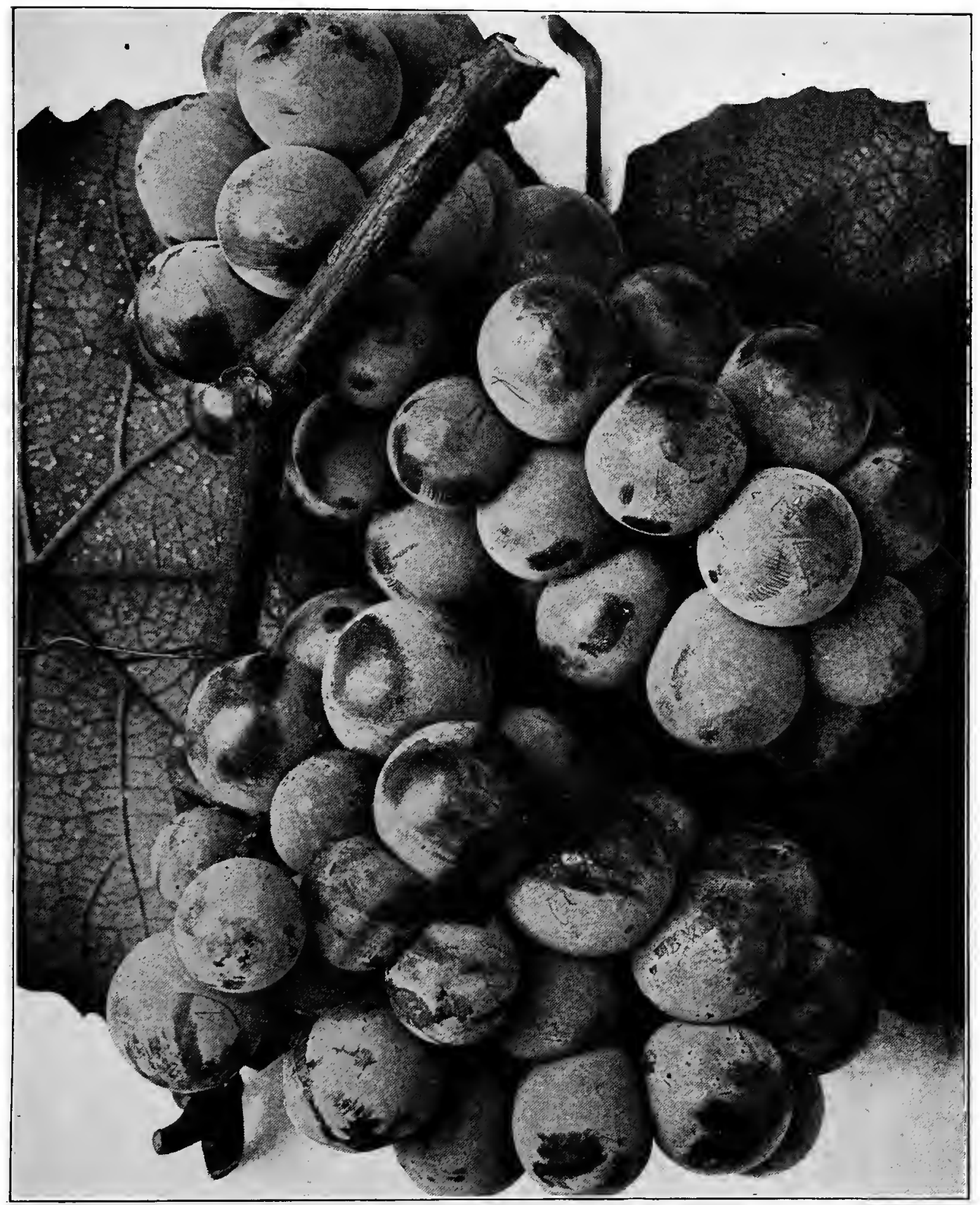

PLATE LI. HERNITO. (See page 166.) 
IVES, originated by Henry Ives, of Cincinnati, about the year 1844, but not disseminated to great extent until about 1865 . It was claimed by Mr. Ives that he grew it from seed of the Malaga! (Vinifera); but its every character is pure Labrusca, and it resembles much the old Alexander, that was found wild in Pennsylvania, and extensively used by Nicholas Longworth of Cincinnati for making wine, and it in all probability is an accidental seedling of that variety come up in the tub, in which Mr. Ives planted Malaga seeds, and thus deceived him. The letter of Mr. Ives to Jno. A. Warder claiming it to be a Malaga seedling is now in the writer's possession. ( $\left.\frac{5}{1}\right)$. It is vigorous and healthy, free from mildew and rot, and very prolific of medium, compact. cylindrical clusters, of medium size, slightly ovoid, black berries, which hang well to the cluster. Skin thin, tough, pulp very tough and sour about the seeds; colors early, but is not properly ripe before the Concord. It is usually taken to market in bushel baskets when it first colors, by those persons who still plant it, and it brings a price that pays no one a living. and has the effect to disgust and warn grape lovers not to buy. grapes while it lasts. A coarse, harsh wine can be made from it, by using much sugar and water to reduce the excess of acid,stuff unfit for any stomach. Only because the variety produces abundantly under careless culture and without spraying, does the lazy man still grow it. (See Plate XLVIII., page 156.)

LADY, originated by James Imlay, of Ohio, from Concord seed, and introduced by Geo. W. Campbell, of Delaware, Ohio, in 1874-5. ( $\left(\frac{5}{4}\right)$. Vine a weak grower, and shy bearer, cluster medium, compact; berry large, yellowish-white, globular; skin very tender, easily cracks, subject to rot, quality the best of any Concord seedling; very early, unprofitable.

LUTIE, originated by Dr. L. C. Chisholm, of Nashville, Tenn., about 1883 or 1884, from seed of Dracut Amber, probably, as it in almost every way resembles that variety, but ripens to a darker shade of red. ( $\left.\frac{5}{2}\right)$. It is early, thick-skinned, pulpy, exceedingly foxy, yet. withal, there are those who like these foxy things, thinking foxiness fine flavor!

MARTHA, originated by Judge Samuel Miller, of Bluffton, Mo., some fifty years ago, from seed of Concord,- - probably the first white seedling ever produced from it. ( $\left.\frac{5}{5}\right)$. It was, for many years, considered the best American white grape, and was much planted, but is little planted now, as it is a light cropper Vine resembling Concord, but less vigorous, cluster small, shouldered, open, berry medium, globular, yellowish, skin thin, but seldom cracks; ripens early; pulp tender. much sweeter than Concord, and more foxy when fully ripe. Now unprofitable in comparison with Niagara, Diamond, etc.

MOORE EARLY, originated by J. B. Moore, Concord, Mass., in 1872, fram Concord seed, and introduced in 1877. ( $\frac{5}{3}$ ). Its vine greatly resembles Concord, but is less vigorous, very healthy and the fruit not attacked by Black'Rot so much, nor does it crack. Bunch medium, compact, little shouldered; berry is very large, black, persistent to pedicel, skin tougher than in Concord; pulp still firmer than Concord, but yet much the best black Labrusca variety ripening at that time, which is very early, soon after Champion. Not valuable for the extreme South, but much liked as an early market grape in the North.

PERKINS, originated in Massachusetts, and is probably a chance seedling of Dracut Amber, which it resembles in many points, but has less color, a thinner skin and a more tender pulp. It is a slight improvement. ( $\left.\frac{5}{3}\right)$. Cluster above medium, cylindrical, compact berry slightly ovoid, pale dull red, free from mildew and rot; ripe early; remains in good condition only a short time, when it shrivels and drops.

POCKLINGTON, vine vigorous, healthy, prolific, a seedling of Concord produced by John Pocklington, Sandy Hill, N. Y., and introduced about 1877-8. ( $\left.\frac{5}{10}\right)$. Cluster large, shouldered, compact; berry large, yellowish-green, slightly oblate or globular; skin thick, tough; pulp rather tougher than Concord, aroma and flavor very foxy, and altogether not so good in quality as Concord; seeds large; ripe a week or more later than Concord, berries drop from cluster in basket. It is much less planted than formerly. 
RED GIANT, originated in Pennsylvania, and introduced in 1898 by T. V. Munson \& Son, on account of its mammoth size of berry, its vigor, health and productiveness. (, $\left.\frac{5}{4}\right)$. Cluster small, compact, shouldered, berries of largest size, one to one and a quarter inches in diameter, dull bronzy red, skin very thick, pulp tough, and foxy in the extreme, sweet for so large a berry; drops easily when ripe, ripe early; seeds large. Good for jelly and jam, and is a basis for breeding very large varieties of this species. Flowers imperfect, requiring a pollenizer. On this account, it is convenient to hybridize. (See Plate XLIX., page 157.)

TELEGRAPH, originated by Christine, of Westchester, $\mathrm{Pa}$., and named and introduced by P. R. Freas, Editor Germantown Telegraph, about 1865. (' $\left.\frac{5}{3}\right)$. Probably a chance seedling of Hartford, which it closely resembles. It is considered a little better than that variety in quality.

VERGENNES, an accidental seedling originating in the garden of Wm. E. Green, of Vergennes, Vt., in 1874, and introduced in 1880-1. ( $\left(\begin{array}{c}5 \\ 5\end{array}\right)$. Vine vigorous, hardy, healthy, productive; rots and mildews in the South; cluster medium, berry medium to large, persistent, color pale, dull red, skin thick, quality about same as Perkins. It is probably a seedling of Dracut Amber, Good only in the extreme North, where finer varieties cannot be grown.

WORDEN, originated from Concord seed by Mr. S. Worden, of Minetto, N: Y., early in the eighties of last century. ( $\left.\frac{5}{5}\right)$. Generally considered the best black pure seedling of Concord yet produced. It differs from Concord in having larger, more compact clusters, and more tender, better quality, and for local market in the North, is preferred to Concord, but too tender for shipping; South it cracks, drops and rots so much as to be unprofitable.

\section{Labrusca-Vinifera Hybrids}

AGAWAM (No. 15), originated by E. S. Rogers, of Salem, Mass., about 1856 . (' $\left.\frac{5}{8}\right)$. Vine vigorous, fairly productive, a little subject to mildew of foliage and rot of fruit, cluster medium, rather compact, shouldered; berries large to very large, bronzy red; skin thick; pulp rather tender, of sprightly aromatic flavor,--a refined foxiness; ripe about with Concord.

BLACK EAGLE, produced by Stephen W. Underhill, of Croton-on-Hudson, by uniting Concord with Black St. Peters. (, $\left.\frac{5}{3}\right)$. Vine of good growth, showing more Vinifera character than Labrusca. Leaves deep, three to five-lobed; cluster long, cylindrical, rather loose; berries large, ovoid, black; skin thin, pulp tender, juicy, of fine quality; early. The flowers set their fruit only when pollinated by other kinds. Very sensitive to mildew and rot.

BRIGHTON, a combination of Concord, Diana and Black Hamburg, by Jacob Moore, of Brighton, N. Y. ( $\left(\frac{5}{3}\right)$. Vine vigorous, not much subject to mildew, but very sensitive to Black Rot. Brilliant, a good pollinator; cluster large, fairly compact; berry medium to large, persistent, bright red; skin thin, pulp tender, of fine quality, ripe nearly a week earler than Delaware. With careful pollenization and spraying, profitable from Texas to Michigan.

CAMPBELL EARLY, originated by G. W. Campbell, of Delaware, Ohio, during the early nineties, by combining Concord, Moore Early and Muscat-Hamburg. (' $\left.\frac{5}{4}\right)$. Vine not very vigorous on its own roots, but, grafted on strong stock, grows and bears well, healthy; clusters very large with large shoulder, or side cluster; berry persistent, very large, slightly ovoid, black, of somewhat less pulp, and better quality than Concord, but equally as much or more foxy; ripe with Moore Early; a very showy and salable grape, of Concord type.

CATAWBA, found in the woods near the Catawba river in North Carolina, in 1801, by Mr. Murray, on the summit of Black Ridge, in Buncome Co. General Davy, living not far distant, propagated and cultivated some vines of $i$, about 1807 , and 1816 sent vines of it to friends in Maryland. It was mentioned in a little work on grapes by John Adlum, nurseryman, of the District of Columbia, in 1823, as the Tokay, on the strength of the assertion of a German priest, that it was the same as the Tokay he had known in Germany, but learning its true history, and the name Catawba, given by Davy, he gave it correctly in the second edition of his book. 


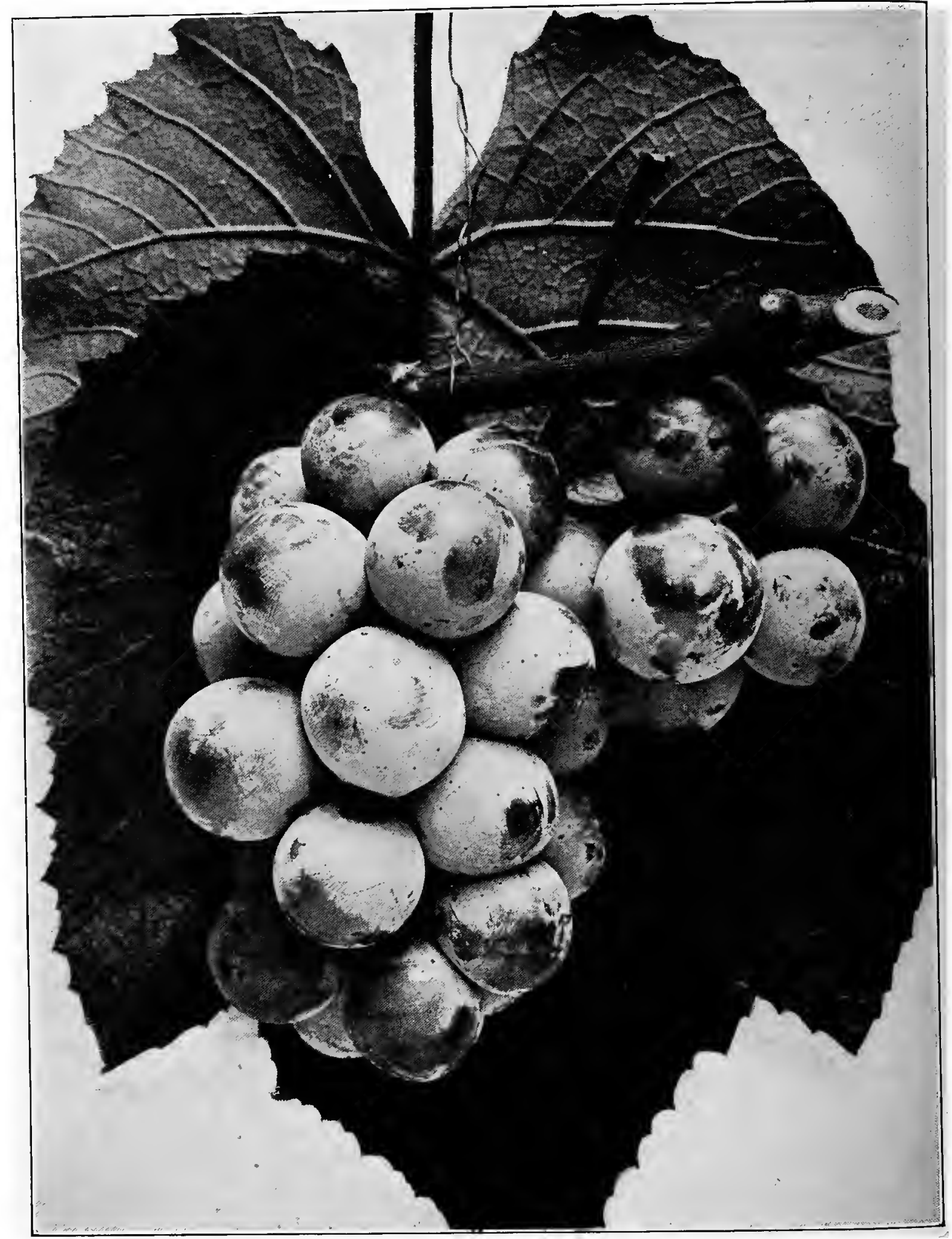

PLATE LII. UNION VILLAGE. (See page 166, under Isabella.) 


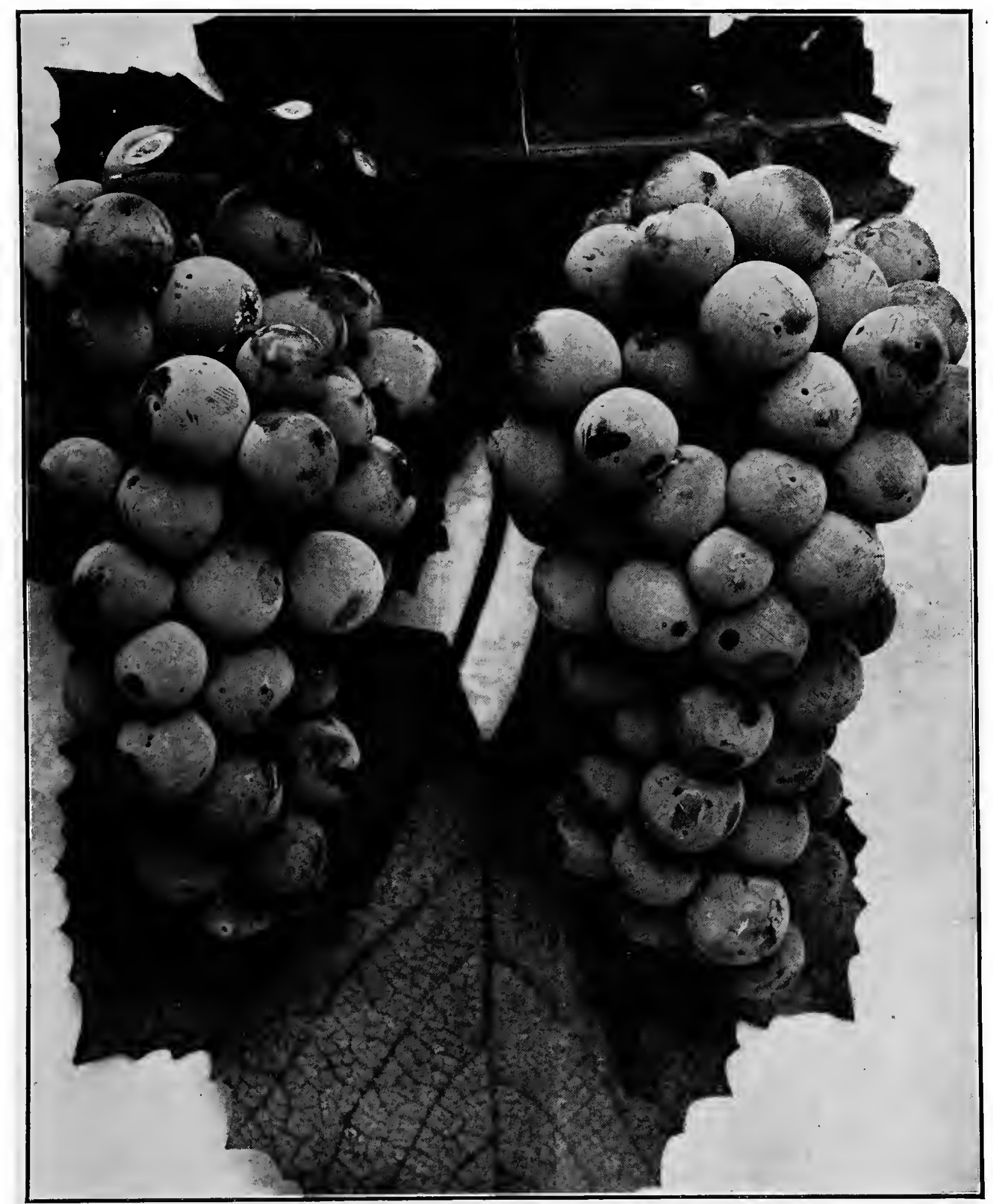

PLATE LIII. BRILliant. (See page 167.) 


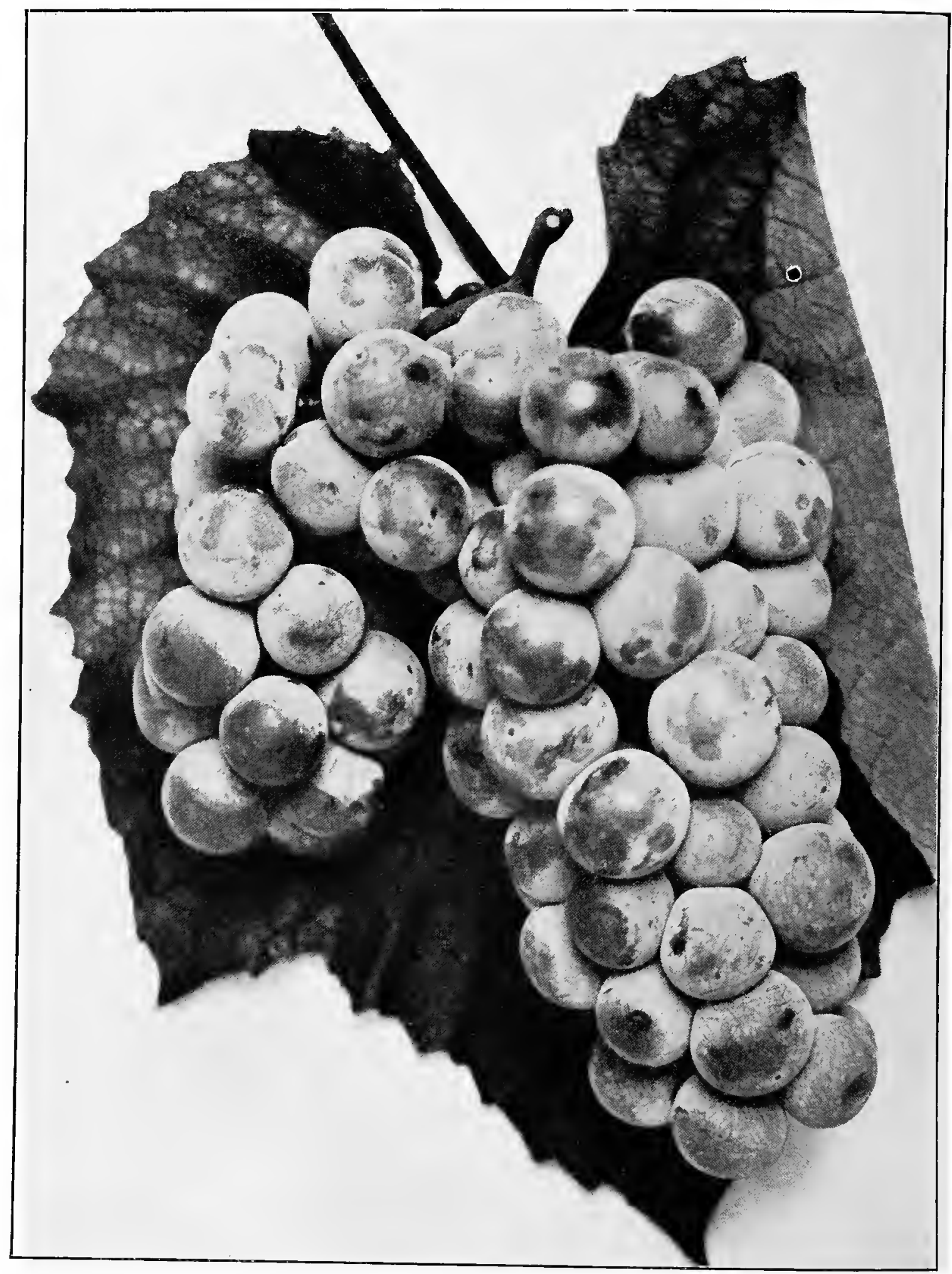

PLATE LIV. WAPANUKa. (See page 173.) 


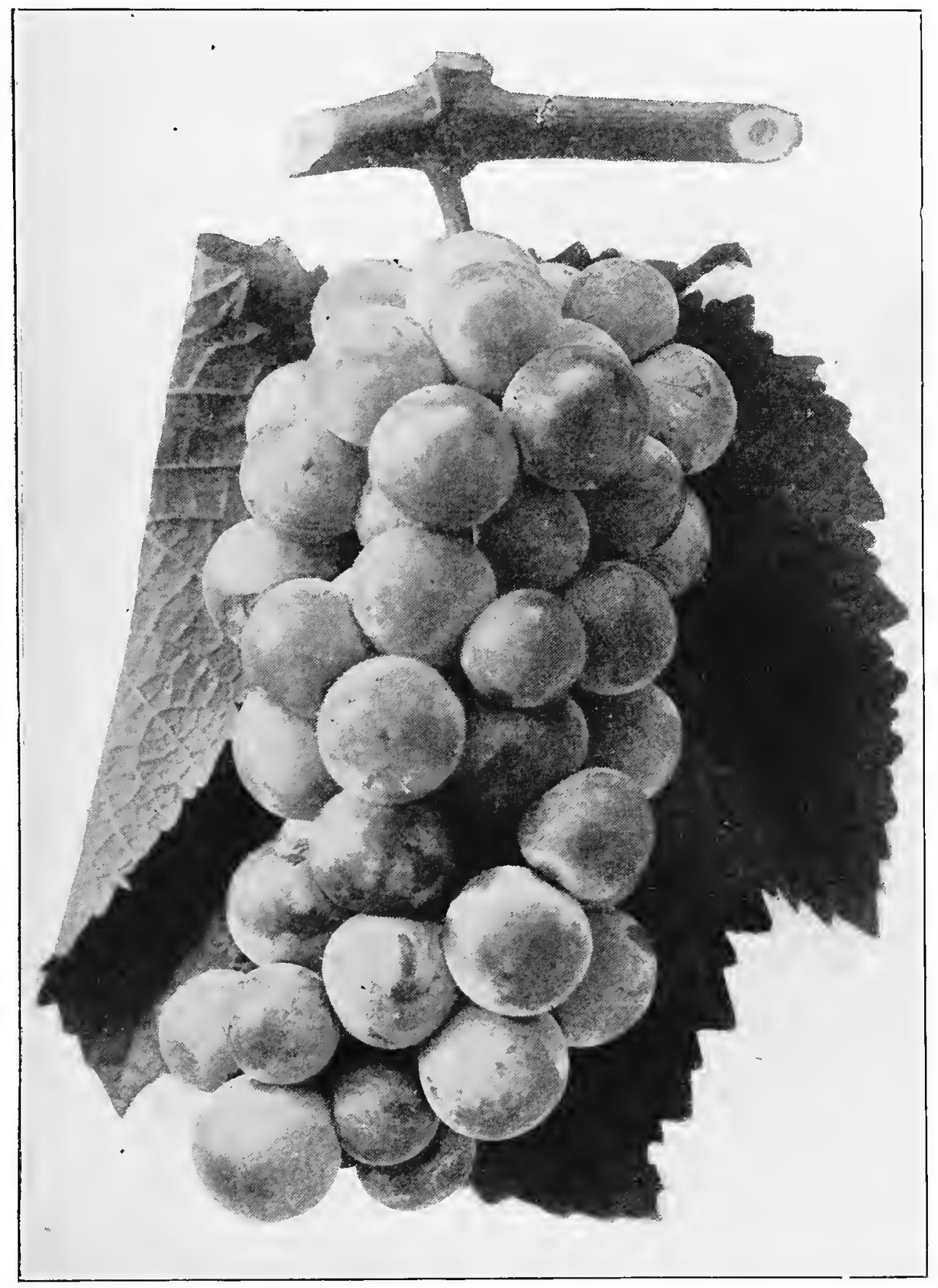

PLATE LV. ROMMEL. (See page 178.) 
This variety was a great pioneer in establishing the fact, that successful grape growing in the Atlantic states must be built upon the native vines of the country. For nearly a century the Catawba has been classified as a pure Labrusca variety, but a careful study of its botanical characteristics, and its pure seedlings, of which many have been produced, its hybrid character is surely revealed, as a combination of Labrusca and Vinifera. The wind or bees visiting foreign vines in some garden in that region had carried pollen to wild vines in the woods, or vice versa, and the hybridized seed carried and dropped by birds produced the Catawba, in all probability; for it is well known history, that numerous European vines were planted in the South in its early settlement. ( $\left.\frac{\mathbf{C}^{5}}{\mathbf{5}}\right)$.

Vine vigorous, little subject to mildew, but sensitive to Anthracnose and Black Rot; flowers perfect, cluster medium, conical; berries above medium, clear dark red, globose, skin thin, tough, pulp rather tender, juicy, sprightly, with a slight muscat flavor, not foxy, seeds medium, much resembles in vine, foliage and fruit some of Rogers' red hybrids. Ripens quite late, and hangs to cluster and keeps well. An excellent table and wine grape. (See Plate L., page 158.)

DIAMOND, produced by Jacob Moore, of New York, in 1873, by pollenizing Concord with Iona. (' $\frac{5}{4}$ ). Vine vigorous, prolific, somewhat attacked by mildew, and much subject to Black Rot; cluster large, compact, berry large, globular, yellowish, persistent, skin thin, sometimes cracking, pulp tender, of excellent quality, much better than Niagara; ripens about with Delaware, vine short-lived in the South.

GOETHE, Rogers No. 1. ( $\left.\frac{5}{6}\right)$. Vine vigorous, productive, fairly healthy, but fruit sensitive to the Black and White Rots. Cluster medium, rather open, berry ovoid, very large, persistent, pale pinkish-red; pulp tender, highly flavored, very juicy and sprightly; ripens very late and unevenly.

HERBERT, Rogers No. 44. Wild Labrusca of Massachusetts, pollinated by Black Hamburg. $\left(, \frac{5}{4}\right)$. Vine vigorous, healthy, and among the hardiest of this class, productive. Generally ranks as the best of Rogers' black varieties; cluster medium to large, with short peduncle; berry very large, black, globular, persistent; skin rather thick, pulp more tender than that of Concord and quality better; ripens earlier, and remains in good condition longer, after ripening.

HERNITO, a pure seedling of Herbert, produced by T. V. Munson, in 1900, with similar cluster and larger berry, a more vigorous and healthy vine, ripening later, and evenly, doing better than Concord. ( $\left.\frac{5}{8}\right)$. (See Plate LI., page 159.)

ISABELLA, found as a chance seedling, in some garden, or in the vicinity of Dorchester, South Carolina, before 1816, and about that time was taken North by Mrs. Isabella Gibbs, of Brooklyn, from whom W. R. Prince obtained it, and named it Isabella, in honor of Mrs. Gibbs. It succeeded well in that region and soon spread throughout the country, and was generally regarded by most writers on grapes, as a pure Labrusca variety, but botanical analysis and seedlings, as with the Catawba, reveal in it an element of Vinifera. ( $\left.\frac{5}{8}\right)$. Vine vigorous, prolific, leaves large, very Labrusca-like, but subject to mildew, and the fruit to Black Rot. Cluster large, compound (Vinifera character), berry large, ovoid, purplish-black, persistent; pulp tough, of good quality, with little foxiness, but some Vinifera flavor; seeds large, showing plainly Vinifera character in combination with Labrusca; ripens unevenly.

The Union Village (renamed "Columbian" and "Columbian Imperial") is one of its seedlings, having iminensely large purple berries ripening very late and unevenly, with vine and leaves almost exactly like its parent, showing in fruit and seed, characteristics of Black Hamburg, but owing to the uneven ripening and the severe attacks of the Bunch Worm and Grape Curculio, the variety is of little value, except for jelly. ( $\frac{5}{10}$ ). (See Plate LII., page 162.)

JEFFERSON, a cross of Iona on Concord, by J. H. Ricketts, of Newburg, N. I., brought out early in the eighties of last century. ( $\left.\frac{5}{9}\right)$. Vine fairly vigorous, foliage little subject to mildew, and the fruit quite resistant to Black Rot: cluster large, compact; berries large, globose, 
red, covered with delicate bloom, persistent, skin tough; pulp juicy, rather tender, of very good quality, ripens late.

LINDLEY, Rogers No. 9, a combination of a large Massachusetts Labrusca with Golden Chasselas. $\left(, \frac{5}{4}\right)$. Vine vigorous, prolific, foliage mildews less than Delaware; cluster above medium cylindrical, with long peduncle; berries large, brick-red, skin thin, tough; flesh tender, juicy, with distinct, agreeable flavor, not in the least foxy; quite resistant to Black Rot, ripe about with Delaware; for polliriation, plant near such as Delaware and Brilliant.

NIAGARA, produced by Hoag and Clark, of Lockport, N. Y., in 1872, and introduced by them. ( $\left(\frac{5}{5}\right)$. It is a cross of Concord with Cassady (the latter having an element of Vinifera in its composition, and it is a white grape), vine of medium vigor, foliage mildews about same as Brighton, prolific of large, compact clusters, berry large, yellowish-green at full maturity; skin tender, juicy, of considerably better quality than Concord, but not quite so good as Diamond. Very subject to Black Rot, and easily damages itself by overbearing. Succeeds better in the South than Concord.

NORFOLK, produced by N. B. White, of Norwood, Mass. ( $\left.\frac{5}{3}\right)$. Vigorous, prolific, cluster large, shouldered, compact, berry large, globose, red, skin thin, does not often crack, pulp tender, good, with a little Muscat flavor; inclined to drop in basket; ripe nearly with Moore Early; very subject to Black Rot.

PRESIDENT, a sister of Hernito, every way quite similar, but berry not quite so large, about a week or ten days earlier, about with Moore Early and better. ( $\frac{5}{4}$ ).

TRIUMPH, a Concord-Muscat hybrid, produced by G. W. Campbell, of Ohio, early in the seventies of last century. ( $\left.\frac{5}{10}\right)$. Vine of good vigor, foliage smaller than Concord, with teeth resembling Muscat, and of good firm texture, stocky, very prolific, of very large, compact clusters, of large, globular, yellowish-green berries; skin thin, tender, sometimes cracking; pulp melting, sprightly, much like Muscat, less meaty, with similar flavor; seeds small. Succeds well in Western Texas, and has been quite profitable at Denison, Texas; ripens as late or later than Catawba.

WOODRUFF, a supposed cross of Concord and Catawba, by C. H. Woodruff, of Ann Arbor, Mich., in 1874. ( ( $\left.\frac{5}{3}\right)$. Vine vigorous, healthy and excessively prolific; cluster medium, shouldered, very compact, causing the berries to almost invariably crack, if a rain strikes them near ripening time; berry large, globular, red, resists rot well, skin thin, pulp tough, juicy, of good quality, but considerably foxy; ripens early and keeps well, when not cracked. Not adapted South.

\section{Labrusca-Vinifera-Bourquiniana Hybrids}

BRILLIAN'T, T. V. M. 1883 (Lindley x Delaware). (' $\left.\frac{5}{5}\right)$. Growth strong. Vine endures winters anywhere up to 15 degrees below zero. Endures Texas climate well. Clusters large, cylindrical, or somewhat conical, often shouldered, open to compact. Berries large, globular, light to dark red, translucent, with a thin bloom, very handsome when well ripened; skin thin, rather tender, but seldom cracks; pulp meaty, yet very tender, melting and delicious, usually preferred for table and eating fresh, to Delaware, with which it outsells 5 to 10 cents per eightpound basket in the markets where it is known. Seeds readily part from the pulp; ripens just before the Delaware and yields on an average fully twice as much. It ships about equally as well or better than Concord. Its foliage is less attacked by mildew than Delaware, and spraying with Bordeaux mixture will entirely prevent this. Endures heat and drouth fairly well, much better than Concord. Making a fine record in Georgia, as well as in Texas. Adapted South and North. Fine reports of it from New York. Eight feet, short arm pruning. Well adapted to limy as well as sandy soils. (See Plate LIII., page 163.)

CAPTIVATOR, T. V. M. 1902 (Herbert x Meladel). (' $\frac{5}{8}$ ). (The Meladel is a seedling of Delago crossed with Brilliant, a large fine red variety.) Vine of good, vigorous growth, similar to Brilliant, but of a more lively green and less attacked by mildew, short jointed. Cluster large, 


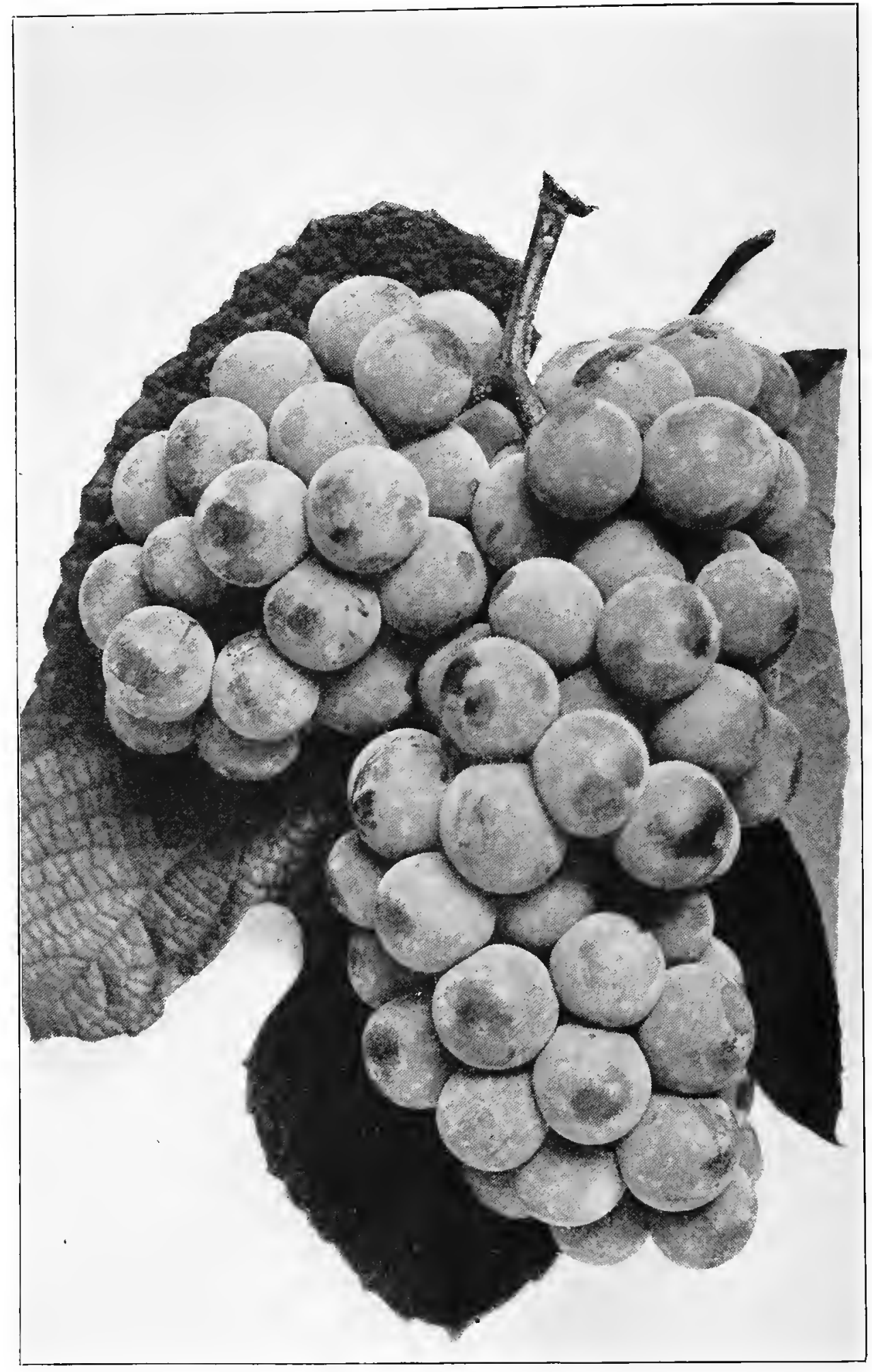

Plate LVI. EARLy PURPLE. (V. Lincecumii, var. glauca.) (See page 179.) 


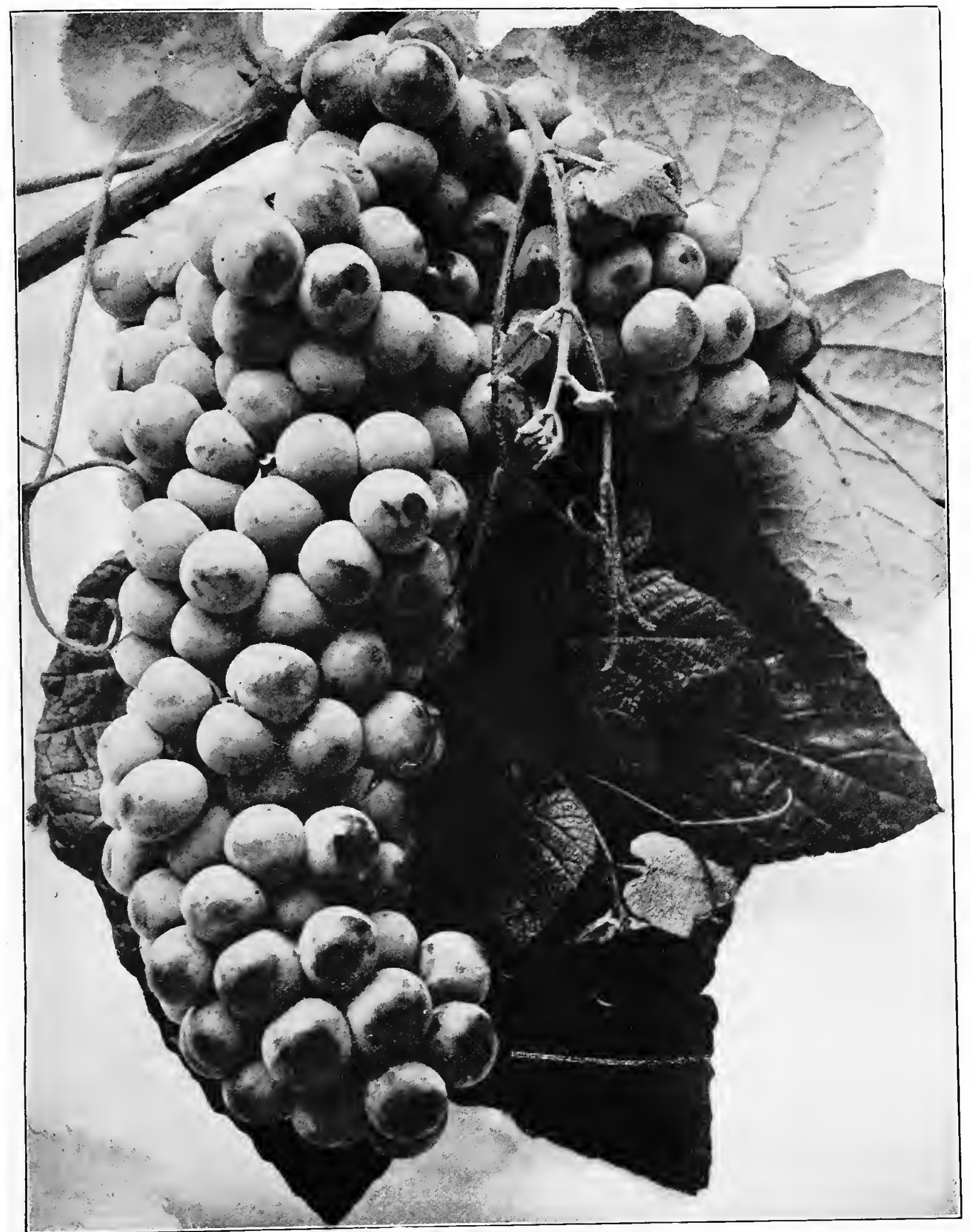

PLATE LVII. VITIS LINCECUMII. 6b. (Var. glauca, Munson.) Jaeger 43 Post-Oak Grape. Southwest Missouri. (See page 179.) 


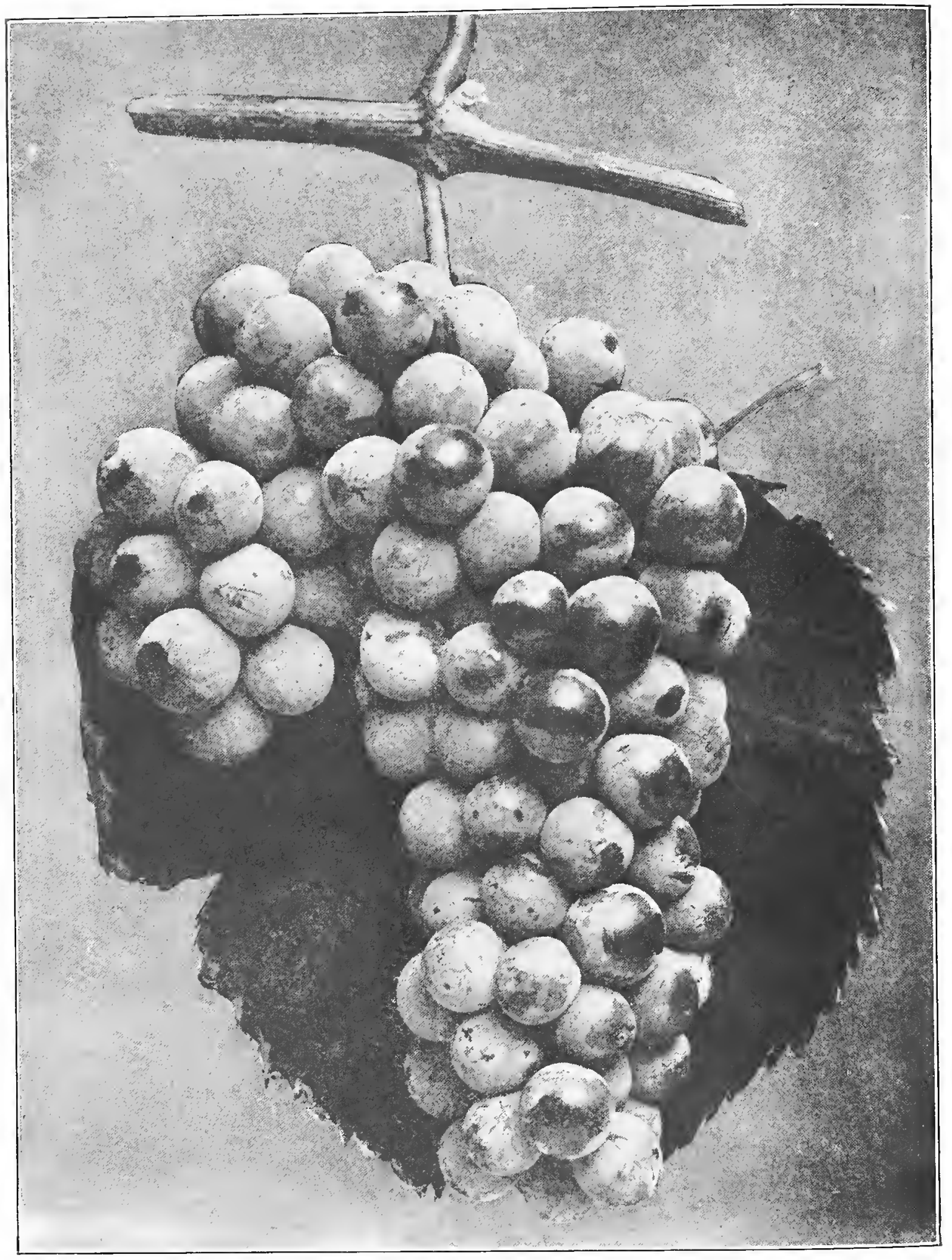

PLATE LVIII. BLONDIN. (See page 184.) 


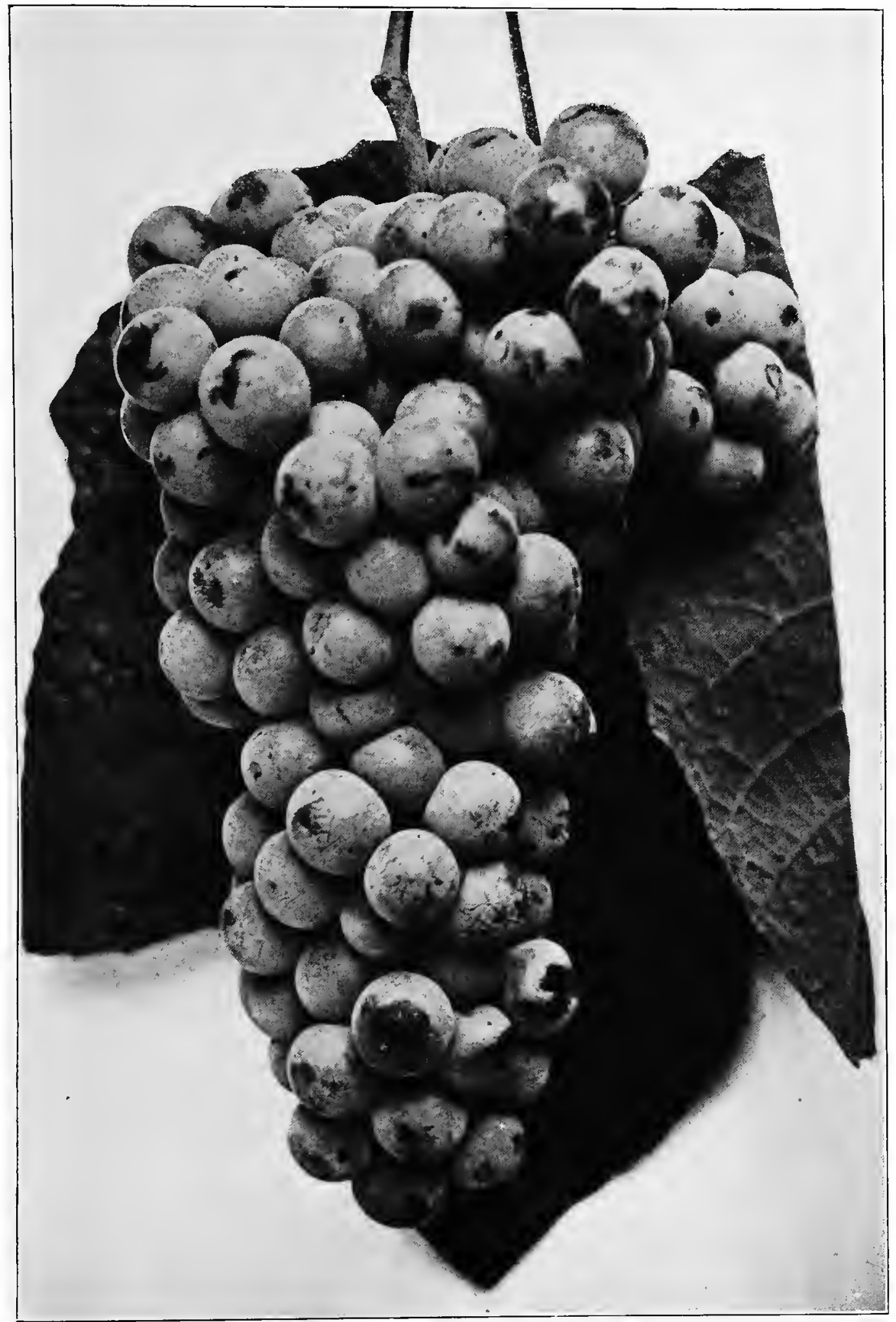

PLATE LIX. KIOWA. (See page 185.) 
cylindrical, sometimes shouldered, properly compact; berries persistent, large to very large, globular, clear lively translucent red; skin thin, tough, pulp tender, melting, sweet and of the most"delicious quality; seeds few, ripens just before Delaware. Probably no more attractive grape has ever been produced in the United States.

GREEN MOUNTAIN, an accidental seedling found by a Mr. Paul in Vermont in the region of the Green Mountains, and disseminated by Stephen Hoyt's Sons in the eighties. It seems to be a combination of Niagara-Delaware. It certainly has Delaware blood in it, as the shape of cluster and the flavor testify, while the leaf and vine approach Niagara. So sure am $I$ of the correctness of this analysis, that I have placed it in this group, as its proper place, having carefully studied it for years. (It is not the same as Winchell. The latter has larger berries, larger leaves and is not quite so early and its vine is much more robust.) ( $\frac{6}{6}$ ).

The cluster of Green Mountain is of same shape as that of Delaware, but a little larger, berries medium in size, slightly ovoid, persistent, greenish-white, skin thin, but does not crack, pulp tender, very sweet and of high quality, seeds few, ripens almost with Moore Early; very prolific; hardy and well adapted to the North, and does well in Texas, when not subjected to too great drouth, which it endures poorly.

WYOMING (Syn. Wilmington Red), produced by Dr. S. J. Parker, of Ithaca, N. Y., in the seventies. $\left(, \frac{5}{6}\right)$. In analysis it seems to embody some very poor Labrusca, such as Champion with Delaware, so I place it here. Vine much more robust and healthy than Delaware; cluster and berry somewhat resembles Delaware, but a good size larger; like a big Delaware with all the richness taken out; ripens just before Delaware, berries of a lighter, brighter red than Delaware; very prolific, and sells pretty well, until its poor quality is discovered.

\section{Labrusca-Vinifera-Bourquiniana-Æstivalis Hybrid}

WETUMKA, T. V. M. 1893. (' $\frac{5}{10}$ ) (Elvira $x$ Herbemont x Gold Coin). Growth medium, healthy, withstands mildew and rot well. Clusters medium to large, ovate, sometimes shouldered; peduncle medium; berries large, globular, persistent, yellowish-green; skin never cracks; pulp juicy; tender, freeing the seeds easily; quality better than Niagara. Ripe late after Concord is off. Bears heavily on short arms. A profitable market and table grape and will make an excellent white wine. Eight feet. Adapted for the South, and same range as Gold Coin, Texas to Missouri.

\section{Labrusca-Vulpina Hybrids}

CLINTON, a wild vine planted in the grounds of Prof. Noyes, College Hill, N. Y., by Hon. Hugh White in 1821. ( $\left.\frac{5}{1}\right)$. Writers on grapes have generally denominated it of the Riparia (Vulpina) species, but its analysis and numerous seedlings clearly point its hybrid character, as given in the above heading. Vine a strong grower, and very hardy to withstand cold in winter; foliage, of medium size, dark lively green, pushing very early; cluster small, compact, cylindrical, peduncle an inch or more; berries round, black, small, persistent, skin thin, never cracks, pulp tender, juicy, sprightly, acid until very ripe, juice of a dark red color, seeds small. The variety is good only to make a coarse red wine, and to use as a base on which to improve by hybridizing, with larger, sweeter kinds for northern regions. The Bacchus, produced by J. H. Ricketts as an improvement, is a pure Clinton seedling, almost undistinguishable from the parent.

ELVIRA, produced by Jacob Rommel, of Morrison, Mo., about 1870, as a seedling of Taylor (see page 173), and introduced in 1874, by Bush and Son and Meissner, of Bushberg, Mo. (' $\frac{5}{3}$ ). Vine healthy, vigorous, very short-jointed, stocky, very hardy; clusters, four and five in succession, small, very compact, almost without a peduncle, seeming to spring directly from the branch bearing it, hence requires care in gathering; berries small to medium, round, greenish-yellow when dead ripe, persistent, skin very thin and tender, and cracks so badly as to render the variety almost worthless, but the flesh is very delicate, tender, melting, of a peculiar gooseberry flavor, 
much liked by some and disliked by others, seeds rather large for so small a berry. The variety makes a fine white wine. Numerous seedlings and hybrids of it have been produced. The Rommel is undoubtedly the best. (See page 178.)

MONTEFIORE, another of Jacob Rommel's Taylor seedlings, but it seems to have more Labrusca element, as though the Taylor had been pollinated by Hartford. ( ' $\left.\frac{5}{3}\right)$. Less vigorous. than Elvira, very hardy, enduring the winters of Wisconsin, at Mauston, without protection. Cluster small to medium, cylindrical, with shoulder, and an inch or two of peduncle, berries round, black, skin thin, does not crack, pulp juicy, juice of red color, makes a red wine of much better quality than that of Clinton. A good breeding stock for the far North.

NOAH, a Taylor seedling produced by Otto Wasserzieher, of Nauvoo, Ill, in 1869, and disseminated by Bush \& Son \& Meissner in 1876. ( $\left.\frac{5}{8}\right)$. Vine of good growth; foliage rather large, subject to mildew, seems to be a Taylor x Labrusca hybrid, probably with Hartford; cluster medium, cylindrical, with peduncle an inch or two long, berry round, medium, yellowish-white; inclined to drop, skin tough, pulp quite tough, seeds large, quality good: with faint foxy flavor; makes a good white wine; considerably used in parts of France for making wine, as it is prolific and the root resists Phylloxera, but in the United States it is rarely planted now.

TAYLOR. (,$\left.\frac{5}{1}\right)$. An accidental hybrid of Labrusca with native Vulpina (Riparia), of Kentucky, found and introduced by Judge Taylor, of Jericho, Henry County, Ky., about the middle of last century; vine vigorous, healthy, with light colored wood, and lively green, large toothed Vulpina-like leaves; tendrils continuous for several nodes without a skip, which reveals Labrusca blood; cluster very small, usually straggling, as the flower is imperfect; berries small, round, yellowish-white, translucent, of pure good quality, seeds small. The variety is valueless for direct production, but has been used extensively in France as a resistant graft stock, and in this country has been of great value as a hardy, healthy, high quality base from which to breed, and has yielded many hybrids with Labrusca and other species, of which we mention only a. few of the best (see immediately above and below).

\section{Labrusca-Vulpina-Bourquiniana-Vinifera Hybrids}

BELL, T. V. M. 1883 (Elvira x Delaware). ( $\frac{5}{8}$ ). Vine vigorous, healthy, free from mildew and Leaf-Folder, very hardy, a good, sure producer; cluster medium, cylindrical, often with a shoulder, fairly compact; berry medium, round, greenish-yellow, rarely attacked with Black Rot; skin thin, sufficiently tough to prevent cracking under ordinary weather changes; pulp rather tender, juicy, very sweet and agreeably flavored; ripens just before Concord. We consider it a superior grape to the Green Mountain. Successful in Texas northward.

Have received very flattering testimonials of this grape.

WAPANUKA, T.V.M.1893. ( $\left(\frac{5}{4}\right)$. (Rommel x Brilliant). Growth medium to strong, equal with Concord, less attacked by mildew than Brilliant. Cluster medium to large, cylindrical, shouldered, properly compact; peduncle short to medium. Berries large, five-eighths to seveneighths inch in diameter, globular, persistent, rich yellowish-white, translucent; skin very thin. and delicate, yet seldom cracks, and handles better than Rommel. Ripe about with Delaware. Far superior to Niagara and Green Mountain. For nearby market and table grape there is no. other variety superior, if equal, to it. Very prolific, requires short pruning. Succeeds well North and South. Reported as enduring drouth in Western Texas among the best. Undoubtedly one of the best, if not the best, table and eating grapes produced in the United States. Takes the place of the Rommel, it being superior to it, although the Rommel is near the top for extra fine quality and flavor. Plant 8 feet. Short arm pruning. (See Plate LIV., page 164.)

\section{Labrusca-Vulpina-Candicans Hybrid}

ELVICAND, T. V. M. 1885. ( $\left(\frac{5}{5}\right)$. (Elvira $x$ Mustang). This is the best of three accidenta1 hybrids of Elvira with the native Mustang grape growing wild near my vineyard,-about 


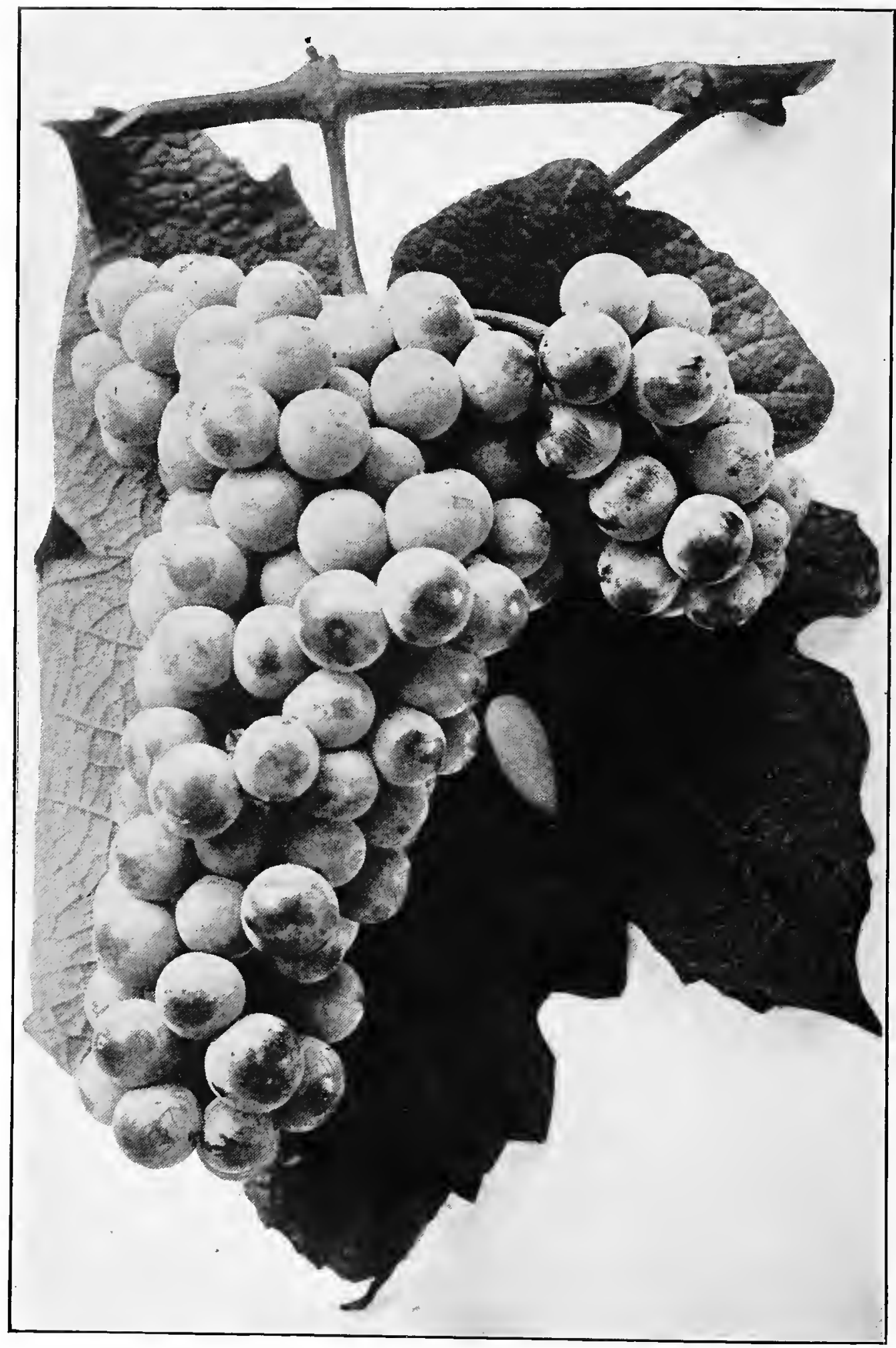

PLATE LX. MARGUERITE. (V. Lincecumii $x$ V. Bourquiniana.)

Hybrid, Secundo $x$ Herbemont. (See page 185.) 


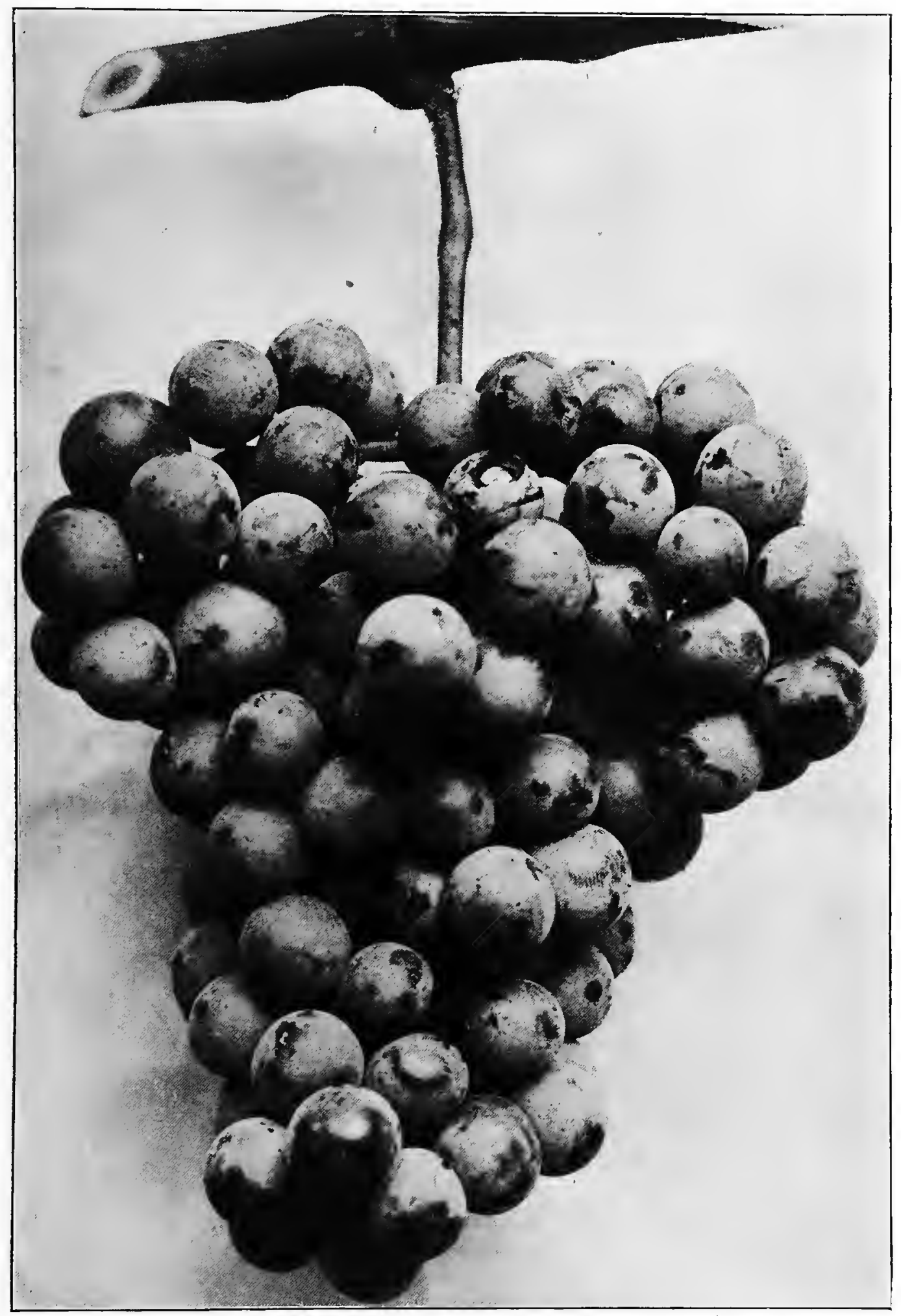

PLATE LXI. MUENCH. (See page 185.) 


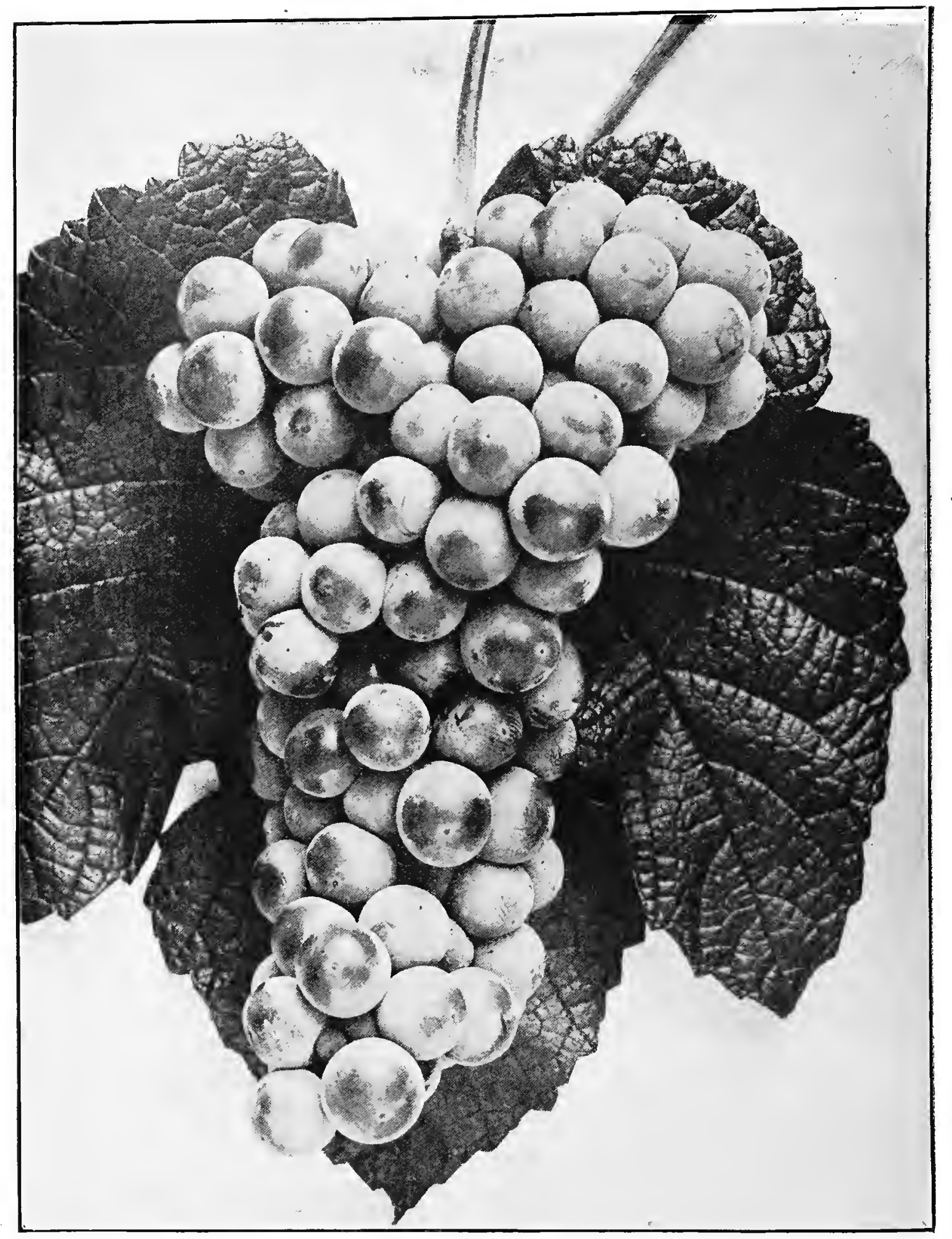

PLATE LXII. NEVA MUNSON. (See page 185.) 


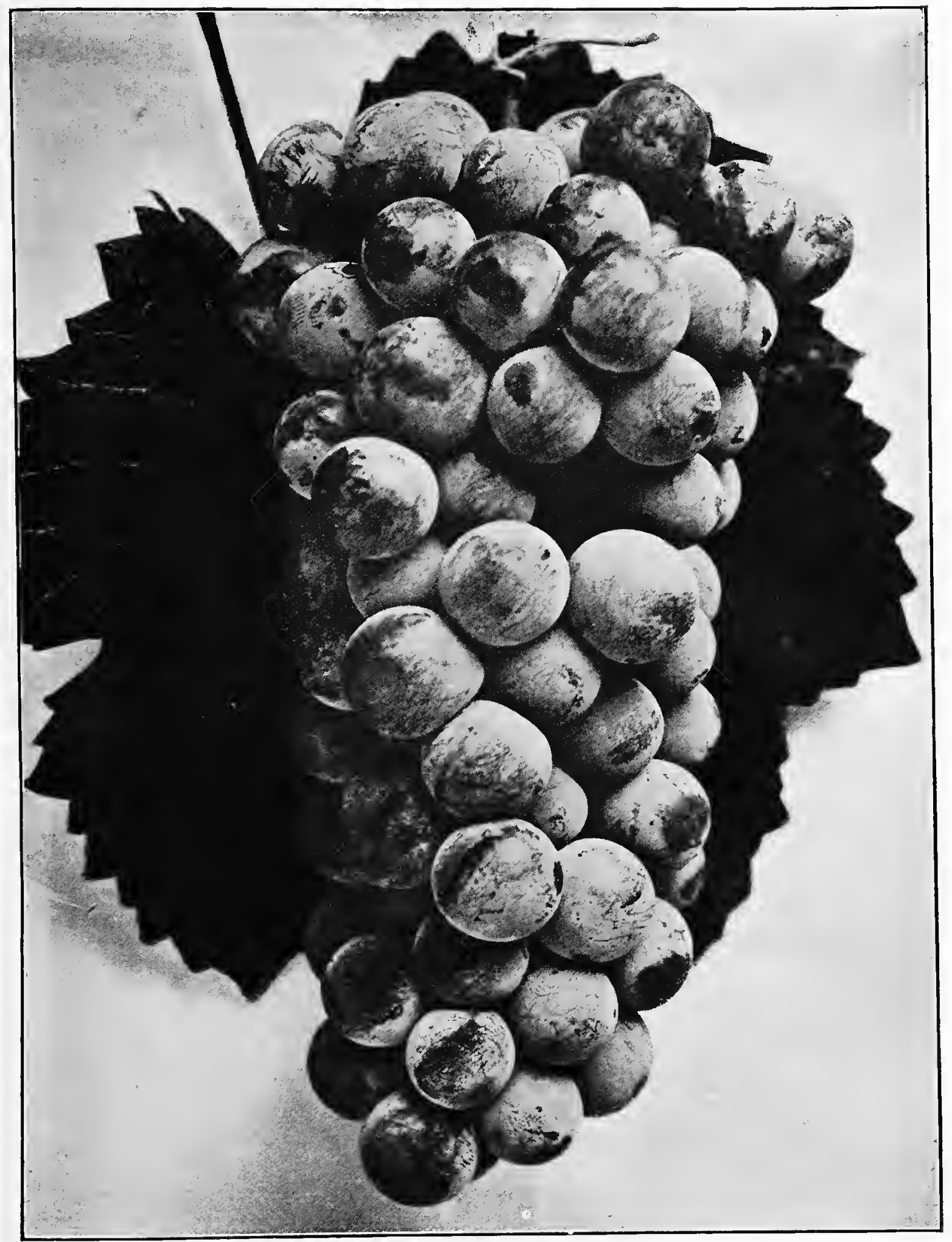

PLATE LXIII. BEACON (See page 185.) 
a half mile distant, - and illustrates how readily hybrids between cultivated and wild grapes occur. Had a bird obtained those hybrid seeds from my vineyard, and dropped them far distant in the woods and grew vines, that afterward some hunter had found full of ripe grapes, he could have claimed that he had found a beautiful clear red Mustang grape about as good as Catawba (for there is no mistaking that the variety shows Mustang much more than Elvira), and it was Elvira that bore the seed from which I grew Elvicand. Here is a pure natural compromise of three very distinct species, - - one from the far Northeast, Labrusca, one from the cold North, Vulpina, and one from the hot Southwest, Candicans, giving us a vine of great vigor and rampant growth, leaves of medium size, leathery, dark green above, covered with dense white woolly felt on under side and on young wood; cluster small, compact, shouldered, peduncle short; berry globular, clear translucent red, above medium size, very persistent, the pedicel extracting a small core, when berry is pulled off, as in Mustang; pulp tender, juicy, of a very sprightly sweet, slight Mustang flavor. Vine bears heavily with long arm pruning. Colors at mid-season but should hang several weeks to reach its best quality. Birds do not bother it until quite ripe. This variety has received very favorable notice in South Texas and in California, as making a peculiar, very agreeable light white wine. The fruit neither rots or cracks, and the foliage never mildews. Here is a base on which to build a distinct very successful class of high colored grapes for all the country south of Mason and Dixon's line.

\section{Labrusca-Vulpina-Candicans-Bourquiniana-Vinifera Hybrid}

VALHALLAH, T. V. M. 1893. ( $\frac{5}{8}$ ). (Elvicand x Brilliant). Vine a strong grower, foliage much more resembling Brilliant than Elvicand, and a little subject to mildew in wet seasons. Cluster small to medium, shouldered; berries large, dark, translucent red, globular, persistent, skin tough, pulp tender, juicy, of very good quality,-an improvement on Elvicand; has a trace of Mustang pulp flavor, but none of the twang of skin; ripe a little later than Concord and hangs sound a long time. Adapted to same range as Elvicand, and especially suitable for very limy soil. Plant 10 feet apart, give long arm pruning.

\section{Labrusca-Vulpina-Vinifera Hybrid}

ROMMEL, T. V. M. 1883. ( $\left.\frac{5}{4}\right)$. (Elvira x Triumph). Vine short-jointed, stocky, vigorous, foliage clear green, having little pubescence, leaves of medium size, large, sharp-toothed, reminding one of Vinifera more than Labrusca, subject to mildew late in summer, cluster good medium size, compact, often shouldered, peduncle short; berry globular, medium to large, persistent, greenish until fully ripe, then becomes a pale yellowish tint; skin very thin and delicate, yet it rarely cracks; flesh a sprightly melting jelly of the most agreeable delicate flavor, liked by everyone. Too tender for shipping, but fine for local market; ripe with Concord. (See Plate LV., page 165.)

\section{Vitis Lincecumii (Post-Oak-Grape) Varieties}

Of many thousands of wild vines of this species visited and tasted in the woods of Southwest Missouri by Mr. Hermann Jaeger, and in Oklahoma, North and East Texas, by the writer, the following were put in vineyard and used as mothers from which to breed varieties for cultivation: Big Berry, Early Purple, Jaeger Nos. 43 and 52, Lucky, Neosho, Premier, Secundo and Ten Dollar Prize. 43, 52 and Neosho, were found in Missouri by Mr. Jaeger, and the others in the Post-Oak timbered sandy lands in Grayson County, Texas, within a few miles of Denison, during the years 1876 to 1884 , when little of the country was fenced, and wild grapes were found everywhere hereabouts, but where now rarely can a wild vine of this species be found. owing to grape-hunters pulling the vines from the trees for their fruit, and stock-browsing, and clearing of land. The finding and bringing into cultivation and using these vines as breeders marks an epoch in American viticrlture that will go down in history with more value and renown than even the Norton and Concord and Herbemont. 
Mr. Jaeger made a few hybrids of his Nos. 43 and 52, and the writer has used all except Jaeger's 52 in making many thousands of hybrids as well as using in hybrid combinations almost every American species, to find the best for breeding purposes, and it is the Post-Oak-Grape that to him towers far above any other species in forming the basis of our future viticulture, but which is greatly aided by other species.

I give a short description of each of these pioneer breeding vines. They all had to be used as mothers as they all have small reflexed stamens, with impotent-pollen; then I shall follow with a few of the most meritorious hybrids produced from them.

BIG BERRY, grown from a seed of a vine fo :nd west of Denison, Texas, about four miles, on the Alkire Sand Hill, about 1880. (,$\left.\frac{5}{14}\right)$. V'ne very vigorous, stocky, prolific; leaves very large, lea thery, slightly lobed; cluster medium to large, ovoid cylindrical, shouldered; berry larger than that of Concord, round, black, fairly persistent, skin rather thick, tough, pulp juicy, a little tough, but less so than Concord, flavor and sweetness higher than Concord; bloomed and ripened a week later than Concord. I use Concord for comparison, because everybody knows it, and it is a standard black grape. The vine was lost in 1889. by careless renters of the "Old Place."

EARLY PURPLE, grown from seed of a vine on a sand hill, north of the Morrow-Place, three miles west of Denison, found in 1884. $\left(, \frac{5}{13}\right)$. Vine and fruit of very similar description to Big Berry; more persistent berry; vine and fruit have never mildewed, or been attacked by rot. Its hybrids are pistillate so far, and have a flavor, not quite satisfactory, hence have introduced none of them. Vine very prolific, and yet vigoruus. (See Plate LVI., page 168.)

JAEGER 43, found by Hermann Jaeger in the early eighties, in Newton County, Mo. $\left(, \frac{5}{20}\right)$. The vine is very vigorous and perfectly healthy; the cluster is large cylindrical, shouldered, compact; berry medium, round, black with much bloom; seeds small, skin thin, tough; pulp tender, of excellent, peculiar flavor; blooms and ripens very late,- three weeks or more after Concord. Mr. Jaeger always regarded this as the best variety of this species he had ever found. The only hybrid he produced of it, and named, was his No. 70, named by him Munson (which see page 196), a hybrid of 43 with a male seedling of his No. 60, Vitis rupestris, considered his best variety of that species. (See Plate LVII., page 169.)

I have introduced one hybrid of Herbemont on Jaeger 43,- the Kiowa (see page 185).

LUCKY, found in 1884, three miles southwest of Denison, filling a Black Jack Oak, forty feet high, with vine loaded with fine clusters, and berries size and shape of Hartford, but of far better quality; a beautiful sight, that made me leap with joy. $\left(, \frac{5}{13}\right)$. Berries inclined to $d r o p$ when over-ripe. Ripens earlier than Concord, vine vigorous and healthy, prolific. Have made few hybrids with this, none worthy of introduction. Vine propagated from cutting yet alive and hearty. Well worthy of breeding up for early varieties of this species.

$\mathrm{NEOSHO}$, found by $\mathrm{H}$. Jaeger, in 1868, near Neosho, Mo., on farm of E. Shoenborn; vine healthy and vigorous, never known to rot or mildew. (, $\left.\frac{5}{6}\right)$. Clusteri and berry similar to Norton, and quality about equal, with more astringency; pulp meaty, not very juicy, juice brownish; makes a choice wine. From this the writer bred a lot of hybrids with Herbemont, two of which are very fine, and have been introduced (see Muench and Neva Munson).

PREMIER, found by the writer in 1880, three miles west of Denison (about the center of a little region three of four miles across in which $I$ found more good wild grapes than in all other of my ramblings), and the best one ever found by me, and the first to be transplanted to my vineyard, the first and most extensively hybridized upon, save the Ten Dollar Prize, as to numbers of hybrids, and the first to be lost in the tender mercies of renters of our first home just north of Denison. $\left(, \frac{5}{15}\right)$. The vine was a good short-jointed, perfectly healthy prolific one with cluster and berry about the size of Norton, compact, berries persistent, in quality better than Norton, to my taste.

SECUNDO, grown from seed of the same vine that produced Big Berry, but the cluster and berry were smaller, more persistent and better. From this was produced a good many hybrids, 


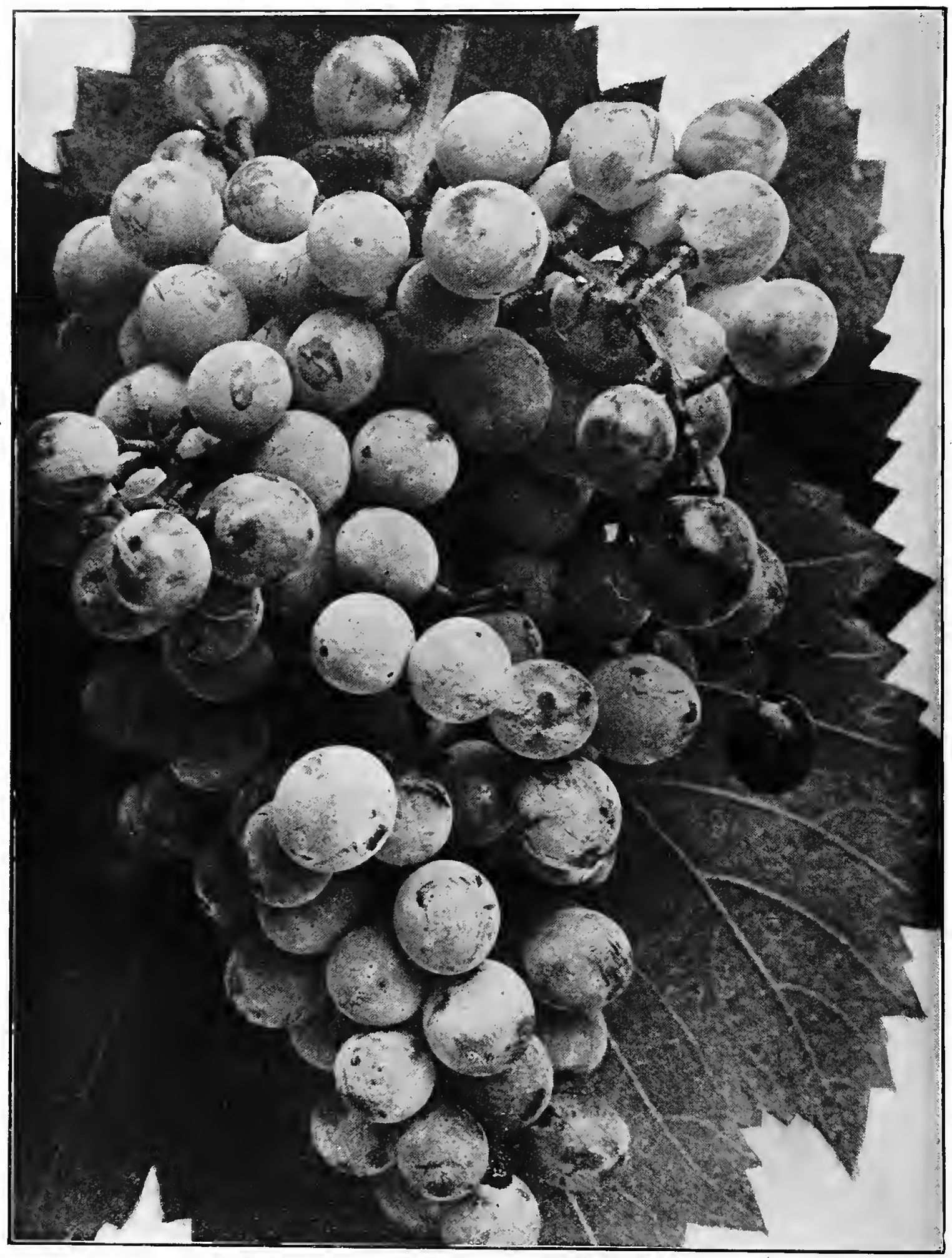

PLATE LXIV. ARMADO. (See page 190.) 


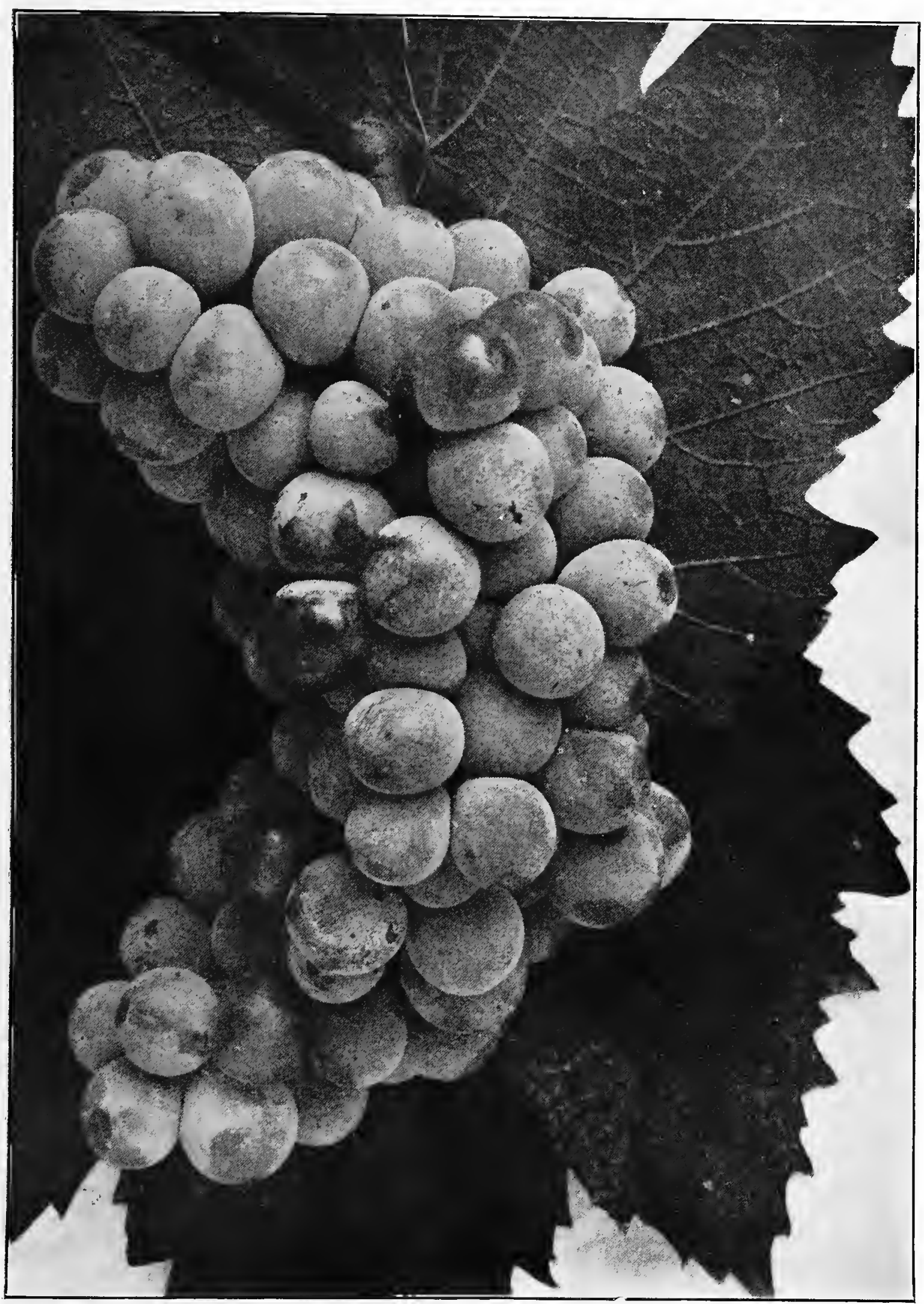

PLATE LXV. ARMALAGA. (See page 190.) 


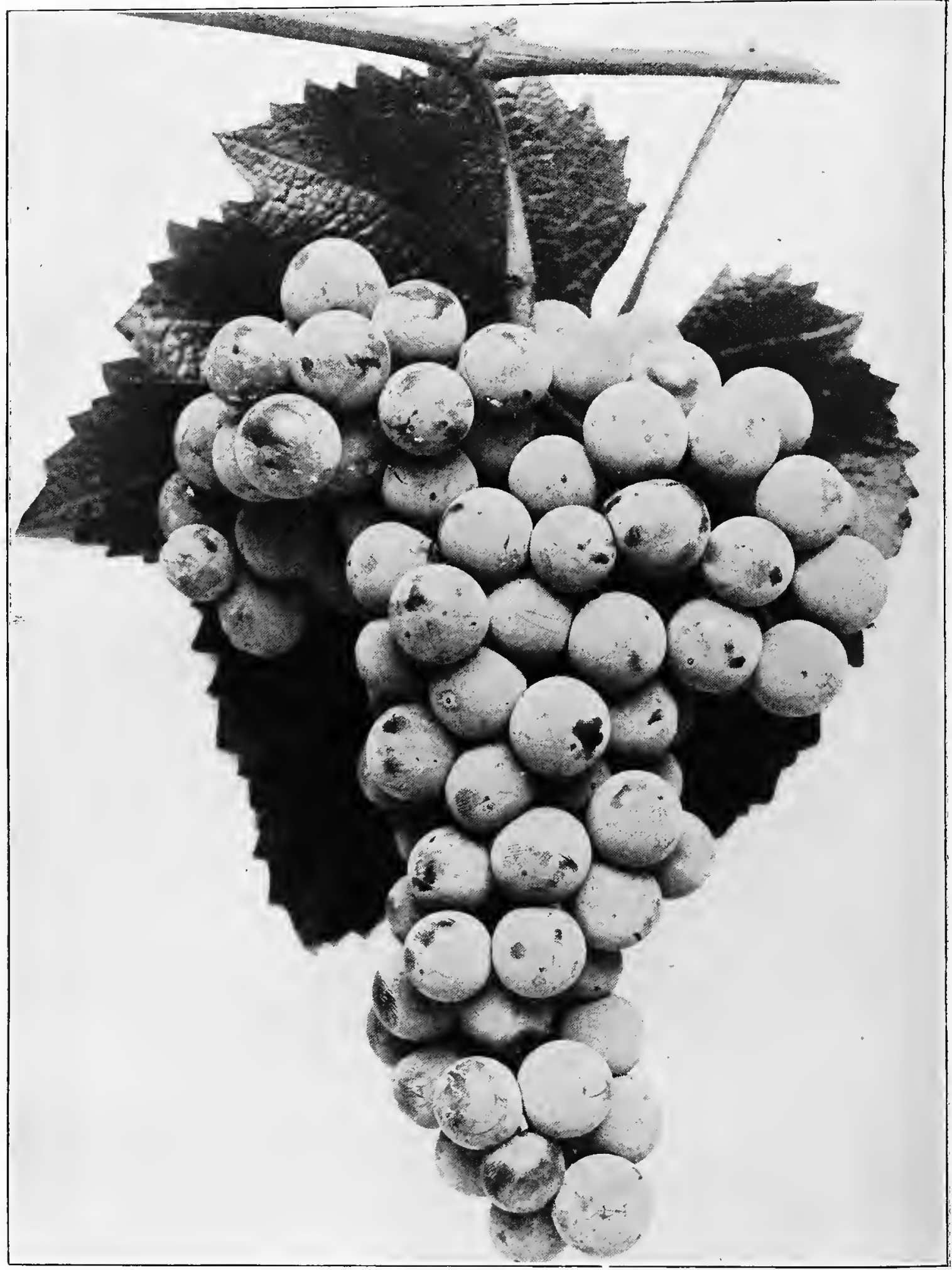

PLATE LXVI. CARMAN. (See page 190.) 


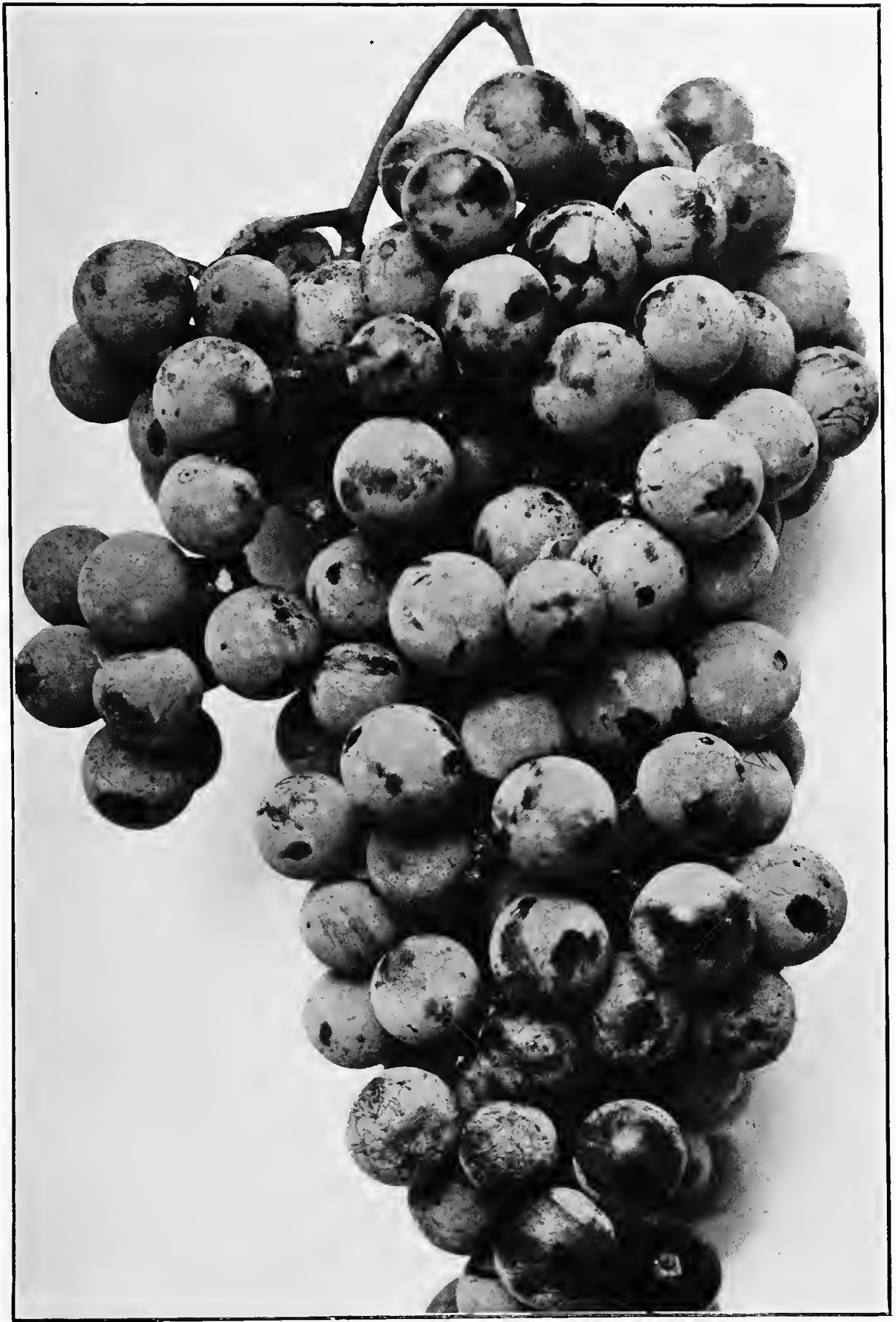

PLATE LXVII. ARMLONG. (See page 190.) 
two of which very late, with Herbemont, Marguerite and Perry, were introduced. Perry mildewed and rotted some but is much liked in Southwest Texas, Marguerite is perfectly healthy (see page 185).

TEN DOLLAR PRIZE. In 1882 I offered a prize of $\$ 10$ to the one who would show the best ripe wild Post-Oak Grape (section of vine in fruit), on a certain day in August, with the understanding that I was to become sole owner of the vine getting the prize. A committee of five good grape and wine judges was selected. There were Concord and Delaware sections of vines, full of full ripe fruit, supplied as standards of comparison. The day came, bright and fine. The show was grand. All around the hall were hung the vines full of fruit, 'and foliage, some twenty or thirty kinds. The committee tasted long and repeatedly, showing some close competition. The decision fell on a variety growing in the grounds of Mr. John Hopkins (deceased Oct. 20, 1883), living a mile southeast of the city. It was named Ten Dollar Prize, and in November following, was moved into my vineyard, and from this many hybrids have been produced, some now in the third generation just completing most rigid test of several years, a few of which will be described further on. $\left(, \frac{5}{20}\right)$. The vine of Ten Dollar Prize was vigorous, stocky, perfectly healthy in leaf and fruit, exceedingly prolific; cluster large, shouldered, cylindrical, compact; berries of good medium size, round, black, very persistent, skin thin, tough, pulp meaty, but tender, and juicy, of pure, high quality, tho somewhat astringent, seeds small, ripe exceedingly late. Original vine lost.

The vines were left hanging in the hall on exhibition for four or five days in very hot dry weather, when the leaves of Concord and Delaware were brown and dry enough to powder into dust, while the leaves of all the Post-Oak varieties were yet green and wilted but little, showing how well this species is prepared, by dense leaf-tissues, to prevent evaporation, and thereby, and with very deeply penetrating roots, to endure drouth, and that Concord with its shallow system of roots, and its porous leaves, is not adapted to the South.

Now let us examine a few of the various groups of hybrid varieties of this species.

\section{Lincecumii-Æstivalis Hybrids}

Of these quite a number were produced between Ten Dollar Prize and Norton, and the best and only one disseminated is:

HOPKINS. (Commemorative of the finder of the Ten Dollar Prize). T. V. M. 1888. (, $\left.\frac{5}{19}\right)$. Vine much more robust than Norton, perfectly. healthy in leaf and fruit, very prolific, cluster and berry much like Norton, but larger; juice red. E. J. Ayers, of Villa Ridge, Ill., commends it highly as one of his most profitable market grapes, but I would term it a wine-grape, rather than for market.

\section{Lincecumii-Æstivalis-Bourquiniana Hybrids}

ALBANIA, T. V. M. 1896. ( $\frac{5}{15}$ ). (Ten Dollar Prize $\mathrm{x}$ Norton $\mathrm{x}$ Herbemont). Vine very vigorous, but subject to Anthracnose in cold wet springs, and the fruit, when young, to Black Rot; foliage larger than Herbemont, of a little less lively green, prolific. Cluster large to very large, shouldered; berry medium, translucent white; skin thin and tough; pulp very tender and juicy, sprightly, with Herbemont character, but sweeter; uses, late market, table and white wine. Late, ripening with Fern, will remain on until frost; the latest white grape in cultivation. Ten feet, long pruning. Specially adapted to West Texas.

BLONDIN, T. V. M. 1896. ( $\frac{5}{12}$ ). Combination of Ten Dollar Prize Post-Oak, Norton Virginia and Herbemont. Very vigorous, prolific. Cluster large, compact, shouldered; berry medium, white translucent; skin very thin and tough; pulp very tender, juicy, sprightly, quality excellent, nearly best. Late, with Triumph and Catawba in season. Very valuable as a late market and white wine grape. Ten feet, medium pruning. (See Plate LVIII., page 170.) 


\section{Lincecumii-Æstivalis-Labrusca Hybrid}

LAUSSEL, T. V. M. 1886. (' $\frac{5}{17}$ ). (Secundo $x$ Gold Coin). Vine very robust, stocky, perfectly healthy, very difficult to grow from cuttings, prolific only with long arm pruning; cluster medium, very compact, shouldered, short peduncle; berry medium to large, globular, dark purple, persistent, skin thin, tough, pulp meaty, rather firm, juicy, of a very agreeable, peculiar flavor, fine for late market and white wine. Ten feet, long arm pruning.

\section{Lincecumii-Bourquiniana Hybrids}

HERMANN JAEGER, T. V. M. 1883. ( $\left(\frac{5}{12}\right)$. (Premier $x$ Herbemont). Growth very strong, endures the Texas climate well. Clusters large to very large, shouldered, conical, very compact; peduncle short. Berries small to medium, black, persistent; skin thin, tough, does not crack; pulp tender, very juicy, easily freeing the seeds. Quality better than Concord. A profitable market and table grape. Ripens a week later than Concord. Not attacked to any extent by mildew, rot or leaf-folder. Valuable in Southwest Texas especially, and successful throughout the South. 10 to 12 feet, long arm pruning.

KIOWA, T. V. M. 1893. ( $\frac{\mathbf{5}}{16}$ ). (Jaeger $43 x$ Herbemont). Growth very strong and healthy. Cluster large, cylindrical, shouldered and sometimes branched; peduncle of medium length. Berries small to medium, a good size larger than the Herbemont; juice red. Rarely touched by rot. A good market and an excellent wine grape. Ripens with Herbemont. Requires wide planting and long pruning. 12 to 14 feet. Adapted for the South. (See Plate LIX., page 171.)

MARGUERITE, T. V. M. 1886. ( $\left.\frac{5}{21}\right)$. (Secundo $x$ Herbemont). Growth very strong, not attacked by mildew, endures Texas climate perfectly. Clusters medium, cylindrical, shouldered, with short peduncle, compact. Berries a good size larger than Herbemont, globular, dark purple, persistent; skin thin and tough, never cracks; pulp tender, juicy, sprightly, about equal to Herbemont. Ripens some three weeks later than Herbemont, and hangs on through September and sells well in the market. It makes a fine white wine. A shy bearer on short arm pruning, but on long arms it bears heavily. Succeeds everywhere in the South. A splendid arbor grape. 14 to 16 feet. (See Plate LX., page 174.)

MUENCH, T. V..M. 1886. ( $\left.\frac{5}{18}\right)$. A hybrid of Neosho and Herbemont. Vine very vigorous and free from all diseases; cluster large to very large; berries above medium, purplish-black; pulp very tender and meaty of fine quality. Sells readily in the market, also fine for table. Well adapted to the South. Ripens very late, after Herbemont. Plant 10 feet, long arm pruning. (See Plate LXI., page 175.)

NEVA MUNSON, T. V. M. 1886. ( $\frac{5}{21}$ ). (Neosho $x$ Herbemont). Vine vigorous, healthy and productive. Cluster long and showy. Berry small to medium; color dark purple. A most excellent wine grape, as testified by expert wine growers. Ripens very late. Plant 12 feet, long arm. (See Plate LXII., page 176.)

\section{Lincecumii-Labrusca Hybrids}

BEACON, T. V. M. 1886. ( $\frac{5}{10}$ ). (Big Berry $x$ Concord). Growth medium in South Texas, becoming stronger in North Texas to very strong in Missouri. Very prolific, of large cylindrical clusters, often shouldered, moderately compact. Berries as large or larger than Concord, black, with rather heavy white bloom, hang to cluster about equally well with Concord, but not so well as Bailey; skin a little tougher than Concord, never cracks; pulp rather more tender than Concord; very juicy, sprightly and of a very similar flavor to Concord; rather more agreeable; seeds readily leave the pulp. Ripe here July 15 to 25 . The vines have continuously borne very heavily and endured the climatic hardships well in Texas, Missouri and Illinois, pass- 


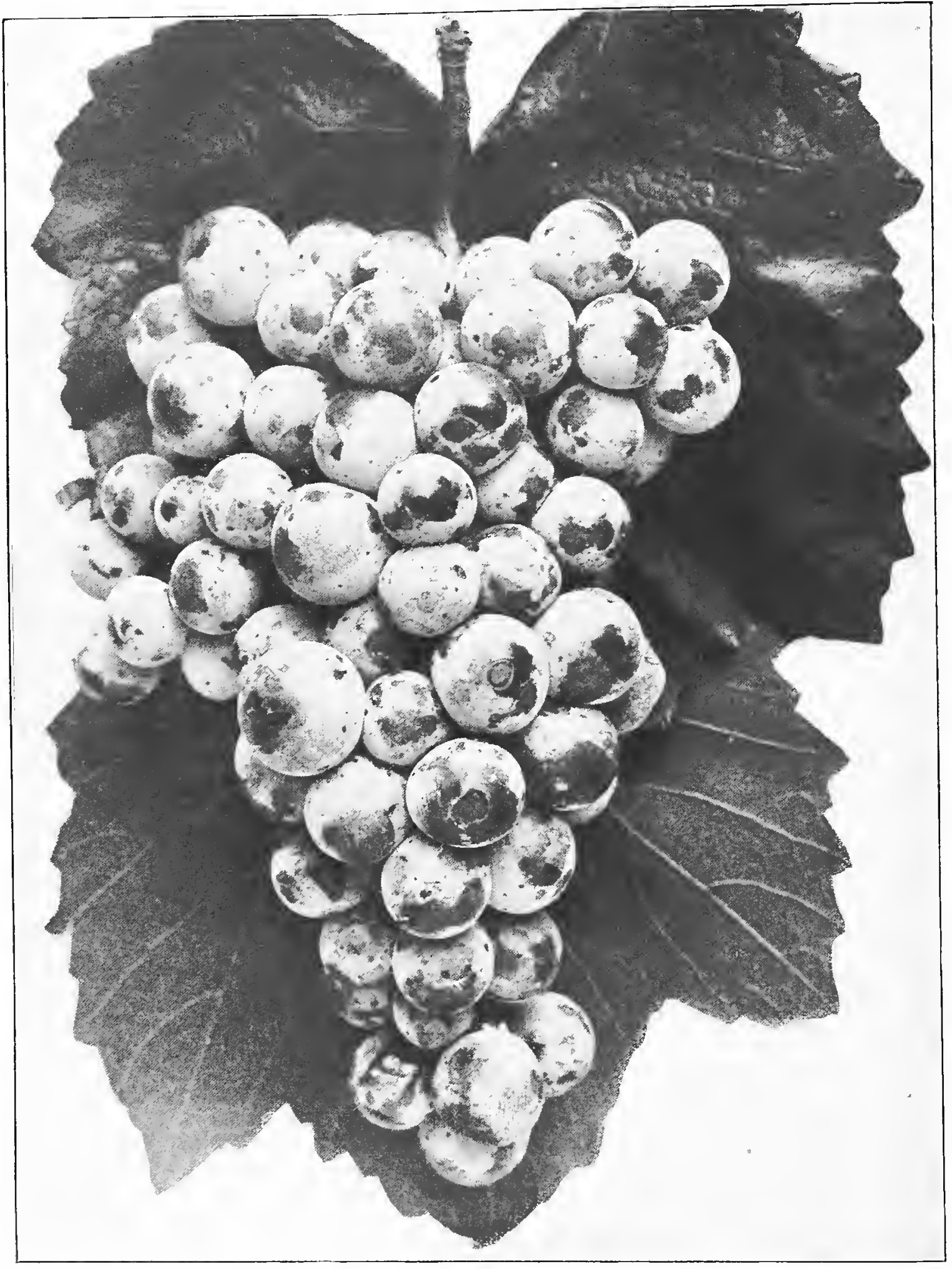

PLATE LXVIII. ELLEN SCOTT. (See page 191.) 


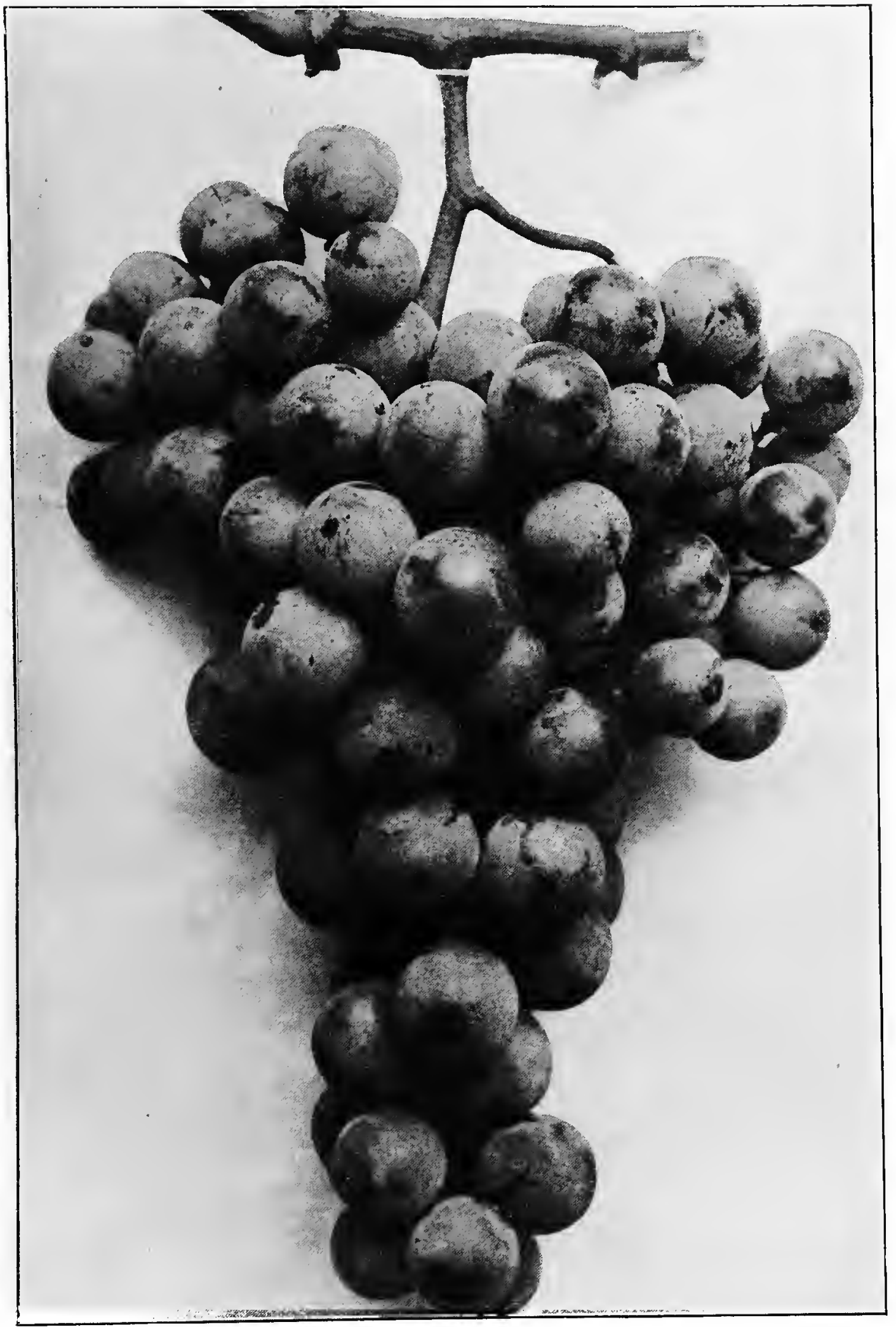

PLATE LXIX. FERN MUNSON. (See page 191.) 


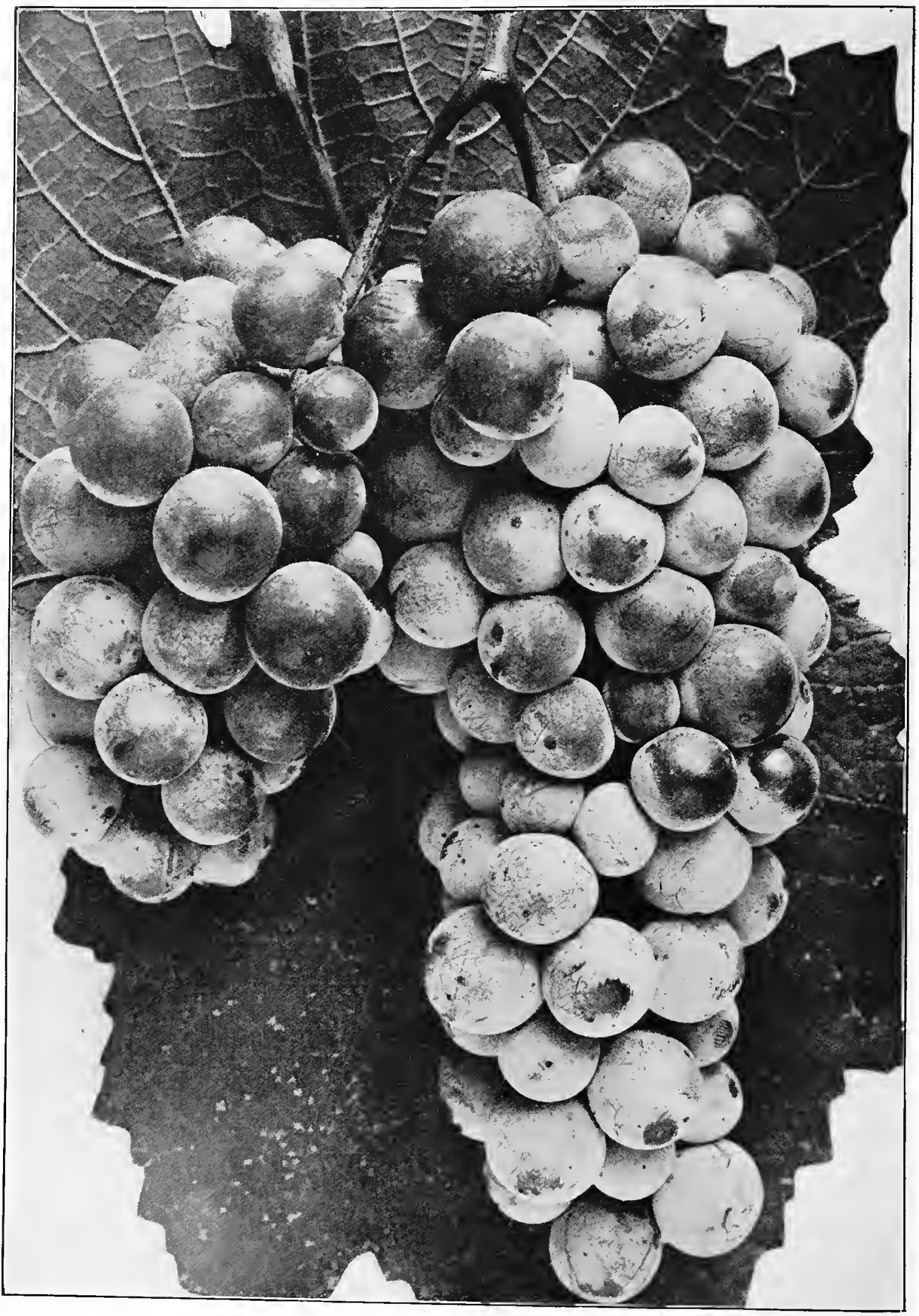

PLATE LXX. LAST ROSE. (See page 191.) 


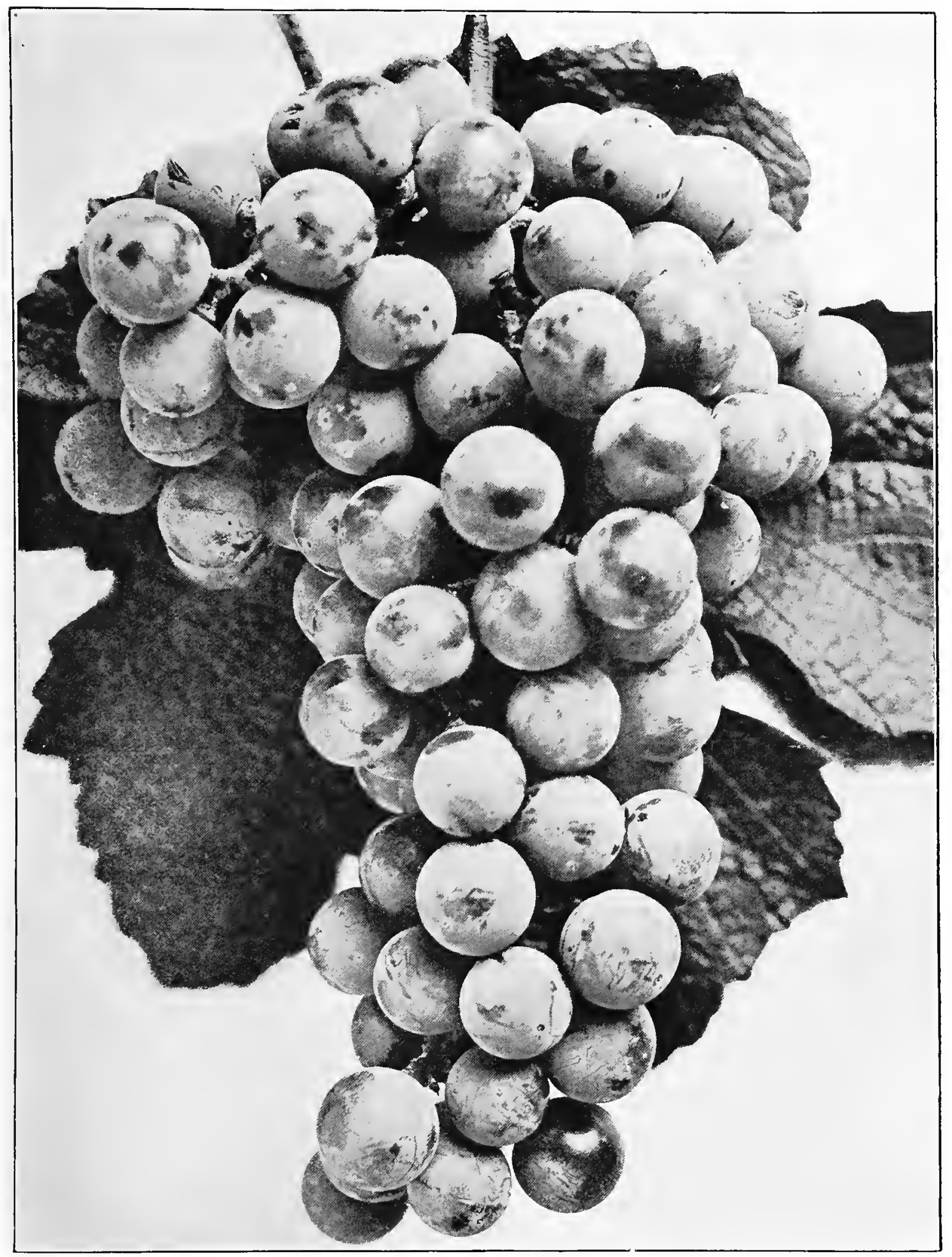

PLATE LXXI. R. W. MUNSON. (See page 191.) 
ing 27 degrees below zero at Palmyra, Missouri, in the grounds of Dr. Jaudon, and bore heavily the following season. Adapted South and North. (See Plate LXIII., page 177.)

DR. COLLIER, T. V M. 1885. (' $\left.\frac{5}{10}\right)$. (Ten Dollar Prize x Concord). Vine vigorous, large leaves, stocky, prolific. Cluster large, conical, not very compact; berries large, globular, clear handsome red, persistent, does not drop or crack, skin thin, flesh little pulpy, very juicy; should be thoroly ripe, as otherwise rather acid, quality good; ripe about a week later than Concord. In Oklahoma this grape is put at the head as a profitable market variety. Soil and climate there just suit it.

OZARK, produced by Dr. J. Stayman, of Leavenworth, Kansas. Analysis shows it to be a combination of Post-Oak Grape $x$ Concord. $\left(, \frac{5}{10}\right)$. Vine vigorous, healthy, prolific. Cluster above medium, sub-conical; shouldered, with long peduncle; berry black, round, with heavy Concordlike bloom, medium size, skin never cracks, rather thin; flesh meaty, tender, of agreeable, very good quality; juice red; ripens unevenly, like Concord, and a week or two later. An excellent red wine grape. Plant 10 feet apart; give medium to long pruning.

\section{Lincecumii-Labrusca-Vinifera Hybrids.}

ARMADO, T. V. M. 1902. ( $\left.\frac{5}{15}\right)$. (Armlong x Griesa de Piemonte). Vine good grower, healthy, prolific; cluster very large, compound, producing 150 to 200 berries, which are persistent, ovoid, medium in size, black, skin thin, tenacious; flesh tender, very juicy, juice of a claret color; flavor pure, fine, the richest in sugar of any variety tested in 1907 . Altogether an exceedingly promising variety for late market and red wine. Not yet introduced. (See Plate LXIV., page 180.)

ARMALAGA, T. V. M. 1902. (" $\left.\frac{5}{14}\right)$. (Armlong x Malaga). Vine very robust, stocky, short jointed, but little attacked by mildew in wet seasons; leaves of medium size, prominent, acute teeth, little pubescent on lower side; cluster large to very large, compact, handsome, shouldered; berry large, clear yellowish-white, skin thin, tough, does not crack; pulp melting, very juicy, sprightly, of best quality, richer than Malaga; very promising. Specially adapted for Gulf Coast, and the parts of Texas, Oklahoma, west of the 97 th meridian, succeeding well at Denison, Texas. Has endured six degrees below zero without injury. (See Plate LXV., page 181.)

ARMLONG, T. V. M. 1886. (, $\frac{\mathbf{5}}{\mathbf{6}}$ ). (Ten Dollar Prize x Black Eagle). Vine vigorous; stocky, healthy or little affected by mildew and rot; leaf large, three to five lobed; slightly downy on under side; cluster exceedingly large; often double, that is the shoulder so long as to seem a secondary cluster; ten to twelve inches, common length, loose; long peduncle; berry large, globular, black, skin thin, tough; pulp tender, juicy, spicy and pure, of fine flavor, seeds small; ripens late, some three weeks after Concord. On account of having imperfect flowers; it has not been introduced, but has been used with splendid results in breeding. See Armado, Armalaga, Ellen Scott, Last Rose, the best selections out of many hundreds. (See) Plate LXVII., page 183.)

BAILEY, T. V. M. 1886. (' $\left.\frac{5}{12}\right)$. (Big Berry x Triumph). Growth strong. Clusters large to very large, cylindrical or often branching, generally compact. Berries persistent, large, black, with little bloom; skin thin and tough, never cracking; pulp meaty, but not tough, juicy, sprightly, of pure very good quality, considerably above Concord; seeds readily parting from pulp. Ripe about July 10 to 30. A valuable market grape, easily superseding Concord, especially in South-Central and Southwest Texas, where it has done remarkably well. Plant 10 to 12 feet apart; medium to long pruning.

CARMAN, T. V. M. 1883. ( $\frac{5}{12}$ ). (Premier $\mathrm{x}$ Triumph). Growth vigorous; foliage never attacked by leaf-folder or mildew; very prolific. Cluster large to very large, have reached two pounds in rare instances, shouldered or branched, conical, very compact. Berries persistent, 
medium, globular, black with thin bloom; skin thin and tough, never cracking; pulp meaty, firm, yet tender when fully ripe, of pure, rich quality, much superior to Concord; seeds easily leaving the pulp. Vines now 20 years old, have borne 17 heavy crops. Has always been one of the most profitable varieties with us and greatly praised in many sections of the South as far north as 40 degrees latitude. Ripe one to three weeks after Concord is gone. Will hang on the vines many days after becoming ripe without deteriorating. Plant 10 to 12 feet apart. Médium pruning. (See Plate LXVI., page 182.)

ELLEN SCOTT, T. V. M. 1902. ( ‘ $\left.\frac{5}{12}\right)$. (Armlong x Malaga). Vine a stocky, vigorous, healthy grower; leaf not lobed, smooth, dark green, cluster very large, conical, often shouldered, short peduncle; berry very persistent, large to very large, round, dark translucent violet, skin thin, but does not crack, delicate, flesh breaking, melting, of most sprightly delicious character, ripens late, after Catawba. This is exceedingly promising as a splendid commercial grape, and unexcelled as a dessert variety, even among foreign kinds. Named for my wife. (See Plate LXVIII., page 186.)

EXTRA, T. V. M. 1886. ( $\left.\frac{5}{14}\right)$. (Big Berry x Triumph). Growth strong; cluster oblong to cylindrical, sometimes shouldered, moderately compact. Berries persistent, globular, medium to large, dark purple to black, with moderate bloom, skin thin, tough, never cracks; pulp tender, juicy, sprightly, agreeable, sweet; seeds easily passing from the pulp. Ripe July 25 to August 10 at Denison. Does well in South Texas. An excellent market and wine grape. William Pfeffer of Santa Clara County, California, a wine-maker of reputation, writes in the "Pacific Tree and Vine": "The Post-Oak family of hybrids are most vigorous, good bearers, the best resistants, and make very fine wines. In fact, there is no Zinfandel, Mataro or Carignan wines, not to name a long list of standards, that can equal a wine of Neva or of Big Extra, and no light claret as refreshing as one of Elvicand."

FERN MUNSON, T. V. M. 1883. ( ' $\left.\frac{5}{19}\right)$. (Premier $x$ Catawba). Growth' very strong. Cluster medium to large with long peduncle. Berries globular, medium to large, very persistent; very dark purplish-red to nearly black; skin thin, tough; pulp firm, but not tough; very juicy, sprightly, with very agreeable Catawba flavor when fully ripe; seeds leave the pulp readily. Ripens very late in August or early in September, and hangs on until frost if desired, becoming excellent in quality and giving full satisfaction in market. Very profitable, as it ripens when all old varieties are gone. Free from Black Rot. Has endured 27 degrees below zero in Missouri and has borne well the following season. It endures drouth excellently. Adapted for the South and North to latitude 40 degrees. 10 to 14 feet, long pruning. (See Plate LXIX., page 187.)

LAST ROSE, T. V. M. 1902. (,$\left.\frac{5}{14}\right)$. (Armlong $x$ Jefferson). Vine robust, healthy, prolific; cluster very large, heavily shouldered, compact; berry large, rich rosy red, globular, persistent, very showy and handsome; skin thin, tough; flesh tender, juicy, of "excellent quality, ripe the latest of any grape in the list,-in September, and will hang in good condition until frost. Exceedingly promising for the South. It will require to have perfect flowered kinds near it blooming at same period. (See Plate LXX., page 188.)

R. W. MUNSON, T. V. M. 1886. (' $\left.\frac{5}{10}\right)$. (Big Berry $x$ Triumph). Growth strong, perfectly healthy; clusters medium to large, cylindrical, often shouldered, peduncle medium; berries, when well grown, medium to large, globular, persistent, black without bloom; skin never cracks; pulp tender, juicy and of a very good quality, better than Concord or Beacon. Ripe just before Concord. Gives good satisfaction on market. Bears heavily on long pruning and when pollinated by other erect-stamened varieties flowering at same time,-its own pollen not being fully adequate, although its flowers are apparently perfect. Concord and Brilliant good pollinators for it. Ships well. 10 to 12 feet apart. A. M. Bowman, of Salem, Va., after fruiting this variety, pronounces it the best American grape in vine and fruit. (See Plate LXXI., page 189.) 


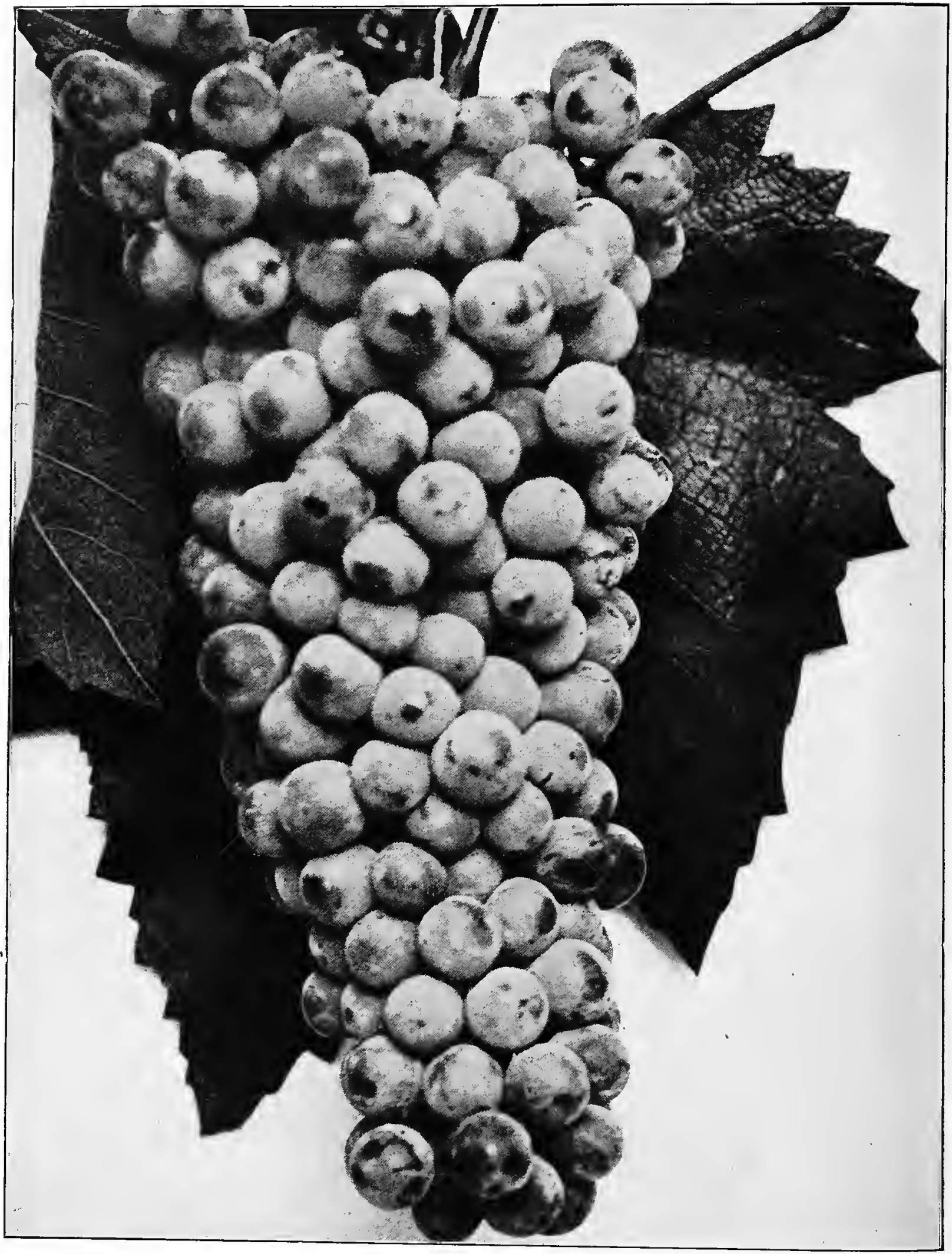

PLATE LXXII. HUSMANN. (See page 196.) 


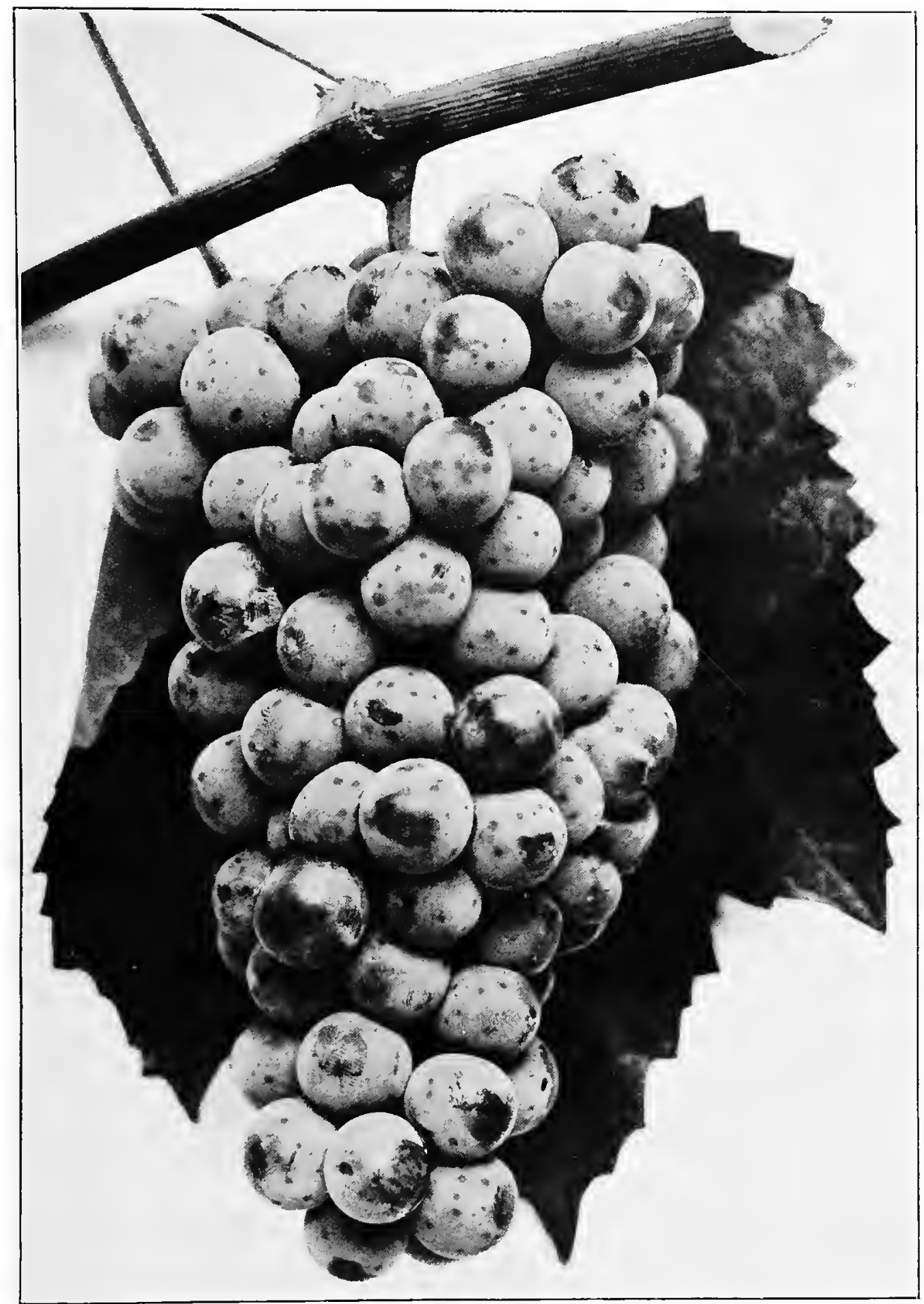

PLATE LXXIII. AMERICA. (See page 196.) 


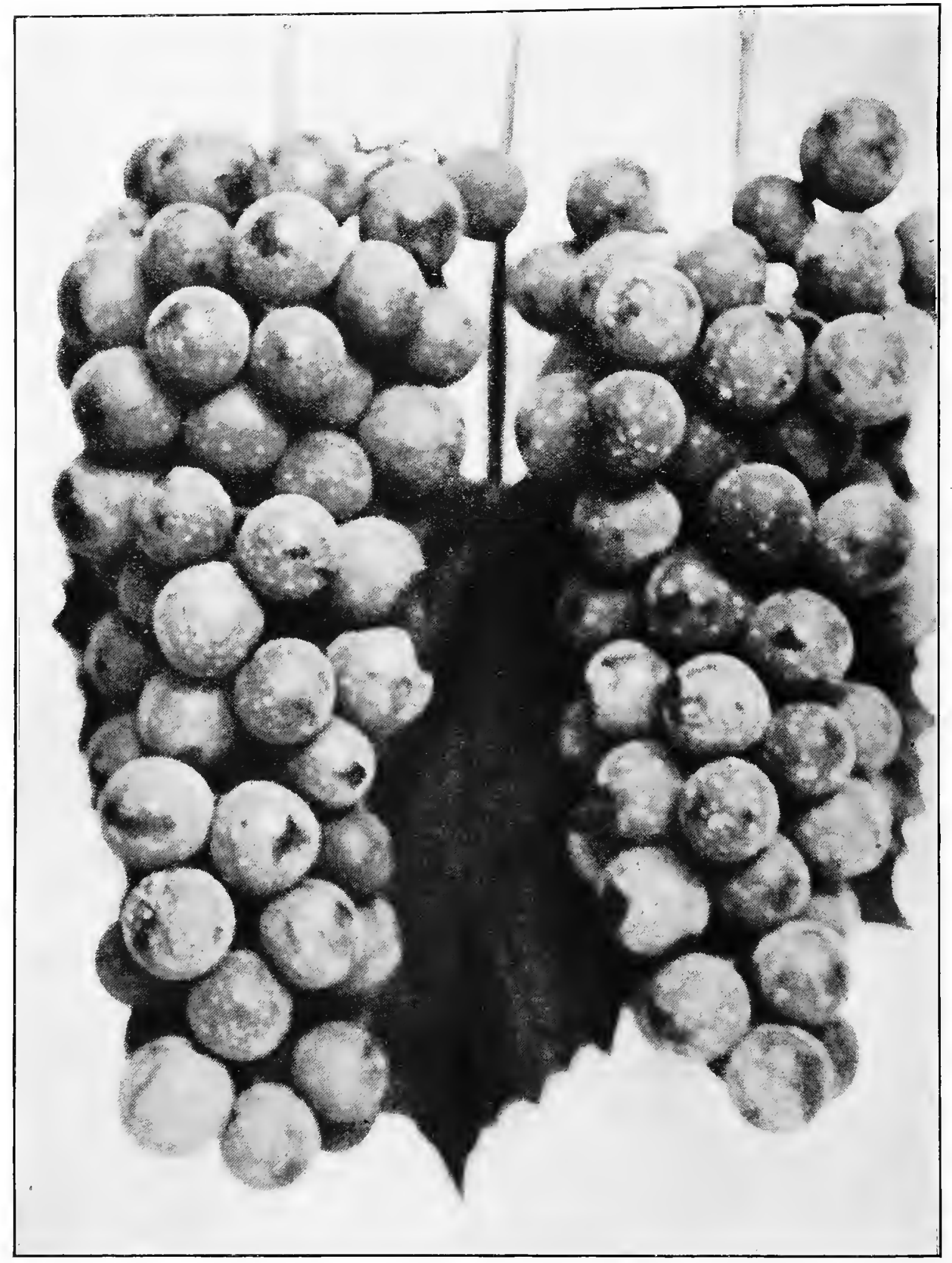

PLATE LXXIV. MANITO. (See page 197.) 


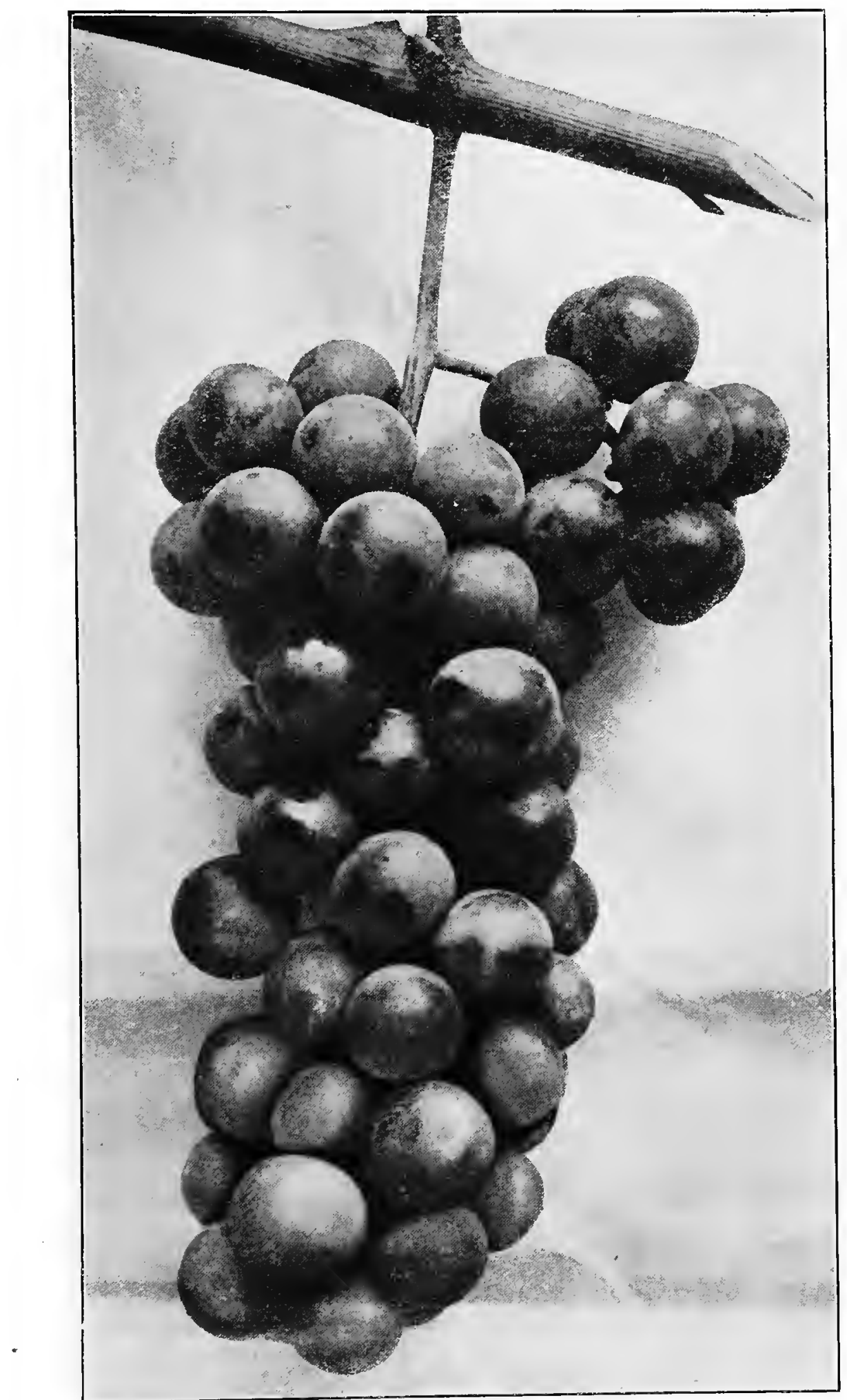

PLATE LXXV. MERICADEL. (See page 197.) 


\section{Lincecumii-Labrusca-Vinifera-Æstivalis Hybrid}

MANSON, T. V. M. 1897. ( $\left(\frac{5}{11}\right)$. Leaf is subject to mildew in wet seasons. An exceedingly sweet white grape. A hybrid of R. W. Munson with Gold Coin. Vigorous and productive; clusters medium, berry above medium, of yellow color; skin thin and tough; pulp tender, quality excellent; ripens late, with Triumph.

\section{Lincecumii-Labrusca-Vinifera-Bourquiniana Hybrids}

DELiCATESSEN, T. V. M. 1902. (' $\left.\frac{5}{11}\right)$. (R. W. Munson $x$ Delicious). (Delicious is a Big Berry Post-Oak x Herbemont hybrid.) Vine vigorous, healthy, leaves three to five lobed, dark green; prolific, stocky; cluster above medium, conical, shouldered, long peduncle, fairly compact; berry round, black, above medium. persistent; skin thin, does not crack, flesh tender, juicy, sprightly, with a distinct very agreeable, delicate flavor, juice clear red; a very promising hardy market table and wine grape.

HUSManN, T. V. M. 1892. ( ‘ $\left.\frac{5}{17}\right)$. (Armlong x Perry). Combination of Ten Dollar Prize and Secundo Post-Oak grapes, with Black Eagle and Herbemont. Growth vigorous, endures Texas slimate well; foliage mildews in wet seasons; clusters very large, long, cylindrical, sometimes shouldered, on medium peduncles, compact; berries medium size, globular. black, persistent; skin thin, delicate, yet tough; pulp melting, very juicy, sprightly, of high, pure flavor. More satisfactory by far as a market and table grape than Herbemont. This variety is giving fine satisfaction in California, where tried, as a red wine grape. Prolific. (See Plate LXXII., page 192.)

\section{Lincecumii-Rupestris Hybrids}

AMERICA, T. V. M. 1885. (' $\frac{5}{10}$ ). (Seedling of Jaeger No. 70). Growth very strong. Cluster conical, sufficiently compact; berries very persistent, medium size, globular, black with little bloom, and scatteringly dotted jet black with white speck in center of dots; skin thin and tender, but does not crack; pulp melting, juicy, easily freeing the slender seeds; when fully sripe very rich in sugar, also rich in agreeable acid; possesses a very distinct peculiar flavor, much liked by some, not "foxy," making a good combination market and wine grape. Juice intensely violet red. A very good port wine has been made from it without "fortifying." Ripens at Denison, Texas, July 20 th to August 1st, a little after Concord, and always evenly. Very prolific with long arm pruning and when pollenized by other varieties, as it does not thoroly pollenize itself. Beacon and Concord are good mates. Endures the severest drouth with ease. Has passed through 27 degrees below zero without damage. Not attacked by mildew, rot or leaf-folder, and has given excellent results in California as a resistant graft stock for Vinifera varieties. Adapted South and North. Plant 12 to 14 feet apart. (See Plate LXXIII., page 193.)

MUNSON (Jaeger No. 70). (,$\left.\frac{5}{10}\right)$. Originated by Hermann Jaeger (and by him named for the writer), Neosho, Mo., by hybridizing his No. 43 Post-Oak grape with a select staminate vine of Rupestris, - a seedling of his Rupestris No. 60. In every way similar to America, except its leaf, cluster and berry are smaller, and the quality is not so good. When well pollinated, it bears immense crops, and is a fine red wine grape. I mention it, so as to show the prime origin of this vigorous, hardy, healthy family that promises to play an important part in American viticulture.

ENOLIAN, T. V. M. 1902. (' $\frac{5}{12}$ ). (Amsion x Malaga). The Amsion is a combination of America, Norton and Ten Dollar Prize. Vine vigorous, healthy, prolific, leaf of medium size; 
cluster large, compact, producing about 80 berries to a cluster; berry round, black, medium; skin thin, never cracks, flesh very juicy, juice of claret color, fine quality, very promising red wine grape, and large enough for market. Ripe late. Not yet introduced.

\section{Lincecumii-Rupestris-Bourquiniana-Labrusca-Vinifera Hybrids}

ATOKA, T. V. M. 1893. ( $\left(\frac{5}{12}\right)$. (America x Delaware). Growth vigorous; cluster large, slightly conical to nearly cylindrical, often with short shoulder, fairly compact; berries persistent, small to medium, globular, dark purplish-red, with little bloom; skin thin and sufficiently tough, never cracks; pulp juicy, tender, very sprightly and agreeable when ripened, easily freeing the seeds; rich both in sugar and in acid; quality pure and fine, sells readily in the market, and gives satisfaction. Resists disease and climatic changes excellently. Adapted South and North. 10 to 12 feet apart. Long arm pruning.

MANITO (America $x$ Brilliant). Growth very similar to America, endures extremes of climate very well. Clusters long, cylindrical, rather open, with long peduncle; flowers apparently perfect, but does not bear well alone, very prolific; berries medium, globular, persistent, dark purple, with white specks; very distinct and unique in appearance; skin thin and tough; pulp very tender, juicy, sweet and agreeable, parting from the seeds with ease. Ripens very early, about with Moore Early, packs beautifully and ships excellently. A very profitable market grape, also a good wine grape. Adapted for generil North and South. Reported doing well in Massachusetts and Ontario. 8 to 10 feet, medium arms. (See Plate LXXIV., page 194.)

MERICADEL, T. V. M. 1893. ( $\left(\frac{5}{10}\right)$. A hybrid of America with Delaware. Vine very vigorous and very productive; cluster large, berry medium, purple, translucent, very persistent to cluster; skin thin and tough; pulp tender and meaty, of very best quality; fine for table and market. Ripens late, just after Concord. Doing finely in Florida and Southeastern part of United States. Pronounced of the best quality by many who have taken part in our "grapetasting parties." Plant 8 feet apart, medium arms in pruning. (See Plate LXXV., page 195.)

\section{Lincecumii-Rupestris-Labrusca Hybrids}

CAPTAIN, T. V. M. 1896. ( ( $\frac{5}{9}$ ). Parentage,-America crossed with R. W. Munson. See description of these. Cluster very large; long, cylindrical, reaching ten to twelve inches; berry'large, black with white bloom; skin thin; ships well; pulp tender, freeing seeds easily, quality much better than Concord. Exceedingly vigorous and prolific. Uses, market, table, red wine; medium season. 10 to 12 feet, medium pruning. Altho the flowers of this variety appear perfect, yet they are not sufficiently self-fertile so that, in some years, the clusters fail to set full, hence some proper pollinator such as Beacon, R. W. Munson, Mericadel, Valhallah, Xenia, Hidalgo, or Concord, should be planted near it. (See Plate LXXVI., page 198.)

\section{Lincecumii-Rupestris-Labrusca $\llcorner$ Vinifera Hybrids}

WINNER, T. V. M. 1902. (' $\left.\frac{5}{10}\right)$. (America $x$ Badart). Vine very robust, healthy and prolific; cluster large, peduncle long, conical, sometimes shouldered; berry medium to large, tound, black, persistent, skin thin, but does not crack, flesh melting, very rich in a most sprightly, agreeable flavor, peculiar to all of this group. The juice of Winner has a clear claret color. The variety ought to, by its composition, succeed over a wide range from South to North. Not yet introduced. The Badart is a hybrid of the Ten Dollar Prize Post-Oak grape with Triumph.

XLNTA, T. V. M. 1893. (,$\left.\frac{5}{5}\right)$. (America x R. W. Munson). Growth strong; clusters large, cylindrical, shouldered, with medium peduncle, fairly compact, unless not well pollenized, then loose; flowers have reflexed stamens and perfect flowering kinds should be planted near, such as Brilliant, Delaware, Concord. Berries medium to large, globular, persistent, black, with little bloom; skin thin, never cracks, pulp meaty, tender and of a very agreeable, sprightly quality. 


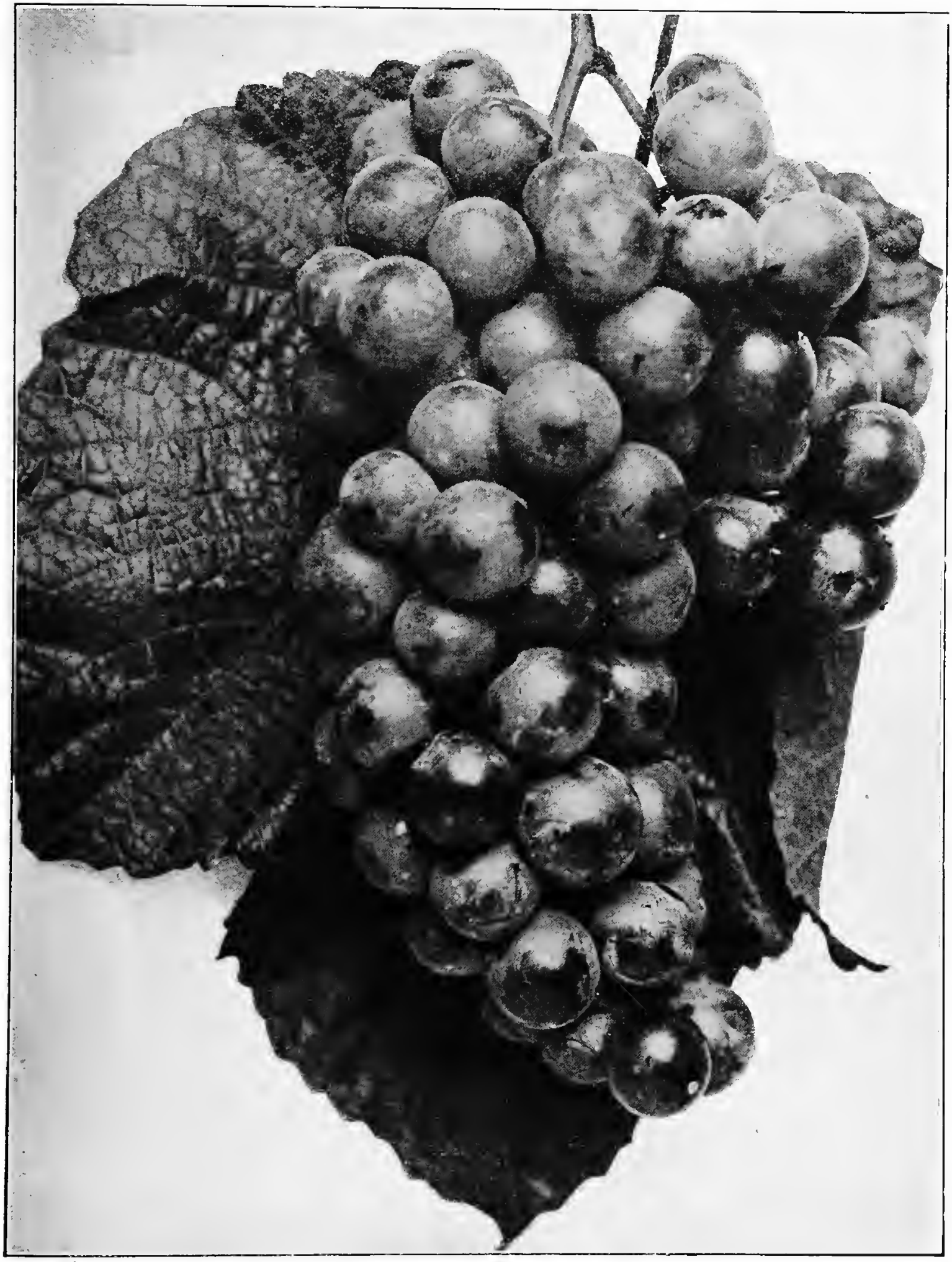

PLATE LXXVII XLNTA. (See page 197.) 


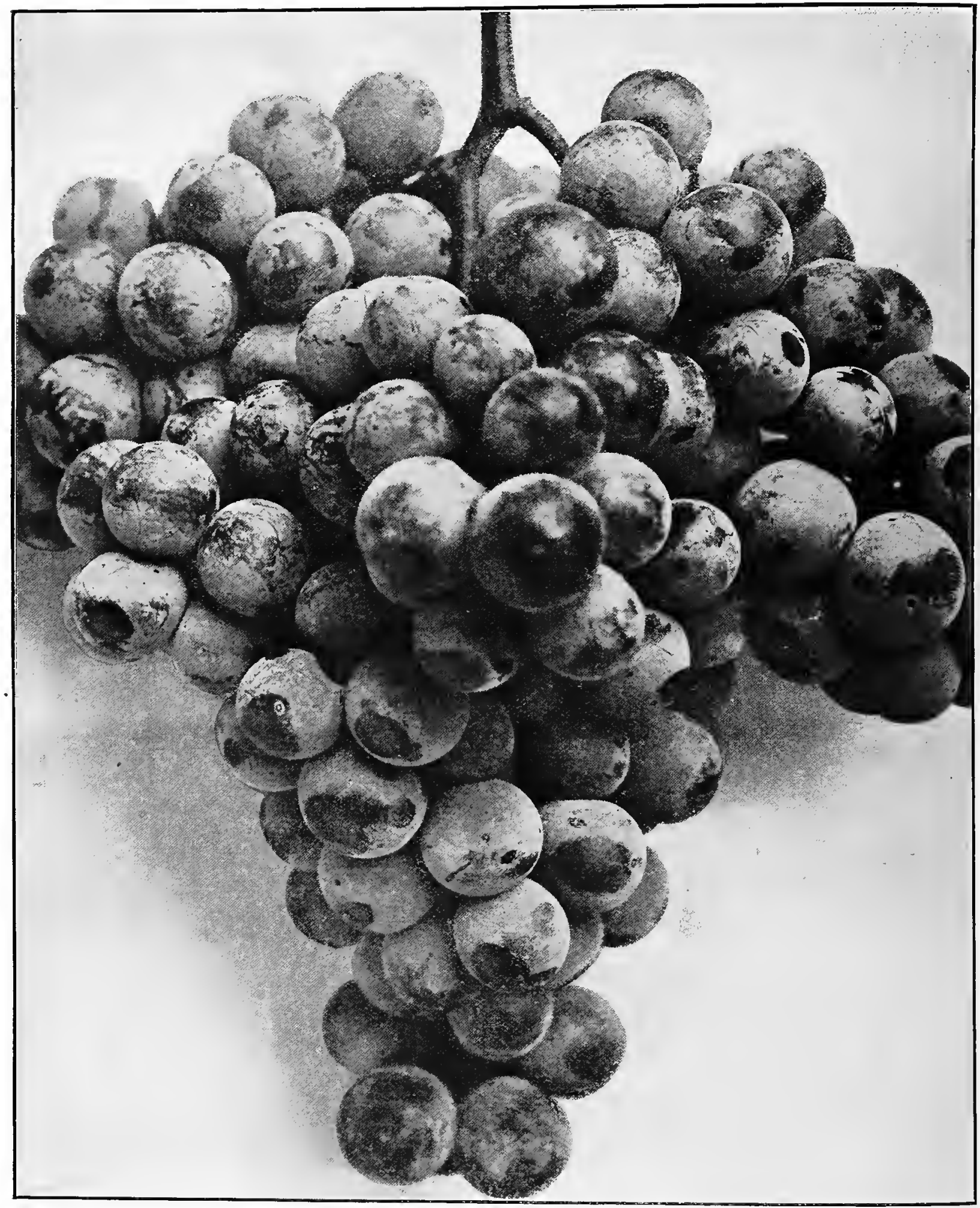

PLATE LXXVIII. GRIESA DE PIEMONTE. (See page 202.) 


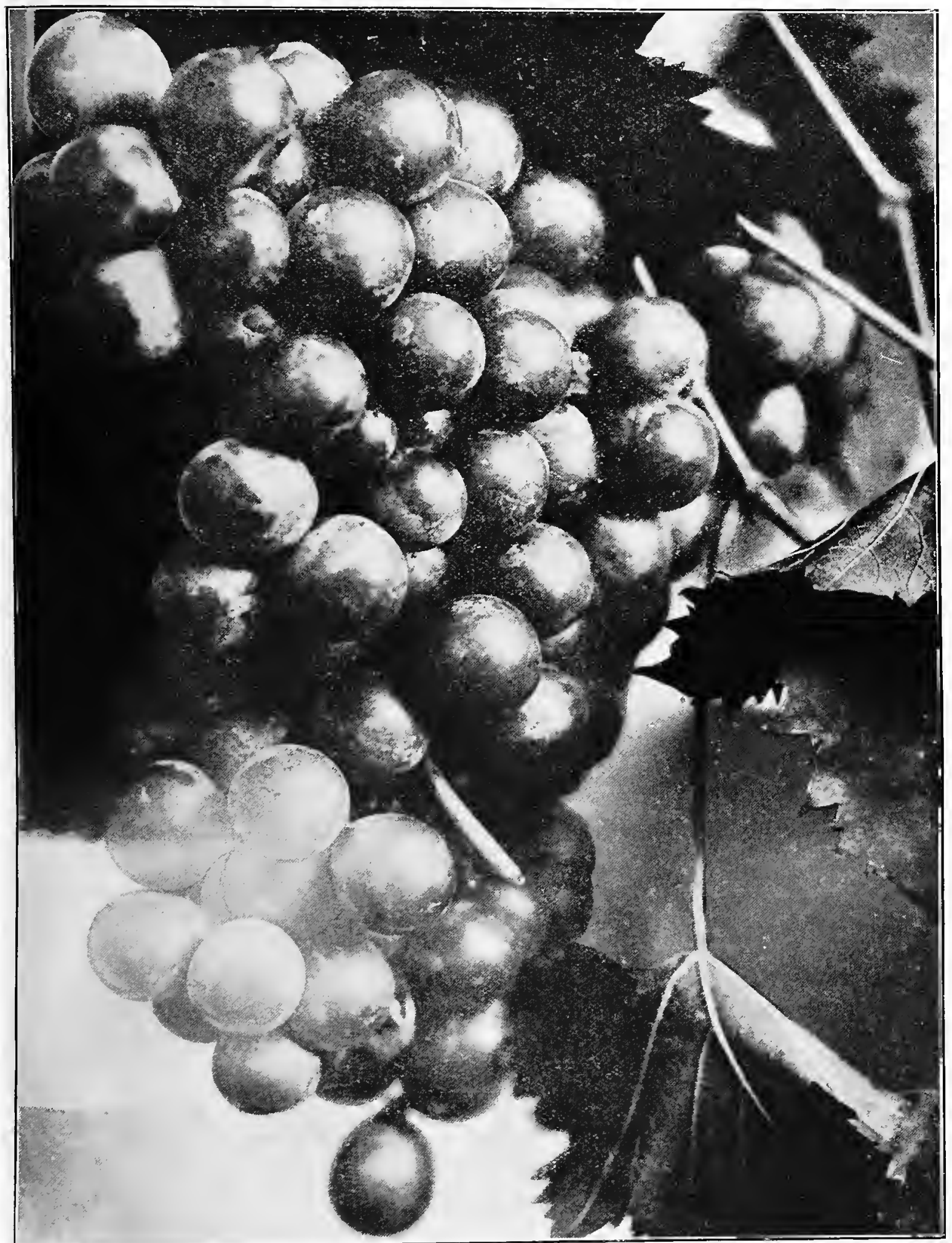

PLATE LXXIX. MUSCAT OF ALEXANDRIA. (See page 202, ) 
Ripe with or later than Concord. Very prolific on medium to long pruning; an excellent market and wine grape. Endures climatic extremes well. Ten feet. Adapted throughout the South and North to the Ohio River. (See Plate LXXVII., page 199.)

\section{Vinifera Varieties}

Of some sixty leading varieties of Vinifera grapes, collected from Japan, Persia, Greece, Italy, Spain, Hungary and France, and tested as to hardiness, healthiness, bearing qualities, size, beauty, quality, market and wine properties, have selected the following as the most desirable and that are proving profitable in Western and Southwestern Texas under irrigation and in places without irrigation.

CALABRIAN. Cluster and berry very large, globular, color yellowish-white, persistent, firm, early to medium season, a fine shipper, quality fine.

CHASSELAS DE FONTAINBLEAU (Sweetwater). Cluster large, berry medium, spherical, yellowish, of fine quality, very early.

FLAME TOKAY. Cluster and berry of great size, berry obovate, pink or rose color, very persistent, firm, quality good when well ripened, very attractive and a great seller and shipper.

FEHER SZAGOS. Cluster and berry very large, berry persistent, white, ovoid, ripens late, of very excellent quality, better than Malaga, the most vigorous of the Viniferas tried, even than Malaga, but not so resistant to Mildew and Black Rot.

GRIESA DE PIEMONTE. Cluster. very large, comparing favorably with Black Hamburg, black, globular, firm, meaty, excellent quality, vine more vigorous and healthy in open ground at Denison, Texas, than Black Hamburg, rather late. (See Plate LXXVIII., page 200.)

MUSCAT OF ALEXANDRIA. Cluster and berry very large, berry ovoid, greenish-yellow, persistent, firm, of highest quality, both in sweetness and peculiar, rich flavor. Vine of medium vigor, sensitive to mildew. Best for raisins. (See Plate LXXIX., page 201.)

PERLE OF ANVERS. Cluster and berry very large, persistent, very late, white, firm, very fine quality.

PENSE (MALAGA). Cluster and berry large, persistent, berry ovoid, firm, juicy, pure and quite sweet when thoroly ripe, very prolific.

QUAGLIANO. Cluster and berry medium to large, berry spherical, clear pink, of high quality, late, vine very vigorous.

RED CORNICHON. Cluster medium to large, berry large to very large, oblong, dark purple, quality fair, not a very good shipper. (See Plate LXXX., page 204.)

ROSE OF PERU. Cluster large, berry medium, round, dark purple, very fine quality, vine healthy.

MUSCAT ROSE. Cluster and berry large, violet, ovoid, meaty, firm, a good shipper, quality in sugar, and a distinct bumble-bee-honey flavor, of the highest. Vine one of the most vigorous and healthy of this class. (See Plate LXXXI., page 205.)

SAUVIGNON JAUNE. Cluster and berry medium, berry yellowish, globular, very juicy and delicious, makes a fine white wine.

SEMENDIA. Hungarian, of recent importation, cluster and berry large, berry ovoid, yellowish, firm, of pure excellent quality, early, one of the healthiest of this class, very prolific. (See Plate LXXXII., page 206.)

SULTANINA (THOMPSON'S SEEDLESS). Cluster very large, berry medium, oblong, yellowish-amber, very beautiful and good; seedless, makes the finest of seedless raisins, vine vigorous, but very sensitive to mildew and cold.

SWEETWATER. See Chasselas de Fontainbleau. 
VERDELHO. Vigorous, healthy, cluster and berry large, berry ovoid, yellowish, meaty, juicy, a fine table variety.

VIOLET CHASSELAS. Vigorous, clusters and berries large, berry ovoid, violet, beautiful, excellent quality, meaty, a fairly good shipper; ripens early.

The above named exotic grapes, if grafted upon the good resistant native grape roots, and the vines carefully sprayed with Bordeaux Mixture, (page 236) will succeed all through the South to about the 35 th parallel. In the northern parts of this region, winter protection will be needed. A covering of straw, leaves, stocks or weeds will be sufficient. In the moister regions it will be much more difficult to succeed with these kinds than in the arid regions, and their quality will be much better in the drier parts. This class of grapes is extensively and very profitably grown along the Pecos River and near E1 Paso, Texas, without trellising, on the stub-system as used in California, but in the moister regions will require trellising.

\section{Vinifera-Bourquiniana Hybrids}

OLIVONTA, T. V. M. 1899 . ( $\frac{5}{17}$ ) (Olivett de Cadinet $\mathrm{x}$ Herbemont). (The Olivette de Cadinet is an Italian variety, having very fine clusters of large ovoid black berries of high quality, with a healthy but not a very robust vine, with pistillate flowers.) Vine of good vigor, much resembles Herbemont; healthy and a good bearer; cluster medium, compact, much resembling the Petit Syrah, but is larger, handsomer and ripens evenly, which the Petit Syrah does not, in all seasons; berries black ovoid, a little under medium; skin thin, tough; flesh tender, melting, juicy, the juice being red, of pure, high quality, better decidedly than Petit Syrah, and promises to be a better wine grape than that famous variety. (See Plate LXXXIII., page 207.)

\section{Vulpina Varieties}

There have been introduced no pure Vulpina varieties of any commercial value, and only one, ever successfully used as a mother breeder, from which varieties of any value were produced. Such one was found wild by Mr. Louis Suelter, of Carver, Minn., near that place. It was a white, or yellowish-white, variety, the only wild white variety of the species reported so far as I know. He pollenized it with Concord pollen, from which hybridized seed he grew a number of black varieties of medium size, similar to each other, ripening very early. The vines were vigorous and healthy and perfectly endured $40^{\circ}$ below zero in Minnesota. Four varieties were named as follows: Beta, Dakota, Monitor, Suelter, all these except Suelter had ascending or erect stamens, bloomed about the 20 th to 25 th of April, and ripened very early, -about June 25th to July 1st, at Denison, Texas, and were passably good for very early kinds, but the Texas climate was too hot and dry for them and they all died within six to eight years. This is a suggestion and a starter for development of a race of exceeding hardy varieties for the cold Northwest.

\section{Vulpina-Vinifera Hybrids}

OHIO (Syn. Cigar Box). From some grape-cuttings left in a cigar box at the residence of the elder Longworth of Cincinnati, some vines were grown, which attracted attention, and became scatteringly disseminated, and confused in description with the Lenoir by writers on grapes, and put down by some as a synonym of it (see Bushberg Manual, pp. 164-5). Having obtained vines of this from Mr. Elbert Wakeman, of Millneck, L. I., obtained by him from Mr. G. W. Campbell, of Ohio, I have carefully studied it and find, beyond doubt, that it is a Vulpina (Riparia) $\mathrm{x}$ Vinifera hybrid, that, in general aspect, would be easily mistaken for a variety of the "Southern Estivalis" class (V. Bourquiniana), where Mr. Isidor Bush placed it. At first glance, the vine in foliage reminds one of Lenoir, but the analysis quickly shows it to be really widely different. It has a stocky, healthy, short-jointed growth, leaves medium with deep-cut large teeth, blooms early, ripens early; cluster medium to large, conical, compact; berries medium or below, black, round, skin thin, tough, pulp tender, spicy, juicy, juice bright red, quality excellent. This discovery reveals what may prove of great value in the North as a basis for great improvement of the Labrusca varieties. 


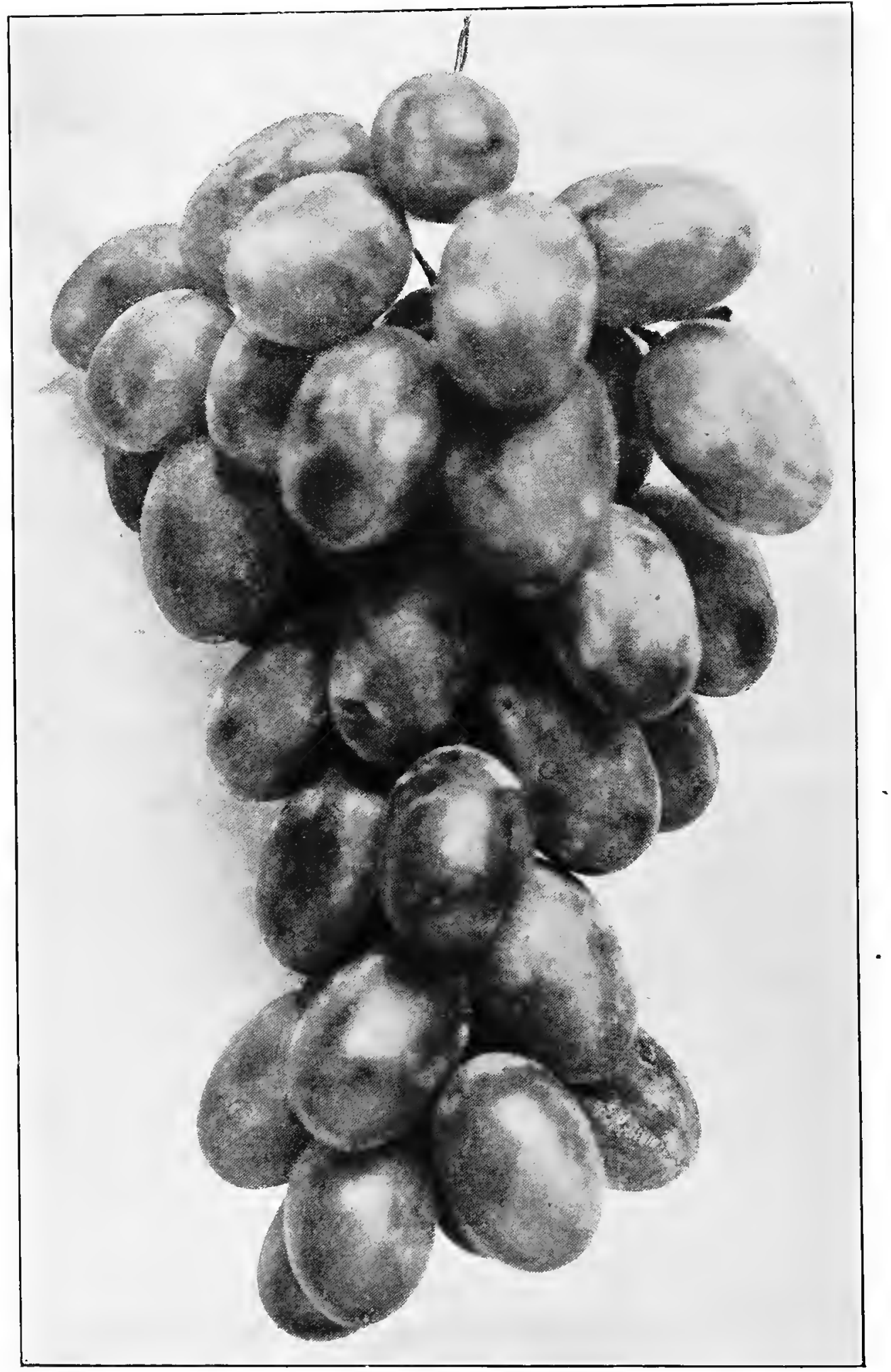

PLATE LXXX. RED CORNICHON. (See page 202.) 


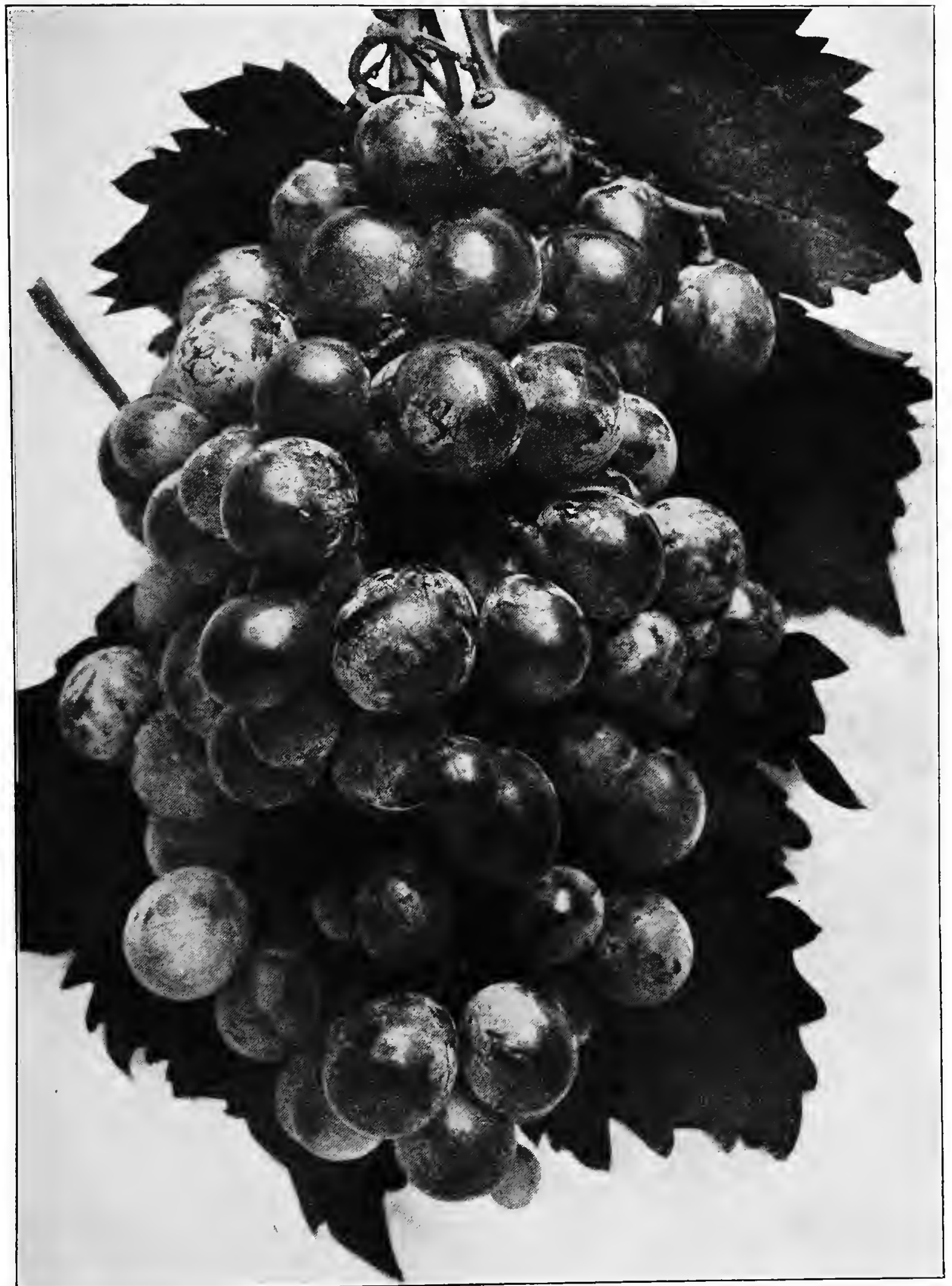

PLATE LXXXI. MUSCAT ROSE. (See page 202.) 


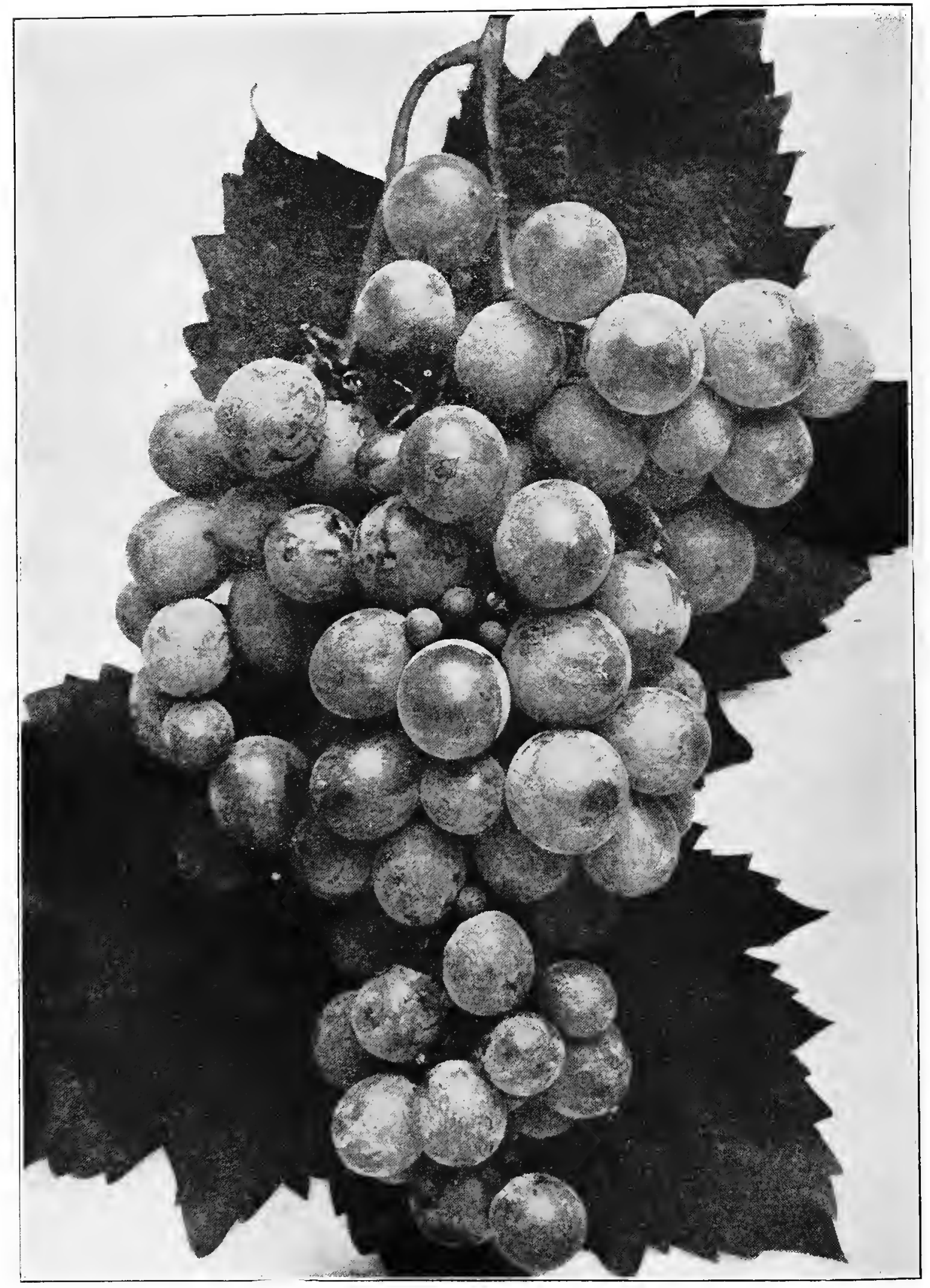

PLATE LXXXII. SEMENDIA. (See page 202.) 


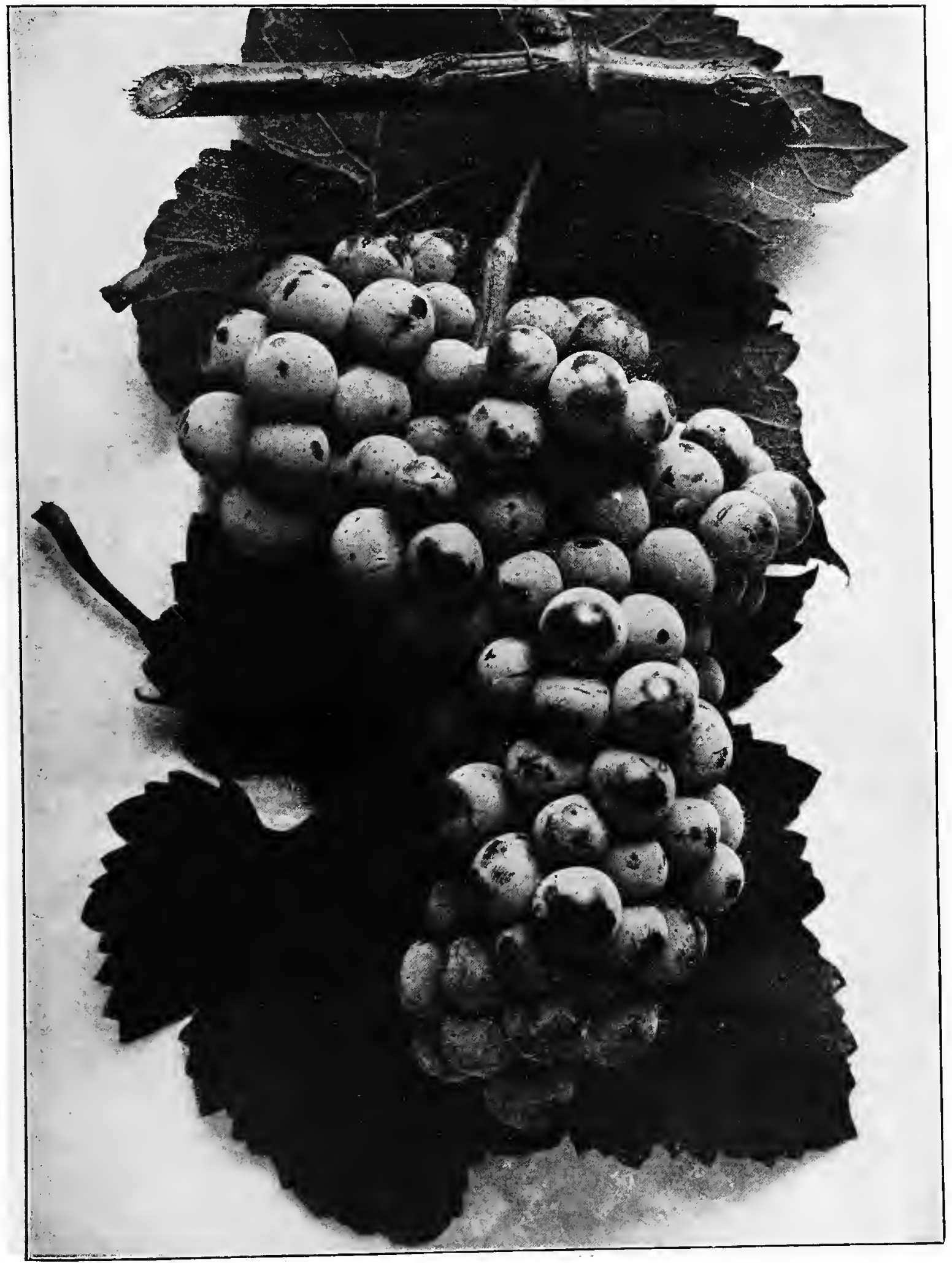

PLATE LXXXIII. OLIVONTA. (See page 203.) 


\section{Southern Muscadine Grapes. ( $V$. rotundifolia.)}

In this group all known fruiting varieties have imperfect flowers, and require staminate vines of same species growing near. One staminate vine to six or eight bearing vines is sufficient.

\section{Varieties}

All varieties of this class require to be propagated by layering.

Of some eight varieties of this species found wild, only two or three have become generally known and planted in the South. The list is Flowers, James, Memory, Mish, Pedee, Scuppernong, Tenderpulp, and Thomas. The best three of these, and all I shall describe, are James, Scuppernong, and Thomas. None are fully hardy north of $35^{\circ}$ latitude, except in California.

JAMES. Originated and introduced by J. Van Lindley, of North Carolina. Like all varieties of this class, the vine is vigorous and perfectly healthy; cluster the largest and most prolific of any pure blood of the species introduced; 8 to 15 berries, large, black, round; skin thick, flesh pulpy, of fair quality, musky; seeds large; begins ripening at Denison, Texas, about August 10th, and continues a month, drops when ripc like all others of the species.

SCUPPERNONG (Syn. Bullace, Roanoke). Found by some member of Walter Raleigh's colony in 1554 on an island in the Scuppernong river in North Carolina. The original vine, which at first was supported by a tree, still stood at the close of the War of States like a gnarled old tree, its former support having died and rotted away. Whether yet living or not I cannot say. It is the only white (bronzy) variety reported that was found wild. The cluster bears two to eight yellowish-amber colored large globular berries, with thick, leathery skin, yet thin in comparison with most other varieties of this class; flesh pulpy, tender for the class, flavor and odor musky,-different from "foxy" of Labrusca and much more agreeable; very much liked by Southrons generally; seeds medium for this class, but large, as grape seeds generally; ripe in August and September. Considerable quantities of wine are made from the Scuppernong in the older Southern States, especially in the Carolinas, and it is considered a very delicate and characteristic wine. (See Plate LXXXIV., page 210.)

THOMAS. (See Plate XXXV. in Chapter I., page 105.) Found wild in South Carolina, and introduced by Drury Thomas. Cluster a little larger than Scuppernong, -six to ten berries; berries, larger than Scuppernong, often an inch or more in diameter; skin equally thick, rather more pulpy than Scuppernong, and not quite so high in sugar.

All these varieties require much trellis room. They should be at least 16 feet apart for: training on the Munson Trellis (page 224). Excellent results have been obtained by pruning according to the long arm renewal system. If allowed to mass, according to the old Southern method, on a wide extending overhead arbor-trellis, the clusters and berries are much smaller than with pruning and training. The pruning should be done in early winter.

\section{Scuppernong Hybrids}

Before 1877, Dr. A. P. Wylie, of South Carolina, had made some hybrids of Scuppernong, and showed fruit of them at a meeting of the American Pomological Society in Baltimore in that year. These varieties were never disseminated to any considerable extent and probably all perished after his death a few years later. Those produced later by Prof. A. Millardet, in France, seem also to have been lost. At any rate it remained to the writer to produce the only hybrids of this class that have been disseminated widely. In 1891 he saved seeds from a single Scuppernong vine, having no staminate vines of this species then in his vineyards, but there were a number of Post-Oak x Herbemont hybrids growing near, that flowered very late, and seemingly the only source of pollen supply for the Scuppernong then blooming. The seeds grew well, producing a few hundred vines, among which some half a hundred had leaves with lobes, and aspect resembling some of the Post-Oak hybrids, and a few showed forked tendrils, but on the whole much more like Muscadines than any other species. The writer had noted what Professor Millardet had written him about "false hybrids," including all his Scuppernong hybrids as such; that while 
they were actual hand-made hybrids, yet the Rotundifolia was so firmly fixed that its characteristics were the chief to show forth in the hybrid, those of the other parent being "recessive," according to Mendel's characterization.

The writer put in test vineyard about 50 of his Scuppernong seedlings, having the somewhat hybrid appearance. In 1895 some fruited, and in 1896, all the pistillate vines of the lot bore; about half of the seedlings proving to be staminate. There was much variation among them: Several had clusters two to four times as large as Scuppernong; all had black berries. Of the lot two were so much more prolific, thinner skinned, more tender in pulp and better in quality, though not quite so large, as the mother, that they were named (La Salle and San Jacinto), propagated and disseminated. They have received high commendation from some, and adverse reports from others: With the writer they have continued exceedingly prolific and sell well in baskets, "shelled," as, like other Muscadines, they do not cling well to the clusters, when fully ripe.

In 1898 the writer found some clusters of his Brilliant grape blooming at same time with the San Jacinto. These were used in pollenizing a number of clusters of San Jacinto, which bore well, and the seeds of these hand-pollenized clusters, that were protected under tissue paper sacks, were saved and planted. About 85 out of some 200 plants that came from the seeds, were selected and planted in test vineyard. Much variation existed among them. Three were red, with thin skins and tender pulp, reminding one much of Brilliant, two were white, of high quality, the others various sizes of black. Three or four showed decided Herbemont character in fruit and seed, showing by reversion, it is supposed, Herbemont blood in the mother, San Jacinto. The saccharometer showed in a number of them much higher degree of sugar than the Scuppernong showed under same conditions. (See Table of Sweetness and Acidity, pp.124-125.) But it is remarkable that the vines continue to resemble Muscadines much more than any other species. Yet some have the surface of the leaves much more wrinkled, like Brilliant, than do any pure Rotundifolia, and the bark on most of them is much more shreddy than in the pure Muscadines.

Of the lot four have been selected, propagated and disseminated.

The following six are the best of my efforts in this direction:

LA SALLE, T. V. M. 1891. (,$\left.\frac{6}{11}\right)$. Supposed hybrid of some Post-Oak x Herbemont hybrid with Scuppernong; clusters have 15 to 30 berries when set full, berry large, round, black, skin much thinner, and pulp tenderer than Scuppernong, ripens about a week earlier. (See Plate LXXXV., page 211. )

SAN JACINTO. Same in origin as La Salle; cluster a little larger, berry not quite so large, black, quality better, juice showing $76^{\circ}$ sugar when Scuppernong showed $65^{\circ}$. Ripens a week later than La Salle. (See Plate LXXXVI., page 214.)*

SANALBA, T. V. M. 1898. (, $\left.\frac{6}{6}\right)$. (San Jacinto $x$ Brilliant). Cluster with 15 to 30 berries when full, berries yellowish-white, translucent, skin thin, flesh melting, very juicy, of very fine quality, only a trace of muskiness. Sugar $93^{\circ}$ when Scuppernong was $65^{\circ}$. Ripe late in September at Denison, Texas.

SANMELASKA, T. V. M. 1898. $\left(, \frac{6}{8}\right)$. Same parentage as Sanalba, much resembles San Jacinto, but sweeter, leaves more wrinkled. Berries black.

SANMONTA, T. V. M. 1898. (,$\left.\frac{6}{7}\right)$. From same lot as Sanalba, but berry is small, some larger than Herbemont, black, skin thin, flesh without pulp, very juicy, sprightly, reminding much of Herbemont in quality. The clusters have 20 to 30 berries, and the vine very prolific.

SANRUBRA, T. V. M. 1898. (,$\left.\frac{6}{8}\right)$. Same lot as Sanalba; red, semi-translucent clusters from 15 to 25 berries when full set; ripe with La Salle; skin thin, pulp melting, fine.

* The De Soto shown above San Jacinto, Plate LXXXVI., was a Scuppernong $x$ Munsoniana hybrid, that proved too tender to endure the winters of North Texas. It is good as a basis on which to breed up semitropical varieties. 


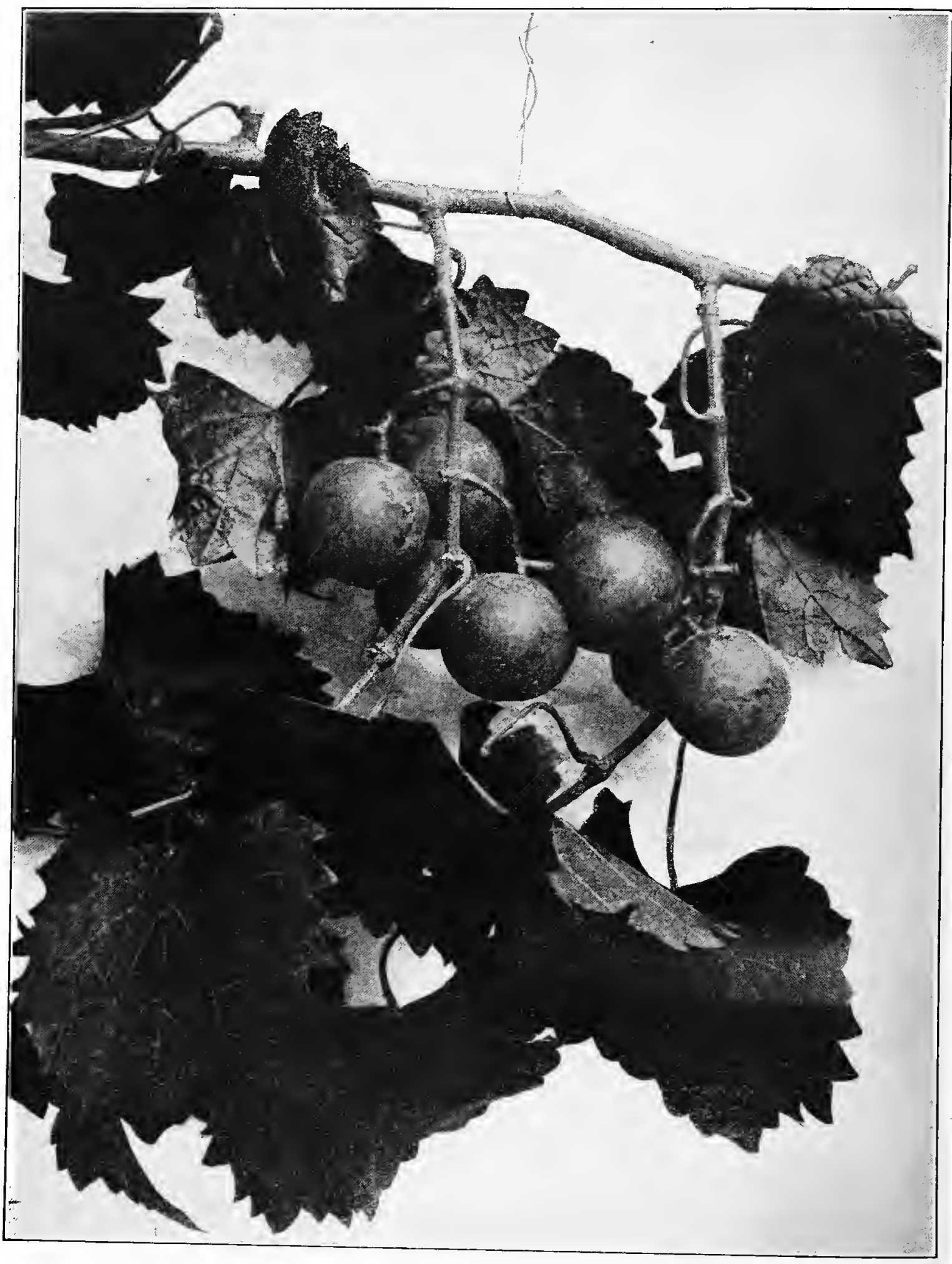

PLATE LXXXIV. SCUPPERNONG. (See page 208.) 


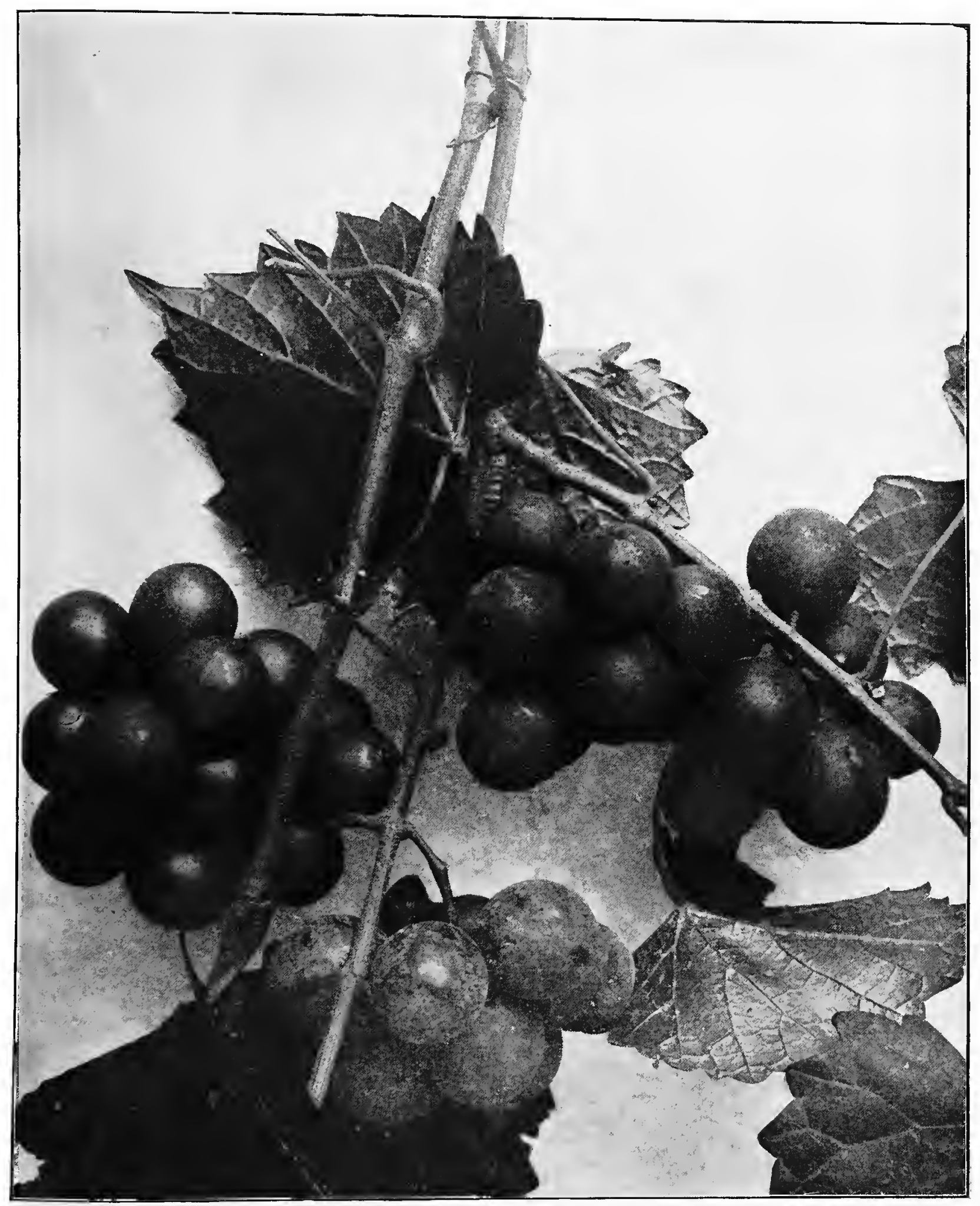

PLATE LXXXV. LA SALlE. (See page 209.) 


\section{Guide to Selecting Varieties of Grapes for Various Regions, Soils and Purposes.}

\section{Kinds named in Order of Ripening, in a normal season, at Denison, Texas: Latitude nearly $340 \mathrm{~N}$.}
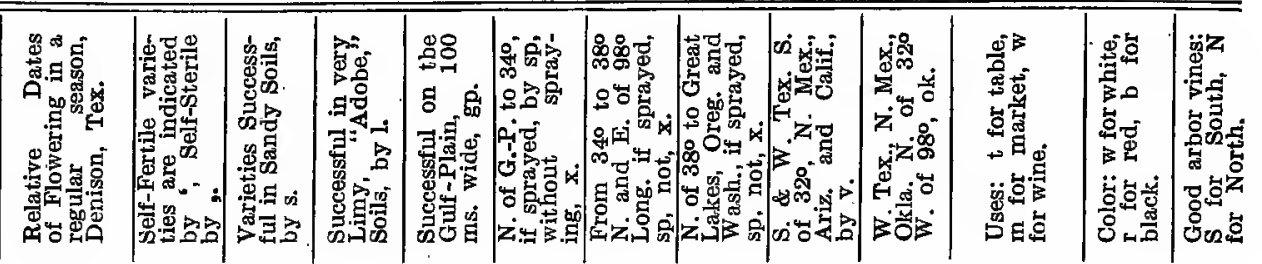

Pearl of Casaba. . . Apr. 19

Headlight........ A pr. 19

Moore Early....... A Apr. 17

Manito.......... Apr. 20

Green Mountain... A Apr. 17

Brilliant........... Apr. 17

Brighton ......... A Apr. 16

Campbell Early... A Apr. 15

Sweetwater....... Apr. 20

Wapanuka........ Apr. 17

President......... Apr. 18

Delaware........ A A pr. 20

Hidalgo.......... A Apr. 16

Captivator........ Apr. 18

Delakins.......... Apr. 20

Rommel.......... Apr. 18

Worden......... Apr. 17

Bell............. Apr. 15

Lukfata.......... Apr. 20

Serriendia......... Apr. 22

Salem........... Apr. 17

R. W. Munson.... Apr. 23

Agawam......... Apr. 16

Sauvignon Jaune. . Apr. 21

Lindley.......... Apr. 18

Moore Diamond. . . Apr. 17

Beacon.......... Apr. 22

Muscat Rose... . . A Apr. 24

Niagara......... A pr. 17

King........... Apr. 18

Concord......... A pr. 18

Hernito......... A pr. 26

Pense (Malaga).... A A A r. 28

Cloeta............ Apr. 25

Delicatessen....... A pr. 23

Captain......... Apr. 20

Xlnta.......... A pr. 22

Feher Szagos... . . . A A Apr. 28

Mericadel......... A A pr. 26

Calabrian......... A pr. 28

Krause........... Apr. 20

America.......... Apr. 23

Champanel........ A pr. 20

Elvicand........ Apr. 19

Xenia........... Apr. 20

Bailey........... Apr. 26

Valhallah.......... Apr. 20

Muscat of Alex... Apr. 26

Manson.......... A Apr. 26

Ben Hur......... Apr. 28

Extra.......... May 1

Wetumka........ Apr. 22

Catawba.......... Apr. 18

Flame Tokay...... A Apr. 29

Triumph.......... Apr. 23

Carman......... Apr, 26

Gold Coin.......... Apr. 23

Goethe.......... Apr. 23

Blondin.......... Apr. 30

Wine King.........

\begin{tabular}{|c|c|c|c|c|c|c|c|c|c|c|c|c|}
\hline ' & $\mathbf{s}$ & 1 & & & & & $\mathbf{v}$ & & $\mathrm{t} \mathrm{m}$ & & $w$ & \\
\hline , & $\mathbf{s}$ & 1 & gp & sp & sp & $\mathrm{sp}$ & $\mathrm{V}$ & ok & $\mathrm{t} \mathrm{m}$ & & $r$ & \\
\hline 6 & $\mathbf{s}$ & & & & $\mathbf{x}$ & $\mathbf{x}$ & & ok & $\mathrm{m}$ & & b & \\
\hline , & $\mathrm{s}$ & 1 & $\mathrm{gp}$ & sp & $\mathrm{sp}$ & $\mathrm{x}$ & & ok & m & $\mathbf{w}$ & b & $\mathrm{N}$ \\
\hline 6 & $\mathbf{s}$ & & & $\mathrm{sp}$ & $\mathrm{sp}$ & $\mathrm{sp}$ & & ok & $\mathrm{t} \mathrm{m}$ & & w & \\
\hline " & $\mathbf{s}$ & 1 & $\mathrm{gp}$ & sp & sp & $\mathrm{sp}$ & v & ok & $\mathrm{t} \mathrm{m}$ & & $r$ & \\
\hline$?$ & $\mathbf{s}$ & & $\mathrm{gp}$ & $\mathrm{sp}$ & $\mathrm{sp}$ & $\mathrm{sp}$ & v & ok & $\mathrm{t} \mathrm{m}$ & & $\mathrm{r}$ & \\
\hline . & $\mathbf{S}$ & & & & & $\mathrm{sp}$ & & ok & $\mathrm{t} m$ & & b & \\
\hline$،$ & s & 1 & & sn & & & $\mathrm{v}$ & ok & $\mathrm{t} \mathrm{m}$ & & w & $\mathbf{N}$ \\
\hline 4 & $\mathbf{s}$ & & gP & sp & $\begin{array}{l}\text { sp } \\
s p\end{array}$ & $\begin{array}{l}\mathrm{sp} \\
\mathrm{sp}\end{array}$ & $v$ & ok & $t$ & $w$ & $w$ & IN \\
\hline ' & $\mathbf{s}$ & 1 & $\mathrm{gp}$ & $\mathrm{sp}$ & $\mathrm{sp}$ & $\mathrm{sp}$ & & ok & $\mathbf{t} \mathrm{m}$ & & $r$ & \\
\hline ' & $\mathbf{s}$ & 1 & $\mathrm{gp}$ & sp & sp & $\mathrm{sp}$ & $\mathrm{v}$ & ok & $\mathrm{t} \mathrm{m}$ & & $\mathbf{w}$ & \\
\hline ' & $\mathbf{s}$ & 1 & gp & $\mathrm{sp}$ & sp & sp & V & ok & $\mathbf{t} \mathrm{m}$ & & $r$ & \\
\hline ' & $\mathbf{s}$ & & & sp & sp & sp & & ok & $\mathrm{t} \mathrm{m}$ & & $\Gamma$ & $\mathbf{N}$ \\
\hline 6 & $\mathbf{s}$ & 1 & & $s p$ & sp & sp & v & ok & $\mathbf{t}$ & $w$ & $\dot{w}$ & \\
\hline ' & $\mathbf{s}$ & & & & sp & $\mathbf{x}$ & & ok & $\mathrm{t} \mathrm{m}$ & & b & $\mathrm{N}$ \\
\hline 1 & $s$ & & & $\mathrm{sp}$ & $\mathrm{x}$ & $\mathrm{x}$ & & ok & $t$ & w & $\mathbf{w}$ & $\mathbf{N}$ \\
\hline ? & $\mathbf{s}$ & 1 & $\mathrm{gp}$ & $\boldsymbol{x}$ & $\mathbf{x}$ & & & & $\mathrm{m}$ & & b & $S N$ \\
\hline & $\mathbf{s}$ & & & & & & v & & $t=m$ & & $\mathbf{w}$ & \\
\hline , & s & & & & sp & sp & & ok & $\mathrm{t} \mathrm{m}$ & & $r$ & \\
\hline$?$ & s & & $\begin{array}{l}\text { gP } \\
\text { gp }\end{array}$ & $\begin{array}{l}\lambda \\
\text { sp }\end{array}$ & $\begin{array}{c}\mathrm{X} \\
\mathrm{sp}\end{array}$ & $\begin{array}{c}\mathbf{X} \\
\mathrm{sp}\end{array}$ & & ok & $\mathrm{tm}$ & $w$ & b & \\
\hline 6 & $\mathbf{s}$ & 1 & & & & $\mathrm{sp}$ & V & OK & $\begin{array}{l}\mathrm{t} m \\
\mathrm{t}\end{array}$ & $\mathbf{w}$ & $\begin{array}{l}\mathrm{I} \\
\mathbf{W}\end{array}$ & \\
\hline ? & $s$ & & & sp & $\mathrm{sp}$ & $\mathrm{sp}$ & & ok & $\mathrm{t} \mathrm{m}$ & & I & \\
\hline & $\mathbf{s}$ & & & $\mathrm{sp}$ & $\mathrm{sp}$ & sp & & ok & $\mathrm{t} m$ & & $\mathbf{w}$ & \\
\hline 6 & $\mathbf{s}$ & & gp & $\mathrm{sp}$ & sp & $\mathrm{x}$ & & ok & $\mathrm{t} \mathrm{m}$ & $\mathbf{w}$ & b & $\mathrm{S} N$ \\
\hline 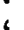 & $\mathrm{s}$ & 1 & gp & $\mathrm{sp}$ & & & $\mathrm{V}$ & & $\mathrm{t} \mathrm{m}$ & $\mathbf{w}$ & b & \\
\hline 6 & $\mathbf{s}$ & & gp & sp & $\mathrm{sp}$ & sp & & ok & $\mathrm{t} \mathrm{m}$ & & $\mathbf{w}$ & \\
\hline 6 & $\begin{array}{l}S \\
s\end{array}$ & & & & $\mathrm{sp}$ & sp & & ok & $\mathrm{t} \mathrm{m}$ & & b & $\mathrm{N}$ \\
\hline ' & $\mathrm{s}$ & & & & sp & sp & & ok & $\mathrm{t} m$ & $w$ & b & $\mathbf{N}$ \\
\hline ' & $\mathbf{s}$ & 1 & $\mathrm{gp}$ & sp & sp & $s p$ & $\mathrm{v}$ & ok & $\mathrm{t} m$ & $w$ & b & $\mathbf{N}$ \\
\hline 4 & $\mathbf{s}$ & & gp & $\mathrm{sp}$ & $\mathbf{x}$ & & & ok & $\mathrm{t} m$ & w & w & - \\
\hline ' & $\mathrm{s}$ & & $\mathrm{gp}$ & $\mathrm{sp}$ & $\mathrm{sp}$ & & & $\begin{array}{l}\text { OK } \\
\text { ok }\end{array}$ & $\mathrm{t} \mathrm{m}$ & $\mathbf{w}$ & $b$ & $\mathrm{~S}^{4} \mathrm{~N}$ \\
\hline " & $\mathbf{s}$ & & gp & sp & $\mathrm{sp}$ & & & ok & $\begin{array}{ll}\mathrm{l} \\
\mathrm{t}\end{array}$ & $\begin{array}{l}\mathbf{W} \\
\mathbf{w}\end{array}$ & $\begin{array}{l}\mathrm{D} \\
\mathrm{b}\end{array}$ & S \\
\hline , & $\mathbf{S}$ & & $\mathrm{gp}$ & sp & $\mathrm{sp}$ & & & ok & $\mathrm{t} \mathrm{m}$ & $\mathrm{w}$ & $\mathrm{b}$ & \\
\hline 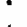 & $\mathbf{S}$ & 1 & & & & & $\mathrm{v}$ & & $\mathrm{t} \mathrm{m}$ & $\mathbf{w}$ & $\mathbf{w}$ & \\
\hline$"$ & $\mathbf{s}$ & 1 & gp & $\mathrm{sp}$ & $\mathbf{x}$ & $x$ & & ok & $\mathrm{t} \mathrm{m}$ & $w$ & $r$ & $S \mathrm{~N}$ \\
\hline 6 & $s$ & 1 & & $\mathrm{sp}$ & & & $\mathrm{v}$ & & $\mathrm{t} \mathrm{m}$ & & $\mathbf{w}^{\prime}$ & \\
\hline ' & $\mathrm{s}$ & 1 & $\mathrm{gp}$ & sp & $\mathrm{sp}$ & & $\mathrm{V}$ & ok & $\mathrm{t} \mathrm{m}$ & $w$ & $w$ & \\
\hline , & $s$ & & $\mathrm{gp}$ & $\mathrm{x}$ & $\mathbf{x}$ & & & ok & $\mathrm{m}$ & $w$ & $\mathrm{~b}$ & $S$ \\
\hline c & $\mathbf{s}$ & 1 & $\mathrm{gp}$ & $\mathbf{x}$ & $\mathrm{x}$ & & & ok & $\mathrm{m}$ & $\mathbf{w}$ & $\mathrm{b}$ & $\mathrm{S}$ \\
\hline 6 & $s$ & 1 & $\mathrm{gp}$ & $\mathbf{x}$ & $\mathbf{x}$ & & & ok & & $\mathbf{w}$ & $r$ & $S$ \\
\hline ، & s & & $\mathrm{gp}$ & sp & $\mathrm{sp}$ & & v & ok & $\mathrm{t} \mathrm{m}$ & $\mathbf{w}$ & $W$ & \\
\hline 6 & $\mathrm{~s}$ & 1 & $\underset{g p}{g P}$ & sp & sp & & $\mathrm{V}$ & ok & $\mathrm{t} \mathrm{m}$ & $w$ & b & \\
\hline “ & $\mathbf{s}$ & 1 & $5 P$ & $\mathrm{sp}$ & $\mathrm{sp}$ & & $y$ & ok & $\mathrm{t} \mathrm{m}$ & $\mathbf{w}$ & $\mathrm{I}$ & \\
\hline 4 & $\mathrm{~s}$ & & & $\mathrm{sp}$ & $\mathrm{sp}$ & & & ok & $\begin{array}{ll}\mathrm{l} \\
\mathrm{t} m\end{array}$ & w & $w$ & \\
\hline c & $\mathbf{s}$ & & gp & sp & $\mathrm{x}$ & & & ok & & $w$ & b & $\mathrm{S}$ \\
\hline ، & $\mathbf{s}$ & & gp & sp & $\mathrm{sp}$ & & & ok & $t m$ & $\mathrm{w}$ & b & \\
\hline 6 & $\mathbf{s}$ & & & sp & sp & & & ok & $t \mathrm{~m}$ & $w$ & $\mathbf{w}$ & \\
\hline 6 & $\mathrm{~s}$ & & & sp & $\mathrm{sp}$ & $\mathrm{sp}$ & & ok & $t \mathrm{~m}$ & $\mathbf{w}$ & $r$ & \\
\hline ' & $\mathbf{s}$ & 1 & & & & & $\mathrm{v}$ & & $\mathrm{t} \mathrm{m}$ & & $I$ & \\
\hline “ & $\mathbf{s}$ & & - & $\mathrm{sp}$ & sp & & $\mathrm{v}$ & ok & $t \mathrm{~m}$ & & w & \\
\hline “ & $\mathbf{s}$ & & $\mathrm{gP}$ & $\mathbf{x}$ & $\mathbf{X}$ & & & ok & $\mathrm{t} \mathrm{m}$ & w & b & $\mathbf{S}$ \\
\hline 6 & $\mathbf{s}$ & & $\mathrm{gP}$ & $\mathbf{x}$ & $\mathbf{x}$ & & & ok & $\mathrm{t} \mathrm{m}$ & $w$ & $w$ & \\
\hline 6 & $\mathbf{s}$ & 1 & gP & sp & $\mathrm{sp}$ & & $\mathrm{v}$ & ok & $t$ & & $r$ & \\
\hline 6 & $\mathbf{S}$ & & gP & $\mathbf{x}$ & $\mathbf{x}$ & & & ok & $\mathrm{t} \mathrm{m}$ & $w$ & $w$ & $\mathrm{SN}$ \\
\hline 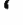 & $\mathbf{s}$ & & gp & $\mathbf{x}$ & $\mathbf{x}$ & $\mathbf{x}^{\circ}$ & & .ok & & $\mathbf{w}$ & b & $\mathbf{S}$ \\
\hline
\end{tabular}


Guide to Selecting Varieties of Grapes for Various Regions, Soils and Purposes. Continued.

\begin{tabular}{|c|c|c|c|c|c|c|c|c|c|c|c|c|c|c|}
\hline $\begin{array}{l}\text { Kinds named in } \\
\text { Order of Ripening, } \\
\text { in a normal season, } \\
\text { at Denison, Texas; } \\
\text { Latitude nearly } \\
\text { 340 N. }\end{array}$ & 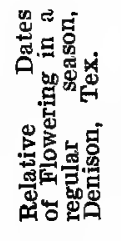 & 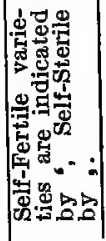 & 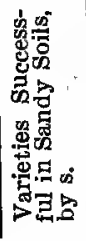 & 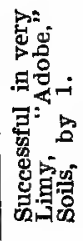 & 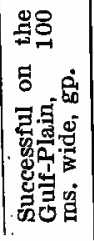 & 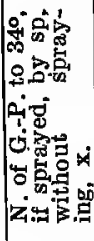 & 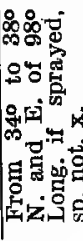 & 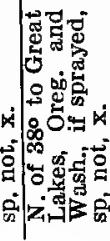 & 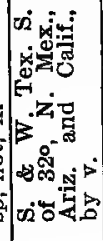 & 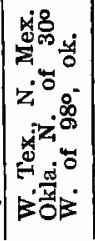 & 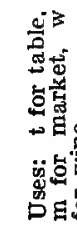 & & 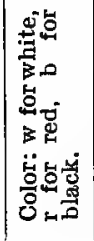 & 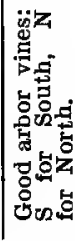 \\
\hline 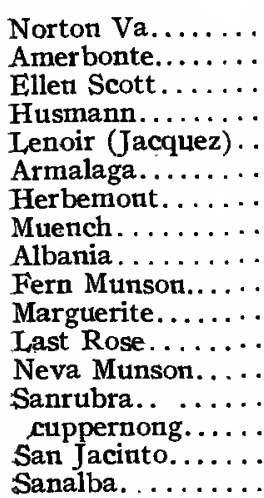 & $\begin{array}{l}\text { May 2 } \\
\text { Apr. 29 } \\
\text { May } 3 \\
\text { May } 1 \\
\text { May } 1 \\
\text { May } 2 \\
\text { May 4 } \\
\text { May 2 } \\
\text { May } 2 \\
\text { May } 4 \\
\text { May } 7 \\
\text { May } 5 \\
\text { May } 7 \\
\text { Jure } 1 \\
\text { June } 1 \\
\text { Jute 3 } \\
\text { Jute 4 }\end{array}$ & ! & $\begin{array}{l}\mathrm{s} \\
\mathrm{s} \\
\mathrm{s} \\
\mathrm{s} \\
\mathrm{s} \\
\mathrm{s} \\
\mathrm{s} \\
\mathrm{s} \\
\mathrm{s} \\
\mathrm{s} \\
\mathrm{s} \\
\mathrm{s} \\
\mathrm{s} \\
\mathrm{s} \\
\mathrm{s} \\
\mathrm{s} \\
\mathrm{s}\end{array}$ & $\begin{array}{l}1 \\
1 \\
1\end{array}$ & $\begin{array}{l}\text { gp } \\
\text { gp } \\
\text { gp } \\
\text { gp } \\
\text { gp } \\
\text { gp } \\
\text { gp } \\
\text { gp } \\
\text { gp } \\
\text { gp } \\
\text { gp } \\
\text { gp } \\
\text { gp } \\
\text { gp } \\
\text { gp } \\
\text { gp }\end{array}$ & $\begin{array}{l}\mathrm{x} \\
\mathrm{sp} \\
\mathrm{sp} \\
\mathrm{sp} \\
\mathrm{sp} \\
\mathrm{sp} \\
\mathrm{sp} \\
\mathrm{x}\end{array}$ & $\begin{array}{l}\mathrm{x} \\
\mathrm{sp} \\
\mathrm{sp} \\
\mathrm{sp} \\
\mathrm{sp} \\
\mathrm{sp} \\
\mathrm{x} \\
\\
\mathrm{sp} \\
\mathrm{x} \\
\mathrm{sp} \\
\mathrm{x}\end{array}$ & $\mathbf{x}$ & $\begin{array}{l}\mathrm{v} \\
\mathrm{v} \\
\mathrm{v} \\
\mathrm{v} \\
\mathrm{v} \\
\mathrm{v} \\
\mathrm{v} \\
\mathrm{v} \\
\mathrm{v} \\
\mathrm{v} \\
\mathrm{v}\end{array}$ & $\begin{array}{l}\text { ok } \\
\text { ok } \\
\text { ok } \\
\text { ok } \\
\text { ok }\end{array}$ & $\begin{array}{l}\mathrm{t} \mathrm{m} \\
\mathrm{t} \mathrm{m} \\
\mathrm{t} \mathrm{m} \\
\mathrm{t} \mathrm{m} \\
\mathrm{t} \mathrm{m} \\
\mathrm{t} \mathrm{m} \\
\mathrm{t} \mathrm{m} \\
\mathrm{t} \\
\mathrm{t} \\
\mathrm{t} \\
\mathrm{t}\end{array}$ & $\begin{array}{l}\text { w } \\
w \\
w \\
w \\
w \\
w \\
w \\
w \\
w \\
w \\
w \\
w \\
w \\
w \\
w \\
w \\
w\end{array}$ & \begin{tabular}{|c}
$\mathrm{b}$ \\
$\mathrm{r}$ \\
violet \\
$\mathrm{b}$ \\
$\mathrm{b}$ \\
$\mathrm{w}$ \\
$\mathrm{r}$ \\
$\mathrm{b}$ \\
$\mathrm{w}$ \\
$\mathrm{b}$ \\
$\mathrm{r}$ \\
$\mathrm{r}$ \\
$\mathrm{prpl}$ \\
$\mathrm{r}$ \\
$\mathrm{w}$ \\
$\mathrm{b}$ \\
$\mathrm{w}$ \\
\end{tabular} & $\begin{array}{l}\mathbf{S} \\
\mathbf{S} \\
\mathbf{S} \\
\mathbf{S} \\
\mathbf{S}\end{array}$ \\
\hline
\end{tabular}




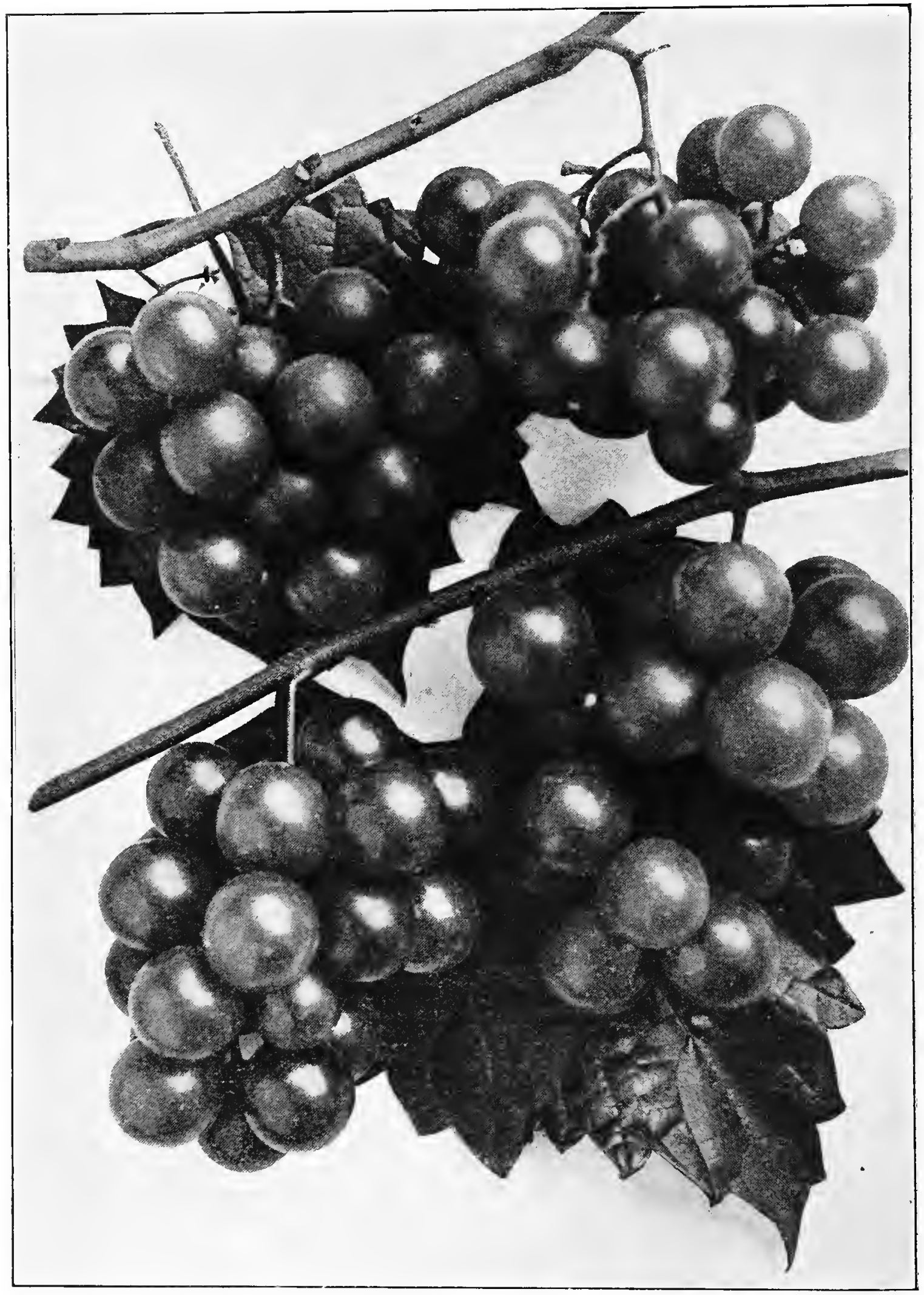

PLATE LXXXVI. DE SOTO (upper). SAN JACINTO (lower). (See page 209.) $-214-$ 


\section{Chapter IV.}

\section{Adaptation of Varieties}

(Consult table, pp. 212-213.)

\section{Resistance to Cold, Heat, Wet, Drouth, Soils, Insects, Fungi in Grapes}

As a general, if not a universal, law of adaptation of plants to environment, we find that the natives in the environment are better adapted than the exotics.

The vine is no exception to this law. Let us test the assertion by comparison.

What species and varieties of grapes resist winter's cold best? Certainly the vines, and vineyard varieties derived therefrom, native in cold regions, known as Vitis vulpina (riparia); northern section of $V$. labrusca; $V$. cordifolia, northern section; $V$. bicolor; $V$. cinerea, northern section; V.rubra.

Of these, $V$. vulpinä of Wisconsin, Minnesota and Dakota readily endures, without protection, $-40^{\circ}$ to $-50^{\circ} \mathrm{F}$. But Vulpina of Virginia and North Texas can endure only $-15^{\circ}$ to $-20^{\circ}$ The Labruscas of Massachusetts can withstand $-20^{\circ}$ to $-25^{\circ}$, while those of South Carolina perish in $-10^{\circ}$ to $-25^{\circ}$. The Cordifolia of Central Illinois and Ohio (about the northern limit of this species), endures $-15^{\circ}$ to $-25^{\circ}$, while the Florida Cordifolia is sometimes killed to the ground in Northern Texas with zero or a few degrees colder. $V$. bicolor of Southern Wisconsin endures $-30^{\circ}$ readily, while Norton Virginia of the nearly allied species of Estivalis, finds its northern limits about Louisville and Cincinnati. So we might continue with all the species and their varieties.

The limiting lines of hardiness to withstand cold do not follow the parallels of latitude but the isothermal lines. Hence we have wild grapes in Northwest Texas that readily endure the winters of Massachusetts, and the Vitis Californica, found along Rogue River in Southern Oregon, -its extreme northern range-winter kills to the ground, when grown at Denison, Texas. The Post-Oak grape of Northern Texas endures the winters perfectly in Middle Ohio, where temperature sinks to $-25^{\circ}$ sometimes. But when we come to reverse the test, the Massachusetts and Ohio grapes cannot endure the Texas summers anything nearly so well as do the native Post-Oak and Mustang grape. The Concord, that remains vigorous for fifty years in Massachusetts, its native state, survives only 8 to 15 years in Texas with equally good treatment. This brings into consideration another element of hardiness, - the power to withstand great or small range of climatic change. In this the general law still holds good. Those species with their varieties native in a region subject to great and sudden ranges of temperature; can endure well, while those brought into such regions from where the range is small, will suffer, as is the case with grapes of Florida or New England brought into Northwestern Texas. Both suffer, while the vines of Northwestern Texas thrive well, both in Florida and New England, so far as resistance to heat and cold are concerned. In other words Northwest Texas plants have a much wider range of climatic endurance than have either those of Florida or Massachusetts.

No other section of the United States has so great a range of climatic conditions as Northern Texas and Oklahoma.

This will suffice as to cold, heat, wet and drouth; but we must not fail to observe that some individuals of a species have greater resistive power than others, all developed in the same climate, soil, etc. This fact is seized by the plant-breeder with great avidity, to increase the hardiness of his varieties of same blood and nativity by selection. depending on the law of inheritance to sustain his selections. 
As to soil, the law holds good so far as resisting an excessive, or injurious chemical element. For example, some varieties of grapes, the Labrusca, Lincecumii and Rotundifolia varieties especially, chlorose very badly (turn a pale sickly yellow in foliage), if set in soils having above forty per cent of carbonate of lime, while the Vinifera, Cordifolia, Cinerea, Berlandieri, Champini, Candicans, Rupestris and Monticola thrive in such soils. We find those that chlorose badly are natives of very sandy soils, along the banks of streams and lakes, or on sand hills, as is the PostOak grape of Texas, while those that grow best in very limy soils, belong to species native in such soils.

We find, however, that in some cases varieties of species, native in very sterile soils, take on far more vigorous growth when put into soils richer in humus and the chief elements of plantfood; and this causes excess of wood and leaf-growth, to the detriment of fruit bearing, when carried to the extreme.

Nearly all species of grapes are native in warm, loamy, well drained soils, and such cannot long endure with roots in permanent water or in cold, livery, compact clays, but a few species are known, that cannot long survive in soils not sub-irrigated. Such are Vulpina, Rupestris, Cordifolia, Cinerea, Rotundifolia and Simpsoni. The last named is often found with the roots perpetually submerged in the borders of swamps and making immense growth. In such situations, the Vinifera, native on the limy hills of Southwest Asia, and Pcat-Oak grapes of the Texas sand hills, would survive only a short time.

In land that is seepy during rainy weather and some time after, but $\mathbf{l} \mathbf{u}$ the dry, hol $\mathbf{3}$ ummers, dries out and becomes hard, no grape thrives. Cordifolia, above all other species, perhaps, can endure such situations longest.

Concerning resistance to mildews, rots, etc., it is true that all species native in high arid regions, are very quickly and destructively attacked by the cryptogamic parasites, when moved into humid situations where such organisms exist. For resistance to these parasites, natives of the parasitic regions must be sought. Perfectly resisting varieties in such regions, when hybridized with non-resisting varieties, produce only partially, or weakly resisting varieties.

Take a vine from a parasitic region, loaded with the parasites of mildew and rot, and plant it in an arid region, and it becomes free of these fungi, simply because the parasites must have much moisture in the air to propagate.

This law does not hold good as to root parasites, or bacterial blights that live within the cells. For example, the Anaheim grape disease, of California, thrives in the moist regions of Northern California as well as in the dry region of Southern California, where it originated, just as pear-blight when once introduced into California and Colorado, is as contagious and destructive as in Georgia or Texas.

The insects that infest grapes know no specific bounds. The Rose Chafer, the Fidia, the Leaf-Folder, the Leaf-Hopper, are just as bad in one region as another in which they can endure the winters, and on one species as another with few exceptions. Certain varieties resist, or are distasteful to these insects, and thereby escape, while others are greatly liked and damaged by them. (See pages 230 to 235 for descriptions of insects.)

The Leaf-Folder never hurts a vine that has leaves that are glabrous, that is entirely without pubescence, or down of any kind on the upper side of the leaves. The egg is laid on upper side and the larva, finding no pubescence to tie its webs to, and thus unable to draw the leaf together over it, soon perishes in the sun, or is eaten by birds; hence only grapes with leaves more or less downy on upper side of the leaves are damaged by the Leaf-Folder.

There are some varieties of grapes much less bothered by the Leaf-Hopper, than others. These generally are the varieties with very firm, dense tissue, such as the Post-Oak grapes of Texas. The Fidia and Rose Chafers make little choice of kinds, and are voracious feeders on the foliage.

The Phylloxera comes well under the genera1 rule. It can do little damage to those species of grapes native in the same regions where the Phylloxera is native, yet there is much difference 
in resistance there. For example, V. rotundifolia is entirely immune, then Rupestris, Vulpina, Cinerea, Berlandieri, Champini, Candicans, Doaniana, Astivalis and Lincecumii are so high in resistance as to be practically uninjured, though they may be attacked, while Labrusca is low in resistance and is much weakened in clay soils, if infested, and Vinifera is entirely non-resistant. It is a native of regions never infested by Phylloxera, until introduced among cultivated vines.

\section{Select Lists of Varieties for Various Regions}

I shall now name from among the varieties described in the foregoing part of this chapter those especially adapted to the various distinct climatic sections. The varieties named for each section will be mentioned in their alphabetical order. Those better adapted for very limy soils will be followed by the letter (L). All succeed well in sandy lands. For fuller descriptions of each variety, refer to that given in Chapter III. I make no pretense to name all the varieties that will succeed in each zone but give the best selection generally known. There are local varieties, probably, quite as good, in many sections, but have not been widely tested, or become generally known.

ZONE 1. For the cold Northwestern States of Montana, Wyoming, Dakotas, Minnesota, North Nebraska, North Iowa, and Wisconsin, without winter protection, but on southeastern slopes, in loamy, well-drained soil, with timber protection on north and west, the following succeed. By laying down thru winter and covering with leaves, straw, etc., the varieties mentioned for Zone 2 may be successfully grown in Zone 1.

Beta, Clinton, Dakota, Monitor, Montefiore, Suelter. None of these can endure very limy soil.

Professor N. E. Hanson, connected with the Agricultural College of South Dakota, at Brookings, among much work in plant-breeding, has produced some hardy grapes, that may well be added to the above, when disseminated; and the Experiment Station at St. Anthony's Park, Minn., has also been testing grapes, and probably can name a few others for this extremely cold region. It greatly needs further development.

ZONE 2. For the territory among the Great Lakes, and eastward, including Michigan, Ontario (in part), N. E. New York, Southern Vermont, New Hampshire and Maine, in protected situations, the following can be grown without winter covering: Beacon, Bell, Campbell Early, Colerian, Concord, Dracut Amber, Early Ohio, Green Mountain, Headlight, Ives, Lutie, Lucile, Moore Early, Perkins, Vergennes, Woodruff, Worden, Wyoming, and all named for Zone 1. None of these can endure excessively limy soils. The Bell, Green Mountain and Headlight will endure more than the others. By covering through winter, the earlier ripening varieties named for Zone 3 can be grown successfully in Zone 2 . Some of the kinds named will require spraying with Bordeaux, or mildew will ruin them in this region, and all will be benefited by it.

ZONE 3. This region stretches across the continent. It includes Southern Washington, Oregon, Southern Idaho, N. and E. Colorado, Southern Wyoming, Southern Nebraska, Northern Kansas, Southern Iowa, Northern Missouri, Illinois, Indiana, Ohio, W. and S. New York, Massachusetts, Connecticut, Rhode Island. In this region, westward from Missouri the fungus parasites will nct be of serious consequence, but eastward, spraying will be necessary to prevent mildew and rot in all Delaware and Vinifera combinations and also in some of the pure natives. All varieties that can be grown in Zone 2 can also be grown in this to still better advantage, excepting those with such poor quality that they would be valueless. Agawam, America, Atoka, Brighton (L), Brilliant (L), Catawba, Delaware (L), Diamond, Dr. Collier, Elvira (for drier parts), Herbert, Hernito, Hopkins (southern parts); Isabella (southern parts); Kentucky (southern parts); Lukfata (L), Lindley, Manson (southern parts); Mericadel (L), Niagara, Norfolk, Ohio, Pocklington, President, Rommel, R. W. Munson, Walter, Wine King, Wapanuka, Xinta. In Southern Nebraska, Northern Kansas and Southern Iowa, and northern parts of Illinois, Indiana and Ohio, winter protection for most of these will be required. 
ZONE 4. This belt also reaches across the continent and accommodates those named for Zone 3, even better than Zone 3. But for some of those named for Zone 2, Zone 4 is rather too hot. The territory of this belt comprises California north of Redding; Nevada, north of Carson City; Colorado, west of the Rockies; Southern Kansas; Northwestern Texas; Oklahoma, north of Oklahoma City and McAlester; Arlansas, north of Fort Smith; Missouri, south of St. Louis; Kentucky; Tennessee; West Virginia; Pennsylvania; Maryland; New Jersey, and Delaware. It has also arid and humid sections. In the latter spraying must be resorted to, to make grape growing profitable with most varieties, that otherwise succeed well. Its best varieties are those named for Zone 3, and the following: Albania, Amethyst (L), Augustina (L), Blondin, Bailey, Captain, Carman, Extra, Fern Munson, Goethe (L), Gold Coin, Hidalgo (L), Hermann Jaeger, Jefferson, Krause (L), Kiowa, Laussel, Muench, Norton, Onderdonk (L), Ozark, Triumph, Valhallah (L), Wetumka, Xenia, Xlnta.

ZONE 5. This may well be named the Vinifera Zone. It includes California, south of Redding; Southern Nevada; Arizona; New Mexico, west of the Rockies; all of Texas south of New Mexico and southwest of a line drawn from Colorado, Texas, through San Antonio to Aransas Pass. While all varieties named for Zones 4,6 and 7, will thrive in Zone 5, when put in suitable soils and under irrigation, the Vinifera, that have proven vigorous, healthy, prolific, and good shipping, fine table grapes, are the best for commercial planting, of which I name the following for table and shipping. (All Vinifera varieties endure limy soil). Calabrian, Chasselas de Fontainbleau (Sweetwater), Feher Szagos, Flame Tokay, Griesa de Piemonte, Muscat of Alexandria, Perle of Anvers, Pense (Malaga), Quagliano, Red Cornichon, Rose of Peru, Semendia, Sultaniana (Thompson's Seedless), Verdelho, Violet Chasselas, Muscat Rose. Many other fine varieties are grown in California. For Wine: Carignan (L), Extra, Herbemont (L), Hopkins, Husmann (L), Kiowa, Lenoir (L), Mataro (L), Neva Munson, Petit Syrah (L), Sanvignon Jaune (L), Wine King, Xlnta, Zinfandel (L), and many others grown in California.

In the above list of wine grapes, I have included Extra, Herbemont, Hopkins, Husmann, Kiowa, Lenoir, Neva Munson, XInta, Wine King, because they are resistant to Phylloxera on their own roots, are vigorous, prolific and endure great heat and drouth, and make high-class wines. It must be remembered that all Vinifera varieties to grow in Phylloxera infested districts, must be grafted upon resistant graft-stocks, acclimated to the region where planted (see page 219 for graft stocks). (Method of Grafting, page 231.) All the foreign table grapes for this zone may be grown on the stool-system of training without trellising.

ZONE 6. This is a triangular area lying west of the 97 th meridian, south of the 35th parallel, extending west to the Staked Plains of Texas, and the line from Colorado, Texas, to Aransas Pass, through San Antonio, in which all varieties named in Zone 4 (except Norton, Gold Coin, and Ozark, which belong farther east and north), and the following named for Zone 3: Agawam, America, Brighton, Brilliant, Diamond, Herbert, Hernito, Lindley, Mericadel, Niagara (northern part), Norfolk, President, Rommel, R. W. Munson, Wapanuka, Xlnta, and by covering in winter in its northern and central parts, the varieties named for Zone 5 can be well grown with little or no spraying, and without covering in its southern parts, but the Viniferas must be grafted. To this may be added Champanel, Elvicand, for very limy soils. This makes a large, varied list, ripening from early to late. The extensive red or chocolate soils, and high semi-arid climate of this region, highly fit it for growing grapes. The Vinifera hybrids with Labruscas and Lincecumii species are excellently suited to this region. Only the Lincecumii $x$ Bourquiniana hybrids should be largely used in its southern parts for general vineyard work.

ZONE 7. In this I include Texas, east of the 97 th meridian and north of the $33 \mathrm{~d}$ parallel of latitude, extending north to the 35th parallel, and eastward to the Atlantic, lying immediately south of Zone 4 , and including Virginia east of the Mountains.

In this region spraying will be required for most of the true "Bunch Grapes," and the following kinds may be successfully grown by using the Munson Trellis, (page 224) and spraying 
diligently as directed in Chapter VI., page 236: Agawam, Amethyst (L), America, Armalaga (L), Atoka, Blondin, Brighton (L), Brilliant (L), Captain, Carman, Catawba, Delaware (L), Diamond, Dr. Collier, Extra, Fern, Herbert, Gold Coin, Hidalgo (L), Hopkins, Hermann Jaeger, Kentucky, Kiowa, Krause (L), Laussel, Mericadel (L), Muench, Niagara, Norton, Norfolk, Ozark, President, R. W. Munson, Wetumka, Wine King, XInta, and all the Muscadine varieties and hybrids can be grown in open vineyard without spraying. By grafting, planting on high ground and spraying very thoroly, the Vinifera varieties may also be grown.' What a wealth of varieties this belt enjoys!

ZONE 8. This is the Gulf-belt, lying south of Zone 7 all the way and includes Florida. It is highly adapted to the Muscadine varieties and hybrids, namely: James, Scuppernong, Thomas; Hybrids, La Salle, Sanalba, San Jacinto, Sanmelaska, Sanmonta (for wine only) Sanrubra.

The most successful of the Bunch Grapes for this region are: Those requiring little or no spratying: America, Atoka, Bell, Blondin, Beacon, Carman, Elvicand (L), Fern Munson, Gold Coin, Hernito, Hopkins, Hermann Jaeger, Kentucky, Lukfata (L), Laussel, Marguerite, Muench, Meriçadel, Norton, Neva Munson, Onderdonk (L), R. W. Munson, Wine King, Xlnta. For whatever zone these mny have been named heretofore, they are the most resistant to fungus diseases, but all of them are not equally resistant, and better results will come by spraying all but the Muscadines in this Region. Those that require thoro spraying and with it succeed well in this belt, are: Amethyst (L), Augustina (L), Agawam, Albania, Armalaga (L), Brighton (L), Brilliant (L), Bailey, Campbell Early, Captain, Catawba, Delaware (L), Diamond, Extra, Goethe (L), Green Mountain (L), Herbemont (L), Headlight, Hidalgo (L), Husmann, Jefferson, Krause (L), Lindley, Manson, Niagara, Norfolk, President, Rommel, Triumph, Valhallah (L), Walter (L), Wetumka, Wapanuka, Xenia (L), and these will succeed better within thirty to forty miles of the sea coast, than in the more interior parts, as the rots and mildews do not thrive in the sea breeze, so well.

By grafting and spraying the Vinifera varieties, they can be successfully grown in this zone

It is to be observed that the more northern zones cannot succeed with varieties adapted to more southern zones, especially if more than one zone distant, nor with any but early ripening kinds, while the more southern zones can grow the varieties of all the zones, by spraying, grafting, careful trellising and pruning, but all varieties developed from species native in northern latitudes will suffer from the heat and drouth in the South, and prove short-lived and of little profit, hence each section will succeed better by confining itself to the varieties developed largely from species native within it.

It is the opinion of the writer that this chapter is one of the most valuable pieces of grape literature ever presented to the practical grape-growers of the United States, to aid them in wisely selecting varieties for planting their vineyards, and it should be diligently studied by them. It contains about all the cream of American varieties, and, perhaps, has retained too much "blue milk," for fear of losing some "cream. But the wise planter, after studying the chapter, can easily avoid the blue milk.

\section{Some of the Best Tested Resistant Graft-Stocks}

For Zones 1, 2, 3 and 4: V. rupestris variety Rupestris St. George: V. vulpina variety Gloire de Montpelier. For Zone 4: Use Rupeștris St. George, V. Champini varieties Dogridge, DeGrasset and Ramsey; $V$. Longii varieties Motley and Adobe Giant; V. Doaniana variety Ponroy. For Zones 5, 6, 7 and 8 use the V. Champini stocks for limy soil, V. Doaniana and V. Longii for sandy soils. Many varieties require no graft stock as mentioned in their descriptions. It is for the Vinifera varieties that grafting is necessary in Phylloxera infested regions. Where the above named varieties cannot be obtained any strong healthy vines of the same species will answer well. The particular merits and adaptations of each species are fully set forth under "Viticultural Observations and Remarks" under each respective species in Chapter I. 


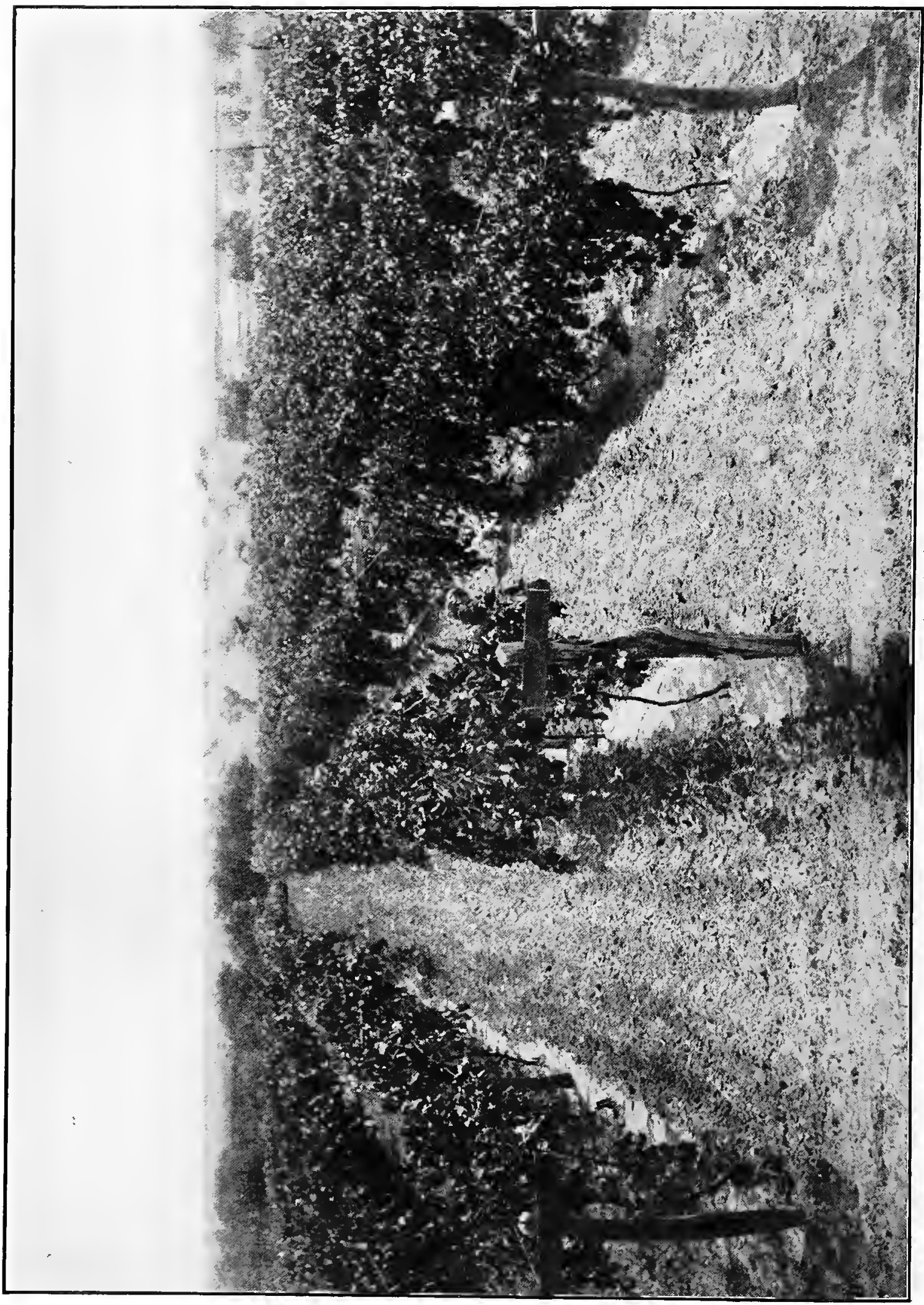

焉 


\section{Part II \\ Practical Grape Growing}

\section{Chapter V \\ How to Start a Vineyard}

The site and soil have much to do with making a vineyard profitable or unprofitable; hence too great care cannot be used in selecting a location.

\section{The Site}

The ideal site has an eastern or southeastern exposure, with sufficient slope to secure surface drainage, but not enough to wash badly in heavy rains, and high land is safer from late frosts than lowland.

\section{The Soil}

The ideal soil is a reddish sandy loam, porous enough and deep enough to a reddish clay subsoil to absorb the heaviest rains without becoming boggy or seepy. Such soils in the South are generally well supplied with potash, one of the most essential soil ingredients for the vine. There are extensive tracts of this soil in many parts of the Southwest, especially bordering rivers and creeks, along the bluffs, where fine sites and drainage are secured. They are frequent on the Red River, five to ten miles wide on either side; also along the Sabine, the Neches, the Trinity, the Brazos, the Colorado, and other streams, and there are vast tracts in the Panhandle of Texas, in Oklahoma, Arkansas, Louisiana, in fact thruout the South, well adapted to the grape.

Such soils and locations are also less invaded by the mildews and rots, so disastrous to vineyards in low, damp, heavy lands, and are less subject to killing by late frosts. In far Western and Southwestern Texas and New Mexico, where irrigation can be applied, the soil and atmosphere are highly congenial to the grape, even to the profitable growing of the Vinifera varieties, if grafted upon resistant roots. (Page 219.)

But no one need be without good table and market grapes, even if his soil is heavy, and damp, for a little drainage, subsoiling and fertilizing will largely correct what nature has failed to do.

Next to the red and chocolate sandy soils come the black sandy soils on red or yellow clay. The poorest are the low blue livery soils, that are seepy in wet, and "hard as a bone" in dry weather. But the black waxy and adobe soils, in good sites, planted to some varieties, give good results:

\section{Preparation of the Sorl}

Having chosen the site, the soil should be thoroughly prepared. Failure to do this will. cause many sad crops of disappointment.

The land, if beset with stumps and rocks, should have them all dug or pulled out to a depth below where the plow will reach. When the land is free to be worked at your will by the plow in all its parts, to at least two feet in depth, lay off the rows-preferably running from northeast to southwest, if land will permit-then plow in narrow lands, the width that the rows are to be apart. 
I have found nine feet from row to row the most desirable width, so a wagon can bedriven between. Begin plowing each land midway between where the rows are to stand, and back furrow to this center, following the first plow with another, preferably a subsoil plow, as deeply as a heavy team can draw it, remembering that never after the vines have once filled the soil with their roots can deep plowing be done in the vineyard during its life without great damage. In finishing each land go an extra round or two in the dead-furrow, throwing out as deeply as possible, not less than two feet. Then let land lie idle awhile to receive ameliorating influences of weather. This preparation is best done in the fall, and planting in December or February in the South and April in the North.

If the land is heavy or seepy, or poor, the dead-furrow should have placed along its bottom, three or four inches in depth, poles and brush, lying close down lengthwise, with crushed bones and leaf-mold from the woods intermingled. When ready to plant, begin at the dead-furrow with a broad, heavy turning plow, and turn the land back over the poles, bones, etc., until the soil is two feet deep over the poles, and the final dead-furrow, which need not be opened very deep, is midway between where the rows are to be set. A cross section of the lands thus prepared would present something of appearance, shown in figure below.

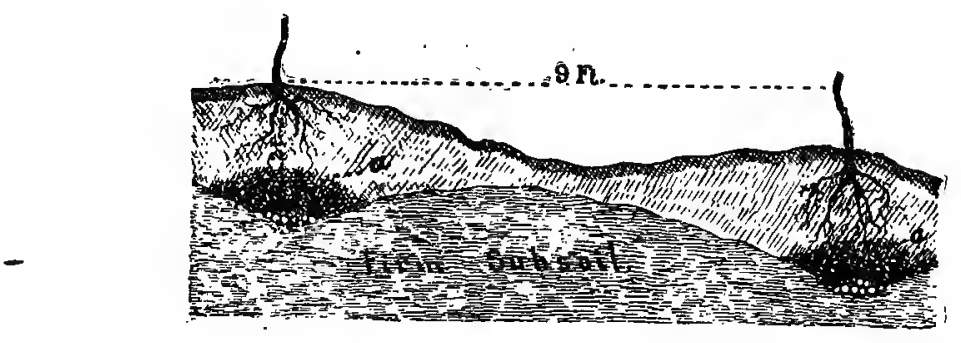

\section{Section Across Rows.}

\section{A. A. Poles, Brush, Bones, Leaf-Mold, etc.}

A vineyard planted on land thus prepared, and of varieties adapted to the climate, should, with proper care, live fifty to one hundred years under profitable bearing.

\section{The Selection of Varieties}

In planting a vineyard it is desirable to have varieties that, in good soil and location for the vine, will, under good cultivation and proper training, yield the following results: first, health, resisting phylloxera at the root, mildew, anthrax, and black rot on young shoots, foliage and fruit, enduring extremes of heat and cold, drouth and wet weather; long life, not less than twenty years, and extending to fifty years or more under favorable circumstances; a succession in ripening in the Southwest of not less than three months of black, red and white, table and market varieties at all times, and in the North four to six weeks.

The varieties are not yet in existence which will make a vineyard up to that standard all the way thru; nor can we fill a period of a week with such varieties in every respect. So it is clear that there is much need yet of new varieties until the requirement can be fully met, for there is a brisk, profitable demand for really good eating grapes all thru the South from July 1st until November.

With the old Labrusca such as Ives, Perkins, Concord, and Labrusca $\times$ Vinifera hybrid varieties, such as Rogers, Ricketts, etc., the grape season at Denison, Texas, began about July 1st and ended about August 1st to 10th, leaving the fall season, when grapes are so much relished, without grapes, except those imported from California and the northern states.

During the last twenty years new, southern-bred varieties, have been produced, ripening all along from June 20th to October, much longer lived, more prolific, freer from disease; than the 
northeastern kinds. which generally die out in from six to fifteen years, until a really profitable list can now be had, altho many gaps in season and color still exist for future originators to fill.

At this point you should diligently study Chapter III., which will well prepare you for making the best selections for each section of the country. (Also see pages 212, 213, 217, 218, 219.)

\section{Setting the Vines}

Strong, healthy one-, or two-year-old plants-never older, unless to save rare varietiesshould be used.

Cut the roots back to six or eight inches with sharp knife or shears, and tops to two or three buds. Have all the plants thus prepared and tied in bundles of as many as there will be vines in row, if the vineyard is to be of considerable size; each variety correctly labeled and separate. Have the vines thus prepared, heeled in moist soil near where they are to be planted and arranged in order in which they are to be set.

With a turning plow let a careful man, going by stakes set in straight line at right angles across the rows as already prepared, lay off straight furrows four feet apart.

After the vineyard ground is thus laid off one way, set the stakes in a straight row, directly over the line of buried poles, or the deep dead-furrow first made, which is now under where each row is to stand.

Let one person take the vines of the first variety, and if such be Delaware, Moore Early, Ives, Concord, or other varieties of moderate growth, place a vine properly in every other cross.* furrow, thus putting them eight feet apart along the row, while another person attends him with a spade, and covers the roots carefully with mellow fine soil, finally pressing it down firmly with the foot all round, leaving the two buds just above the surface of soil. If the variety is Herbemont, Lenoir, or hybrids of these, or Post-Oak grape hybrids, set a vine in every third cross-furrow, thus giving each twelve feet distance to next vine in the row. If the land is very strong, these varieties will do better set sixteen feet apart-one in every fourth cross-furrowand will fill the entire space of trellis well with fruit, and fare much better than if set closer and pruned shorter.

Scuppernong, Thomas and others of the Muscadine varieties should never have less than sixteen feet space.

If any varieties have imperfect flowers, such as Brighton and some others, plant next row to them in kinds with perfect flowers that bloom at the same time. (See table, pages 212, 213.)

\section{Recording the Vineyard}

After the vines are all thus carefully set, make a record of the plantation in a book for the purpose, and.preserve for future reference. It will save much confusion and be a great satisfaction in comparing varieties.

Varieties of grapes are less known and understood generally among nurserymen than are varieties of almost any other class of fruits; hence you should be especially careful to secure vines from thoroly posted and reliable growers.

\section{Trellising}

Numerous methods of trellising have been invented and practiced; numerous books explaining these methods have been published, yet improvements not given in the books have been made.

Years ago the writer went extensively into the study and testing of the various leading methods in vogue, to determine, if possible, the most economical and the most efficient for commercial vineyard purposes, and as a result found a trellis of his own invention, which with constant use in his vineyards for over twenty years, has given much better results, with greater saving of 
time in pruning and tying, with many other advantages over trellises ordinarily in use. This has not been patented. It is freely given to the world. It, in its earlier cruder form, several times has been published and illustrated, but my latest method is an improvement in economical construction of what is known as the Munson Three Wire Canopy Trellis.

The vine in nature invariably tries to make a canopy of its foliage over its fruit, body and root, and yet above ground sufficiently to allow ventilation and diffused light enough to favor the proper development and ripening of the fruit. This was the key to my invention.

With the single post, the winds thrashed and twisted the vines about until the ties were worn off, and down they came, full of fruit, to the ground, the crop greatly damaged and requiring immediate attention in tying up again in the very busiest season. Besides, there was never room for the vine to properly expand itself. The lower part of the body was exposed to the baking sun, and in a few years killed along its southwest side. The foliage either matted up in a bundle, choking the fruit, or had to be kept cut back too closely for the health of the vine. The crops were small and uneven in quality, and the vines short-lived. Besides, the post in the center was a perpetual harbor for insects and fungi, ready to prey on vine and fruit.

In the vertical three or two-wire trellis was found a large improvement, especially with the Kniffin method of long-arm pruning and drooping training. The fan-training on such trellises was next best, and the Fuller system poorest, because so tedious in detail and the incessant pinching necessary to maintain the balance of the vine. All, however, lacked the proper canopy of shade, permitted uneven exposure of foliage and fruit to wind and light, presented a broad surface of resistance to storms, and when the ground became saturated and soft, or the trellis a little old, whole rows would go down with a crush of fruit in a heavy blow.

Besides, the vertical wire trellises in a vineyard allow no free ventilation when full of foliage and fruit, and are the same as so many fences to oppose one's passing from row to row at any point in the vineyard.

So, I might show the defects of all the other trellises commonly used, and I will illustrate only the one proven best.
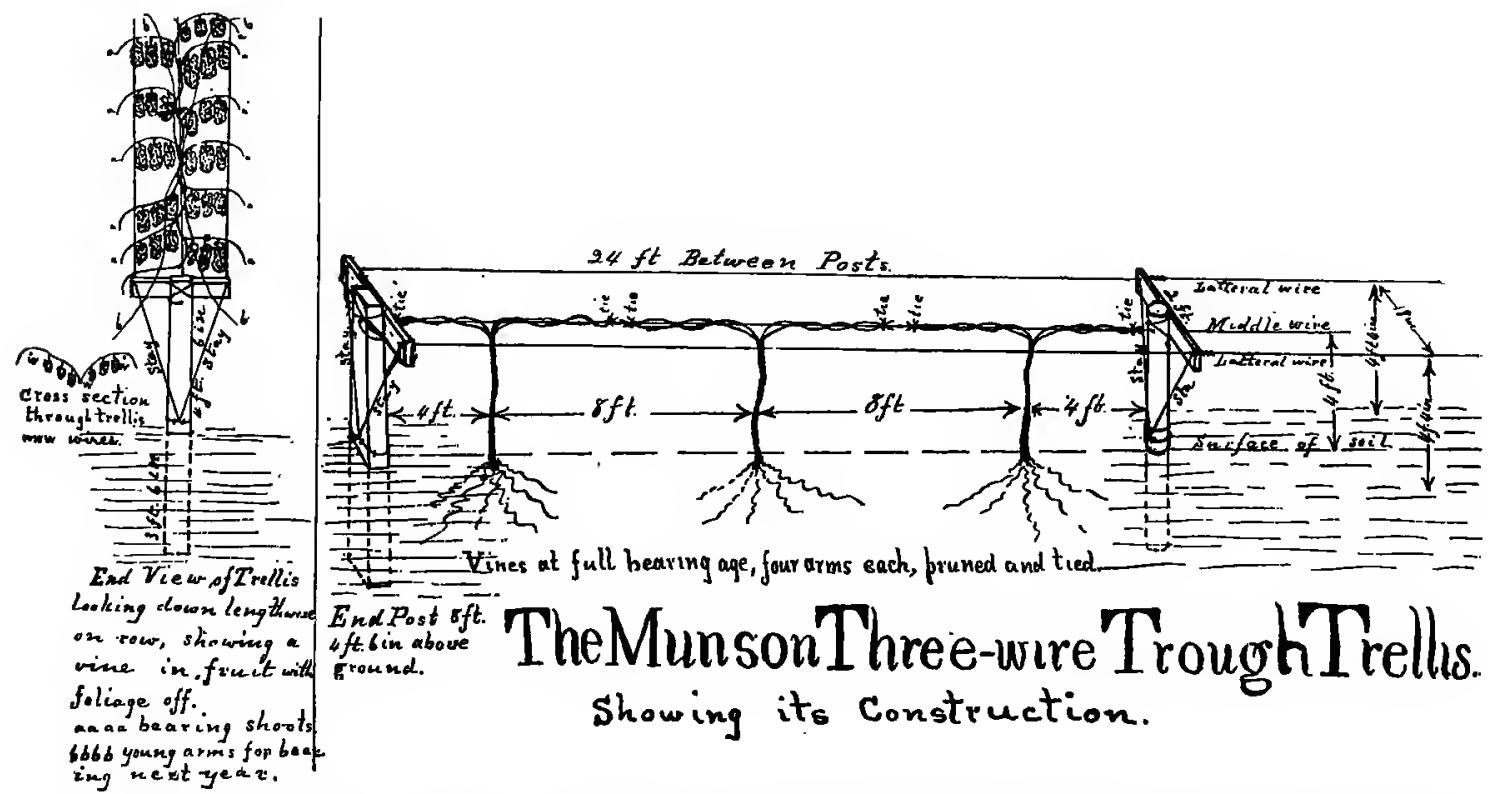

showing its Construction.

The posts should be of some durable strong wood, such as Bois d'Arc (Osage), Cedar, heart wood of Catalpa, Black Locust, or White Oak. The end posts of every row should be large and strong and be set three and one-half or four feet in the ground and well tamped. The intermediate posts, which may be much lighter than the end posts, should be six and one-half or seven feet 
long and set two to two and one-half feet in the ground, with twenty-four feet spaces between posts, which will take three vines, eight feet apart, or two vines twelve feet apart. After the posts are set, a three-eighths-inch hole should be bored through each post, four feet from the surface of the ground, in the direction in which the row runs, leaving six inches or more of post above the hole. These holes are for the admittance of the middle, lower wire, of the trellis.

For each end post prepare for cross-arm, a piece of two by four hard pine or oak, two feet lcng, and at one inch from either end, and one inch from the upper side, bore a three-eighths of an inch bit-hole, or saw into upper side half an inch, which will take less time and do as well, to pass the lateral wires through, and in the middle of the lower side, saw a notch one-half inch deep. For each intermediate post, prepare a board of similar wood, two feet long, one inch thick by four broad, and likewise bore or notch.

Through the holes in the posts run a No. 11 galvanized wire, fasten at one end, tighten at the other end by a wire stretcher and fasten. This will be the middle and lower wire of the trellis, and all that will be needed the first year, when the young vines are trained up a string, tied from the vine (when set) to the wire, and along it.

The arms, and the two lateral wires which they bear, need not be put on the trellis until after the vines are pruned and tied the next winter.

To put on the cross-arms, use no bolts or nails, only No. 11 galvanized wire.

Each end cross-arm is placed inside the post, and against it on top of the wire, already thru the posts, notch-side downward, straddling the wire, to keep it from sliding. Then take a piece of same size wire, about seven feet long, pass one end thru the bit-hole, or saw-notch, in one end of arm and fasten it by looping and twisting about six inches of the end back upon itself, then while one person holds the cross-arm in place, the operator carries the wire down around the post once near the ground, staples it on each side and brings the other end up to the opposite end of arm, puts it thru the bit hole, or saw-notch, draws it tightly, keeping the arm level, and fastens the end of the wire as was done the other. Wire nippers and pliers will be needed for this work. Then take another piece of wire about two feet long, and put it twice around the cross-arm and the post where they come together, above the middle wire, and firmly tie them together, crossing the wire as it goes around. This will hold the arm in place and not weaken or split the arm as do nails and bolts, and will be longer-lasting, quicker and cheaper, and more elastic, so that when struck by the hames or collar in cultivation, it gives a little, receiving no damage.

Likewise place the cross-arms on the intermediate posts, leaving the ends of the wire projecting about six inches after fastening, for a purpose soon to be mentioned. Then draw the two lateral wires thru the bit holes in the ends of the arms, or drop into the saw-notches, if such are made, thruout the row, tighten with the wire stretcher and fasten. Then return along each lateral wire, wrapping ends of wire at the ends of the arms very closely and tightly around the thru-going lateral wires, as telegraph and telephone wires are wrapped in splicing. This is quickly done with the proper pliers, and prevents the arms from slipping out of proper position. Now the trellis is complete, and will need little or no repairs, and looks very neat, especially if painted.

One other matter should not be neglected. Into the soil at the foot of the middle post of each row, a wire should te run into the earth deeply, say two or three feet, which can usually be done with the hands, if the soil is moist and not too rocky, then the wire should be brought up by the post, wound tightly once or twice around the middle wire and then be cut off some eight or ten inches above, and left projecting straight up, to serve as a lightning rod: A vineyard thus provided with lightning arresters will take off, noiselessly and harmlessly, the heaviest of charges from a cloud. I have had rows of vines, not provided with the ground wires, almost destroyed by lightning. 


\section{Pruning and Training the Vines}

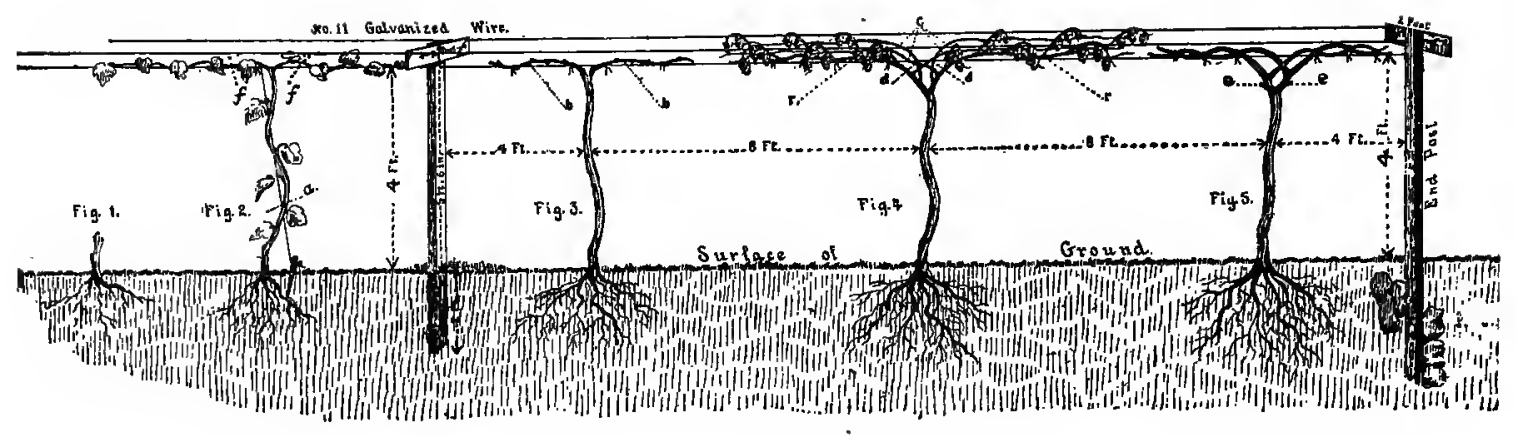

The Munson Three-Wire Canopy Trellis and Renewal System Training

Drawn and Described by the Inventor

Figure 1 shows plant when set, cut back to two eyes.

Figure 2 shows the vine at end of first season's growth, trained in one cane, up twine, to lower (center) wire. To be cut back to $a$ in fall and to be likewise trained second season, when it will be much stronger, ready to bear a small crop, as shown in Figure 2, and larger in Figure 4. But if the vine has made a very strong growth it may be cut at $f . f$.

Figure 3 shows the vine, after second season's growth, pruned and tied-arms $b b$ to be left longer or shorter according to vigor of vine. The vine should not be allowed to bear more than two or three clusters the year previous to this-that is, the second season, when cut back at $f . f$. There are ten buds shown on the pruned arms beyond the first ties next the crotch, to be allowed to bear. Counting three clusters to each makes 30 clusters-enough for first crop.

Figure 4 shows vine in bearing, third season's growth, when the first profitable crop may be expected. (Foliage omitted from figure to show branching arms clearly.) In the following fallNovember or December--the two bearing arms $r r$ should be cut off at $d d$ and the four new arms $c$ cut back according to strength of vine and tied as in Figure 5. They should be started near crotch of vine and not allowed to bear nor be pinched back as are the bearing shoots, during summer pruning.

Figure 5 shows the vine three years in vineyard-pruned and tied, two arms to right and two to left along lower (central) wire-ready for full bearing, and will in fruit appear like vine in Figure 4, except that the bearing shoots will be nearly twice as many. Last year's arms were cut off at $e e$. In succeeding years the pruning and tying will vary little from this.

\section{Pruning and Training}

on the Munson trellis is very simple and easy with a little instruction for a few minutes with a vine or two pruned for example. The vine the first season is allowed to grow up onto the middle wire by a string around which it is coiled by hand, by going over the vineyard once or twice until the selected shoot of each vine is upon the wire, after which it is allowed to ramble at freedom over the wires. By getting onto the trellis the first year, one strong shoot, and allowing no other to grow, a partial crop can be had the second year, without damage, on all but weak growers, like Delaware, that should not be allowed to bear until the third year. At the first regular pruning (all prunings should be done in November or December, after leaf fall, and never so late as to cause the vines to bleed), the vine should be cut back to two or three buds that have reached the middle wire, if weak growers, if strong, with heavy growth, six or eight buds each, to two arms, one going each way along the lower wire from where the ascending vine first touches the wire. After the vines are thus pruned, the outer end of each arm is firmly tied to the lower 
wire, along which it is gently coiled. These two ties hold the vine firmly in place. The buds on the arms, push and ascend, passing over the lateral wires, clinging thereto with their tendrils, and hang over like a beautiful green drapery shading the fruit and body of the vine according to its natural habit.

\section{Summer Pruning}

On the canopy trellis, all the summer pruning required is, to go thru the vineyard at or a few days before blooming time, and with a light, sharp butcher knife, clip off the tips of all advanced shoots to be left for bearing, leaving two or three leaves beyond the outer flower cluster. From the shoots near the crotch, selected for bearing arms the next year, pick the flower clusters, and strip off or rub off all shoots and buds that start on trunk of vine below crotch. This latter is very important, as such shoots, if left, eat up the nourishment of the land with no return but added work at pruning time.

It will be found that the shoots at the ends of the arms usually start first and strongest, and if not clipped back, will not allow the buds back toward the crotch to start well, but if clipped, all other desirable buds then push.

In about six to ten days after first clipping, a second one is usually necessary, especially if the weather is moist and warm, and the land rich. The first clipped shoots, as well as those not clipped the first time, will need clipping back this time, the end buds on the first clipped having pushed vigorously.

At second year's pruning and others following, the old arms with all the bearing shoots on them are cut off down to the new arms and the new arms cut back to lengths they can fill with fruit and well mature. In this, critical judgment and knowledge of capabilities of different varieties are more required in the pruner than in any other of the training work. Some varieties, such as the Delaware, cannot carry more than three to four arms, two feet long, while Herbemont can more easily carry four arms each eight feet long, hence such as Delaware should be planted eight feet or less apart, while Herbemont and most of the Post-Oak grape hybrids, should be twelve to sixteen feet apart. In other words, each variety should be set that distance apart that it will fill the trellis with fruit from end to end, and mature it well, so as to better economize space.

By the third year, the vine should come to full bearing, and be pruned with four bearing arms, two to go each way along the lower wire of trellis, gently coiling around the wire, one arm in one direction, the other in opposite direction, and should be of about equal lengths, so that one firm tie with jute yarn, near the ends, will be all the tying the vines will need-that is, two ties to each vine-the least required by any trellis system, and the pruning is also simplest and the results every way the best. In variety descriptions in Chapter III. recommendations are made as to short, medium or long arms. Short arms are 2 to $3 \mathrm{ft}$.; medium, 3 to $5 \mathrm{ft}$; long, 5 to $8 \mathrm{ft}$. or more.

Some of the advantages of this trellis are its cheapness, its simplicity, bringing the work up breast-high so that pruning, tying, harvesting, spraying, can be done in an erect position, saving back strain; perfect distribution of light, heat, and air to foliage and fruit; shielding from sunscald and birds; giving free ventilation and easy passage of wind through the vineyard without blowing down the trellis or tender shoots from the vines, and allowing ready passage from row to row, without going around, thus getting larger and better crops at less expense and increasing length of life of vineyard and the pleasure of taking care of it.

The cause of the lagging of viticulture in this country is not, as some suppose, the want of profit in its pursuit, as, for many years, we have in connection with our nursery business grown berries, plums, pears, peaches, apples, and grapes, in considerable quantities for market, and altho our vineyards were largely devoted to testing new varieties, we found the grape steadily the surest to bear annually, and more readily marketed and more profitable in proportion to outlay. The chief cause, I fully believe, is the lack of practical knowledge of the business. If I am correct in this, then the remedy is education of fruit growers on the subject. 


\section{Cultivation}

As the feeding roots of the vine spread in every direction only a few inches under the surface of the soil, and extend as far, probably, as do the vines above, it is evident that the cultivation to avoid damaging, must be shallow, - not deeper than four or five inches. When the vineyard is young, the ground should be stirred deeper than in after years, in order to force the main roots as deeply into the soil as possible, so that after cultivation may not tear them up. Level cultivation is necessary to allow uniform depth to the roots, and to prevent heavy rains from washing away and gullying the land. One of the best implements for such work is a light Acme harrow, three or four feet wide, with extension more on one side of draft than the other and provided with handles for guiding, so that side can be made to reach up close to the vines under the trellis, and that one animal can draw it. It should be run as soon after each considerable rain falls, as the soil will pulverize well, and always before weeds are an inch high, when it will completely destroy them. This will leave a narrow strip along the row to be cleaned with the hoe. Next to the Acme harrow, is the five-toothed cultivator, set to run shallow.

The first cultivation in spring should be deepest, before roots begin feeding much, and is best done with a small turning-plow. For very sandy land, the chilled cast plow is far the most durable.

Cultivation in the vineyard should be thoro and continued thruout the season, so as to have no grass or weeds to devour the fertility of the soil, or to seed and befoul the land for the next season, or to burn through the vineyard, after becoming dry, doing great damage, as is sometimes seen in poorly-cared-for vineyards; or to harbor insects that prey upon the vine. Nowhere does clean, careful culture pay better than in the vineyard. No person should be tolerated in the vineyard, who is so careless as to bruise and bark roots and vines with the plow or hoe.

\section{Fertilization}

If the vineyard was properly prepared, and fresh, rich land used, or else well enriched, no further enrichment will be needed for four to six years. By the time three or four good crops have been taken off, the vineyard will be seen to wane a little in vigor and in size of clusters and berries. This is the proper signal for giving the vines more food. If the green of foliage is less dark than formerly, nitrogen is needed; if the wood-growth is becoming shorter, more slender, potash is wanted; if the fruit is less richly flavored and colored than formerly, the phosphoric acid of the soil is becoming exhausted.

Usually all the three prime essentials named above, disappear together, and then a fertilizer containing all three, known among commercial brands as, "complete fertilizer," and found in good proportion in stable and cow-lot manure,- the latter better for vineyards, and in cotton seed and cotton-seed meal. All are good for the vine. Twenty-five large ton loads of well rotted barnyard or stable manure per acre, applied once every three or four years, will keep the vineyard in good growth. It should be applied broadcast and cultivated in. A ton of cotton seed per acre every two years, or a ton of cotton-seed meal and two tons of cotton-seed hulls every four years, drilled in with a cotton-seed planter, will do better, being more durable and free from weed-seeds. A ton of complete commercial fertilizer drilled in every four years will also answer well.

For nitrogen alone, nitrate of soda is the cheapest source, unless slaughterhouse offal is to be had cheaply near by. For potash, Kainit is the cheapest, unless fresh wood ashes can be secured near by at a low rate. For phosphoric acid, phosphate rock treated with sulphuric acid, known as acid phosphate, is the cheapest source.

As in all other agriculture, vine culture has the same law, that is, if you wish your land to feed you well, you must feed and groom it well. 
Remember that each year tons of wood pruned away, of fruit harvested, and of leaves cut by frost and by winter winds blown from the vineyard, are the heavy tax the land bears, that you may pocket from $\$ 50$ to several hundred dollars per acre annually according to your deserts as the owner. Fortunately, any good soil contains the many other elements necessary for good growth in sufficient supply for all time; but these three,-nitrogen, phosphoric acid and potash, -will soon be used up and production cease unless they are replenished from time to time. The French viregrowers appreciate these economies so well, that the best cultivators run all the prunings of their vineyards through a mill which cuts the brush into short bits and crushes them into pulp, and all is returned to the vineyard and spread over the ground and cultivated in. Also the drifted leaves are piled, rotted and returned to the soil. Americans will soon have to learn and practice such economics, or come to serious want. 


\section{Chapter VI}

\section{Protecting the Vineyard from Insects and Fungi}

If I should name, describe and prescribe against all the insect and fungus parasites of the grape, it would require a considerable book. Fortunately among such a host, there are only five insects that seriously damage grapes in the United States, so that they require combatting to secure success, whenever they attack in great numbers, and likewise only four or five serious fungi to fight. In combatting all these, prevention is the only remedy, for cure is impossible after the damage has been inflicted. In other words we must ward off, or kill the insects and fungi that do serious damage, before they do their eating of the tissues of the vine.

\section{Insects That Must be Fought to Prevent Serious Damage}

\section{The Root Louse. (Phylloxera vastatrix.)}

The Phylloxera is a minute aphis, scarcely visible to the unaided eye. It has several different forms, winged and unwinged, male and female. The winged form issues from the ground about midsummer and lays eggs upon the under side of young leaves of the grape. The eggs soon hatch into invisible larvæ, and their irritation causes a small wart or gall to form on the under side of the leaf. These young aphises, each in a gall of its own making, soon lay eggs which hatch in the galls, are male and female, which pair and finally emerge from the galls on under side of leaf. All are wingless that continue to breed on the leaves. The females again cause galls and lay eggs and so continue as long as young leaves can be found or till cool nights of fall. In fall the females lay larger, hardy eggs in the crevices of the bark, and other places, to winter over and begin generation on the leaves next season. When young leaves cannot be found to work upon the insects go into the soil and attack the tender rootlets. It is here where their chief harm is done. In puncturing the rootlets of very tender rooted kinds, such as Vinifera, they introduce into the juices of the young cells a species of bacterium (discovered by Millardet), that, similar to the pearblight (Bacillus amyilovorus), introduced into the flowers or growing tips by insects, destroys the tree, unless cut out and burned; or the malarial bacterium, introduced into the human by a mosquito, causes death unless checked.

The underground root-louse continues to multiply along the roots for several generations, and may not produce any winged forms for several years, unless favorable seasons occur, when a few of the females, in midsummer, acquire wings, and leave the ground to lay their eggs on the young leaves, to breed there thru summer, as already described.

As the insect is a native in all parts of the United Siztes east of the Rockies, the native vines there have become immune to the influences of the Eacterium that the louse introduces, while species of grapes not native in regions where the louse is native, especially the soft-rooted Vinifera, are not immune.

This is the reason that Vinifera grows well in the milder regions east of the Rockies, when grafted on native American grape roots, but perishes in a few years if on its own roots.

By so grafting the more robust of the foreign grapes in most parts of the South and spraying carefully with Bordeaux Mixture, these kinds can be successfully and profitably grown there almost as well as in California and France, especially so in Southwest 'Texas, west of the 98th meridian.

Only the Old World grapes ( $V$. vinifera) must be protected against this, as American grapesthat is, varieties sprung from species native in the United States east of the Rocky Mountains, -are resistant.

There has been only one remedy found that is fairly satisfactory, and that is, 


\section{Grafting the Foreign Varieties Upon American Stocks}

The best stocks for different climates and soils are mentioned on pages 126 and 219 .

The Phylloxera cannot live in very sandy soils.

\section{Grafting the Grape}

Grafting the grape is a simple and easy matter, requiring sharp tools, a good eye and judgment.

The grafting may be done on young vines, one or two years old, either where they grow and are to stand in the vineyard, when it is known as Field-Grafting; or at the bench in the grafting house, known as Bench-Grafting.

In Bench-Grafting, the stocks to be grafted are grown from cuttings in the nursery until large enough to graft, which is from one-fourth to one-half inch in diameter at collar, - the grafting point-and usually reached in one year's growth from cutting, in good soil and culture. When time comes for grafting,-- late in winter, just before buds begin to swell,--the stocks are dug and taken to grafting house, also good healthy scions taken from varieties to be grafted, are procured.

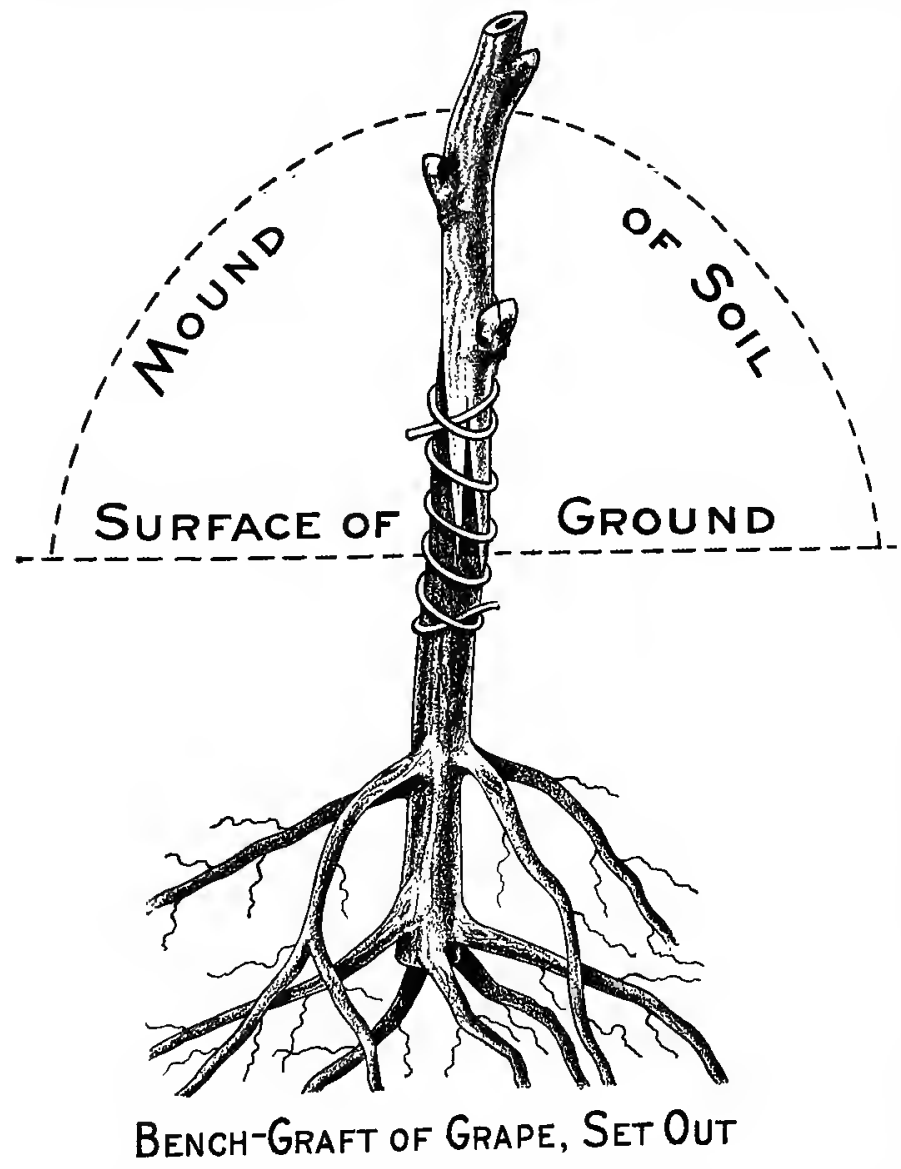

With a single steady slanting cut through the collar of the stock with a sharp knife, and then a splitting cut, on face of first cut, starting one-third of the way from top of slant to bottom, half to three-fourths of an inch deep, making the tongue, which is to enter the split of the scion. Then take a piece of scion one-fourth inch or more in diameter, containing two to three buds, and starting opposite, or a little above lower bud, cut through with same slant as that made on stock, and make a like splitting cut, then insert the tongue of each in the split of the other, and tie with darning yarn as shown in cut.

When the grafts are thus prepared, they are packed in damp moss or cloths, and planted in place in vineyard, mounding up the damp, mellow soil to the top bud. In due time the buds of the graft will push, and the branches they make must be trained up onto the trellis.

In grafting in place, the stocks are grown in place in the vineyard and grafted there, - a much more tedious work, but more certain, and about a year's time in growth is gained,

Sometimes it is desired to graft an old vine, to get a vine of better kind, as well as to avoid damage from 'Phylloxera. The difference in operation, is to saw off the body of the stock, as near the ground as a straight portion, two or three inches in length, can be found. Then smooth the cut with a sharp knife, and with a broad chisel, split the stock an inch or more, being careful to not break loose the bark. Then take good, strong scion of last season's growth, cut two pieces with three or four buds each. At base-end of each, shape to an evenly tapering wedge, with a 


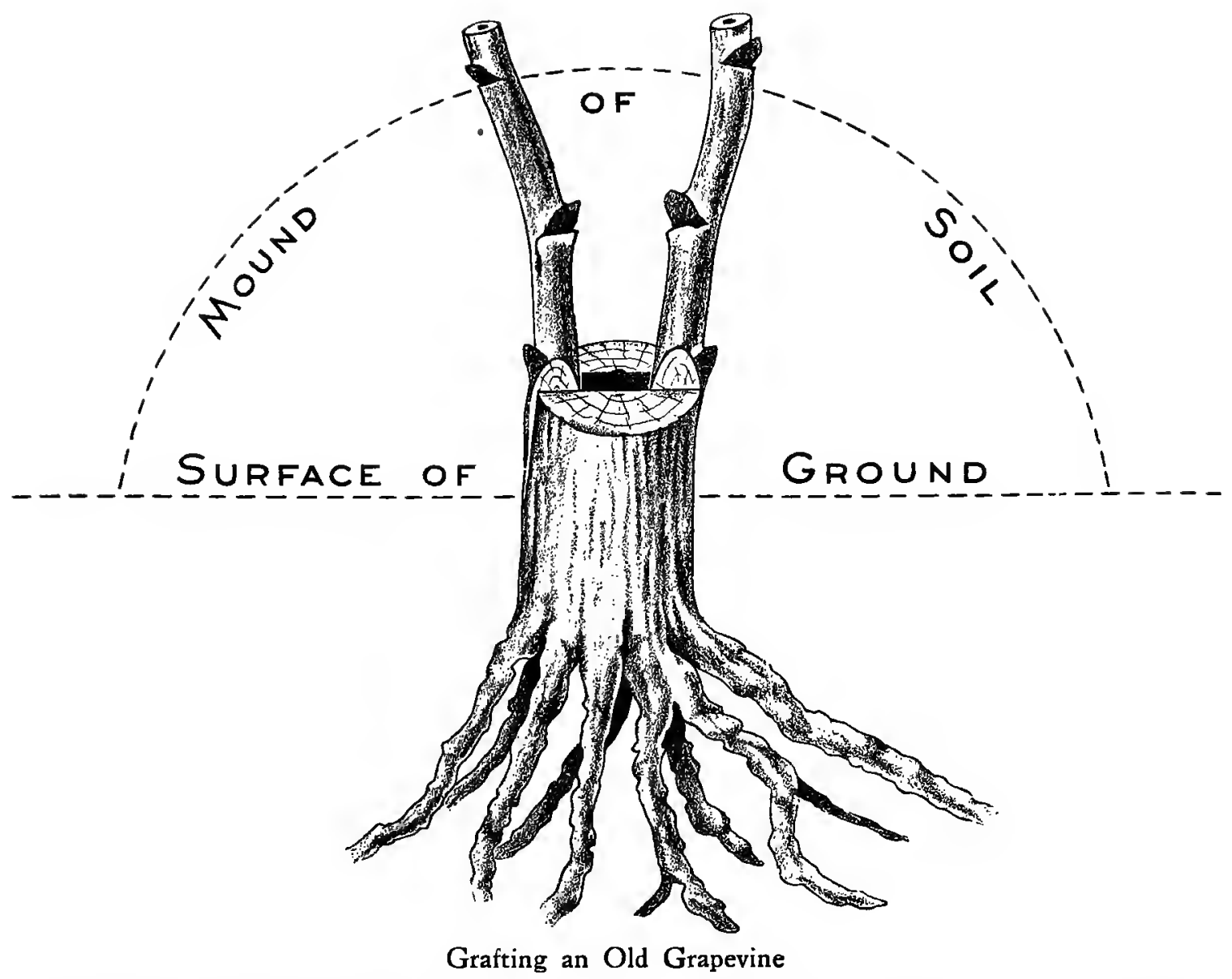

bud at base of wedge, leaving the wedge slightly thicker on the side of bud than on the other side. Now with a narrow wedge of wood or metal, driven into center of cleft in stock, until cleft is opened enough to receive the wedge-end of scion up to the bud at its base, insert the scions, being careful that the scions lean outward a little, their bark crossing the bark of stock, so the rising sap of stock will feed the scion from the start. Remove wedge, and the scions will be held firmly. Then with moist, mellow, clean soil, mound up around the stock, pressing the damp soil between and around the scions where they enter the stock, not in the least displacing the scions, and mound the soil up to last bud on each scion, as shown in above figure.

The work is done. Keep the mound free from weeds, and the sprouts that may spring up from the stock, and in a month or six weeks, if successful, nice thrifty shoots will be coming up from the buds of the scions. Select one or two of the best and train them up where you wish them and remove all others. The next season such grafts will be strong enough to bear a good crop.

\section{The Rose Chafer. (Macrodactylus subspinosus.)}

When this beetle becomes numerous, as it does some seasons in some sections of the country, it quickly defoliates the vines, doing them great damage. The larva develops under ground and cannot well be fought. It is the beetle that feeds upon the foliage that, like other leaf-eating insects, can be easily poisoned by putting into the Bordeaux Mixture, used in first application after the foliage of the vine appears, before the grapes bloom, two pounds of arsenate of lead to every 50 gallons of water. The beetle is dark gray, nearly one-half inch in length and, when disturbed, quickly drops to the ground, as tho dead. 


\section{The Grape-Leaf Fidia. (Fidia viticida.)}

This often is mistaken for the Rose-Chafer, as it likewise feeds upon the leaves of the vine. It is of an ashy-gray color, about one-third of an inch long. It "plays "possum," also, and may be caught in broad pans, or on sheets held under the vines when jarred and the beetles quickly emptied into a vessel containing some water covered with a layer of kerosene; or chickens may be trained to pick them up when jarred down. As they appear early in the season, the early spraying with arsenate of lead in the Bordeaux Mixture quickly exterminates them.

\section{The Grape Flea-Beetle. (Haltica chalybea.)}

This is a small steel-blue beetle, a little over one-eighth of an inch long, which spryly hops and flies away when approached. Both it and its larvæ (one-fourth of an inch long and covered with minute black dots), feed voraciously upon the upper surface of leaves. Bordeaux with Arsenate of Lead, Paris Green or London Purple sprayed over the foliage kills them. If Paris Green or London Purple is used, put in ten or twelve ounces to every 50 gallons of water. These poisons must not be used after the young grapes are larger than goose shot.

\section{The Grape Leaf Folder. (Desmia funeralis.)}

This is a bright green "worm"-larva-of a miller or moth with black wings bordered with white and having two white elliptical spots on upper side of outer wing in both male and female, and one on under wing of male, and two on under wing of female. The moth measures about one inch, or more, from tip to tip of wings when spread, and it flies chiefly at night and lays its green eggs, singly, on upper side of the leaves. These hatching, the larva begins at once to feed on the leaf, and if the leaf have any pubescent down on that side, it attaches its web to the hairs, first on one side, then the other of itself, and draws a portion of the leaf over itself for protection and continues to eat and skeletonize the leaf, until full grown, when it goes into the chrysalis state, within the fold of leaf, and soon comes out another moth, pairs and lays more eggs. It does its work mostly in after part of summer. It cannot work upon leaves that are entirely devoid of pubescence, hence such varieties escape it. The Bordeaux and Arsenate of Lead spray applied thoroly, as soon as the crop is gathered, stops it, as well as the mildew that does so much damage late in summer on some varieties. The Bordeaux spray alone holds it in check before that.

\section{The Grape Leaf-Hopper. (Erythroneura vitis.)}

This is a small sap-sucking winged insect, that is very active, in dodging, hopping and flying. It is about $3 / 16$ of an inch long, is white or yellowish with delicate and variable wing-markings. It lives on the under sides of the leaves which it punctures, and sucks out the juices, causing the leaves to look grayish above, when much punctured, and finally to drop prematurely. The insect multiplies at an enormous rate. It cannot be poisoned by the arsenic poisons, as it does not eat the tissue. It some seasons greatly injures the vines, and must be fought. This is done by drawing a large sheet iron pan with glowing coals in it, onto which coal oil is occasionally poured in small quantities, along between the rows, while another person goes along opposite on each side, on outside of the two rows, jarring the vines, when the insects fly out on other side and dash into the flame. By this means they can be held in check, so as to do little damage.

The insects hibernate under grass and leaves, if left in the vineyard, and among weeds, leaves and grass surrounding the vineyard. These should be collected in the vineyard and buried or burned and the rubbish surrounding the vineyard plowed under or burned.

I have found the Bordeaux spray efficient in holding them in check, if abundantly applied on all the underside of foliage, as is necessary to prevent Downy Mildew. The leaves seem to absorb some of the copper and change to a darker green, and prevent the multiplication of the insect. (?) 


\section{The Grape Berry "Worms"}

There are two species. One is the larva of a moth (Lobesia botrana), half an inch long, of a bluish-black color, that spins a web and lets itself to the ground. The other is the larva of a curculio (Coliodes inequalis), about one-fourth of an inch long, the beetle one-eighth of an inch. Some seasons they are quite numerous, so as to cause considerable loss of fruit and ragged appearance of clusters, unless diligently sprayed with Bordeaux, forcing spray each time abundantly thru all the cluster, which I have found to be a fairly good preventive. Frequent hand-picking and burning all the affected berries, which may be done in a small family vineyard, will also prevent much damage.

There are some 200 insects that in some way or another prey upon the vine and its fruit, but the above are all that require special treatment, in the United States, to secure success in the vineyard.

\section{Chief Fungus Parasites of the Grape.}

\section{The Downy Mildew. (Peronospera viticola.)}

This fungus flourishes on the under side of the leaves of nearly all varieties of Vinifera grapes and their hybrids in moist sultry weather in all countries having much constant moisture in the air, except near bodies of salt water, the breeze from which seems to be a partial or entire preventive. It first appears as downy white spots, which spread rapidiy, and in favorable weather, soon cover the entire under side of the leaf, which finally turns brown and crisp and drops off. The white appearance is due to myriads of microscopic ellipsoidal pearly white spores that soon ripen and fly in the air to alight and root in the tissues of younger leaves. It soon spreads in favorable weather to all vines in the vineyard not immune. All species of grapes native in arid regions are subject to it when moved in to sultry, moist inland regions, in low altitudes. Most species native in the low, moist, sultry regions are immune to it in part or whole, and their hybrids with Vinifera, generally much less subject than pure Vinifera, and there is much difference among Vinifera varieties in resisting it. It is more widely distributed over the world than any other fungus parasite of the grape. It is readily held in check by timely and thoro application of the Bordeaux Mixture, except when it takes on the form of Ripe Grape Rot, which is exceedingly difficult, or impossible to treat without spoiling the fruit, except by frequent and thorough applications while the grapes are green so as to have the vineyard clean of mildew when grapes are ripening.

\section{Powdery Mildew. (Uncinula spiralis.)}

This fungus is known in Europe generally under the name Ouidium. It is a troublesome pest, both in Europe and California, confining itself to the Vinifera varieties, and its delicate leaved hybrids. It quickly spreads all over the leaves and fruit, as a dull, bluish-white powdery growth, that weakens the vine and ruins the fruit. It is generally treated with flower of sulphur, thoroly dusted with bellows through the foliage, beginning early in the season and making frequent applications. Bordeaux is equally efficient, and with the improved spraying machinery is far more thoroly, quickly and cheaply applied.

\section{Anthracnose or Bird's-Eye Rot. (Spaceloma ampelinum.)}

Some varieties of grapes are subject to this parasite in the damp, chilly weather of spring, when the young shoots have pushed very rapidly before the cool rainy weather comes on. It quickly shows in little irregular black blotches upon the delicate young wood, the leaf-stems and on the stems of clusters and on the young berries. The blotches spread lengthwise along the wood and often run unto one another, and eventually leave deep and permanent sores or depressions in the wood. On the berries, each single spore or center of infection enlarges in a circular black spot, often with concentric rings of different shades of grayish-brown and crimson, if large, but, 
if small, then of a grayish-white color and finally hardens into a depressed scab, while the remaining part of the berry will live and ripen. Prompt and thorough application of Bordeaux at the approach of such weather as favors its attacks will ward it off.

\section{Black Rot. (Guignardia Bidwellii.)}

Black Rot prevails everywhere east of the Rocky Mountains, where the weather in May and June is moist and sultry. A vineyard planted in a new place sonie distance from where other vineyards exist or have recently existed, will for one or two years show little or no Black Rot, but by the third year, it will be found on almost all Vinifera varieties and their hybrids, if in the vineyard, and even Concord will be attacked, but most native varieties in cultivation, such as Norton, Ives, Perkins, Dracut, will escape. Delaware, though a hybrid combination, resists it, altho its foliage is quite sensitive to Downy Mildew. But in a few years longer, if the vineyard remain untreated, and the vines become a little weakened by bearing and the vineyard thoroly infested, all varieties will be more or less attacked by the Black Rot, especially if the season is very favorable for its growth, and from then on the vineyard is worthless, unless renovated by thoro spraying with the copper solutions.

The parasite in spring first shows itself on the upper side of leaves in reddish-brown circular spots, one-eighth to one-half inch in diameter, having a ring of minute black pustules, barely visible to the eye, near the outer part of the brown spot. The pustules eventually open and discharge thousands of microscopic spores, to fly in the air to other leaves and the young fruit. If this first crop of spores on the foliage is prevented by early spraying, the after attacks will be greatly reduced and easily controlled. The fruit when attacked, first shows a mere puncture point around which a whitish blister grows in circular form, that turns brown and then black, spreading over the berry entirely, and the berry shrivels and dries hard, remaining attached to cluster, the minute black pustules appęaring all over the berry.

There is no cure after the fungus has once penetrated the berry. The spray must beat the germ to the leaf and berry and then, when the spore alights, the copper compound prevents it from germinating. That is the prime essential in spraying. Get there first! The last crop of rot spores are larger and thicker in cell-wall than the first in the season, and can endure freezing without damage; remain sticking to the old mummy berries, the vines, the wires and posts of trellis and on the ground, thru winter, ready to fly in the wind or be washed on to the foliage the next spring and start new growth. This suggests spraying in winter or early spring before growth starts. Such spray should be a simple solution of Bluestone (copper sulphate), 1 pound to 25 gallons of water, thoroly sprayed over all parts of the vines and trellis and on the surface of ground in vineyard. Such spraying is equally good, against winter spores of other fungi, but it cannot be used on foliage as it will burn it. The next spraying should be with Bordeaux just before blooming time, to catch the Black Rot and other fungi on young foliage, and the third application as soon as the grapes are out of bloom. A fourth some nine days later will be necessary if the vineyard is badly infested.

\section{A Universal Treatment Against Fungi and Insects, Preying Upon Grapes}

It will be noticed by the careful reader that for each insect and fungus, I have recommended the same remedies in nearly every case. Bordeaux itself is very offensive to the insects and actually destructive to some, especially their eggs, and a universal preventive of fungus germination when in contact, and all the insects worthy of serious attention, except the leaf-hopper and berry worms, are destroyed by arsenical poisons on the foliage, hence one general line of treatment suffices for all. It is as follows:

1. With simple solution of bluestone, one pound to twenty-five gallons of water, spray the trellises in every part, the vines and the ground in vineyard, thoroly, early in winter, or at any rate before buds push. 
2. Just before blooming time, spray thoroughly with Bordeaux 3 pounds copper sulphate, 3 pounds fresh lime, 2 pounds arsenate of lead to 45 or 50 gallons of water.

3. Spray again in nine or ten days after second application, or just after the vines have bloomed, with same material.

4. Spray again just after grape harvest with same material as No. 2, to keep down late mildew and Leaf-Folder. If any spraying is done between 3 and 4 , use no arsenical poisons in them.

Be careful to use no arsenate on fruit after it is one-fourth grown, as poisoning might possibly result from applications made near ripening time. As directed, no harm may be feared. All spraying preparations should be kept constantly labeled POISON, and care be used in handling and applying.

\section{To Make Bordeaux Mixture}

Dissolve two pounds of bluestone (copper sulphate) in fifteen gallons of water, by hanging the bluestone in a coarse sack in the water over night, in a wooden vessel,- tub, keg or barrel.

Slake two pounds of strong fresh lime in water sufficient-two or three gallons, - in another vessel; covered while slaking. When fully slaked, add enough water to bring up to fifteen gallons, strain through burlap or fine wire screen, and let stand over night.

Next morning take equal quantities of the bluestone solution and lime-wash and pour slowly together into a barrel at the same time, so the streams intermingle thoroly, one person pouring the lime-wash, another the bluestone solution, and a third stirring the intermingling solutions all the time, using wooden vessels and wooden paddle. The result will be thirty gallons of perfect Bordeaux. For insects as well as fungi, add one to two pounds arsenate of lead.

This quantity will be sufficient to spray thoroly once, one hundred and fifty, to two hundred average sized bearing vines, in foliage. For half so many vines use half the quantity of each material, and for larger numbers of vines, proportionately larger quantities.

For making large quantities, have large barrels, set up with faucets to empty, set in near the bottoms, so they will flow together into a third vessel or vessels of wood holding as much as desired. Have the bluestone solution in one of the fauceted barrels and the limewash in the other in equal quantities. Open both faucets equally wide at the same time and stir the mixing liquids all the time they are flowing together.

\section{Applying the Spray}

The sprays, applied either for insects or fungi, to be thoroly efficient, must be, not only of proper chemicals, make and strength, but in the form of a fog, so as to move all among the foliage and fruit, reaching every part. This requires high pressure force-pumps, of good make, brass, or brass-lined, and proper nozzles that evenly distribute the spray. Such are made by a number of reliable manufacturers, and widely advertised, so names and descriptions need not be mentioned here. The Auto-Sprayers are preferable to those requiring attention of the operator in pumping. A knapsack sprayer will answer for family vineyards up to half an acre, but a power sprayer is more economical for vineyards of several acres.

A sprayer that sprinkles instead of fogs, is very inefficient and unsatisfactory.

A liquid spray has been proven much more efficient than dust spray.

By selecting, grafting, and judicious pruning, training and spraying, not only may the native and hybrid grapes produce as grand and profitable results, but many of the fine Vinifera varieties may be made to flourish and bear their gorgeous and liscious loads of nectar drops all through the South, and in favorable locations with winter protection in much of the North in open ground and our markets should be filled from June 15 th to November with great variety and excellence of this queen of all fruits. America is the native home of many times more good species of grapes than all the world besides, and by natural rights ought to be the greatest grape country in the world, and will be, when the fruit-growers wake up to the possibilities surrounding them. 


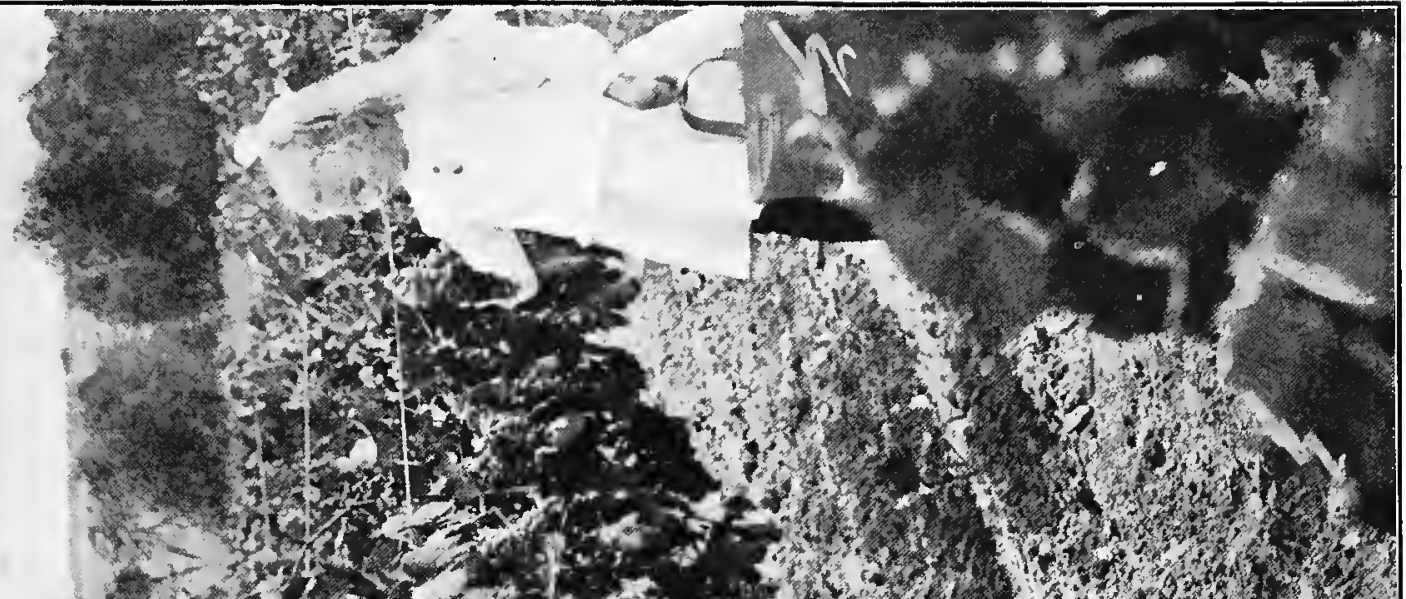

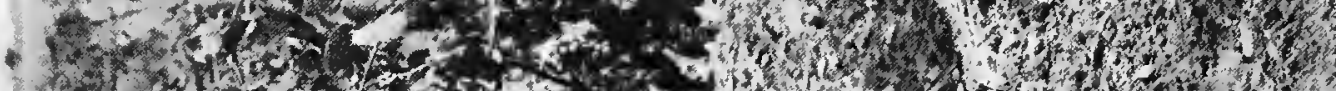

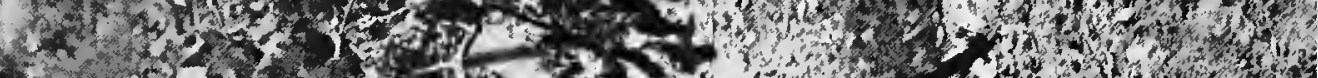

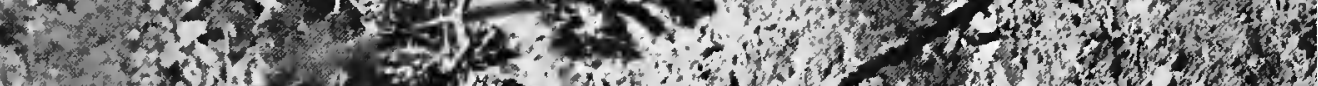

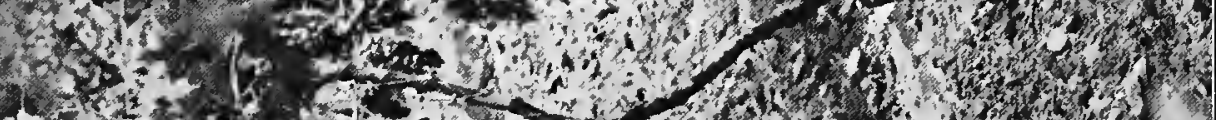

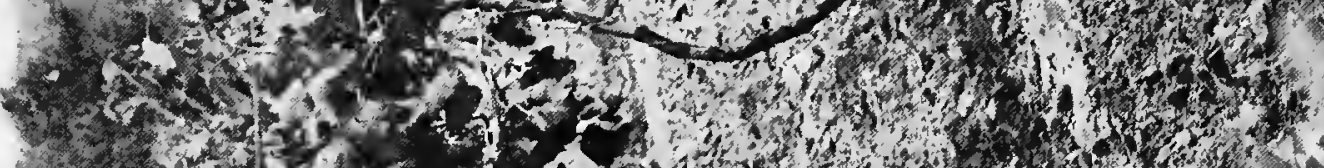

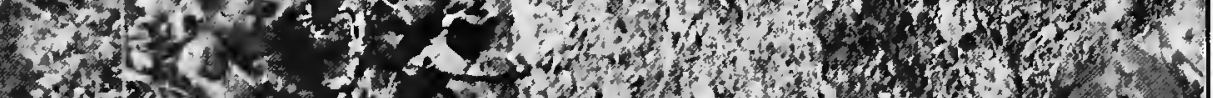

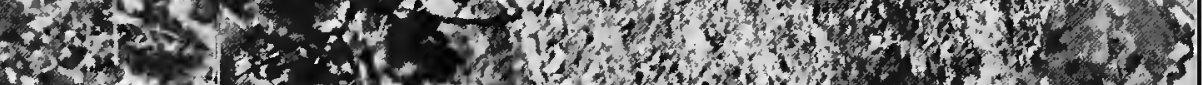

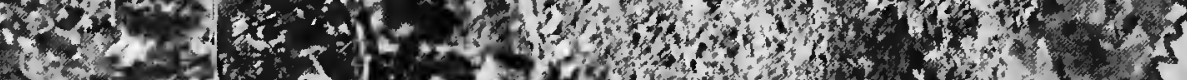

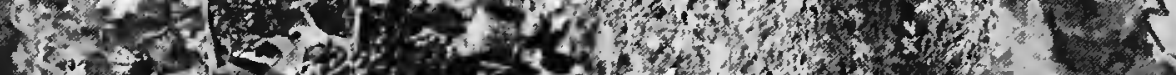

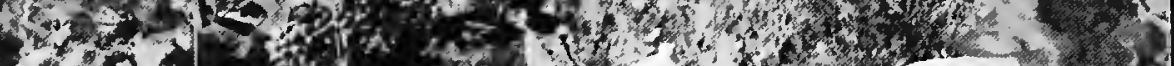

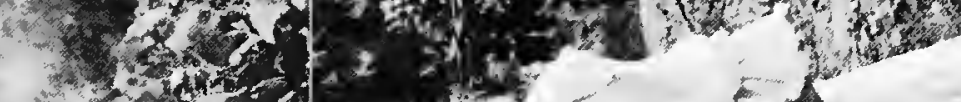

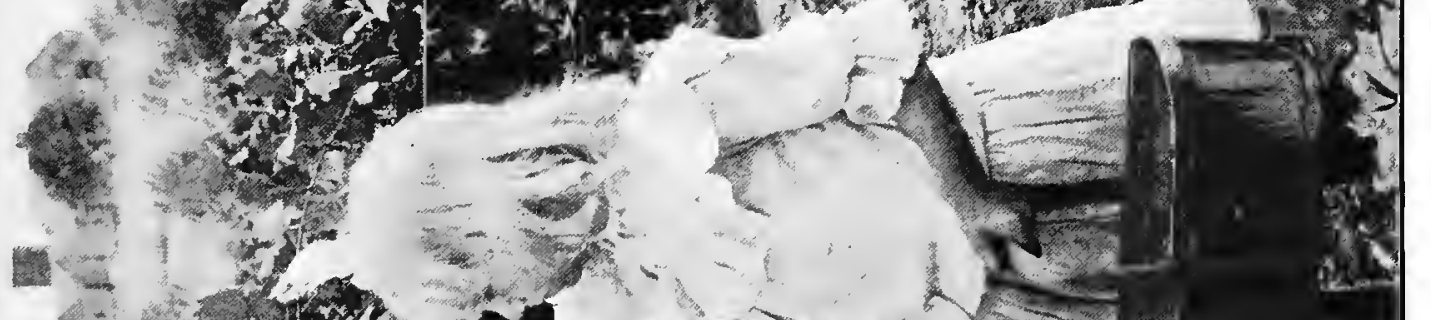




\section{Chapter VII}

\section{Disposition of the Crop}

The vineyardist is never more anxious or at his wits end, to know just what to do, than when his crop of grapes is ripe, unless he has well prepared himself for this event.

If he is growing to sell fresh in the market, he has grown-only the most attractive, prolific and good shipping varieties of red, black and white colors covering the entire grape season of his region.

He must realize, that appearance on the fruit stands, means almost everything in making sales to start with. Next, the quality must be so good that a customer always wants more of the same.

The appearance in market depends not alone on the fruit but is greatly heightened by the style of package, display, etc. The display depends upon the manner of package and packing, and the system, taste, and facilities of the house selling the fruit; hence the shrewd business grape grower will have provided all these things in advance, before his crop is ready for harvest. He will have visited the markets into which he expects to enter and become acquainted with the best, reliable houses observed and learned what are the best packages, arranged to ship to his chosen houses, preferably by direct sale to them, and have laid in sufficient stock of packing material for the season and had it made up ready for use in the packing sheds.

He will have engaged his help to harvest and pack, with experts enough to regulate the whole, when the timer comes.

Proper strong gathering baskets will have been provided, and sufficient packing-shed room to allow the crop to be handled carefully and securely from sudden showers, with room enough for all help to retreat out of rain.

The pickers take and distribute their gathering baskets along under the rows ready to be picked and, with picking shears, take off carefully each cluster and lay it in the basket without handling so as to retain the bloom, and only such persons should pick as know at what stage of ripeness to gather.

If the crop is of considerable extent, a spring wagon, with one horse that can pass between the rows, collects the baskets and delivers them in the packing house without jolting.

The packers take up the clusters by the stem, one at a time, and with small pairs of sharp scissors clip out all defective and green berries, if any, and place the clusters in regular layers in the baskets so as to finish off smoothly and compactly so that the lid will require pressing down somewhat to reach its proper place, if a single basket. The four pound basket is now generally preferred to eight and ten pound baskets by dealers, as they sell entire to most customers and save weighing out as well as having remnants left in baskets, which is generally lost when the fruit is weighed out in small quantities. If the four basket crates are used, they should be full enough to have the cover fit closely against the fruit. The packages should be clean and bright, well and neatly made and tops securely fastened so as to endure any reasonable handling without harm. The marking should be done with neat rubber stamps and each day the shipments for the next day or two ahead should be determined. If in the business to stay one should have a trade-mark brand.

All the subject of selling fruits fresh, has so often and thoroughly been written up in Horticultural Journals and books, and the different styles are so well represented in city markets, that there is little need of repeating in books to-day.. A few hints are sufficient for any beginner that will ever make a success and I let it go at that. 


\section{Manufactured Products of the Grape}

In countries where the grape is one of the great commercial crops, the manufactured products far outrun the sale of fresh fruits.

\section{Wine and Brandy}

In all countries growing grapes extensively, wine is the chief and most profitable product, and large capital in great wineries is required to compete successfully in the wine markets of the world. This work is not designed to treat that subject. Such establishments are managed by expert cnologists, who must be educated specially for the work, and there are already abundance of thoro works, treating the subject.

Brandy is, in a manner, a by-product of great wineries. As prohibitive laws in many states of the Union interdict wine and brandy-making by the common grape grower, I shall say no more of them, but it is a fact that the interdiction cuts off from the most of our country one great. industry and source of wealth, that the country might otherwise enjoy to as great extent as even France, for we have the soils, the climates and the varieties that succeed well in all parts.

\section{Fresh Grape Juice}

This is a product coming more and more into popular favor and can be put up at little expense by any family, and in which large capital has been invested with good profits, and the pure, properly preserved juice of ripe grapes is more refreshing, invigorating and appetizing to young and old than wine. Its preparation should be largely encouraged. Commercial establishments for the purpose have much special apparatus and equipment that only professional experts can well manage.

For use of the family and small vineyardists little apparatus is required. A flat-top stove and a flat-bottom boiler that will hold five to ten gallons of water will do for a Pasteurizer. The principle is to clarify the pure juice and to destroy all germ-life in it, without changing the fresh grape flavor, and to hermetically seal up the juice in this condition, so that, when kept in a dark place with moderate regular temperature, it will remain fresh and good for years, if so desired.

\section{The Process to Preserve Fresh Grape Juice}

Gather thoroly ripe, clean grapes; pick out all defective and green berries. Run thru a cider mill-thoroly clean and screen out the stems. The mill must be set so as not to crack the seeds, but to break all the berries. Put the crushed berries into long, narrow, coarse, clean cotton or linen sacks, hang over deep jars, let drain for several hours in cool room, free from all insects. With a rubber siphon-tube, draw off the clear juice into clean pint beer bottles level full. Have the boiler on stove with sufficient water in it to come up to within an inch-and-a-half of top of bottles when set as full of bottles as one course makes. The water should not be over $150^{\circ} \mathrm{F}$. when the bottles of juice are set in. Then raise the temperature to 200 degrees and hold it at that 30 or 40 minutes. A little scum will rise in the bottles and flow off. Keep all of the bottles full by pouring hot juice into them from one of them. Then take out the bottles, set on strong table and cork tightly with suitable, good quality corks, driving them in with a cork-driver onefourth of an inch below the top of the bottle; then wipe top of bottle and cork dry and, with best express wax, seal over cork to top of bottle, being sure to make a perfect seal. Do this quickly after taking out of boiler. The juice in cooling will shrink away from cork about oneand-a-half inches, which space is a vacuum. When the bottles are cool, wipe them clean and dry and lay them on their sides in boxes in a cool dry cellar. A few will ferment in a few days and blow the corks out, on account of defective corking. If all ferment the cause is defective cooking. If the temperature is raised to the boiling point and continued too long the juice will have a cooked flavor. This spoils its sale. Sort over the bottles, clean them that remain sound, and 
pack away again, and such will generally keep several years in good condition. Larger bottles are undesirable, as juice not used within 24 hours after opening in warm weather, unless kept on ice, will begin fermenting, and often not more than one pint is wanted at one time.

America, and Xinta are especially recommended for making a high grade of grape juice with pleasing flavors. Concord and Worden are also fine.

\section{Raisins}

This commercial product can be made only in arid countries and only from a few Vinifera varieties, and must be produced in large quantities, so as to have uniform brands. This business is conducted by much capital with expert help, and information is abundant in special works, and o11t of place here.

\section{Canned Grapes and Jellies}

There are only a few grapes that make a profitable product canned. These must be large, high flavored, with small soft seeds, such as the Muscat of Alexandria and a few others of high, aromatic flavors. The canning process is similar to that of other fruits canned whole, such as cherries, syruped figs, etc., and generally well understood by every skilled housewife.

Jellies can be made from almost any kind of grape, if taken rare-ripe, as, if dead ripe, they do not jelly well. This is a product that every family should put up in good supply, and let it drive commercial candies entirely away from the table. No sweetmeat is more delicious and wholesome. On account of its peculiar but fine flavor, the America makes one of the best grape jams or marmalades. 


\section{Chapter VIII}

\section{The Grapevine for Home Adornment, Shade, Fruit and Health}

This short chapter is intended to answer many questions about grapes arid grape culture, especially for the yard and garden planting, for beautifying the home and supplying its table with the handsomest and richest fruit that grows. Grapes, among the most profitable, wholesome and nutritious of fruits, deserve more general and extensive planting.

By chemical analysis good ripe grapes have been found to supply a greater per cent of sugar and muscle-making material per pound than any other fruit we grow. The sprightly, nicely proportioned acids, and aromatic flavors have a cooling, exhilarating, laxative effect, possessed by no other fruit. No other fruit so surely yields, for a long series of years, abundant annual crops. No other can be so successfully grown in such a variety of situations at so little expense.

As a trailer about the kitchen porch, spread over the rear walls of the house, or barn, or stable, along the garden fence, or over the arbor to outhouses, or on the vineyard trellis, it is persistently faithful in yielding its comely aspect and generous loads of black, white, violet, pink and golden clusters in return each year for a few moments given in cultivating, pruning and spraying. It asks only the place where it is planted to be made well drained, warm and loamy, and annually a layer of leaf-mold or similar fertilizer spread on the soil around it.

It is probably one of the first, if not the very first, of fruits used and brought into cultivation by man and it has more faithfully, than others, stood by him in all temperate and warm climates ever since, and yet it is yielding finer and finer improvements for the table, for raisins, for fresh juice and for wine, as the ages run on.

But our modern big peaches and apples, by their very bigness more than actually superior merits, in many sections have overshadowed the grape. Besides, few persons in the country east of the Rockies have learned the few simple facts necessary to successful grape growing, and are actually scared off by the mention of trellis and pruning and spraying, while they will essay the planting of big peach orchards that require even greater expense and care to get paying results.

By using the different classes of varieties of grapes for the different latitudes, soils and purposes, there is scarcely a farm between the Great Lakes and the Gulf but can successfully grow grapes. Of only one or two other fruits, - the strawberry and blackberry-can as much be said. And this means the development of three great industries, namely-fresh grapes for market and table from June 1 in Southwest Texas, to November in the North; wine for home table and market the year through, and raisins for culinary and table use all the year long, but more especially in the mince-pie season.

The first thing for anyone to do, who thinks of planting a grapevine or more, is to find the positions about the home where vines can be grown. to advantage. Having located the spots, these should be prepared in the best manner by clearing away grass, weeds or undesirable shrubs or trees, and working up a wide deep bed of soil, remembering that the ground can never be worked deeply after the vine is once established. Seepy ground that cannot be well underdrained by tile, or trench filled with stones, should not be'used. Work into the soil, if thin and poor, plenty of leaf mold, ground bone or manure from the cow-yard. Secure vigorous, healthy, one or two year old plants from some reliable source, of the varieties best suited to your purpose; cut the top back to 3 or 4 good buds and the roots to 8 or 10 inches. In the prepared bed in which to be planted, open a hole deep enough to let the plant down as deep as it grew in nursery, making 
a little mound in center of bottom of hole on which to set the plant, letting the roots slant downward all round, this:

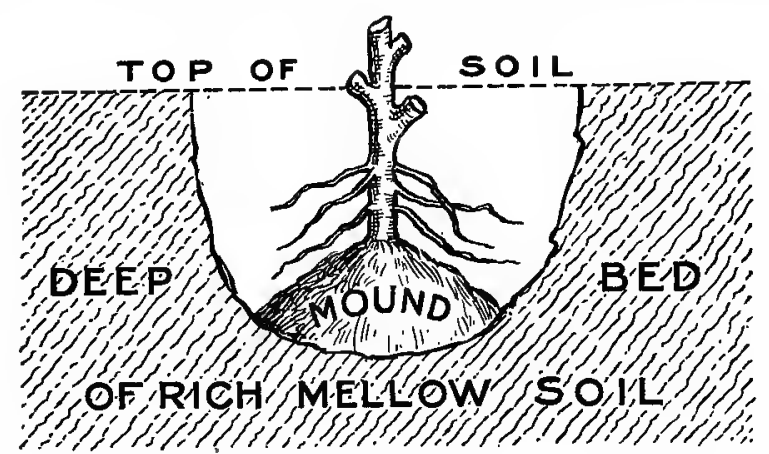

and then fill in with fine mellow earth until the roots are covered, then press down firmly all round with the feet, and on top leave a loose layer level with surface of the ground.

When the vine begins to grow in spring train up one or two shoots on a stake or twine to the wall, or fence, or arbor, or trellis on which it is to remain permanently.

The proper time to plant is any open weather in the South from time of leaf fall in November to March 10th, and in the North, October, April and May.

If there be some stiff-looking, ungraceful trees about the yard, such as old oaks, they can, in a few years, be made graceful and charming by training up their bodies among the branches, grapevines planted near their roots, of such varieties as Herbemont, Lenoir, Scuppernong, Thomas, or the hybrids of the native post-oak grape, such as Carman, Fern, Blondin, Marguerite, Albania, and the hybrids of the Scuppernong,-LaSalle, San Jacinto, Sanalba, and Sanrubra for the Southern States, and for the Northern States, such as Beacon, Berckmans, Brilliant, Clinton, Colerian, Concord, Diamond, Dracut Amber, Green Mountain, Headlight, King, Lucile, Manito, Moore Early, Niagara, Vergennes, Wyoming, and Janesville and Monitor for the extreme North. For descriptions of these varieties, see Chapter III., and also various catalogs of nurserymen.

All of these produce abundantly of fine or good, early, medium and late in ripening; some with small berries in large clusters and some with big berries in fair clusters; some black, some red, some white. All the varieties named for the South have such climbing powers that they can ascend to the tops of tall trees, and then throw out pendant arms that, swaying gracefully in the air, give a charm of which the Babylonian willow may well be jealous. Add to this a tree-top full of luscious clusters of fruit, such as the vine-canopied trees in the woods, that made our hearts leap with joy at finding when a youth, and you have an object in the home that every boy and girl thereof will remember with affection through life. Every farm having such objects about it will marry the boys and girls perpetually to farm life, resolved to some day have such charming features in their own homes when they nestle with their mates "under their own vine and fig tree."

Grapes in trees are little bothered by rot and mildew. It is when the vines are held down on trellis near the ground in dense mass that these diseases attack worst.

But if there should be no suitable trees about the home, on which to train vines, there may be a broad expanse of naked brick or stone wall on rear side of house or barn on which vines may be trained, by looping up in leather bands or wires arranged in open network fashion, or in horizontal strands, so that the vines may clamber to the eaves close to the wall and escape the drip that would spoil them if falling directly on them. The same varieties as named above are good for this, and tender kinds can do well on walls that would fail in open vineyard. Some of the fine Vinifera varieties can thus be grown even as far north as Southern Oklahoma and Tennessee, requiring a little care in spraying to prevent mildew and rot. A wall covered with vines well grown, shingled with rich foliage through which peep many luscious clusters of black, red and white grapes, will be an attraction to the boys, as they pass out to and back from their work, 
that will likely make them frequent trespassers on the patient generous vines, when grapes are ripening. But let the girls and boys own certain of the vines and be required to plant and care for them and freely enjoy the product of their own, with their friends, and be early taught the virtue of respecting the rights of others and that it is far more joyous to be generous than selfish, and you are laying the best possible foundation in your child for a noble citizen, that each should grow up to be.

Perhaps there may be a garden fence, or cross fence, or a line between front and back yard where you want a screen. Such places afford space for growing a family supply of grapes, without practically occupying any more ground than the fence requires, the same varieties and treatment will answer as for regular vineyard trellis, and, being draped with vines well cared for, give beauty as well as food and added comfort to the home.

\section{The Grape Arbor and Pergola}

The humblest cottager and the millionaire may engage with pleasure and success in producing han'dsome clusters, luscious berries and comforting shade. The plebeian is the more likely to succeed best and enjoy "the fruits most, for he works with his head and hands in partnership, while the aristocrat depends on his gardener, and has such a multiplicity of other cares that he has few moments to spend in his "pergola" that has cost hundreds of dollars where the simple arbor of the toiler has cost cents.

Grape arbors vary as much in design and style, almost, as do houses, but one as durable and successful as any, and quite as enjoyable, can be made for a few dollars.

Such I shall describe, and he who would prefer a pergola, will do better by consulting a professional landscape architect.

In the first place, determine the form or style of arbor desired and its dimensions. These will largely depend on the yard space you have, or rather the distance from the residence rear door to outhouse, the wood-shed, the stable or the summer-house, the flower garden, the fountain or the tennis court, or wherever you wish from a side door. If built along one side of a building, one line of posts only will be needed, and such places favor a veranda or pergola form. If in open ground, two lines having posts opposite, and about eight feet apart between rows, and the posts in each row. But these spaces will vary according to entire space to be occupied. The posts should be of durable wood, as of white-oak, post-oak, black locust, catalpa, bois d'arc, mesquite, etc. To be neat and durable, should be sawn or hewn, and painted or whitewashed every second year. A good height is eight feet when set, and should be set two feet deep, requiring posts ten feet long. Along the top of each line of posts, and crossing from pair to pair of posts, a plate of durable wood, $2 \times 6$ inches, should be spiked or bolted. If to be the simplest kind of flat-topped arbor, the frame as described above is sufficient, and is quickly finished by stapling on each side from two to three feet from ground, up over the top, No. 9 galvanized wire, lengthwise of trellis or on outside of posts and on top of crosspieces, 12 inches apart; so that the trellis when finished will be somewhat as indicated by Figure 1.

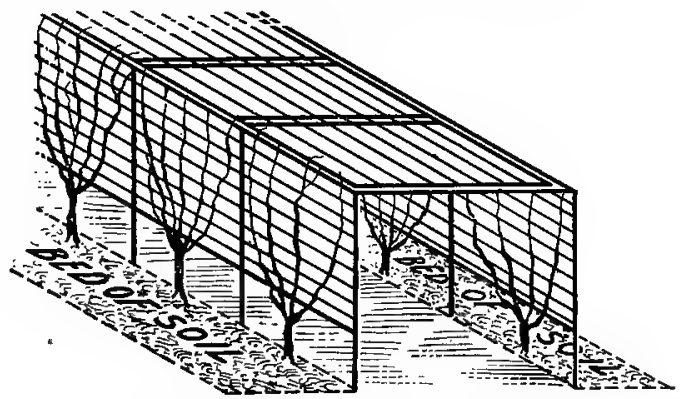

Figure 1-View of one end of arbor.

If it be desired to give the trellis a more ornamental finish, it can be quickly done at small additional expense by cutting lumber suitably and erecting on the square flat frame (shown in 
Fig. 1) a dome, which may be triangular, by joining a pair of straight rafters at comb, with the feet resting over each pair of posts, house fashion (as in Fig. 2), or curved pieces so as to form a rounding dome (as in Fig. 3), or double curves (as in Fig. 4). In each case, a ridge or combplate runs entirely through the top of arbor to join it all together and give it rigidity; and a pair of braces at each end will be necessary to prevent collapsing.

In the pergola, pillars of concrete or stone, or steel, will take the place of wood; and bars of steel the place of the wire, and the ornamentation made to match.

\section{The Bed of Soil}

As the ground about the arbor can never be deeply worked after the vines are once planted and occupy the soil with their roots, which extend under the ground as far or farther than the vines above, it is quite important to give the vines a good start, to have made before planting, a broad bed 5 or 6 feet wide, and 12 to 15 inches deep, of rich soil on each side of the arbor in

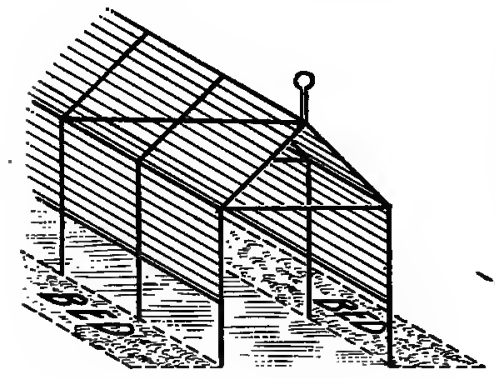

Figure 2

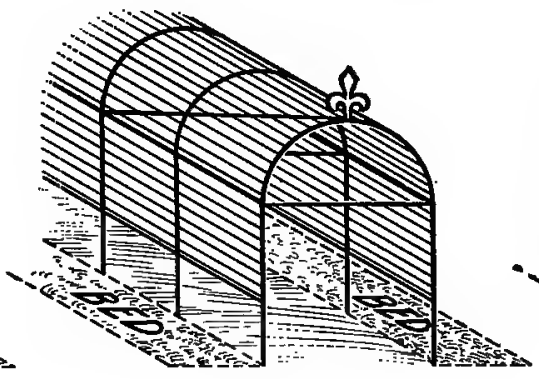

Figure 3

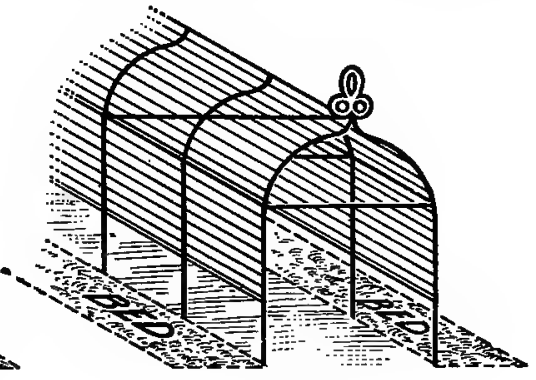

Figure 4

which set the vines, as shown on page 242. Each season afterward the beds should be kept free of weeds and the surface well pulverized with rake or scufflehoe. After the vines have come into bearing, a top dressing of leaf mold, cow-yard manure, bone or cotton seed meal should be given annually and raked in. A half-bushel of manure or leaf mold, or a peck of meal, to each vine, evenly scattered over the surface of the bed, will keep the vines in fine vigor. Wood ashes may be occasionally scattered over the beds to good adrantage. If the vines become too rank, cease fertilizing until they show by lessened growth that they need more food.

\section{Varieties Best Adapted for Arbor}

Varieties for arbors, especially if the arbors are high and broad, should be strong growers. Weak and strong growers should never be put onto the same trellis, for the strong will overgrow and choke out the weak; for example, a Delaware could never hold its own by the side of a Herbemont. For broad high arbor, use the following varieties for the South to as far north as Tennessee, Northern Arkansas, Northern Oklahoma, New Mexico: Herbemont, Lenoir (better for arid regions), America, Cloeta, Blondin, Wine King, Carman, Muench, Fern (in moister regions, as they resist rot and mildew better, but succeed equally well in the dry regions). Also, for the moister regions of the South, and especially good for the extreme South, use the Muscadine varieties, such as Scuppernong, Thomas, San Jacinto, Sanrubra, Sanalba. All the Muscadines are entirely exempt from rot and mildew. No other class of vines should be grown on the same arbor with Muscadines. Several kinds of the same class should always be grown on the one arbor, as they pollinate each other better than themselves; and there should be one pair of male Muscadine vines about the center of the Muscadine arbor. The vines on each side of the arbor should be paired with the same kind opposite on the other side of the arbor, so as to maintain symmetry and uniformity of growth over all parts of the arbor.

For lower, narrower arbors, which are more suitable in the North, and where the northern varieties succeed best, and are of less rampant growth, use those named previously for walls and trees in the North. 


\section{List of Illustrations}

PAGE cestivalis, Vitis (of Virginia).........47 astivalis, Vitis (of Georgia)............49 America.................... . . . 193 Amethyst........... . . . . . . . . 144 Arbor Frames...... . . . . . . . . 243, 244 Arizonica, Vitis... ...............91 Armado... . . . . . . . . . . . . . . . . 180 Armalaga............ . . . . . . . . . . 181 Armlong......... . . . . . . . . 182

Baileyana, Vitis................72

Beacon......................... 177

Bench-Graft of Grapevine. . . . . . . . . 231

Berlandieri, Vitis........... ..70

bicolor, Vitis.................45

Blancoii, Vitis...............61

Blondin ............. . . . . 170

Bourquiniana, Vitis..............55

Brilliant................... 163

Californica, Vitis...............85

candicans, Vitis..... . . . . ...32

Captain...... . . . . . . . . . 198

Caribea, Vitis......... . . . . ..63

Carman..... . . . . . . . . . . . . 183

Carman on Vines in Vineyard.........237

Catawba....... . . . . . . . . . . 158

Champini, Vitis...............37

cinerea, Vitis.................65

cinerea, Vitis (var. Floridana) . . . . . .67

Concord........ .............153

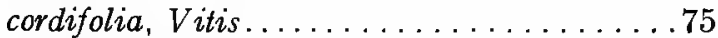

coriacea, Vitis................29

Delaware........... ..........145

DeSoto.......................214

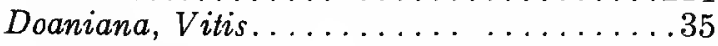

Early Purple. . . . . . . . . . . . . . . . . 168

Ellen Scott. . . . . . . . . . . . . . . . . 186

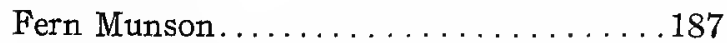

Flame Tokay . . . . . . . . . . . . . 53

Flower Clusters of Grapes.. 111, 112, 113, 131

Girdiana, Vitis................ . 88

Grafting the Grape. . . . . . . . . . . 231, 232

Grape Flowers.........111, 112, 113, 131

Grapes on Munson Trellis...... . . . . .220

Headlight. . ... . . . . . . . . 146

Herbemont. . . . . . . . . . . . . . . .55

Hernito. . . . . . . . . . . . . . . . . . . .159

Hidalgo..... . . . . . . . . . . . . 147

Husmann. . . . . . . . . . . . . . . . . . 192

Ives. . . . . . . . . . . . . . . . . . 156

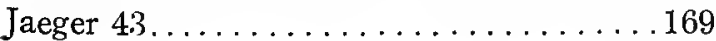

Krause. . . . . . . . . . . . . . . 150

labrusca, Vitis................26

LaSalle.......................211

Lincecumii, Vitis...................40

Lincecumii, Vitis, var. glauca..........43

Lincecumii, Vitis, var. glauca . . . . . . . . 169

Longii, Vitis. . . . . . . . . . . . . . . . 999

Lukfata. . . . . . . . . . . . . . . . . . 152

Manito....................... 194

Marguerite...... . . . . . . . . . . . 174

Mericadel..................... . . 195

monticola, Vitis.................82

Muench. . . . . . . . . . . . . . . . 175

Muscat of Alexandria............. . 201

Muscat Rose.....................205

Munsoniana, Vitis............... . 108

Munson Trellis.. . . . . . . . . . 224, 226

Neva Munson. ........ . . . . . . . . 176

Olivonta....................207

Pergola.................. . . .244

Planting a Young Vine............. . 242

Red Cornichon.... .............204

Red Giant... . . . . . . . . . . . . . . 157

Rommel........ . . . . . . . . . . . 165

rotundifolia, Vitis...............105

rubra, Vitis... . . . . . . . . . . .79

rupestris, Vitis. . . . . . .......... 102

R. W. Munson. . . . . . . . . . . . . . 189

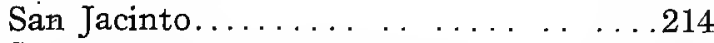

Scuppernong....................... . . . . .

Section of Vineyard Row..... . . . . . . .222

Seeds. . . . . .................... . . 15

Semendia...... . . . . . . . .206

Simpsoni, Vitis.................51

Structure of Grape Flowers... . . . . . . . 131

Thomas......................105

Treleasei, Vitis................993

Trellis, Grapes on...............220

Trellis, The Munson. . . . . . . . . . 224, 226

Tuskahoma.................. . . . .

Union Village. . . . . . . . . . . . . 162

vinifera, Vitis................53

vulpina, Vitis..............95

Wapanuka..................... 164

Wood of Species, Mature Annual....17 to 23

$\mathrm{X} \ln$ ta. 


\section{Synopsis of Chapters}

\section{Preface}

Native Grapes of America-Passion for Experimentation-Special Study of Grape Botany-Author's Educational Work-The Chief Work-Basis of Improvement-An Ideal List-Vineyards Planted-Grape Nurseries.

Pages 5 to 11 .

\section{Chapter I.}

\section{Botany of American Grapes}

Introductory Remarks-Classification-Critical Botanical Description of Species, with Viticultural Observations and Remarlse.

Pages 13 to 113 .

\section{Chapter II. \\ Breeding of Varieties of Grapes}

Thorobred Vines-Hunting and Selecting Parent Varieties-Variation and Division-Study of Characteristics-Length of Life-Relative Longevity of Species and Varieties-Cultural Properties-Climatic Conditions-Sugar and Acid in Juice of Species and Varieties-The Specific Basis-List of Varieties in Hand-The Ideal Variety-Qualifications in Originator-Pure Breeding and Crossing-Selecting-Grape Flowers-General Laws-Method of Crossing and Hybridizing-Preserving Pollen-Saving Seeds-Tending and Culling Seedlings-Testing and Selecting Varieties-Development of a Variety-Percentage of Meritorious Varieties-Breeding for Special Purpose-Prepotency of Parents in Controlling Characters-Field of Development. Pages 114 to 140 .

\section{Chapter III. \\ Description of Varieties}

Select Families and Varieties for Practical Vine Growers-How Related and Classified- . Explanation of Signs and Figures-Critical Descriptions of Varieties-Table for Selecting Varieties.

Pages 141 to 214. 


\section{Chapter IV. \\ Adaptation of Varieties}

Resistance to Weather Conditions, Insects and Fungi-Select Lists for Various Regions and Zones-Graft-Stocks.

Pages 215 to 219 .

\section{Chapter V. \\ How to Start a Vineyard}

The Site-The Soil and Preparation-Selection of Varieties, and Vines-PlantingRecording-Trellising-The Munson Trellis-Pruning-Cultivation-Fertilization:

Pages 221 to 229 .

\section{Chapter VI.}

\section{Protecting the Vineyard from Insects and Fungi}

Insects Must be Fought-Names and Descriptions of Insects-Grafting the GrapeFungus Parasites-Universal Treatment-Bordeaux Mixture-Spraying.

Pages 230 to 236 .

\section{Chapter VII.}

\section{Disposition of the Crop}

The Market Demands-Gathering-Packing-Wine-Grape Juice and Jellies-How to Make the Grape Juice-Raisins

Pages 238 to 240.

\section{Chapter VIII.}

\section{The Grape for Home Adornment, Shade, Fruit and Health} for Such.

Hints for Planting, Pruning, and Care for the Yard, Arbor and Pergola--List of Varieties Pages 241 to 244 . 


\section{Index of Species and Varieties}

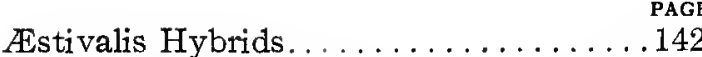

Estivales (Series III.) . . . . . . . . . . . . . 39

Astivalis Varieties. . . . . . . . . . . . . . . . 142

astivalis, Vitis..................46

Agawam................... . . . 161

Albania. . . . . . . . . . . . . . . . . . 184

America ... . . . . . . . . . . . . . . . . 196

Amethyst................. . . . . 143

Arizonica, Vitis...............90

Armado... . . . . . . . ...... . . . . 190

Armalaga........ . . . . . . . . . . . 190

Armlong...................... . . 190

Atoka..................... . . . 197

Augustina. . . . . . . . . . . . . . . . . 143

Bailey.............. . . . . . . . 190

Baileyana, Vitis................71

Beacon............... . . . . . . . 185

Bell.............. . . . . . . . . 173

Berlandieri, Vitis.......... ...69

bicolor, Vitis.................44

Big Berry . . . . . . . . . . . . . . . . . 179

Black Eagle........... . . . . . . . 161

Blancoii, Vitis.................660

Blondin....... . . . . . . . . . . . . . . 184

Bourquiniana Hybrids. . . . . . . . . . . . 143

Bourquiniana Varieties...... . . . . . . . 143

Bourquiniana, Vitis...............54

Brighton. . . . . . . . . . . . . . . 161

Brilliant...................... . . . . .

Calabrian......................202

Californica, Vitis. . . . . . . . . . . .84

Campbell Early. . . . . . . . . . . . . . 161

candicans, Vitis.....................

Captain... . . . . . . . . . . . . . . . . 197

Captivator............... . . . 167

Caribca, Vitis..................62

Carman... . . .................190

Catawba........................... $\ldots 161$

Champanel...................... . . . . . .

Champini Hybrids. . . . . . . . . . . . . . . 149

Champini, Vitis. . . . . . .

Champion. . .................. . . 154

Chasselas de Fontainbleau . . . . . . . . . . .202

Cigar Box. . . . . . . . . . . . . . . . . . . 203

Cinerascentes (Series V.) . . . . . . . . .60

cinerea, Vitis......................64

Clinton....... . . . . . . . . . . . . . 172

Colerain..................... . . 154

Columbian ............ . . . . . . 166

Concord..................... . 155

cordifolia, Vitis ........... . .74

Cordifolice (Series VI.1. ..... . . . . . 74

coriacea, Vitis..................28

Coriacece (Series II.). . . . . . . . . . 28
Cottage. .................. 155

Cynthiana.................... 142

Delago.......................143

Delaware... . . . . . . . . . . . . . . . 143

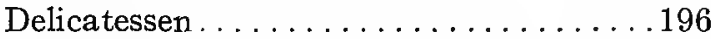

Diamond. . . . . . . . . . . . . . . . . . 166

Doaniana, Vitis...................34

Dracut Amber. . . . . . . . . . . . . . . . 155

Dr. Collier........ . . . . . . . . . . . 190

Early Ohio... . . ................ . . . . . . .

Early Purple............ . . . . . . . 179

Eaton. . . . . . . . . . . . . . . . . . . 155

Ellen Scott. . . . . . . . . . . . . . . . .191

Elvicand.................... . . . . . . . . .

Elvira........................ . . . . . . . . .

Enolian... . . . . . . . . . . . . . .196

Extra....................... . . . . . . . .

Feher Szagos........ . . . . . . . . . 202

Fern Munson................... . . 191

Flame Tokay. . . . . . . . . . . . . . . .202

Girdiana, Vitis...............87

Gold Coin. . . . . . . . . . . . . . . . . . . . 142

Goethe.... . . ............ . . 166

Green Mountain. . . . . . . . . . . . . . . . 172

Griesa de Piemonte... . . . . . . . . . . . .202

Hartford. . . . . . . . . . . . . . . . 155

Hayes........ . . . . . . . . . . . . 155

Headlight. . . . . . . . . . . . . . . 148

Herbemont. . . . . . . . . ... . . . . . . 143

Herbert... . . . . . . . . . . . 166

Hermann Jaeger..... . . . . ... . . . . . 185

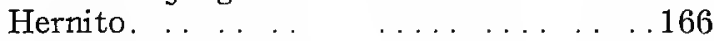

Hidalgo. . . . . . . . . . . . . . . 148

Hopkins...... . . . . . . . . . . . . . . . 184

Husmann. . . . . . . . . . . . . . . . . . . 196

Isabella. . . . . . . . . . . . . . . . 166

Ives . . . . . . . . . . . . . . . . . . . . . 160

Jaeger $43 \ldots \ldots \ldots \ldots \ldots$

Jaeger $70 \ldots \ldots \ldots \ldots \ldots \ldots \ldots . \ldots \ldots$

James........... . . . . . . . . . . 208

Jefferson................... . 166

Kentucky ... . . . . . . . . . . . . . 142

Kiowa. . ..................... . . . . . . . . . .

$\begin{array}{lllllll}\text { Krause. . . . . . . . . . . . . . . . . . } 148 & \end{array}$

Labrusca (Series I.). . . . . . . . . . . . . 25

Labrusca Hybrids............. . 161 to 178

Labrusca Varieties............. 154 to 161

labrusca, Vitis................25

Ladano. . . . . . . . . . . . . . . . . . . . . . . 149 
LaSalle. . . . . . . . . . . . . . . . . . 209

Laussel. . . . . . . . . . . . . . . . . . . . . . 185

Last Rose. . . . . . . . . . . . . . . . . . . 191

Lenoir. . . . . . . . . . . . . . . . . . . . . . 143

Lincecumii Hybrids....... . . . . 184 to 197

Lincecumii Varieties........... 178 to 184

Lincecumii, Vitis.... ........... . .39

Lindley.................. . 167

Lomanto. . . . . . . . . . . . . . . . . . . . 149

Longii, Vitis........... . . . . . .98

Lucky....... . . . . . . . . . . 179

Lukfata... . . . . . . . . . . . . . . . 149

Lutie. . . . . . . . . . . . . . . . 160

Malaga........ . . . . . . . . 202

Manito......... . . . . . . . . 197

Manson. . . . . . . . . . . . . . . . . . . 196

Marguerite........... ........ 185

Martha....... ...............160

Mericadel..... . . . . . . . . . 197

Montefiore..... . . . . . . . . . . 173

monticola, Vitis...............81

Moore Early... . . . . . . . . . . . . . 160

Munson. ................... 196

Munsoniana, Vitis.................... 107

Muscadines.... . . . . . . . . . . . 208

Muscadinia (Series IX.). . . . . . . . . . . . 104

Muscat of Alexandria. . . . . . . . 202

Muscat Rose... . . . . . . . . . . . . . . . . 202

Neosho...... . . . . . . . . . . . . . . . . . 179

Neva Munson. . . . . . . . . . . . . . . 185

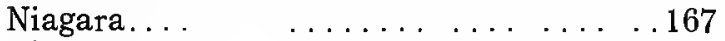

Nitodal. . . . . . . . . . . . . . . . . . . 154

Noah. ..... ... . .. .... . 173

Norfolk. . . . . . . . . . . . . . . . 167

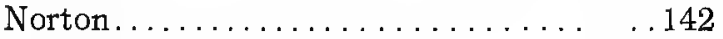

Occidentales (Series VII.). . . ........84

Ohio.... . .. . .... . ... . . 203

Olivonta..................203

Onderdonk. . . . . . . . . . . . . . . . . . .148

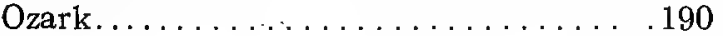

Pense... . . . . . . . . . . . . . . . . . .202

Perkins............. . . . . . . . . . 160

Perle of Anvers. . . . . . . . . . . . . . . . . .202

Pocklington............. . . . 160

Post-Oak-Grape..... . . . . . . . . ..... 39

Post-Oak-Grape Hybrids. . . . , . . 184 to 197

Post-Oak-Grape Varieties. . . . . . . . 178 to 184

Precoces (Series VIII.)........ . . . . . .994

Premier.............. . . . . . . 179

President.... . . . . . . . . . . . 167

Quagliano. . ...................202

Red Cornichon. . . . . . . . . . . . . . . . . 202

Red Giant...... ... . . . . . . . . 161

Rommel........................ PAGE

Rose of Peru.................. . 191

Rotundifolia Hybrids . $\ldots \ldots \ldots \ldots \ldots .202$

Rotundifolia Varieties........... . . . . . 208

rotundifolia, Vitis..................... 104

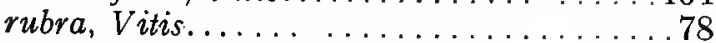

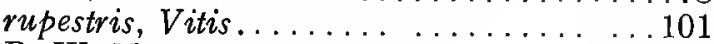

R. W. Munson. . . . . . . . . . . . . . . 191

Sabinal. ...... . . . . . . . . . . . . 154

Salado. . . . . . . . . . . . . . . . . . . 149

Sanalba. . . . . . . . . . . . . . . . . .209

San Jacinto. ................... . . .209

Sanmelaska..... . . . . . . . . . . . . . 209

Sanmonta. . . . . . . . . . . . . . 209

Sanrubra... . . . . . . . . . . . . . . . . 209

Scuppernong................. . . . 208

Scuppernong Hybrids. . . . . . . . . . . . . 209

Sauvignon Jaune. . . . . . . . . . . . .202

Secundo. . . . . . . . . . . . . . . . . 179

Semendia.................... . . 202

Simpsoni, Vitis...... . . ........ .50

Southern Muscadines..... . . . . . . . . . 208

Sultanina....... . . . . . . . . . . . .202

Sweetwater... . . . . . . . . . . . . . 202

Taylor. . . . . . . . . . . . . . . . 173

Telegraph.................... . . . . . .

Ten-Dollar-Prize. ..... . . . . . . . . . 184

Thomas................ . . . 208

Thompson Seedless... . . . . . . . . . .202

Treleasei, Vitis... . . . . . . . . . . . . . $\quad .92$

Triumph.... . . . . . . . . . . . . . . 167

Tuskahoma................. $\ldots 148$

Union Village............. . . . 166

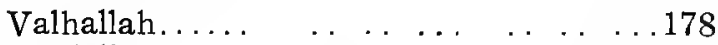

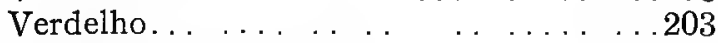

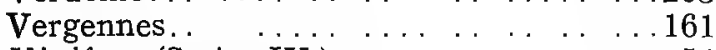

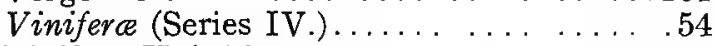

Vinifera Hybrids. . . . . . . . . . . . . . . .203

Vinifera Varieties...... . ... . . . . . . 202

vinifera, Vitis..................... 54

Violet Chasselas. . . . . . . . . . . . . . . .203

Vulpina Hybrids... . . . . . . . . . . . .203

Vulpina Varieties...... . . . . . . . .203

vulpina, Vitis.................. . 22

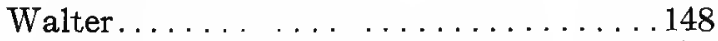

Wapanuka.................... 173

Wetumka..................... . . . . . . .

Wine King. . . . . . . . . . . . . . . . . 142

Winner.......... . . . . . . . . . . 197

Woodruff...... . . . . . . . . . .

Worden. .. ................ . . . 161

Wyoming...... . . . . . . . . . . 172

Xenia........................149

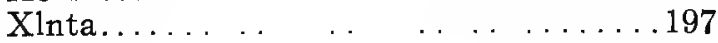




\section{Index of Topics}

PAGE

Acid in Grapes, Degrees of............ 124

Adaptation of Varieties............. . . 215

Anthracnose................ . . 234

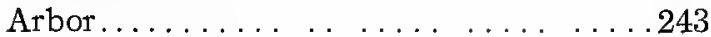

Arms, Length of . . . . . . . . . . . . . . 227

Authors of Species....... . . . . . . . 119

Bench-Grafting. ................231

Berry Worms.....................234

Bird's-eye Rot. . . . . . . . . . . . . . . . . 234

Blooming Dates of Varieties 127, 129, 212, 213

Black Rot.... ... . .... . . . . . . .235

Bordeaux Mixture... . . . . . . . . . .236

Botany of Grapes........ . . . . . . . . 13

Breeding.................114, 130

Canned Grapes... . . . . . . . . . . . . . . . 240

Character of Flowers........ . 127 to 129,212

Character of Species......... . . . . .119

Climatic Conditions at Denison. . . . . . . 122

Classification, Remarks on............13

Classification, Scheme of...... . . . . . . 24

Common Names of Species......... 119, 121

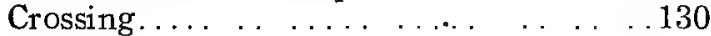

Crop, Disposition of ...... . . . . . . 238

Coliodes. . . . . . . . . . . . . . . . . . . . 234

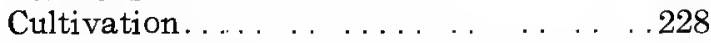

Cultural Properties of Species. . . . . . . .121

Dates of Blooming.......127, 128, 129, 212

Dedication........................ . .

Desmia ........................ . .233

Direct Producers, Breeding for...... . . 126

Diseases ............... .. . 234

Downy Mildew...... . . . . . . . . . . . 234

Endurance of Species..................

Erythroneura.....................233

Explanation of Figures ............. . 127, 141

Explanation of Letters.............118,217

Explanation of Phrases.... . . . . . . . . 142

Explanation of Signs..... ...25, 118, 122

Explanation of Tables.........118, 122, 125

Fertilization......................228

Fidia.................... . . 233

Field of Development.............. 139

Flowers, Kinds of........111 to $113,131,212$

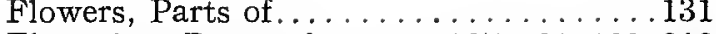

Flowering, Dates of. . . . . . 127, 128, 129, 212

Fresh Grape Juice... . . . . . . . . . . . . . 239

Fungi..................... . . . . . . . . . . . . . . .

Gathering the Crop. . . . . . . . . . . . . 238

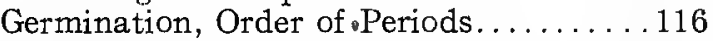

Grafting : ..... . . . . . . . . . . . . . . . . . . . . . . .

Graft-Stocks. . . . . . . . . . . . 122, 126, 219

Grapes, Growing on Munson Grounds. . . . 127

Grape Juice. . . . . . . . . . . . . . . . . . . 239

Grape Products. . . . . . . . . . . . . . . 239

Grape Flea-Beetle. . . . . . . . . . . . . . . . . . . . . . . . . . . . . 33

Grape-Leaf Fidia.... . . . . . . . . . . . . . . . . . . . . . .

Grape-Leaf Folder. . . . . . . . . . . . . . . . . . . . . . . . . . . .

Grape-Leaf Hopper. . . . . . . . . . . . . . . . . . . . . . . . . . . . . .

Grape-Berry Worms. . . . . . . . . . . . . . . 234

Guignardia. . . . . ......... . . . . . . . . . . .

Haltica............. ... . . . . . 233

Hermaphrodite Flowers. . . . . . . . . . 131

Hopper, Grape-Leaf. . . . . . . . . . . . . . 233

Hybridizing . . . . . . . . . . . . . . . 130, 134

Ideal Variety....... . . . . . . . . .9, 129

Impregnation. . . . . . . . . . . . .

Insects................. . .230

Jellies.................. . . . . .240

Juice of the Grape...... . . . . . . . .239

Juice, Color of. ........ . . . . . . . . 124

Juice, Richness of. . . . . . . . . . . . . . 124

Juice, Acid and Sugar of .......... . $\quad .124$

Laws of Development......... . . . . 132

Leaf-Hopper and Leaf-Folder....... . . 233

Lightning Atrester. .......... . . . . . .225

Life, Length of...... . . . . . . . . $\quad .117$

Limy Soils, Species for.............. . . .212

Limy Soils, Species found in......... .118

Lobesia. . ..................... . 234

Longevity of Species................. . 119

Longevity of Varieties............... 120

Macrodactylus. . . . ..............232

Marketing... . . . . . . . . . . . 238

Male Vines......................... 131

Method of Hybridizing..............133 


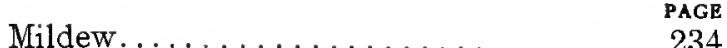

Munson Trellis . . . . . . . . . 234

Old Vines, Grafting of . . . . . . . . . . . .232

Eschle's Scale. . . . . . . . . . . . . . . . . 124

Parents Controlling Progeny ........... . 138

Parent Varieties, Selecting...... . . . . 115

Pergola........ ..... .......243

Peronospera... . ..... . . . . . . .2234

Phylloxera.......... . ... . ...230

Phylloxera-Resistant Vines, Native

Habitats of ... . . . . . . . . . . 122

Pistillate Flowers . . . . . . . . . . . 131

Planting.............. .222, 242

Pollen, Collecting and Preserving....... 134

Pollination............... . . . . 132

Powdery Mildew. ...... . . . . . . . . 234

Products of the Grape...... . . . . . . . .239

Practical Grape Growing. . . . . . . . . . .221

Pruning..... . . . . . . . . . . . .226

Profitableness of Varieties. . . . . . . . . . 100

Properties of Species... . . . . . . . . . . 121

Quality of Grapes.................. . 122

Qualifications of Originator. . . . . . . . . . 129

Raisins... . . . . . . . . . . . . . . . . . . . . 240

Resistance of Varieties... $\quad \ldots \quad \ldots . \quad .215$

Resistance of Species........ . . . . 121

Resistant Stocks........ . . . . . . . $\quad .219$

Recording the Vineyard... . . . . . . 223

Regions, Graft Stocks for... . . 122, 126, 219

Regions, Varieties for. . . . . . . . 212, 217

Ripening, Order of...... . . . . . 212

Root-Louse... . . . . . . . . . . . . . 230

Rose-Chafer. . . . . . . . . . . . . . . . . 232

Season of Leafing and Flowering. . . . . 121

Seeds, Saving of........ . . . . . . . 135

Seeds, Planting of . . . . . . . . . . . . 135

Seedlings, Tending and Culling of...... 135

Seedless Varieties... . . . . . . . . . . . . . 131

Selection of Varieties.......... . . . . .222

Selection of Vines............. . . . . 223

Sex in Grapes........ . . . . . .131

Simple Selection....... . . . . . . . . 130

Site, The Vineyard......... . . . .221

Soils, Varieties for.... . . . . . . . .212, 217

Soil, The Ideal Vineyard.......... . .221

Soil, Preparation of .............221
Soil for Arbor. . . . . . . . . . . . . . . . . . . 244

Soil Preferred by Species... . . . . . . . . . 121

Species Grown on the Munson Grounds... 127

Special Purpose, Breeding for.......... 137

Species, Descriptions of . . . . . . .25 to 111

Specific Basis of American Viticulture.. . 127

Specific Characteristics....... . . . . . . . 116

Specific Blood of Varieties.... . . . . 120

Species for Wine................. 126

Species for Graft-Stocks. . . . . . 122-126, 219

Spaceloma................... . .234

Spray, How to Apply ... . . . . . . . . . . . 2236

Speedy Method of Hybridizing .......... 133

Stocks, Grape. .... . . . . . . 122-126, 219

Sugar in Grapes... . . . . . . . . . . . . . 124

Strmmer Pruning. . . . . . . . . . . . . . . . . . 227

Tables, Discussion of....... . . . 122, 125

Tables, Practical Use of. . . . . . . . . . . 122

Tables, Explanation of..... . . 118, 122, 125

Testing Varieties.................. 136

Thorobred Vines.................. .114

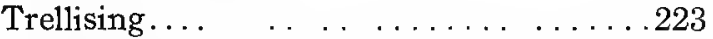

Training................... .226

Treatment against Insects and Fungi... . 235

Twitchell's Acidometer... . . . . . . . . . 124

Unfermented Juice............ . . . 239

Unicnula........... . . . . . . . .234

Variety, Development of. . . . . . . 136

Varieties, Percentage of. . . . . . . . . . 136

Varieties, in Order of Ripening.... . . . 212

Varieties, for Regions and Zones....217, 212

Varieties, for Arbor............... . . 244

Varieties, Selection of... . . . . . . . . 222

Varieties, Description of.........141 to 211

Varieties on Munson Grounds... . . . . . . 128

Varietal Characteristics.............116

Variation...................... 116

Vines, Selection of........ . . . . . . 223

Vineyard, Recording of....... . . . . .223

Vineyard, Protection of . . . . . . . . . . 230

Vineyard, How to Start. . . . . . . . . 221

Wine and Brandy.... . . . . . . . . . 239

Wine, Best Species for.......... . . . 126

Wild Grapes for Parents........ . . . . 115

Wood, Explanation of Plates........ 16 to 22

Zones, Variety.................217 


\section{List of Tables}

Classification of American Grapes... . . . . . . . . . . . . . . . . . . . . . 124

Comparative Longevity and Profitableness of Cultivated Grapes. . . . . . . . . . . . 120

Cultural Properties of Grape Species. . . . . . . . . . . . . . . . . . . . . . . . . . . . 121

Guide to Selecting Varieties for Various Regions, Soils and Purposes ..... . . . . . 212.213

Most Available List of Varieties.................................... 10

Order of Succession of Periods of Seed Germination.. . . . . . . . . . . . . . . . . 116

Order of Succession of Blooming Periods of Species.......................... 117

Relative Longevity of Species in Sandy Soil................................. 119

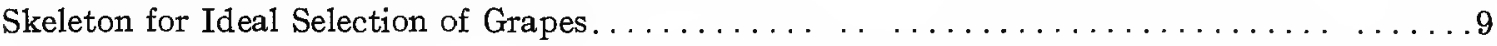

Sugar and Acid in the Juice of Different Varieties of Grapes.................124, 125 





